UNIVERSIDADE DE SÃO PAULO

FACULDADE DE FILOSOFIA, LETRAS E CIÊNCIAS HUMANAS

DEPARTAMENTO DE GEOGRAFIA

PROGRAMA DE PÓS-GRADUAÇÃO EM GEOGRAFIA HUMANA

\title{
Materiais Didáticos para Cartografia Escolar: metodologias para a construção de mapas em sala de aula
}

VERSÃO REVISADA

Gerson Rodrigues Leite

São Paulo 
UNIVERSIDADE DE SÃO PAULO

FACULDADE DE FILOSOFIA, LETRAS E CIÊNCIAS HUMANAS

DEPARTAMENTO DE GEOGRAFIA

PROGRAMA DE PÓS-GRADUAÇÃO EM GEOGRAFIA HUMANA

\title{
Materiais Didáticos para Cartografia Escolar: metodologias para a construção de mapas em sala de aula
}

Gerson Rodrigues Leite

\begin{abstract}
Dissertação apresentada ao Departamento de Geografia da Faculdade de Filosofia, Letras e Ciências Humanas da Universidade de São Paulo para a obtenção do título de mestre em Geografia.
\end{abstract}

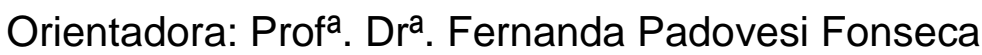

São Paulo 
Nome: LEITE, Gerson Rodrigues.

Título: Materiais Didáticos para Cartografia Escolar: metodologias para a construção de mapas em sala de aula.

Dissertação apresentada ao Departamento de Geografia da Faculdade de Filosofia, Letras e Ciências Humanas da Universidade de São Paulo para a obtenção do título de mestre em Geografia.

BANCA EXAMINADORA

Prof . Dr : Instituição:

Julgamento: Assinatura:

Prof . Dr : Instituição:

Julgamento: Assinatura:

Prof . Dr .: Instituição:

Julgamento: Assinatura: 
Aos professores do Ensino Fundamental, Médio e Superior que buscam constantemente aprimorar suas práticas didáticas em sala de aula. 


\section{AGRADECIMENTOS}

Agradeço especialmente a minha orientadora Prof ${ }^{\underline{a}} \operatorname{Dr}^{\underline{a}}$ Fernanda Padovesi Fonseca, pelos encaminhamentos, correções e acompanhamento de todos os trabalhos, e pela grande dedicação oferecida durante todo o período.

Ao Prof. Dr. Marcello Martinelli e Prof ${ }^{a}$ Dr$^{a}$ Sonia Castellar pelos encaminhamentos durante o curso das disciplinas.

À Banca Examinadora do Exame de Qualificação, Prof ${ }^{a}$ Dr $^{\mathrm{a}}$ Maria Elena Simielli e Prof ${ }^{\mathrm{a}} \mathrm{Dr}^{\mathrm{a}}$ Gisele Girardi (UFES) pelas orientações e encaminhamentos durante os trabalhos.

À Prof ${ }^{a}$ Dra. Maria Elena Simielli e Prof ${ }^{a}$ Dra. Carla Sena (UNESP) pelas correções, sugestões e encaminhamentos para a publicação do trabalho.

Ao Prof. Anderson José Albano e seus alunos, pela aplicação das atividades e acompanhamento durante todo o período de avaliação dos trabalhos.

À Prof ${ }^{a}$ Dr ${ }^{a}$ Marilena Nakano, Prof. Me. Marcos Marsitsh, Prof. Dr. Bruno José Daniel Filho, Prof $\stackrel{a}{\text { alana }}$ Cosin, Prof ${ }^{a}$ Kelly Coutinho, Prof ${ }^{a}$ Larissa Correia, Prof ${ }^{a}$ Tatiane Moreira, Prof ${ }^{a}$ Thaís Santos e alunas do Curso de Pedagogia, pelas contribuições e sugestões durante a realização dos trabalhos na Fundação Santo André.

Às professoras Gabriela Mascarenhas e Vanessa Albano, pela assessoria em línguas estrangeiras.

Ao Prof. Túlio Sérgio Bulcão (Faculdade Senador Fláquer, 1996), pelos ensinamentos, práticas didáticas e sugestões de materiais didáticos.

À Beatriz Leite Lamego, Regiane Leite e Regina Leite, pela ajuda na busca e organização de dados estatísticos e fontes de pesquisas.

À Cilene Aparecida dos Santos, pela contribuição no preparo e aperfeiçoamento dos materiais didáticos, e Danielle Santos pelos materiais de apoio.

Aos amigos Eduardo Zamborlini, Idinei Tinoco, Marco Molina e Maurício Bellinelo, pela assessoria em informática para a elaboração dos materiais didáticos.

Ao C.E.U. Jardim da Conquista - Prefeitura de São Paulo (Direção, Coordenação Pedagógica, professores), que permitiram e apoiaram a realização das atividades com seus alunos.

Ao Colégio Singular Júnior/ Santo André e toda a equipe: Direção, Coordenação Pedagógica, Corpo Docente e Administrativo por todo 0 apoio e liberdade de trabalho oferecido para a realização das atividades com os alunos (Adélia, Adrienne, Andrée, Andrea, Carol, Cláudio, Cleiton, Cristina, Daniela, Eduardo, Elaine, Elisa, Eloísa, Érica, Geórgia, Ivani, Ivete, Leandro, Léia, Marisa, Marli, Néia, Nathalie, Tio Paulo, Regina, Rúbia, Sheila, Simone, Sueli).

À Fundação Santo André, pela autorização de estágio com as Turmas de Pedagogia.

Ao Tribunal Regional do Trabalho, Administração, superiores hierárquicos e amigos, pelo apoio, sugestões e adaptação de carga horária (Ágatha, Agnes Rama, Alex, Alexandre Bissoli, Alice Lopes, Alice Monteiro, Dr. André Wenzel, Andréa, Carla, Cassia Sodré, Daniel, Danilo, Déborah, Denise, Fabiana, Felipe, Gedélcio, Inês, Ingrid, Isabel Mendes, Isaura, Julio Lucatto, Larissa, Liz Laine, Luciana Ávila, Luciana Marino, Lucia, Dr ${ }^{a}$ Luciane Storel, Lucielis, Marcelo, Marcos, Maria José, Matheus, Monteiro, Nívea, Regina Orii, Regina Pasuld, Ricardo Colin, Ricardo Oliveira, Dr ${ }^{\mathrm{a}}$ Salete Barreira, Silvio Gabaldo, Talita, Thaís, $\mathrm{Dr}^{\mathrm{a}}$ Teresa Pedrasi, Virginia, Weber).

Aos alunos e alunas de todas as séries que participaram das atividades, pelas valiosas críticas e sugestões de aperfeiçoamento dos materiais didáticos.

À Universidade de São Paulo, LEMADI (Waldirene do Carmo) e às colegas de equipe pelas sugestões bibliográficas e práticas didáticas (Caroline Araújo, Cristina Novaes, Fernanda Righi, Helaine Simião, Karen Fonseca, Lucinda Bittencourt, Ludmila Girardi, Vânia Gonçalves).

A todos que contribuíram para a realização deste trabalho, muito obrigado. 


\section{SUMÁRIO}

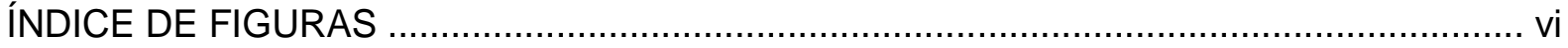

ÍNDICE DE TABELAS

ÍNDICE DE MATERIAIS DIDÁTICOS EM APÊNDICE …........................................... xiii

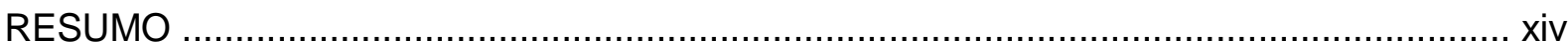

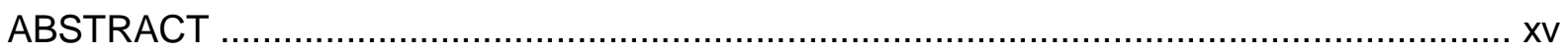

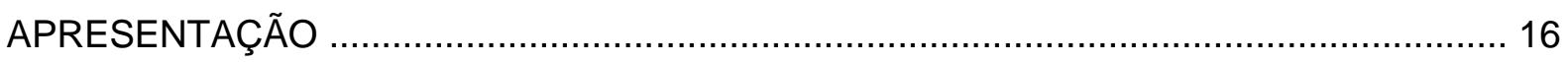

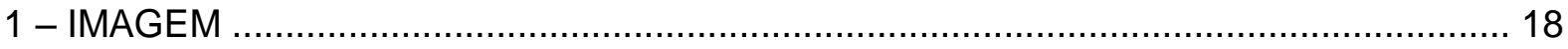

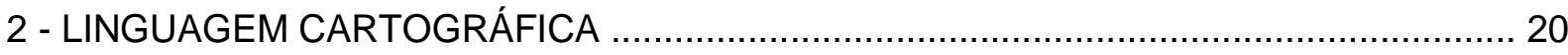

2.1 - Semiologia Gráfica ........................................................................ 24

2.2 - A Possibilidade de Construir Mapas Escolares Artesanais ........................... 28

2.3 - A Cartografia Escolar na proposta dos Parâmetros Curriculares Nacionais ... 39

2.4 - Diferenças e utilidades dos mapas topográficos e temáticos ........................ 42

2.5 - Propostas para a construção de mapas com escalas diversas ....................... 43

3 - O DESAFIO DE CONSTRUIR MAPAS EM SALA DE AULA ....................................... 47

3.1 - Simplificação de Fundos de Mapas, Matrizes e Tabelas de Dados.................. 49

3.2 - Metodologia para a Construção dos Materiais Didáticos ................................ 54

3.3 - Descrição dos Materiais Didáticos Propostos................................................ 57

3.3.1 - Gabaritos de Mapas para Elaboração em Lousa ..............................60

3.3.2 - Gabaritos de Símbolos para Elaboração de Mapas ......................... 64

3.3.3 - Tabelas e Matrizes para Elaboração de Mapas Temáticos ............... 67

3.4 - Procedimentos para Utilização dos Materiais Didáticos ................................. 69

3.4 .1 - Utilização de gabaritos para lousas ............................................69 69

3.4 .2 - Utilização de gabaritos individuais ............................................. 71

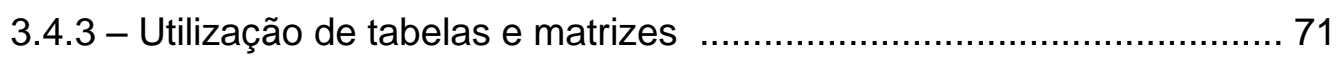

4 - EXPERIÊNCIAS COM A ELABORAÇÃO DE MAPAS TEMÁTICOS ESCOLARES ...... 77

4.1 - Atividades realizadas com alunos de 6을 Ano de escola pública ...................... 80

4.2 - Atividades realizadas com alunos de 9o Ano de escola particular .................. 102

4.3 - Atividades realizadas com alunos de Curso de Formação de Professores ... 145

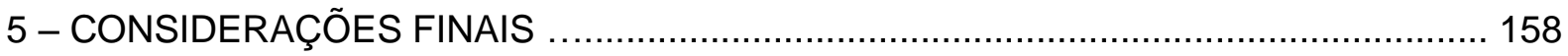

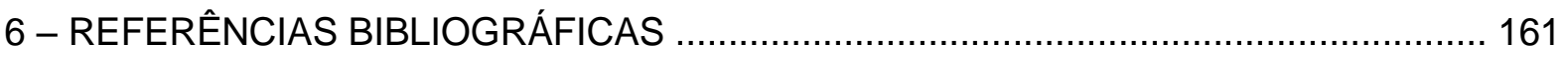

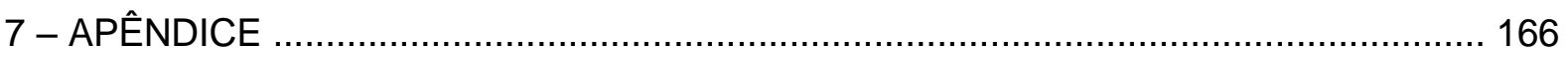




\section{ÍNDICE DE FIGURAS}

Figura 01: Critérios para organização e cálculos de dados em tabelas.

Figura 02 - Comparação de dois mapas com os mesmos dados estatísticos elaborados com critérios diferentes.

Figura 03 - Mapa construído em um fundo de mapa mudo em duplicata do planisfério.

Figura 04 - Modelo de ábaco de Raio de circunferências para figuras planas.

Figura 05 - Modelo de disco de proporção utilizado por desenhistas e projetistas.

Figura 06 - Critério para elaboração do gabarito de círculos proporcionais. Sequência de 1 ao 10 convertido do tamanho 10 ao 100 e sequência intermediária de 3 a 4 fracionada (30 a 40) 53

Figura 07 - Gabaritos de círculos, curvas e símbolos proporcionais recortados manualmente. 54

Figura 08 - Radiografia descartada para banho em cloro e retirada do nitrato de prata. 59

Figura 09 - Radiografia após a lavagem em cloro para demarcação dos tracejados do mapa. 60

Figura 10 - Folha de rosto da base de recorte do gabarito do mapa do Brasil. 63

Figura 11 - Folha de rosto da base de recorte do gabarito de símbolos para lousa. 63

Figura 12 - Demarcação das radiografias para transferir os tracejados da base em papel. 64

Figura 13 - Recorte da radiografia separada na parte tracejada com estilete.

Figura 14 - Gabarito de símbolos após a impressão da radiografia em impressora. 65

Figura 15 - Folha de rosto da base de recorte do gabarito de curvas proporcionais. 67

Figura 16 - Radiografia impressa pelo lado ilegível em impressora para o recorte.

Figura 17 - Tabela em formato A-5 com espaço para transcrever dados com até 30 elementos para a construção de mapas ordenados, quantitativos, qualitativos ou dinâmicos.

Figura 18 - Tabela em formato A-6 utilizada para elaborar mapas com poucos elementos. 69

Figura 19 - Matriz com espaço para o fundo de mapa em branco. 69

Figura 20 - Aplicação de pó de giz sobre toda a superfície do gabarito.

Figura 21 - Preenchimento do mapa em lousa com gabarito do mapa do Brasil.

Figura 22 - Preenchimento de círculos proporcionais com gabarito individual. 72 
Figura 23 - Tabela com dados em valores relativos para mapas ordenados.

Figura 24 - Matriz com fundo de mapa da América do sul e elaboração do mapa. 73

Figura 25 - Tabela pequena (tamanho A-6) para mapas quantitativos. 74

Figura 26 - Matriz com o planisfério equidistante centralizado na China. 74

Figura 27 - Mapa qualitativo em lousa elaborado com gabarito de símbolos ampliados. 75

Figura 28 - Matriz para a elaboração do mapa da lousa com gabarito de símbolos. 75

Figura 29 - Tabela com dados adaptados para a construção de mapas dinâmicos. 76

Figura 30 - Matriz com a projeção poliédrica e elaboração de mapa dinâmico com gabarito. 76

Figura 31 - Matriz utilizada para a construção do mapa quantitativo com círculos proporcionais. ..... 93

Figura 32 - Matriz utilizada para a construção do mapa ordenado. 93

Figura 33 - Modelo da avaliação aplicada nas três Turmas de 6으 Ano em 2010. 94

Figura 34 - Modelo da avaliação aplicada nas Turmas de 8ํㅡㄹ Ano em 2012. 95

Figura 35 - 6ำ Ano A -Mapa do Brasil - Regiões - População Absoluta. 96

Figura 36 - 6ํㅗ Ano C - Mapa do Brasil - Regiões - População Relativa. 96

Figura 37 - Mapa elaborado por F.S.S. Aluno com graves problemas de aprendizagem. 97

Figura 38 - Avaliação do aluno autista R. P.. 97

Figura 39 - Avaliação do aluno S.S.G. 98

Figura 40 - Avaliação de K.S.R. 98

Figura 41 - Preenchimento dos círculos proporcionais no mapa quantitativo utilizando gabarito. 99

Figura 42 - Procedimentos em lousa para a elaboração do mapa quantitativo a partir do gabarito de mapa do Brasil.

Figura 43 - Preenchimento do mapa ordenado com grafite em escala de granulação. 100

Figura 44 - Elaboração do mapa ordenado em lousa a partir do gabarito do mapa do Brasil. 100

Figura 45 - Parte expositiva da aula após os alunos construírem o mapa das regiões brasileiras. . 101

Figura 46 - Avaliação realizada com as mesmas Turmas dois anos após as atividades de elaboração de mapas em 2010.

Figura 47 - Avaliação sem consulta realizada em abril de 2011 com as três Turmas. 
Figura 50 - Matriz da primeira atividade da Turma 9J1 de elaboração de mapa dinâmico com tabela (origem / destino) em três classificações (alto / médio / baixo).

Figura 51 - Matriz simplificada da primeira atividade de elaboração de mapa.

Figura 52 - Matriz simplificada da primeira atividade da Turma 9J5 de elaboração de mapa quantitativo com o uso de gabarito de círculos.

Figura 53 - Matriz sem tabela com dados para a elaboração de mapa dinâmico.

Figura 54 - Matriz da Turma 9J5 do Planisfério em duplicata para raport (emenda das longitudes), com possibilidade de centralização no maior país produtor do minério escolhido.

Figura 55 - Matriz da atividade aplicada na Turma 9J3 com dados sobre os recursos hídricos do Oriente Médio.

Figura 56 - Matriz para elaboração de um mapa ordenado para as três Turmas a partir de uma tabela com diversos dados estatísticos da América do Sul.

Figura 57 - Tabela e matriz utilizada nas três Turmas para elaboração de três mapas analíticos e um mapa de síntese.

Figura 58 - Mapa ordenado elaborado na Turma 9J3 em aproximadamente 40 minutos utilizando granulações em grafite.

Figura 59 - Mapa dinâmico elaborado na Turma 9J1 em aproximadamente 50 minutos utilizando gabarito de curvas proporcionais.

Figura 60 - Mapa quantitativo elaborado na Turma 9J5 em aproximadamente 30 minutos utilizando gabarito de círculos proporcionais.

Figura 61 - Mapa ordenado elaborado individualmente nas três Turmas em aproximadamente 40 minutos.

Figura 62 - Mapa dinâmico elaborado pela Turma $9 \mathrm{~J} 1$ em aproximadamente 50 minutos com gabarito de curvas proporcionais.

Figura 63 - Mapa de síntese elaborado pelas três Turmas entre 60 a 80 minutos a partir do cálculo de três mapas analíticos.

Figura 64 - Mapa ordenado da América do Sul elaborado com critérios de classificação de dados próprios de cada aluno.

Figura 65 - Mapa quantitativo elaborado com gabarito de círculos proporcionais com tema relacionado ao assunto em estudo (Economia da América do Sul).

Figura 66 - Mapa ordenado da América do Sul com o tema: "automóveis no continente". 
Figura 67 - Mapa dinâmico do Japão elaborado com gabarito de curvas proporcionais. 138

Figura 68 - Mapa ordenado do Oriente Médio elaborado com critérios de classificação de dados próprios de cada aluno.

Figura 69 - Exemplos de mapas temáticos estudados durante a parte teórica sobre o tema. 139

Figura 70 - Preenchimento de mapa ordenado da África com granulações utilizando grafite. 140

Figura 71 - Croqui das regiões africanas e tabela elaborada para explicação dos procedimentos.. 140

Figura 72 - Elaboração de mapa dinâmico com o uso de gabarito de curvas proporcionais. 141

Figura 73 - Croqui e tabela em lousa para procedimentos de elaboração de mapa dinâmico.

Figura 74 - Planisfério elaborado com gabarito em duplicata para centralização na longitude $180^{\circ}$.

Figura 75 - Elaboração de mapa com os principais parceiros comerciais do Japão utilizando gabarito de curvas proporcionais e matriz com tabela "origem/destino".

Figura 76 - Planisfério elaborado em lousa com gabarito em duplicata centralizado no Japão. 143

Figura 77 - Preenchimento de mapa quantitativo com o uso de gabarito de círculos proporcionais e matriz em duplicata para raport (emenda das longitudes) centralizado em qualquer localidade. ..... 143

Figura 78 - Elaboração de mapas analíticos e de síntese do Grande ABC a partir de dados em valores relativos apresentados em tabela para construção de mapas ordenados.

Figura 79 - Mapa do Grande ABC e critérios escritos na lousa para explicação dos procedimentos de elaboração de mapas ordenados.

Figura 80 - Frente do material utilizado para a parte teórica com noções básicas de Cartografia

Temática, Semiologia Gráfica e exemplos das variáveis visuais da imagem.

Figura 81 - Verso do material com exemplos de mapas e procedimentos para elaboração

de mapas ordenados, quantitativos e diversos.

Figura 82 - Exercícios prévios dos procedimentos para elaboração de mapas temáticos.

Figura 83 - Tabelas, classificações e tipos de mapas exemplificados em lousa para acompanhamento das alunas.

Figura 84 - Preenchimento do mapa ordenado após os exercícios, com utilização de lápis de cor. 150

Figura 85 - Preenchimento do mapa ordenado com cores ordenadas. 151

Figura 86 - Preenchimento do mapa quantitativo com gabarito de círculos proporcionais. 151

Figura 87 - Preenchimento do mapa qualitativo com gabarito de símbolos diversos. 152

Figura 88 - Preenchimento do contorno do mapa qualitativo e acabamento final do mapa. 152 
Figura 89 - Exemplo de um mapa ordenado acabado, com tabelas de distribuição,

classificação e conversão de dados.

Figura 90 - Exemplo de um mapa quantitativo acabado, com tabelas de distribuição, classificação e conversão de dados em matriz para os três tipos de mapas.

Figura 91 - Exemplo de um mapa qualitativo acabado, com tabela de dados em matriz para os três tipos de mapas.

Figura 92 - Exposição de mapas temáticos ordenados em papel para sobreposição

de mapas em transparências com círculos proporcionais.

Figura 93 - Exemplo de mapas de Santo André em papel com temas sobrepostos

em transparências com diversos temas relacionados à educação.

Figura 94 - Exemplo de mapas do Grande ABC com temas sobrepostos em transparências.

Figura 95 - Matriz do mapa de Santo André dividido por aglomerados dos bairros. 156

Figura 96 - Matriz e mapa mudo de Santo André para mapa ordenado, quantitativo ou qualitativo. 156

Figura 97 - Matriz com tabela, procedimentos e mapa mudo do Grande ABC para

elaboração de mapa ordenado, quantitativo ou qualitativo. 157

Figura 98 - Tabela com procedimentos para elaboração de mapa ordenado, quantitativo ou qualitativo do município de Santo André. 


\section{ÍNDICE DE TABELAS}

Tabela 01 - Tabela com os tipos de linguagens e suas classificações.

Tabela 02 - Tabela de Jacques Bertin com as variáveis visuais apresentadas nos mapas. ............. 26

Tabela 03 - Subdivisão dos mapas analógicos e os mapas temáticos escolares. .............................. 29

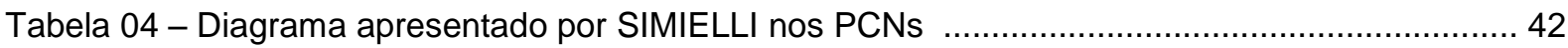

Tabela 05 - Base de cálculo utilizada para ampliação com porcentagem em fotocopiadoras. .......... 52

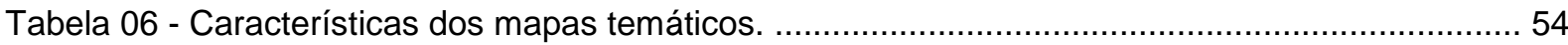

Tabela 07 - Organograma dos gabaritos e matrizes elaborados e disponibilizados neste trabalho. . 58

Tabela 08 - Cronograma de todas as atividades e avaliações realizadas entre 2010 e 2012. .......... 79

Tabela 09 - Avaliação de desempenho entre as três Turmas do 6ำ Ano. ......................................... 86

Tabela 10 - Relatório dos alunos classificados "não-satisfatórios"(NS) pelo professor do $6^{\circ}$ Ano. .... 87

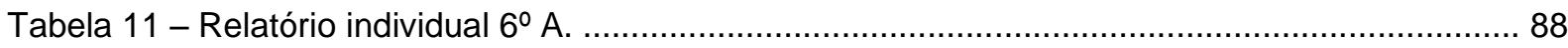

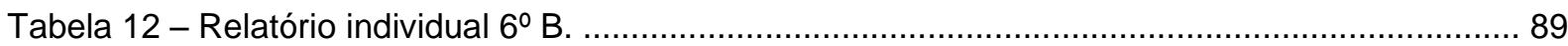

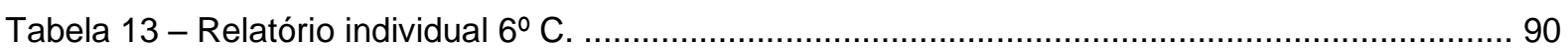

Tabela 14 - Relatório comparativo do 6ํㅡㄹ Ano em 2010 e 2012. (participantes em 2010) .................. 91

Tabela 15 - Relatório comparativo do 6ํA Ano em 2010 e 2012. (não participantes em 2010) ............ 92

Tabela 16 - Relatório comparativo do 6ํㅗ Ano em 2010 e 2012. (geral) …........................................ 92

Tabela 17 - Relatório geral de abril de 2011 com resultado abaixo do esperado em relação à assimilação do tipo de mapa que cada Turma elaborou.

Tabela 18 - Relatório de desempenho dos alunos com rendimento superior a 70\% da avaliação total da prova de Geografia entre as Turmas de 9o Ano realizadas em abril de 2011.

Tabela 19 - Relatório de desempenho dos alunos com rendimento inferior a $70 \%$ da avaliação entre as Turmas de 9ํㅡㄹ Ano realizadas em abril de 2011.

Tabela 20 - Relatório individual de leitura cartográfica da Turma 9J1 com os temas abordados na avaliação de abril de 2011.

Tabela 21 - Relatório individual de leitura cartográfica da Turma 9J3 com os temas abordados na avaliação de abril de 2011 
Tabela 22 - Relatório individual de leitura cartográfica da Turma 9J5 com os temas abordados na avaliação de abril de 2011.

Tabela 23 - Relatório geral de desempenho das atividades realizadas em agosto de 2011.

Tabela 24 - Relatório de desempenho dos alunos com rendimento superior a 70\% da avaliação total da prova de Geografia entre as Turmas de 9o Ano realizadas em agosto de 2011.

Tabela 25 - Relatório de desempenho dos alunos com rendimento inferior a 70\% das atividades de agosto de 2011.

Tabela 26 - Relatório individual de leitura cartográfica da Turma 9J1 com os temas abordados na avaliação de agosto de 2011.

Tabela 27 - Relatório individual de leitura cartográfica da Turma 9J3 com os temas abordados na avaliação de agosto de 2011.

Tabela 28 - Relatório individual de leitura cartográfica da Turma $9 \mathrm{~J} 5$ com os temas abordados na avaliação de agosto de 2011.

Tabela 29 - Relatório geral de desempenho entre as Turmas de 9ํㅡㅇ Ano com as atividades e avaliações realizadas em novembro de 2011.

Tabela 30 - Relatório de desempenho dos alunos com rendimento superior a $70 \%$ da avaliação total da prova de Geografia entre as Turmas de 9o Ano realizadas em novembro de 2011.

Tabela 31 - Relatório de desempenho dos alunos com rendimento inferior a $70 \%$ da avaliação total da prova de Geografia entre as Turmas de 9o Ano realizadas em novembro de 2011.

Tabela 32 - Relatório individual de leitura cartográfica da Turma 9J1 com os temas abordados na avaliação de novembro de 2011.

Tabela 33 - Relatório individual de leitura cartográfica da Turma 9J3 com os temas abordados na avaliação de novembro de 2011.

Tabela 34 - Relatório individual de leitura cartográfica da Turma 9J5 com os temas abordados na avaliação de novembro de 2011. 


\section{ÍNDICE DE MATERIAIS DIDÁTICOS EM APÊNDICE}

\section{GABARITOS PARA LOUSA}

Material 01 - Gabarito de mapa mudo - BRASIL 168

Material 02 - Gabarito de mapa mudo - AMÉRICA DO SUL 178

Material 03 - Gabarito de mapa mudo - PLANISFÉRIO - projeção equivalente 187

Material 04 - Gabarito de mapa mudo - PLANISFÉRIO - projeção equidistante . 194

Material 05 - Gabarito de mapa mudo - PLANISFÉRIO - projeção poliédrica 203

Material 06 - Gabarito de CíRCULOS PROPORCIONAIS - lousa 208

Material 07 - Gabarito de SÍMBOLOS DIVERSOS / PROPORCIONAIS - lousa 211

\section{GABARITOS INDIVIDUAIS}

Material 08 - Gabarito de CÍRCULOS PROPORCIONAIS - individual 214

Material 09 - Gabarito de SÍMBOLOS DIVERSOS / PROPORCIONAIS - individual 216

Material 10 - Gabarito de CURVAS PROPORCIONAIS - individual 218

\section{TABELAS E MATRIZES INDIVIDUAIS}

Material 11 - Tabela e procedimentos para cálculos de dados estatísticos - tamanho A-5 ........... 220

Material 12 - Tabela e procedimentos para cálculos de dados estatísticos - tamanho A-6 ........... 221

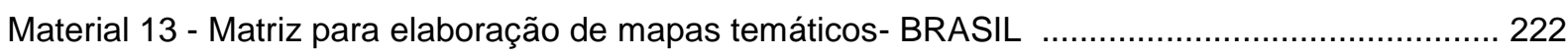

Material 14 - Matriz para elaboração de mapas temáticos- AMÉRICA DO SUL ................................ 223

Material 15 - Matriz para elaboração de mapas temáticos- PLANISFÉRIO- projeção equivalente . 224

Material 16 - Matriz para elaboração de mapas temáticos- PLANISFÉRIO- projeção equidistante 225

Material 17 - Matriz para elaboração de mapas temáticos- PLANISFÉRIO- projeção poliédrica ... 226

Material 18 - Matriz para elaboração de mapas temáticos- EM BRANCO …..................................... 227

Material 19 - PLANISFÉRIO em duplicata para raport (emenda das longitudes) ............................ 228 


\section{RESUMO}

LEITE, Gerson Rodrigues. Materiais Didáticos para Cartografia Escolar: metodologias para a construção de mapas em sala de aula. Dissertação (Mestrado). FFLCH, Universidade de São Paulo, São Paulo, 2014.

A partir de experiências como docente da disciplina de Geografia no Ensino Fundamental e Médio, foi possível analisar as práticas didáticas que contribuem positivamente com o estudo da Geografia em sala de aula, especialmente atividades que envolvem a análise e elaboração de mapas temáticos em conjunto com o conteúdo programático aplicado durante o ano letivo. Neste cenário foi possível

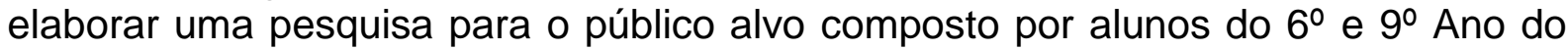
Ensino Fundamental e 3ํㅡㄹ Ano do Ensino Superior, com aplicação de atividades e avaliações entre o período de 2010 e 2012 em conjunto com o conteúdo programático de cada período. Esta pesquisa visou analisar o potencial e a viabilidade de aplicação de atividades de construção de mapas temáticos em sala de aula. Para tanto, foram desenvolvidos e adaptados materiais didáticos com recursos alternativos de baixo custo, como radiografias recicladas e papel, além de metodologias para reduzir o tempo de elaboração de mapas em sala de aula. Os critérios de avaliação dos alunos que participaram das atividades foram definidos para avaliar o grau de leitura cartográfica anterior e após a realização das atividades propostas. Para subsidiar a pesquisa, foi feita uma análise bibliográfica sobre a importância da Cartografia no Ensino de Geografia e os fatores que facilitam ou dificultam a realização de atividades práticas durante as aulas. Outro objetivo desta pesquisa foi disponibilizar os materiais aos professores de Geografia para reprodução e/ou adaptação. Assim, os materiais produzidos foram padronizados e apresentados da maneira mais simples possível, a partir de matérias-primas de fácil acesso em qualquer localidade. Os resultados obtidos mostram que após a construção de mapas temáticos em sala de aula, os alunos apresentam melhor rendimento na leitura e interpretação de mapas e temas relacionados à Geografia, especialmente os alunos com maiores dificuldades de aprendizagem. É possível assim, afirmar que a construção de mapas em sala de aula de forma constante é viável, contribui para o ensino de Geografia, e, consequentemente, para a formação escolar de alunos de todos os níveis do Ensino.

Palavras Chave: Educação, Ensino de Geografia, Cartografia Escolar, Material Didático, Elaboração de Mapas, Material Reciclado. 


\section{ABSTRACT}

LEITE, Gerson Rodrigues. Instructional Materials for School Cartography: methodologies for the construction of maps in the classroom. Thesis (Master). FFLCH, University of São Paulo, São Paulo, Brazil, 2014.

From experiences as a Geography teacher in elementary and high school, it was possible to analyze the teaching practices that contribute positively to the study of geography in the classroom, especially activities that involve the analysis and preparation of thematic maps in together with the curriculum implemented during the school year. In this scenario it was possible to develop a survey for the target audience that consists of students from 6th and 9th year of elementary school and 3 Year Higher Education, with application activities and assessments between the period 2010 and 2012 in conjunction with the syllabus of each period. This research aimed to analyze the potential and feasibility of construction activities of thematic maps in the classroom. Thus, we developed and adapted learning materials with low cost alternative resources, such as radiographs and recycled paper, and methodologies to reduce the time of preparation of maps in the classroom. The evaluation criteria of the students who participated in the activities were defined to assess the degree of previous cartographic reading and following completion of the proposed activities. To support the research, an analysis of the literature on the importance of cartography in the Teaching of Geography and the factors that facilitate or hinder the achievement of practical activities during lessons. Another objective of this research was providing materials to teachers of Geography for reproduction and / or adaptation. Thus, the materials produced were standardized and presented in the simplest possible way, from raw materials for easy access from any location. The results show that after the construction of thematic maps in the classroom, students have better performance in reading and interpreting maps and topics related to geography, especially students with major learning difficulties. You can thus say that the construction of maps in the classroom is feasible steadily contributing to the teaching of geography, and, consequently, for the schooling of students from all levels of education.

Keywords: Education, Teaching Geography, Cartography School, Educational Material, Elaboration of Maps, Recycled Material. 


\section{APRESENTAÇÃO}

A Cartografia Escolar é um campo de grande importância para pesquisadores no desenvolvimento e utilização de mapas em todos os níveis do Ensino, desde a pré-escola com análises e propostas de atividades cartográficas, até o Ensino Superior, com a formação e preparação de professores para o Ensino Fundamental.

Este trabalho surgiu a partir da observação do cotidiano das práticas didáticas de Geografia no Ensino Fundamental II, especificamente com o uso da Cartografia Temática Escolar na disciplina. Muitas vezes o professor encontra dados estatísticos suficientes de uma localidade específica, com possibilidade de fazer cruzamentos e cálculos para produzir mapas sobre um tema geográfico e acaba abandonando sua ideia pela falta de recursos para encontrar mapas adequados às suas necessidades.

As questões apresentadas a partir desta observação foram principalmente as dificuldades que os professores do Ensino Fundamental encontram para aplicar atividades cartográficas durante as aulas de Geografia, a baixa carga horária semanal para um conteúdo programático extenso da disciplina e a falta de recursos financeiros, didáticos e tecnológicos para aplicar atividades práticas durante as aulas.

O objetivo deste trabalho é apresentar aos professores de Geografia entre outros profissionais, a possibilidade de construir seus próprios mapas para realizar atividades relacionadas a Cartografia, especialmente a Cartografia Escolar, em conjunto com outras atividades práticas manuais em sala de aula. São apresentados mapas com diversas escalas e projeções que podem ser adequados de acordo com a conveniência e necessidade de cada professor não só do Ensino Fundamental e Médio, mas também de professores do Ensino Superior, especialmente dos cursos de Licenciaturas, e até mesmo na área de Geoprocessamento, como foi possível observar durante as experiências das atividades aplicadas.

Para a realização desta dissertação, foi feita uma avaliação sobre a importância da Cartografia no Ensino de Geografia considerando que no Ensino Fundamental, os melhores resultados no processo ensino-aprendizagem são alcançados com métodos didáticos que se utilizam da construção e/ou observação 
dos fenômenos geográficos estudados.

Por isto, esta pesquisa tem como objetivo, apresentar aos profissionais da Geografia e do Ensino, materiais e metodologias alternativas de construção de mapas temáticos escolares que podem ser aplicados de maneira simples, rápida e com baixo custo nas escolas de Ensino Fundamental, Médio e Superior, e contribuir para a difusão da linguagem cartográfica em sala de aula. Além disto, propor aos professores de Geografia, autores de livros didáticos e ao público em geral, metodologias de elaboração e exercícios práticos de construção de mapas temáticos no Ensino Fundamental II e Médio, que podem ser adaptados à realidade encontrada em cada escola ou sala de aula nas diferentes séries.

A partir de dados estatísticos, tabelas para manuseio de dados e matrizes com mapas mudos, é possível construir uma infinidade de mapas temáticos de forma artesanal utilizando critérios técnicos semelhantes aos mapas produzidos por cartógrafos por meio digital ou analógico. Porém, neste trabalho, a proposta de elaboração de mapas é de construção de maneira artesanal com a utilização de procedimentos com adaptações e simplificação de dados, mas com objetivo de não prejudicar a comunicação visual dos mapas e tornar possível sua elaboração na sala de aula em até cinquenta minutos. Com o auxílio de gabaritos de mapas e símbolos em pequenos e grandes formatos, se torna mais fácil a elaboração de mapas em papel, e também em lousa, para facilitar a compreensão e o acompanhamento dos alunos.

Em alguns tipos de mapas propostos, com apenas dez fotocópias de uma tabela e vinte cópias de uma matriz com fundo de mapa em papel, é possível fazer uma atividade de construção de mapas ordenados para quarenta alunos. Para outros tipos de materiais apresentados, é possível elaborar gabaritos para construir também mapas quantitativos, qualitativos e dinâmicos em modos de implantação pontual, linear e zonal.

Este trabalho pretende apresentar a linguagem da Cartografia escolar como recurso para a construção do conhecimento e do raciocínio do aluno não só com suas técnicas de elaboração de mapas, mas também de forma cognitiva em outros campos da Geografia, e entre outras áreas da Ciência. 


\section{1 - IMAGEM}

Existem vários conceitos e definições que são atribuídos à "IMAGEM", que vão desde as mais antigas, definidas por Platão, até teóricos contemporâneos. Para analisar a linguagem cartográfica, Archela define "imagem" como:

Todos os documentos cujo suporte é a utilização das duas dimensões do plano que se apresentam diante de nossos olhos a um momento qualquer, seja em um texto como ilustração, ou como um instrumento para orientar o discurso científico através do conteúdo da informação apresentada, é considerado imagem. (ARCHELA, 1999, p. 5).

As imagens de duas dimensões são compostas por desenhos, pinturas, traços, fotografias, mapas, etc., e pertencem ao mundo da comunicação visual. (MARTINELLI, 1993)

Aprender a ler imagens, observá-las, decodificá-las ou codificá-las, é uma tarefa que se aprende no cotidiano, incluindo o espaço escolar. Para este aprendizado podemos denominar "alfabetização visual". (SANTAELLA, 2012, p. 13)

A linguagem visual é composta por imagens que estão presentes nas pessoas durante todo o instante, incluindo durante o sono, por meio dos sonhos. (SANTAELLA, 2012, p. 8) Além das imagens receptadas pela retina, o cérebro também forma imagens constantemente a partir da observação ou da abstração, que pode ser de uma ação involuntária ou induzida pelo observador, incluindo o deficiente visual.

Ensinar ao aluno, ou mesmo aprimorar sua capacidade de abstrair imagens, é de grande importância e ao mesmo tempo um desafio para o professor do Ensino Fundamental. As pessoas, e especialmente as crianças, vivem cercadas por linguagens visuais, como desenhos que observam ou constroem constantemente na pré-escola, ou desenhos animados que assistem na mídia.

Desenvolver habilidades de leitura e interpretação de imagens é uma tarefa complexa para o professor do Ensino Fundamental, que procura suportes em várias disciplinas, como Literatura, Artes, História, Sociologia, Geografia, entre outras.

Especificamente para a leitura cartográfica, o trabalho é ainda mais complexo devido às particularidades do mapa e seus códigos específicos. Porém, não podemos generalizar o termo "alfabetização visual" buscando compará-la a 
linguagem verbal. Alfabetização visual significa aprender a ler imagens, desenvolver a observação de seus aspectos e traços que constituem a imagem. (SANTAELLA, 2012, p. 13)

Para a leitura do mapa como uma forma de linguagem, composto por imagens visuais, é importante que se dê a mesma importância oferecida para a leitura de outras linguagens, como a escrita. "Assim, podemos passar a chamar de leitor não apenas aquele que lê livros, mas também o que lê imagens". (SANTAELLA, 2012, p. 10.)

O mapa não é como um desenho elaborado de forma artística ou sem critérios, e sim um complexo meio de comunicação que envolve diversas áreas científicas, especialmente a Cartografia, foco do nosso trabalho. Da mesma forma, a leitura de mapas também é algo importante para as pessoas.

$\mathrm{Na}$ elaboração de mapas temáticos, as propriedades da imagem visual são utilizadas para mostrar as relações de diferença, ordem e proporcionalidade entre os dados estatísticos. (BERTIN, 2000)

Assim como a linguagem escrita, o mapa requer técnicas de aprendizagem tanto para sua leitura como para sua elaboração e diversos teóricos produziram e produzem inúmeros trabalhos relacionados a este tema. Aparecem cada vez mais, novos métodos de elaboração de mapas para diversas áreas, o que torna imprescindível conhecer este universo da Cartografia.

Para a representação do espaço concreto que os alunos do Ensino Fundamental estudam durante as aulas de Geografia, torna-se necessário considerar as diversidades e as habilidades que cada aluno traz como pré-requisito das séries anteriores. Almeida e Passini (2001, p. 27) afirmam que por volta de $11 \mathrm{e}$ 12 anos de idade, os alunos podem compreender os elementos do espaço concreto apenas com sua representação em um mapa, o que pode ser exercitado com o acompanhamento do professor em sala de aula. E isto é importante para que o professor compreenda e elabore sua didática de acordo com a realidade de cada turma ou aluno. 


\section{2 - LINGUAGEM CARTOGRÁFICA}

A linguagem cartográfica é um complexo meio de comunicação que apresenta duas linguagens: o mapa propriamente dito e a escrita verbal.

O mapa segue as regras da linguagem gráfica, formada por imagens diversas em duas dimensões do plano, e que o observador atribui um sentido geográfico de acordo com sua formação cultural e seu conhecimento da linguagem cartográfica. A escrita verbal é atribuída como meio de comunicação ao mapa onde a linguagem gráfica não pode ser aplicada, ou é menos eficiente, como na legenda, título, fonte pesquisada, e informações complementares utilizadas nos mapas.

A linguagem apresentada pelos mapas, especificamente pelos mapas temáticos produzidos por escolares, necessita de várias etapas para que os alunos possam decodificá-la e interpretá-la. Para a compreensão da linguagem cartográfica pelos alunos, são necessárias inúmeras atividades prévias que podem ser praticadas em sala de aula, como exercícios práticos para estudar a visão vertical e oblíqua, o mapeamento do trajeto casa-escola, e outras etapas que podem ser apresentadas na pré-escola e Ensino Fundamental I. A linguagem cartográfica aplicada à área escolar está associada ao estudo da semiótica, ciência geral de todas as linguagens, especialmente dos signos.

O signo é algo que representa o seu próprio objeto. Ele só é signo se tiver o poder de representar esse objeto, colocar-se no lugar dele, e, então, ele só pode representar esse objeto de um certo modo e com uma certa capacidade. O signo só pode representar seu objeto para um intérprete, produzindo na mente deste, um outro signo, considerando o fato de que o significado de um signo é outro signo. (SIMIELLI, 2007, p. 78)

Além disto, as imagens são auto-suficientes e pode-se dizer que a linguagem escrita e a linguagem visual se completam representando seus signos específicos. (SANTAELLA, 2012, p.129)

As linguagens se classificam e se subdividem em:

- sequenciais e verbais, quando é preciso ter uma sequencia de leitura para interpretação, como textos escritos, discursos orais, etc.; 
- sequenciais e não-verbais, quando é necessário estabelecer uma sequência para compreender as linguagens que não se utilizam de textos verbais, como música, matemática, filmes ou quadrinhos;

- não-sequenciais e verbais, quando figuras verbais são utilizadas em quadros ou obras de arte, sem a necessidade de o leitor seguir uma sequencia para interpretação;

- não sequenciais e não-verbais, quando a linguagem não é composta por textos verbais e não há necessidade de seguir uma sequencia para interpretação, como fotografias, pinturas e mapas, como mostra a tabela a seguir:

\begin{tabular}{|c|c|c|c|}
\hline \multicolumn{4}{|c|}{ UMA CLASSIFICAÇÃO ELEMENTAR DAS LINGUAGENS } \\
\hline & & \multicolumn{2}{|c|}{ Verbal } \\
\hline & & $\operatorname{sim}$ & não \\
\hline \multirow{2}{*}{ Sequencial } & sim & $\begin{array}{l}\text { discursos verbais } \\
\text { (orais e escritos) }\end{array}$ & $\begin{array}{l}\text { música, matemática } \\
\text { filmes, quadrinhos }\end{array}$ \\
\hline & não & $\begin{array}{l}\text { quadros, figuras } \\
\text { verbais-gráficas }\end{array}$ & $\begin{array}{l}\text { pinturas, fotografias, figuras } \\
\text { não-verbais, cartas e mapas }\end{array}$ \\
\hline
\end{tabular}

Tabela 01 - Tabela com os tipos de linguagens e suas classificações quanto à sua comunicação em relação à sequência e a utilização ou não da linguagem verbal para sua leitura.

A imagem do mapa é considerada uma linguagem "não-verbal" e "nãosequencial" (NVNS), pois para ser interpretada, não é preciso necessariamente depender da linguagem escrita, com exceção da legenda, título e fonte, e o leitor não precisa seguir uma sequência de leitura. Pode ser ainda mais comunicativa e eficiente se aproveitar as regras de construção de mapas, como as regras da Semiologia Gráfica. Se for possível se comunicar de maneira mais eficaz utilizando o mapa, o mesmo pode ser ainda mais eficiente se apresentar a informação de maneira que o leitor, após observar "a imagem do mapa", seguindo diretamente para o título, já possa compreender a informação apresentada. O mapa necessita de um tratamento visual para ser "visto" e não "lido", como a linguagem verbal. (FONSECA, 2004, p. 204)

É preciso compreender a diferença entre um trabalho artístico e uma representação gráfica elaborada pelo aluno. $\mathrm{Na}$ arte existe uma chamada "liberdade de criação" que possibilita escolher de forma aleatória, cor, forma, ou tamanho para a elaboração de um trabalho em uma superfície bidimensional. Para a elaboração de 
um mapa temático, é necessário obedecer a uma série de regras para que o leitor da obra elaborada tenha condições de interpretá-la da maneira mais objetiva possível. Segundo Bertin:

A representação gráfica não é uma arte. Ao contrário do "grafismo", é uma linguagem rigorosamente definida, aliás, é a única que opera sobre conjuntos rigorosamente definidos. Não é, portanto, regida nem pela "teoria da comunicação" nem pela psicologia. De fato, observar um cartaz, um sinal de trânsito ou ler uma palavra exige apenas um tempo de percepção: "do que se trata"? Agora, perceber um gráfico exige como acabamos de ver, dois tempos distintos de percepção: 1 De quais componentes se trata/ 2 - Quais são as relações entre esses componentes? (BERTIN, 1980, p. 168)

A escolha pela comunicação cartográfica para transmitir uma informação geográfica necessita de regras básicas de elaboração de mapas, para que sua visualização não traga dúvidas a respeito da informação, ou mesmo que confunda o leitor. Se o mapa não apresentar estas características, é considerado "inútil”.

Numerosas construções, numerosos mapas e diagramas são inúteis
ou porque a transcrição visual é ruim ou então porque elas não levam
em conta a "gramática gráfica", desobedecendo as leis de percepção
visual. Ora, uma imagem gráfica é feita para ser VISTA e a primeira
impressão, o primeiro impacto visual é o que fica retido na memória.
Um mapa mal visualizado pode então comunicar uma falsa
informação. (BONIN, 1982, p. 83)

Em sala de aula, as infinitas possibilidades de elaboração de mapas com uso de critérios diferentes para apenas um dado estatístico, pode servir para muitas discussões com os alunos a respeito dos critérios utilizados por cartógrafos para a manipulação de dados estatísticos, critérios de escolhas de cores e formas, entre outros assuntos que serão abordados adiante.

Para mapas elaborados por alunos do Ensino Fundamental, embora seja de forma artesanal, podem perfeitamente ser elaborados com base em regras básicas para a construção de mapas, com o objetivo de não apresentar ambiguidades, ou seja, não confundir ou mesmo apresentar uma resposta visual falsa para o leitor. Questão nem sempre considerada em livros didáticos, Atlas ou mídias digitais. Mapas que apresentam cores sem critérios, ou uma sobrecarga de detalhes inúteis, dificilmente são utilizáveis. (BONIN, 1982, p. 82) 
Da mesma forma que um artista plástico se esforça para que sua obra artística apresente uma linguagem polissêmica, com diversas interpretações, o cartógrafo, em tese, procura elaborar mapas utilizando forma, cores, textos etc., com a finalidade de apresentar um trabalho monossêmico, sem ambiguidades, com uma linguagem que apresente as informações com a mesma objetividade e compreensão entre os diversos tipos de leitores. "Reduzir a polissemia da imagem é um cuidado constante, se quisermos realmente atingir o usuário, e não somente impressioná-lo." (ARCHELA, 1999, p. 6)

Em escolas de Ensino Fundamental e Médio, é comum observar a utilização da linguagem escrita por professores de Geografia e em livros didáticos e, ao mesmo tempo, a subutilização de linguagens visuais como fotografias, vídeos, gráficos e mapas, embora no cotidiano dos alunos nos últimos anos, seja cada vez mais crescente o uso de imagens nos meios digitais portáteis e de grande porte.

Especificamente na disciplina de Geografia, a linguagem escrita é muito utilizada para a descrição e argumentação de fenômenos espaciais, que muitas vezes podem ser substituídas por outras linguagens mais eficientes, como ilustrações, fotografias, vídeos, animações e mapas.

O grande desafio é tratar a linguagem visual como transmissora de conhecimentos, e valorizar seu estudo da mesma forma em que é valorizada a linguagem escrita, uma vez que as duas se complementam (SANTAELLA, 2012, p. 14). A expressão linguistica e a visual são reinos distintos, como modos de representação e significados próprios de cada uma. Uma linguagem não substitui a outra. Portanto, não se justifica a ideia de que a leitura seja restrita à decifração de letras. Historicamente o código escrito foi se mesclando entre o alfabeto, os desenhos, as fotografias, os gráficos, os mapas etc. (SANTAELLA, 2012, p. 11)

As diferentes formas de linguagem se complementam e se auxiliam. Quando uma forma de linguagem é mais eficaz, ela pode naturalmente substituir a outra menos eficiente de acordo com a percepção de quem a elabora para transmití-la da melhor maneira possível ao receptor da linguagem. Santaella (2012, p. 111) afirma que as relações entre textos e imagem podem ser observadas de muitos pontos de vista, com significados subjetivos de acordo com a leitura atribuída pelo receptor. 


\section{1 - Semiologia Gráfica}

A Semiologia Gráfica compreende um conjunto de diretrizes utilizadas para a elaboração de mapas, gráficos e outras linguagens visuais utilizadas para transcrever a informação. Foi sistematizado na década de 1950 por Jacques Bertin e publicado na década de $1960 \mathrm{com}$ a utilização de um sistema de símbolos gráficos, e é considerado o único grande projeto na qual se encontram sistematizadas as regras para a construção de imagens racionais na comunicação de informações de caráter científico. (GIRARDI, 2000, p. 42)

A obra "A Neográfica e o Tratamento Gráfico da Informação", editada em 1986, contribuiu para a difusão da Semiologia Gráfica no Brasil, especialmente na área cartográfica. Até os dias atuais, a ciência apresentada pela Semiologia Gráfica desperta interesse de profissionais de diversas áreas relacionadas à comunicação visual, que procuram as melhores formas de comunicar a informação. (MARTINELLI, 2002, p. 125)

Segundo LE SANN, a Semiologia Gráfica se baseia na "percepção e na lógica" da visualização de imagens que todas as pessoas possuem, especialmente as crianças, que "ainda" não sofreram a interferência na sua leitura visual como os adultos.

A semiologia Gráfica constitui-se no instrumento de trabalho que utiliza todas as propriedades da percepção visual. É um instrumento construído por nós mesmos, que pode ser completado ou reduzido, transformado e classificado de novo. A Semiologia Gráfica é a forma visual da reflexão lógica. O visual e a lógica são dois domínios nos quais a criança é excelente. (Bertin Le test de base de La graphique.) A semiologia gráfica constitui-se numa linguagem visual, cujas bases são a percepção e a lógica. É um instrumento que possibilita "ver para aprender. (LE SANN, 2007, p. 102)

Jacques Bertin definiu as variáveis visuais e as primeiras regras de construção de imagem gráfica, que estrutura grande parte das construções gráficas. Ele sintetiza em uma tabela as variáveis visuais da imagem nas duas dimensões do plano para orientar o cartógrafo na elaboração de mapas temáticos. Os significados da imagem são os seguintes:

- tamanho: variação do grande, médio e pequeno; 
- valor: variação de tonalidade do branco ao preto;

- granulação: variação da repartição do preto no branco onde se deve manter a mesma proporção de preto e de branco;

- cor: variação das cores do arco-íris, sem variação de tonalidade, tendo as cores a mesma intensidade. Por exemplo: usar azul, vermelho e verde é usar a variável visual "cor". O uso do azul-claro, azul médio e azul escuro corresponde à variável "valor";

- orientação: são as variáveis de posição entre o vertical, o oblíquo e o horizontal;

- forma: agrupa todas as variações geométricas ou não;

Elas são múltiplas e diversas. (ARCHELA, 1999, p. 6)

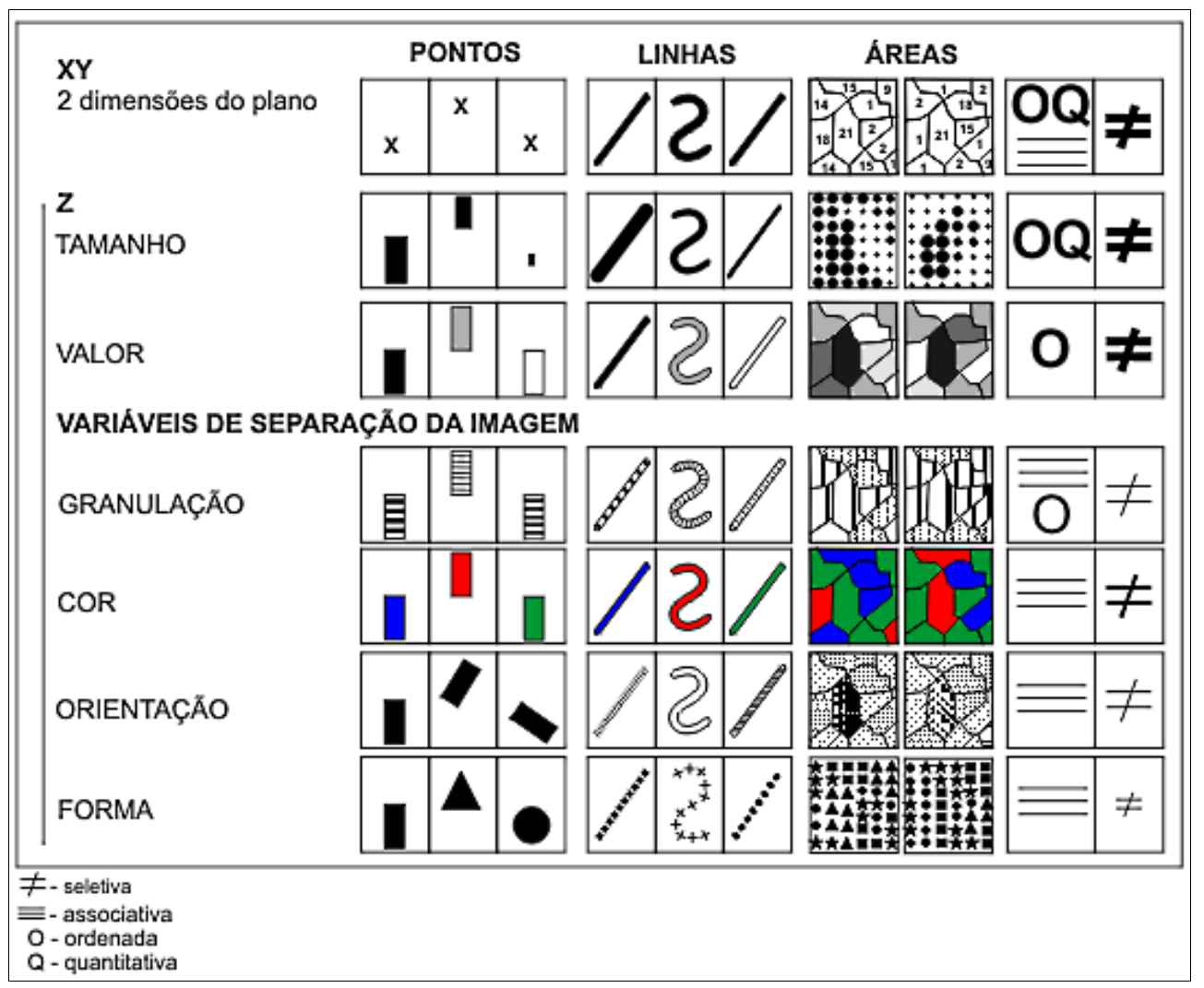

Tabela 02 - Tabela de Jacques Bertin com as variáveis visuais apresentadas nos mapas. (Fonte: BERTIN, 2000)

Para a representação de uma informação geográfica, a imagem gráfica pode ao mesmo tempo transmitir ao receptor as informações relacionadas à quantidade, ordem ou semelhança/diferença de um determinado fenômeno espacial e mostrar "onde ocorre", utilizando o mapa como recurso. A imagem gráfica é a forma visual percebida em um só golpe de vista, em um instante de tempo pelo leitor (BERTIN, 2000). 
Não existem mapas bons ou ruins, o que existe são construções que respondem ou não as questões que lhes são formuladas (BERTIN, 1980, p. 161). As duas questões básicas que um mapa precisa responder sem que o leitor recorra à legenda são:

1 - onde está o fenômeno representado?

2 - onde ocorre com maior ou menor intensidade? (nos mapas quantitativos) ou 0 que é diferente ou semelhante? (nos mapas qualitativos).

Bertin identifica três relações entre os elementos apresentados pelo mapa similaridade, ordem e proporcionalidade -, que consistem nos significados da representação gráfica, e são expressas pelas variáveis visuais - tamanho, valor, textura, cor, orientação e forma. Essas variáveis visuais têm ainda três modos de implantação: o pontual, o linear e o zonal. As duas dimensões do plano, mais as variáveis visuais - tamanho e valor- , são ditas "Variáveis da Imagem", pois constroem a imagem; porém a granulação, a cor, a orientação e a forma são ditas "Variáveis de Separação", pois, separam os elementos da imagem. (QUEIROZ, 2000, p. 122)

Infelizmente o uso de mapas temáticos em sala de aula ainda é um desafio nos dias atuais, principalmente sua elaboração por alunos durante as aulas de Geografia. Existe uma resistência por parte dos professores em trabalhar com a linguagem cartográfica no Ensino fundamental, e quando isto ocorre, os mapas utilizados são meras ilustrações para "mostrar" a localização do tema estudado, e não a distribuição espacial do fenômeno geográfico.

Embora as regras da Semiologia sejam limitadas para os novos recursos cartográficos que estão surgindo, para a elaboração de mapas escolares, ela foi ignorada durante muito tempo pelos educadores, especialmente ligados à Geografia, até mesmo por quem valoriza atividades construtivistas em sala de aula (FONSECA, 2004, p. 149)

Atividades de construção de mapas temáticos aplicadas no Ensino Fundamental, como o trabalho do professor Roberto Gimeno na década de 1980, comprovam a eficácia da Semiologia Gráfica aplicada à elaboração de mapas em sala de aula, fator que serviu como referência na elaboração desta pesquisa na qual foram adaptadas as metodologias e os materiais utilizados na época para a 
realidade atual de grande parte das escolas brasileiras. As técnicas de utilização de cores, granulações, linhas, curvas, círculos etc., em atividades com base na Semiologia Gráfica podem contribuir para o desenvolvimento do raciocínio dos alunos em sala de aula, e até serem adaptadas por outras disciplinas, como Artes e Matemática, por exemplo. 


\section{2 - A Possibilidade de Construir Mapas Escolares Artesanais}

Além da divisão entre criação e uso de mapas, também podemos subdividir a Cartografia em vários campos, e a criação ou elaboração de mapas pode ser de forma digital com recursos de informática ou analógica com recursos artesanais.

Também podem ser técnicos, com precisão de traçados, dados estatísticos, escala, tamanho de símbolos proporcionais, etc., ou escolar, com as mesmas características do mapa técnico, porém, elaborado de forma simplificada para viabilizar sua construção em sala de aula.

Para a elaboração de mapas artesanais em sala de aula, também podem ser aproveitados recursos digitais como fundo de mapas, matrizes de símbolos proporcionais e diversos, contornos de legendas, etc., conforme descrito na tabela 03. Estes recursos reduzem significativamente o tempo de elaboração pelos alunos, e não prejudica sua comunicação visual.

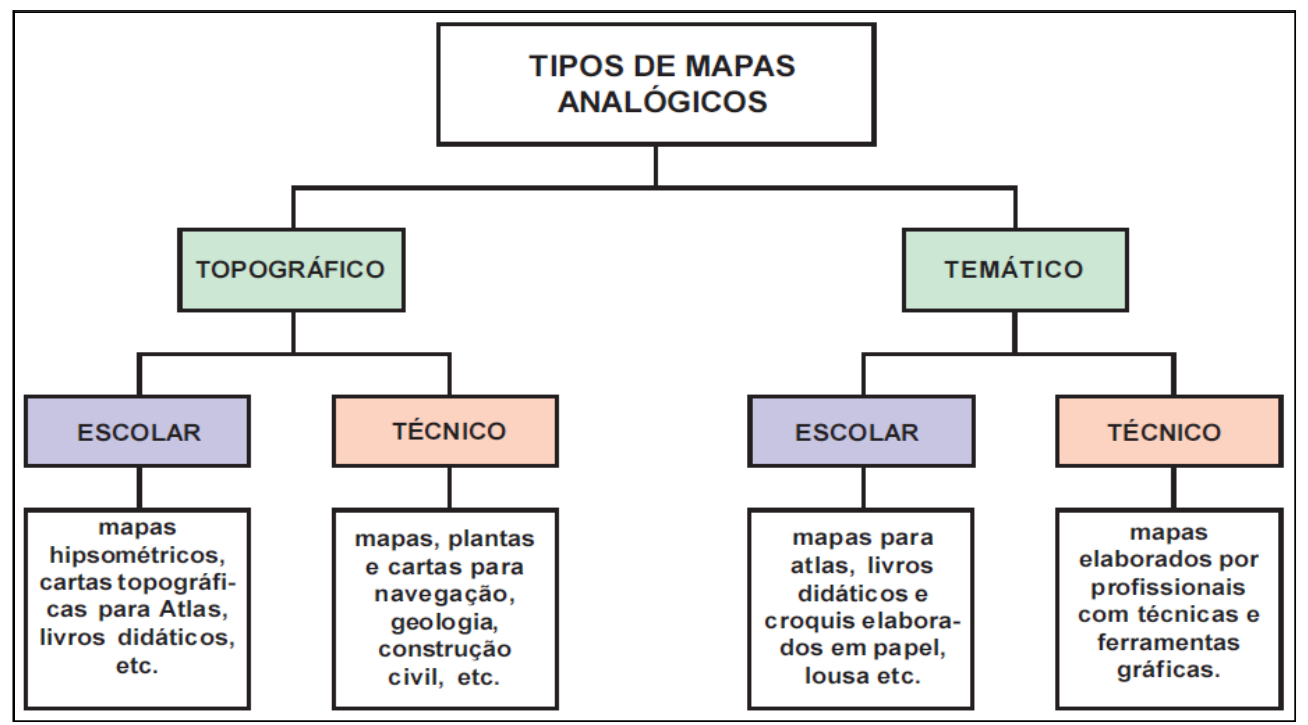

Tabela 03 - Subdivisão dos mapas analógicos em que se enquadram os mapas temáticos escolares. (LEITE, 2014)

O atributo da ciência cartográfica é a representação do espaço, em especial, do espaço geográfico, por meio de cartas, mapas, plantas, croquis, imagens, etc. (FRANCISCHETT, 2007, p. 4)

Existem vários mecanismos para simplificar os procedimentos de elaboração de mapas, como generalizações de dados, redução de elementos e fundos de 
mapas, cores e granulações, número de tamanhos de círculos e símbolos e uma infinidade de técnicas. Nesta proposta, o parâmetro estabelecido foi o máximo de simplificação dos procedimentos, até o limite de não prejudicar a comunicação dos mapas, ou seja, que visualmente os mapas possam responder sem recorrer à legenda, as duas perguntas básicas propostas por Bertin: - em tal lugar, o que há? tal caráter, onde está ? (BERTIN, 1988, p. 47)

Os temas escolhidos para compor os mapas visaram o acompanhamento do conteúdo programático de Geografia na ocasião da aplicação das atividades e também para avaliação da capacidade de leitura de mapas dos alunos, como foram demonstrados nas avaliações individuais e gerais.

A transferência da cartografia ensinada e praticada no ensino universitário para uma cartografia praticada e ensinada em sala de aula é um tema de muita discussão pela Cartografia Escolar.

Lívia de Oliveira mostra que existe uma infinidade de temas estudados pela Geografia que podem perfeitamente ser representados pela Cartografia Temática com a utilização de dados estatísticos, fundo de mapas, símbolos simplificados para a elaboração de mapas por alunos do Ensino Fundamental II de forma artesanal. Relevo, vegetação, clima, meio ambiente, demografia, geopolítica, e outros temas estudados em sala de aula em conjunto com a Cartografia, especialmente com a construção de mapas pelos alunos de forma constante. (OLIVEIRA, 2007, p. 24)

Em 1981, o professor Roberto Gimeno realizou uma atividade de elaboração de mapas temáticos na França para alunos da Escola Elementar (Ensino Fundamental). No trabalho "Uma Nova Abordagem da Cartografia na Escola Elementar" ' 1 , foi proposta uma atividade completa com todas as etapas para elaboração de mapas a partir da distribuição de dados estatísticos até o preenchimento dos mapas com cores, tons ou granulações. Trabalho realizado em seis semanas, com duração de 9 horas/aula apenas para as aulas de Geografia, além do apoio da disciplina de Matemática para a sistematização dos dados estatísticos. (GIMENO, 1991, p. 106)

O objetivo na época foi mostrar que é possível trabalhar cartograficamente informações geográficas seja qual for sua complexidade, com alunos da Escola

\footnotetext{
${ }^{1}$ Artigo traduzido para o português da Tese de Doutorado de GIMENO, Roberto. Apprendre à l'école par la graphique. Paris, Editions Retz, 1980, 192 p.
} 
Elementar (Ensino Fundamental). (GIMENO, 1991, p. 104) As tarefas foram divididas em:

- construção de tabelas de dados;

- construção de fundo de mapas;

- transcrição de dados;

- distribuição e classificação de dados;

- construção gráfica dos mapas analíticos;

- construção de mapas de síntese.

Este trabalho de Gimeno mostrou que as crianças são capazes de construir mapas e tomar decisões sobre o que é mapeado, além de fazer correlações e leitura crítica de mapas.

Para nosso trabalho, as atividades foram simplificadas com o objetivo de reduzir o tempo de elaboração de mapas em sala de aula, para viabilizar sua construção sem que seja necessário alterar o calendário do conteúdo programático pelo professor. As etapas de construção foram simplificadas para as atividades de acordo com a ocasião e o perfil da turma, seguindo basicamente os seguintes procedimentos:

- preenchimento dos dados estatísticos em tabela (ou até apresentando os dados prontos);

- distribuição, classificação e conversão de dados em tabela;

- preenchimento gráfico do mapa, título, legenda, fonte e acabamento em matriz.

Os dados estatísticos foram entregues prontos em tabelas para os alunos, preenchidos em lousa para a transcrição na tabela pelos alunos, ou até prontos nas avaliações. Para facilitar ainda mais os procedimentos, as etapas de distribuição, classificação e conversão de dados foram diagramadas na sequência em uma tabela única para elaboração de mapas ordenados, quantitativos, qualitativos e dinâmicos.

Os fundos de mapas também foram entregues prontos aos alunos em matrizes com espaço para o preenchimento de título, legenda e fonte pesquisada.

Estas adaptações possibilitaram construir mapas em até 30 minutos em sala de aula. Também foram realizadas atividades para construção de mapas de síntese, que mostrou a facilidade que os alunos têm em construir mapas após algumas experiências em atividades cartográficas mais simples. 
Nas Turmas do 9ำ Ano, os alunos construíram apenas as últimas etapas para se acostumarem com os procedimentos nos primeiros mapas, com a inclusão das outras etapas nos mapas seguintes.

Após a realização das atividades, foi possível afirmar que o ensino da linguagem cartográfica no Ensino Fundamental II necessita de um acompanhamento por parte dos professores para identificar o grau de conhecimentos básicos prévios dos alunos. Este fator muitas vezes dificulta a aplicação de atividades cartográficas, pois de acordo com a Turma em que está lecionando, é preciso realizar algumas atividades prévias, que incluem conhecimentos de outras disciplinas.

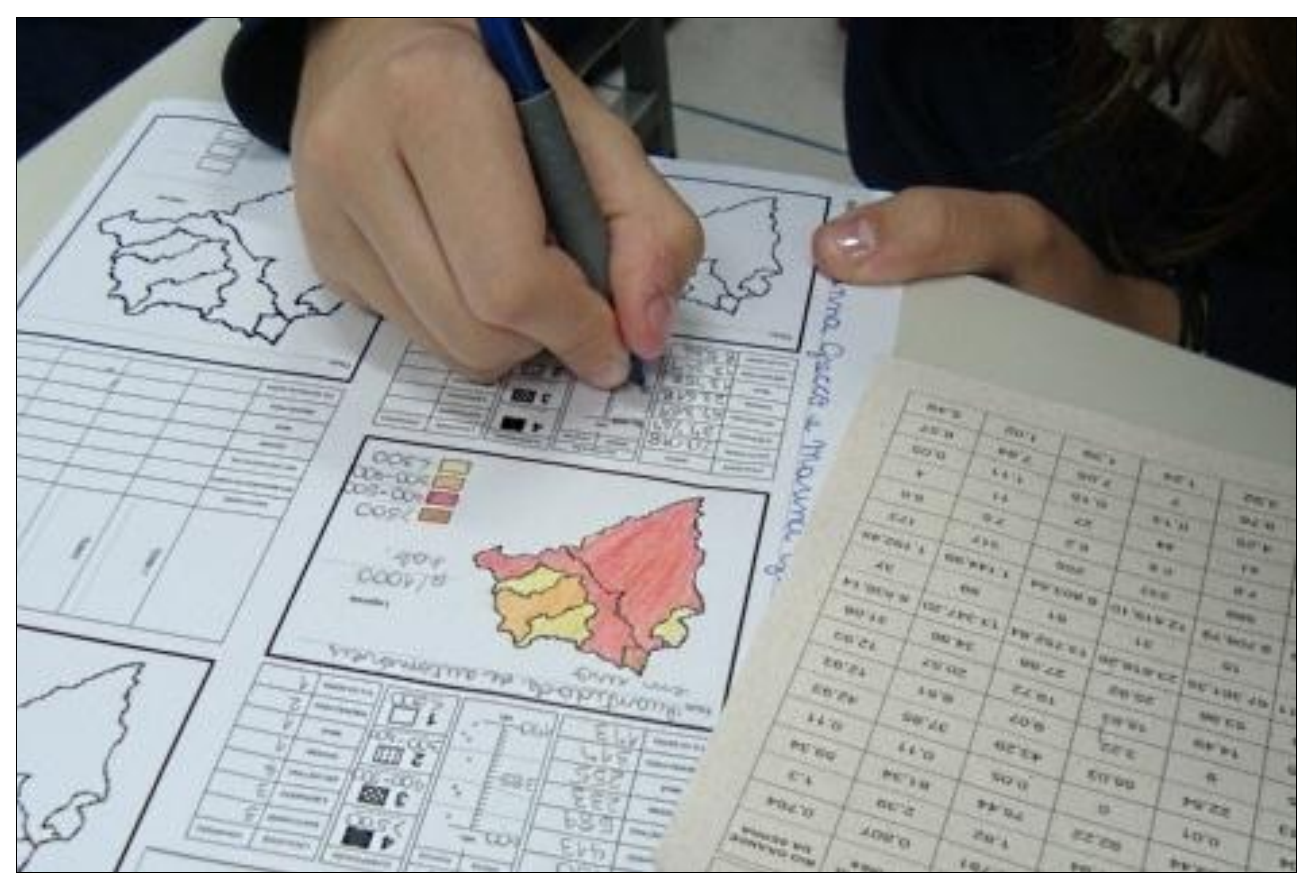

Figura 01: Critérios para organização e cálculos de dados em tabelas são pré-requisitos para a construção de mapas em sala de aula, como neste exemplo de mapa de síntese.

Isto pode ocorrer no Ensino Médio, quando, por exemplo, o professor precisa rever com seus alunos conhecimentos prévios de simplificação (generalizações) de dados estatísticos adquiridos no Ensino Fundamental II, durante a análise de uma tabela de dupla entrada (Eixo Cartesiano), ou mesmo no Ensino Fundamental I, com noções de lateralidade para orientação em espaços desconhecidos, como afirma Le Sann em seu relatório sobre uma atividade cartográfica realizada com alunos do Ensino Fundamental I: 
A análise do teste evidenciou a falta de atenção dos alunos. Verificouse que a régua milimetrada não pode ser introduzida antes da percepção das proporções não quantificadas. Os alunos apresentaram muitas dificuldades nos exercícios sobre as noções de espaço e de localização. São privilegiados os fatos no espaço, em detrimento do estudo do espaço em si. Por isso, muitos adultos têm dificuldades com a sua lateralidade e para orientar-se em espaços desconhecidos. $O$ exercício de classificação múltipla, no caso um quadro de dupla entrada, revelou que, apesar de amplamente utilizado na escola e na vida cotidiana, não foi assimilado como ferramenta para estruturação do pensamento lógico. Globalmente, esse teste mostrou que as crianças ingressam na quinta série, despreparadas para trabalhar com quadros de dados e mapas. Quando não assimiladas, as noções geográficas de base têm que ser, sistematicamente, retomadas. (LE SANN, 2011, p. 98)

Durante as atividades realizadas em todas as turmas, apareceram diversos questionamentos por parte dos alunos que deveriam ser pré-requisitos já estudados em séries anteriores em outras disciplinas. $O$ uso da calculadora para calcular os tamanhos dos círculos proporcionais com o uso da Regra de Três, levantou dúvidas de vários alunos no Ensino Superior.

Com os alunos do 6o Ano de escola pública, a dificuldade na leitura e interpretação dos enunciados das avaliações foi o maior obstáculo encontrado, mesmo considerando que algumas etapas dos procedimentos de elaboração dos mapas foram entregues prontas para maior familiaridade dos alunos com exercício apenas do preenchimento do fundo de mapa.

Para o 9 Ano de escola particular, turma com maior período de acompanhamento e realização das atividades e avaliações, as técnicas de distribuição e classificação de dados para mapas ordenados, foram as que mais levantaram dúvidas pelos alunos.

Mas a etapa de maior complexidade para os alunos de todas as turmas, inclusive do Ensino Superior, foi para a utilização de cores e granulações no preenchimento dos mapas. Foram vários alunos que não compreenderam como "ordenar" ou "diferenciar" cores e granulações dos tons mais claros aos mais escuros ou diferentes e semelhantes. Talvez fosse um assunto para a disciplina de Artes, mas o melhor caminho encontrado após perceber estas dificuldades, foi aplicar alguns exercícios prévios das técnicas para posteriormente construir os mapas (vide relatório de atividades com o Ensino Superior). 
Oferecer atividades relacionadas à leitura cartográfica desde as primeiras séries do Ensino Fundamental contribui para desenvolver e ampliar a capacidade cognitiva do aluno como leitor de mapas cotidianamente, além de colocar o mapa como transmissor de informações, e não apenas como desenhos de representações espaciais. (CASTELLAR, 2011, p. 127)

Outra questão frequentemente levantada pelos autores que tratam da Cartografia Escolar, é que o mapa não é utilizado suficientemente em sala de aula pelo fato dos alunos não aprenderem a leitura cartográfica, que por sua vez, os professores do Ensino Fundamental e Médio e das Licenciaturas também não aprenderam a trabalhar com mapas quando estiveram em sala de aula como alunos.

A realidade apresentada nas escolas em que alunos não utilizam suficientemente o mapa e todas as possibilidades que o cercam em sala de aula é porque eles não aprenderam a usá-lo. Mas também o mapa não é ensinado, já que os professores do ensino fundamental e das licenciaturas em geografia também não aprenderam o trabalho com o mapa quando estiveram em sala de aula como alunos. Desta forma, é criado um círculo vicioso que perpetua o pouco conhecimento cartográfico por parte dos alunos e futuros professores do Ensino Fundamental e das Licenciaturas (SIMIELLI, 2007, p. 84)

A partir do conhecimento desta questão, esta pesquisa procurou apresentar materiais didáticos, atividades e os resultados das atividades cartográficas para oferecer ao professor de Geografia e outros interessados, procedimentos passo a passo para possibilitar a aplicação de atividades cartográficas em sala de aula. É um esforço para tentar quebrar o círculo vicioso relatado, uma vez que apresenta a possibilidade do professor construir seus próprios materiais e atividades de acordo com a realidade encontrada em cada sala de aula em diferentes turmas.

A capacitação de professores para o trabalho com linguagem cartográfica no Ensino Fundamental e Médio, é um tema sempre lembrado no meio acadêmico como o grande desafio de levar a Cartografia para a sala de aula. A falta de preparo de boa parte dos professores reproduz aos alunos as dificuldades na leitura e interpretação da linguagem cartográfica, como afirma Simielli:

Pelos testes aplicados e pela análise estatística feita, percebeu-se que realmente o nível de leitura poderia ser ainda melhor se os professores estivessem aptos a ler a mensagem transmitida pelo mapa e, assim, poder explicar aos seus alunos como essa leitura poderia ser feita. Em 
cursos ministrados em diferentes cidades do Estado, percebeu-se que boa parte do professorado não domina noções elementares de Cartografia, como: escalas, leitura da legenda, métodos cartográficos elementares, projeções etc. Consequentemente, esse professor não terá condições de trabalhar amplamente com o mapa, usando-o apenas como recurso visual. (SIMIELLI, 2007, p. 87)

Isto contribui para agravar o problema da deficiência da aprendizagem da linguagem cartográfica no Ensino Fundamental, composto pelo aluno e futuro professor de Geografia que desconhecem a linguagem cartográfica. No cotidiano das aulas de Geografia, é comum encontrar textos extensos escritos em lousa, ou mesmo em grande parte dos livros didáticos, com poucos mapas ilustrativos ou apenas alguns mapas políticos sem referências aos temas em estudo.

Ensinar Geografia, assim como qualquer disciplina no Ensino Fundamental, requer inúmeras estratégias que visam transmitir ao aluno, o máximo de informações da forma mais didática possível. O que muitas vezes significa além de prender a atenção do aluno, encontrar a forma mais concreta para que o aluno compreenda o que está sendo transmitido. "Em geral se descrevem paisagens distantes e, com as próximas, fazem-se descrições tão impessoais que não parecem ser o mundo em que se vive. $O$ grande desafio é tornar as coisas mais concretas e mais reais (CALLAI, 2001, p. 142). No caso da Geografia, uma das formas de mostrar e estudar algo distante, é por meio da linguagem cartográfica.

A realidade de uma escola de Ensino Fundamental comprova que embora os professores de Geografia considerem importante o uso de mapas durante suas aulas, mesmo que sejam apenas mapas físicos e políticos em formato painel, nem estes estão presentes, ou melhor, são até despercebidos e armazenados em locais inacessíveis aos professores. (FRANCISCHETT, 2010, p. 7)

É possível afirmar que a leitura cartográfica se aprende na escola, principalmente no Ensino Fundamental, etapa em que o ensino da Cartografia está associado ao cotidiano do aluno, e servirá como subsídio ou pré-requisito aos futuros alunos, que optarão pela profissão de geógrafos durante o Curso Superior.

Para o professor de Geografia do Ensino Fundamental, além de textos e mapas, também são necessários vários tipos de materiais didáticos com o objetivo de exemplificar ou apresentar os fenômenos geográficos. Muitos destes materiais podem ser confeccionados pelo professor em conjunto com os alunos, outros confeccionados pelo professor apenas, e utilizados como material permanente, além 
dos que podem ser adquiridos prontos pelo professor ou pelos alunos. Oliveira cita alguns deles:

\begin{abstract}
Além dos vários tipos de mapa e globo, devem ser lembrados os materiais cartográficos que precisam ser incluídos no ensino do mapa. Esses materiais são aqueles que ou o professor ou os alunos utilizam quando trabalham com as representações espaciais gráficas. Pode-se citar, entre alguns desses materiais: os mapas mudos; os contornos de mapas de diversos materiais, principalmente os plásticos; as transparências para retroprojetor; os moldes para contornos de mapas; os blocos-diagramas; os mapas em relevo etc. (OLIVEIRA, 2007, p. 23)
\end{abstract}

Alguns materiais didáticos citados por Oliveira se tornaram obsoletos, como os blocos diagramas e as transparências para retroprojetor, embora muitas escolas ainda se utilizem destes recursos. Mas os moldes de mapas, citados acima e propostos neste trabalho, são pouco utilizados e ainda não foram substituídos, uma vez que a grande maioria das escolas utiliza lousas de giz ou mesmo lousa branca. Por isto, é importante que o professor de Geografia conheça e produza seus próprios materiais didáticos, que podem ser elaborados de diversas formas.

Existem os materiais produzidos pelos alunos que se tornam permanentes e expostos em sala ambiente, ou produtos didáticos elaborados individualmente pelos alunos para colar no caderno ou levar para casa para análise posterior.

Podemos resumir os tipos de materiais didáticos mais utilizados nas aulas de Geografia do Ensino Fundamental em:

a) elaborado de forma artesanal pelo professor em conjunto com os alunos;

b) elaborado de forma digital pelo professor em conjunto com os alunos;

c) elaborado de forma artesanal pelo professor (extraclasse) para ser utilizado de forma permanente;

d) elaborado de forma digital pelo professor (extraclasse) para ser utilizado de forma permanente;

e) adquirido pronto para ser utilizado de forma permanente em sala de aula;

f) adquirido pronto para ser utilizado de forma individual pelos alunos.

Para qualquer material didático adquirido pronto ou elaborado pelo professor, é preciso adaptações para o contexto em que será utilizado pelos alunos. Existem diversos trabalhos publicados sobre a elaboração de mapas temáticos por alunos do Ensino Fundamental e Médio, assim como a importância do ensino da linguagem cartográfica, mas há um hiato na formação dos professores no que diz respeito ao 
ensino da linguagem constituinte dos chamados mapas temáticos. Os mapas não servem apenas como ilustração, devem ser vistos e compreendidos (PRADO, et al. 2010).

A utilização do mapa como forma de linguagem transmissora da informação geográfica por alunos do Ensino Fundamental depende obrigatoriamente da formação do professor de Geografia, como afirma Simielli:

O aluno precisa conhecer qual é o melhor caminho para conseguir ler o mapa e nisso deve ser orientado pelo professor, que lhe ensinará o alfabeto cartográfico. O aluno só lerá o mapa se for capacitado para isso; - o professor precisa estar bem informado quanto ao alfabeto cartográfico, pois só assim saberá transmiti-lo ao aluno. Isso diz respeito à formação dos professores e à sua capacidade para usar 0 mapa como meio de comunicação. (SIMIELLI, 2007, p. 89)

Vários autores afirmam a necessidade da elaboração de mapas por "não especialistas", como os estudantes:

É necessário desmistificar a elaboração do mapa como mero exercício de codificação feito por especialistas, onde é necessário estabelecer convenções, atentando para que o inestimável valor de sua construção está em trabalhá-los com base na correta exploração das regras da sintaxe da linguagem cartográfica. (...) O posterior aprendizado de sua leitura, análise e interpretação encaminharia os sujeitos para um consciente questionamento sobre seus constructos: o que o mapa revelou. Ao descobrirem esta resposta ficaria confirmada a participação do mapa na construção do conhecimento. (PASSINI; ALMEIDA; MARTINELLI, 1999, p. 134)

As experiências de elaboração de mapas em sala de aula ainda causam polêmica sobre o que pode e o que é mapeado. Muitas vezes, os mapas construídos pelos alunos servem apenas para localização, sem se relacionar com a compreensão da espacialidade. (PASSINI, 2006, p. 7) Em sala de aula, para aprender a interpretar e extrair a maior quantidade e qualidade de informação dos gráficos e mapas, o aluno deve ser capaz de construí-los. Isto quer dizer que não basta fazer a "leitura e interpretação" do gráfico e mapa, muitas vezes é preciso "redigir". (AZEVEDO, 1993, p. 1)

Diante do quadro apresentado por diversos autores, como exemplificado acima, ao professor de Geografia que durante sua formação não foi preparado para ensinar Cartografia aos seus alunos, torna-se importante seu aperfeiçoamento 
profissional com pesquisas e cursos de capacitação para aprimorar seus métodos didáticos em sala de aula. $O$ que passa pelos conhecimentos sobre a Cartografia Escolar.

Para atividades com alunos do Ensino Médio, EJA (Educação de Jovens e Adultos) e até nas últimas séries do Ensino Fundamental dependendo da maturidade dos alunos, já é possível estudar as imagens e informações apresentadas por mapas por meio de livros didáticos, jornais, revistas ou digitais, e mesmo por mapas construídos pelos próprios alunos (SIMIÃO, 2011, p. 98), que podem apresentar grandes variações sobre um mesmo tema, como no exemplo a seguir:

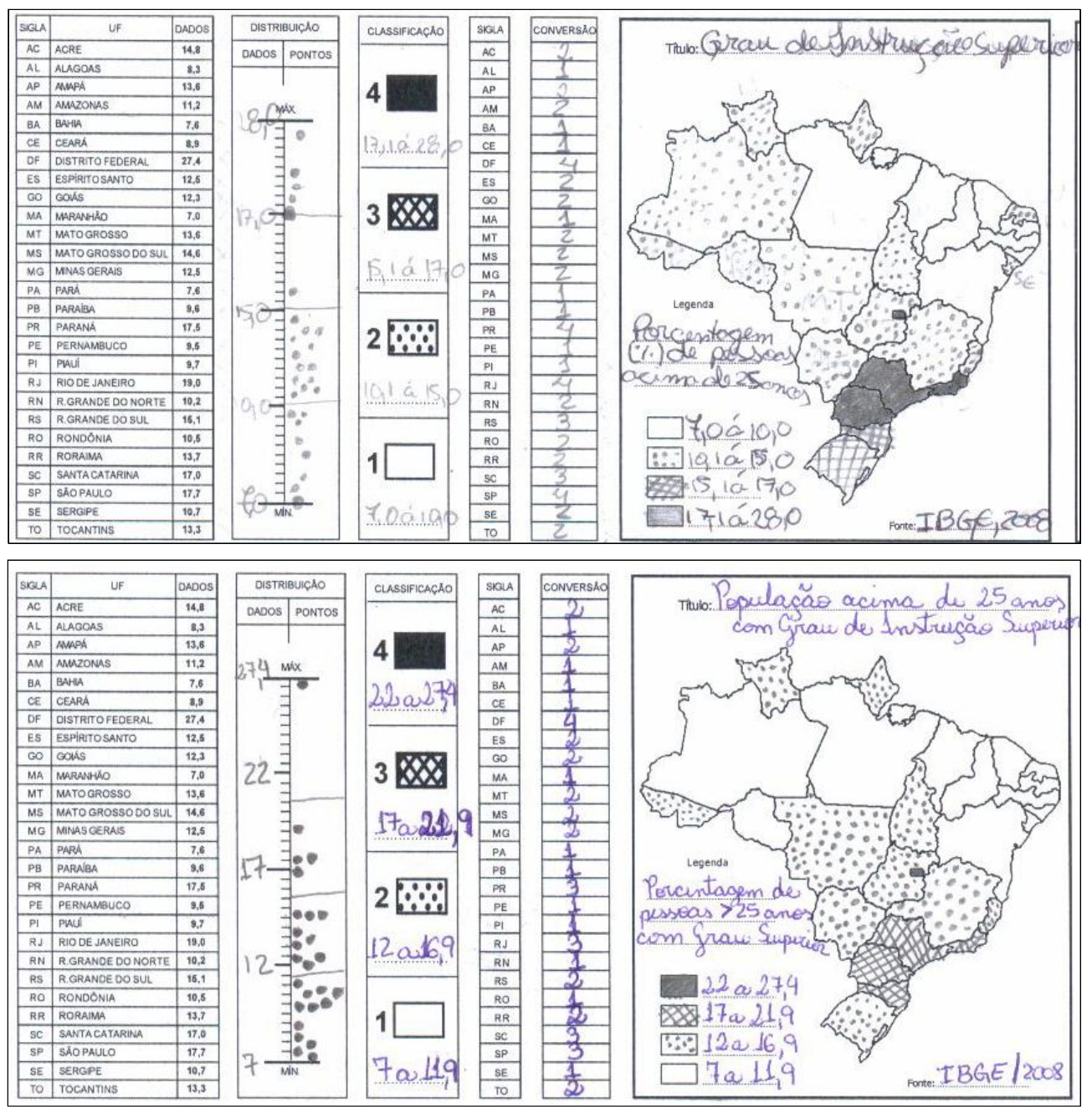

Figura 02 - Comparação de dois mapas com os mesmos dados estatísticos elaborados com critérios diferentes por alunos do $9^{\circ}$ Ano do Ensino Fundamental.

Quando os alunos percebem e comparam as diferenças que aparecem em um mesmo mapa temático, utilizando os mesmos dados estatísticos de acordo com 
os critérios de elaboração utilizados por eles, pode-se levantar uma questão para ser dialogada em sala de aula, como no exemplo acima em que os dados estatísticos são distribuídos com critérios diferentes entre os dois mapas elaborados.

Pelo fato da imagem transmitir um efeito de verdade, é preciso formar leitores críticos para alertar sobre sua "eficiência em enganar", pois toda a linguagem, e especialmente a linguagem visual pode ser transmissora e produtora de ideologias (FONSECA, 2007, p. 92). Segundo Brian Harley:

O cartógrafo nunca foi um artista, um artesão ou um técnico independente. Por trás do criador dos mapas se esconde um conjunto de relações de poder, que cria suas próprias especificações. Sejam impostas por um particular, pela burocracia do Estado, ou pelo mercado, estas regras podem, às vezes, ser reconstruídas a partir de um conteúdo dos mapas e do modo de representação cartográfica. Adaptando as projeções individuais, manipulando as escalas, aumentando excessivamente ou deslocando os sinais ou a topografia, utilizando cores com forte poder emotivo... (HARLEY, 2009, p. 9)

A linguagem cartográfica inserida nas aulas de Geografia contribui para estimular o raciocínio e senso crítico do aluno, além de contribuir para sua formação e compreensão do mundo real, mediante da autonomia da capacidade de discernir (BRASIL 2000, p. 15). Vários autores lembram que a Cartografia foi utilizada pela humanidade antes mesmo antes da escrita. (PASSINI; ALMEIDA; MARTINELLI, 1999, p. 129) O histórico da Cartografia Escolar mostra um longo caminho percorrido por inúmeros autores para sua valorização no campo científico, especialmente relacionado à área escolar e o que pode ser estudado pela ciência geográfica, a Geografia Escolar, a Cartografia e a Cartografia Escolar.

No Brasil, os trabalhos pioneiros e até hoje, referência para novos trabalhos sobre a Cartografia Escolar, foram produzidos por diversos autores a partir de 1978 e contribuíram para o estudo do tema em artigos, dissertações e teses em diversas universidades de todo o país ${ }^{2}$.

\footnotetext{
2 Os primeiros trabalhos foram publicados por Lívia de Oliveira, "Estudo metodológico e cognitivo do mapa" (1978); Tomoko Paganelli, "Para a construção do espaço geográfico na criança (1982); Maria Elena Simielli, "O mapa como meio de comunicação: implicações no ensino de Geografia no $1^{\circ}$ Grau" (1986); Janine Le Sann, "Metodologia para introduzir a Geografia no Ensino Fundamental" (1989); Regina Vasconcelos, "A cartografia tátil e o deficiente visual: uma avaliação das etapas de produção e uso do mapa" (1993); Rosângela Doin de Almeida "Uma proposta metodológica para a compreensão de mapas geográficos" (1994); Elza Passini "Os gráficos em livros didáticos de Geografia de $5^{a}$ série: seu significado para alunos e professores" (1997).
} 
A partir destes teóricos, surgiram dezenas de pesquisadores em todo o país que desenvolveram trabalhos relacionados ao tema, especialmente sobre a importância do ensino da linguagem cartográfica no Ensino Fundamental e Médio.

Embora no Brasil já existam diversos trabalhos relacionados à importância da Cartografia Escolar, o universo da Cartografia praticada pelos professores do Ensino Fundamental II ainda é pouco conhecido, e é o grande desafio para pesquisadores que procuram conhecê-lo não só para ensinar Cartografia, mas também para ensinar Geografia. (OLIVEIRA, 2008, p. 483)

\section{3 - A Cartografia Escolar na proposta dos Parâmetros Curriculares Nacionais}

Como uma forma de estabelecer e apresentar referências sobre o processo educativo para o ensino de Geografia no Brasil, foram elaborados os Parâmetros Curriculares Nacionais (PCNs) no final da década de 1990. São mencionados atributos e objetivos para serem alcançados no Ensino Fundamental e Médio, que visam a formação cidadã do aluno, assim como o uso de diferentes linguagens em sala de aula, como verbal, musical, matemática, gráfica, plástica e corporal (BRASIL, 1998, p. 07), o que também pode ser incluído a linguagem visual, e especialmente as atividades cartográficas de construção de mapas em sala de aula.

Nos PCNs são citadas as atividades cartográficas clássicas utilizadas durante as aulas de Geografia durante décadas, e que são excelentes e de grande importância para a formação dos alunos. Porém são atividades que podem ser mais exploradas e contribuir para o aprendizado do aluno em conjunto com outros temas estudados pela disciplina em sala de aula.

A forma mais usual de trabalhar com a linguagem gráfica na escola é por meio de situações em que os alunos têm de colorir mapas, copiálos, escrever os nomes de rios ou cidades, memorizar as informações neles representadas. Mas esse tratamento não garante que eles construam os conhecimentos necessários, tanto para ler mapas como para representar o espaço geográfico. Para isso, é preciso partir da idéia de que a linguagem gráfica é um sistema de símbolos que envolve proporcionalidade, uso de signos ordenados e técnicas de projeção. Também é uma forma de atender a diversas necessidades, das mais cotidianas (chegar a um lugar que não se conhece, entender o trajeto dos mananciais, por exemplo), às mais específicas (como delimitar áreas de plantio, compreender zonas de influência do clima). É importante que a escola crie oportunidades para que os alunos 
construam conhecimentos sobre essa linguagem nos dois sentidos: como pessoas que representam e codificam o espaço e como leitores das informações expressas por ela. (BRASIL, 1998, p. 34)

Embora os PCNs alertem para a necessidade de explorar outras linguagens visuais para estudar o espaço geográfico, não são apresentadas estratégias e metodologias para que isto possa ocorrer de forma concreta em sala de aula. É recomendado apenas para que "a escola crie oportunidades", como descrito no fragmento acima. Sem dúvida uma questão-chave para nosso objetivo principal deste trabalho que é desenvolver maneiras para que os alunos de Geografia possam construir mapas em sala de aula.

Os PCNs descrevem muito bem a diferença entre o aluno "mapeador mecânico", também conhecido como copiador de contornos de mapas, para o "mapeador consciente", que "pensa e interage" no mapa em que constrói.

Espera-se que ao longo de oito anos do Ensino Fundamental (atualmente nove anos) que os alunos sejam capazes de compreender a espacialidade e a temporalidade dos fenômenos geográficos estudados em suas dinâmicas e interações (BRASIL, 1998, p.35). Além disto, também é mencionada a necessidade do aluno aprender os elementos básicos da representação cartográfica para que possa efetivamente ler o mapa (BRASIL, 1998, p.77). 


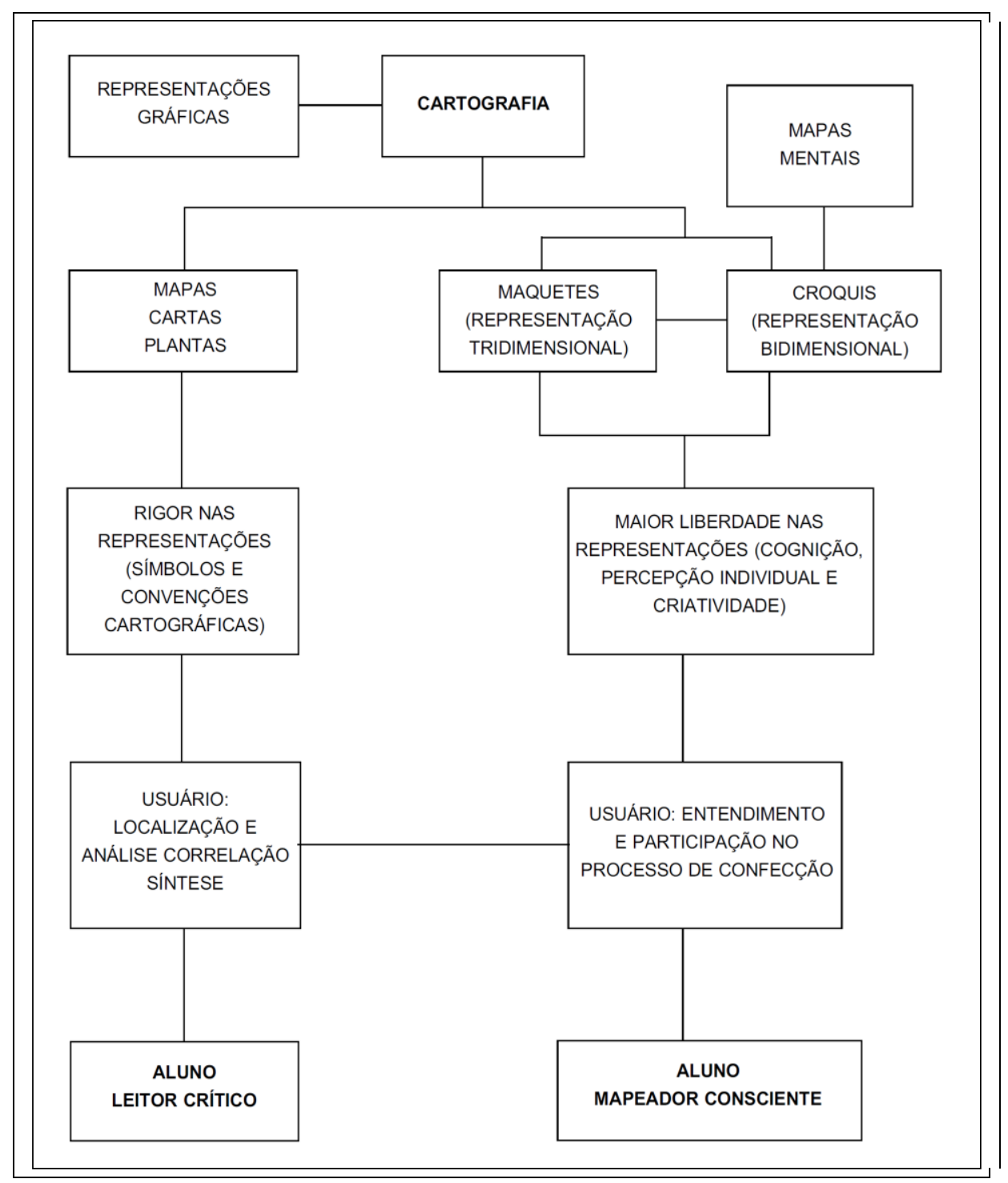

Tabela 04 - Diagrama apresentado por SIMIELLI e reproduzido nos PCNs a respeito da Cartografia no Ensino Fundamental e a formação do aluno mapeador consciente. (SIMIELLI, 1994. Apud BRASIL, 1998, p. 79)

No diagrama proposto por Simielli, o processo de confecção de mapas aparece como um dos objetivos da Cartografia no Ensino Fundamental II, citado como "aluno mapeador consciente", o que mostra a importância da construção de mapas em sala de aula, porém, uma tarefa com grandes dificuldades conforme citado anteriormente. Mas como fazer com que o aluno seja um mapeador consciente, ou mesmo apenas um mapeador? Certamente um grande desafio para os profissionais da área de Educação e Geografia. 


\section{4 - Diferenças e utilidades dos mapas topográficos e temáticos}

Muitos cartógrafos defendem a ideia de que uma representação para ser considerada "mapa", precisa necessariamente ter em seu traçado a fidelidade do espaço real do terreno em escala reduzida. Geralmente uma superfície em papel, em que se pode "conferir" sua precisão calculando sua escala. Isto se torna inviável para mapas como Planisférios por exemplo, uma vez que o formato esférico da superfície terrestre dificulta este tipo de representação sem algum tipo de distorção.

Representar a terra esférica num plano é uma tarefa geométrica necessária e incontornável para que o mapa exista. Mas isso sempre se dá com um resultado insatisfatório. Nenhum tipo de projeção conserva, ao mesmo tempo, todas as propriedades geométricas do globo. (FONSECA; OLIVA 2013, p. 63)

Este é o tema mais difundido sobre Cartografia em sala de aula, e que grande parte dos professores de Geografia assimilam de forma inconsciente. Fator que faz com que um mapa temático se torne aparentemente mais associado a "cálculos matemáticos" do que à "formação da imagem".

De qualquer maneira, nos mapas temáticos, o que importa é o "tema" e não a "localização precisa dos objetos representados" do fundo de mapa utilizado. Utilizar o mapa apenas para fins de localização, é subestimar o potencial da imagem. Bertin afirma que a apreensão da imagem formada pelo mapa, ainda está esmagada sob o peso dos hábitos milenares da "leitura topográfica" (BERTIN, 1988, p. 53).

Além da preocupação com a "precisão" dos traçados dos mapas temáticos, o uso cotidiano de uma única projeção cartográfica limita a utilização de outras projeções de mapas, que muitas vezes podem ser mais eficientes tanto para apresentar uma informação geográfica, como para mostrar aos alunos que existem outras formas de representação cartográfica.

Na escola a prática dominante é o uso do mapa para a localização dos lugares, naturalizando essas localizações que são sempre relativas e construídas historicamente, por exemplo, pela centragem européia nos 
planisférios. Definir a localização dos objetos como a função exclusiva do mapa "engessa" o trabalho do professor e o olhar do aluno. (FONSECA; OLIVA, 2013, p. 63)

Neste trabalho é apresentada uma projeção do planisfério equidistante em duplicata para que o aluno possa construir mapas centralizados em qualquer meridiano. É uma forma de mostrar ao aluno que não existe apenas um tipo de projeção do planeta centralizado no Meridiano de origem, Greenwich, que apresenta a Europa no centro do mapa, mas que qualquer localidade pode estar no centro do planisfério.

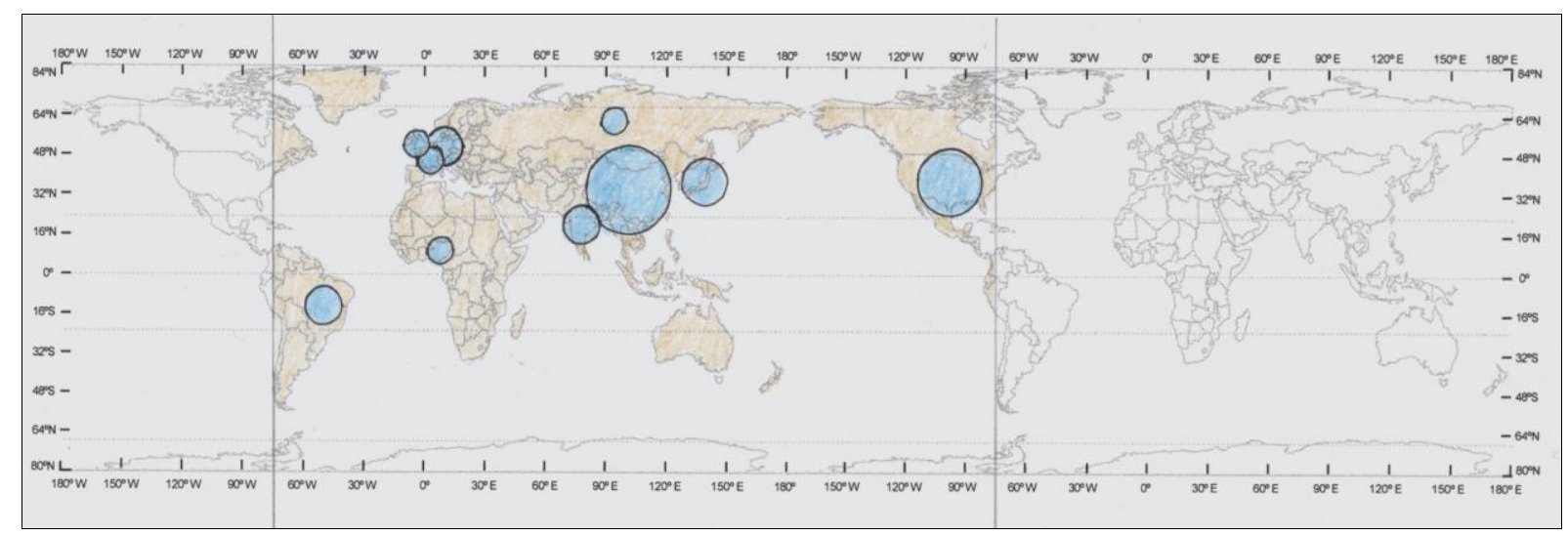

Figura 03 - Mapa construído em um fundo de mapa mudo em duplicata do planisfério para centralização em qualquer meridiano. Neste tema, a centralização escolhida foi na China, onde o fenômeno apresentado pelo mapa ocorre em maior quantidade (mapa quantitativo elaborado com gabarito de círculos proporcionais para o tema: Os Dez Países com Maior Número de Usuários de Internet no Mundo)

\section{5 - Propostas para a construção de mapas com escalas diversas}

Em grande parte dos mapas que são elaborados, existe uma padronização que supervaloriza a precisão de escalas, mesmo que não levam em conta distorções comuns e inevitáveis encontradas nos planisférios, por exemplo, o que impossibilita apresentar apenas uma escala para todo o mapa. O fundo de mapa, ou "mapa mudo", termo utilizado nesta pesquisa para os contornos de mapas das matrizes, é o resultado da combinação da escala, projeção e a métrica. (FONSECA; OLIVA, 2013) 
Nas últimas décadas, os dados estatísticos se renovaram de forma significativa, com novas pesquisas e cruzamentos, que visam apresentar outros fenômenos sociais e econômicos, como o IDH, GINI ${ }^{3}$, etc.

Da mesma forma, a cartografia também procura acompanhar esta renovação, porém, enfrenta grandes obstáculos por parte de especialistas da área, que ainda resistem em associar o mapa à precisão de sua escala para suas representações.

O objetivo do mapa topográfico é a precisão de seu traçado e escala, além de informações detalhadas transcritas na legenda. Alguns autores afirmam ainda que:

O progresso cartográfico foi pautado principalmente pelo paradigma da precisão espacial, na qualidade e domínio das informações globais sejam elas políticas ou físicas. Mapas do tipo topográfico, por exemplo, são constituídos em uma estrutura baseada na precisão que tem como função delimitar, reconhecer e dominar territórios. Basicamente cumpre um dos requisitos mais elementares da manutenção do Estado-nação. Compreender essa função política de manutenção do Estado é um passo importante no entendimento do porque ainda se reproduz este modo de elaboração de mapas pelo paradigma da precisão que leva a uma imaginação única sobre a espacialidade. (GIRARDI; LACERDA; VARGAS; LIMA, 2011, p. 4)

Dos diversos tipos de projeções encontradas para o planisfério, como a projeção equivalente, equidistante, poliédrica, azimutal, entre outras, a que prevalece é a que centraliza o mapa do Planisfério no continente europeu, e com a direção Norte à frente.

Raramente é priorizado a melhor comunicação possível para o mapa, que muitas vezes pode ser substituída por diversas projeções em inúmeras centralizações, ou até mesmo utilizar outra métrica para representar um fenômeno geográfico diferente da área das localidades.

Apesar das limitações do método de construção de mapas artesanais com poucos recursos e tempo hábil, são apresentadas algumas opções de matrizes com fundos de mapas que permitem construir mapas em projeções pouco utilizadas como a

\footnotetext{
${ }^{3}$ O Índice de Desenvolvimento Humano (IDH) e o Coeficiente de GINI, são sínteses de dados estatísticos que classificam o grau de desenvolvimento humano e a desigualdade social com base em informações coletadas nos institutos de pesquisas de diversos países e organizações. Os mapas de síntese também são elaborados a partir do resultado de diversas informações, que são calculadas e definidas em um único mapa.
} 
projeção poliédrica, que apresenta melhores resultados em mapas dinâmicos, além do planisfério equidistante em duplicata, que permite centralizar o mapa em qualquer longitude. Todos sem escala, uma vez que o objetivo das matrizes é a elaboração de mapas temáticos, e não mapas topográficos, ou seja, para estes tipos de mapas, até mesmo calcular a escala na Linha do Equador, é algo desnecessário. Embora todo mapa seja considerado temático (Joly, 1990), nem todos os mapas são elaborados com o objetivo de ter precisão em relação ao traçado, escala ou contornos. Para estes mapas, "o tema" é o único objetivo relevante. (LE SANN, 2005, p. 62) O mapa possui particularidades que dificilmente o tornará obsoleto ou ultrapassado. (LÉVY, 2008, p. 159)

Todas estas propostas de diferentes tipos de mapas contribuem para que 0 aluno não permaneça limitado a conhecer e estudar apenas um tipo de mapa que muitas vezes não é o mais indicado para representar um determinado tema, como já mencionado. 


\section{3 - O DESAFIO DE CONSTRUIR MAPAS EM SALA DE AULA}

Durante a realização das atividades desta pesquisa na região metropolitana de São Paulo, foi possível perceber no ambiente escolar que a disciplina de Geografia e especialmente a Cartografia são vistas como algo supérfluo por alguns coordenadores e diretores de escolas, embora os PCNs e profissionais da Cartografia Escolar alertem para a importância da construção de mapas em sala de aula na formação acadêmica dos alunos, como foi possível perceber durante a aplicação das atividades deste trabalho.

No Colégio em que foi realizada a maior parte das atividades cartográficas, a carga horária para a disciplina foi reduzida para apenas duas aulas semanais de cinquenta minutos. Na escola pública escolhida para outra parte das atividades, foi preciso um trabalho de convencimento por parte do professor de Geografia perante a Direção e Coordenação Pedagógica da escola, com relação à importância de realizar e registrar as atividades com os alunos. (vide relação das escolas na página 77)

O Sistema de Ensino adotado pelo Colégio particular utiliza no 6ํㅡㄹ Ano uma apostila que transfere para a disciplina de Matemática o tema Fusos Horários, mesmo considerando que a escolha de horários é feita de acordo com critérios políticos, e não matemáticos. Questões simples, por exemplo, sobre a utilização do mesmo horário entre Bariloche, na Argentina, que está localizada à $70^{\circ}$ de longitude oeste e João Pessoa, na Paraíba, que está a 30ํㅡㄹ requer não apenas conhecimentos matemáticos, mas políticos, geográficos e espaciais. Tema que pode ser mais proveitoso se compartilhado com outras disciplinas, especialmente, a Geografia. Da mesma forma ocorre com o tema: Movimentos da Terra, abordado apenas pela disciplina de Ciências.

Algumas questões levantadas por Lívia de Oliveira na década de 1970, ainda puderam ser observadas na prática da presente pesquisa. Houve dificuldade em fixar materiais didáticos em sala de aula, e até mesmo a necessidade de manter suportes (pregos ou similares) para a utilização de mapas em formato painel nas paredes e lousas, uma vez que algumas escolas não permitem a manutenção destes materiais. Talvez estes fatos possam contribuir para compreender os poucos 
projetos, dissertações e teses sobre a construção de mapas em sala de aula que são colocados em prática pelos professores.

O grande desafio aos professores de Geografia é estudar a melhor maneira de participar da formação acadêmica dos estudantes, para que estes utilizem e valorizem o conhecimento geográfico como parte importante de sua formação profissional e social. E o conhecimento e a prática da linguagem cartográfica em sala de aula podem contribuir para que isto ocorra. 


\section{1 - Simplificação de Fundos de Mapas, Matrizes e Tabelas de Dados}

É importante não só para professores do Ensino Fundamental, mas para qualquer pessoa interessada em construir mapas, conhecer as regras de construção de mapas, para que possa transmitir a informação ao leitor com a maior clareza possível. Embora a tecnologia da informação tenha realizado uma verdadeira revolução na área gráfica, não basta dominar apenas os conhecimentos de informática para elaborar mapas, como afirmam Archela e Théry:

Desde que se conheça a linguagem dos mapas e a gramática cartográfica, existem ferramentas computacionais que ajudam na construção de mapas. Softwares livres disponíveis na Internet como o Philcartho (WANIEZ, 2007) e o Spring (INPE, 2007) podem ajudar a reunir e compilar dados espaciais na forma de mapas. No entanto, (...) o computador não faz tudo, ele é somente uma ferramenta na mão do construtor de mapas. Os mapas elaborados para comunicação, construídos para uso público, são julgados por sua aparência e utilidade. Por isso, buscar conceitos e conhecimentos cartográficos para sua elaboração é imprescindível, especialmente, quando se deseja revelar algo por meio da visualização. Conhecendo as regras cartográficas, é mais fácil superar os limites técnicos de produção, impostos pelo software escolhido. Isto é, a definição da escala, linhas, pontos, cores e textos, que só serão superados na medida em que o "construtor" de mapas domine o software. Geralmente, para resultados que envolvem mapas impressos, é necessário ainda, utilizar mais de um software e incluir os de designer gráfico, fato que reforça a necessidade de melhor preparo do profissional pesquisador para a elaboração de mapas úteis. (ARCHELA; THÉRY, 2008)

A precisão cartográfica necessária para elaboração de mapas ou mesmo gráficos e tabelas, também sofrem generalizações ou arredondamentos de dados para viabilizar suas elaborações, como afirma Bertin:

No momento da decisão, não podemos, rigorosamente, considerar e levar em conta toda essa enorme quantidade de dados elementares que constituem a informação. Torna-se necessário reduzi-los, isto é, descobrir elementos semelhantes, agrupá-los, classificá-los. É somente a esse preço que se pode compreender e decidir. (BERTIN, 1980 p. 161)

Para a elaboração de mapas escolares artesanais, contornos generalizados, legendas simples, limite de informação, etc., além de facilitar e agilizar os 
procedimentos em sala de aula, ajudam a concentrar o olhar do leitor sobre o essencial, como afirma Levy:

A supressão dos ruídos visuais permite evitar os "efeitos secundários" sobre a mensagem de informações acessórias. O recurso a contornos "generalizados" (quer dizer, simplificados) parece legítimo, posto que contribui para concentrar o olhar do leitor sobre o essencial. (LÉVY, 2008 p. 157)

Com base na Semiologia Gráfica é possível elaborar grande parte dos mapas que conhecemos. As escolhas dos símbolos, cores, legendas etc., tem o objetivo de atingir a comunicação visual da forma mais eficiente possível. Existem vários materiais e ferramentas para trabalhar com ampliação e redução de áreas planas, como cálculo e conversão de Raios de círculos, disco de proporção, tabelas de cálculos, etc.

O ábaco para figura plana faz uma conversão de tamanhos proporcionais de Raio que pode ser utilizado diretamente sobre o mapa ou até para a elaboração de gabarito com o uso de compasso. O cálculo de Raio para círculos proporcionais é um ótimo recurso para ser utilizado com compasso, porém, requer um tempo precioso dos alunos durante as atividades, tanto para calcular, como para preencher os contornos dos círculos.

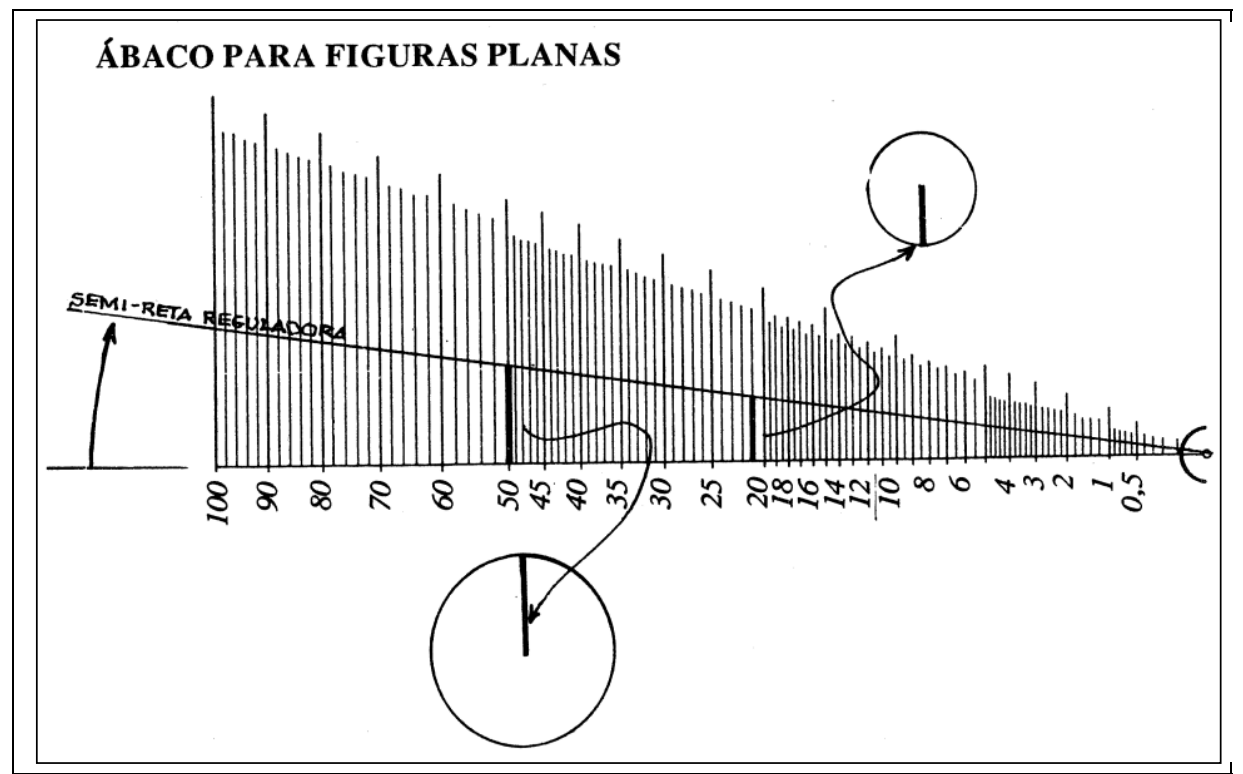

Figura 04 - Modelo de ábaco de Raio de circunferências para figuras planas utilizado com compasso para desenhar círculos proporcionais. (Fonte: Martinelli, 1991 p. 83) 
O disco de proporção é utilizado para fazer cálculos simples. Para obter maior precisão nas ampliações, não é recomendado este equipamento por apresentar apenas cálculos aproximados aos projetistas. Serve apenas para obter um cálculo de proporção de forma rápida.

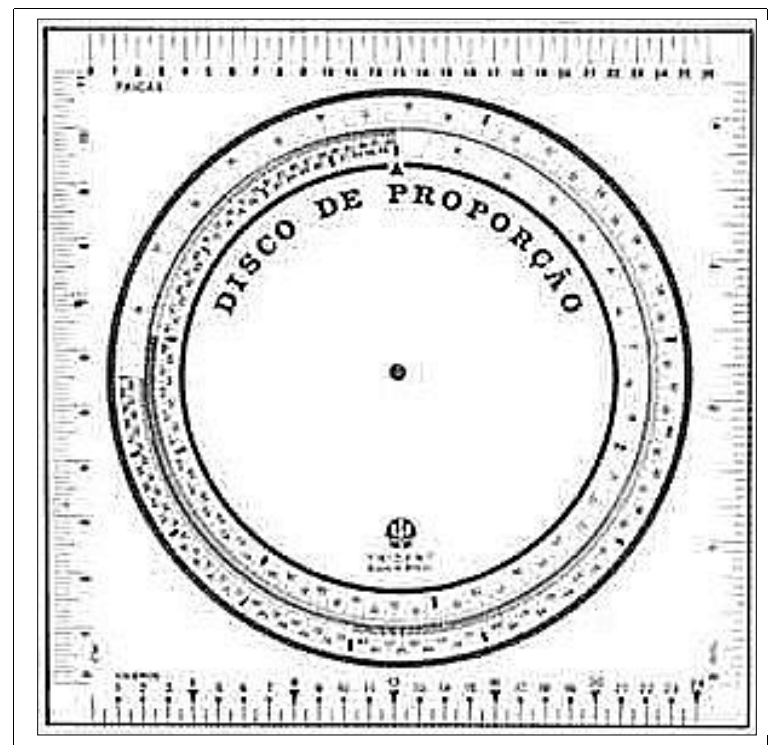

Figura 05 - Modelo de disco de proporção utilizado por desenhistas e projetistas para cálculos de proporções aproximados. (Fonte: www.grafittiartes.com.br)

Para a elaboração dos gabaritos proporcionais apresentados neste trabalho, foi aplicada uma tabela de cálculo de ampliação utilizada em equipamentos de fotocópias considerando como tamanho natural $100 \%$, e com valores ampliados de acordo com o tamanho ou espessura desejada, como mostra a tabela a seguir:

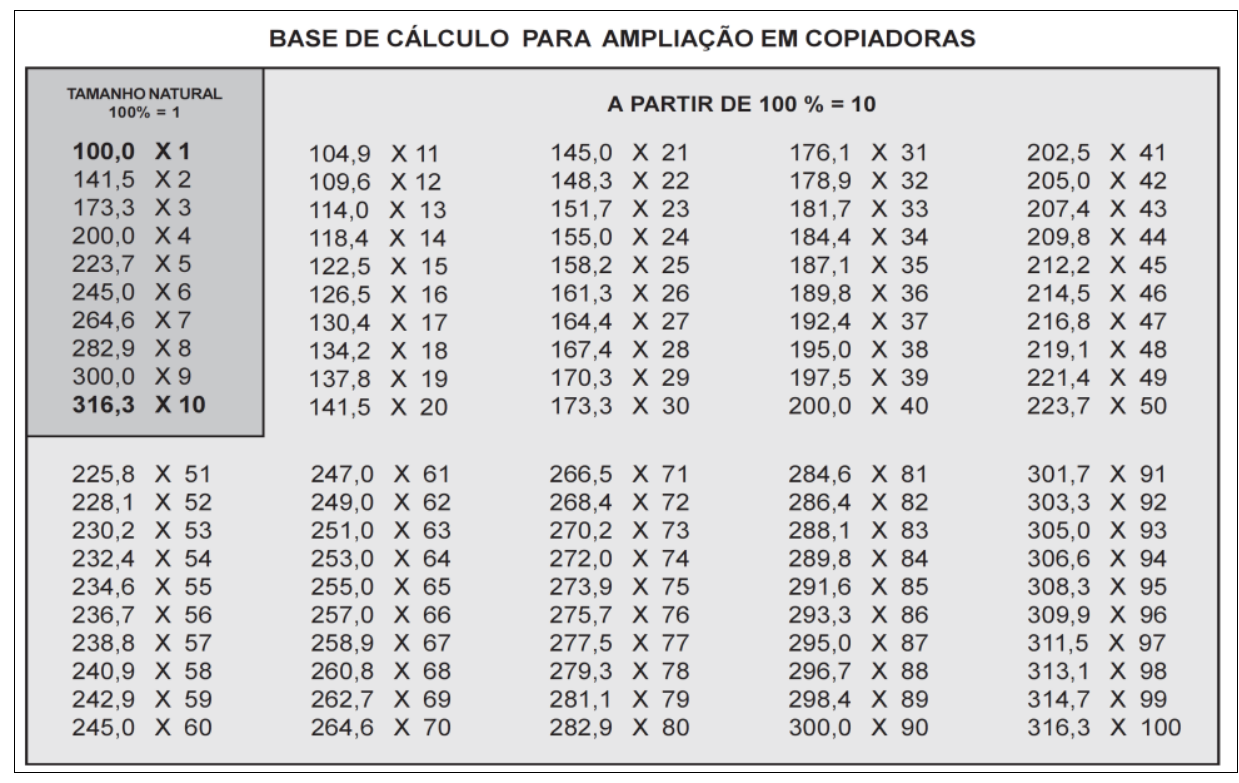

Tabela 05 - Base de cálculo utilizada para ampliação com porcentagem em fotocopiadoras, mantendo a proporção da área ampliada. (LEITE, 2014) 
Exemplo: para ampliar uma imagem original $X(100 \%)$ para $3 X$, programe a copiadora para $173,3 \%$. Para ampliar X (100\%) para $15 X$, primeiramente amplie para $X 10$ programando a copiadora para $316,3 \%$, e a partir da cópia, programe $122,5 \%$, para obter $\mathrm{X} 15$, assim como nos demais tamanhos.

Tanto os círculos proporcionais quanto os símbolos e curvas, foram ampliados seguindo este critério. Os círculos foram calculados em 10 tamanhos multiplicados por 10 para simplificar a elaboração dos gabaritos mantendo a proporção da área dos círculos. Além disto, visualmente, é praticamente impossível diferenciar círculos ampliados do tamanho 01 ao 100 como mostra o exemplo com os tamanhos 3 e 4 (30 e 40) e os tamanhos intermediários 31 a 39:

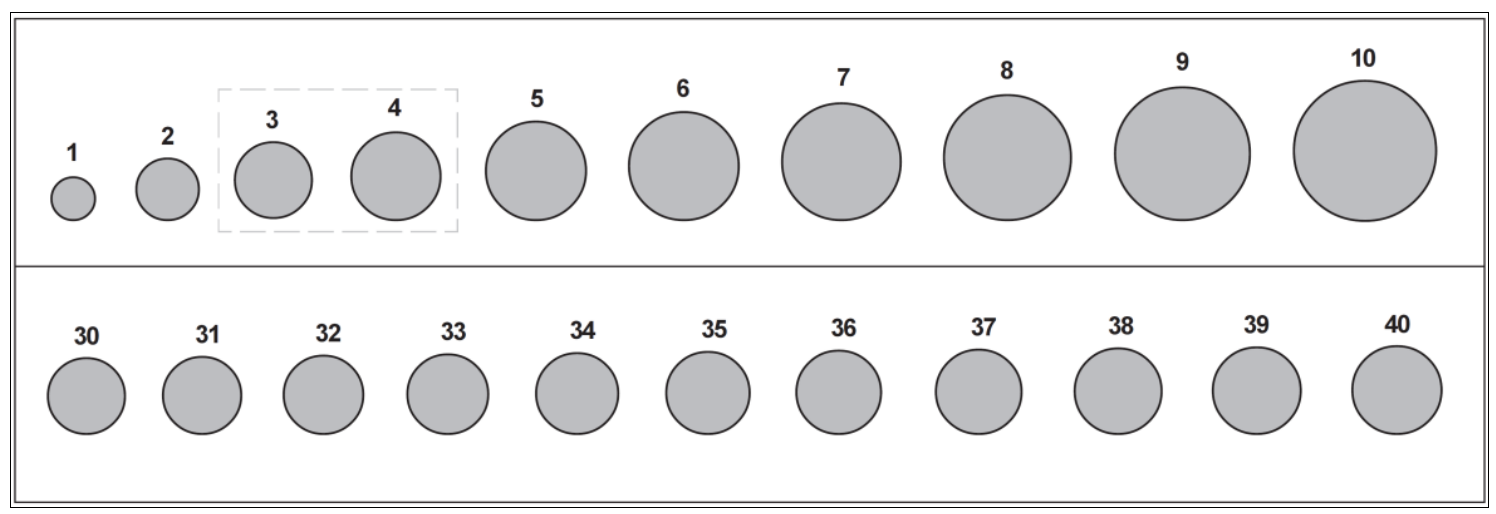

Figura 06 - Sequência de 1 ao 10 convertido do tamanho 10 ao 100 e a sequência intermediária de 3 a 4 fracionada (30 a 40), em que os tamanhos se confundem visualmente. (LEITE, 2014)

Para a elaboração dos mapas quantitativos, foi elaborada uma conversão com simplificação dos dados para encontrar os tamanhos dos círculos de acordo com os valores.

Nos mapas qualitativos pontuais são utilizados gabaritos de símbolos diversos e/ou proporcionais em três tamanhos múltiplos (X1, X2 e X3), assim como para as curvas proporcionais para elaboração de mapas dinâmicos. Neste caso, a classificação "alto/médio/baixo", "bom/regular/ruim" ou "grande/médio/pequeno", é suficiente para construir um mapa temático escolar, e ao mesmo tempo, viabilizar sua elaboração em sala de aula. Os símbolos são infinitos, mas alguns mais utilizados, foram adaptados para gabaritos, como mostram as figuras a seguir: 


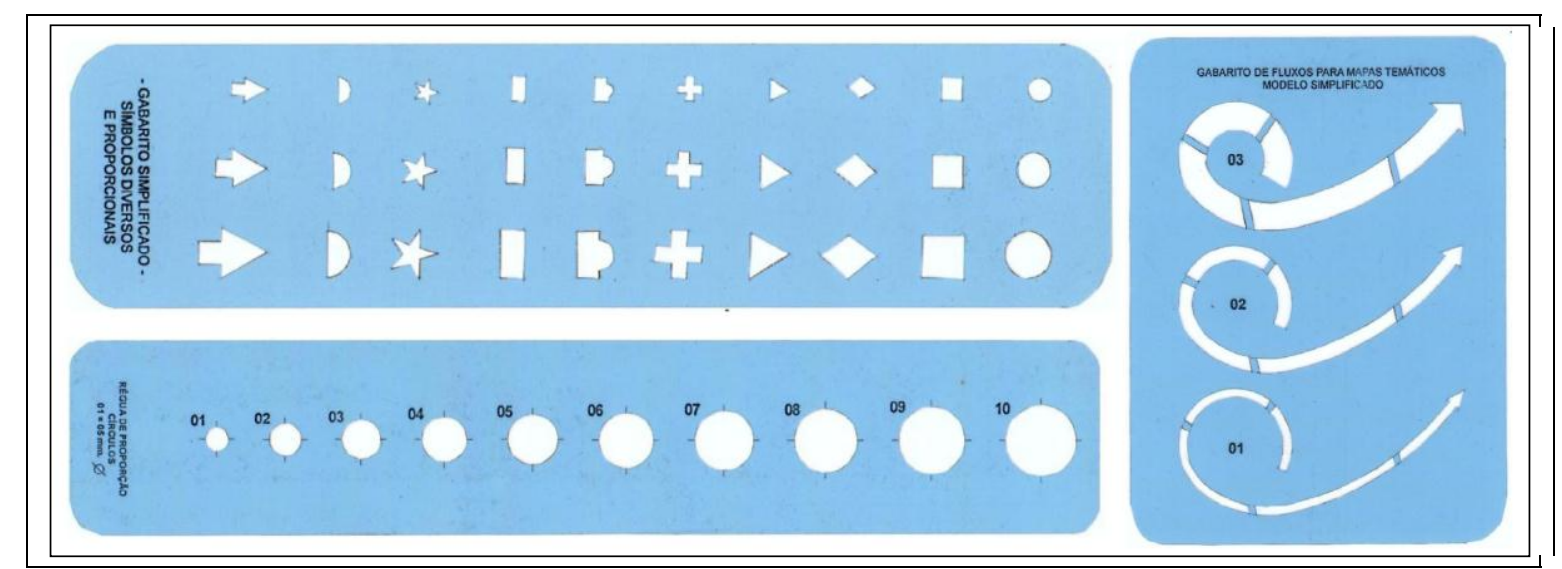

Figura 07 - Gabaritos de círculos, curvas e símbolos proporcionais recortados manualmente. (LEITE, 2014)

Nas atividades apresentadas neste trabalho, os dados dos mapas ordenados são distribuídos em quatro ou cinco gradações que são preenchidas com cores ordenadas ou granulações.

Além da questão da proporção, os mapas temáticos também apresentam outras características. Segundo Bertin, todos os mapas apresentam método, modo de implantação, variável visual e relações expressas, como mostra a tabela a seguir:

\begin{tabular}{|l|l|l|l|}
\hline \multicolumn{5}{|c|}{$\begin{array}{c}\text { CARACTERÍSTICAS DOS MAPAS TEMÁTICOS } \\
\text { (uma ou mais por coluna) }\end{array}$} \\
\hline O - MÉTODO & B-MODO DE IMPLANTAÇÃO & C - VARIÁVEL VISUAL & D - RELAÇÃO EXPRESSA \\
\hline 1 - Qualitativo & 1- Pontual & 1- Cor & 1- Diversidade/Similaridade \\
\hline 2 - Quantitativo & 2 - Linear & 2 - Forma & 2 - Ordem \\
\hline 3 - Ordenado & 3 - Zonal & 3 - Tamanho & 3 - Proporcionalidade \\
\hline 4 - Dinâmico & & 4 - Valor & \\
\hline & & 5 - Granulação (Textura) & \\
\hline & & 6 - Orientação & \\
\hline
\end{tabular}

Tabela 06 - Características dos mapas temáticos. Adaptado de BERTIN, 2000. 


\section{2 - Metodologia para a Construção dos Materiais Didáticos}

Os materiais didáticos propostos para este trabalho estão divididos essencialmente em gabaritos elaborados com radiografias recicladas, além de tabelas e matrizes em papel para fotocopiadoras. Para os gabaritos, foram adaptados os métodos utilizados por artistas plásticos para elaboração de moldes com demarcação em superfícies diversas, além dos métodos químicos utilizados por fotógrafos laboratoristas para o aproveitamento do poliéster de radiografias e outras películas fotográficas. Os formatos dos mapas e símbolos foram adaptados em computador com software livre (Paintnet, OpenOffice, Bullzip...) e diagramados seguindo critérios gráficos de espaçamento para melhor aproveitamento e resistência dos gabaritos, tabelas e matrizes.

Para as tabelas e matrizes, os procedimentos propostos pelo professor Roberto Gimeno para alunos da Escola Elementar (Ensino Fundamental) foram adaptados neste trabalho para a realidade das escolas brasileiras. Na obra "Uma Nova Abordagem da Cartografia na Escola Elementar", Gimeno realizou uma atividade completa com todas as etapas para elaboração de mapas a partir da distribuição de dados estatísticos até o preenchimento dos mapas com cores, tons ou granulações. Trabalho realizado em seis semanas, com duração de 9 horas/aula.

Os procedimentos apresentados neste trabalho, em grande parte com base nos trabalhos do professor Gimeno e em conhecimentos da área gráfica e educacional, foram simplificados para viabilizar as atividades de construção de mapas, porém, sem fugir de sua essência que é "construir mapas temáticos artesanais em sala de aula com os mesmos critérios utilizados por cartógrafos".

Algumas etapas dos procedimentos foram simplificadas, substituídas ou até retiradas das atividades com o objetivo de viabilizar o tempo de elaboração dos mapas.

\section{Tabela única para diversos tipos de mapas:}

Em uma única tabela é possível distribuir e classificar dados para a elaboração de mapas ordenados, quantitativos, qualitativos e dinâmicos. Esta opção de formato de tabela contendo os procedimentos de construção para cada tipo de mapa tem o 
objetivo de possibilitar o trabalho com os dados de forma individual e estanque. Após a transcrição de todas as informações necessárias para a elaboração do mapa nesta tabela, é possível construir mapas sem recorrer a outras bases de dados ou cálculos. (vide figura 17)

\section{Matriz única para diversos fundos de mapas (mapas mudos):}

Como continuação dos procedimentos da tabela única, a matriz também foi preparada para a elaboração dos quatro tipos de mapas já descritos. No espaço para o fundo de mapa, pode ser inserido qualquer mapa mudo que se relacione com os dados da tabela. Para facilitar o trabalho do professor, foram elaboradas diversas matrizes para fotocópias utilizando vários fundos de mapas, incluindo uma matriz sem o fundo de mapa, para adaptação de acordo com a necessidade do professor. (vide figura 19)

Os gabaritos para lousas são úteis para o professor mostrar passo a passo os procedimentos aos alunos, para que os mesmos possam acompanhá-lo preenchendo as tabelas e matrizes.

Após a elaboração do mapa mudo em lousa com o auxílio do gabarito, as etapas para o preenchimento das tabelas e as matrizes com os mapas pelos alunos são divididas em:

a - dados estatísticos: apresentados em lousa ou em papel aos alunos para o preenchimento da tabela de classificação.

b - distribuição, classificação e conversão dos dados estatísticos: espaço na tabela para a preparação dos dados numéricos em classificação gráfica para a elaboração do mapa.

C - fundo de mapa: elaborados em formatos A-5 para melhor aproveitamento e redução de custos com fotocópias. Em cada matriz contém um mapa mudo e espaço demarcado para legenda, título e fonte pesquisada.

d - preenchimento da legenda, título e fonte dos dados: após a construção do mapa, os alunos completam com o título, os textos na legenda, geralmente detalhes do tema, e citam a fonte dos dados utilizados.

e - acabamento do mapa: os alunos complementam com o acabamento do mapa com contornos em tons, granulações ou cores mais apropriadas para realçar as informações apresentadas. 
Estes materiais didáticos passaram por diversas mudanças $\mathrm{e}$ aperfeiçoamentos durante o período de realização das atividades apresentadas neste trabalho, e podem ser ainda mais aprimorados a partir da realidade encontrada pelo professor em seu cotidiano com seus alunos. É importante lembrar que durante a aplicação das atividades com estes materiais, diversos alunos em todas as séries trabalhadas apresentaram dúvidas, críticas e sugestões importantíssimas em sala de aula para corrigir inúmeras falhas dos métodos e procedimentos utilizados para a elaboração dos mapas. 


\subsection{Descrição dos Materiais Didáticos Propostos}

Todos os materiais didáticos apresentados foram aprimorados e adaptados para auxiliar o professor de Geografia em atividades de construção de mapas temáticos. Na tabela a seguir, estão os tipos e materiais propostos.

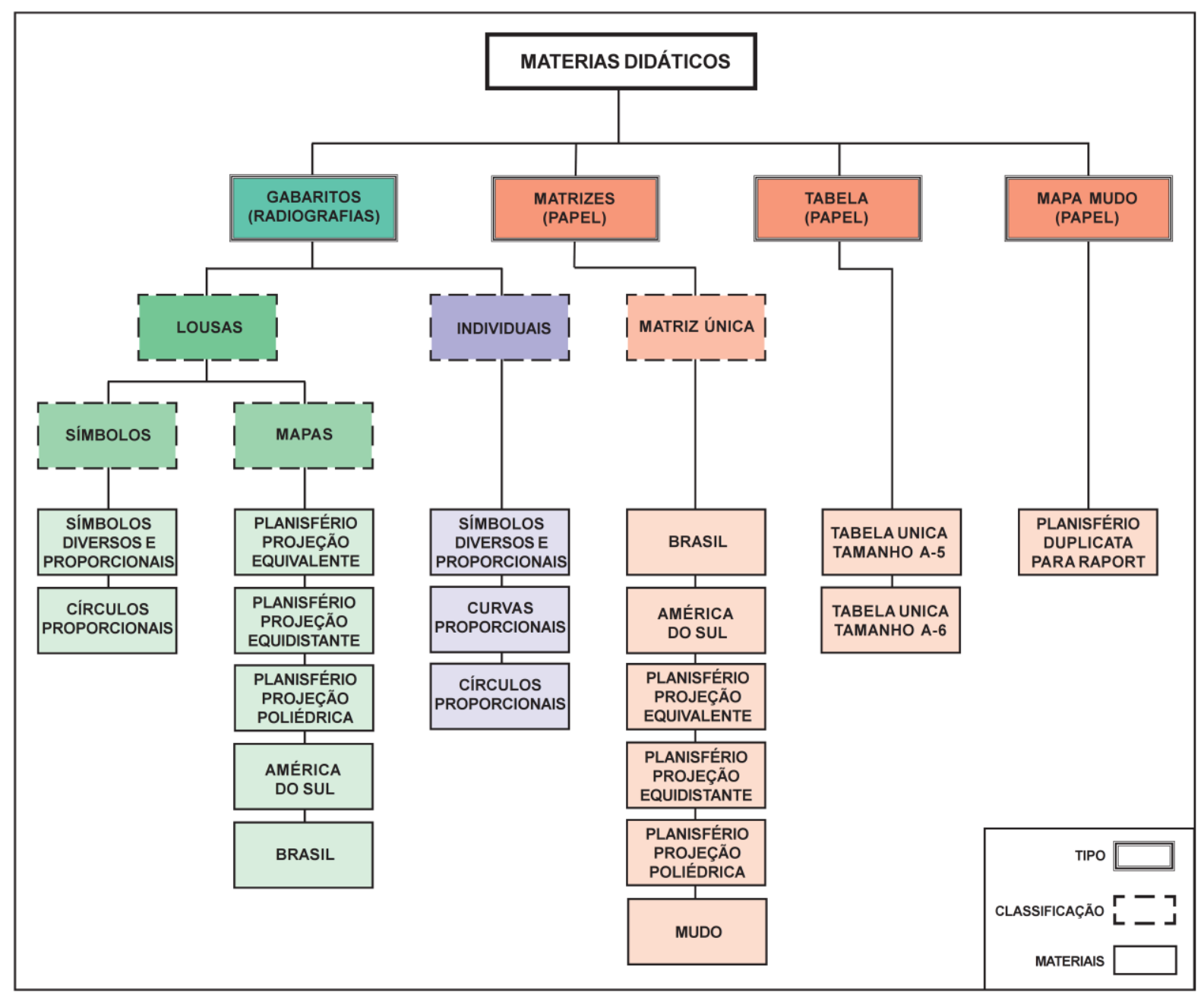

Tabela 07 - Organograma dos gabaritos e matrizes elaborados e disponibilizados neste trabalho.

\section{Descrição da matéria-prima (radiografias)}

A matéria-prima básica para a fabricação de radiografias é o poliéster (derivado do petróleo), além de uma camada de material à base de prata aplicado pela indústria de materiais fotográficos. Depois de ser sensibilizada, a imagem é 
revelada em uma solução a base de hipossulfito de sódio, ácido acético, entre outros componentes.

A escolha por radiografias para a elaboração dos gabaritos se deve ao fato de ser um material de fácil acesso, baixo custo e de excelente estabilidade dimensional, uma vez que suporta altas temperaturas sem apresentar deformações, como pode ocorrer no interior de veículos expostos a luz solar. Mas também existem outros materiais semelhantes com características parecidas, como acetato, plástico em lâminas, etc.

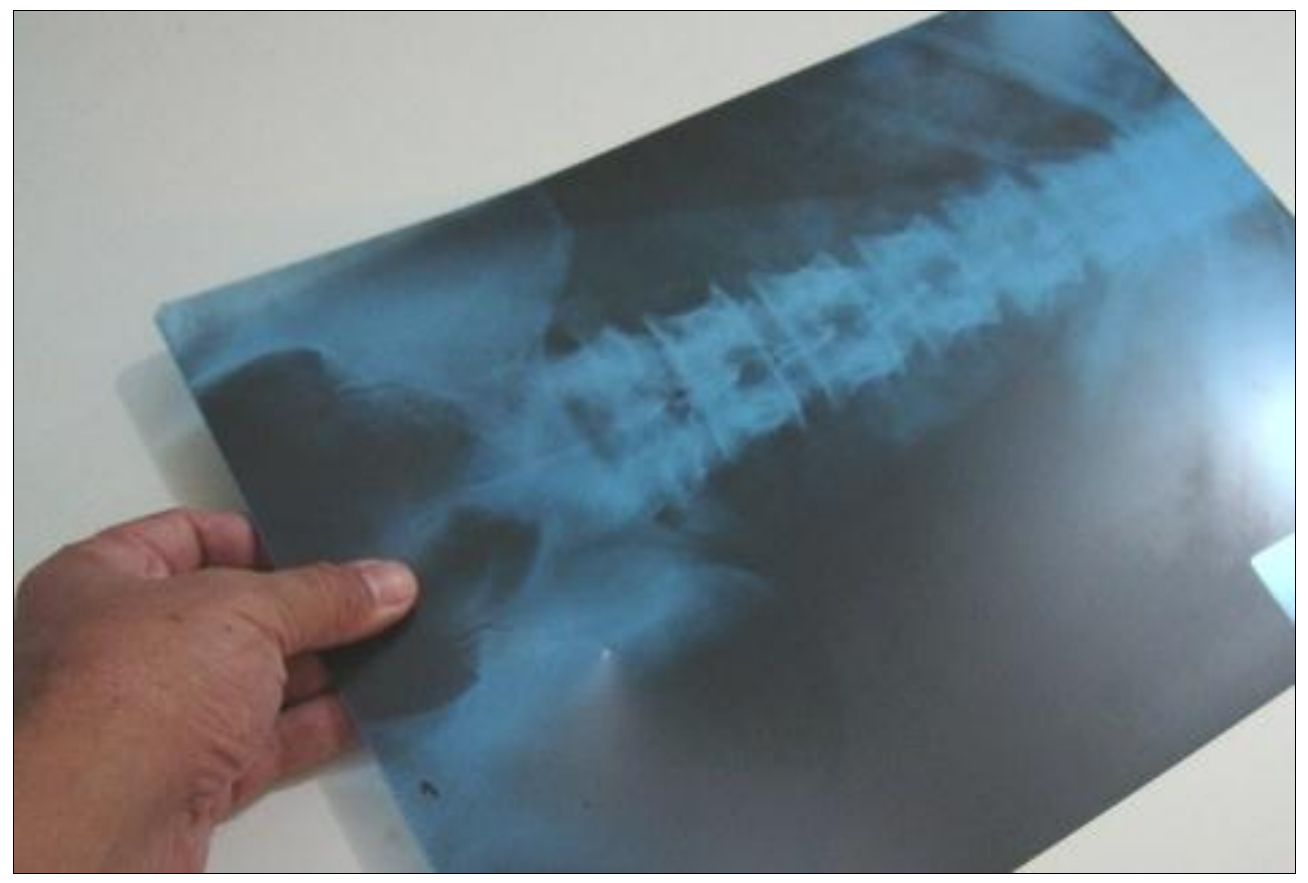

Figura 08 - Radiografia descartada para banho em cloro e retirada do nitrato de prata.

Por ser "ainda" um material muito utilizado no campo da medicina, é facilmente encontrado em residências, em que geralmente ficam guardados durante alguns anos e depois são simplesmente descartados em aterros sanitários. Já existem diversas empresas e pessoas que reciclam a prata para fins lucrativos, mas o poliéster ainda é pouco reutilizado. Em algumas radiografias mais modernas (ressonâncias), somente cloro não é suficiente para retirar a camada de prata, o que impossibilita sua utilização para este tipo de trabalho.

Para a retirada da prata utilizando cloro, é importante ter o cuidado de realizar este procedimento em locais arejados utilizando luvas, e em seguida, lavá-las em água corrente. 


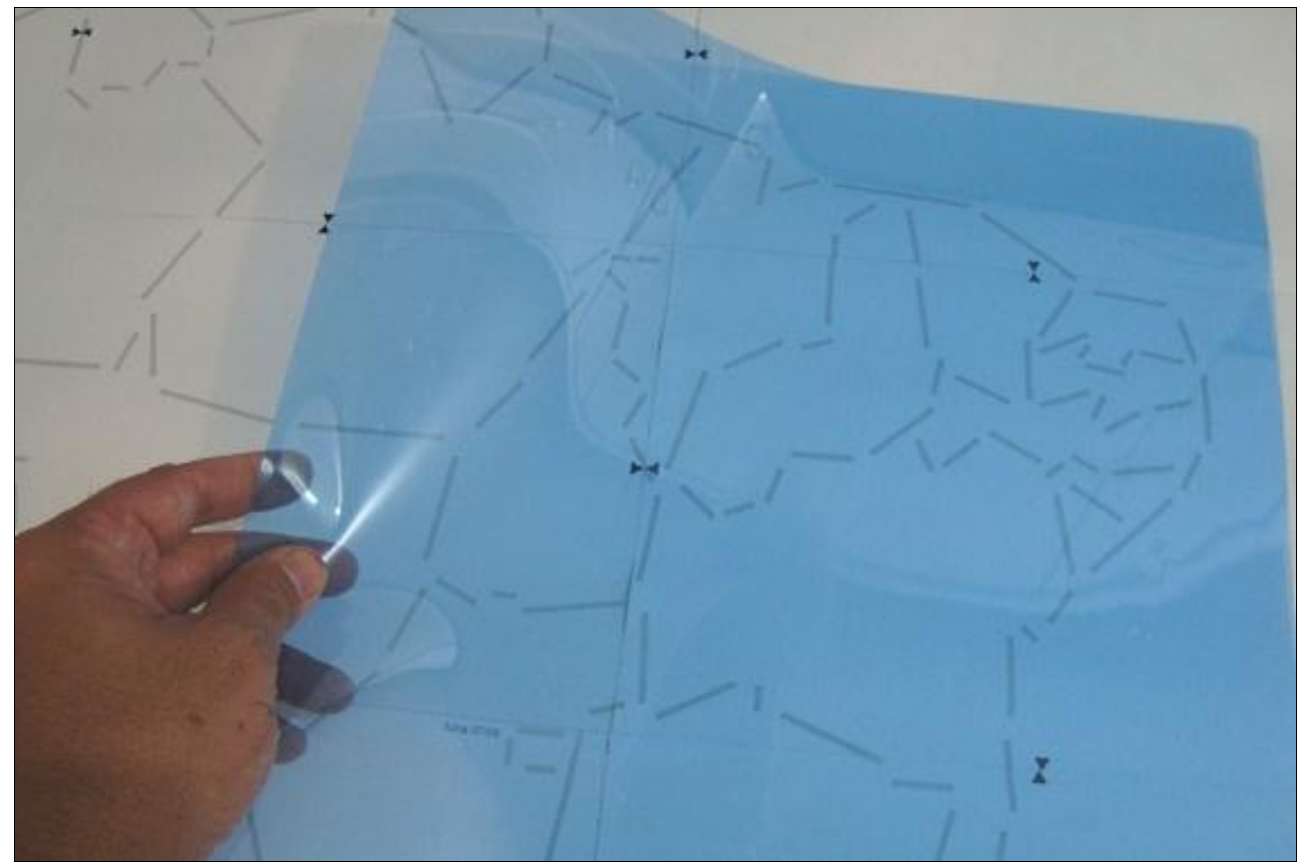

Figura 09 - Radiografia após a lavagem em cloro para demarcação dos tracejados do mapa.

Quanto aos impactos ambientais, os resíduos das radiografias não causam problemas ao Meio Ambiente, como contaminação de lençóis freáticos ou áreas de mananciais, como afirma a engenheira química especializada em saneamento ambiental Ellen GOETTEMS:

Vários estudos não indicaram nenhuma evidência de que a prata proveniente dos efluentes de fotoprocessamento seja tóxica. (...) A prata pode existir sob diversas formas, desde a forma iônica até complexos solúveis e sulfetos insolúveis, este fenômeno é conhecido cientificamente como especiação. A prata dos efluentes fotográficos encontra-se na forma de tiossulfato de prata. Apesar de estudos feitos em laboratórios terem demonstrado que a prata iônica (não encontrada nos efluentes fotográficos) pode ser tóxica, outros estudos revelam que até mesmo este tipo de prata não permanece no meioambiente em forma tóxica. (GOETTEMS, 1997).

Assim como o processo fotográfico químico foi substituído pela tecnologia digital, é provável que as radiografias tenham o mesmo destino. Porém, é um material facilmente substituível por acetato, ou outros materiais de baixo custo com características semelhantes. 


\subsection{1 - Gabaritos de Mapas para Elaboração em Lousa}

Este material é elaborado com o princípio dos gabaritos perfurados utilizados por artistas plásticos para a transposição de desenhos em superfícies verticais e tetos (REED, 1965). Tem como matéria-prima o poliéster reutilizado de radiografias inutilizadas após um banho químico em cloro (água sanitária), e depois de elaborado o mapa ou símbolos proporcionais desejados com caneta hidrocor, é feito um recorte intermitente sobre o traçado.

Para sua utilização, é colocado sobre a lousa e em seguida, é aplicado pó de giz ou outro material semelhante sobre toda a superfície do gabarito, a qual é fica marcada sobre a lousa. Em seguida, é feito o preenchimento final do mapa mudo ou dos gabaritos proporcionais com giz ou pincel atômico.

Neste trabalho, os traçados dos gabaritos foram elaborados em formato PDF para impressão em papel A-4 como matrizes para a demarcação nas radiografias. Em cada material contém a descrição dos procedimentos passo a passo para a confecção dos gabaritos, com a vantagem de reproduzir os gabaritos sem descartar as bases em papel. Todas as bases de recorte estão disponíveis nos apêndices para serem consultadas e reproduzidas. Como neste exemplo do mapa do Brasil, as etapas para elaboração dos gabaritos se subdividem em:

\section{MATERIAIS NECESSÁRIOS PARA A ELABORAÇÃO DO GABARITO}

1 - Base de recorte impressa em 09 folhas A-4.

2 - Radiografias inutilizadas lavadas em cloro (água sanitária).

3 - Fita crepe, tesoura, estilete e cola.

4 - Caneta hidrocor ponta grossa vermelha ou preta.

5 - Estilete escolar pequeno.

6 - Base de vidro de $20 \mathrm{~cm}^{2}$ ou mais.

\section{PROCEDIMENTOS}

\section{A - BASE DE RECORTE}

1 - Imprima a base para recorte das 09 folhas seguintes em papel A-4. 
2 - Recorte apenas as linhas pontilhadas indicadas em cada folha.

3 - Cole as partes indicadas seguindo as setas de orientação

\section{B - MONTAGEM DO GABARITO}

1 - Centralize as radiografias sobre a base do mapa, prendendo-as com fita crepe apenas nas extremidades pelo lado legível (frente). A ampliação do mapa foi calculada sobre duas radiografias grandes $(43 \times 35 \mathrm{~cm})$, e uma média $(40 \times 30 \mathrm{~cm})$ recortada posteriormente para a dobra do gabarito (figura menor), mas também pode ser elaborada com outros tamanhos de radiografias.

2 - Utilize uma caneta hidrocor de ponta grossa para transferir o traçado da base para as radiografias.

3 - Retire a fita crepe da base e recorte as áreas demarcadas com estilete escolar pequeno sobre uma base rígida (vidro, de preferência, para facilitar o recorte). É importante utilizar o estilete em uma inclinação de aproximadamente 30 graus durante o recorte para manter a ponta da lâmina bem afiada por mais tempo.

4 - Recorte a radiografia para que o conjunto seja dobrável (linha pontilhada da figura menor).

5 - Monte as radiografias pelo verso e prenda-as com fita crepe em todas as junções.

\section{C - APLICAÇÃO}

1 - Prenda o gabarito sobre a lousa e aplique o apagador com pó de giz sobre toda a superfície do mapa.

2 - Retire o gabarito e preencha o contorno do mapa mudo com giz (quadro negro) ou pincel atômico (quadro branco). 


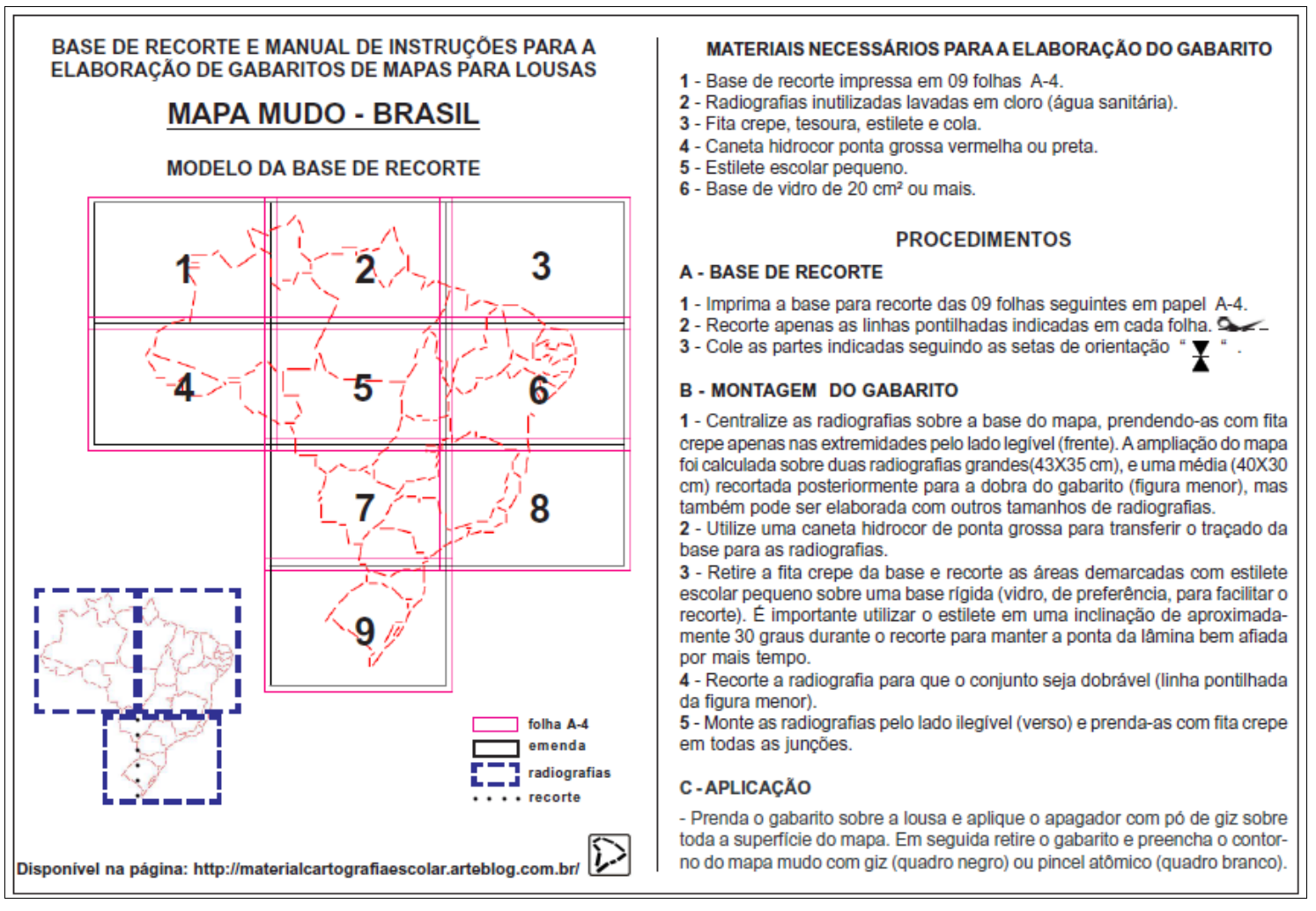

Figura 10 - Folha de rosto da base de recorte do gabarito do mapa do Brasil. (LEITE, 2014)

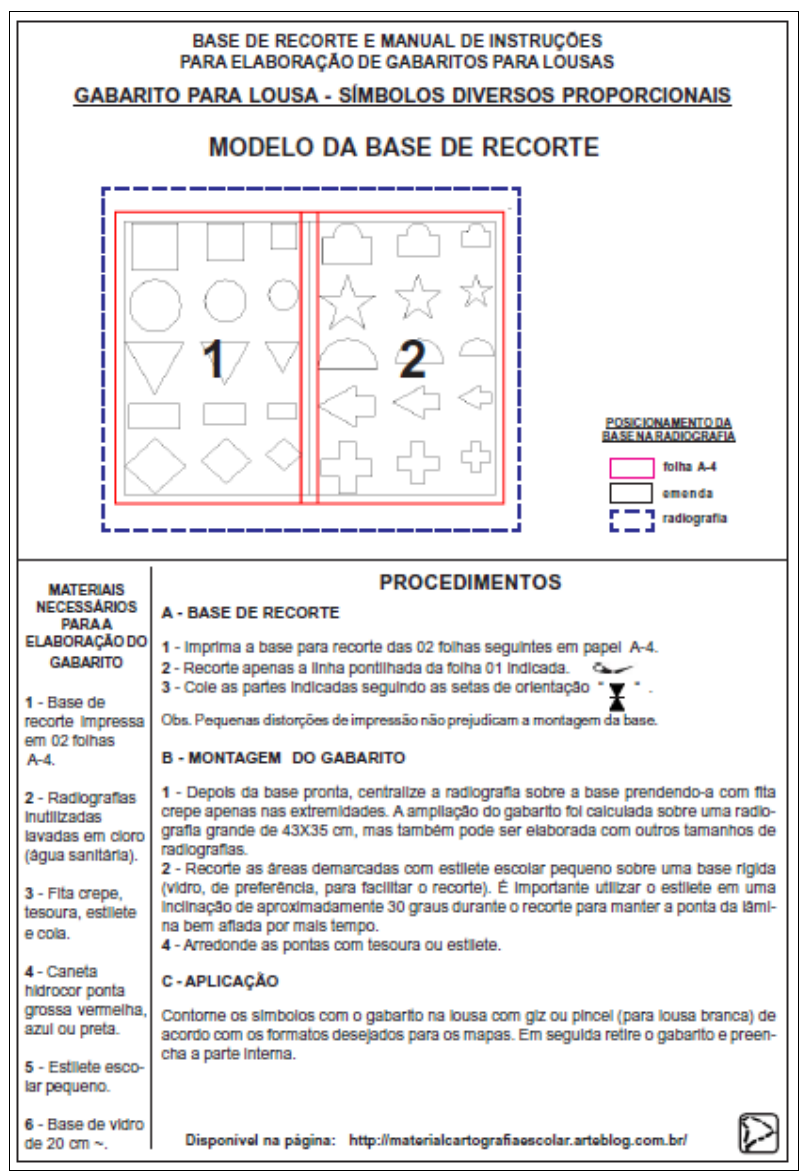

Figura 11 - folha de rosto da base de recorte do gabarito de símbolos para lousa. (LEITE, 2014) 


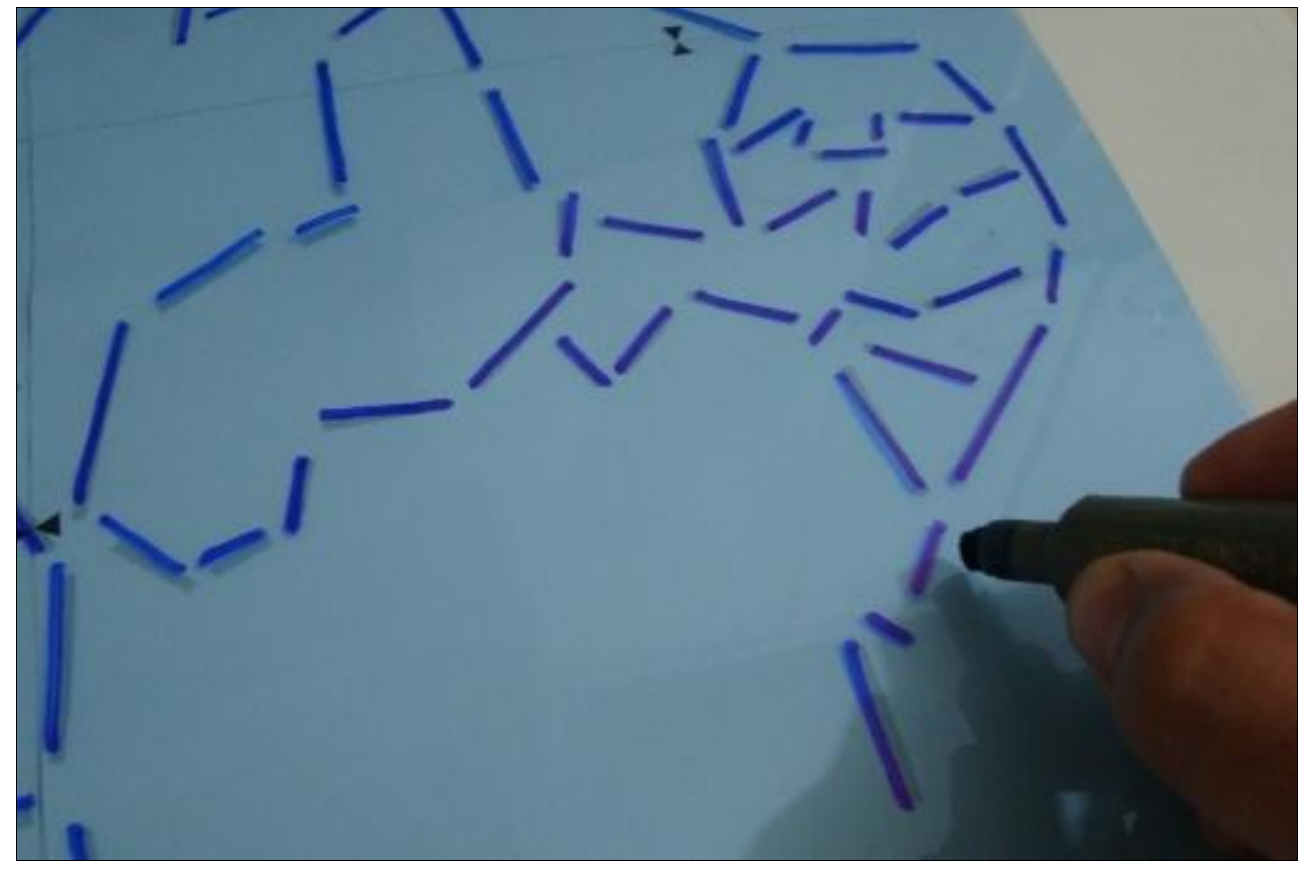

Figura 12 - Demarcação no conjunto de radiografias para transferir os tracejados da base em papel com caneta hidrocor.

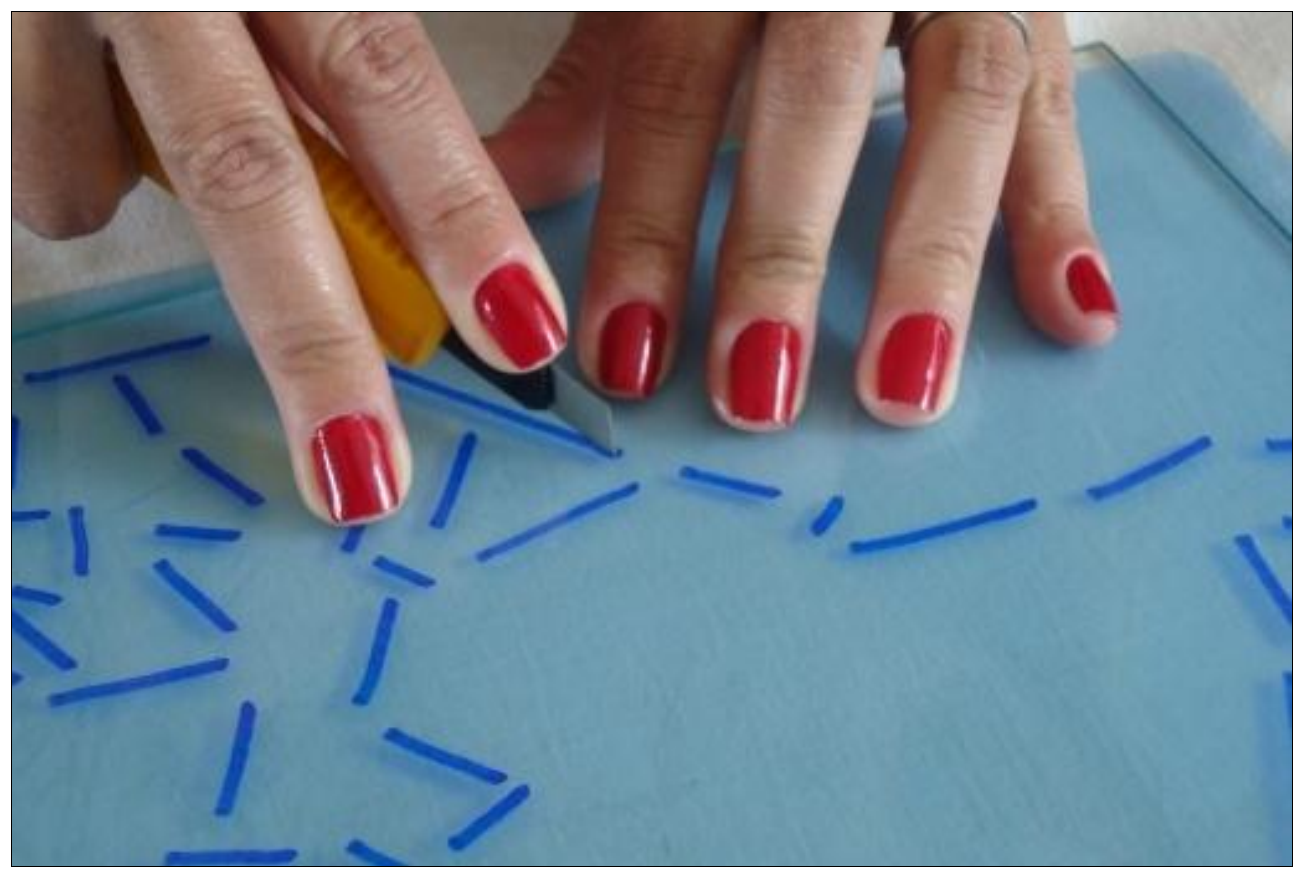

Figura 13 - Recorte da radiografia separada na parte tracejada com estilete. 


\subsection{2 - Gabaritos de Símbolos para Elaboração de Mapas}

Elaborado com o princípio dos gabaritos utilizados por engenheiros projetistas, a matéria-prima básica para este material é a mesma dos gabaritos para lousas, porém, o poliéster é recortado no formato A-4. Em seguida, os símbolos proporcionais (círculos, símbolos, fluxos...) em arquivos PDF são impressos diretamente sobre a superfície em impressoras laser (preferencialmente) ou jato de tinta, e em seguida, recortados manualmente com estilete. Embora seja um procedimento trabalhoso e demorado, é um material permanente para o professor e de longa durabilidade, o que justifica sua elaboração em conjuntos de 15 a 40 peças, para a utilização dos alunos individualmente ou em duplas.

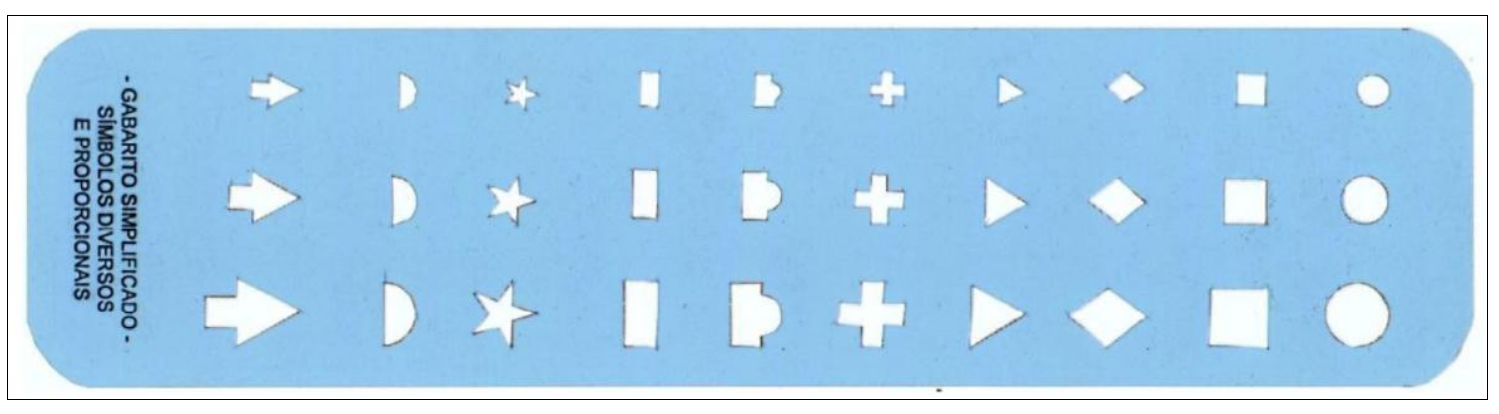

Figura 14 - Gabarito de símbolos após a impressão da radiografia em impressora laser e recorte com estilete. (LEITE, 2014)

Para maior durabilidade dos números e letras impressas, os gabaritos estão elaborados pelo lado avesso (ilegível), e é possível aplicar uma camada de verniz em spray para proteção, mas também seus números podem ser restaurados manualmente com pincel atômico. Como neste exemplo do gabarito de curvas, as etapas para elaboração dos gabaritos se subdividem em: 


\section{MATERIAIS NECESSÁRIOS PARA A ELABORAÇÃO DO GABARITO}

1 - Radiografias inutilizadas lavadas em cloro (água sanitária).

2 - Impressora Laser ou Jato de Tinta, para imprimir a base diretamente do arquivo PDF na radiografia, ou cópia em papel para impressão em fotocopiadoras diretamente na radiografia.

3 - Estilete escolar pequeno.

4 - Base de vidro de $20 \mathrm{~cm}$ aproximadamente ou maior.

\section{PROCEDIMENTOS}

1 - DIRETAMENTE DE ARQUIVO PDF - Imprima a base para recorte dos símbolos em impressoras Laser ou Jato de Tinta utilizando radiografia pequena $(23,7 \times 17,7$ $\mathrm{cm})$ ou maior até o tamanho A-4.

- A PARTIR DE MATRIZ EM PAPEL - Com a base do gabarito impressa em papel, utilize-a como original na máquina de fotocópias substituindo as folhas por uma radiografia em formato A-4 na gaveta de folhas em branco.

Obs. as letras e números das quatro peças estão impressas pelo lado avesso (ilegível). Para maior durabilidade do texto, também pode ser aplicada uma camada de verniz em spray ou outro material semelhante sobre a radiografia.

2 - Com estilete pequeno separe as quatro peças na área demarcada e em seguida recorte os círculos sobre uma base rígida (vidro, de preferência, para facilitar o recorte). É importante utilizar o estilete em uma inclinação de aproximadamente 30 graus durante o recorte para manter a ponta da lâmina bem afiada por mais tempo.

3 - Arredonde as pontas com tesoura ou estilete. 


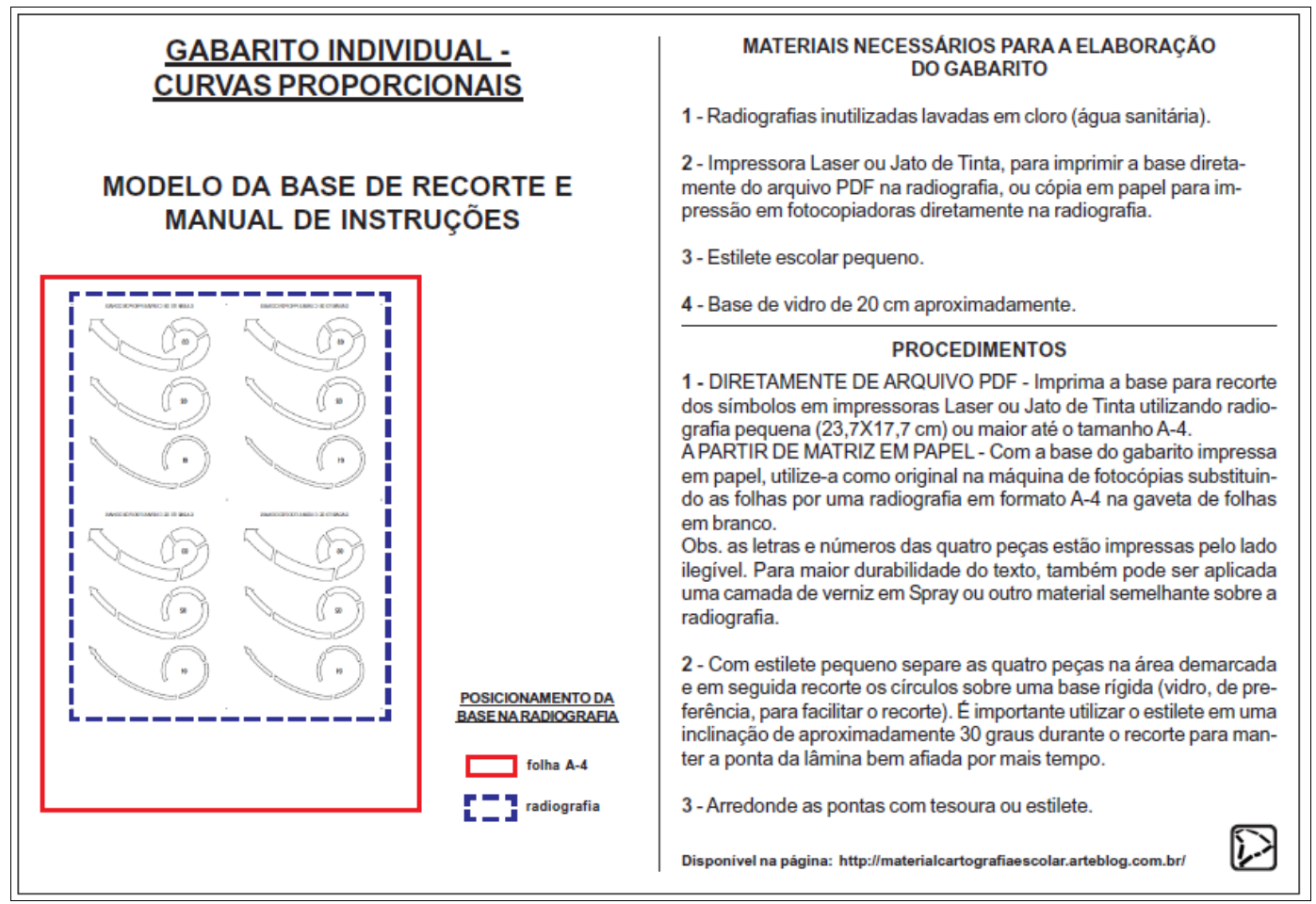

Figura 15 - folha de rosto da base de recorte do gabarito individual de curvas proporcionais. (LEITE, 2014)

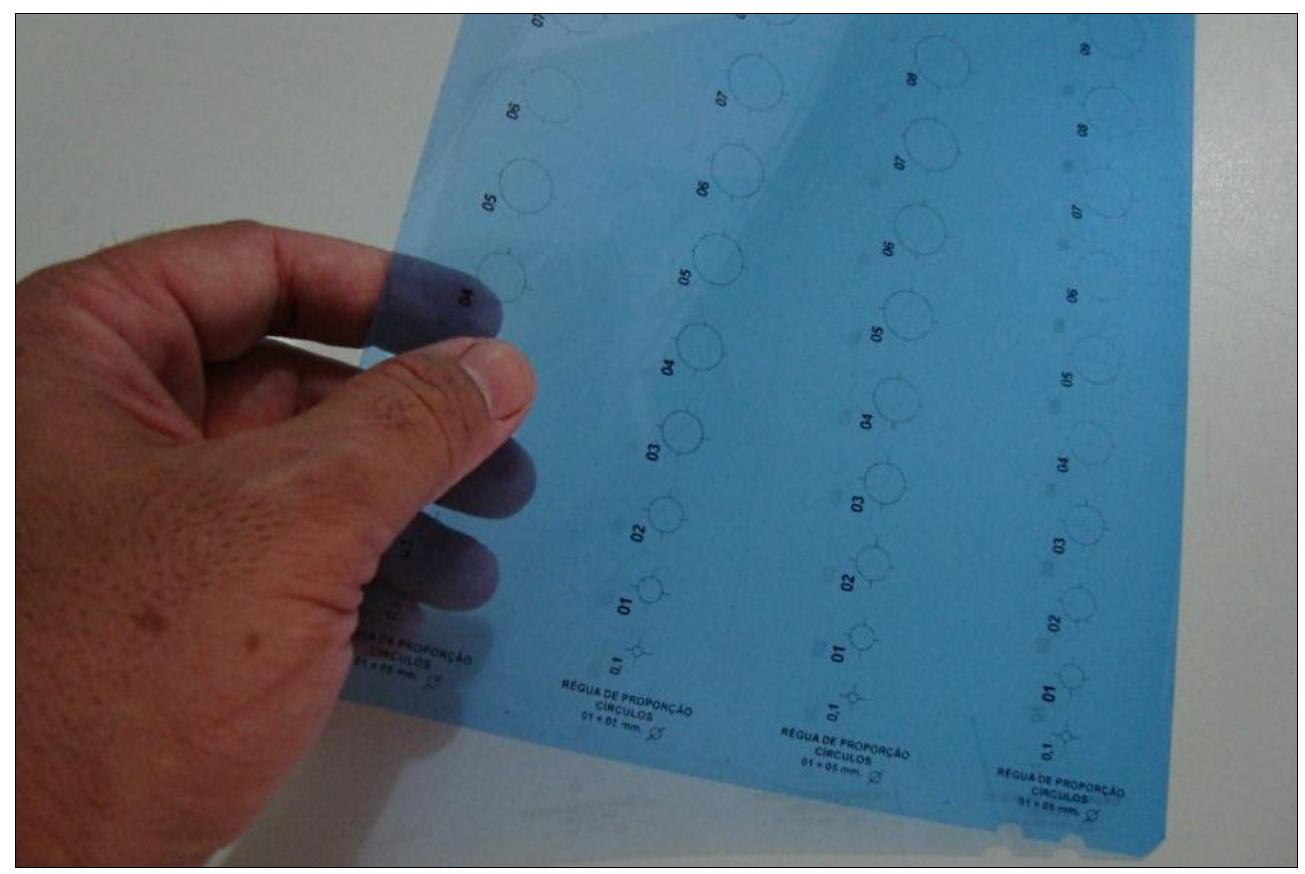

Figura 16 - Radiografia impressa pelo lado avesso (ilegível) em impressora para o recorte. 


\subsection{3 - Tabelas e Matrizes para Elaboração de Mapas Temáticos}

Consiste em um formato simplificado em papel, de uma tabela para a construção juntamente com espaços para conversão, distribuição e classificação de dados. Todos em formato A-5, A-6, ou outro tamanho com o objetivo de aproveitar ao máximo a divisão do formato $\mathrm{A}-4$, com o mínimo desperdício de material. Também pode ser ampliado de acordo com a necessidade do professor.

Com apenas uma tabela, é possível elaborar mapas ordenados, quantitativos, qualitativos e dinâmicos de maneira independente, e os procedimentos para elaboração de cada tipo de mapa estão descritos na própria tabela, como apresentada a seguir:

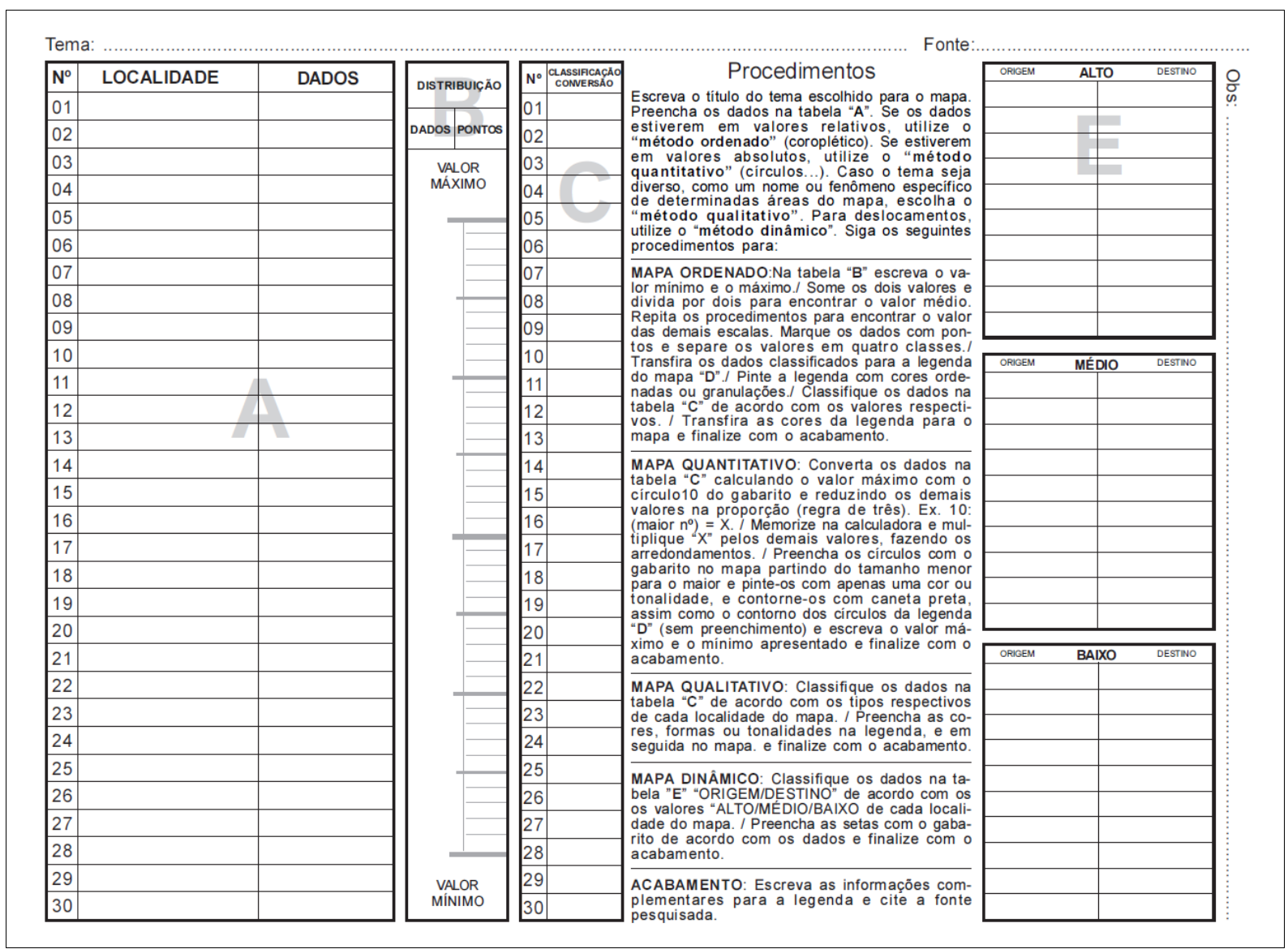

Figura 17 - Tabela em formato A-5 com espaço para transcrever dados com até 30 elementos para a construção de mapas ordenados, quantitativos, qualitativos ou dinâmicos com espaço origem-destino para até 10 dados de fluxos divididos em alto, médio e baixo. (LEITE, 2014) 


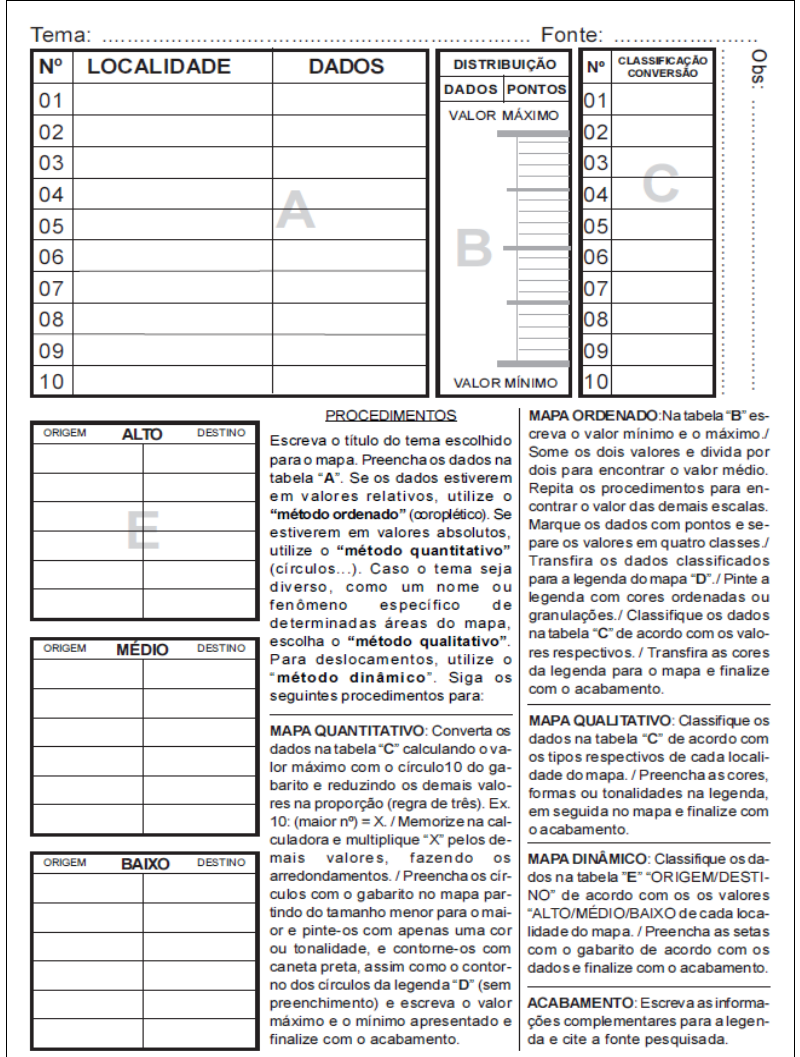

Figura 18 - Tabela em formato A-6 utilizada para elaborar mapas com poucos elementos, para economia de material. (LEITE, 2014)

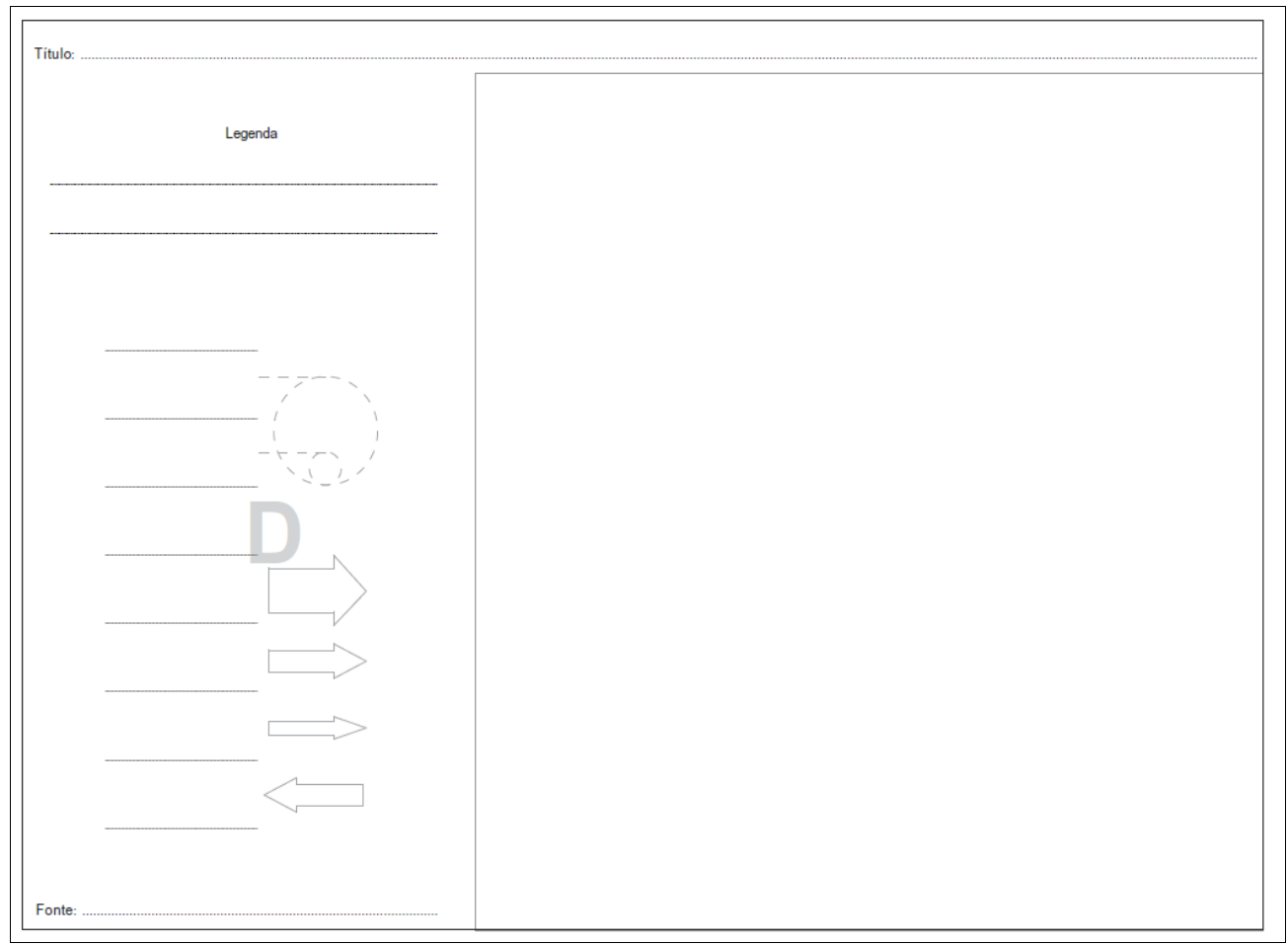

Figura 19 - Matriz com espaço para o fundo de mapa para elaboração dos mesmos tipos de mapas contidos na tabela, porém de forma independente, ou seja, o aluno pode fazer inúmeros mapas de diversas cores e contornos, por exemplo, sem descartar os dados calculados da tabela. (LEITE, 2014) 


\section{4 - Procedimentos para Utilização dos Materiais Didáticos}

Todos os materiais didáticos apresentados neste trabalho foram desenvolvidos a partir de diversas técnicas utilizadas pela humanidade durante séculos. As possibilidades de adaptações e utilizações são infinitas. Por isto, serão descritos apenas os procedimentos utilizados nas atividades desenvolvidas entre 0 período de 2009 e 2013.

A partir do momento em que o professor de Geografia utilizar estes materiais em sala de aula, poderá surgir idéias ou sugestões diversas para aprimorar ainda mais os materiais e os procedimentos para a construção de mapas.

\subsection{1 - Utilização de gabaritos para lousas}

Para a utilização dos gabaritos para lousas, é importante "limpar" bem a superfície da lousa de giz ou lousa branca, em que será desenhado o mapa, e no gabarito, "sujar" o material com pó de giz para as primeiras aplicações para demarcar a lousa após a aplicação com o apagador.

Após a fixação do gabarito na lousa com uma fita crepe para as primeiras aplicações (com a prática, é possível segurar o gabarito e passar o apagador sobre o mesmo mantendo-o fixo !), passe o apagador sobre toda a superfície demarcada com o apagador "sujo" de pó de giz branco ou outra cor clara, e para lousa branca, com pó de giz de cor mais forte, como azul ou vermelho. (Vídeo com os procedimentos de aplicação de gabaritos disponível na Internet no endereço: http://materialcartografiaescolar.arteblog.com.br/632471/Video-Elaboracao-de-mapamudo-com-gabarito-em-lousa/) 


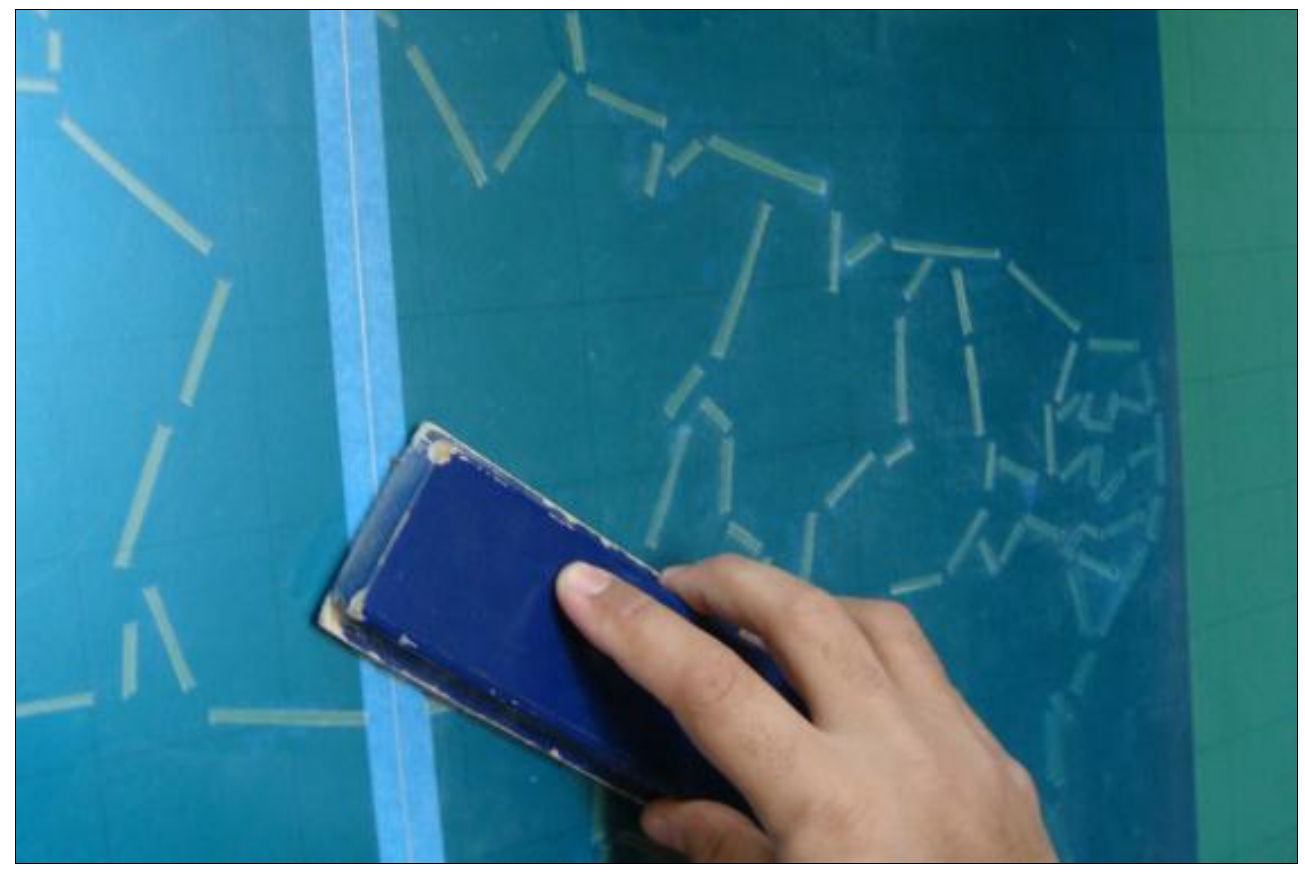

Figura 20 - Aplicação de pó de giz sobre toda a superfície perfurada do gabarito.

Em seguida, preencha os contornos demarcados para finalizar o mapa mudo (fundo de mapa) ou os símbolos proporcionais e diversos.

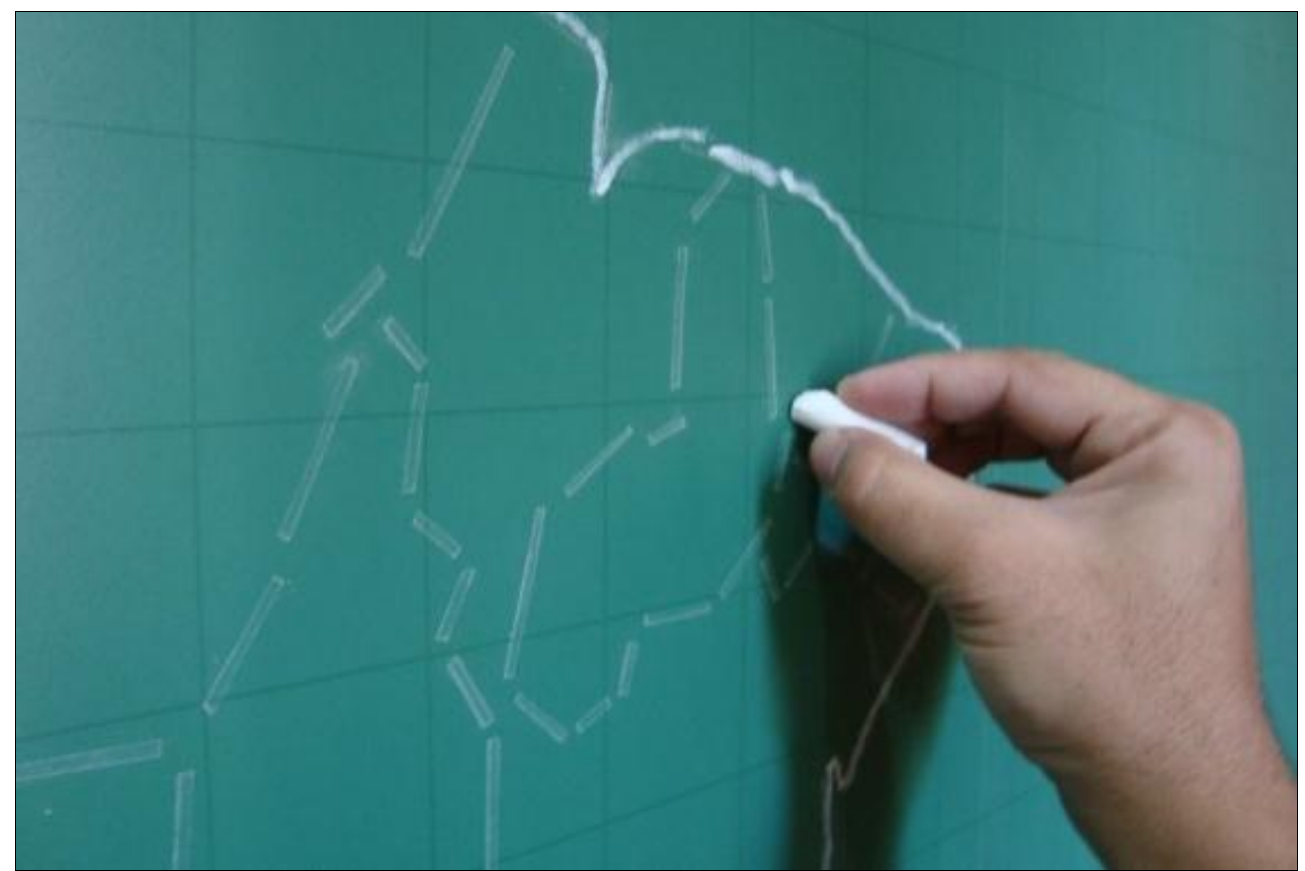

Figura 21 - Preenchimento do mapa em lousa após a aplicação do apagador com pó de giz sobre o gabarito do mapa do Brasil. 


\subsection{2 - Utilização de gabaritos individuais}

Os gabaritos individuais são utilizados para contornar símbolos ou círculos proporcionais sobre o fundo de mapa de acordo com os dados estatísticos calculados. É importante primeiramente contornar os círculos ou símbolos com lápis ou caneta preta, para posteriormente preenchê-los com cores.

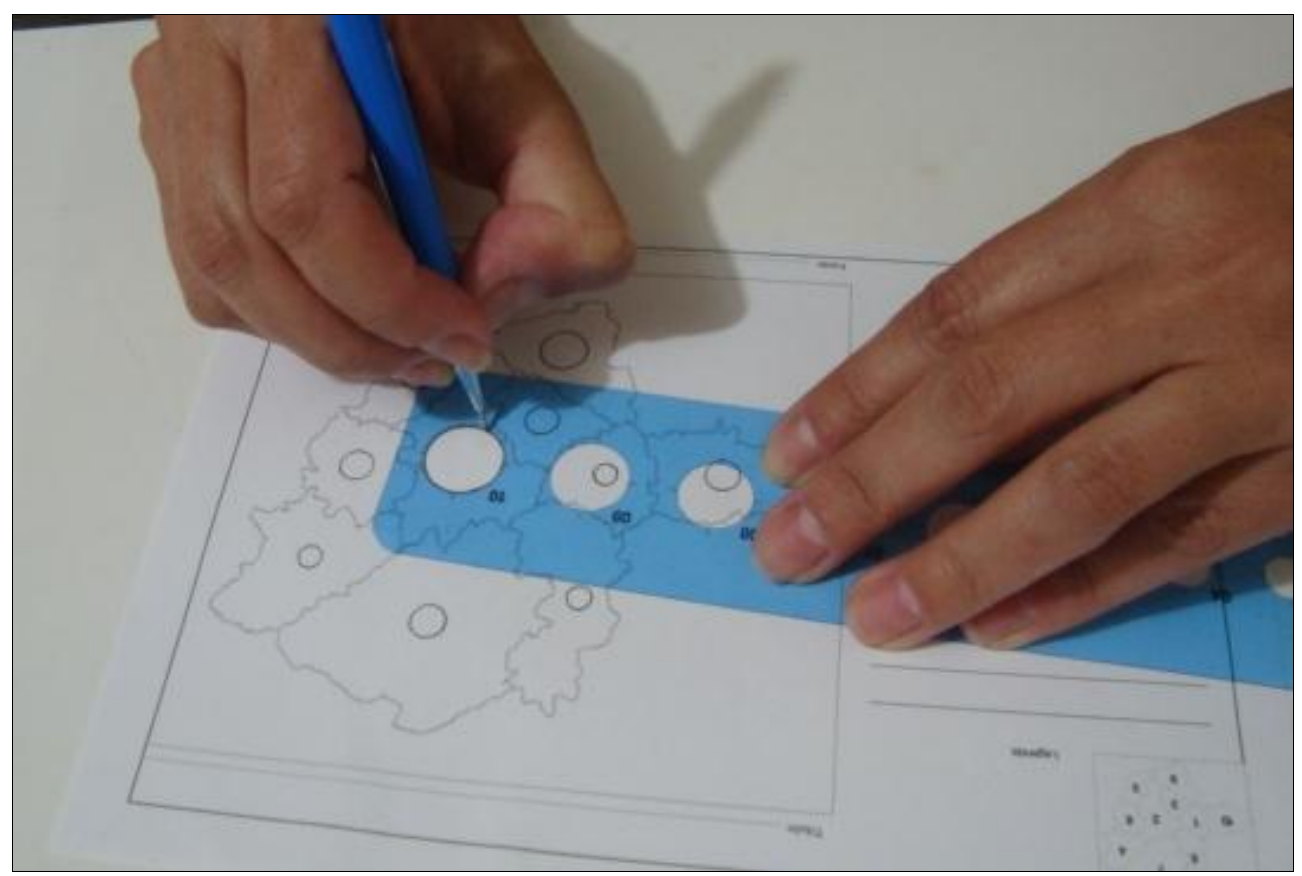

Figura 22 - Preenchimento de círculos proporcionais com gabarito individual.

\subsection{3 - Utilização de tabelas e matrizes}

Para iniciar a atividade de elaboração de mapa, é preciso ter em mãos os dados estatísticos desejados para definir o tipo de mapa que será construído, assim como o fundo de mapa mais adequado (vide capítulo: Semiologia Gráfica). Em seguida, siga os procedimentos descritos na tabela, como transcritos a seguir:

\section{PROCEDIMENTOS}

Escreva o título do tema escolhido para o mapa. Preencha os dados na tabela "A". Se os dados estiverem em valores relativos, utilize o "método ordenado" (coroplético). Se estiverem em valores absolutos, utilize o "método quantitativo" (círculos...). Caso o tema seja diverso, como um nome ou fenômeno específico de determinadas áreas do mapa, escolha o "método qualitativo". Para deslocamentos, utilize o "método dinâmico". Siga os seguintes procedimentos para: 
MAPA ORDENADO: Na tabela "B" escreva o valor mínimo e o máximo./ Some os dois valores e divida por dois para encontrar o valor médio. Repita os procedimentos para encontrar o valor das demais escalas. Marque os dados com pontos e separe os valores em quatro classes./ Transfira os dados classificados para a legenda do mapa "D"./ Pinte a legenda com cores ordenadas ou granulações./ Classifique os dados na tabela "C" de acordo com os valores respectivos. / Transfira as cores da legenda para o mapa e finalize com o acabamento.

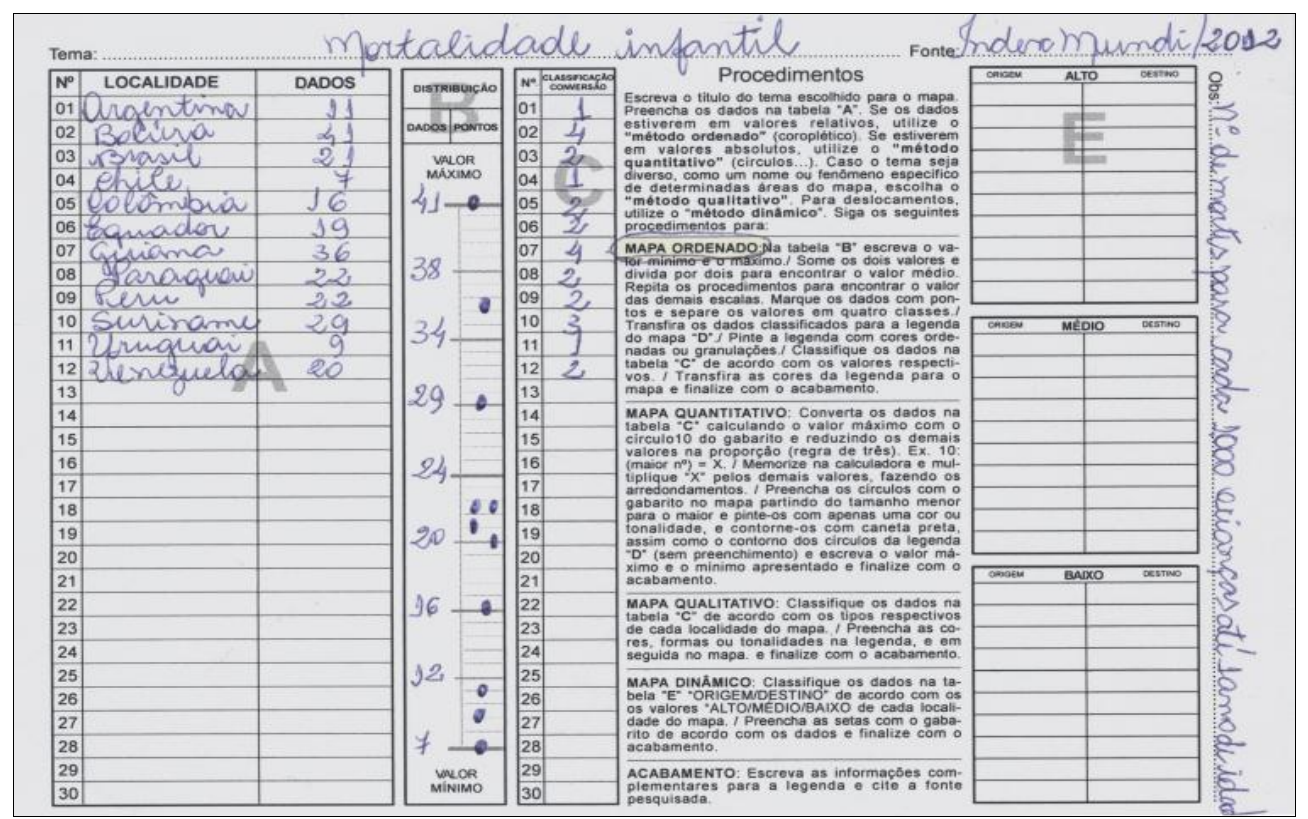

Figura 23 - Tabela com dados em valores relativos para mapas ordenados (coropléticos). Tema: Mortalidade infantil por 1000 na América do Sul.

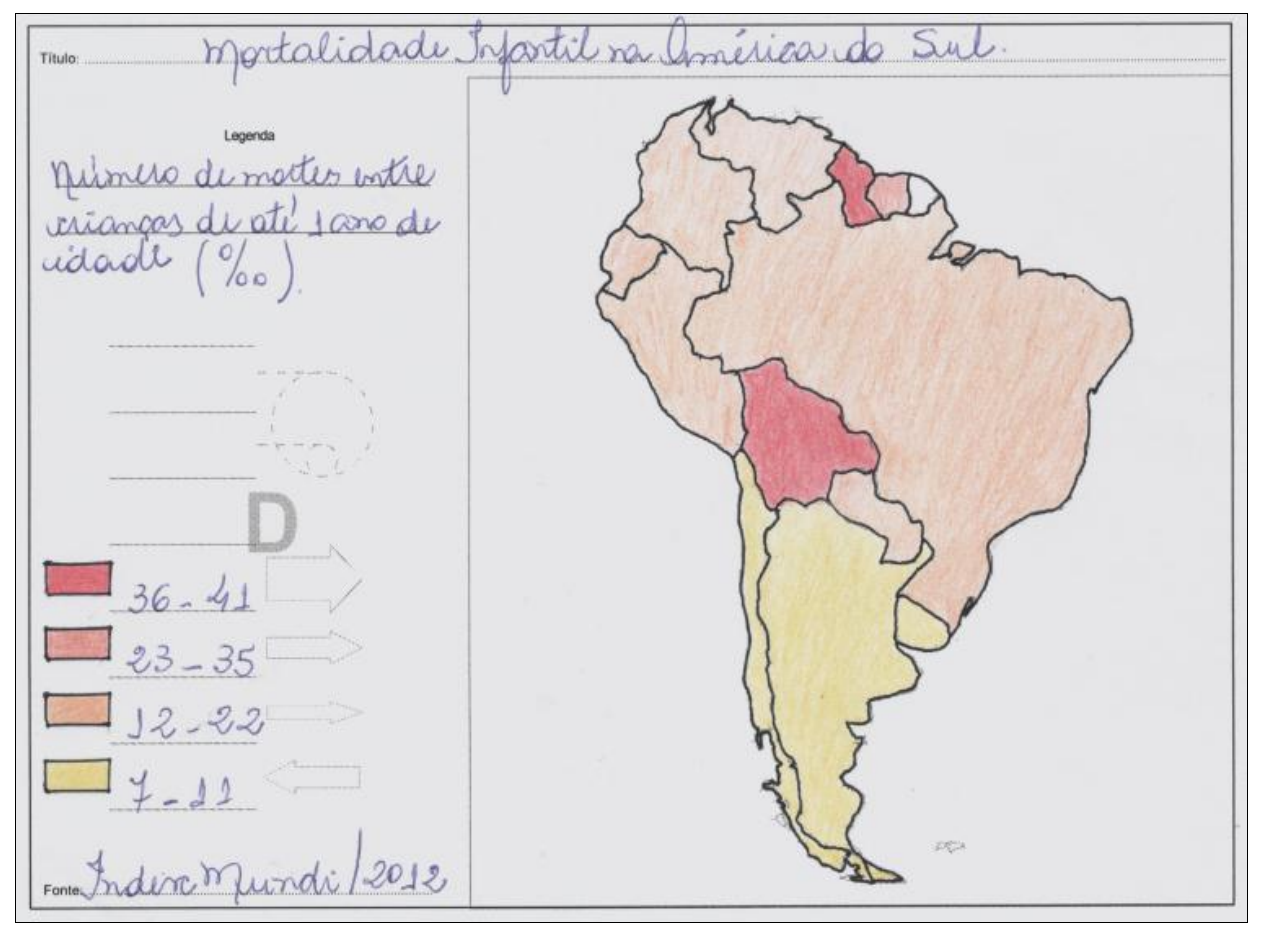

Figura 24 - Matriz com fundo de mapa da América do sul e elaboração do mapa com os dados da tabela acima. Sem inutilizar a tabela, é possível construir outros mapas. 
MAPA QUANTITATIVO: Converta os dados na tabela "C" calculando o valor máximo com o círculo 10 do gabarito e reduzindo os demais valores na proporção (regra de três). Ex. 10: (maior $\mathrm{n}^{\circ}$ ) = X./ Memorize na calculadora e multiplique "X" pelos demais valores, fazendo os arredondamentos./ Preencha os círculos com o gabarito no mapa "partindo do tamanho menor para o maior" e pinte-os com apenas uma cor ou tonalidade. Contorne-os com caneta preta, assim como o contorno dos círculos da legenda " $D$ " (sem preenchimento) e escreva o valor máximo e o mínimo apresentado, finalizando com o acabamento do mapa.

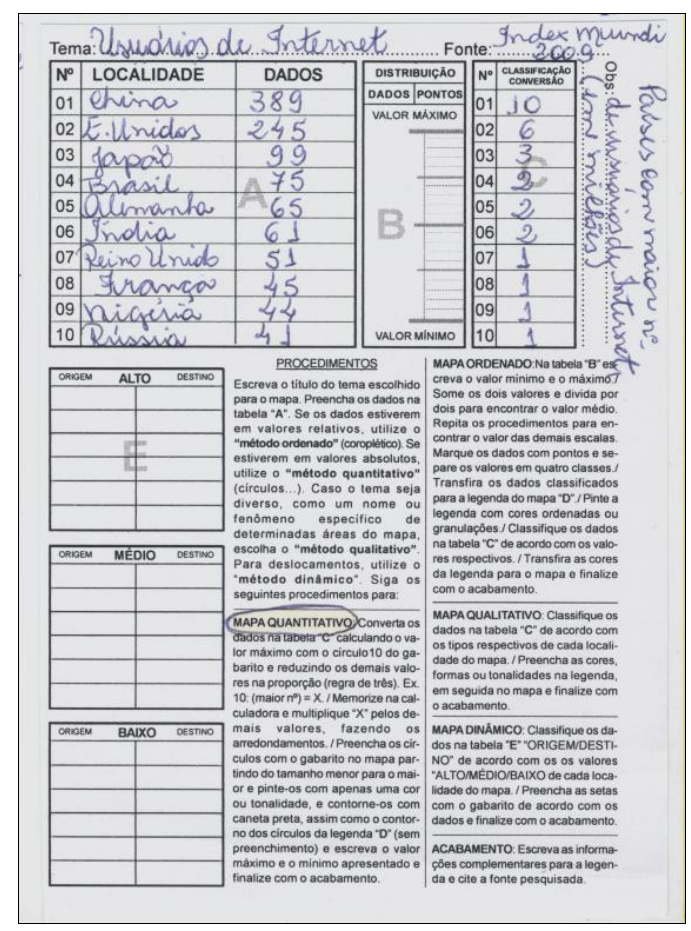

Figura 25 - Tabela pequena (tamanho A-6) com dados em valores absolutos para mapas quantitativos. Tema: Os Dez Países com Maior Número de Usuários de Internet.

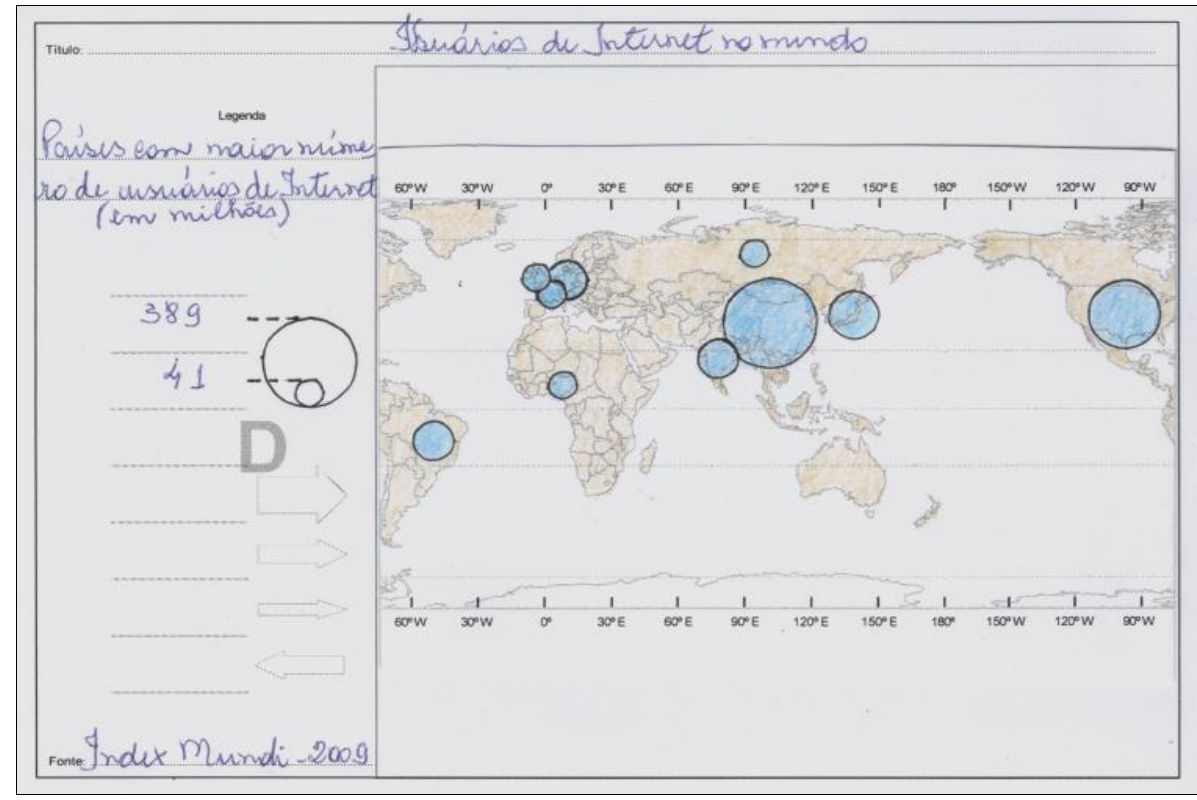

Figura 26 - Matriz com o planisfério equidistante colado após a elaboração dos círculos e centralizado na china, país com maior número de usuários de Internet (vide planisfério sobre fundos de mapas). 
MAPA QUALITATIVO: Classifique os dados na tabela "C" de acordo com os tipos respectivos de cada localidade do mapa./ Preencha as cores, formas ou tonalidades na legenda, e em seguida no mapa./ Finalize com o acabamento.

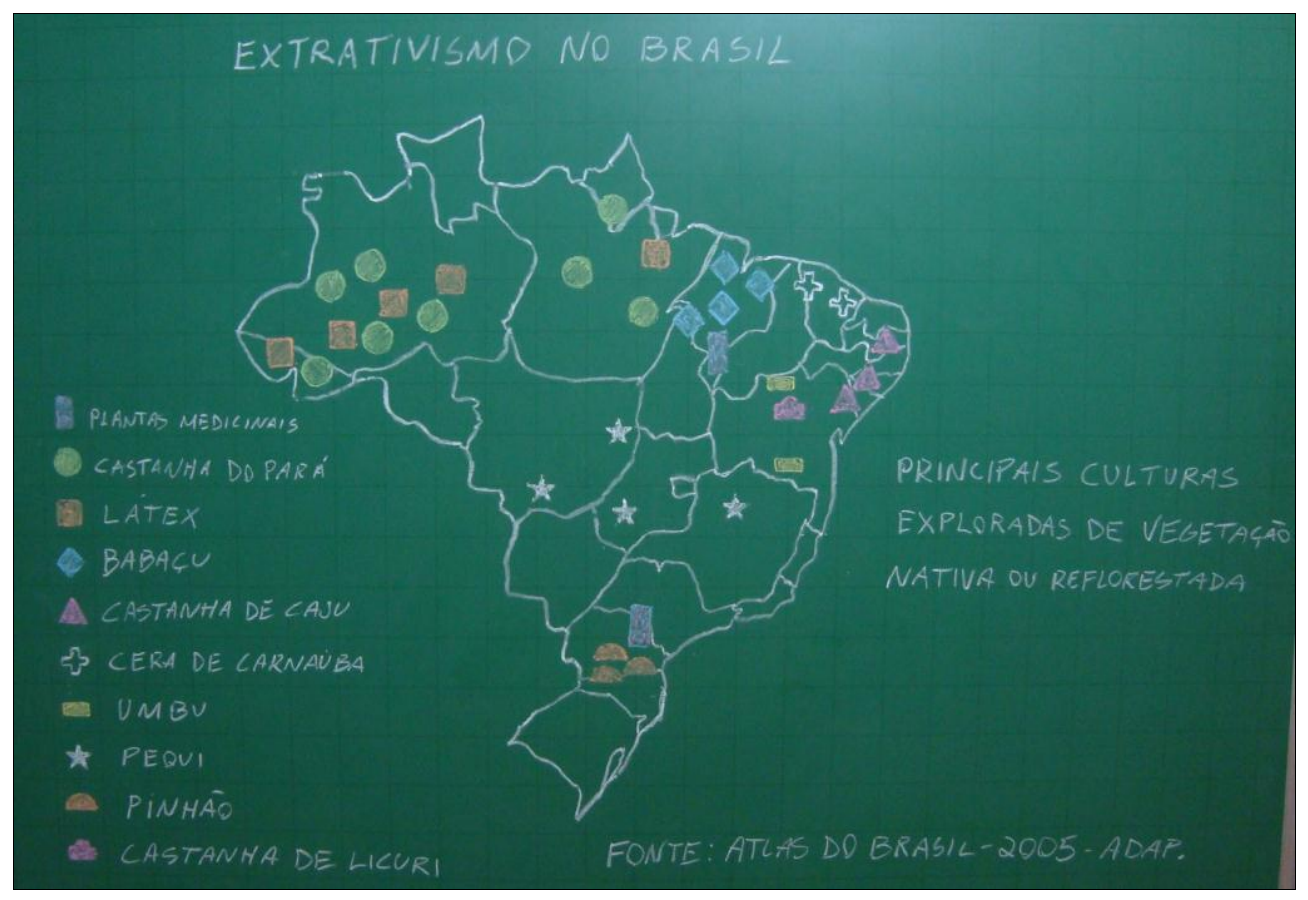

Figura 27 - Mapa qualitativo em lousa elaborado com gabarito de fundo de mapa e de símbolos ampliados com cores diversas.

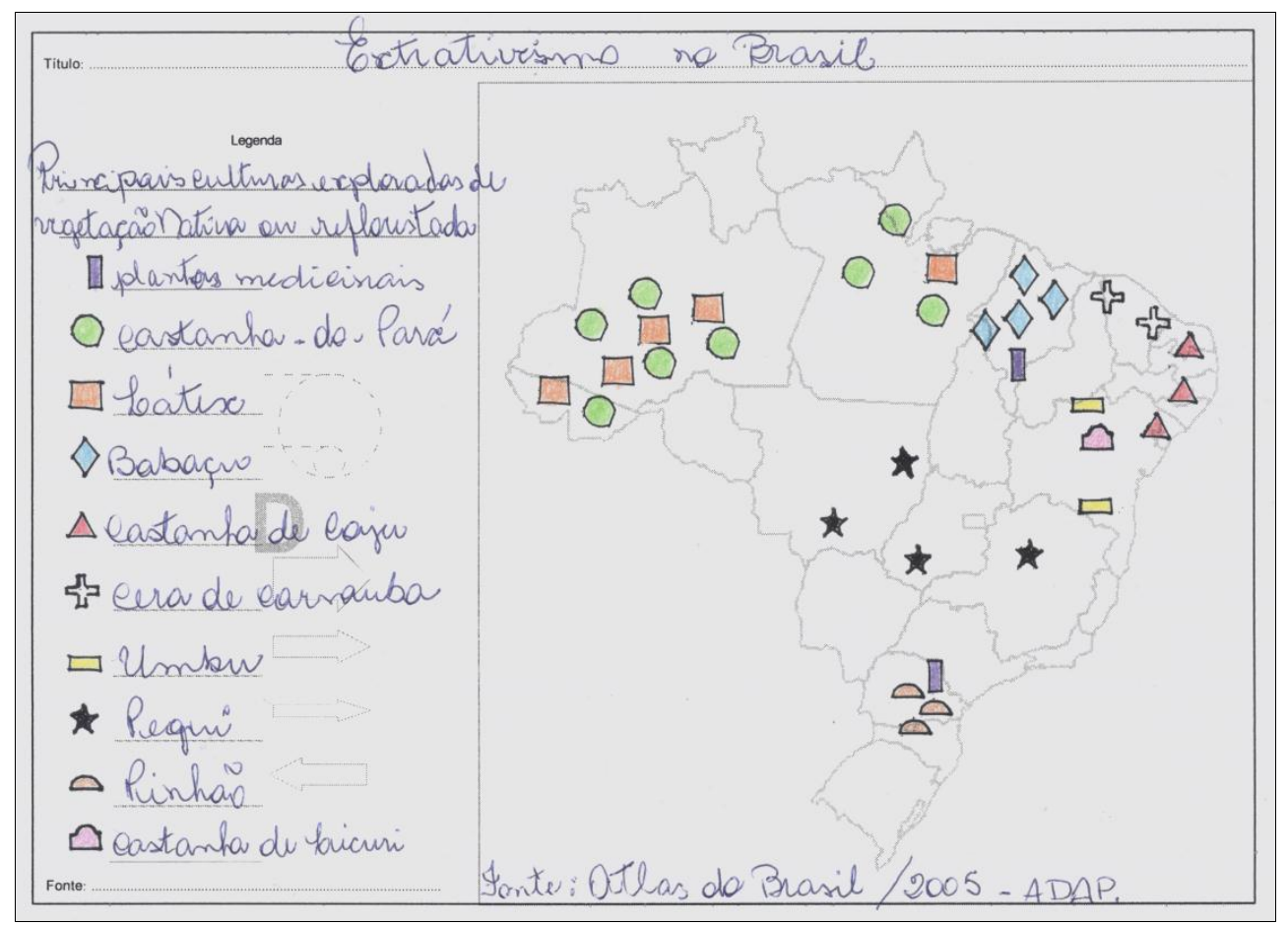

Figura 28 - Matriz para a elaboração do mapa da lousa (figura anterior) com gabarito de símbolos. 
MAPA DINÂMICO: Classifique os dados na tabela "E" "ORIGEM/DESTINO" de acordo com os valores "ALTO/MÉDIO/BAIXO de cada localidade do mapa. I Preencha as curvas com o gabarito de acordo com os dados e finalize com 0 acabamento.

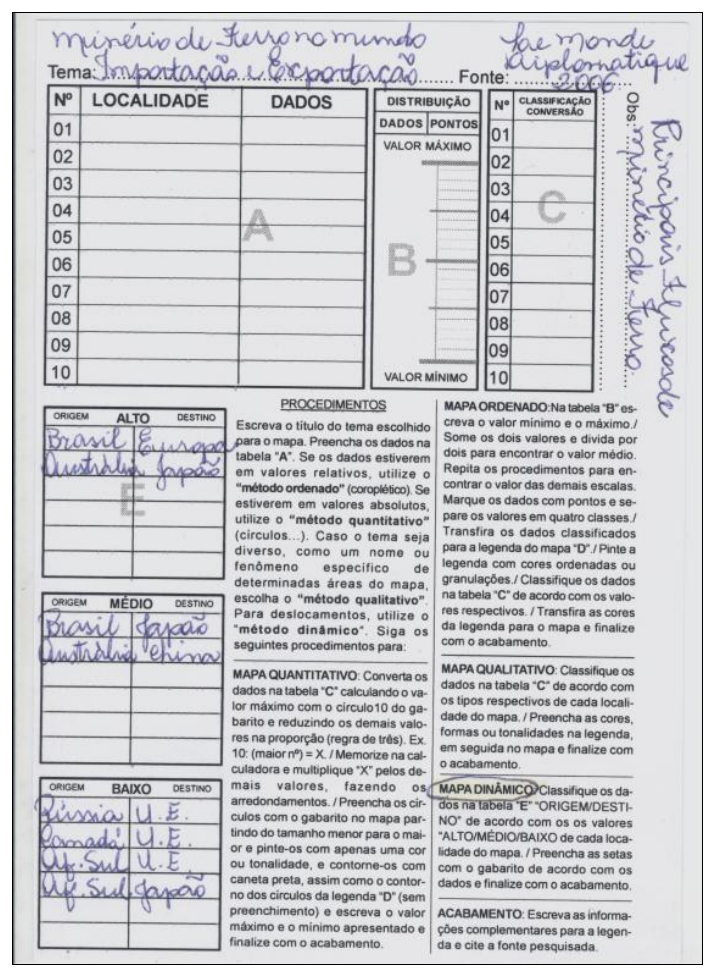

Figura 29 - Tabela com dados adaptados sobre a origem/destino e a classificação alto/médio/baixo para a construção de mapas dinâmicos.

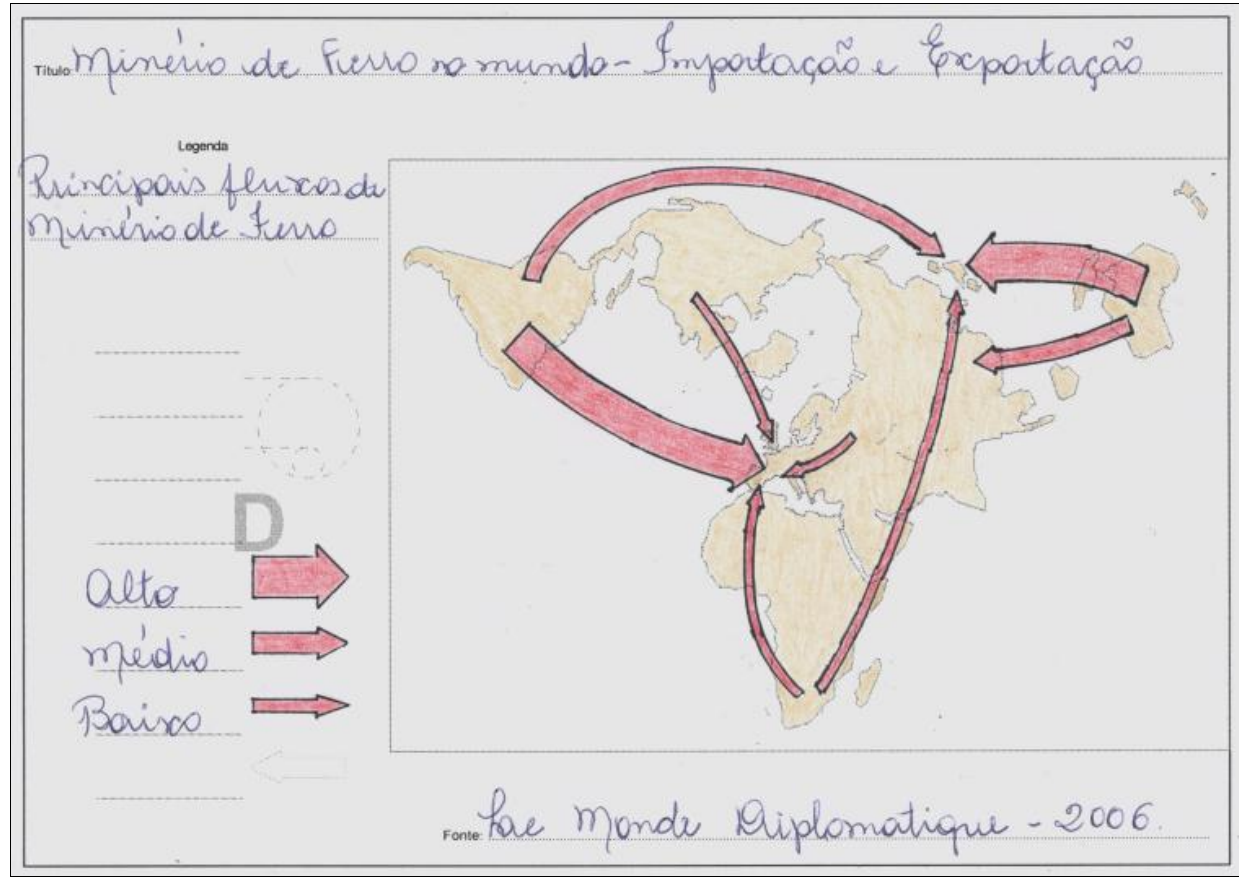

Figura 30 - Matriz com a projeção poliédrica do planisfério e elaboração de mapa dinâmico com gabarito de curvas proporcionais a partir de informações de um mapa digitalizado.

ACABAMENTO: Escreva as informações complementares para a legenda e cite a fonte pesquisada. 


\section{4 - EXPERIÊNCIAS COM ELABORAÇÃO DE MAPAS TEMÁTICOS ESCOLARES}

Entre 2010 e 2012 foram realizadas dezoito atividades e avaliações com alunos do Ensino Fundamental e do curso de Pedagogia com o objetivo de comprovar a possibilidade de trabalhar com mapas "constantemente" em sala de aula.

A partir da idealização dos trabalhos prévios para construção de mapas em sala de aula, e do desenvolvimento e adaptação dos materiais didáticos, como bases de gabaritos para lousas, cálculos dos tamanhos dos círculos proporcionais e símbolos, tabelas de distribuição e conversão de dados, matrizes de mapas para construção com base na Semiologia Gráfica e exercícios práticos elaborados especialmente para cada Turma, em sincronismo com o conteúdo programático trabalhado em cada período, foi possível aplicar as atividades cartográficas e, ao mesmo tempo, corrigir inúmeras falhas que eventualmente ocorreram durante o período de 2010 e 2012 em todas as Turmas.

Neste período vários materiais didáticos foram desenvolvidos ou aprimorados com o propósito de facilitar e agilizar os procedimentos para elaboração de mapas temáticos escolares construídos de forma artesanal, utilizando gabaritos e matrizes de mapas mudos e símbolos quantitativos e qualitativos.

Após duas atividades de construção de mapas ordenados, por exemplo, já foi possível observar que os próprios alunos já compreenderam os procedimentos de distribuição e classificação de dados, o que permitiu que eles próprios, sem o acompanhamento do professor, pudessem construir seus próprios mapas com a utilização de granulações e tonalidades de forma independente, como é mostrado na figura 02.

Foram escolhidos como amostragem, três tipos de escolares distintos para a aplicação deste projeto:

- alunos do 6을 Ano escola pública da periferia de São Paulo;

- alunos do 9 Ano de escola particular do Grande ABC;

- alunos do $3^{\circ}$ Ano do Curso de Pedagogia de Santo André.

Em cada grupo, a elaboração de mapas, avaliações e teorias foram realizadas de formas diferentes, de acordo com a realidade encontrada. Para o 6은 
Ano, as matrizes foram apresentadas prontas, inclusive com o cálculo e conversão dos dados estatísticos para confeccionar os mapas.

No 9 Ano, o acompanhamento foi mais intenso, iniciando com matrizes já calculadas no início do Ano Letivo até a confecção dos mapas pelos alunos a partir do mapa mudo no final do ano, totalizando oito atividades com as três Turmas em todo o período.

Para o 3ำ Ano de Pedagogia, foi apresentada uma aula teórica simplificada sobre os critérios de elaboração de mapas, exercícios e elaboração de mapas temáticos em pequeno e grande formato.

Em todos os trabalhos, foi possível perceber o interesse por atividades práticas em todas as Turmas e ao mesmo tempo, a "dificuldade" encontrada no início dos trabalhos, e a "facilidade" em construir e interpretar mapas no final do período, conforme descrito nos relatórios a seguir.

No 6ํㅡㄹ Ano de escola pública, os inúmeros problemas enfrentados pelos alunos no período extraclasse, podem ser inseridos de forma positiva ou negativa nos resultados das atividades, como a convivência com os temas apresentados nos mapas das avaliações nos comentários que surgiram durante a aplicação dos testes. 


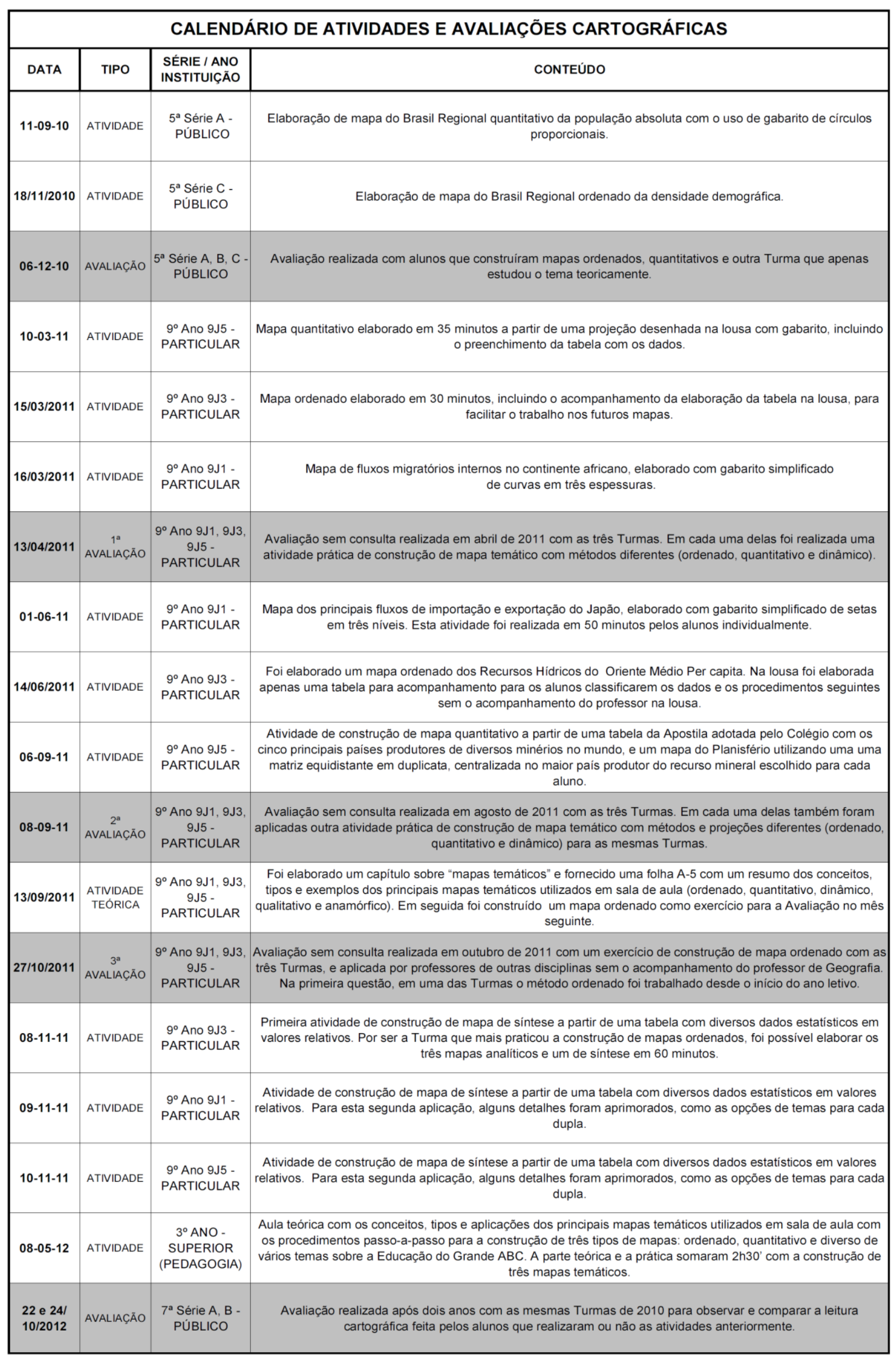




\section{1 - Atividades realizadas com alunos de 6ำ Ano de escola pública}

Esta atividade foi realizada em 2010 para uma turma de 5 serie $^{\text {a }}$ do Ensino Fundamental da rede pública municipal de ensino de São Paulo/SP, composta por três salas: $5^{\underline{a}}$ A, $5^{\underline{a}} B$ e $5^{\underline{a}}$ C. A partir de 2011, a Rede Municipal de Ensino passou a utilizar a nova nomenclatura para o Ensino Fundamental do $1^{\circ}$ ao $9^{\circ}$ Ano. Neste trabalho os relatórios foram elaborados em 2011 com a nomenclatura antiga e a nova nomenclatura nos textos e comentários entre parênteses.

Em 2012 foi realizada uma nova avaliação com as mesmas Turmas, incluindo os novos alunos ingressados neste intervalo.

Local de aplicação das atividades

Instituição de ensino: escola pública municipal - Centro Educacional Unificado (C.E.U.) Localização: Rua Curumatim, 201 - Jardim da Conquista II - São Mateus - São Paulo/SP Série selecionada: $5^{\text {a }}$ Série (6ำAno)

Número de alunos por sala: 30

Período de realização: novembro / dezembro de 2010

Professor da Disciplina: Anderson José Albano

Neste trabalho foi proposta uma atividade de construção de mapas temáticos a partir de uma base de mapa mudo do Brasil com divisão regional e uma avaliação simples para observar a eficiência do método aplicado, além do conhecimento cartográfico pré-existente dos alunos.

A partir das informações apresentadas pelo professor de Geografia, foram elaboradas as atividades partindo do tema: População Absoluta e Relativa nas Regiões Brasileiras.

Para a escolha desta Turma, considerou-se o fato da escola estar localizada na periferia de São Paulo e ser pública, além de possuir alunos em diferentes estágios de instrução escolar na mesma Turma, especialmente na disciplina de Geografia, conforme informado pelo professor de Geografia Anderson Albano, colaborador desta atividade. 


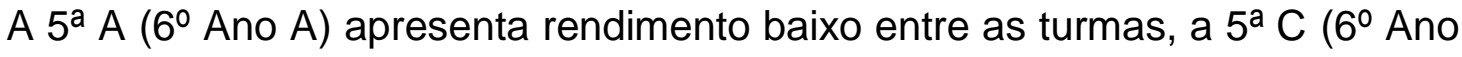
C), um rendimento médio e a 5a $\mathrm{B}$ (6ำ Ano B), o melhor aproveitamento e vários alunos (as) com rendimento acima da média.

Para a escolha do tema "Demografia", foram considerados os assuntos trabalhados no período, assim como o mapa regional do Brasil, por conter apenas cinco elementos para a distribuição e classificação dos dados estatísticos, o que reduz o tempo de elaboração dos mapas.

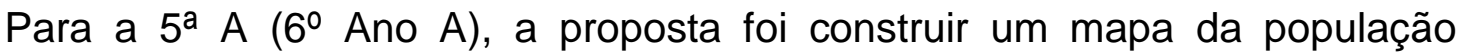
absoluta brasileira utilizando círculos proporcionais já calculados em um gabarito de círculos proporcionais com escala de 01 a 10, numa tabela de formato A-5, com os dados numéricos e o cálculo do tamanho dos círculos já "prontos" para reduzir o tempo de construção do mapa.

Os alunos reforçaram o contorno do mapa do Brasil e das Regiões administrativas acompanhando as orientações do professor que preparou na lousa a tabela com os dados e o esboço do mapa com um gabarito de mapa mudo.

Durante o preenchimento dos contornos das Regiões brasileiras na lousa, o professor foi citando constantemente o nome das Regiões com intervalos para algumas áreas com nomes específicos que associam o contorno a imagens conhecidas pelos alunos, como: Cabeça do Cachorro na Região Norte e Bico do Papagaio entre o Norte e Nordeste.

Após esta etapa, o professor descreveu brevemente a quantidade de habitantes de cada Região comparando as regiões de maior área e menor número de habitantes. Em seguida, o professor orientou os alunos a construir um mapa com as informações apresentadas na tabela, como o círculo número 02 sobre a Região Norte, 05 para o Nordeste, e assim por diante nas demais regiões.

No Sudeste, os alunos estranharam o tamanho do círculo 08, que ultrapassou a área demarcada, mas o professor alertou que não há problema desde que o centro do círculo esteja centralizado na área delimitada.

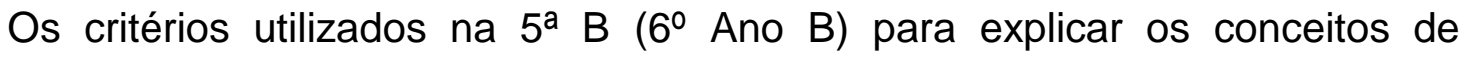
população absoluta e relativa, assim como mapas e gráficos, foram apenas expositivos. Com esta turma, os mapas sobre densidade demográfica e gráficos foram apresentados prontos, apenas como ilustração em lousa e livro didático.

Por ser considerada a Turma mais adiantada, segundo o professor da disciplina, foi decidido trabalhar o tema apenas teoricamente em aula expositiva, 
para comparar o desempenho com as demais salas. O professor de Geografia utiliza constantemente gabaritos de mapas na lousa.

$\mathrm{Na} 5^{\mathrm{a}} \mathrm{C}\left(6^{\circ}\right.$ Ano $\left.\mathrm{C}\right)$, foi utilizado o método de construção de mapa ordenado com cinco granulações decrescentes do tom mais escuro para o tom mais claro. Assim como no mapa quantitativo, os dados numéricos, a distribuição e a classificação foram entregues prontos para agilizar a construção do mapa. Na lousa, o professor preparou os dados numéricos e o mapa mudo do Brasil, preenchendo o contorno e depois a divisão regional.

Na tabela em formato A-5 fornecida para os alunos, além da divisão regional, o traçado das UFs foram mais destacados. Embora a classificação tenha sido elaborada por regiões, o professor foi preparando e apontando cada UF para os alunos memorizarem o nome das UFs, especialmente o estado de São Paulo.

Entre o preenchimento de cada UF, foram feitas algumas perguntas aos alunos, especialmente aos descendentes de nordestinos, o que foi prontamente respondida por vários alunos com parentesco em Pernambuco, Bahia, entre outros estados de origem de seus familiares.

Neste trabalho, procurou-se escolher os temas dos mapas com o objetivo de facilitar a leitura, interpretação e correlação, como a "coleta de lixo" junto com um tema de "saúde pública". O título "Animais Domésticos nos Bairros de São Paulo", foi escolhido para associar algo próximo do cotidiano com o formato do mapa.

Para avaliar os resultados das atividades e avaliações realizadas com as Turmas, foi elaborada uma tabela separando os atributos, conceitos e conhecimentos adquiridos, em tese, nesta atividade, ou previamente pelos alunos em seu convívio social.

Os itens escolhidos foram: leitura de enunciado e da linguagem cartográfica temática, subdivididos em título, legenda, conteúdo e correlação de mapas, além de outras atribuições como memorização, conhecimento de projeções cartográficas diversas e conceitos de assuntos abordados durante a avaliação, como "centroperiferia".

Em 2012, foi realizada uma nova avaliação com as mesmas Turmas, incluindo os novos alunos que ingressaram em 2011 e 2012.

Os mapas e as questões elaboradas nesta avaliação foram adaptados ao tema estudado na $7^{a}$ série ( $8^{\circ}$ Ano) (Urbanização), assuntos tratados pela mídia, especialmente relacionados a população da periferia de São Paulo (incêndios em 
favelas), além de uma questão diversa solicitada pelo professor para aproveitar a atividade (Ilha de Calor).

Mesmo aplicado como uma atividade facultativa realizada em 40 minutos durante uma aula de geografia, todos os alunos, sem exceção, construíram seus mapas, mesmo aqueles que apresentam defasagens de aprendizagem ou comodismo durante as aulas.

Pelo fato dos alunos desconhecerem os procedimentos utilizados para esta atividade, e inclusive, nunca terem construído um mapa temático, os resultados foram satisfatórios. Na leitura e interpretação de mapas ordenados, não houve diferença significativa entre a $5^{\text {a }} \mathrm{C}\left(6^{\circ}\right.$ Ano $\left.\mathrm{C}\right)$, que construiu o mapa com as demais salas.

Com relação aos mapas quantitativos, a $5^{\underline{a}} A\left(6^{\circ} A\right.$ Ano $\left.A\right)$ não correspondeu às expectativas, mas mesmo sendo uma sala com baixo rendimento e menor quantidade de alunos classificados como "PS" (Plenamente Satisfatório) pelo professor (23\%), o trabalho de memorização das regiões brasileiras superou as demais salas. Vale lembrar que a construção do mapa ocorreu em 17/11/2010, e a avaliação no dia 08/12/2010. Vinte dias após a atividade.

No mapa ordenado do município de São Paulo, juntamente com outro fundo de mapa com o nome dos bairros foi bem assimilado pela 5 a $\mathrm{C}$ (6ำ Ano C) (70\%), sala com médio rendimento. A memorização da Região Nordeste teve melhor resultado na $5^{\text {a }} A$ (6ํㅡㄹ $A$ Ano a sala em que a região foi mais enfatizada, principalmente entre os alunos classificados como "NS".

$\mathrm{Na}$ correlação entre as informações entre dois mapas (quantitativo e ordenado), apenas a $5^{\text {a }}$ B (6 Ano B) foi orientada a responder a questão, o que apresentou $43 \%$ de rendimento, enquanto nas demais salas, apenas uma aluna da 5 - C fez a correlação espontaneamente. Embora todos os alunos, sem exceção,

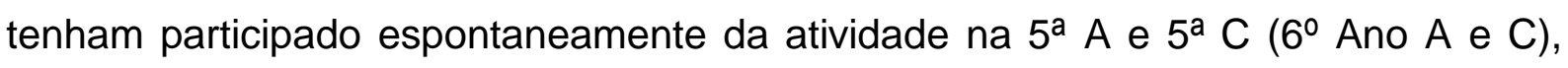
alguns alunos não se interessaram em responder as questões da avaliação, incluindo alunos classificados como "PS" pelo professor.

Também é importante acrescentar que a avaliação foi realizada em aproximadamente dez minutos durante a aula de outras disciplinas, por professores diversos, com exceção da $5^{\mathrm{a}} \mathrm{B}$ (6ำ Ano B).

O aluno F.S.S. (6ำ Ano A), transferido de escola pública estadual e aprovado pelo sistema de Progressão Continuada, foi o que apresentou maior defasagem 
durante a atividade. Mesmo com acompanhamento individual do professor, teve dificuldade em contornar o mapa mudo do Brasil. Além disto, apesar de seu esforço explícito, também não conseguiu interpretar uma frase simples.

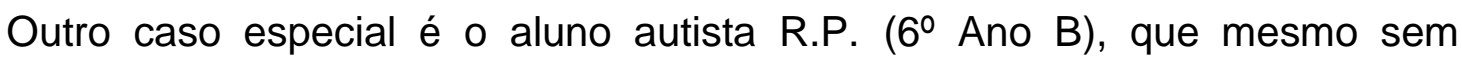
construir um mapa temático, respondeu as questões propostas corretamente, com exceção da correlação entre os mapas. Segundo o professor, o aluno passa boa parte do tempo elaborando plantas e mapas dos arredores da escola e do bairro.

Também é importante citar a familiaridade dos alunos com o uso constante de mapa mudo na lousa pelo professor de geografia, além de seu carisma com os alunos, fator imprescindível para a participação espontânea dos alunos durante a atividade e o desinteresse de alguns em responder as questões na ausência do professor.

Para avaliar o grau de assimilação, além de raciocínio lógico e conceitos, foi apresentado um mapa temático do município de São Paulo com um tema próximo do cotidiano dos alunos (animais domésticos), além de um mapa com a divisão administrativa dos bairros no verso da folha de avaliação.

Mesmo tentando evitar propositalmente a abordagem de temas relacionados à violência (presente no cotidiano dos alunos), o professor ouviu alguns comentários durante a aplicação da avaliação para o formato do mapa de São Paulo: -- Parece um revólver apontado para baixo! A realidade da escola pública de periferia comprova que a maior parte dos alunos convive com a violência de forma cotidiana.

Os mapas de São Paulo com diferentes escalas e separados (frente e verso) foram bem compreendidos pela maioria dos alunos, que mesmo confundindo bairros com município, fizeram a correlação entre o mapa temático e o mapa políticoadministrativo.

A maior dificuldade encontrada neste trabalho foi o grande número de alunos que ainda apresentam defasagens na leitura e interpretação de textos (enunciado). Foi possível observar, inclusive, que alguns alunos compreenderam melhor a linguagem cartográfica que a linguagem verbal.

$\mathrm{Na}$ avaliação realizada em 2012, foi possível verificar que os alunos que participaram das atividades e avaliações com análise e correlação de mapas, apresentaram os melhores resultados, embora, apenas poucos correlacionaram os temas apresentados nos mapas (28\% entre os alunos de 2010 e $17 \%$ entre os novos alunos). 
Vários alunos que realizaram as atividades em 2010 não participaram em 2012, assim como vários alunos ingressaram nas Turmas em 2011 e 2012. Uma rotatividade comum nas escolas públicas, segundo o professor da disciplina. A Turma C não foi avaliada em 2012 devido à mudança de professor Geografia.

A leitura do enunciado e o título dos mapas foram os únicos itens em que os novos alunos superaram os alunos de 2010, e mesmo assim, os $92 \%$ dos novos alunos, comparado com $88 \%$ dos alunos de 2010, é resultado dos alunos com grandes dificuldades em leitura de textos verbais, que não foram capazes de responder as questões apresentadas. Alguns alunos também questionaram o fato de o bairro onde moram e estudam pertencer a Zona Sudeste e não Zona Leste, como estão acostumados a ouvir. Uma falha na elaboração desta avaliação, mas considerada durante a análise, uma vez que vários alunos se referiram ao seu bairro como "Zona Leste" sem fazer a leitura e correlação entre o mapa regional e o mapa dos bairros.

$\mathrm{Na}$ avaliação aplicada após duas e três semanas seguintes, foi possível perceber que uma pequena atividade pode contribuir, e muito, para a eficiência do processo ensino-aprendizagem durante as aulas de geografia.

No caso específico desta avaliação, os resultados foram ainda melhores entre os alunos classificados como "não-satisfatórios" (NS) pelo professor da disciplina. Isto mostra que além da linguagem verbal, outras linguagens também podem contribuir para a formação acadêmica dos alunos durante o Ensino Fundamental e o quanto a linguagem cartográfica ainda é pouco explorada e ignorada por grande parte dos alunos, que observam mapas apenas como figuras ilustrativas.

Embora esta primeira atividade de construção de mapas temáticos pelos alunos não tenha alcançado todos os objetivos calculados como mostram os relatórios de desempenho, serviu para mostrar que a construção de mapas temáticos durante as aulas de geografia não é algo tão difícil e extenso de ser aplicado, e pode perfeitamente fazer parte do cotidiano das aulas, e, inclusive, de cadernos de exercícios de apostilas e livros didáticos. Para a avaliação dos procedimentos realizados nesta atividade, foram elaborados relatórios de desempenho entre as três Turmas e individualmente, além de comparações sobre cada tema para análise.

\section{Relatórios, avaliacõos e imagens das atividades:}



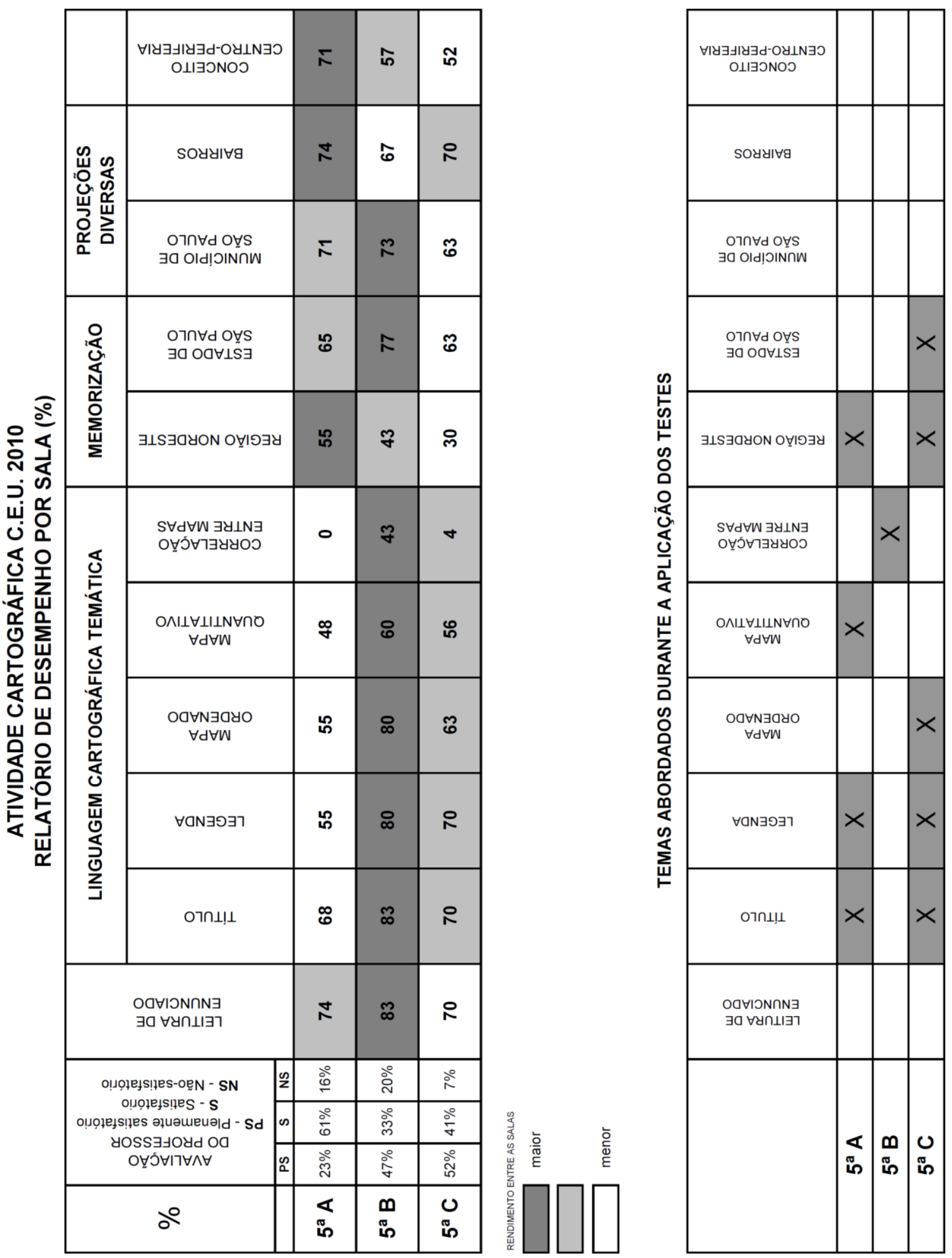

Tabela 09 - Entre as três Turmas, a $5^{\text {a }} \mathrm{B}\left(6^{\circ}\right.$ Ano B) apresentou melhor desempenho, como já tinha alertado o professor de Geografia sobre o aproveitamento geral da sala. A 5 $5^{\underline{a}}$ C (6을 Ano C), por ser considerada a sala de aproveitamento médio, apresentou melhores resultados nos temas relacionados aos mapas que construíram como a análise do mapa ordenado, diferente da $5^{\underline{a}} \mathrm{~A}$ (6응 Ano A) que sobressaiu nas questões de memorização e leitura de projeções diferentes das apresentadas nas atividades. 


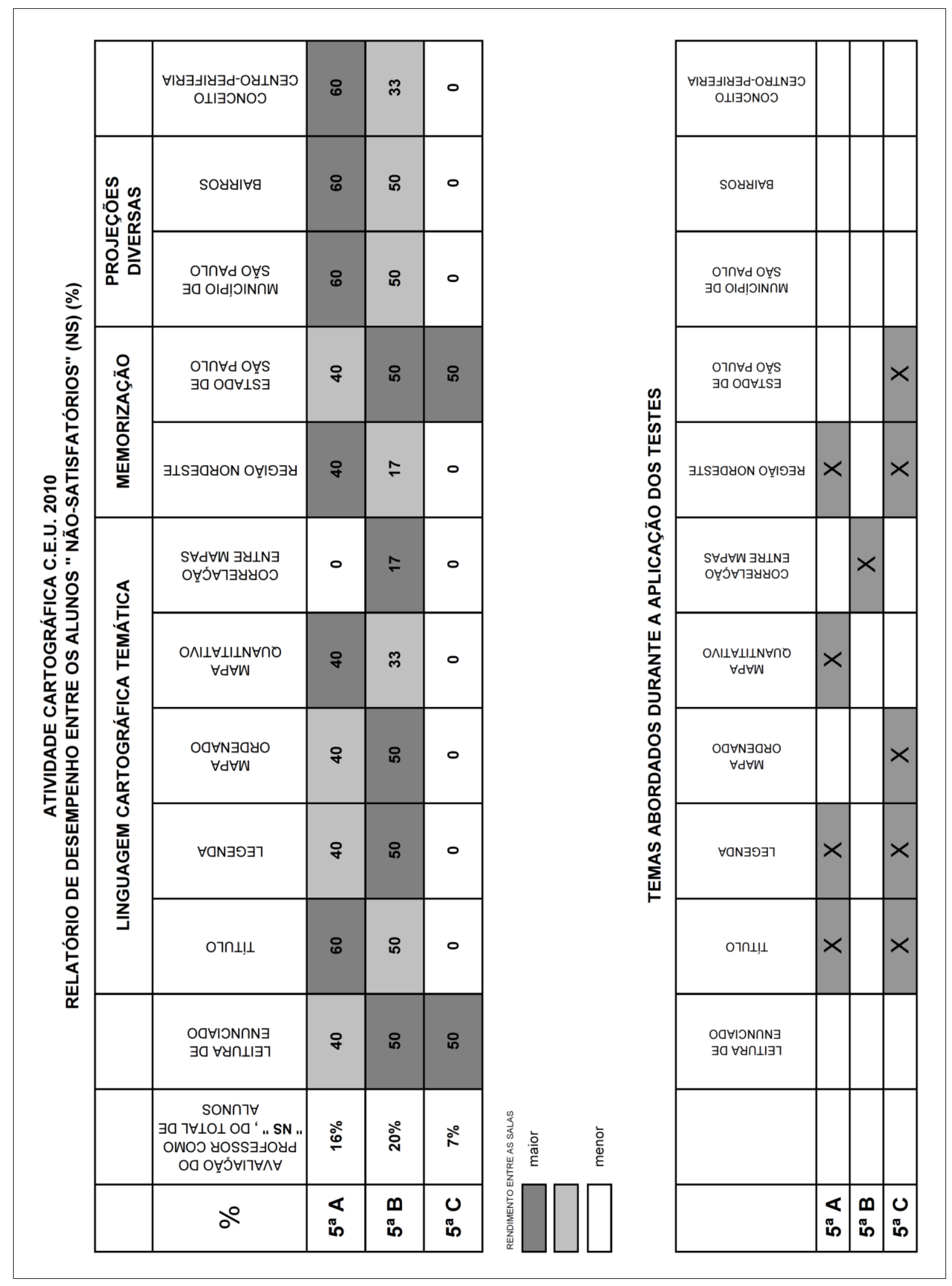

Tabela 10 - Entre os alunos classificados como "não-satisfatórios" (NS) pelo professor, os resultados foram melhores, com exceção da $5^{\text {a }} \mathrm{C}$ (6ำ Ano $\left.\mathrm{C}\right)$, sala que apresenta vários alunos com grande dificuldade em leitura e interpretação de textos. Em vários itens, a $5^{\text {a }} A\left(6^{\circ}\right.$ Ano $A$ ) teve desempenho melhor que a $5^{\text {a }}$ B (6ํㅡㄹ Ano $)$, considerada a sala mais adiantada. 


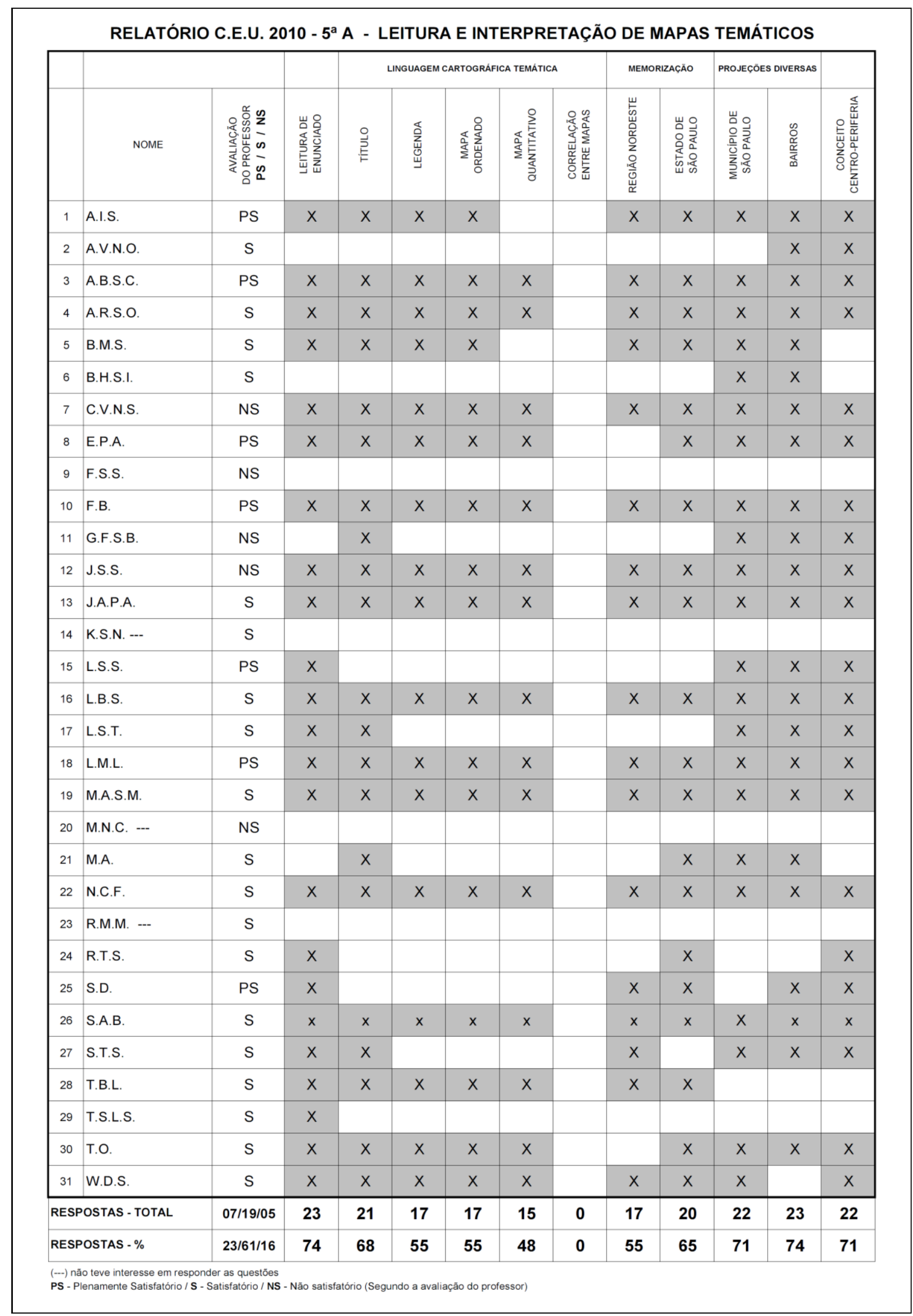

Tabela 11 - Relatório da $5^{\underline{a}}$ A ( $6^{\circ}$ Ano A) - Apresentou rendimento abaixo do esperado em relação ao tipo de mapa que construíram (quantitativo). Nenhum aluno fez a correlação entre os temas apresentados nos mapas. 


\begin{tabular}{|c|c|c|c|c|c|c|c|c|c|c|c|c|c|}
\hline \multicolumn{14}{|c|}{ RELATÓRIO C.E.U. 2010 - 5a B - LEITURA E INTERPRETAÇÃO DE MAPAS TEMÁTICOS } \\
\hline & \multirow[b]{2}{*}{ NOME } & \multirow[b]{2}{*}{ 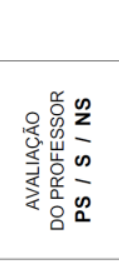 } & \multirow[b]{2}{*}{ 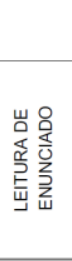 } & \multicolumn{5}{|c|}{ LINGUAGEM CARTOGRAFICA TEMATICA } & \multicolumn{2}{|c|}{ MEMORIZAÇÃo } & \multicolumn{2}{|c|}{ PROJEÇốES DIVERSAS } & \multirow[b]{2}{*}{ 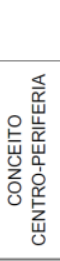 } \\
\hline & & & & 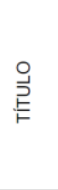 & 㤩 & 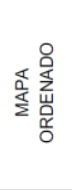 & 变 & 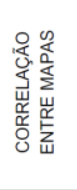 & 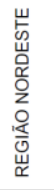 & 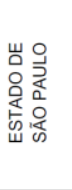 & 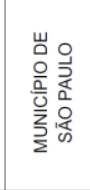 & 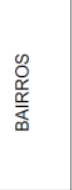 & \\
\hline 1 & A.B.L. & PS & $x$ & $x$ & $\mathrm{x}$ & $x$ & $x$ & $\mathrm{x}$ & $x$ & $x$ & $x$ & & $x$ \\
\hline 2 & A.P. --- & NS & & & & & & & & & & & \\
\hline 3 & B.M.B. & $S$ & $x$ & $x$ & $x$ & $x$ & $x$ & & $x$ & $x$ & & & \\
\hline 4 & E.H.F. & NS & $x$ & $x$ & $x$ & $x$ & $x$ & & $x$ & $x$ & & & \\
\hline 5 & E.S.S. --- & NS & & & & & & & & & & & \\
\hline 6 & G.S.P. & PS & $x$ & $x$ & $x$ & $x$ & $x$ & $\mathrm{x}$ & $x$ & $x$ & $x$ & $x$ & $x$ \\
\hline 7 & G.A.L. & PS & $x$ & $x$ & $x$ & $x$ & $x$ & $x$ & $x$ & $x$ & $x$ & $x$ & $x$ \\
\hline 8 & G.L.L. & PS & $x$ & $x$ & $x$ & $x$ & $x$ & $x$ & $x$ & $x$ & $x$ & $x$ & $x$ \\
\hline 9 & I.R.R. & PS & $x$ & $x$ & $x$ & $x$ & & & & & & & \\
\hline 10 & I.S.S. & PS & $x$ & $x$ & $x$ & $x$ & & & & $x$ & $x$ & $x$ & \\
\hline 11 & J.L.S. & PS & $x$ & $x$ & $x$ & $x$ & $x$ & $x$ & $x$ & $x$ & $x$ & $x$ & $x$ \\
\hline 12 & J.S.M. & $S$ & $x$ & $x$ & $x$ & $x$ & & & & $x$ & & & \\
\hline 13 & J.M.M. --- & S & & & & & & & & & & & \\
\hline 14 & K.S.O. & NS & & & & & & & & & $x$ & $x$ & $x$ \\
\hline 15 & K.C.O.S. & PS & $x$ & $x$ & $x$ & $x$ & $x$ & $x$ & $x$ & $x$ & $x$ & $x$ & $x$ \\
\hline 16 & K.D.P. & S & $x$ & $x$ & $x$ & $x$ & $x$ & & $x$ & $x$ & $x$ & $x$ & $x$ \\
\hline 17 & L.B. & S & $x$ & $x$ & $x$ & $x$ & $x$ & & & $x$ & $x$ & $x$ & \\
\hline 18 & L.S. & NS & $x$ & $x$ & $x$ & $x$ & $x$ & $x$ & & $x$ & $x$ & $x$ & $x$ \\
\hline 19 & L.F. & S & $x$ & $x$ & $x$ & $x$ & $x$ & & $x$ & $x$ & $x$ & $x$ & $x$ \\
\hline 20 & L.B.. & PS & $x$ & $x$ & & & & $x$ & & & $x$ & $x$ & $x$ \\
\hline 21 & M.T.S.A. & PS & $x$ & $x$ & $x$ & $x$ & $x$ & $x$ & $x$ & $x$ & $x$ & $x$ & $x$ \\
\hline 22 & N.F.P. & PS & $x$ & $x$ & $x$ & $x$ & $x$ & $x$ & & $x$ & $x$ & $x$ & $x$ \\
\hline 23 & P.V. & PS & $x$ & $x$ & $x$ & $x$ & $x$ & $x$ & & $x$ & $x$ & $x$ & $x$ \\
\hline 24 & S.S.G. & PS & $x$ & $x$ & $x$ & $x$ & $x$ & & & $x$ & $x$ & $x$ & \\
\hline 25 & T.F.S. & S & $x$ & $x$ & $x$ & $x$ & & $x$ & & $x$ & $x$ & & $x$ \\
\hline 26 & R.P. & S & $x$ & $x$ & $x$ & $x$ & $x$ & & $x$ & $x$ & $x$ & $x$ & $x$ \\
\hline 27 & R.S.B. & NS & $x$ & $x$ & $x$ & $x$ & & & & $x$ & $x$ & $x$ & \\
\hline 28 & S.A.P. & $S$ & $x$ & $x$ & $x$ & $x$ & & & & $x$ & $x$ & $x$ & \\
\hline 29 & Y.C.C. & PS & $x$ & $x$ & $x$ & $x$ & $x$ & $x$ & $x$ & $x$ & $x$ & $x$ & $x$ \\
\hline 30 & W.N.S. --- & $S$ & & & & & & & & & & & \\
\hline RES & POSTAS - TOTAL & $14 / 10 / 66$ & 25 & 25 & 24 & 24 & 18 & 13 & 13 & 23 & 22 & 20 & 17 \\
\hline RESI & POSTAS - \% & $47 / 33 / 20$ & 83 & 83 & 80 & 80 & 60 & 43 & 43 & 77 & 73 & 67 & 57 \\
\hline
\end{tabular}

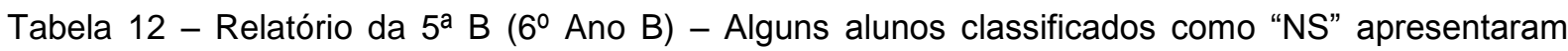
resultados melhores que alunos classificados como "PS" em relação à linguagem cartográfica. Alguns alunos correlacionaram as informações dos mapas por sugestão do professor durante a avaliação. 


\begin{tabular}{|c|c|c|c|c|c|c|c|c|c|c|c|c|c|}
\hline \multicolumn{14}{|c|}{ RELATÓRIO C.E.U. 2010 - 5a C - LEITURA E INTERPRETAÇÃO DE MAPAS TEMÁTICOS } \\
\hline & \multirow[b]{2}{*}{ NOME } & \multirow[b]{2}{*}{ 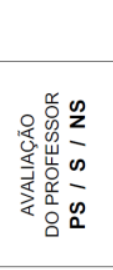 } & \multirow[b]{2}{*}{ 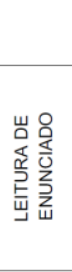 } & \multicolumn{5}{|c|}{ LINGUAGEM CARTOGRAFICA TEMATICA } & \multicolumn{2}{|c|}{ MEMORIZAÇÃo } & \multicolumn{2}{|c|}{ PROJEÇōES DIVERSAS } & \multirow[b]{2}{*}{ 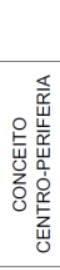 } \\
\hline & & & & $\stackrel{\text { 롤 }}{\text { 点 }}$ & $\begin{array}{l}\text { 总 } \\
\text { 岃 }\end{array}$ & 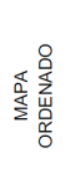 & 童 & 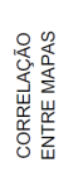 & 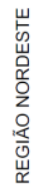 & 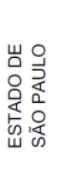 & 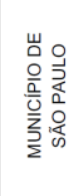 & 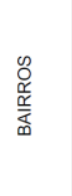 & \\
\hline 1 & A.L. & PS & & & & & & & & $x$ & & $\mathrm{x}$ & \\
\hline 2 & A.G. & PS & & $x$ & $x$ & & & & & & & & \\
\hline 3 & D.P. --- & S & & & & & & & & & & & \\
\hline 4 & E.E. & PS & $\mathrm{X}$ & $\mathrm{X}$ & $\mathrm{x}$ & $x$ & $x$ & & & $x$ & $x$ & $x$ & $x$ \\
\hline 5 & E.R. & $S$ & $x$ & $x$ & $x$ & $x$ & $x$ & & & $x$ & $x$ & $x$ & $x$ \\
\hline 6 & E.C. & $S$ & $x$ & $x$ & $x$ & $x$ & $x$ & & & $x$ & $x$ & $x$ & $x$ \\
\hline 7 & I.C. & $S$ & $x$ & $x$ & $x$ & $x$ & $x$ & & $x$ & $x$ & $x$ & $x$ & \\
\hline 8 & I.A. & $S$ & $x$ & $x$ & $x$ & $x$ & $x$ & & $x$ & $x$ & $x$ & $x$ & $x$ \\
\hline 9 & I.V. & PS & $x$ & $x$ & $x$ & $x$ & & & & $x$ & $x$ & $x$ & \\
\hline 10 & J.M. & $S$ & $x$ & $x$ & $x$ & $x$ & & & & & $x$ & $x$ & \\
\hline 11 & J.V.M.S. & PS & $x$ & $x$ & $x$ & $x$ & $x$ & & & $x$ & $x$ & $x$ & $x$ \\
\hline 12 & K.S.N. --- & PS & & & & & & & & & & & \\
\hline 13 & K.T. & PS & & $x$ & $x$ & & & & & & $x$ & $x$ & \\
\hline 14 & K.S. & $S$ & $x$ & $x$ & $x$ & $x$ & $x$ & & & $x$ & $x$ & $x$ & $x$ \\
\hline 15 & K.F. & PS & $x$ & $x$ & $x$ & $x$ & $x$ & $x$ & $x$ & $x$ & $x$ & $x$ & $x$ \\
\hline 16 & K.A. & PS & $x$ & $x$ & $x$ & $x$ & $x$ & & $x$ & $x$ & $x$ & $x$ & $x$ \\
\hline 17 & L.B. & $S$ & & & & & & & & & & & \\
\hline 18 & L.M. & PS & $x$ & $x$ & $x$ & $x$ & $x$ & & $x$ & $x$ & $x$ & $x$ & $x$ \\
\hline 19 & L.S. & $S$ & $x$ & $x$ & $x$ & $x$ & $x$ & & $x$ & $x$ & & & $x$ \\
\hline 20 & M.S. & NS & $x$ & & & & & & & $x$ & & & \\
\hline 21 & O.R. & PS & $x$ & $x$ & $x$ & $x$ & $x$ & & $x$ & $x$ & $x$ & $x$ & $x$ \\
\hline 22 & P.C. --- & PS & & & & & & & & & & & \\
\hline 23 & P.A. & S & $x$ & & & & & & & & & $x$ & \\
\hline 24 & Q.S. & S & $x$ & $x$ & $x$ & $x$ & $x$ & & $x$ & $x$ & $x$ & $x$ & $x$ \\
\hline 25 & R.O. --- & NS & & & & & & & & & & & \\
\hline 26 & R.R. & PS & $x$ & $x$ & $x$ & $x$ & $x$ & & & $x$ & $x$ & $x$ & $x$ \\
\hline 27 & T.H. & PS & $x$ & $x$ & $x$ & $x$ & $x$ & & & $x$ & $x$ & $x$ & $x$ \\
\hline RESF & POSTAS-TOTAL & $14 / 11 / \_2$ & 19 & 19 & 19 & 17 & 15 & 1 & 8 & 17 & 17 & 19 & 14 \\
\hline RESF & POSTAS - \% & $52 / 41 /{ }_{1} 7$ & 70 & 70 & 70 & 63 & 56 & 4 & 30 & 63 & 63 & 70 & 52 \\
\hline
\end{tabular}

Tabela 13 - Relatório da $5^{\text {a }}$ C (6ำ Ano C) - Apresentou resultado regular na leitura de mapas ordenados, além de uma única aluna que correlacionou os temas espontaneamente. 


\begin{tabular}{|c|c|c|c|c|c|c|c|c|c|c|c|c|c|}
\hline \multirow{2}{*}{\multicolumn{14}{|c|}{$\begin{array}{l}\text { RELATORIO C.E.U. } 2012 \text { - 7a AeB - LEITURA, INTERPRETAÇAOO E CORRELAÇAO DE MAPAS TEMATICOS } \\
\text { (somente alunos que realizaram avaliação em 2010) }\end{array}$}} \\
\hline & & \multirow[b]{2}{*}{ 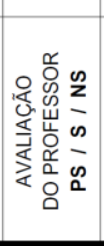 } & & & \multirow[b]{2}{*}{ 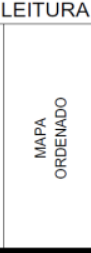 } & INTERF & & & & & & & \\
\hline & NOME & & 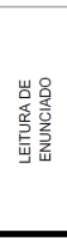 & 总 & & 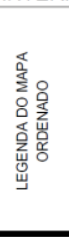 & \multirow[t]{2}{*}{ 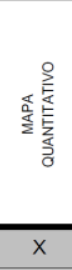 } & \multirow[t]{2}{*}{ 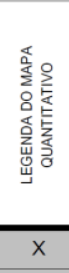 } & 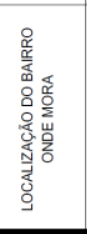 & 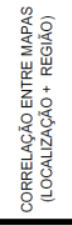 & 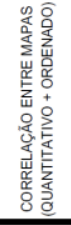 & 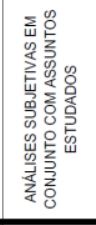 & 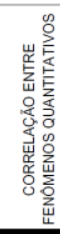 \\
\hline 1 & A.I.S. & PS & $x$ & $x$ & $x$ & $x$ & & & & & $x$ & & \\
\hline 2 & A.B.S.C. & PS & $x$ & $x$ & $x$ & $x$ & $x$ & $x$ & $x$ & $x$ & $x$ & & \\
\hline 3 & A.R.S.O. & PS & $x$ & $x$ & $x$ & $x$ & $x$ & $x$ & & & & & \\
\hline 4 & B.M.B. & PS & $x$ & $x$ & $x$ & $x$ & $x$ & $x$ & & & & & \\
\hline 5 & B.M.S. & $s$ & $x$ & $x$ & $x$ & $x$ & $x$ & $x$ & $x$ & & & & \\
\hline 6 & B.H.S.I. & NS & $x$ & $x$ & $x$ & $x$ & & & $x$ & & & & \\
\hline 7 & C.V. & $s$ & $x$ & $x$ & $x$ & $x$ & $x$ & $x$ & $x$ & & & & \\
\hline 8 & E.H.F. & s & $x$ & $x$ & $x$ & $x$ & $x$ & $x$ & & $x$ & $x$ & & \\
\hline 9 & E.P. ${ }^{a}$ & PS & $x$ & $x$ & $x$ & $x$ & $x$ & $x$ & & $x$ & $x$ & $\mathrm{x}$ & \\
\hline 10 & F.S.S. --- & NS & & & & & & & & & & & \\
\hline 11 & G.F.S.B. -- & $s$ & & & & & & & & & & & \\
\hline 12 & G.S.P. & PS & $x$ & $x$ & $x$ & $x$ & $x$ & $x$ & $x$ & $x$ & $x$ & $x$ & \\
\hline 13 & G.A.L. & s & $x$ & $x$ & $x$ & $x$ & & & $x$ & & & $x$ & \\
\hline 14 & G.L.L. & PS & $x$ & $x$ & & & $x$ & $x$ & & & & & \\
\hline 15 & I.R.R. & $s$ & $x$ & $x$ & $x$ & $x$ & $x$ & $x$ & & $x$ & $x$ & & \\
\hline 16 & J.M.M. & $\mathrm{s}$ & $x$ & $\mathrm{x}$ & $x$ & $x$ & & & $x$ & & & & \\
\hline 17 & V.V.M.S. & NS & $x$ & $x$ & $x$ & $x$ & & & & & & & \\
\hline 18 & J.L.S. & PS & $x$ & $x$ & & & & & & $x$ & $x$ & & \\
\hline 19 & K.s.o. & $\mathrm{s}$ & $x$ & $x$ & $x$ & $x$ & & & $x$ & & & $x$ & \\
\hline 20 & K.S.R. --- & NS & & . & . & . & & & & & & & \\
\hline 21 & K.C.o.s. & PS & $x$ & $x$ & $x$ & $x$ & $x$ & $x$ & $x$ & $x$ & & & \\
\hline 22 & K.D.P. & $s$ & $x$ & $x$ & $x$ & $x$ & $x$ & $\mathrm{x}$ & & $x$ & & $x$ & \\
\hline 23 & L.S.S. & NS & & & & & & & & & & & \\
\hline 24 & L.B.S. & PS & $x$ & $x$ & $x$ & $x$ & $x$ & $x$ & & $x$ & $x$ & & \\
\hline 25 & L.S.T. & PS & $x$ & $x$ & $x$ & $x$ & $x$ & & $x$ & & & & \\
\hline 26 & L.M.L. & PS & $x$ & $x$ & $x$ & $x$ & $x$ & $x$ & $x$ & $x$ & $x$ & $x$ & \\
\hline 27 & L.B. & PS & $x$ & $x$ & $x$ & $x$ & $x$ & $x$ & $x$ & $x$ & & $x$ & \\
\hline 28 & M.A.S.M. & $s$ & $x$ & $x$ & $x$ & $x$ & $x$ & $x$ & & $x$ & $x$ & $x$ & \\
\hline 29 & M.T.S.A. & PS & $x$ & $x$ & $x$ & $x$ & $x$ & $x$ & $x$ & $x$ & & & \\
\hline 30 & M.N.C. --- & $s$ & & & & & & & & & & & \\
\hline 31 & N.C.F. & PS & $x$ & $x$ & $x$ & $x$ & $x$ & $\mathrm{x}$ & $x$ & & & & \\
\hline 32 & N.F.P. & $s$ & $x$ & $x$ & $x$ & $x$ & $x$ & $x$ & $x$ & & & & \\
\hline 33 & R.M.M. & $\mathrm{s}$ & $x$ & $x$ & $x$ & $x$ & $x$ & $x$ & $x$ & & & & \\
\hline 34 & R.T.S. & $s$ & $x$ & $x$ & $x$ & $x$ & $x$ & $x$ & $x$ & & & & \\
\hline 35 & S.A.B. & PS & $x$ & $x$ & $x$ & $x$ & $x$ & $x$ & $x$ & $x$ & $x$ & & \\
\hline 36 & S.A.P. & $\mathrm{s}$ & $x$ & $\mathrm{x}$ & $x$ & $x$ & . & . & $x$ & & & & \\
\hline 37 & S.S.G. & PS & $x$ & $x$ & $x$ & $x$ & $x$ & $x$ & $x$ & $x$ & & $x$ & $x$ \\
\hline 38 & S.I.S. & s & $x$ & $x$ & $x$ & $x$ & $x$ & $x$ & $x$ & $x$ & $x$ & $x$ & \\
\hline 39 & T.B.L. & $\mathrm{s}$ & $x$ & $x$ & $x$ & $x$ & & & $x$ & & & & \\
\hline 40 & T.F.S. & PS & $x$ & $x$ & $x$ & $x$ & & & & & & & \\
\hline 41 & T.S. & $\mathrm{s}$ & $x$ & $x$ & $x$ & $x$ & $x$ & $x$ & $x$ & & & & \\
\hline 42 & W.D.S. & PS & $x$ & $x$ & $x$ & $x$ & $x$ & $x$ & $x$ & & & $x$ & \\
\hline 43 & Y.C.C. & PS & $x$ & $x$ & $x$ & $x$ & $x$ & $x$ & $x$ & & & $x$ & \\
\hline RES & POSTAS - TOTAL & $21 / 18 / 5$ & 38 & 38 & 36 & 36 & 29 & 28 & 25 & 16 & 12 & 12 & 1 \\
\hline RES & POSTAS - \% & & 88 & 88 & 84 & 84 & 67 & 65 & 58 & 37 & 28 & 28 & 2 \\
\hline
\end{tabular}

Tabela 14 - Embora apenas $28 \%$ dos alunos tenham correlacionado os temas propostos nos mapas para responder as questões, foi possível observar maior familiaridade com a linguagem cartográfica em comparação aos alunos que não praticaram os exercícios em 2010. 


\begin{tabular}{|c|c|c|c|c|c|c|c|c|c|c|c|c|}
\hline \multicolumn{13}{|c|}{$\begin{array}{l}\text { RELATÓRIO C.E.U. } 2012-7^{a} \text { AeB - LEITURA, INTERPRETAÇÃO E CORRELAÇÃO DE MAPAS } \\
\text { TEMÁTICOS } \\
\text { (Apenas alunos que não realizaram as avaliações em 2010) }\end{array}$} \\
\hline & \multirow[b]{2}{*}{ NOME } & \multicolumn{7}{|c|}{ LEITURA E INTERPRETAÇÃO } & \multicolumn{3}{|c|}{ CORRELAÇÃO } & \multirow[b]{2}{*}{ 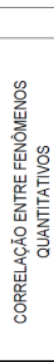 } \\
\hline & & 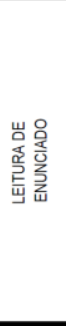 & 总 & 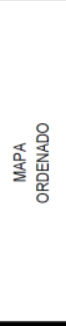 & 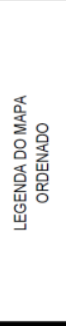 & 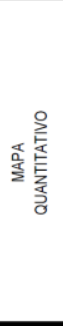 & 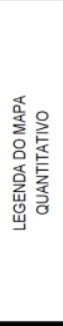 & 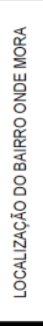 & 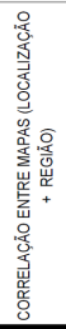 & 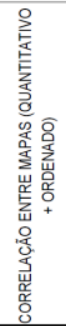 & 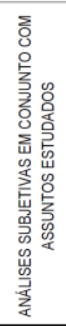 & \\
\hline 1 & E.B.D.S. & $x$ & $x$ & $\mathrm{x}$ & $x$ & $\mathrm{x}$ & $\mathrm{x}$ & $x$ & $\mathrm{x}$ & & $x$ & \\
\hline 2 & F.J. & $x$ & $x$ & $\mathrm{x}$ & $\mathrm{x}$ & & & $\mathrm{x}$ & & & & \\
\hline 3 & G.S.P. & $\mathrm{x}$ & $\mathrm{x}$ & $\mathrm{x}$ & $x$ & $x$ & $\mathrm{x}$ & $\mathrm{x}$ & & & & \\
\hline 4 & I.S.S. & $x$ & $x$ & & & $x$ & $x$ & & & & & \\
\hline 5 & J.A.P.A. & $\mathrm{x}$ & $\mathrm{x}$ & $\mathrm{x}$ & $\mathrm{x}$ & $\mathrm{x}$ & $\mathrm{x}$ & $\mathrm{x}$ & $\mathrm{x}$ & $\mathrm{x}$ & $x$ & \\
\hline 6 & K.C.S. & & & & & & & & & & & \\
\hline 7 & W.N.S. & $\mathrm{x}$ & $x$ & & & & & $x$ & & & & \\
\hline 8 & L.J.D.O. & $x$ & $x$ & $x$ & $x$ & $x$ & $x$ & $\mathrm{x}$ & & & & \\
\hline 9 & M.A.A. & $\mathrm{x}$ & $\mathrm{x}$ & $\mathrm{x}$ & $x$ & $x$ & & & & & & \\
\hline 10 & R.C.M. & $x$ & $x$ & $x$ & $x$ & $x$ & $x$ & & $x$ & $x$ & & \\
\hline 11 & S.T.S. & $x$ & $x$ & $x$ & $x$ & & & $x$ & & & & \\
\hline 12 & V.F.C. & $x$ & $x$ & $x$ & $x$ & & & & & & $x$ & \\
\hline \multicolumn{2}{|c|}{ RESPOSTAS - TOTAL } & 11 & 11 & 9 & 9 & 7 & 6 & 7 & 3 & 2 & 3 & 0 \\
\hline \multicolumn{2}{|c|}{ RESPOSTAS - \% } & 92 & 92 & 75 & 75 & 58 & 50 & 58 & 25 & 17 & 25 & 0 \\
\hline
\end{tabular}

Tabela 15 - Entre os alunos que não realizaram as atividades em 2010, apenas três correlacionaram o mapa apresentado na avaliação com o tema estudado em sala de aula.

\begin{tabular}{|c|c|c|c|c|c|c|c|c|c|c|c|}
\hline \multicolumn{12}{|c|}{$\begin{array}{c}\text { RELATÓRIO C.E.U. } 2012 \text { - } 7^{\text {a }} \text { Série - LEITURA, INTERPRETAÇÃO E CORRELACCÃO DE MAPAS TEMÁTICOS ENTRE OS ALUNOS } \\
\text { QUE PRATICARAM E NÃO PRATICARAM A CONSTRUÇÃO DE MAPAS EM } 2010\end{array}$} \\
\hline EM \% DE APROVEITAMENTO & \multicolumn{7}{|c|}{ LEITURA E INTERPRETAÇÃO } & \multicolumn{4}{|c|}{ CORRELAÇĀ̃o } \\
\hline $\begin{array}{c}\text { PARTICIPAÇÃO EM ATIVIDADE E } \\
\text { AVALIAÇÃO DE MAPAS TEMÁTICOS } \\
\text { EM } 2010\end{array}$ & 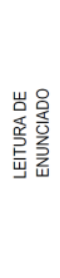 & 寒 & 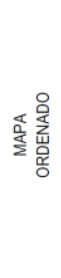 & 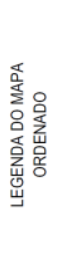 & 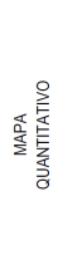 & 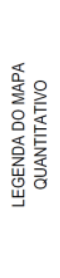 & 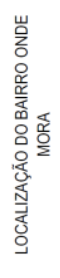 & 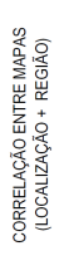 & 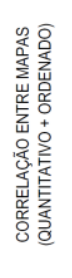 & 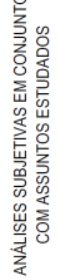 & 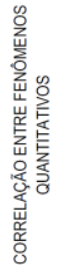 \\
\hline SIM & 88 & 88 & 84 & 84 & 67 & 65 & 58 & 37 & 28 & 28 & 2 \\
\hline NÃO & 92 & 92 & 75 & 75 & 58 & 50 & 58 & 25 & 17 & 25 & 0 \\
\hline
\end{tabular}

Tabela 16 - Dois anos após as atividades de construção de mapas temáticos, foi possível observar os melhores resultados na leitura, interpretação e correlação de mapas temáticos entre os alunos da $7^{a}$ Série ( $8^{\circ}$ Ano) que participaram dos exercícios em 2010. 


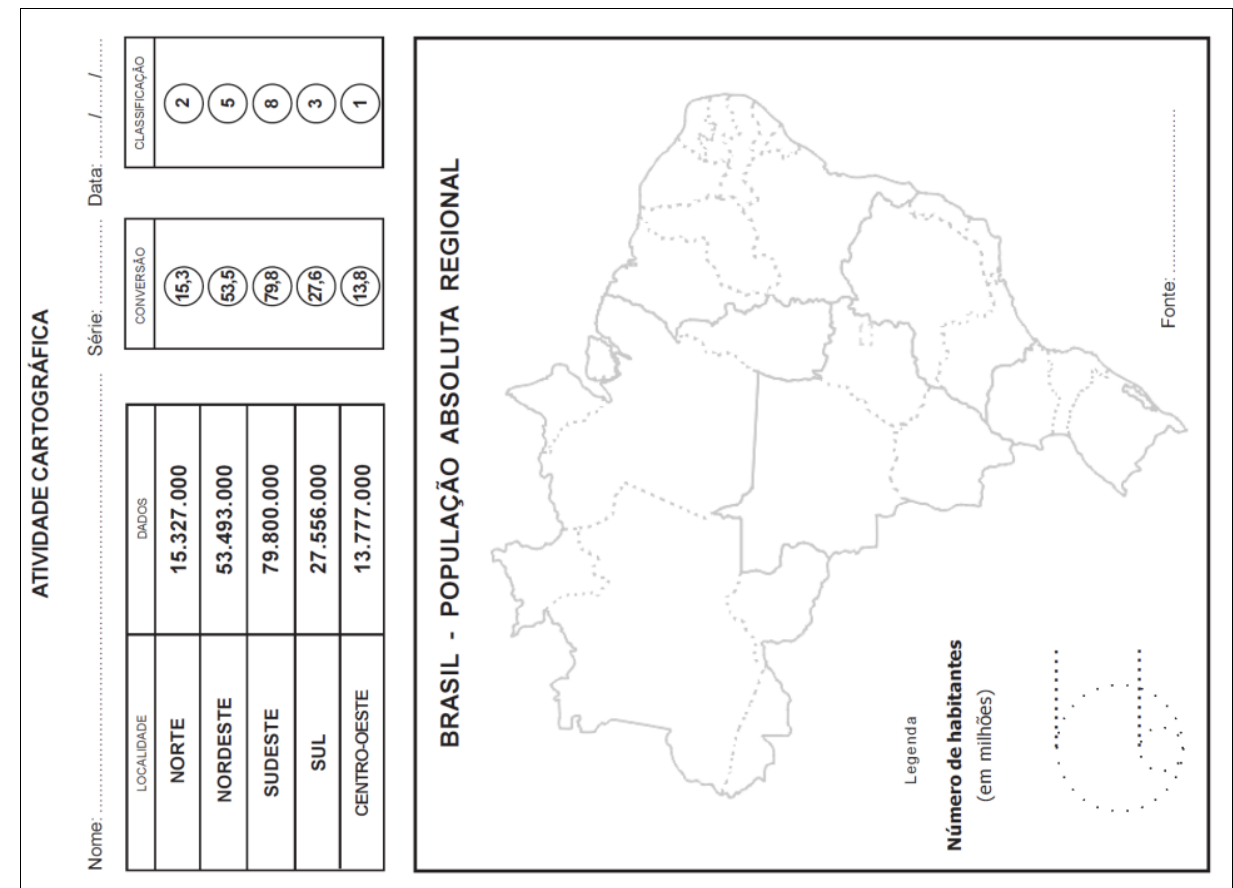

Figura 31 - Matriz utilizada para a construção do mapa quantitativo com círculos proporcionais na $5^{\underline{a}} \mathrm{~A}$ (6읏 A ) com os dados prontos para agilizar os procedimentos.

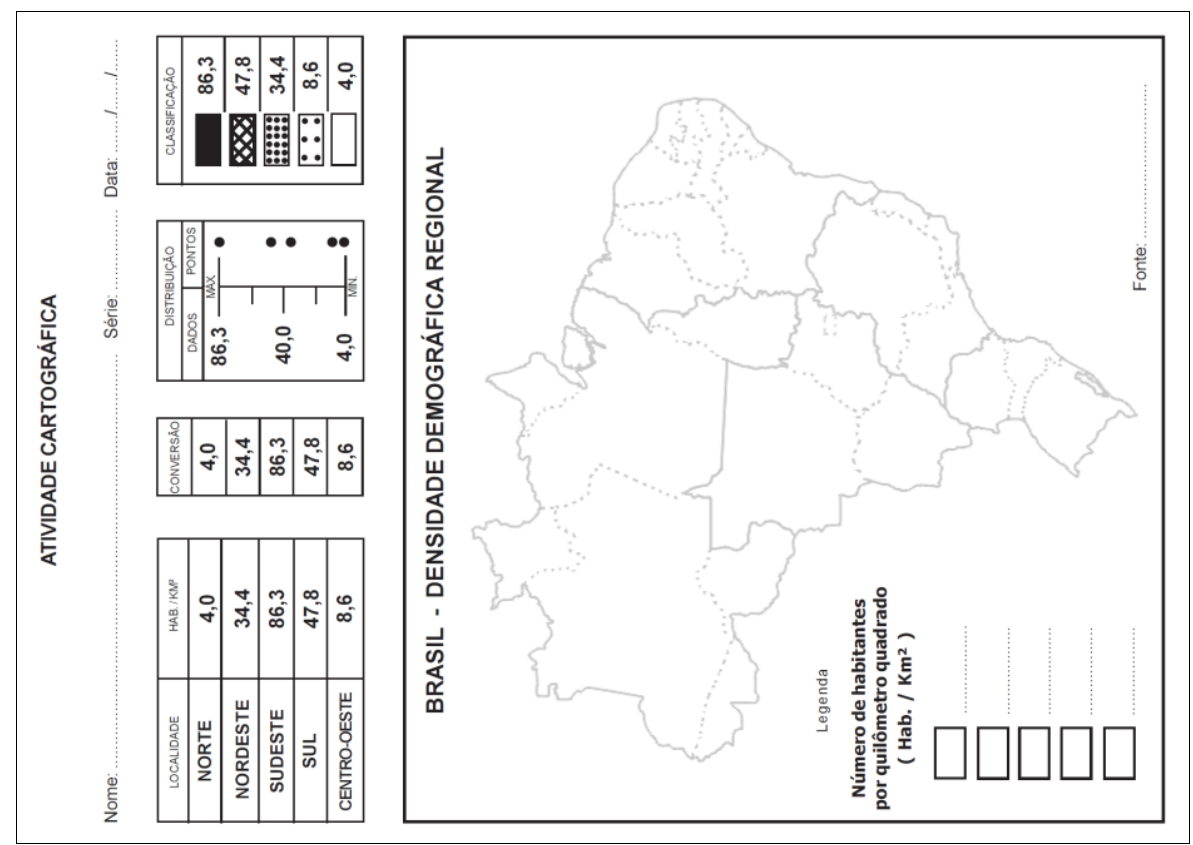

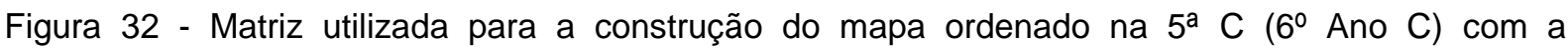
distribuição e classificação dos dados prontos para agilizar os procedimentos e introduzir o método de construção de mapas de forma gradativa. 

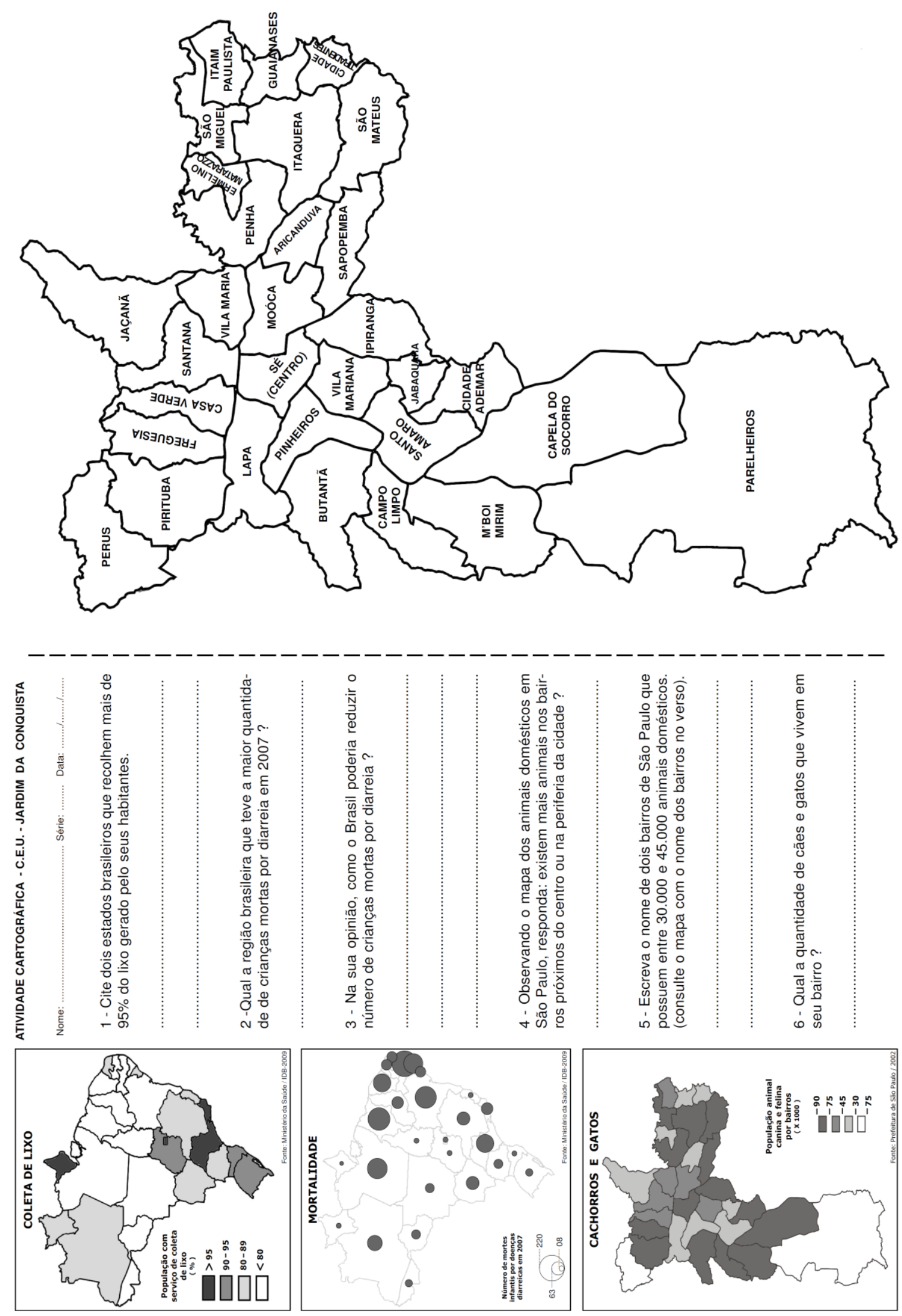

Figura 33 - Modelo da avaliação aplicada nas três Turmas de 5ª Série (6 Ano) em 2010. 


\section{C.E.U. - JARDIM DA CONQUISTA - SÃO MATEUS - SÃO PAULO / SP}

AVALIAÇÃO - GEOGRAFIA - $8^{\circ}$ Ano (7 $7^{\text {S Série }) ~-~ T u r m a: ~}$ - Prof.: Anderson Albano

Aluno(a):

Data:

I

/ 2012

Analise os mapas A, B, C e D, do município de São Paulo, e responda as questões abaixo:
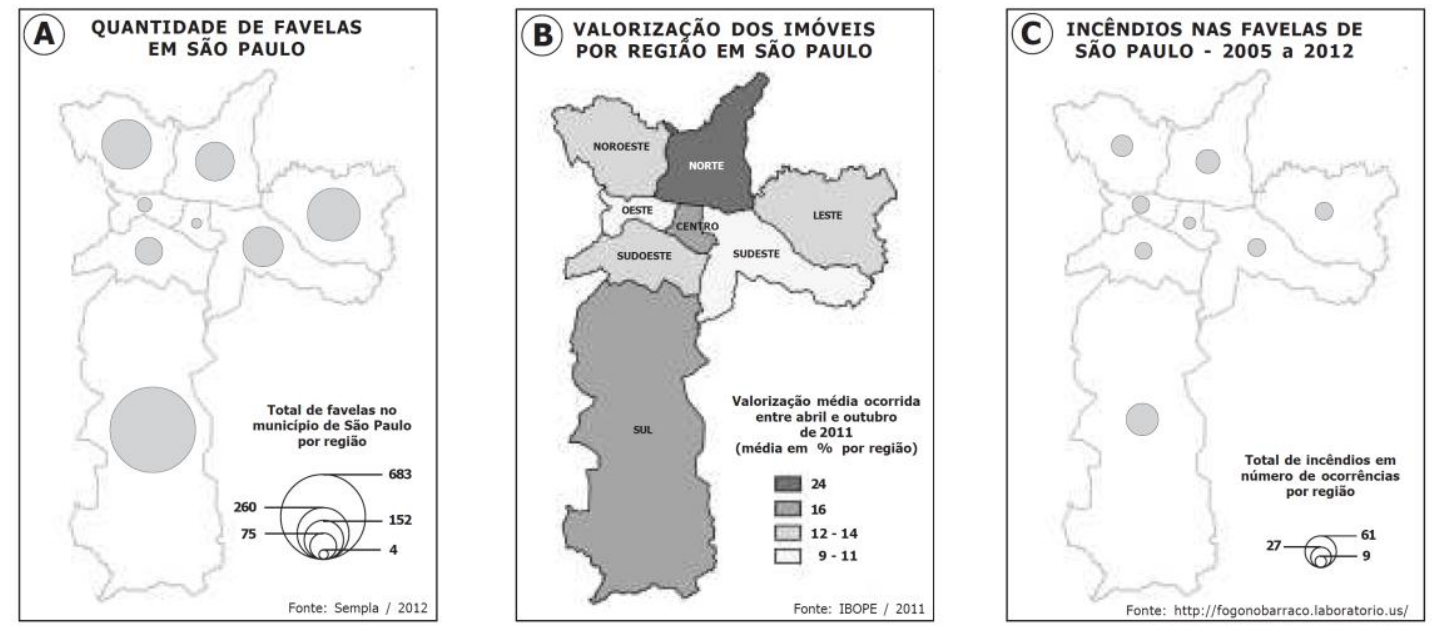

1 - Qual foi a porcentagem (\%) de valorização dos preços dos imóveis na região em que você mora?

2 - Quantas favelas e quantos incêncios são apresentados apenas na região "Centro" do município de São Paulo?

3 - Comparando as regiões "Norte" e "Leste" nos mapas A, B e C, é possivel levantar hipóteses sobre a causa do fenômeno apresentado no mapa "C" ? Explique.

4 - Por que, nas áreas centrais das grandes cidades, a temperatura do ar é superior à da periferia e à zona rural ?
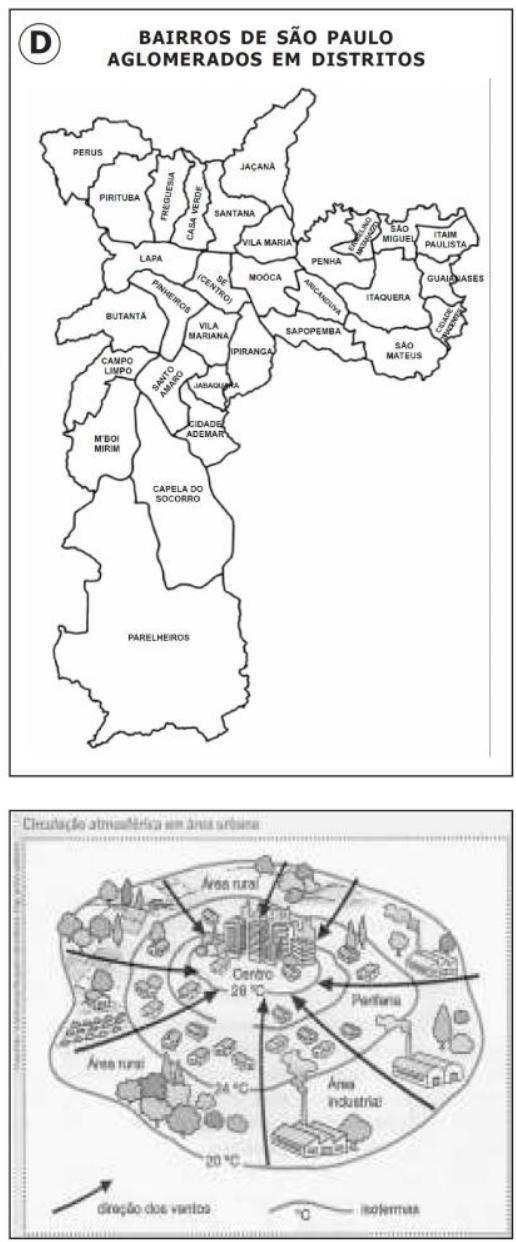

Figura 34 - Modelo da avaliação aplicada nas Turmas de $7^{\text {a }}$ série ( $8^{\circ}$ Ano) em 2012. As questões 4 e 5 não se relacionam a pesquisa. Foram acrescentadas por solicitação do professor para aproveitar a oportunidade de avaliação. 


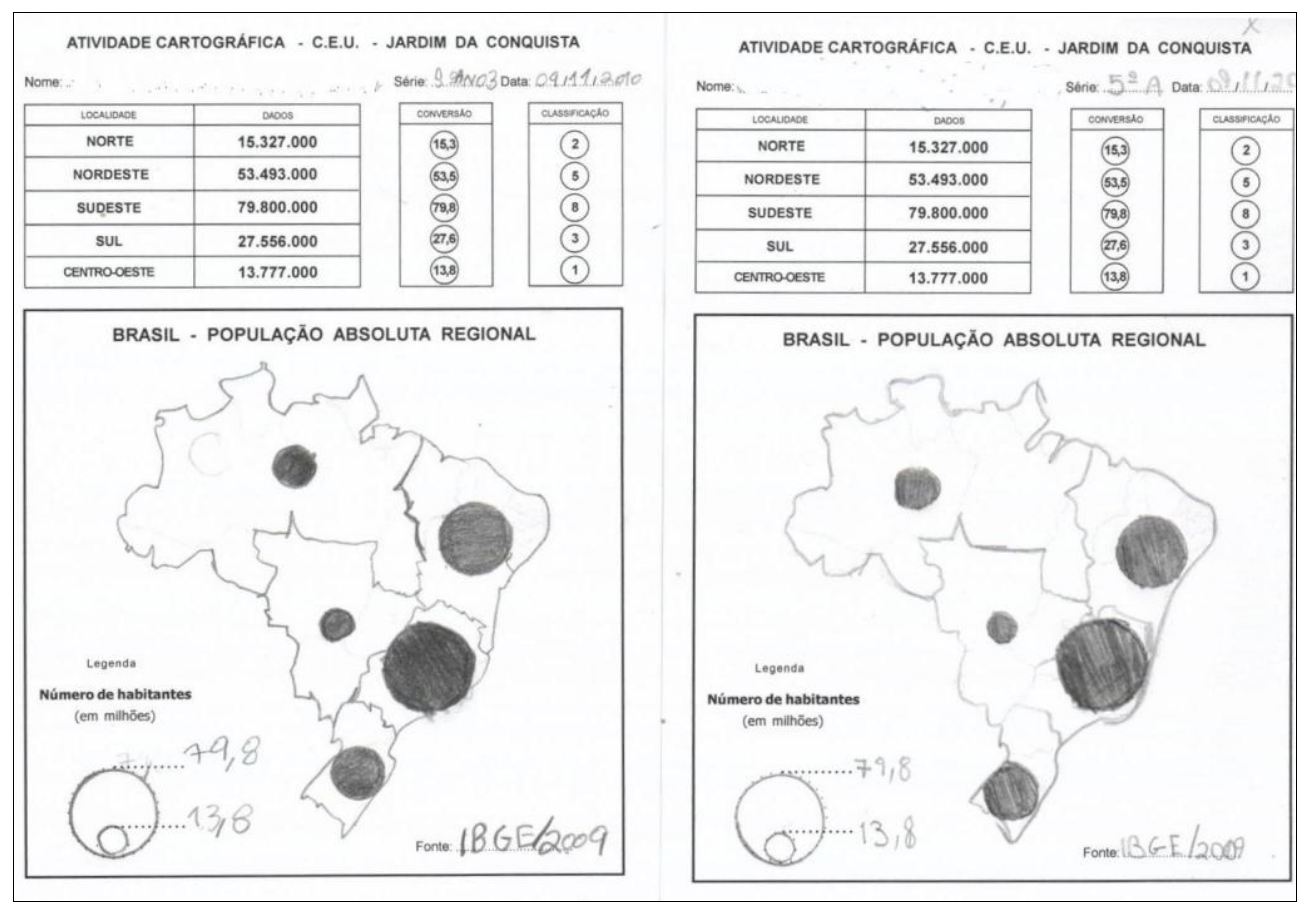

Figura 35 - 5a série A (6ํA Ano A) -Mapa do Brasil - Regiões - População Absoluta - Dois exemplos elaborados pelos alunos com o contorno das Regiões já demarcados na matriz e os círculos quantitativos preenchidos com gabarito.

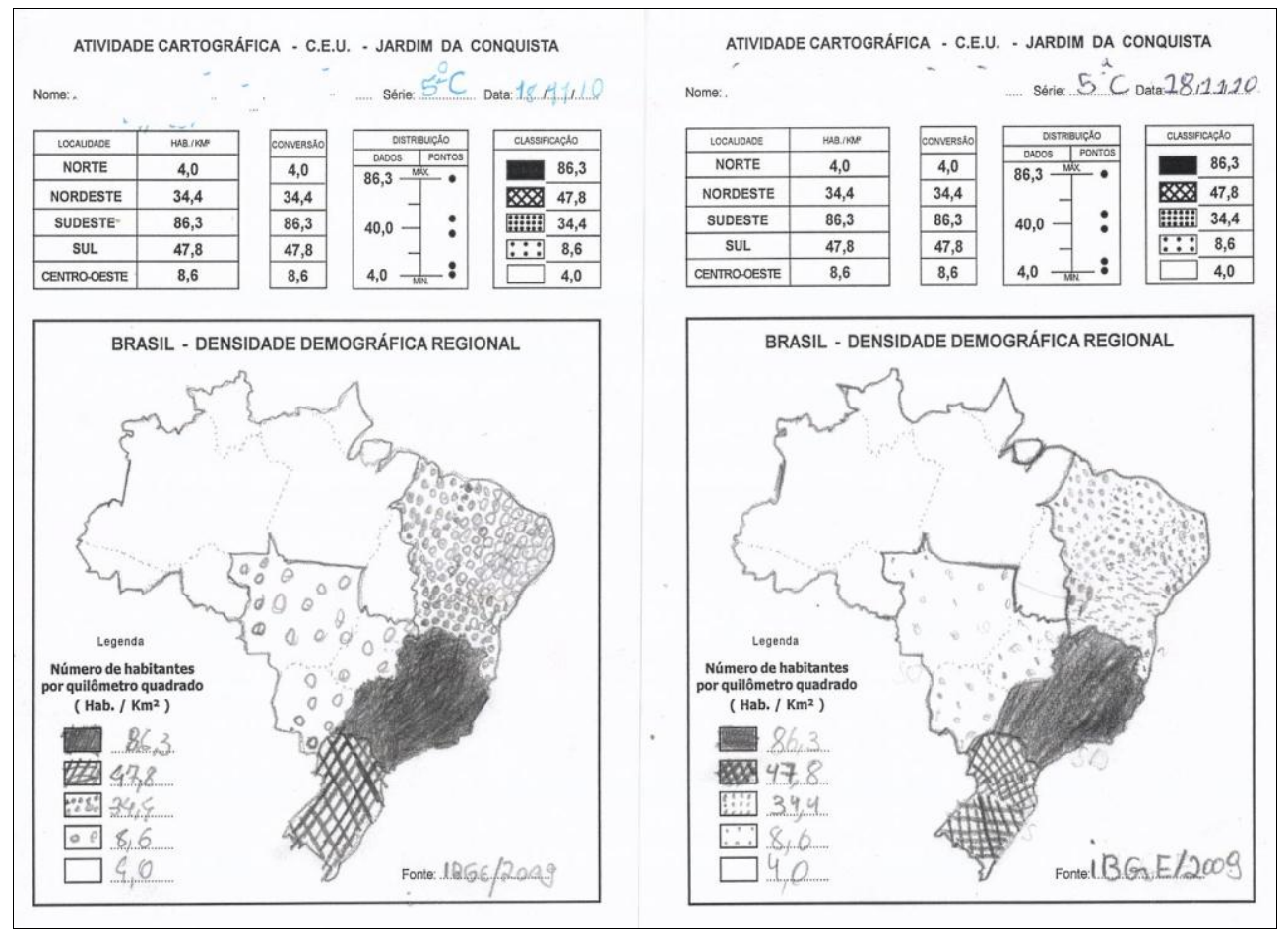

Figura 36 - 5a série C (6ํA Ano C) - Mapa do Brasil - Regiões - População Relativa - Dois exemplos elaborados pelos alunos, seguindo os procedimentos passo a passo do professor na lousa. 


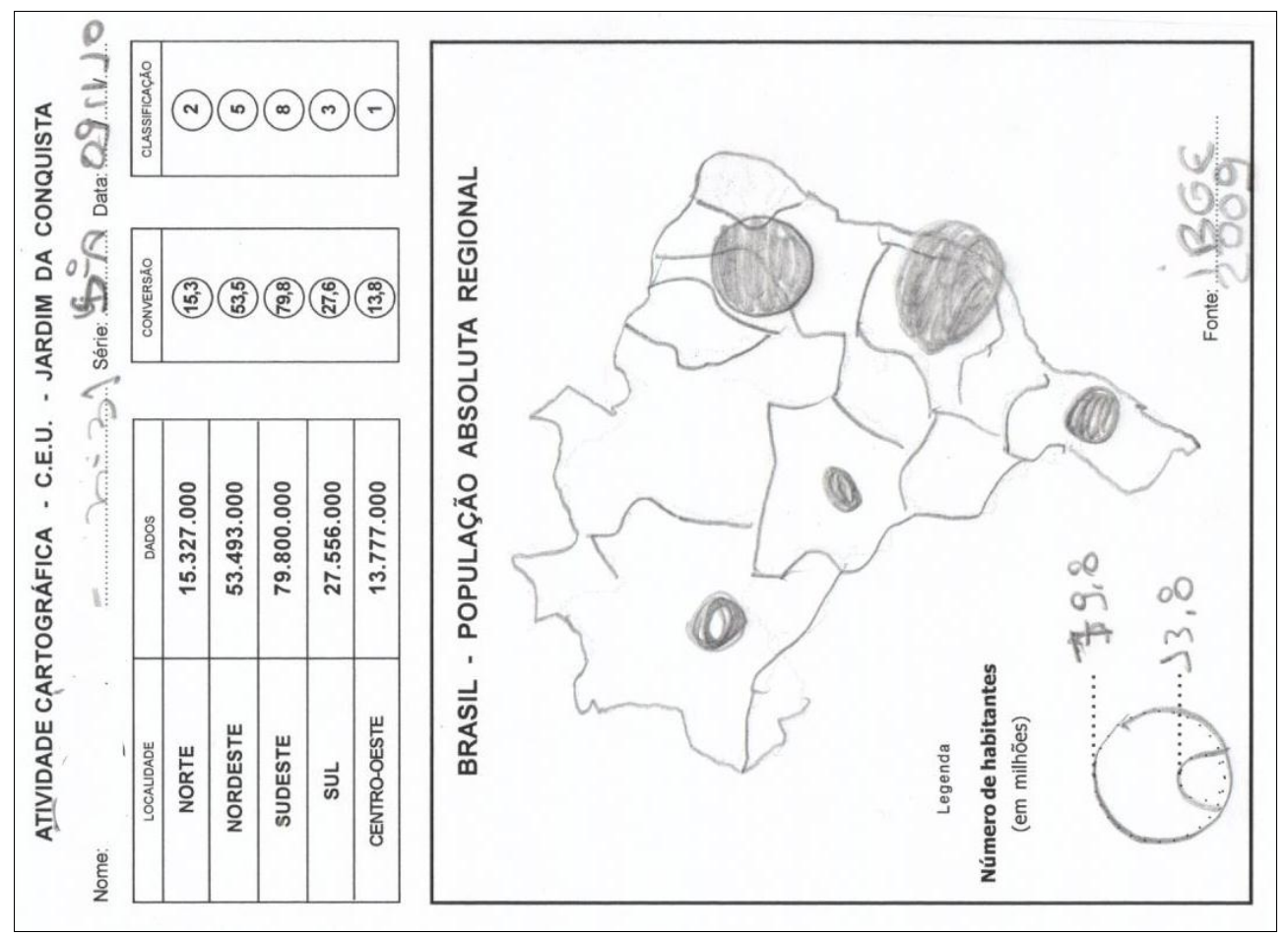

Figura 37 - Mapa elaborado por F.S.S. Aluno com graves problemas de aprendizagem. Na avaliação, escreveu apenas seu primeiro nome.

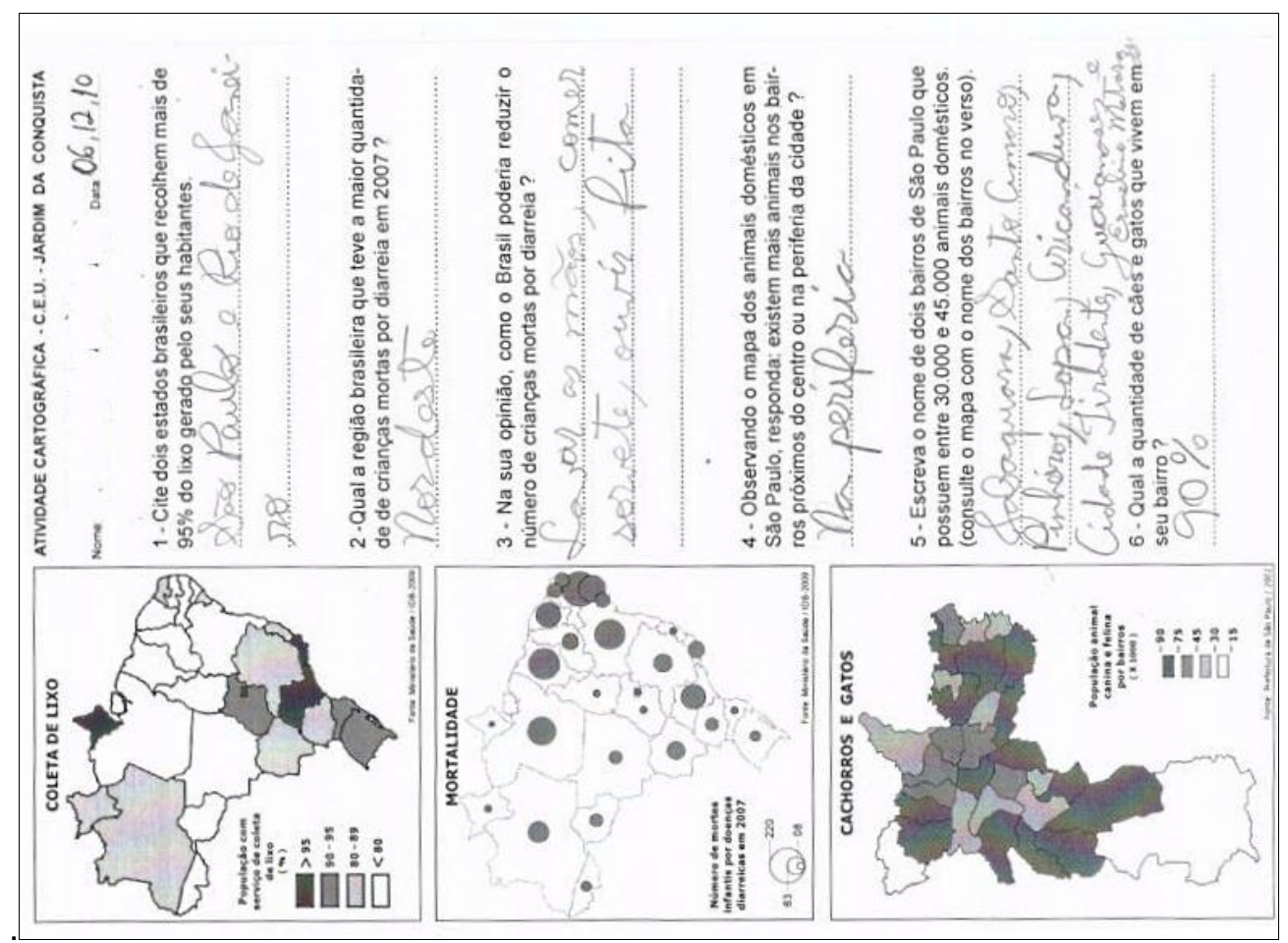

Figura 38 - Avaliação do aluno autista R. P. Faz uma leitura correta dos mapas, apesar de não associar os temas para responder a terceira questão. 


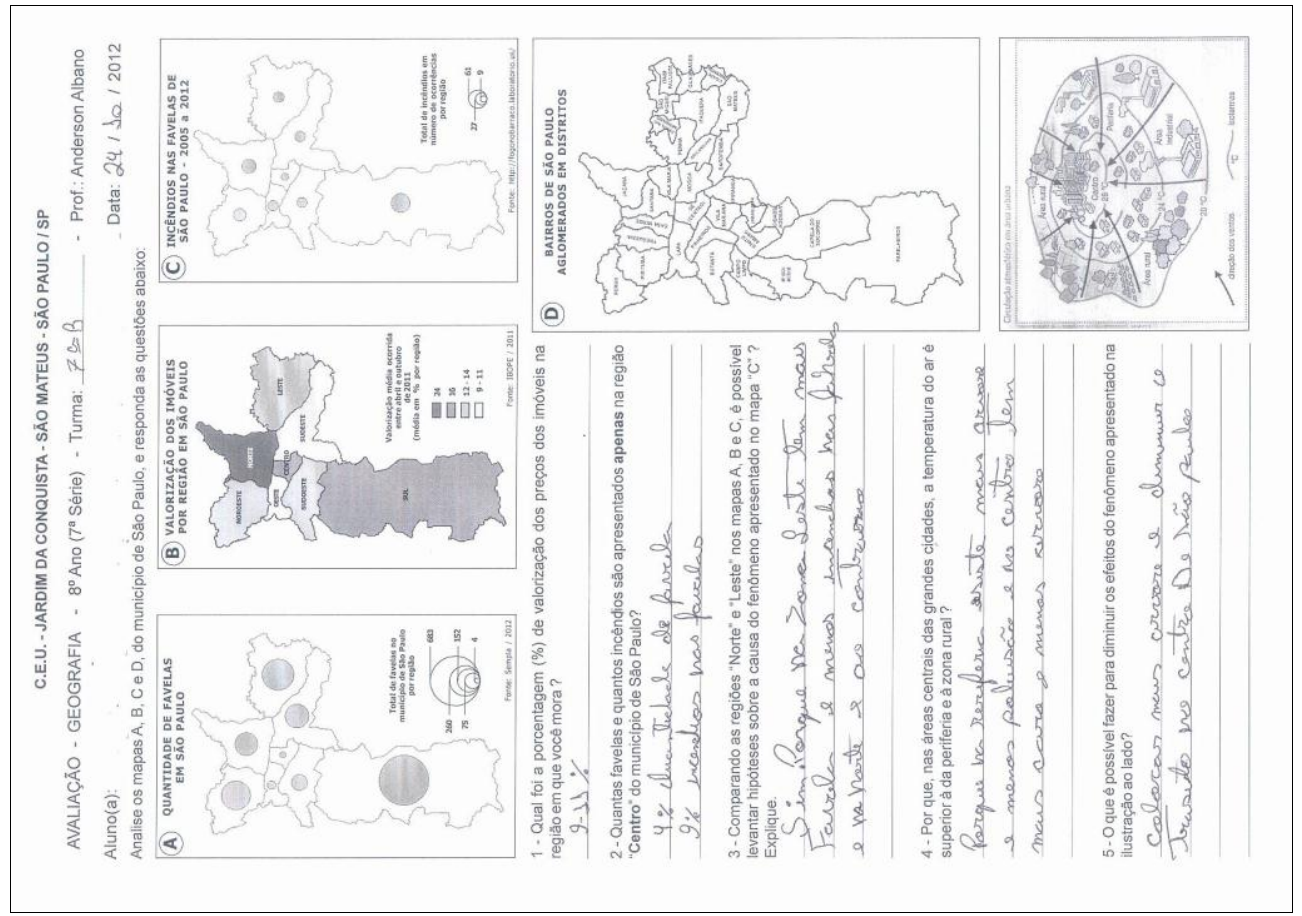

Figura 39 - Avaliação do aluno S.S.G. Um dos poucos que fez a correlação entre os temas dos mapas apresentados.

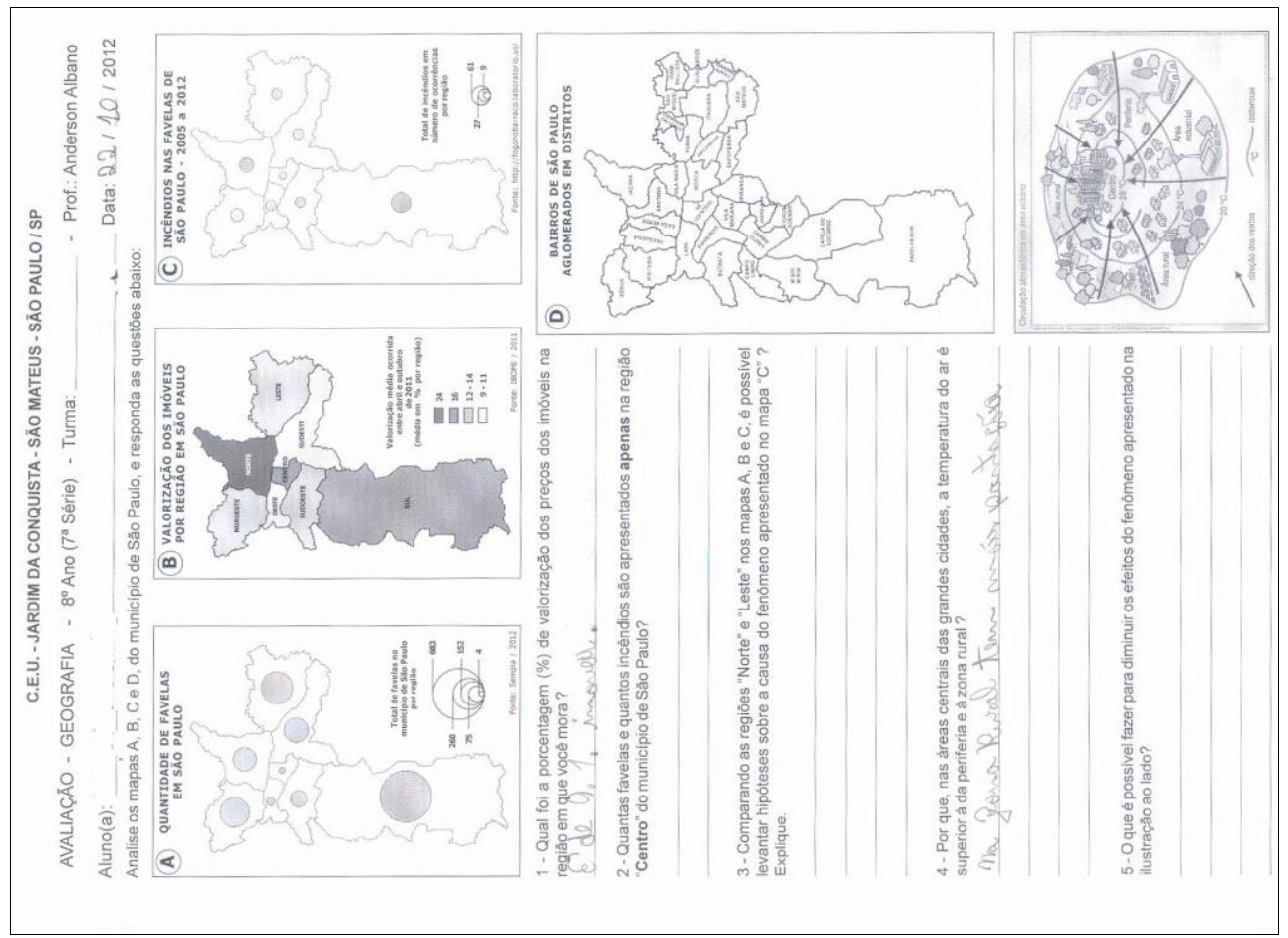

Figura 40 - Avaliação de K.S.R. Aluno classificado como analfabeto funcional. 


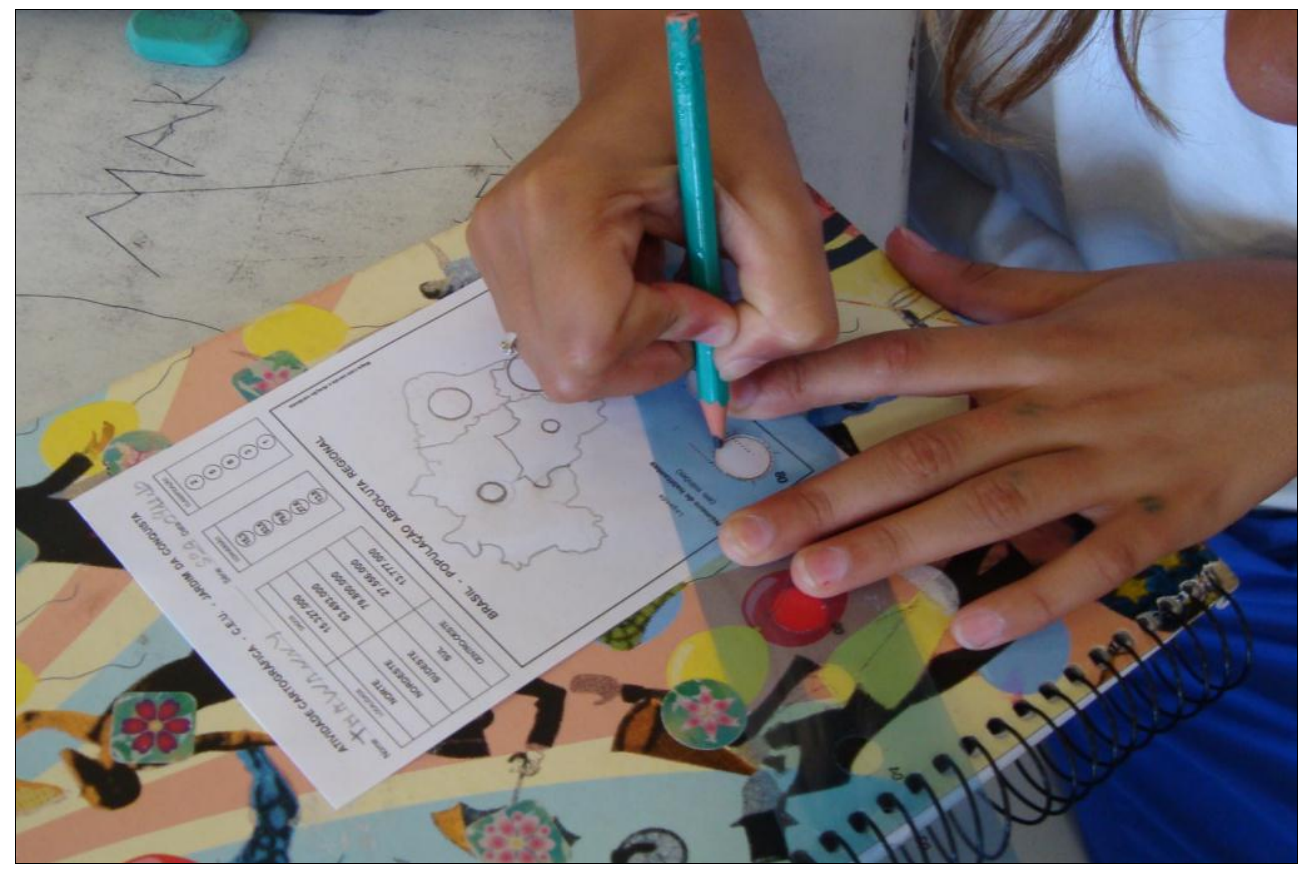

Figura 41 - Preenchimento dos círculos proporcionais no mapa quantitativo utilizando gabarito. Alguns alunos questionaram o tamanho do círculo da Região Sudeste que ultrapassou a área regional.

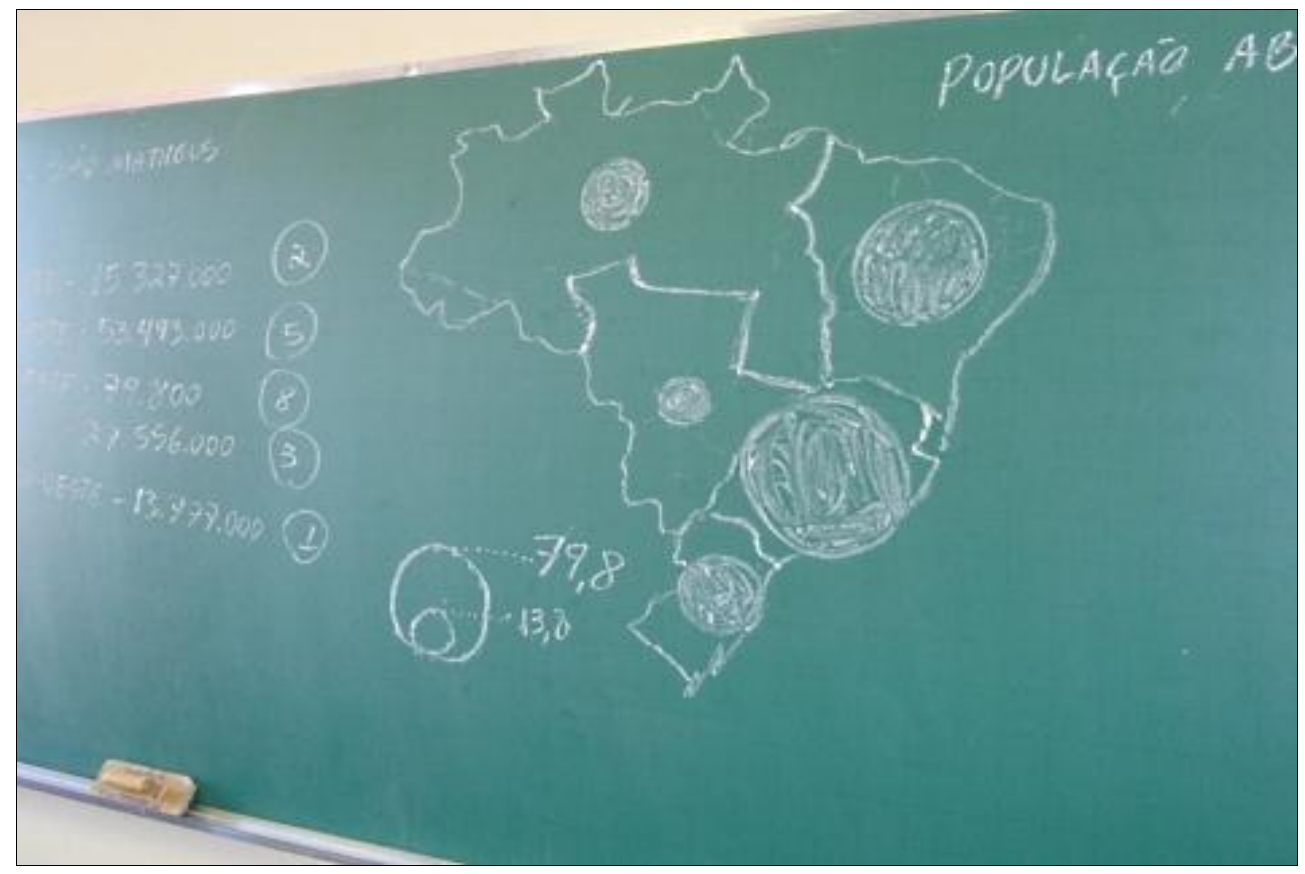

Figura 42 - Procedimentos em lousa para a elaboração do mapa quantitativo da população absoluta regional a partir do gabarito de mapa mudo do Brasil. Os círculos forma elaborados sem proporção apenas para instruir os procedimentos dos alunos. 


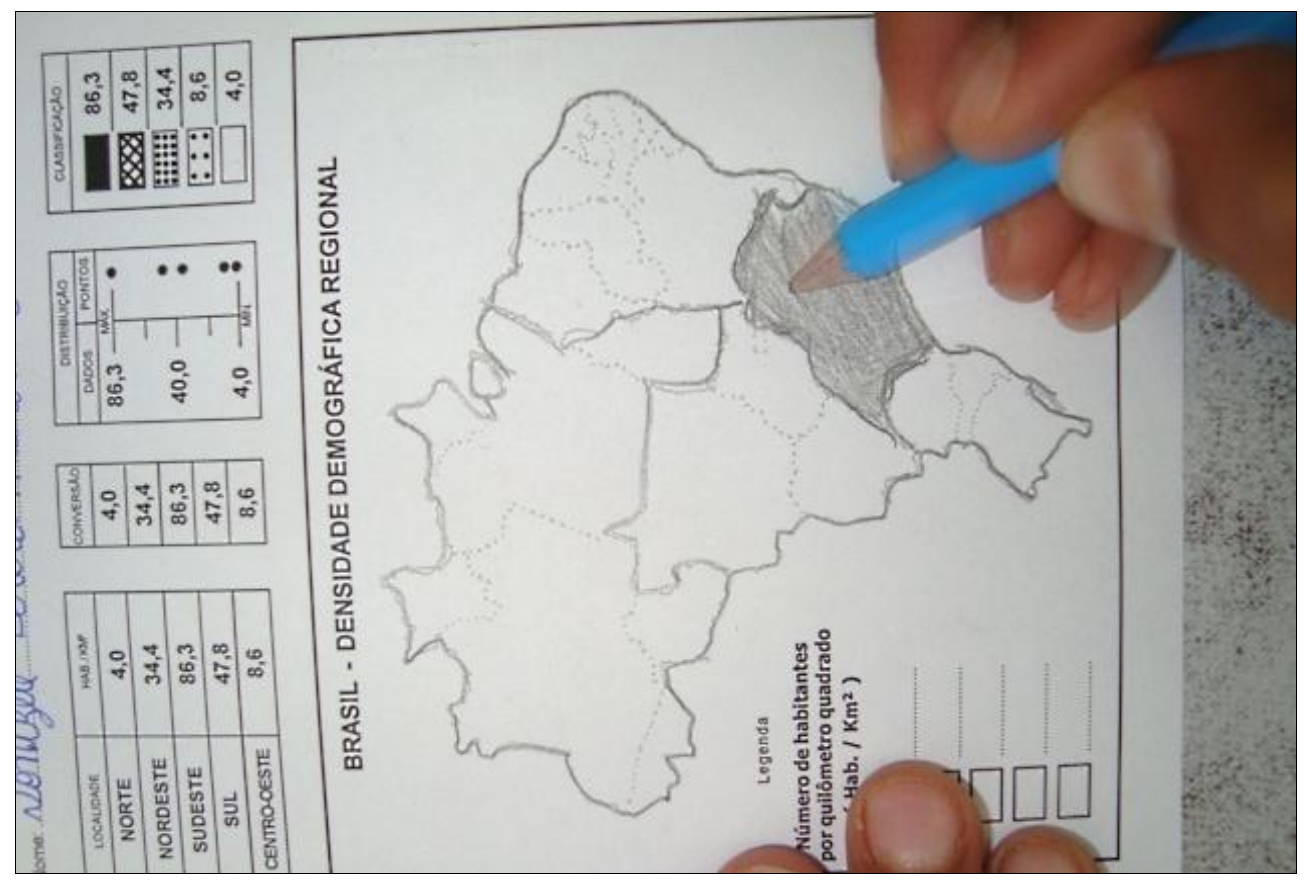

Figura 43 - Preenchimento do mapa ordenado com grafite em escala de granulação. A escolha da granulação ajudou a agilizar os procedimentos e ao mesmo tempo, simplificou a atividade solicitando aos alunos apenas lápis grafite.

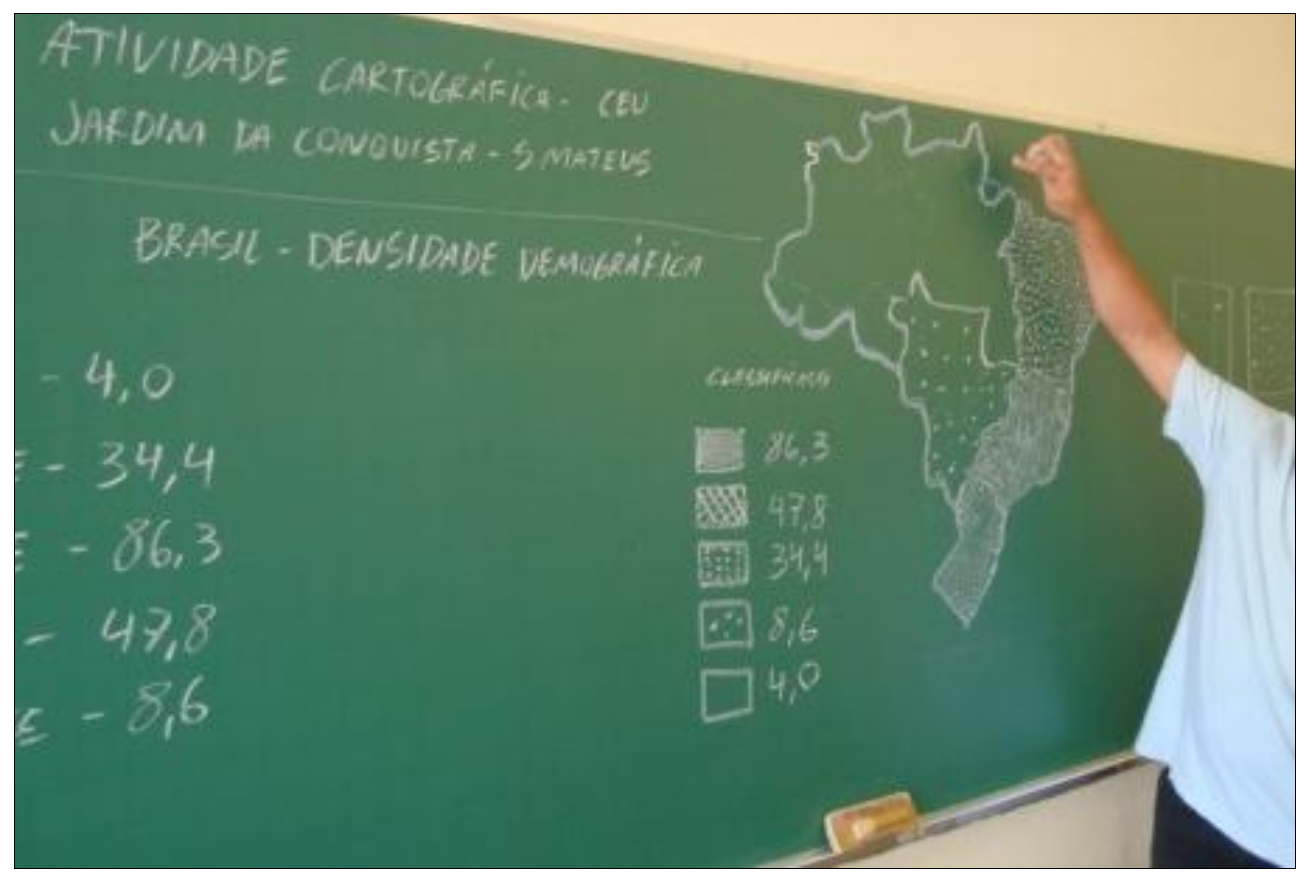

Figura 44 - Elaboração do mapa ordenado em lousa a partir do gabarito do mapa mudo do Brasil. Foi utilizado apenas giz branco com granulações para simplificar os procedimentos. 


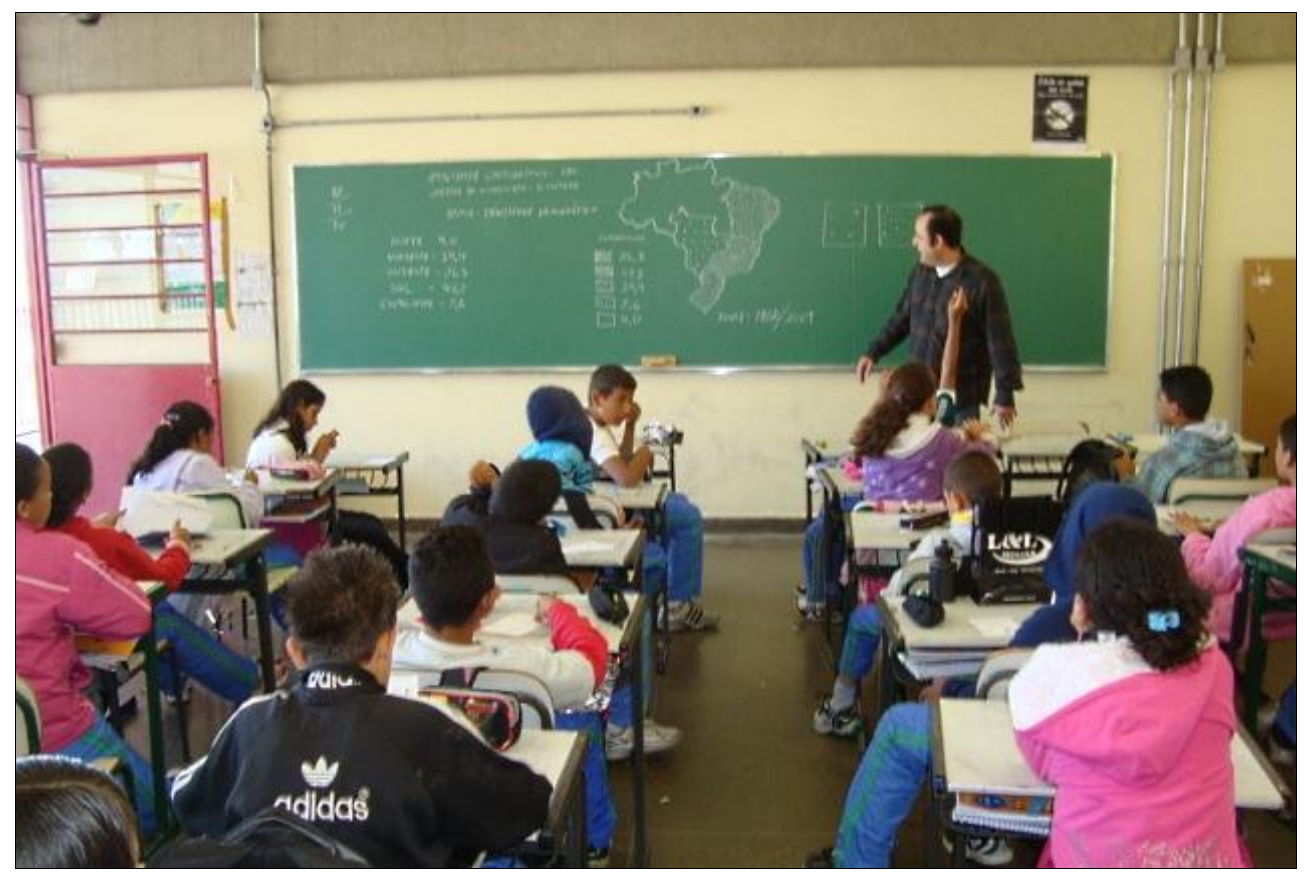

Figura 45 - Parte expositiva da aula após os alunos construírem o mapa da densidade demográfica das regiões brasileiras. O professor de Geografia explicou a diferença entre população absoluta e relativa.

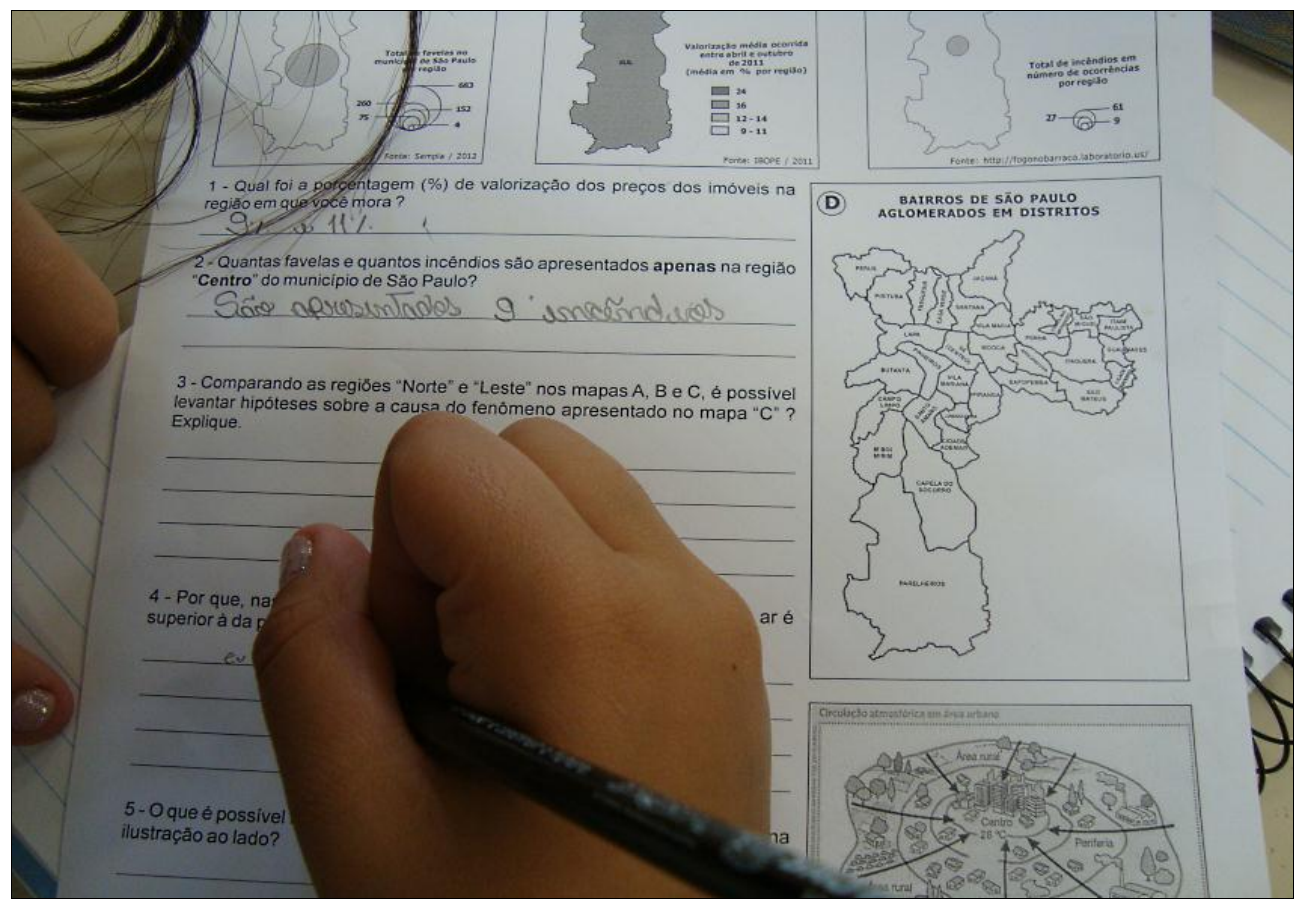

Figura 46 - Avaliação realizada com as mesmas Turmas dois anos após as atividades de elaboração de mapas em 2010. 


\section{2 - Atividades realizadas com alunos de 9ํㅗ Ano de escola particular}

\begin{tabular}{|l|}
\hline \multicolumn{1}{|c|}{ Local de aplicação das atividades } \\
\hline Instituição de ensino: Colégio Singular Júnior \\
Localização: Rua das Figueiras, 2020 - Bairro Campestre - Santo André / SP \\
Série selecionada: 9o Ano \\
Número de alunos por sala: $~ 32$ \\
Período de realização: março a novembro de 2011 \\
Professor da Disciplina: Gerson Rodrigues Leite \\
\hline
\end{tabular}

Durante o ano letivo de 2011, três Turmas do 9ำ Ano de escola particular realizaram uma série de atividades cartográficas temáticas diversas conforme a ideia principal deste projeto, ou seja, praticar constantemente atividades cartográficas de construção de mapas temáticos de forma rápida, e de acordo com os temas estudados durante todas as unidades letivas.

Entre atividades e avaliações, totalizaram sete experiências entre março e novembro de 2011. Foram elaborados mapas ordenados, quantitativos e dinâmicos com diversas projeções e escalas a partir de mapas mudos como: planisférios (centralizados em diversas longitudes), América do Sul, Brasil, Oriente Médio, Grande $\mathrm{ABC}$, além de uma introdução teórica dos principais tipos de mapas temáticos.

Por ser o primeiro trabalho de construção de mapas temáticos a ser aplicado aos alunos do 9o Ano, foi estabelecido como critério, apresentar os dados já calculados para as três Turmas, que apenas copiaram os valores em suas matrizes, seguindo as orientações do professor, que improvisou um croqui do continente africano na lousa e uma tabela para conversão e classificação dos dados.

Ficou definido como critério para cada Turma, praticar com mais destaque, apenas "um tipo" de mapa temático. O Colégio utiliza como nomenclatura para o $9^{\circ}$ Ano, o código 9J1, 9J3 e 9J5, para se referir as três Turmas. A 9J1 priorizou a elaboração de mapas dinâmicos com uso de gabarito de curvas proporcionais. A Turma 9J3 trabalhou com mapas ordenados e a 9J5 com mapas quantitativos utilizando gabarito de círculos proporcionais. 
O Colégio distribui o conteúdo programático anual do Ano Letivo em três Unidades Letivas, cabendo ao professor avaliar os alunos com atividades (uma ou mais a critério do professor) no valor de 2,0 pontos, uma avaliação individual sem consulta com valor de 5,0 pontos e uma prova individual com questões objetivas de múltimpla escolha aplicada pelo Colégio com questões fornecidas pelos professores de todas as disciplinas com valor de 3,0 pontos.

As avaliações são realizadas em todo o Colégio simultaneamente com todas as séries da mesma disciplina em salas mescladas de acordo com um mapa de sala elaborado especialmente para estas ocasiões, com a participação de todos os professores e funcionários de apoio da coordenação pedagógica.

Para o professor de Geografia, a atividade no valor de 2,0 pontos é aplicada livremente em sala de aula ou extraclasse. Para este projeto, ficou definido que as atividades cartográficas não seriam incluídas ou avaliadas para a nota final dos alunos. Seriam atividades de elaboração de mapas inseridas nas duas aulas semanais de 50 minutos cada como um "questionário tradicional" realizado para exercitar o aprendizado de um tema específico.

Todos os mapas produzidos pelos alunos foram digitalizados, analisados e entregues para serem colados no caderno de cada um.

O objetivo inicial foi trabalhar com a construção de mapas como parte de um questionário, para posteriormente analisar os mapas construídos relacionando-os com os temas estudados.

Pelo número de aulas semanais de Geografia ser considerado reduzido em comparação com a maioria das escolas que normalmente apresenta uma grade com três aulas, as duas aulas semanais oferecidas pelo Colégio dificulta o estudo de todo o conteúdo apresentado em quatro Apostilas para o Ano Letivo, o que obriga o professor a priorizar os temas e capítulos para cumprir o calendário anual. Nas três Turmas foram definidas aulas duplas a pedido do professor. O conteúdo de Geografia nas Apostilas do $9^{\circ}$ Ano é dividido em cada uma delas na seguinte forma:

Apostila 1 - África - Aspectos físicos, humanos e econômicos.

Apostila 2 - Ásia - Aspectos físicos, humanos e econômicos.

Apostila 3 - America Latina - Aspectos físicos, humanos e econômicos.

Apostila 4 - Blocos Econômicos e Economia Global. 
No final de cada capítulo é apresentado um caderno de exercícios, com textos verbais, e esporadicamente análise de mapas e construção de gráficos. Entre os textos longos apresentados nos capítulos, há mapas, tabelas e gráficos, sendo grande parte dos mapas apenas físicos e políticos para localização e ilustração.

Os resultados mostram que é possível inserir a Cartografia Temática em todos os temas estudados em Geografia no Ensino Fundamental, e que também é possível aprimorar, a partir de novas experiências, os materiais didáticos que já estão em uso.

\section{Relatórios de atividades cartográficas realizadas entre abril e novembro de $\underline{2011}$}

a) ABRIL / 2011- Atividade cartográfica - África (HIV, Migração Interna e Máquinas Agrícolas)

Em cada uma das turmas foi realizada uma atividade prática de construção de mapa temático com métodos diferentes (ordenado, quantitativo e dinâmico).

$9 \mathrm{~J} 1$ - Para a Turma 9J1, que elaborou o mapa dinâmico dos principais fluxos migratórios da África, o professor montou a tabela dos dados e o croqui para explicar os procedimentos passo a passo aos alunos. Após os alunos copiarem os dados na matriz, o professor distribuiu os gabaritos com curvas proporcionais para os alunos preencherem as curvas de acordo com as quantidades (alto, médio, baixo), acompanhando o mapa político da Apostila para localizar os países.

9J3 - Na Turma 9J3, o exercício foi construir um mapa ordenado com o índice de HIV nas regiões africanas calculados pelo professor. Além de existir uma grande variação entre as regiões, a construção de um mapa ordenado com apenas cinco elementos agiliza os procedimentos e facilita a compreensão e a familiarização da construção de mapas pelos alunos.

Embora o mapa ordenado seja mais simples e não necessite de gabaritos para elaboração, durante a explicação dos procedimentos na lousa utilizando a tabela e o croqui, a etapa mais complexa para os alunos foi a classificação dos dados, na qual dispensou o maior tempo para explicações na lousa e individualmente.

$9 J 5$ - Para a Turma 9J5, foi decidido trabalhar com o Planisfério em mapas quantitativos utilizando gabarito de círculos proporcionais com escala de 01 a 10 . 
Assim como nas outras Turmas, a tabela foi apresentada pronta para a familiarização com o método de construção de mapas temáticos e a agilização dos procedimentos.

Foi solicitado aos alunos contornarem os círculos em cor azul ou preta e preencher com lápis de cor ou caneta hidrocor.

b) ABRIL / 2011 - Avaliação cartográfica

Avaliação sem consulta realizada em abril de 2011 com as três Turmas. As questões foram elaboradas com o objetivo de estabelecer uma relação entre a linguagem da Cartografia Temática, sem textos complementares para descrever os quatro mapas apresentados, e a correlação entre mapa+mapa, mapa+gráfico e mapa+texto.

Nesta avaliação, os resultados foram mais significativos entre os alunos com maiores defasagens, identificado pelo valor da nota final inferior a $60 \%$, em que os alunos desta classificação elaboraram as melhores respostas nas questões que apresentaram os tipos de mapas que praticaram anteriormente.

c) AGOSTO / 2011 - Atividade cartográfica - Japão / Oriente Médio / Planisfério (Fluxos Comerciais, Recursos Minerais)

Em cada uma das Turmas também foi aplicada outra atividade prática de construção de mapa temático com métodos diferentes (ordenado, quantitativo e dinâmico) com os mesmos critérios.

9J1 - Para a 2a Unidade Letiva, a Turma 9J1 elaborou um mapa dos principais fluxos de mercadorias do Japão, utilizando o gabarito de curvas proporcionais e uma matriz do Planisfério equidistante centralizada no Japão. A escolha do tema foi definida para exercitar o estudo de outras projeções diferentes da tradicional visão eurocêntrica para o Planisfério.

9J3 - A proposta para a Turma 9J3 foi elaborar uma mapa ordenado dos Recursos Hídricos do Oriente Médio Per capita. Na lousa foi elaborada apenas uma tabela para acompanhamento para os alunos classificarem os dados e os procedimentos seguintes sem o acompanhamento do professor na lousa.

9J5 - A atividade de construção de mapa aplica na Turma 9J5, seguindo a proposta de trabalhar mapas quantitativos, foi elaborar a partir de uma tabela apresentada na Apostila com os cinco principais países produtores de diversos minérios no mundo, 
um mapa do Planisfério utilizando uma matriz equidistante em duplicata, centralizada no maior país produtor do recurso mineral escolhido para cada aluno pelo professor de acordo com a ordem da lista de presença da sala.

d) AGOSTO / 2011 - Avaliação cartográfica

Avaliação sem consulta realizada em agosto de 2011 com as três Turmas. As questões foram elaboradas com o objetivo de identificar a familiaridade de cada Turma com os tipos de mapas que construíram, além de apresentar pela primeira vez, um mapa do Planisfério com projeção diferente do que os alunos estão acostumados a observar, sem textos complementares para descrever os três mapas apresentados, e também identificar a memorização da Oceania (não descrito no mapa e estudado durante as aulas).

Considerando a série e a leitura cartográfica das Turmas, os mapas da China poderiam ser mais complexos para identificar os alunos com maior ou menor afinidade com mapas ordenados. Entretanto, na interpretação do mapa 01, o maior número de alunos que apresentaram boas respostas coincide com as Turmas que praticaram mapas quantitativos e dinâmicos.

e) SETEMBRO / 2011- Aula teórica sobre mapas temáticos - Exemplos de mapas do Brasil (ordenado, quantitativo, dinâmico, qualitativo e anamórfico)

Em setembro de 2011 foi elaborado um capítulo sobre "mapas temáticos". Foi fornecida para cada aluno nas três Turmas, uma folha em formato A-5 com um resumo dos conceitos, tipos e exemplos dos principais mapas temáticos utilizados em sala de aula (ordenado, quantitativo, dinâmico, qualitativo e anamórfico).

Pelo fato dos alunos já conhecerem a elaboração de um dos tipos de mapas apresentados, o resumo despertou a atenção da maioria nas três Turmas.

Em seguida foi construído um mapa ordenado da América do Sul como exercício para a avaliação no mês seguinte.

f) OUTUBRO / 2011 - Avaliação cartográfica

Avaliação sem consulta realizada em outubro de 2011 com um exercício de construção de mapa ordenado com as três Turmas, e aplicada por professores de outras disciplinas sem o acompanhamento do professor de Geografia. Na primeira 
questão, em uma das Turmas o método ordenado foi trabalhado desde o início do ano letivo. Os demais exercícios foram elaborados com o objetivo de estabelecer uma relação entre a linguagem da Cartografia Temática, sem textos complementares para os seis mapas apresentados (inclusive para o mapa a ser elaborado pelos alunos), um texto de apoio sobre o assunto abordado no período (Geografia Econômica - Guerra Fiscal), e perguntas objetivas com duas alternativas para avaliar a memorização de mapas ocultos (localização da Europa em relação ao Brasil) e o raciocínio lógico dos alunos.

Nesta avaliação, duas Turmas construíram apenas um mapa ordenado como exercício três semanas antes da avaliação, diferentemente da Turma que já tinha elaborado este tipo de mapa desde o início do ano. E mesmo sem a ajuda do professor, elaboraram sem consulta um mapa ordenado partindo da classificação dos dados até a legenda. Nas outras questões, poucos alunos apresentaram dificuldades na interpretação dos mapas, exceto na memorização do continente europeu em relação ao Brasil.

g) NOVEMBRO / 2011 - Atividade cartográfica - Grande ABC (elaboração de mapa de síntese com diversos temas em valores relativos)

Atividade de elaboração de mapas ordenados com variação de cor e/ou granulação. Embora o acabamento dos mapas tenha sido ruim (legenda, título, granulação...), a técnica de classificação de dados para mapas ordenados foi bem compreendida pelos alunos, especialmente da Turma eu mais praticou o método durante $o$ ano letivo, que concluiu o trabalho em 60 minutos. A partir da escolha de um dos quatro assuntos apresentados na matriz, os alunos escolheram três temas para a elaboração dos mapas analíticos e um de síntese a partir do cálculo dos três primeiros. Várias duplas tiveram dúvida em relação à escolha dos temas, escolhendo para o assunto "qualidade de vida", por exemplo, o tema "agências bancárias no ABC", mas não foram impedidos de suas escolhas.

$\underline{\text { Tabelas dos relatórios, avaliações e imagens das atividades }}$ 


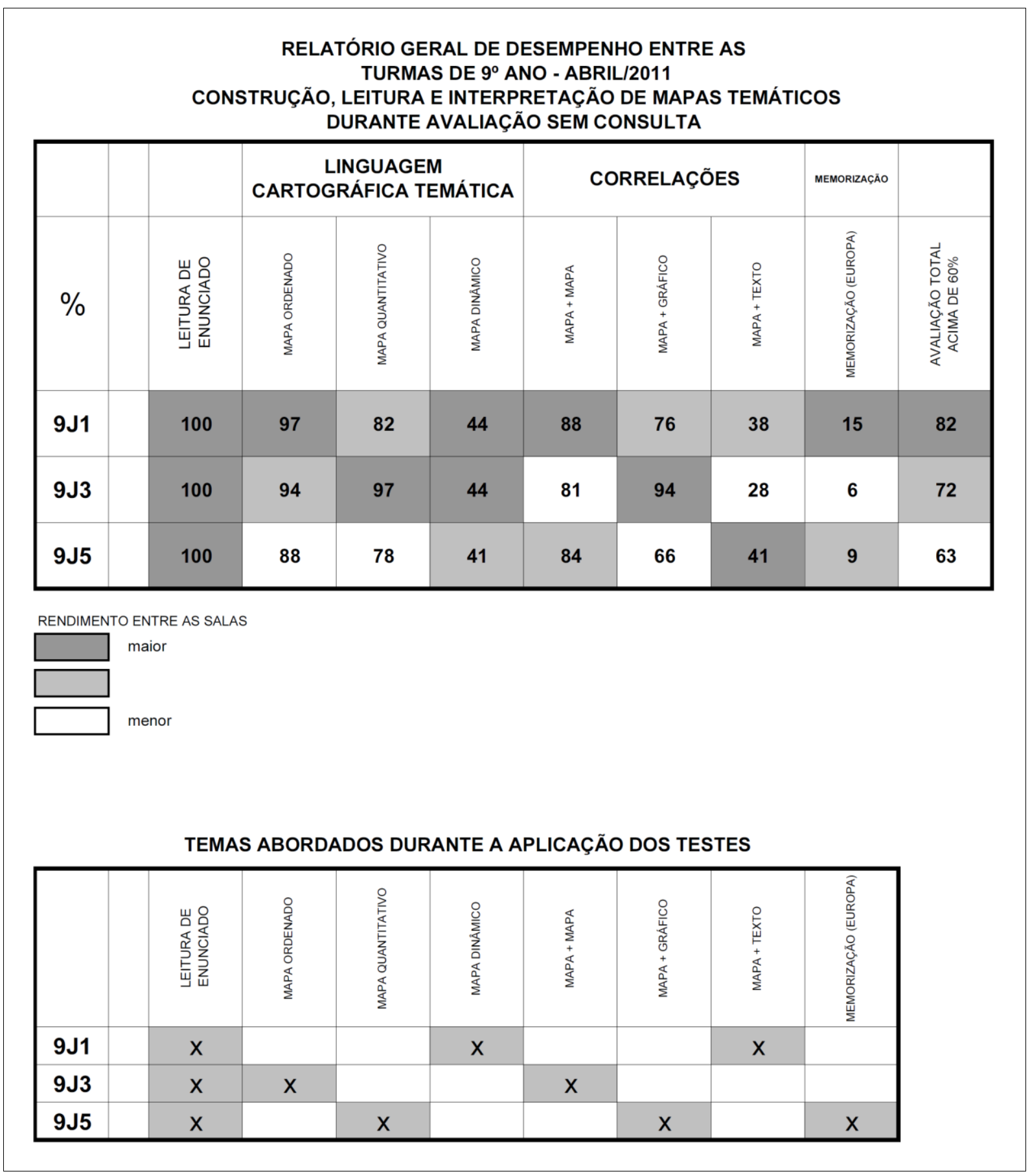

Tabela 17 - Relatório geral de abril de 2011 com resultado abaixo do esperado em relação à assimilação do tipo de mapa que cada Turma elaborou. 
RELATÓRIO DE DESEMPENHO ENTRE TURMAS COM RENDIMENTO SUPERIOR A 70\% DA AVALIAÇÃO TOTAL

( CONSTRUÇÃO, LEITURA E INTERPRETAÇÃO DE MAPAS TEMÁTICOS DURANTE AVALIAÇÃO SEM CONSULTA )

\begin{tabular}{|c|c|c|c|c|c|c|c|c|c|}
\hline \multirow[b]{2}{*}{$\%$} & \multirow[b]{2}{*}{ 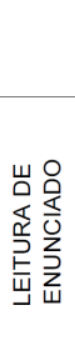 } & \multicolumn{3}{|c|}{$\begin{array}{c}\text { LINGUAGEM } \\
\text { CARTOGRÁFICA TEMÁTICA }\end{array}$} & \multicolumn{3}{|c|}{ CORRELAÇÕES } & \multirow{2}{*}{ 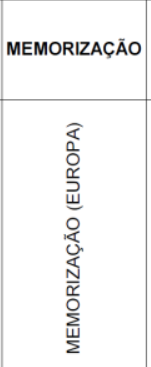 } & \multirow[b]{2}{*}{ 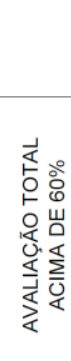 } \\
\hline & & 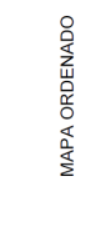 & 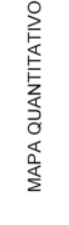 & 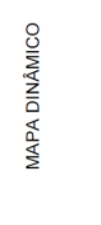 & $\begin{array}{l}\frac{\pi}{a} \\
\frac{1}{5} \\
\sum \\
+ \\
\frac{a}{a} \\
\frac{a}{2} \\
2\end{array}$ & $\begin{array}{l}0 \\
\frac{U}{u} \\
\frac{u}{d} \\
0 \\
+ \\
+ \\
\frac{d}{d} \\
\frac{d}{z}\end{array}$ & 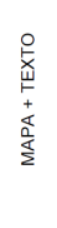 & & \\
\hline 9J1 & 100 & 97 & 90 & 46 & 97 & 82 & 40 & 18 & \\
\hline 9J3 & 100 & 100 & 100 & 50 & 90 & 95 & 32 & 10 & \\
\hline 9J5 & 100 & 90 & 90 & 60 & 95 & 90 & 60 & 15 & \\
\hline
\end{tabular}

RENDIMENTO ENTRE AS SALAS

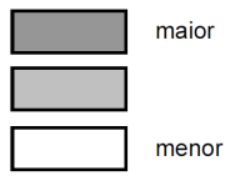

TEMAS ABORDADOS DURANTE A APLICAÇÃO DOS TESTES

\begin{tabular}{|c|c|c|c|c|c|c|c|c|}
\hline & 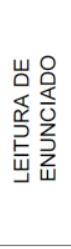 & 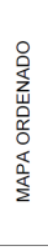 & 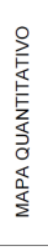 & 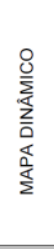 & $\begin{array}{l}\frac{a}{a} \\
\frac{a}{2} \\
+ \\
+\frac{\alpha}{\alpha} \\
\frac{a}{2} \\
\frac{1}{2}\end{array}$ & 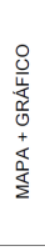 & 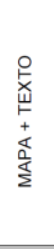 & 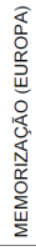 \\
\hline 9J1 & $x$ & & & $x$ & & & $x$ & \\
\hline 9J3 & $X$ & $x$ & & & $X$ & & & \\
\hline 9J5 & $x$ & & $x$ & & & $x$ & & $x$ \\
\hline
\end{tabular}

Tabela 18 - Relatório de desempenho dos alunos com rendimento superior a $70 \%$ da avaliação total da prova de Geografia entre as Turmas de 9ํㅡㄹ Ano realizadas em abril de 2011. 


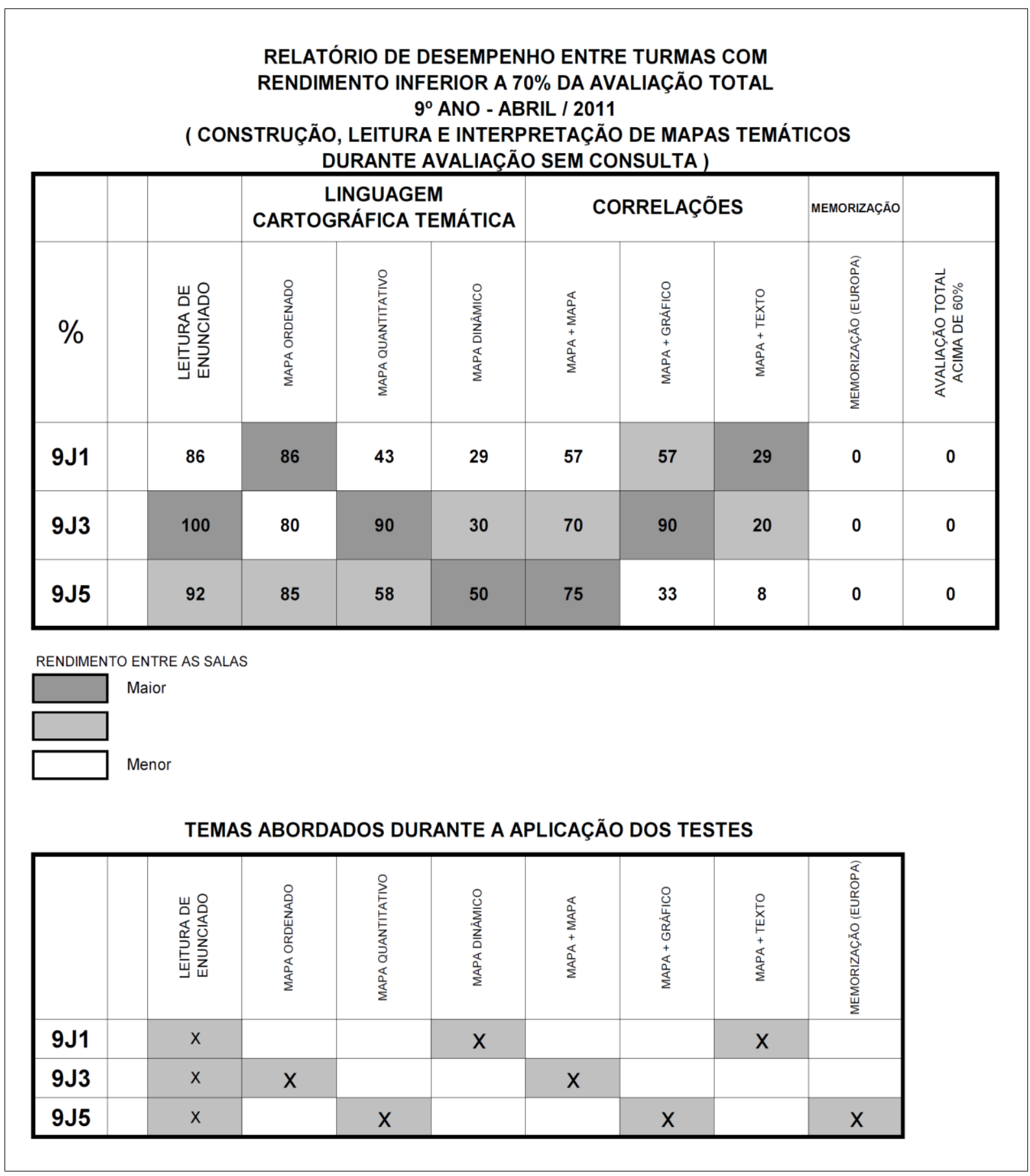

Tabela 19 - Relatório de desempenho dos alunos com rendimento inferior a $70 \%$ da avaliação entre as Turmas de 90 Ano realizadas em abril de 2011. O resultado ficou abaixo do esperado, quando comparado aos Temas abordados em cada Turma durante a aplicação dos testes. 


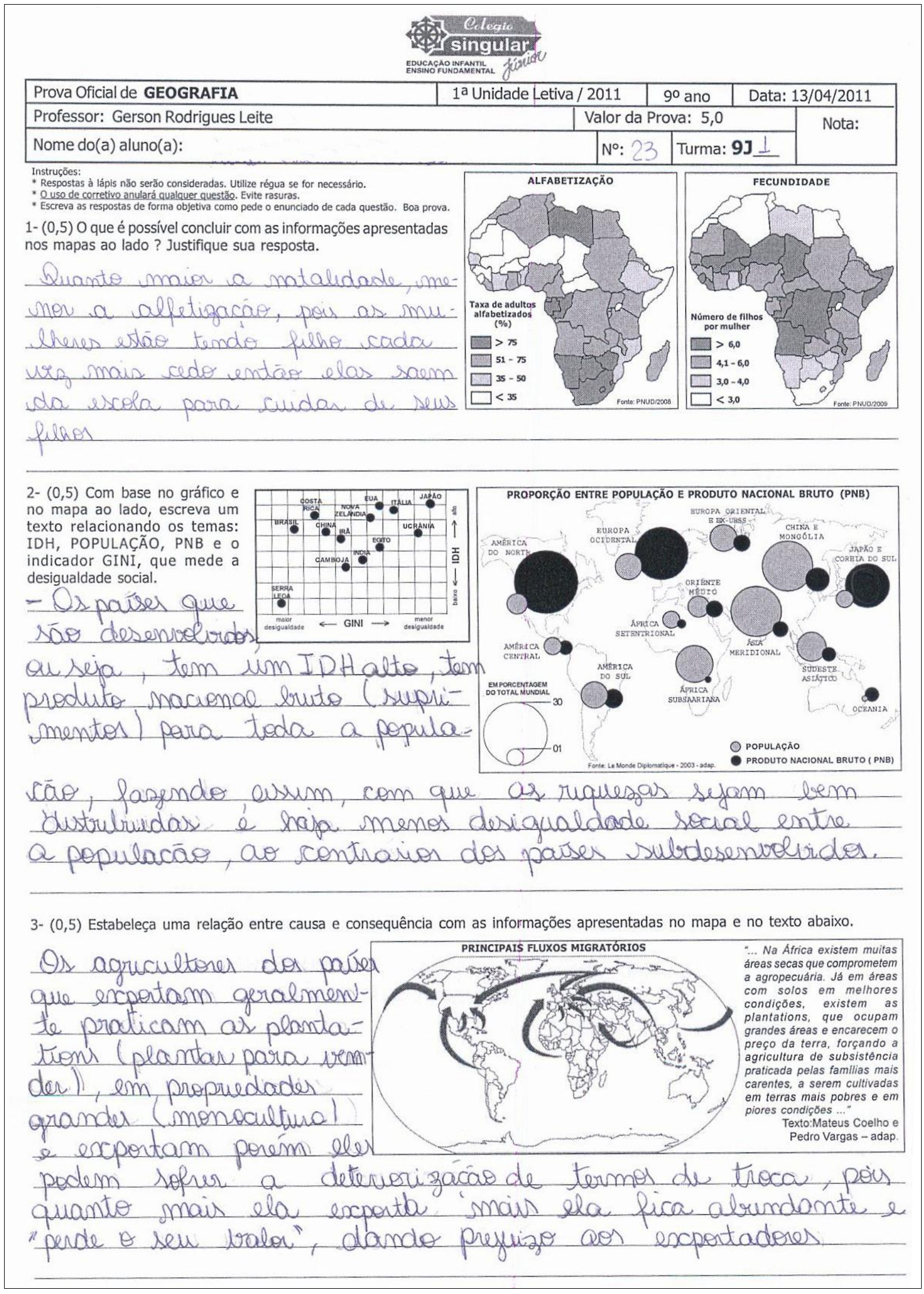

Figura 47 - Avaliação sem consulta realizada em abril de 2011 com as três Turmas. Em cada uma delas foi realizada uma atividade prática de construção de mapa temático com métodos diferentes (ordenado, quantitativo e dinâmico). 


\begin{tabular}{|c|c|c|c|c|c|c|c|c|c|c|}
\hline \multicolumn{11}{|c|}{$\begin{array}{c}\text { RELATÓRIO } 9^{\circ} \text { ANO ABRIL/2011 - COLÉGIO SINGULAR - 9J1 } \\
\text { CONSTRUÇÃO, LEITURA E INTERPRETAÇÃO DE MAPAS TEMATICOS DURANTE } \\
\text { AVALIAÇĀO SEM CONSULTA }\end{array}$} \\
\hline & TURMA - 9J1 & \multirow[b]{2}{*}{$\begin{array}{l}\text { 岁是 } \\
\text { 京 } \\
\text { 点总 } \\
\text { 总 }\end{array}$} & \multicolumn{3}{|c|}{$\begin{array}{l}\text { LINGUAGEM CARTOGRAFICA } \\
\text { TEMATICA }\end{array}$} & \multicolumn{3}{|c|}{ CORRELAÇŌES } & \multirow[b]{2}{*}{ 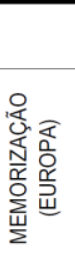 } & \multirow[b]{2}{*}{ 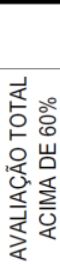 } \\
\hline & NOME & & 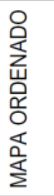 & 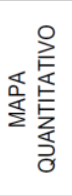 & 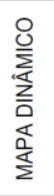 & 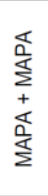 & $\begin{array}{l}\text { O } \\
\frac{0}{4} \\
\text { 离 } \\
0 \\
+ \\
+\frac{d}{0} \\
\frac{1}{2}\end{array}$ & 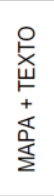 & & \\
\hline 1 & A.S.A. & $x$ & $x$ & $x$ & & $x$ & $x$ & & & $x$ \\
\hline 2 & A.C.S.R. & $x$ & $x$ & & $x$ & $x$ & & $x$ & & \\
\hline 3 & A.E.A.F. & $x$ & $x$ & & & $x$ & & & & $x$ \\
\hline 4 & A.H.O. & $x$ & $x$ & $x$ & & $x$ & $x$ & & & $x$ \\
\hline 5 & B.K.C. & $x$ & $x$ & $x$ & & $x$ & $x$ & & & $x$ \\
\hline 6 & B.S.A.U. & $x$ & $x$ & $x$ & $x$ & $x$ & $x$ & $x$ & $x$ & $x$ \\
\hline 7 & C.F.A.S. & $x$ & $x$ & $x$ & $x$ & $x$ & $x$ & $x$ & & $x$ \\
\hline 8 & C.A.V. & $x$ & $x$ & $x$ & $x$ & $x$ & $x$ & $x$ & & $x$ \\
\hline 9 & F.H.D.F. & $x$ & $x$ & $x$ & & $x$ & $x$ & & & $x$ \\
\hline 10 & F.L.C. & $x$ & $x$ & $x$ & & $x$ & $x$ & & & \\
\hline 11 & G.Q.P.B. & $x$ & $x$ & $x$ & $x$ & $x$ & & & & $x$ \\
\hline 12 & G.A. & $x$ & $x$ & $x$ & $x$ & $x$ & $x$ & $x$ & & \\
\hline 13 & G.P.F. & $x$ & $x$ & $x$ & & $x$ & $x$ & & & $x$ \\
\hline 14 & G.P.R. & $x$ & & $x$ & & & $x$ & & & $x$ \\
\hline 15 & G.C.N. & $x$ & $x$ & $x$ & $x$ & $x$ & $x$ & $x$ & & $x$ \\
\hline 16 & J.M.F. & $x$ & $x$ & $x$ & $x$ & $x$ & $x$ & $x$ & & $x$ \\
\hline 17 & J.C.O.D. & $x$ & $x$ & $x$ & $x$ & $x$ & $x$ & $x$ & $x$ & $x$ \\
\hline 18 & J.T.M. & $x$ & $x$ & $x$ & $x$ & & $x$ & $x$ & $x$ & $x$ \\
\hline 19 & J.P.L.F. & $x$ & $x$ & & & & & & & \\
\hline 20 & J.P.R.Z. & $x$ & $x$ & $x$ & & $x$ & $x$ & & & $x$ \\
\hline 21 & J.H.O. & $x$ & $x$ & $x$ & & $x$ & $x$ & & & $x$ \\
\hline 22 & J.N.T. & $x$ & $x$ & $x$ & & $x$ & $x$ & & & $x$ \\
\hline 23 & L.S.P. & $x$ & $x$ & $x$ & & & $x$ & & & $x$ \\
\hline 24 & L.E.B. & $x$ & $x$ & $x$ & & $x$ & $x$ & & & \\
\hline 25 & L.G.R.M. & $x$ & $x$ & $x$ & & $x$ & & & & $x$ \\
\hline 26 & M.A.M. & $x$ & $x$ & $x$ & $x$ & $x$ & $x$ & $x$ & $x$ & $x$ \\
\hline 27 & P.A.N. & $x$ & $x$ & $x$ & $x$ & $x$ & $\mathrm{x}$ & $\mathrm{x}$ & & $\mathrm{x}$ \\
\hline 28 & P.H.F.Z. & $x$ & $x$ & & & $x$ & & & & $x$ \\
\hline 29 & R.G.L. & $\mathrm{x}$ & $\mathrm{x}$ & & $\mathrm{x}$ & $x$ & & & & $\mathrm{x}$ \\
\hline 30 & T.A.C. & $\mathrm{x}$ & $x$ & $x$ & & $x$ & $x$ & & & $x$ \\
\hline 31 & V.L.S. & $\mathrm{x}$ & $\mathrm{x}$ & $\mathrm{x}$ & $\mathrm{x}$ & $x$ & $x$ & $x$ & & $x$ \\
\hline 32 & V.L.B.F. & $x$ & $x$ & $\mathrm{x}$ & & $x$ & $x$ & & & $x$ \\
\hline 33 & V.R. & $\mathrm{x}$ & $\mathrm{x}$ & & & $x$ & & & & \\
\hline 34 & V.S.T. & $x$ & $x$ & $\mathrm{x}$ & $x$ & $\mathrm{x}$ & $x$ & $\mathrm{x}$ & $x$ & $\mathrm{x}$ \\
\hline RES & POSTAS - TOTAL - 34 & 34 & 33 & 28 & 15 & 30 & 26 & 13 & 5 & 28 \\
\hline RES & POSTAS - \% & 100 & 97 & 82 & 44 & 88 & 76 & 38 & 15 & 82 \\
\hline
\end{tabular}

Tabela 20 - Relatório individual de leitura cartográfica da Turma 9J1 com os temas abordados na avaliação de abril de 2011. 


\begin{tabular}{|c|c|c|c|c|c|c|c|c|c|c|}
\hline \multicolumn{11}{|c|}{$\begin{array}{c}\text { RELATÓRIO } 9^{\circ} \text { ANO ABRIL/2011 - COLÉGIO SINGULAR - 9J3 } \\
\text { CONSTRUÇÃO, LEITURA E INTERPRETAÇÃO DE MAPAS TEMÁTICOS DURANTE } \\
\text { AVALIAÇÃO SEM CONSULTA }\end{array}$} \\
\hline & TURMA - 9J3 & & \multicolumn{3}{|c|}{$\begin{array}{l}\text { LINGUAGEM CARTOGRÁFICA } \\
\text { TEMÁTICA }\end{array}$} & \multicolumn{3}{|c|}{ CORRELAÇŌES } & \multirow[b]{2}{*}{ 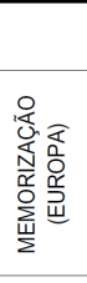 } & \multirow[b]{2}{*}{ 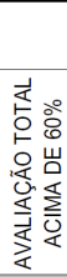 } \\
\hline & NOME & 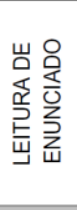 & 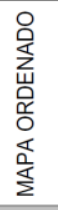 & 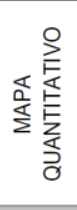 & 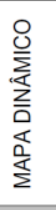 & 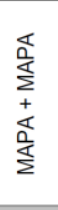 & 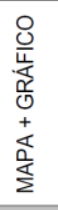 & 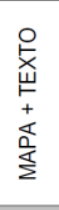 & & \\
\hline 1 & A.C.F. & $x$ & $x$ & $x$ & $x$ & $x$ & $x$ & $x$ & & $x$ \\
\hline 2 & A.C.M. & $x$ & $x$ & $x$ & & $x$ & $x$ & & & $x$ \\
\hline 3 & A.C.A.R. & $x$ & $\mathrm{X}$ & $x$ & & $\mathrm{X}$ & $X$ & & & $x$ \\
\hline 4 & B.B. & $x$ & $x$ & $x$ & $x$ & $x$ & $x$ & $x$ & & $x$ \\
\hline 5 & B.L.C. & $x$ & $x$ & $x$ & $x$ & $x$ & $x$ & $x$ & & $x$ \\
\hline 6 & B.R.C. & $x$ & $x$ & $x$ & $x$ & $x$ & $x$ & & & \\
\hline 7 & C.F.B. & $x$ & $x$ & $x$ & $x$ & $x$ & $x$ & & & $x$ \\
\hline 8 & D.A.F.C. & $x$ & $x$ & & & $x$ & & & & \\
\hline 9 & D.F.P. & $x$ & $x$ & $x$ & $x$ & $x$ & $x$ & $x$ & & $x$ \\
\hline 10 & D.V. & $x$ & $x$ & $x$ & & $x$ & & & & $x$ \\
\hline 11 & G.C.G. & $x$ & $x$ & $x$ & $x$ & $x$ & $x$ & $x$ & & $x$ \\
\hline 12 & G.R.N. & $x$ & $x$ & $x$ & $x$ & $x$ & $x$ & $x$ & & \\
\hline 13 & H.C.F. & $x$ & $x$ & $x$ & $x$ & $x$ & $x$ & & & $x$ \\
\hline 14 & I.M.A. & $x$ & $x$ & $x$ & & $x$ & $\mathrm{X}$ & & & \\
\hline 15 & I.C.R.P. & $x$ & $x$ & $x$ & $x$ & $x$ & $x$ & & & $x$ \\
\hline 16 & J.T.M. & $x$ & $x$ & $x$ & & $x$ & $x$ & & & $x$ \\
\hline 17 & L.F.R.T. & $x$ & $x$ & $x$ & $x$ & $x$ & $x$ & $x$ & & $x$ \\
\hline 18 & G.S.A. & $x$ & $x$ & $x$ & & $x$ & $x$ & & & $x$ \\
\hline 19 & L.H.M.M. & $x$ & $x$ & $x$ & $\mathrm{x}$ & & $x$ & & & $x$ \\
\hline 20 & M.A.R. & $x$ & $x$ & $x$ & & $x$ & $X$ & & & \\
\hline 21 & M.R.C. & $x$ & $\mathrm{x}$ & $x$ & $\mathrm{x}$ & & $x$ & $x$ & $\mathrm{x}$ & $\mathrm{x}$ \\
\hline 22 & M.E.O. & $x$ & $x$ & $x$ & & & $x$ & & & \\
\hline 23 & P.H.P.B. & $x$ & $x$ & $x$ & & $x$ & $x$ & & & $x$ \\
\hline 24 & R.J.S.B. & $x$ & & $x$ & & & $x$ & & & \\
\hline 25 & T.C.N. & $x$ & & $x$ & & & $x$ & & & \\
\hline 26 & V.R. & $x$ & $x$ & $x$ & & $x$ & $x$ & & & $x$ \\
\hline 27 & V.V.S. & $x$ & $\mathrm{X}$ & $x$ & & $x$ & $x$ & & & $\mathrm{X}$ \\
\hline 28 & V.A.B. & $x$ & $x$ & $x$ & & $x$ & $x$ & & & $x$ \\
\hline 29 & V.M.S.O. & $x$ & $x$ & $x$ & & $x$ & $x$ & & & $x$ \\
\hline 30 & V.S.G. & $x$ & $x$ & $x$ & & $\mathrm{X}$ & $x$ & & & $x$ \\
\hline 31 & Y.E.P.B. & $x$ & $x$ & $\mathrm{X}$ & $\mathrm{x}$ & & $x$ & $x$ & $x$ & $x$ \\
\hline 32 & Y.E.P.B. & $x$ & $x$ & $x$ & & $x$ & $x$ & & & \\
\hline \multicolumn{2}{|c|}{ RESPOSTAS - TOTAL- 32} & 32 & 30 & 31 & 14 & 26 & 30 & 9 & 2 & 23 \\
\hline \multicolumn{2}{|c|}{ RESPOSTAS - \% } & 100 & 94 & 97 & 44 & 81 & 94 & 28 & 6 & 72 \\
\hline
\end{tabular}

Tabela 21 - Relatório individual de leitura cartográfica da Turma 9J3 com os temas abordados na avaliação de abril de 2011. 


\begin{tabular}{|c|c|c|c|c|c|c|c|c|c|c|}
\hline \multicolumn{11}{|c|}{$\begin{array}{l}\text { RELATÓRIO } 9^{\circ} \text { ANO ABRIL/2011 - COLÉGIO SINGULAR - 9J5 } \\
\text { CONSTRUÇĀOO, LEITURA E INTERPRETAÇÃOO DE MAPAS TEMATICOS DURANTE } \\
\text { AVALIAÇẤO SEM CONSULTA }\end{array}$} \\
\hline & TURMA - 9J5 & \multirow[b]{2}{*}{ 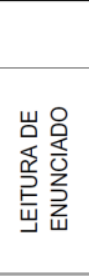 } & \multicolumn{3}{|c|}{$\begin{array}{l}\text { LINGUAGEM CARTOGRAFICA } \\
\text { TEMATICA }\end{array}$} & \multicolumn{3}{|c|}{ CORRELAÇŌES } & \multirow[b]{2}{*}{ 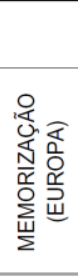 } & \multirow[b]{2}{*}{ 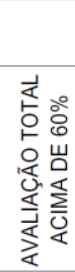 } \\
\hline & NOME & & 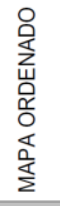 & 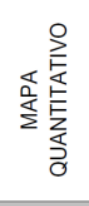 & 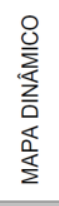 & $\begin{array}{l}\frac{x}{0} \\
\frac{1}{2} \\
+ \\
\frac{d}{0} \\
\frac{0}{2}\end{array}$ & 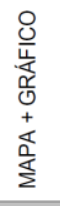 & $\begin{array}{l}\stackrel{0}{x} \\
\stackrel{x}{\uplus} \\
+ \\
+\frac{\pi}{a} \\
\frac{a}{2} \\
\frac{a}{2}\end{array}$ & & \\
\hline 1 & A.R.O.D. & $x$ & $x$ & $x$ & $x$ & $x$ & $x$ & $x$ & $x$ & $x$ \\
\hline 2 & A.V.B. & $x$ & $x$ & & & $x$ & & & & \\
\hline 3 & B.R.V. & $x$ & $x$ & $x$ & & $x$ & $x$ & & & $x$ \\
\hline 4 & C.C.H. & $x$ & $x$ & $x$ & $x$ & & & & & \\
\hline 5 & C.O.M. & $x$ & $x$ & & & $x$ & & & & $x$ \\
\hline 6 & E.F.B. & $x$ & $x$ & $x$ & & $\mathrm{x}$ & $x$ & & & $\mathrm{x}$ \\
\hline 7 & Fa.P. & $x$ & $x$ & $x$ & & $x$ & $x$ & & & $x$ \\
\hline 8 & G.M.G. & $x$ & & $x$ & & & & & & \\
\hline 9 & G.A.S. & $x$ & $x$ & $x$ & & $x$ & $x$ & & & \\
\hline 10 & G.T. & $x$ & $x$ & $x$ & $x$ & $x$ & $x$ & $x$ & & $x$ \\
\hline 11 & G.F.S. & $x$ & $x$ & $x$ & & $x$ & $x$ & & & $x$ \\
\hline 12 & H.B.S. & $x$ & $x$ & & & & & & & \\
\hline 13 & I.M.A. & $x$ & $x$ & $x$ & $x$ & $x$ & $x$ & $x$ & & $x$ \\
\hline 14 & J.V.B.L. & $x$ & $x$ & $x$ & $x$ & $x$ & $x$ & $x$ & $x$ & $x$ \\
\hline 15 & J.H.R.A. & $x$ & $x$ & $x$ & $x$ & $x$ & $x$ & $x$ & & $x$ \\
\hline 16 & L.L.P.S. & $x$ & & $x$ & $x$ & & $x$ & $x$ & & $x$ \\
\hline 17 & L.M.S. & $x$ & $x$ & $x$ & & $x$ & $x$ & & & \\
\hline 18 & M.C.D.C. & $x$ & & $x$ & & & $x$ & & & \\
\hline 19 & M.P.G. & $x$ & $x$ & $x$ & $x$ & $x$ & $x$ & $x$ & & $x$ \\
\hline 20 & M.C.C. & $x$ & $x$ & $x$ & $x$ & $x$ & $x$ & $x$ & & $x$ \\
\hline 21 & M.C.S. & $x$ & $x$ & & & $x$ & & & & $x$ \\
\hline 22 & P.A.V. & $x$ & $x$ & $x$ & $x$ & $x$ & $x$ & $x$ & & $x$ \\
\hline 23 & R.M.B. & $x$ & $x$ & & & $x$ & & & & \\
\hline 24 & R.M.C. & $x$ & $x$ & & & $x$ & & & & \\
\hline 25 & S.A.D.R.F. & $x$ & $x$ & $x$ & $x$ & $x$ & & $x$ & & \\
\hline 26 & T.M.T. & $x$ & $x$ & $x$ & & $x$ & $x$ & & & \\
\hline 27 & T.M.S. & $x$ & $x$ & & & $x$ & & & & \\
\hline 28 & V.H.O. & $x$ & $x$ & $x$ & & $x$ & $x$ & & & $x$ \\
\hline 29 & V.M.M. & $x$ & $x$ & $x$ & & $\mathrm{x}$ & $x$ & & & $\mathrm{x}$ \\
\hline 30 & V.A.O. & $x$ & & $x$ & $\mathrm{x}$ & $x$ & $x$ & $x$ & & $x$ \\
\hline 31 & Y.Y. & $x$ & $\mathrm{x}$ & $x$ & $\mathrm{x}$ & $x$ & $\mathrm{x}$ & $x$ & & $\mathrm{x}$ \\
\hline 32 & G.S.R. & $\mathrm{x}$ & $\mathrm{x}$ & $\mathrm{x}$ & & $x$ & & $x$ & $x$ & $\mathrm{x}$ \\
\hline RES & POSTAS - TOTAL - 32 & 32 & 28 & 25 & 13 & 27 & 21 & 13 & 3 & 20 \\
\hline RES & SPOSTAS - \% & 100 & 88 & 78 & 41 & 84 & 66 & 41 & 9 & 63 \\
\hline
\end{tabular}

Tabela 22 - Relatório individual de leitura cartográfica da Turma 9J5 com os temas abordados na avaliação de abril de 2011. 


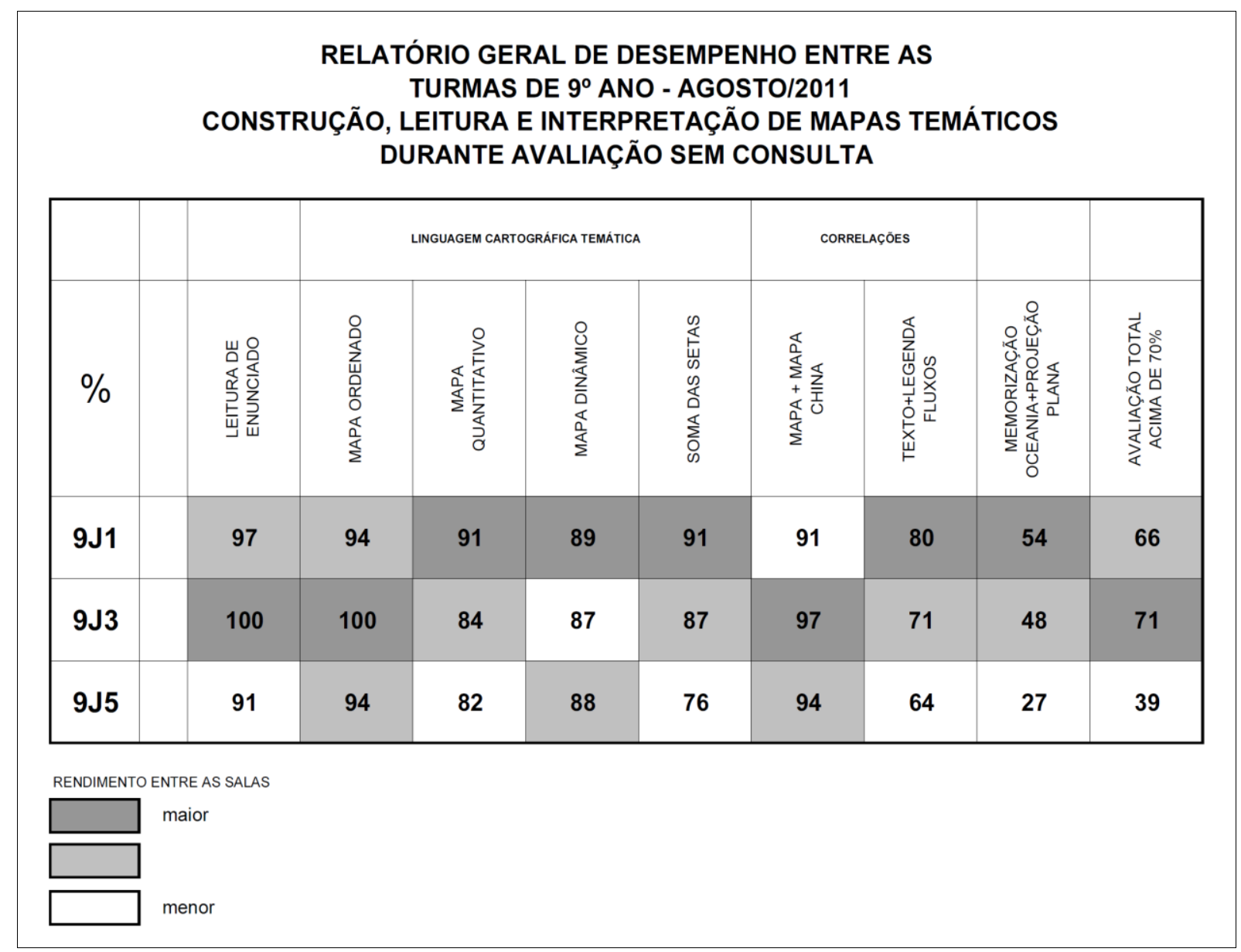

\begin{tabular}{|c|c|c|c|c|c|c|c|c|c|}
\hline \multicolumn{10}{|c|}{ TEMAS ABORDADOS DURANTE A APLICAÇÃO DOS TESTES } \\
\hline & 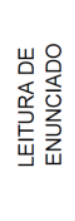 & 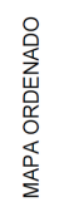 & 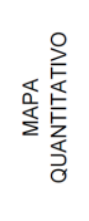 & 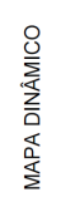 & 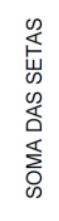 & 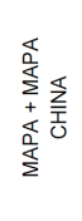 & 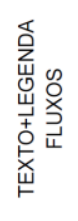 & 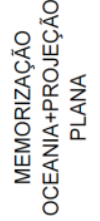 & 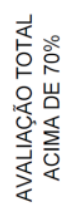 \\
\hline 9J1 & $\mathrm{X}$ & & & $\mathrm{X}$ & & & $\mathrm{X}$ & & \\
\hline $9 \mathrm{~J} 3$ & $\mathrm{X}$ & $\mathrm{X}$ & & & & $\mathrm{X}$ & & & \\
\hline 9J5 & $\mathrm{X}$ & & X & & & & & $\mathrm{X}$ & \\
\hline
\end{tabular}

Tabela 23 - Relatório geral de desempenho das atividades realizadas em agosto de 2011. A assimilação de alguns temas das questões coincide com os tipos de mapas elaborados por cada Turma. 


\begin{tabular}{|c|c|c|c|c|c|c|c|c|c|}
\hline \multicolumn{10}{|c|}{$\begin{array}{c}\text { RELATÓRIO DE DESEMPENHO ENTRE TURMAS COM } \\
\text { RENDIMENTO SUPERIOR A 70\% DA AVALIACCÃO TOTAL } \\
\begin{array}{c}\text { ( CONSTRUÇÃO, LEITURA E INTERPRETAÇÃO DE MAPAS TEMÁTICOS } \\
\text { DURANTE AVALIAÇÃO SEM CONSULTA ) }\end{array}\end{array}$} \\
\hline \multirow[b]{2}{*}{$\%$} & & \multicolumn{4}{|c|}{ LINGUAGEM CARTOGRAFICA TEMÄTICA } & \multicolumn{2}{|c|}{ CoRrELAÇOEES } & \multirow[b]{2}{*}{ 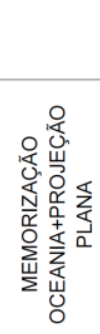 } & \multirow[b]{2}{*}{ 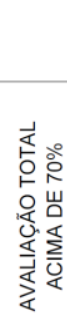 } \\
\hline & 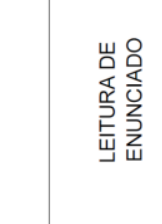 & 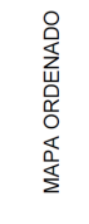 & 变 & 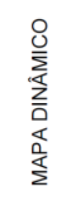 & 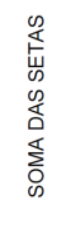 & 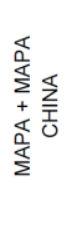 & 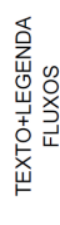 & & \\
\hline 9J1 & 100 & 95 & 95 & 91 & 91 & 91 & 82 & 68 & 100 \\
\hline 9J3 & 100 & 100 & 95 & 100 & 100 & 95 & 82 & 55 & 100 \\
\hline 9J5 & 100 & 100 & 92 & 92 & 85 & 100 & 85 & 38 & 100 \\
\hline \multicolumn{10}{|c|}{ RENDIMENTO ENTRE AS SALAS } \\
\hline & menor & & & & & & & & \\
\hline
\end{tabular}

\begin{tabular}{|c|c|c|c|c|c|c|c|c|c|}
\hline \multicolumn{10}{|c|}{ TEMAS ABORDADOS DURANTE A APLICAÇÃO DOS TESTES } \\
\hline & 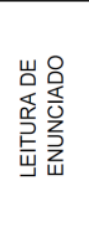 & 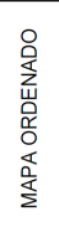 & 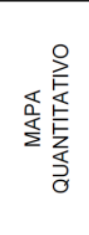 & 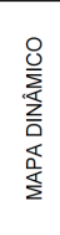 & 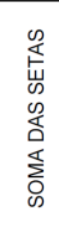 & 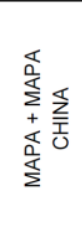 & 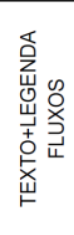 & 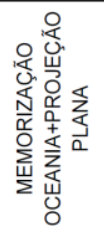 & 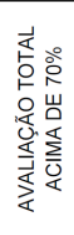 \\
\hline 9J1 & $\mathrm{X}$ & & & $X$ & & & $\mathrm{X}$ & & \\
\hline $9 \mathrm{~J} 3$ & $\mathrm{X}$ & X & & & & X & & & \\
\hline 9J5 & $\mathrm{X}$ & & $\mathrm{X}$ & & & & & $\mathrm{X}$ & \\
\hline
\end{tabular}

Tabela 24 - Relatório de desempenho dos alunos com rendimento superior a 70\% da avaliação total da prova de Geografia entre as Turmas de 9ํㅡㄹ Ano realizadas em agosto de 2011. 


\begin{tabular}{|c|c|c|c|c|c|c|c|c|c|}
\hline \multicolumn{10}{|c|}{$\begin{array}{c}\text { RELATÓRIO DE DESEMPENHO ENTRE TURMAS COM } \\
\text { RENDIMENTO INFERIOR A 70\% DA AVALIACÃO TOTAL } \\
\\
\text { ( CONSTRUÇÃO, LEITURA E INTERPRETAÇÃO DE MAPAS TEMÁTICOS } \\
\text { DURANTE AVALIAÇÃO SEM CONSULTA) }\end{array}$} \\
\hline \multirow[b]{2}{*}{$\%$} & \multirow[b]{2}{*}{ 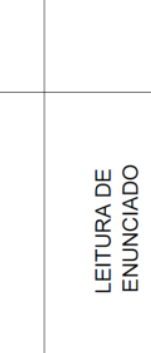 } & \multicolumn{4}{|c|}{ LINGUAGEM CARTOGRÁFICA TEMATTICA } & \multicolumn{2}{|c|}{ CORRELAÇŌES } & \multirow[b]{2}{*}{ 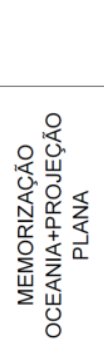 } & \multirow[b]{2}{*}{ 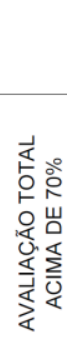 } \\
\hline & & 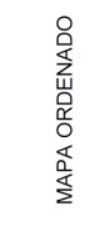 & 章 & 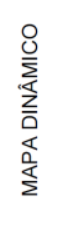 & 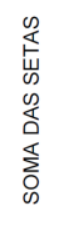 & 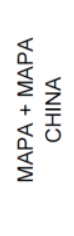 & 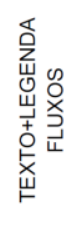 & & \\
\hline 9J1 & 92 & 92 & 85 & 85 & 92 & 92 & 77 & 23 & 0 \\
\hline $9 \mathrm{~J} 3$ & 100 & 100 & 56 & 56 & 56 & 100 & 44 & 22 & 0 \\
\hline 9J5 & 85 & 90 & 75 & 80 & 70 & 90 & 50 & 20 & 0 \\
\hline \multicolumn{10}{|c|}{ RENDIMENTO ENTRE AS SALAS } \\
\hline & \multicolumn{9}{|l|}{ maior } \\
\hline & \multicolumn{9}{|l|}{ menor } \\
\hline
\end{tabular}

\begin{tabular}{|c|c|c|c|c|c|c|c|c|c|}
\hline \multicolumn{10}{|c|}{ TEMAS ABORDADOS DURANTE A APLICAÇÃO DOS TESTES } \\
\hline & 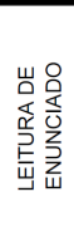 & 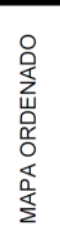 & 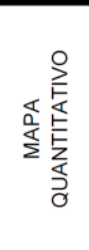 & 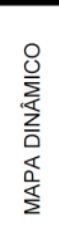 & 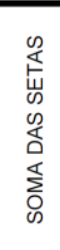 & 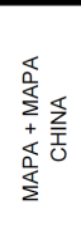 & 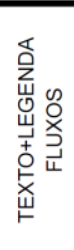 & 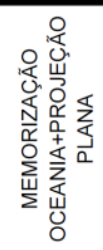 & 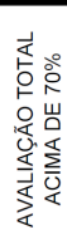 \\
\hline 9J1 & $\mathrm{X}$ & & & $\mathrm{X}$ & & & $\mathrm{X}$ & & \\
\hline $9 \mathrm{~J} 3$ & $X$ & $X$ & & & & $X$ & & & \\
\hline $9 \mathrm{~J} 5$ & $\mathrm{X}$ & & $\mathrm{X}$ & & & & & $X$ & \\
\hline
\end{tabular}

Tabela 25 - Relatório de desempenho dos alunos com rendimento inferior a 70\% das atividades de agosto de 2011. Resultados satisfatórios de leitura e interpretação de mapas que cada aluno construiu. 


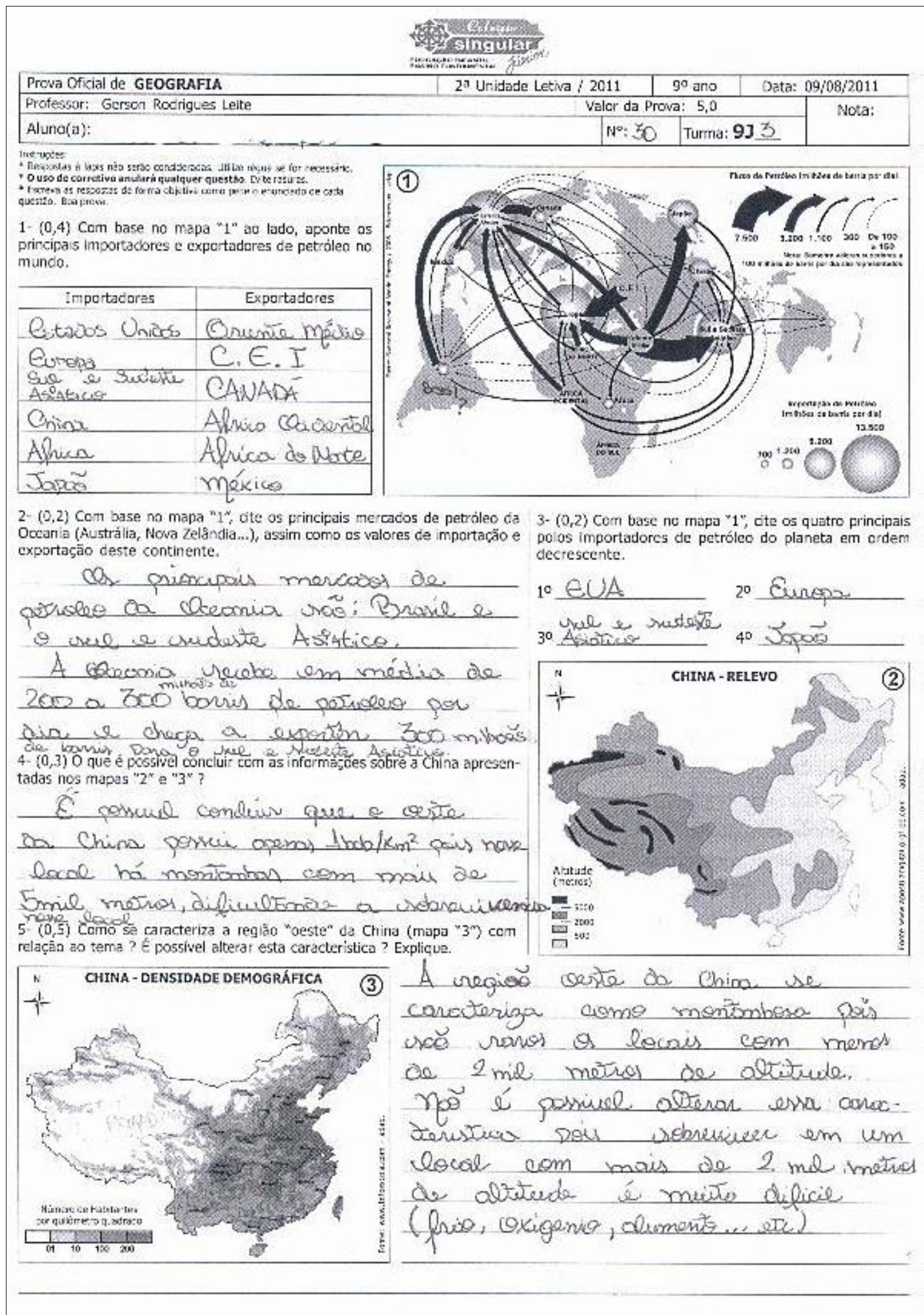

Figura 48 - Avaliação sem consulta realizada em agosto de 2011 com as três Turmas. Em cada uma delas também foi aplicada outra atividade prática de construção de mapa temático com métodos diferentes (ordenado, quantitativo e dinâmico) para as mesmas Turmas. 


\begin{tabular}{|c|c|c|c|c|c|c|c|c|c|c|}
\hline \multicolumn{11}{|c|}{$\begin{array}{c}\text { RELATÓRIO } 9^{\circ} \text { ANO AGOSTO/2011 - COLÉGIO SINGULAR - 9J1 } \\
\text { CONSTRUÇÃO, LEITURA E INTERPRETAÇÃO DE MAPAS TEMÁTICOS } \\
\text { DURANTE AVALIAÇÃO SEM CONSULTA }\end{array}$} \\
\hline & TURMA - 9J1 & \multirow[b]{2}{*}{ 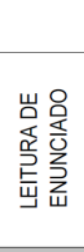 } & \multicolumn{4}{|c|}{ LINGUAGEM CARTOGRÁFICA TEMÁTICA } & \multicolumn{2}{|c|}{ CORRELAÇŌES } & \multirow[b]{2}{*}{ 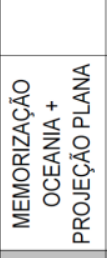 } & \multirow[b]{2}{*}{ 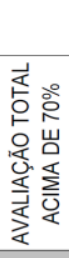 } \\
\hline & NOME & & 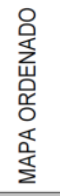 & 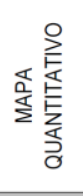 & 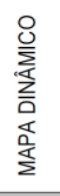 & 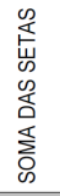 & 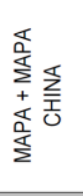 & 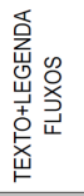 & & \\
\hline 1 & A.S.A. & $\mathrm{x}$ & $\mathrm{x}$ & $\mathrm{x}$ & $\mathrm{x}$ & $\mathrm{x}$ & $\mathrm{x}$ & $\mathrm{x}$ & $\mathrm{x}$ & $\mathrm{x}$ \\
\hline 2 & A.C.S.R. & $\mathrm{x}$ & $\mathrm{x}$ & $\mathrm{x}$ & $\mathrm{x}$ & $\mathrm{x}$ & $\mathrm{x}$ & $\mathrm{x}$ & & \\
\hline 3 & A.E.A.F. & $\mathrm{x}$ & $\mathrm{x}$ & $\mathrm{x}$ & $\mathrm{x}$ & $\mathrm{x}$ & $\mathrm{x}$ & $\mathrm{x}$ & $\mathrm{x}$ & $\mathrm{x}$ \\
\hline 4 & A.S.G. & $x$ & $x$ & $x$ & $x$ & $x$ & $x$ & $x$ & $x$ & $x$ \\
\hline 5 & A.H.O. & $\mathrm{x}$ & $\mathrm{x}$ & $\mathrm{x}$ & $\mathrm{x}$ & $\mathrm{x}$ & $\mathrm{x}$ & $\mathrm{x}$ & $\mathrm{x}$ & $\mathrm{x}$ \\
\hline 6 & B.K.C. & $\mathrm{x}$ & $\mathrm{x}$ & $\mathrm{x}$ & $\mathrm{x}$ & $\mathrm{x}$ & $x$ & $\mathrm{x}$ & $\mathrm{x}$ & $\mathrm{x}$ \\
\hline 7 & B.S.A.U. & $x$ & $x$ & $x$ & $x$ & $x$ & $x$ & $x$ & $x$ & $x$ \\
\hline 8 & C.F.A.S. & $\mathrm{x}$ & & $\mathrm{x}$ & $x$ & $x$ & & $x$ & & \\
\hline 9 & C.A.V. & $\mathrm{x}$ & & $x$ & $\mathrm{x}$ & $\mathrm{x}$ & & $\mathrm{x}$ & & $x$ \\
\hline 10 & F.H.D.F. & $x$ & $\mathrm{x}$ & $x$ & $x$ & $x$ & $x$ & $x$ & $x$ & \\
\hline 11 & F.L.C. & $x$ & $x$ & $x$ & $x$ & $x$ & $x$ & $x$ & & \\
\hline 12 & G.Q.P.B. & $\mathrm{x}$ & $\mathrm{x}$ & $\mathrm{x}$ & $\mathrm{x}$ & $\mathrm{x}$ & $\mathrm{x}$ & $x$ & & \\
\hline 13 & G.A. & $x$ & $x$ & $x$ & $x$ & $x$ & $x$ & $x$ & $x$ & $x$ \\
\hline 14 & G.P.F. & $x$ & $x$ & $x$ & $x$ & $x$ & $x$ & $x$ & & \\
\hline 15 & G.P.R. & $x$ & $x$ & $x$ & $x$ & $x$ & $x$ & $x$ & $x$ & $x$ \\
\hline 16 & G.C.N. & $\mathrm{x}$ & $\mathrm{x}$ & $\mathrm{x}$ & $\mathrm{x}$ & $\mathrm{x}$ & $\mathrm{x}$ & $\mathrm{x}$ & $\mathrm{x}$ & $\mathrm{x}$ \\
\hline 17 & J.M.F. & $x$ & $x$ & & & $x$ & $x$ & $x$ & $x$ & \\
\hline 18 & J.C.O.D. & $x$ & $x$ & $x$ & $x$ & $x$ & $x$ & $x$ & & $x$ \\
\hline 19 & J.T.M. & $x$ & $x$ & $x$ & $x$ & $x$ & $x$ & $x$ & & \\
\hline 20 & J.P.L.F. & $\mathrm{x}$ & $x$ & $x$ & $\mathrm{x}$ & $\mathrm{x}$ & $x$ & $\mathrm{x}$ & $\mathrm{x}$ & $\mathrm{x}$ \\
\hline 21 & J.P.R.Z. & & $x$ & & & & $x$ & & & \\
\hline 22 & J.H.O. & $x$ & $x$ & $x$ & $x$ & $x$ & $x$ & $x$ & & $x$ \\
\hline 23 & J.N.T. & $x$ & $x$ & & & & $x$ & & & $x$ \\
\hline 24 & L.S.P. & $x$ & $x$ & $x$ & $x$ & $x$ & $x$ & $x$ & & \\
\hline 25 & L.E.B. & $x$ & $x$ & $x$ & & & $x$ & & & $x$ \\
\hline 26 & L.G.R.M. & $x$ & $x$ & $x$ & $x$ & $x$ & $x$ & $x$ & & $x$ \\
\hline 27 & M.A.M. & $x$ & $x$ & $x$ & $x$ & $x$ & $x$ & $x$ & $x$ & $x$ \\
\hline 28 & P.A.N. & $x$ & $x$ & $x$ & $x$ & $x$ & $x$ & & & $x$ \\
\hline 29 & P.H.F.Z. & $\mathrm{X}$ & $x$ & $x$ & $x$ & $x$ & $x$ & $x$ & $x$ & $x$ \\
\hline 30 & R.G.L. & $\mathrm{x}$ & $\mathrm{X}$ & $\mathrm{x}$ & $x$ & $\mathrm{x}$ & & & $\mathrm{x}$ & $\mathrm{X}$ \\
\hline 31 & T.A.C. & $x$ & $x$ & $x$ & $x$ & $x$ & $x$ & $x$ & $\mathrm{X}$ & $x$ \\
\hline 32 & V.L.S. & $x$ & $x$ & $x$ & $x$ & $x$ & $x$ & $x$ & $x$ & \\
\hline 33 & V.L.B.F. & $x$ & $x$ & $x$ & $x$ & $x$ & $x$ & & & \\
\hline 34 & V.R. & $x$ & $x$ & $x$ & $x$ & $x$ & $x$ & $x$ & $x$ & $x$ \\
\hline 35 & V.S.T. & $x$ & $x$ & $\mathrm{x}$ & $x$ & $x$ & $x$ & & & \\
\hline RES & POSTAS - TOTAL - 35 & 34 & 33 & 32 & 31 & 32 & 32 & 28 & 19 & 23 \\
\hline RES & POSTAS - \% & 97 & 94 & 91 & 89 & 91 & 91 & 80 & 54 & 66 \\
\hline
\end{tabular}

Tabela 26 - Relatório individual de leitura cartográfica da Turma 9J1 com os temas abordados na avaliação de agosto de 2011. 


\begin{tabular}{|c|c|c|c|c|c|c|c|c|c|c|}
\hline \multicolumn{11}{|c|}{$\begin{array}{c}\text { RELATÓRIO } 9^{\circ} \text { ANO AGOSTO/2011 - COLÉGIO SINGULAR - 9J3 } \\
\text { CONSTRUÇÃO, LEITURA E INTERPRETAÇÃO DE MAPAS TEMÁTICOS } \\
\text { DURANTE AVALIAÇÃO SEM CONSULTA }\end{array}$} \\
\hline & TURMA - 9J3 & & \multicolumn{4}{|c|}{ LINGUAGEM CARTOGRÁFICA TEMÁTICA } & \multicolumn{2}{|c|}{ CORRELAÇŌES } & \multirow[b]{2}{*}{ 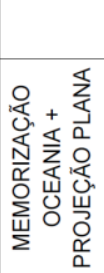 } & \multirow[b]{2}{*}{ 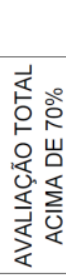 } \\
\hline & NOME & 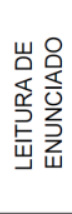 & 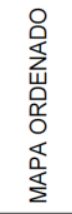 & 总 & 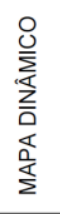 & 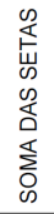 & 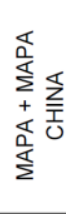 & 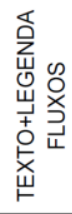 & & \\
\hline 1 & A.C.F. & $x$ & $\mathrm{X}$ & $\mathrm{x}$ & $\mathrm{x}$ & $\mathrm{x}$ & $\mathrm{x}$ & & & \\
\hline 2 & A.C.M. & $\mathrm{X}$ & $\mathrm{X}$ & $\mathrm{X}$ & $\mathrm{X}$ & $\mathrm{x}$ & $\mathrm{x}$ & $\mathrm{x}$ & & \\
\hline 3 & A.C.A.R. & $\mathrm{X}$ & $\mathrm{X}$ & $\mathrm{X}$ & $\mathrm{X}$ & $\mathrm{X}$ & $\mathrm{X}$ & $\mathrm{x}$ & $x$ & $\mathrm{X}$ \\
\hline 4 & B.B. & $\mathrm{x}$ & $\mathrm{X}$ & $\mathrm{x}$ & $\mathrm{x}$ & $\mathrm{x}$ & $\mathrm{X}$ & $\mathrm{x}$ & & $\mathrm{X}$ \\
\hline 5 & B.L.C. & $\mathrm{x}$ & $x$ & $\mathrm{x}$ & $\mathrm{X}$ & $\mathrm{x}$ & $\mathrm{x}$ & $\mathrm{x}$ & & $\mathrm{x}$ \\
\hline 6 & B.R.C. & $\mathrm{x}$ & $\mathrm{x}$ & & & & $\mathrm{x}$ & & $\mathrm{x}$ & \\
\hline 7 & C.F.B. & $\mathrm{x}$ & $\mathrm{X}$ & $\mathrm{x}$ & $\mathrm{x}$ & $\mathrm{X}$ & $\mathrm{X}$ & $\mathrm{x}$ & & \\
\hline 8 & D.A.F.C. & $\mathrm{x}$ & $\mathrm{X}$ & & & & $\mathrm{x}$ & & & \\
\hline 9 & D.F.P. & $\mathrm{x}$ & $\mathrm{X}$ & $\mathrm{x}$ & $X$ & $\mathrm{x}$ & $\mathrm{x}$ & $\mathrm{x}$ & $\mathrm{x}$ & $\mathrm{x}$ \\
\hline 10 & D.V. & $\mathrm{x}$ & $\mathrm{X}$ & $\mathrm{X}$ & & & $\mathrm{x}$ & & & \\
\hline 11 & G.C.G. & $\mathrm{x}$ & $\mathrm{x}$ & $\mathrm{x}$ & $x$ & $x$ & $\mathrm{X}$ & & & $\mathrm{X}$ \\
\hline 12 & G.R.N. & $\mathrm{X}$ & $\mathrm{X}$ & $x$ & $x$ & $\mathrm{X}$ & $\mathrm{X}$ & $\mathrm{X}$ & & $x$ \\
\hline 13 & H.C.F. & $\mathrm{X}$ & $\mathrm{X}$ & $x$ & $x$ & $x$ & $x$ & $x$ & & $x$ \\
\hline 14 & I.M.A. & $x$ & $X$ & & $X$ & $\mathrm{x}$ & $\mathrm{x}$ & & & $x$ \\
\hline 15 & I.C.R.P. & $x$ & $x$ & $x$ & $x$ & $x$ & $\mathrm{X}$ & $x$ & $x$ & $x$ \\
\hline 16 & J.T.M. & $\mathrm{X}$ & $x$ & $x$ & $x$ & $x$ & $\mathrm{X}$ & & & $\mathrm{X}$ \\
\hline 17 & L.F.R.T. & $X$ & $x$ & $X$ & $X$ & $\mathrm{x}$ & $\mathrm{x}$ & $\mathrm{X}$ & $x$ & $x$ \\
\hline 18 & L.S.B.F. & $x$ & $X$ & & $X$ & $\mathrm{x}$ & $\mathrm{x}$ & $\mathrm{x}$ & $x$ & \\
\hline 19 & L.H.M.M. & $x$ & $x$ & $x$ & $X$ & $x$ & $x$ & $X$ & $X$ & $x$ \\
\hline 20 & M.V.H.U. & $x$ & $x$ & $x$ & $\mathrm{x}$ & $x$ & $\mathrm{x}$ & $x$ & $x$ & $\mathrm{X}$ \\
\hline 21 & M.A.R. & $\mathrm{X}$ & $x$ & $x$ & $x$ & $x$ & $x$ & $x$ & & $x$ \\
\hline 22 & M.R.C. & $\mathrm{X}$ & $X$ & $x$ & $x$ & $x$ & & $x$ & $\mathrm{X}$ & $x$ \\
\hline 23 & M.E.O. & $\mathrm{X}$ & $x$ & $x$ & $x$ & $x$ & $\mathrm{X}$ & $\mathrm{X}$ & $x$ & $x$ \\
\hline 24 & P.H.P.B. & $x$ & $x$ & $x$ & $x$ & $x$ & $X$ & $X$ & & \\
\hline 25 & R.J.S.B. & $x$ & $x$ & & & & $x$ & & & \\
\hline 26 & T.C.N. & $\mathrm{X}$ & $x$ & $x$ & $\mathrm{x}$ & $\mathrm{X}$ & $x$ & $x$ & $\mathrm{x}$ & $x$ \\
\hline 27 & V.R. & $x$ & $X$ & $x$ & $\mathrm{X}$ & $\mathrm{X}$ & $x$ & $x$ & $x$ & $x$ \\
\hline 29 & V.A.B. & $x$ & $x$ & $x$ & $x$ & $\mathrm{X}$ & $\mathrm{X}$ & $x$ & $x$ & $\mathrm{X}$ \\
\hline 30 & V.M.S.O. & $\mathrm{X}$ & $x$ & $x$ & $x$ & $x$ & $x$ & $X$ & & $x$ \\
\hline 31 & V.S.G. & $\mathrm{X}$ & $x$ & $X$ & $X$ & $x$ & $x$ & & $x$ & $X$ \\
\hline 32 & Y.E.P.B. & $x$ & $x$ & $x$ & $\mathrm{X}$ & $x$ & $x$ & $x$ & & $\mathrm{X}$ \\
\hline RES & POSTAS - TOTAL - 31 & 31 & 31 & 26 & 27 & 27 & 30 & 22 & 15 & 22 \\
\hline RES & POSTAS - \% & 100 & 100 & 84 & 87 & 87 & 97 & 71 & 48 & 71 \\
\hline
\end{tabular}

Tabela 27 - Relatório individual de leitura cartográfica da Turma 9J3 com os temas abordados na avaliação de agosto de 2011. 


\begin{tabular}{|c|c|c|c|c|c|c|c|c|c|c|}
\hline \multicolumn{11}{|c|}{$\begin{array}{c}\text { RELATÓRIO } 9^{\circ} \text { ANO AGOSTO/2011 - COLÉGIO SINGULAR - 9J5 } \\
\text { CONSTRUÇÃO, LEITURA E INTERPRETAÇÃO DE MAPAS TEMÁTICOS } \\
\text { DURANTE AVALIAÇÃO SEM CONSULTA }\end{array}$} \\
\hline & TURMA - 9J5 & & \multicolumn{4}{|c|}{ LINGUAGEM CARTOGRAFICA TEMÁTICA } & \multicolumn{2}{|c|}{ CORRELAÇŌES } & \multirow[b]{2}{*}{ 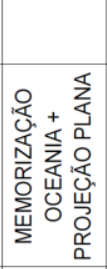 } & \multirow[b]{2}{*}{ 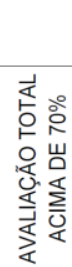 } \\
\hline & NOME & 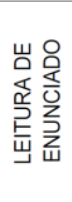 & 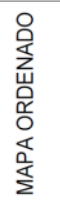 & 章 & 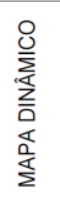 & 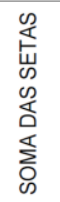 & 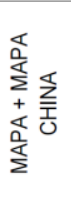 & 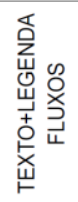 & & \\
\hline 1 & A.R.O.D. & $x$ & $x$ & $x$ & $x$ & $x$ & $x$ & & & $x$ \\
\hline 2 & A.V.B. & $x$ & $x$ & $x$ & $x$ & $x$ & $x$ & $x$ & & $x$ \\
\hline 3 & B.R.V. & $x$ & $x$ & $x$ & $x$ & $x$ & $x$ & $x$ & $x$ & $x$ \\
\hline 4 & C.C.H. & $x$ & $x$ & & $x$ & $x$ & $x$ & & & \\
\hline 5 & C.O.M. & $\mathrm{x}$ & $x$ & $x$ & $x$ & $x$ & $x$ & $x$ & & $x$ \\
\hline 6 & E.F.B. & $x$ & $x$ & $x$ & $x$ & $x$ & $x$ & & & \\
\hline 7 & Fa.P. & $x$ & $x$ & $x$ & & & $x$ & & $x$ & \\
\hline 8 & Fe.P. & $x$ & $x$ & $x$ & $x$ & $x$ & $x$ & $x$ & & \\
\hline 9 & G.M.G. & $x$ & $x$ & $x$ & $x$ & $x$ & $x$ & $x$ & & \\
\hline 10 & G.A.S. & $x$ & $x$ & & & & $x$ & & & \\
\hline 11 & G.T. & $x$ & $x$ & $x$ & $x$ & $x$ & $x$ & $x$ & $x$ & $x$ \\
\hline 12 & G.F.S. & $x$ & $x$ & $x$ & & & $x$ & & & \\
\hline 13 & H.B.S. & $x$ & $x$ & $x$ & $x$ & $x$ & $x$ & $x$ & & \\
\hline 14 & I.M.A. & $x$ & $x$ & $x$ & $x$ & $x$ & $\mathrm{x}$ & $x$ & $x$ & \\
\hline 15 & J.V.B.L. & $x$ & $x$ & $x$ & $x$ & $x$ & $x$ & $x$ & $x$ & $x$ \\
\hline 16 & J.H.R.A. & $x$ & $x$ & & $x$ & $x$ & $x$ & & & \\
\hline 17 & L.L.P.S. & $x$ & $x$ & $x$ & $x$ & $x$ & $x$ & $x$ & & $x$ \\
\hline 18 & L.M.S. & $x$ & $x$ & & $x$ & & $x$ & & & \\
\hline 19 & M.C.D.C. & $x$ & $x$ & $x$ & $x$ & $x$ & $x$ & $x$ & & \\
\hline 20 & M.P.G. & $x$ & $x$ & $x$ & $x$ & $x$ & $x$ & $x$ & $x$ & $x$ \\
\hline 21 & M.C.C. & $x$ & $x$ & $x$ & $x$ & $x$ & $x$ & $x$ & $x$ & $x$ \\
\hline 22 & M.C.S. & $x$ & $x$ & & & & $x$ & & & $x$ \\
\hline 23 & P.A.V. & $x$ & $x$ & $x$ & $x$ & $x$ & $x$ & $x$ & & $x$ \\
\hline 24 & R.M.B. & $x$ & $x$ & $x$ & $x$ & $x$ & $x$ & $x$ & & \\
\hline 25 & R.M.C. & $x$ & $x$ & $x$ & $x$ & & $x$ & $x$ & & $x$ \\
\hline 26 & S.A.D.R.F. & & & $x$ & $x$ & & & & & \\
\hline 27 & T.M.T. & $x$ & $x$ & $x$ & $x$ & $x$ & $x$ & $x$ & & \\
\hline 28 & T.M.S. & $x$ & $x$ & $x$ & $x$ & $x$ & $x$ & $x$ & $x$ & \\
\hline 29 & V.H.O. & & & $x$ & $x$ & $x$ & & & & \\
\hline 30 & V.M.M. & & $x$ & & & & $x$ & & & \\
\hline 31 & V.A.O. & $x$ & $x$ & $x$ & $x$ & $x$ & $x$ & $x$ & & $x$ \\
\hline 32 & Y.Y. & $x$ & $x$ & $x$ & $x$ & $x$ & $x$ & $x$ & & \\
\hline 33 & G.S.R. & $x$ & $x$ & $x$ & $x$ & $x$ & $x$ & $x$ & $x$ & \\
\hline RES & POSTAS - TOTAL - 33 & 30 & 31 & 27 & 29 & 25 & 31 & 21 & 9 & 13 \\
\hline RES & POSTAS - \% & 91 & 94 & 82 & 88 & 76 & 94 & 64 & 27 & 39 \\
\hline
\end{tabular}

Tabela 28 - Relatório individual de leitura cartográfica da Turma 9J5 com os temas abordados na avaliação de agosto de 2011 . 


\section{RELATÓRIO GERAL DE DESEMPENHO ENTRE AS \\ TURMAS DE $9^{\circ}$ ANO - NOV/2011 \\ CONSTRUÇÃO, LEITURA E INTERPRETAÇÃO DE MAPAS TEMÁTICOS \\ DURANTE AVALIAÇÃO SEM CONSULTA}

\begin{tabular}{|c|c|c|c|c|c|c|c|c|c|c|}
\hline \multirow[b]{2}{*}{$\%$} & \multirow[b]{2}{*}{ 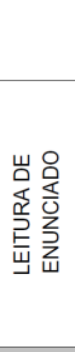 } & \multicolumn{3}{|c|}{$\begin{array}{l}\text { CONSTRUCGAO DE MAPA ORDENADO SEM CONSULTA OU } \\
\text { ORIIENTACGAO }\end{array}$} & \multicolumn{3}{|c|}{$\begin{array}{c}\text { CORRELAÇ̄̄ES } \\
\text { ENTRE MAPAS TEMATICOS DO BRASIL }\end{array}$} & \multicolumn{2}{|c|}{ MEMORIZAÇĀO } & \multirow[b]{2}{*}{ 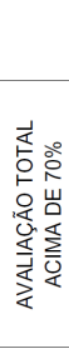 } \\
\hline & & 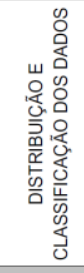 & 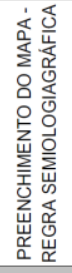 & 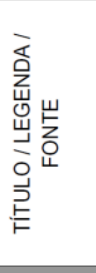 & 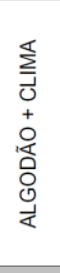 & 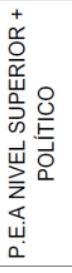 & 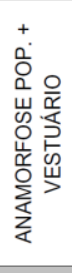 & 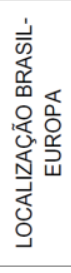 & 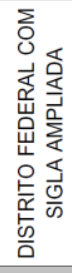 & \\
\hline 9J1 & 97 & 85 & 85 & 97 & 74 & 79 & 68 & 50 & 68 & 71 \\
\hline 9J3 & 100 & 100 & 100 & 94 & 61 & 84 & 74 & 74 & 94 & 87 \\
\hline 9J5 & 100 & 85 & 76 & 79 & 82 & 91 & 58 & 67 & 67 & 85 \\
\hline
\end{tabular}

RENDIMENTO ENTRE AS SALAS

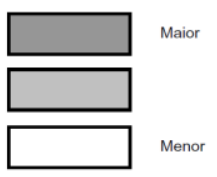

TEMAS ABORDADOS DURANTE TODO O ANO LETIVO ( $\mathrm{X}=$ UMAVEZ )

\begin{tabular}{|c|c|c|c|c|c|c|c|c|c|c|}
\hline & 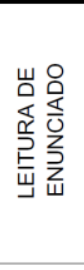 & 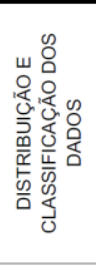 & 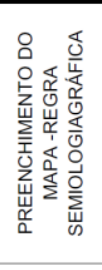 & 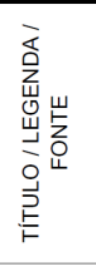 & 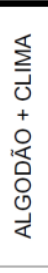 & 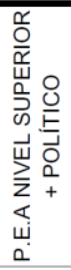 & 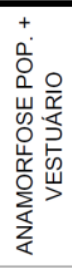 & 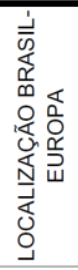 & 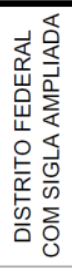 & 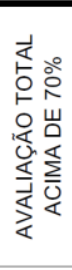 \\
\hline 9J1 & $x$ & $x x$ & $x x$ & $x X X X$ & $x$ & $x$ & $X$ & $x$ & & \\
\hline 9J3 & $x$ & $X X X X$ & $x x x x$ & $x X X X$ & $x$ & $x$ & $X$ & $x$ & & \\
\hline 9J5 & $x$ & $x x$ & $x x$ & $X X X X$ & $x$ & $x$ & $x$ & $x$ & & \\
\hline
\end{tabular}

Tabela 29 - Relatório geral de desempenho entre as Turmas de 9o Ano com as atividades e avaliações realizadas em novembro de 2011. Os melhores resultados obtidos, especialmente com a Turma 9J3, considerada a mais indisciplinada das três Turmas, que superou os resultados da Turma 9J1, considerada a mais adiantada pela coordenação do Colégio. 


\section{RELATÓRIO DE DESEMPENHO ENTRE TURMAS COM RENDIMENTO SUPERIOR A 70\% DA AVALIACÃO TOTAL}

( CONSTRUÇÃO, LEITURA E INTERPRETAÇÃO DE MAPAS TEMÁTICOS DURANTE AVALIAÇÃO SEM CONSULTA )

\begin{tabular}{|c|c|c|c|c|c|c|c|c|c|c|}
\hline \multirow[b]{2}{*}{$\%$} & \multirow[b]{2}{*}{ 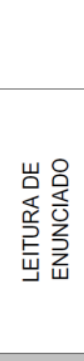 } & \multicolumn{3}{|c|}{$\begin{array}{l}\text { CONSTRUCGAO DE MAPA ORDENADO SEM CONSULTA OU } \\
\text { ORIENTACAO }\end{array}$} & \multicolumn{3}{|c|}{$\begin{array}{l}\text { CORRELAC̄ōES } \\
\text { ENTRE MAPAS TEMATICOS DO BRASIL }\end{array}$} & \multicolumn{2}{|c|}{ MEMORIZAÇĀo } & \multirow[b]{2}{*}{ 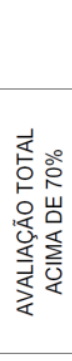 } \\
\hline & & 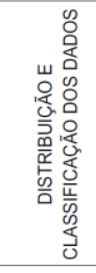 & 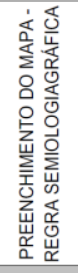 & 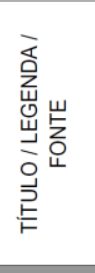 & $\begin{array}{l}\text { ¿ } \\
\vdots \\
0 \\
+ \\
0 \\
0 \\
0 \\
0 \\
0 \\
\frac{1}{\alpha}\end{array}$ & 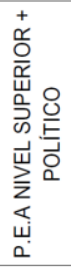 & 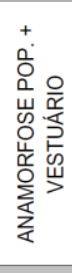 & 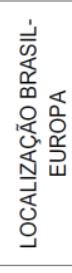 & 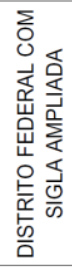 & \\
\hline 9J1 & 96 & 88 & 92 & 96 & 88 & 83 & 75 & 58 & 67 & 100 \\
\hline 9J3 & 100 & 100 & 100 & 96 & 67 & 85 & 81 & 78 & 93 & 100 \\
\hline 9J5 & 100 & 89 & 79 & 86 & 82 & 93 & 57 & 68 & 71 & 100 \\
\hline
\end{tabular}

RENDIMENTO ENTRE AS SALAS

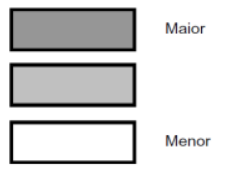

\begin{tabular}{|c|c|c|c|c|c|c|c|c|c|c|}
\hline \multicolumn{11}{|c|}{ TEMAS ABORDADOS DURANTE TODO O ANO LETIVO ( $X=$ UMAVEZ ) } \\
\hline & 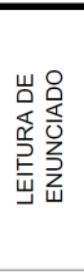 & 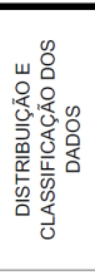 & 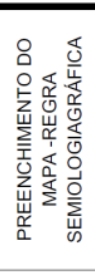 & 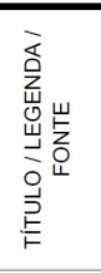 & 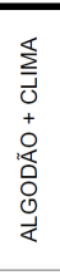 & 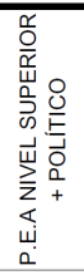 & 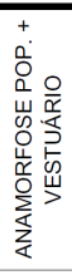 & 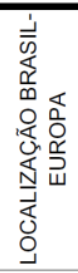 & 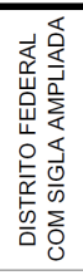 & 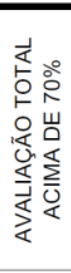 \\
\hline $9 \mathrm{~J} 1$ & $\mathbf{x}$ & $x x$ & $x \mathbf{x}$ & $\mathbf{x X X X}$ & $\mathbf{x}$ & $\mathbf{X}$ & $\mathbf{x}$ & $\mathbf{x}$ & & \\
\hline 9J3 & $x$ & $X X X X$ & XXXX & $x X X X$ & $x$ & $x$ & $x$ & $x$ & & \\
\hline 9J5 & $x$ & $x x$ & $x x$ & $x x x x$ & $x$ & $x$ & $x$ & $x$ & & \\
\hline
\end{tabular}

Tabela 30 - Relatório de desempenho dos alunos com rendimento superior a $70 \%$ da avaliação total da prova de Geografia entre as Turmas de 9ํㅡㄹ Ano realizadas em novembro de 2011. 


\section{RELATÓRIO DE DESEMPENHO ENTRE TURMAS COM RENDIMENTO INFERIOR A 70\% DA AVALIACÃO TOTAL}

( CONSTRUÇÃO, LEITURA E INTERPRETAÇÃO DE MAPAS TEMÁTICOS DURANTE AVALIAÇÃO SEM CONSULTA )

\begin{tabular}{|c|c|c|c|c|c|c|c|c|c|c|}
\hline \multirow[b]{2}{*}{$\%$} & \multirow[b]{2}{*}{ 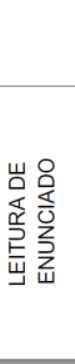 } & \multicolumn{3}{|c|}{$\begin{array}{l}\text { CONSTRUGGAO DE MAPA ORDENADO SEM CONSULTA OU } \\
\text { ORIENTAGAO }\end{array}$} & \multicolumn{3}{|c|}{$\begin{array}{c}\text { CORRELAÇ̄̄ES } \\
\text { ENTRE MAPAS TEMATICOS DO BRASIL }\end{array}$} & \multicolumn{2}{|c|}{ MEMORIZAÇÃo } & \multirow[b]{2}{*}{ 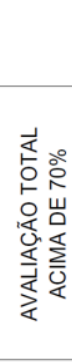 } \\
\hline & & 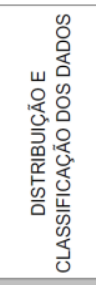 & 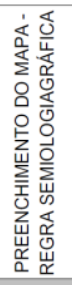 & 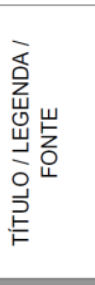 & 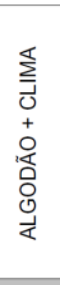 & 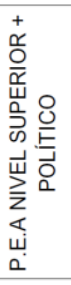 & 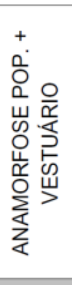 & 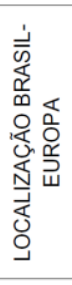 & 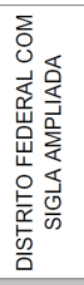 & \\
\hline 9J1 & 100 & 80 & 90 & 100 & 40 & 70 & 40 & 30 & 70 & 0 \\
\hline 9J3 & 100 & 100 & 100 & 75 & 25 & 75 & 25 & 50 & 100 & 0 \\
\hline 9J5 & 100 & 60 & 60 & 40 & 80 & 80 & 60 & 60 & 40 & 0 \\
\hline
\end{tabular}

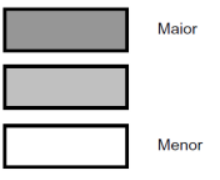

\begin{tabular}{|c|c|c|c|c|c|c|c|c|c|c|}
\hline & 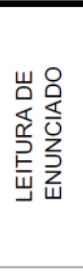 & 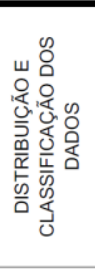 & 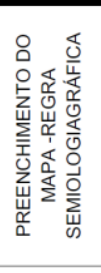 & 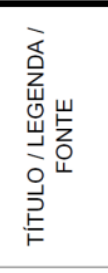 & 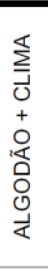 & 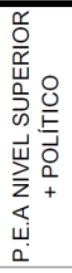 & 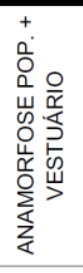 & 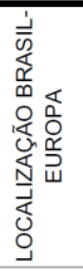 & 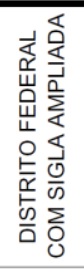 & 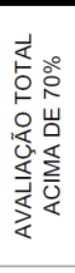 \\
\hline 9J1 & $x$ & $x x$ & $x x$ & $x X X X$ & $x$ & $x$ & $x$ & $x$ & & \\
\hline 9J3 & $x$ & $X X X X$ & $x X X X$ & $x X X X$ & $x$ & $x$ & $x$ & $x$ & & \\
\hline 9J5 & $x$ & $x x$ & $x x$ & $x x x x$ & $x$ & $x$ & $x$ & $x$ & & \\
\hline
\end{tabular}

Tabela 31 - Relatório de desempenho dos alunos com rendimento inferior a $70 \%$ da avaliação total da prova de Geografia entre as Turmas de 9o Ano realizadas em novembro de 2011. 


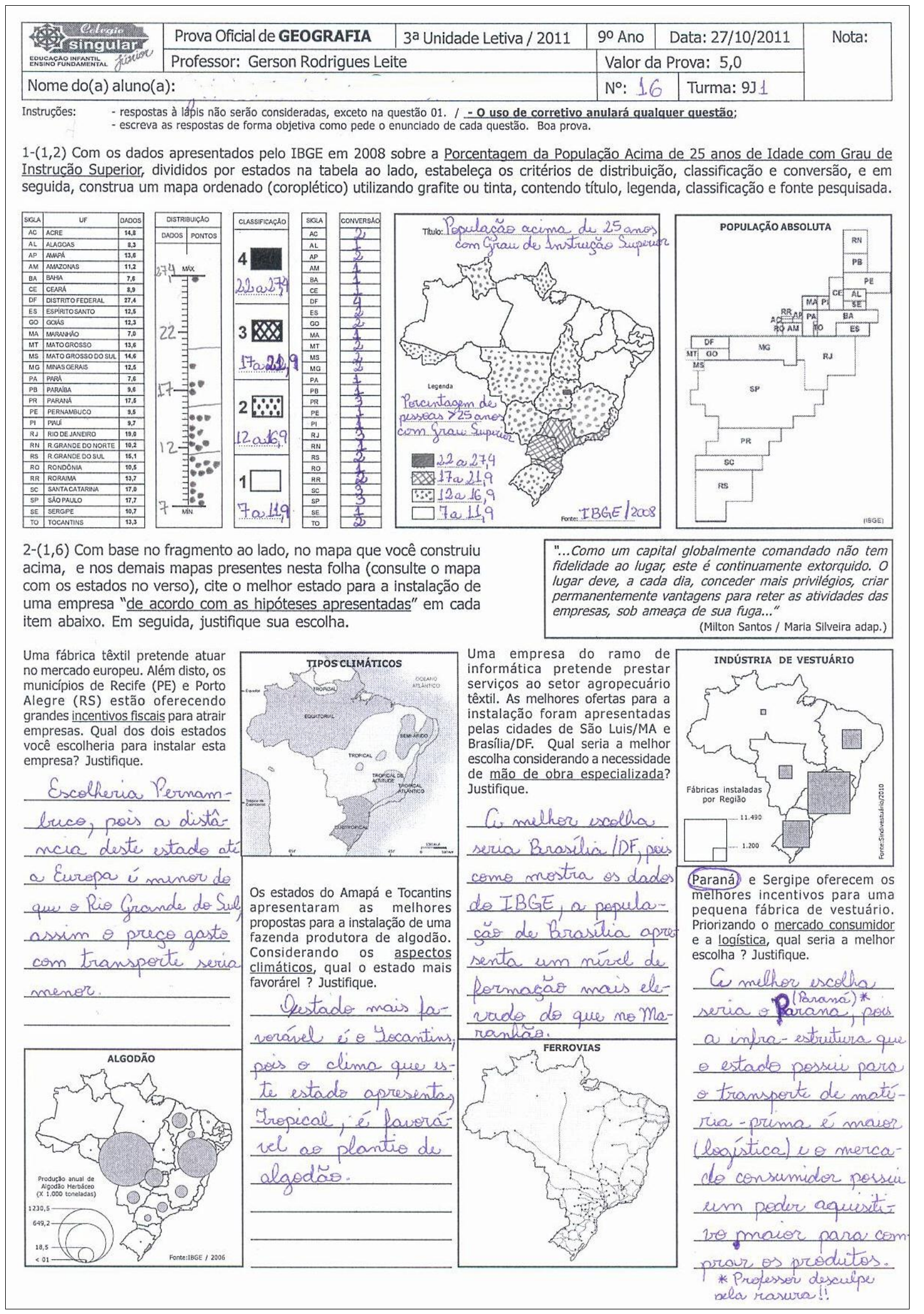

Figura 49 - Avaliação sem consulta realizada em outubro de 2011 com um exercício de construção de mapa ordenado com as três Turmas, e aplicada por professores de outras disciplinas sem o acompanhamento do professor de Geografia. 


\begin{tabular}{|c|c|c|c|c|c|c|c|c|c|c|c|}
\hline \multicolumn{12}{|c|}{$\begin{array}{l}\text { RELATÓRIO } 9^{\circ} \text { ANO NOVEMBRO/2011 - COLÉGIO SINGULAR - } 9 \mathrm{~J} 1 \\
\text { CONSTRUÇÃO, LEITURA E INTERPRETAÇÃO DE MAPAS TEMÁTICOS DURANTE AVALIAÇÃO SEM CONSULTA }\end{array}$} \\
\hline & TURMA - 9J1 & \multirow[b]{2}{*}{ 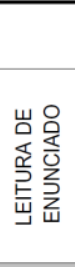 } & \multicolumn{3}{|c|}{$\begin{array}{l}\text { CONSTRUCAO DE MAPA ORDENADO SEM } \\
\text { CONSULTA OU ORIENTAGAO }\end{array}$} & \multicolumn{3}{|c|}{$\begin{array}{l}\text { CORRELAÇŌES } \\
\text { ENTRE MAPAS TEMATICOS DO } \\
\text { BRASIL }\end{array}$} & \multicolumn{2}{|c|}{ MEMORIZAÇÃo } & \multirow[b]{2}{*}{ 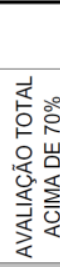 } \\
\hline & NOME & & 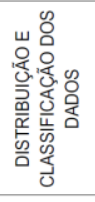 & 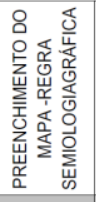 & 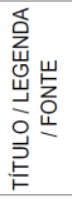 & $\begin{array}{l}\text { a } \\
\vdots \\
0 \\
+ \\
0 \\
0 \\
0 \\
0 \\
0 \\
\frac{0}{\alpha}\end{array}$ & 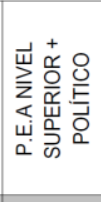 & 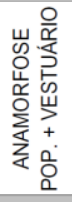 & 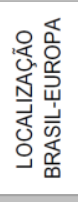 & 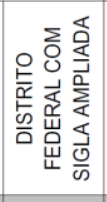 & \\
\hline 1 & A.S.A. & $x$ & & $x$ & & $x$ & $x$ & $x$ & $x$ & $\mathrm{x}$ & $x$ \\
\hline 2 & A.C.S.R. & $x$ & $x$ & $x$ & $x$ & & & & & & \\
\hline 3 & A.E.A.F. & $x$ & $x$ & $x$ & $x$ & $x$ & $x$ & & $x$ & $x$ & \\
\hline 4 & A.H.O. & $x$ & $x$ & $x$ & $x$ & $x$ & $x$ & $x$ & & $x$ & $x$ \\
\hline 5 & B.K.C. & $x$ & $x$ & $x$ & $x$ & $x$ & $x$ & $x$ & $x$ & & $x$ \\
\hline 6 & B.S.A.U. & $x$ & $x$ & $x$ & $x$ & $x$ & $x$ & $x$ & $x$ & $x$ & $x$ \\
\hline 7 & C.F.A.S. & $x$ & $x$ & $x$ & $x$ & $x$ & & & $x$ & $x$ & $x$ \\
\hline 8 & C.A.V. & $x$ & & $x$ & $x$ & $x$ & $x$ & $x$ & $x$ & & $x$ \\
\hline 9 & F.H.D.F. & $x$ & $x$ & $x$ & $x$ & $x$ & $x$ & $x$ & & $x$ & \\
\hline 10 & F.L.C. & & & & $x$ & $x$ & $x$ & $x$ & & & $\mathrm{x}$ \\
\hline 11 & G.Q.P.B. & $x$ & $x$ & $x$ & $x$ & & $x$ & & & $x$ & \\
\hline 12 & G.A. & $x$ & $x$ & $x$ & $x$ & $x$ & $x$ & $x$ & & $x$ & $x$ \\
\hline 13 & G.P.F. & $x$ & & & $x$ & $x$ & $x$ & $x$ & & & \\
\hline 14 & G.P.R. & $x$ & $x$ & $x$ & $x$ & $x$ & $x$ & $x$ & $x$ & $x$ & $x$ \\
\hline 15 & G.C.N. & $x$ & $x$ & $x$ & $x$ & $x$ & $x$ & $x$ & & & $x$ \\
\hline 16 & J.M.F. & $x$ & $x$ & $x$ & $x$ & $x$ & & & & $x$ & $x$ \\
\hline 17 & J.C.O.D. & $x$ & $x$ & $x$ & $x$ & & & $x$ & & $x$ & \\
\hline 18 & J.T.M. & $x$ & $x$ & $x$ & $x$ & $x$ & $x$ & & $x$ & & $x$ \\
\hline 19 & J.P.L.F. & $x$ & $x$ & $x$ & $x$ & & $x$ & $x$ & & $x$ & $x$ \\
\hline 20 & J.P.R.Z. & $x$ & $x$ & $x$ & $\mathrm{x}$ & $x$ & $x$ & $x$ & & $x$ & $x$ \\
\hline 21 & J.H.O. & $x$ & $x$ & $x$ & $x$ & & $x$ & $x$ & $x$ & $x$ & $x$ \\
\hline 22 & J.N.T. & $x$ & $x$ & $x$ & $x$ & $x$ & $x$ & & $x$ & & $\mathrm{x}$ \\
\hline 23 & L.S.P. & $x$ & $x$ & $x$ & $x$ & & & $x$ & & & $x$ \\
\hline 24 & L.E.B. & $x$ & $x$ & $x$ & $x$ & $\mathrm{x}$ & & $x$ & & $x$ & $\mathrm{x}$ \\
\hline 25 & L.G.R.M. & $x$ & $x$ & $x$ & $x$ & & $\mathrm{x}$ & & $x$ & $x$ & \\
\hline 26 & M.A.M. & $x$ & $x$ & $x$ & $\mathrm{x}$ & $x$ & $x$ & $x$ & & $\mathrm{x}$ & $\mathrm{x}$ \\
\hline 27 & P.A.N. & $x$ & $x$ & $x$ & $x$ & $x$ & $x$ & $x$ & $x$ & $x$ & $x$ \\
\hline 28 & P.H.F.Z. & $x$ & $x$ & $x$ & $\mathrm{x}$ & $x$ & $x$ & $\mathrm{x}$ & $\mathrm{x}$ & $x$ & $\mathrm{x}$ \\
\hline 29 & R.G.L. & $x$ & $\mathrm{x}$ & $x$ & $\mathrm{x}$ & $\mathrm{x}$ & $\mathrm{x}$ & $x$ & $x$ & $\mathrm{x}$ & $\mathrm{x}$ \\
\hline 30 & T.A.C. & $x$ & $x$ & & $x$ & $x$ & $\mathrm{x}$ & & $x$ & & $\mathrm{x}$ \\
\hline 31 & V.L.S. & $x$ & $x$ & $x$ & $x$ & & $\mathrm{x}$ & & $x$ & $\mathrm{x}$ & \\
\hline 32 & V.L.B.F. & $x$ & & $x$ & $x$ & & & $\mathrm{x}$ & & $x$ & \\
\hline 33 & V.R. & $x$ & $\mathrm{x}$ & $x$ & $x$ & $x$ & $x$ & $x$ & $x$ & $x$ & $x$ \\
\hline 34 & V.S.T. & $x$ & $x$ & $x$ & $x$ & $x$ & $x$ & & & & \\
\hline RES & SPOSTAS - TOTAL - 34 & 33 & 29 & 29 & 33 & 25 & 27 & 23 & 17 & 23 & 24 \\
\hline RES & SPOSTAS - \% & 97 & 85 & 85 & 97 & 74 & 79 & 68 & 50 & 68 & 71 \\
\hline
\end{tabular}

Tabela 32 - Relatório individual de leitura cartográfica da Turma 9J1 com os temas abordados na avaliação de novembro de 2011. 


\begin{tabular}{|c|c|c|c|c|c|c|c|c|c|c|c|}
\hline & $\begin{array}{r}\text { REL } \\
\text { CONSTRUÇÃO, LEITURA }\end{array}$ & $\begin{array}{l}109^{\circ} \mathrm{A} \\
\mathrm{RPRE}\end{array}$ & $\begin{array}{l}\text { IO NOV } \\
\text { AÇÃO D }\end{array}$ & $\begin{array}{l}\text { MBRO/ } \\
\text { E MAPA }\end{array}$ & $\begin{array}{l}11-C \\
\text { TEMÁ }\end{array}$ & ÉGIC & $\begin{array}{l}\text { INGULA } \\
\text { JRANTE }\end{array}$ & $\begin{array}{l}-9 \mathrm{I} 3 \\
\text { VALIA }\end{array}$ & Ão SE & I CONSI & LTA \\
\hline & TURMA - 9J3 & & $\begin{array}{r}\text { CONSTRUG } \\
\text { CON }\end{array}$ & $\begin{array}{l}\text { ODE MAPA OR } \\
\text { UTA OU ORIE }\end{array}$ & $\begin{array}{l}\text { NADO SEM } \\
\text { CAOO }\end{array}$ & ENTR & $\begin{array}{l}\text { ORRELAÇÖE } \\
\text { IAPAS TEMA } \\
\text { BRASIL. }\end{array}$ & $\cos \mathrm{Do}$ & MEM & RIZAÇĀo & \\
\hline & NOME & 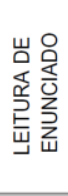 & 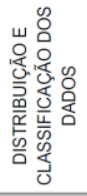 & 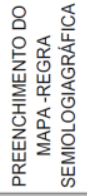 & 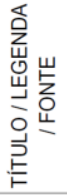 & 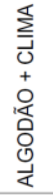 & 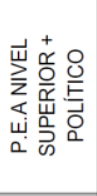 & 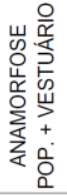 & 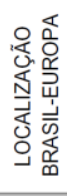 & 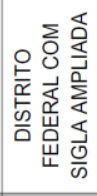 & 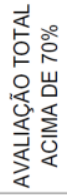 \\
\hline 1 & A.C.F. & $\mathrm{X}$ & $X$ & $x$ & & & $\mathrm{X}$ & & $X$ & $X$ & \\
\hline 2 & A.C.M. & $x$ & $X$ & $X$ & $X$ & $X$ & & & $X$ & $X$ & $x$ \\
\hline 3 & A.C.A.R. & $x$ & $X$ & $X$ & $\mathrm{X}$ & & $X$ & $X$ & $X$ & $X$ & \\
\hline 4 & B.B. & $\mathrm{X}$ & $X$ & $X$ & $X$ & $X$ & $\mathrm{X}$ & $X$ & $X$ & $X$ & $X$ \\
\hline 5 & B.L.C. & $X$ & $X$ & $\mathrm{X}$ & $\mathrm{X}$ & & $X$ & & & $X$ & $x$ \\
\hline 6 & B.R.C. & $X$ & $X$ & $\mathrm{X}$ & $X$ & & & $X$ & $X$ & $X$ & $\mathrm{X}$ \\
\hline 7 & C.F.B. & $\mathrm{X}$ & $X$ & $\mathrm{X}$ & $\mathrm{X}$ & & $X$ & & & $X$ & \\
\hline 8 & D.A.F.C. & $\mathrm{X}$ & $X$ & $X$ & $X$ & & $\mathrm{X}$ & $\mathrm{X}$ & & $X$ & $\mathrm{X}$ \\
\hline 9 & D.F.P. & $X$ & $X$ & $X$ & $X$ & $x$ & $X$ & $X$ & $X$ & $X$ & $X$ \\
\hline 10 & D.V. & $X$ & $X$ & $X$ & $X$ & $x$ & $X$ & $x$ & & $X$ & $X$ \\
\hline 11 & G.C.G. & $\mathrm{X}$ & $\mathrm{X}$ & $X$ & $X$ & & & $\mathrm{X}$ & $X$ & $\mathrm{X}$ & $x$ \\
\hline 12 & G.R.N. & $\mathrm{X}$ & $X$ & $\mathrm{X}$ & $\mathrm{X}$ & $X$ & $X$ & $X$ & $X$ & $X$ & $\mathrm{X}$ \\
\hline 13 & H.C.F. & $\mathrm{X}$ & $X$ & $\mathrm{X}$ & $\mathrm{X}$ & $X$ & $\mathrm{X}$ & $X$ & $X$ & $X$ & $\mathrm{X}$ \\
\hline 14 & I.M.A. & $\mathrm{X}$ & $X$ & $\mathrm{X}$ & $\mathrm{X}$ & $\mathrm{X}$ & $\mathrm{X}$ & $X$ & $X$ & $x$ & $X$ \\
\hline 15 & I.C.R.P. & $x$ & $\mathrm{X}$ & $\mathrm{X}$ & $\mathrm{X}$ & & $\mathrm{X}$ & & $\mathrm{X}$ & 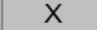 & $x$ \\
\hline 16 & J.T.M. & $X$ & $X$ & $X$ & $\mathrm{X}$ & $X$ & $X$ & $\mathrm{X}$ & $\mathrm{X}$ & $\mathrm{X}$ & $\mathrm{X}$ \\
\hline 17 & L.F.R.T. & $\mathrm{X}$ & $X$ & $X$ & $x$ & $x$ & $X$ & $\mathrm{X}$ & $X$ & $\mathrm{X}$ & $X$ \\
\hline 18 & G.S.A. & $\mathrm{X}$ & $X$ & $\mathrm{X}$ & $\mathrm{X}$ & $\mathrm{X}$ & $x$ & $x$ & & $\mathrm{X}$ & $\mathrm{X}$ \\
\hline 19 & L.H.M.M. & $X$ & $X$ & $x$ & $X$ & $X$ & $X$ & $X$ & $X$ & $X$ & $x$ \\
\hline 20 & M.A.R. & $x$ & $x$ & $x$ & $X$ & & $X$ & $X$ & & $x$ & $x$ \\
\hline 21 & M.R.C. & $x$ & $X$ & $x$ & $x$ & $x$ & $X$ & $x$ & $x$ & $x$ & $x$ \\
\hline 22 & M.E.O. & $x$ & $x$ & $x$ & $\mathrm{X}$ & $x$ & $x$ & $x$ & & $x$ & $x$ \\
\hline 23 & P.H.P.B. & $X$ & $X$ & $\mathrm{X}$ & $\mathrm{X}$ & $x$ & & & & 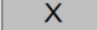 & \\
\hline 24 & R.J.S.B. & $x$ & $X$ & $\mathrm{X}$ & & & & & $\mathrm{X}$ & & $X$ \\
\hline 25 & T.C.N. & $x$ & $x$ & $X$ & $\mathrm{X}$ & $x$ & $X$ & & $X$ & $x$ & $x$ \\
\hline 26 & V.R. & $x$ & $x$ & $x$ & $X$ & & $x$ & $x$ & $X$ & $x$ & $x$ \\
\hline 27 & V.V.S. & $x$ & $x$ & $x$ & $x$ & & $X$ & $x$ & $X$ & $x$ & $x$ \\
\hline 28 & V.A.B. & $x$ & $x$ & $x$ & $x$ & $x$ & $X$ & $x$ & $X$ & $x$ & $x$ \\
\hline 29 & V.M.S.O. & $x$ & $X$ & $X$ & $\mathrm{X}$ & $X$ & $X$ & $X$ & $X$ & & $X$ \\
\hline 30 & V.S.G. & $X$ & $X$ & $\mathrm{X}$ & $\mathrm{X}$ & $X$ & $X$ & $\mathrm{X}$ & $\mathrm{X}$ & $X$ & $X$ \\
\hline 31 & Y.E.P.B. & $\mathrm{X}$ & $x$ & $X$ & $X$ & $x$ & $\mathrm{X}$ & $\mathrm{X}$ & $X$ & $X$ & $\mathrm{X}$ \\
\hline \multicolumn{2}{|c|}{ RESPOSTAS - TOTAL - 31} & 31 & 31 & 31 & 29 & 19 & 26 & 23 & 23 & 29 & 27 \\
\hline \multicolumn{2}{|c|}{ RESPOSTAS - \% } & 100 & 100 & 100 & 94 & 61 & 84 & 74 & 74 & 94 & 87 \\
\hline
\end{tabular}

Tabela 33 - Relatório individual de leitura cartográfica da Turma 9J3 com os temas abordados na avaliação de novembro de 2011. 


\begin{tabular}{|c|c|c|c|c|c|c|c|c|c|c|c|}
\hline \multicolumn{12}{|c|}{$\begin{array}{l}\text { RELATÓRIO } 9^{\circ} \text { ANO NOVEMBRO/2011 - COLÉGIO SINGULAR - 9J5 } \\
\text { CONSTRUÇÃO, LEITURA E INTERPRETAÇÃO DE MAPAS TEMÁTICOS DURANTE AVALIAÇÃO SEM CONSULTA }\end{array}$} \\
\hline & TURMA - 9J5 & \multirow[b]{2}{*}{ 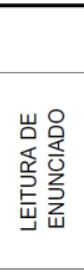 } & \multicolumn{3}{|c|}{$\begin{array}{l}\text { CONSTRUCAA DE MAPA ORDEEARD SEM } \\
\text { CONSULTA OU ORERENTACAOA }\end{array}$} & \multicolumn{3}{|c|}{$\begin{array}{l}\text { CORRELACOOES } \\
\text { ENTRE MAPAS TEMATICOS DO } \\
\text { BRASIL }\end{array}$} & \multicolumn{2}{|c|}{ MEMORIZAÇĀo } & \multirow[b]{2}{*}{ 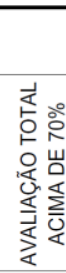 } \\
\hline & NOME & & 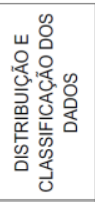 & 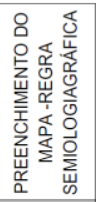 & 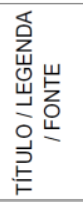 & 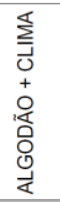 & 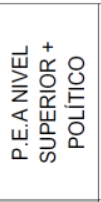 & 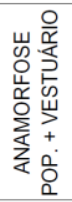 & 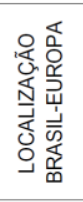 & 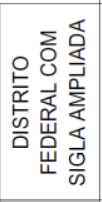 & \\
\hline 1 & A.R.O.D. & $x$ & $x$ & $x$ & $x$ & $\mathrm{x}$ & $x$ & & & $x$ & \\
\hline 2 & A.V.B. & $\mathrm{x}$ & $x$ & & $\mathrm{x}$ & $\mathrm{x}$ & $x$ & & $\mathrm{x}$ & & $\mathrm{x}$ \\
\hline 3 & B.R.V. & $x$ & $\mathrm{x}$ & $x$ & $x$ & $x$ & $x$ & $x$ & $x$ & $x$ & $x$ \\
\hline 4 & C.C.H. & $x$ & $x$ & & $x$ & & $x$ & $\mathrm{x}$ & $x$ & $x$ & $x$ \\
\hline 5 & C.O.M. & $x$ & $x$ & $x$ & $\mathrm{x}$ & $\mathrm{x}$ & $x$ & $\mathrm{x}$ & $x$ & $\mathrm{x}$ & $x$ \\
\hline 6 & E.F.B. & $x$ & $x$ & $x$ & $x$ & $x$ & $x$ & & & $x$ & $x$ \\
\hline 7 & Fa.P. & $x$ & $x$ & $x$ & $x$ & $x$ & $x$ & $x$ & & $x$ & $x$ \\
\hline 8 & Fe.p & $x$ & $x$ & $\mathrm{x}$ & $\mathrm{x}$ & $\mathrm{x}$ & $x$ & $x$ & & $x$ & $x$ \\
\hline 9 & G.M.G. & $x$ & $x$ & $x$ & $\mathrm{x}$ & $x$ & $x$ & $x$ & $\mathrm{x}$ & & $x$ \\
\hline 10 & G.A.S. & $x$ & $\mathrm{x}$ & & $\mathrm{x}$ & $\mathrm{x}$ & $x$ & & & $x$ & $x$ \\
\hline 11 & G.T. & $x$ & $\mathrm{x}$ & $\mathrm{x}$ & $x$ & & $x$ & & $\mathrm{x}$ & $\mathrm{x}$ & $\mathrm{x}$ \\
\hline 12 & G.F.S. & $x$ & & & & & $x$ & $x$ & & & \\
\hline 13 & H.B.S. & $x$ & $\mathrm{x}$ & & & $\mathrm{x}$ & $x$ & $x$ & $\mathrm{x}$ & & $\mathrm{x}$ \\
\hline 14 & I.M.A. & $x$ & . & & $x$ & & $x$ & $x$ & $x$ & & $x$ \\
\hline 15 & J.V.B.L. & $x$ & $x$ & $x$ & $x$ & $x$ & $x$ & $x$ & $x$ & $x$ & $x$ \\
\hline 16 & J.H.R.A. & $x$ & $x$ & $x$ & $\mathrm{x}$ & $x$ & $x$ & $x$ & $x$ & $x$ & $x$ \\
\hline 17 & L.L.P.S. & $x$ & $x$ & $\mathrm{x}$ & $x$ & $x$ & $x$ & & & & $x$ \\
\hline 18 & L.M.S. & $x$ & $x$ & $x$ & $x$ & $x$ & $x$ & & $x$ & $x$ & \\
\hline 19 & M.C.D.C. & $x$ & $x$ & $x$ & $x$ & $x$ & . & & $x$ & & $x$ \\
\hline 20 & M.P.G. & $x$ & $x$ & $\mathrm{x}$ & $x$ & $x$ & $x$ & & $x$ & $x$ & $x$ \\
\hline 21 & M.C.C. & $x$ & $x$ & $\mathrm{x}$ & $\mathrm{x}$ & $\mathrm{x}$ & $x$ & & $x$ & $\mathrm{x}$ & $\mathrm{x}$ \\
\hline 22 & M.C.S. & $x$ & $x$ & $x$ & $x$ & $x$ & $x$ & & $x$ & $x$ & $x$ \\
\hline 23 & P.A.V. & $x$ & $x$ & $x$ & $x$ & $\mathrm{x}$ & $x$ & & $x$ & $x$ & $x$ \\
\hline 24 & R.M.B. & $x$ & $x$ & $x$ & $x$ & & $x$ & $x$ & & & $x$ \\
\hline 25 & R.M.C. & $x$ & $\mathrm{x}$ & $x$ & $x$ & $x$ & $x$ & $x$ & $\mathrm{x}$ & $x$ & $x$ \\
\hline 26 & S.A.D.R.F. & $x$ & & $\mathrm{x}$ & & & $\mathrm{x}$ & $x$ & & $\mathrm{x}$ & $x$ \\
\hline 27 & T.M.T. & $x$ & $x$ & $\mathrm{x}$ & & $x$ & & $x$ & $x$ & & \\
\hline 28 & T.M.S. & $x$ & $\mathrm{x}$ & $x$ & & $x$ & & & & $\mathrm{x}$ & $\mathrm{x}$ \\
\hline 29 & V.H.O. & $x$ & 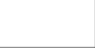 & & & $x$ & $x$ & $x$ & $x$ & & \\
\hline 30 & V.M.M. & $x$ & $x$ & & $x$ & $x$ & $x$ & $x$ & $x$ & $x$ & $x$ \\
\hline 31 & V.A.O. & $x$ & & $x$ & $x$ & $x$ & $x$ & $x$ & $x$ & $x$ & $x$ \\
\hline 32 & Y.Y. & $x$ & $x$ & $x$ & $x$ & $x$ & $x$ & $x$ & & & $x$ \\
\hline 33 & G.S.R. & $x$ & $x$ & $x$ & & $x$ & $x$ & & $x$ & $x$ & $x$ \\
\hline RES & SPOSTAS - TOTAL - 33 & 33 & 28 & 25 & 26 & 27 & 30 & 19 & 22 & 22 & 28 \\
\hline RES & SPOSTAS - \% & 100 & 85 & 76 & 79 & 82 & 91 & 58 & 67 & 67 & 85 \\
\hline
\end{tabular}

Tabela 34 - Relatório individual de leitura cartográfica da Turma 9J5 com os temas abordados na avaliação de novembro de 2011. 


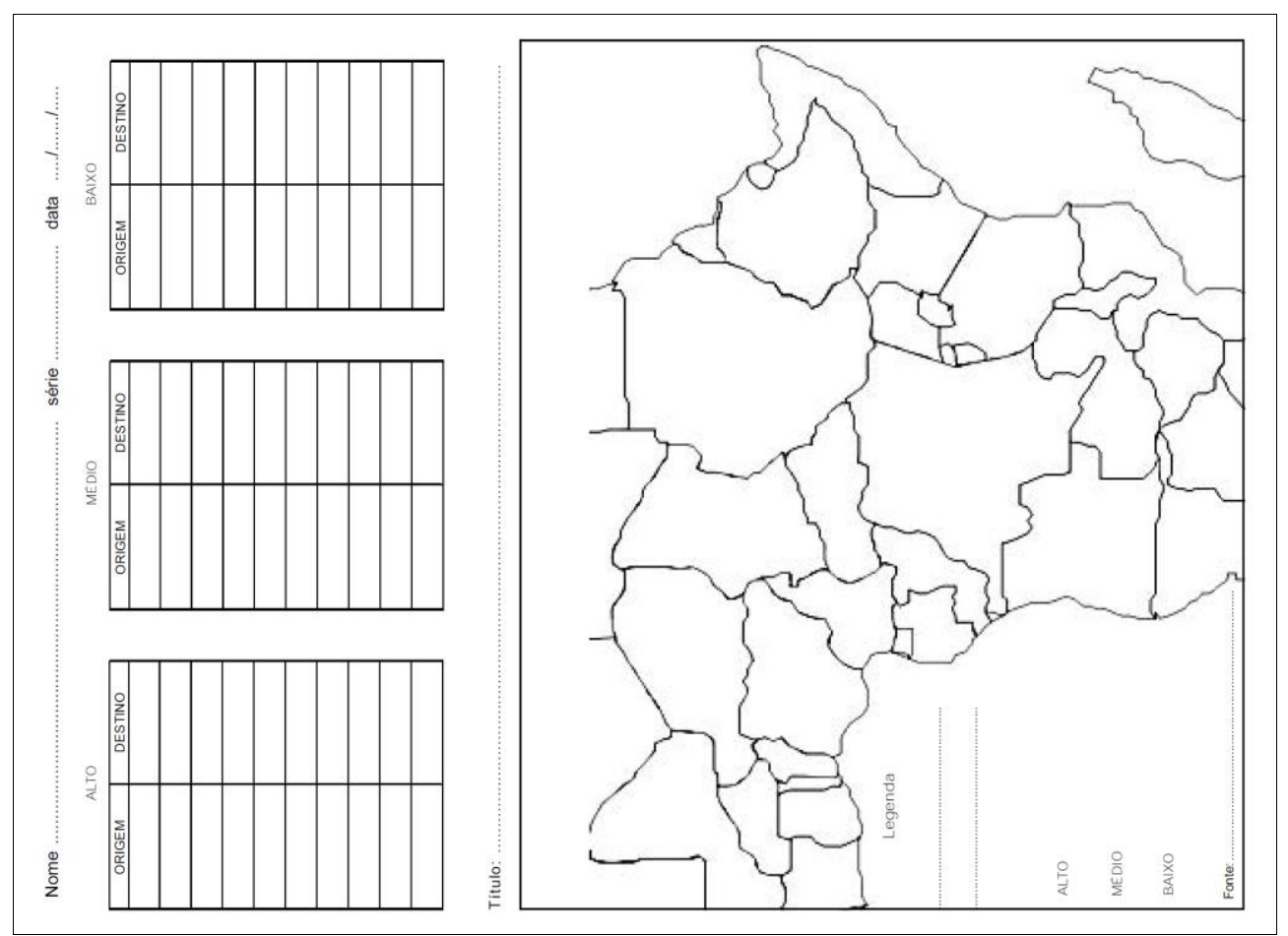

Figura 50 - Matriz da primeira atividade da Turma 9J1 de elaboração de mapa dinâmico com tabela (origem / destino) em três classificações (alto / médio / baixo) para o preenchimento com o gabarito de curvas proporcionais, com o acompanhamento do professor na lousa.

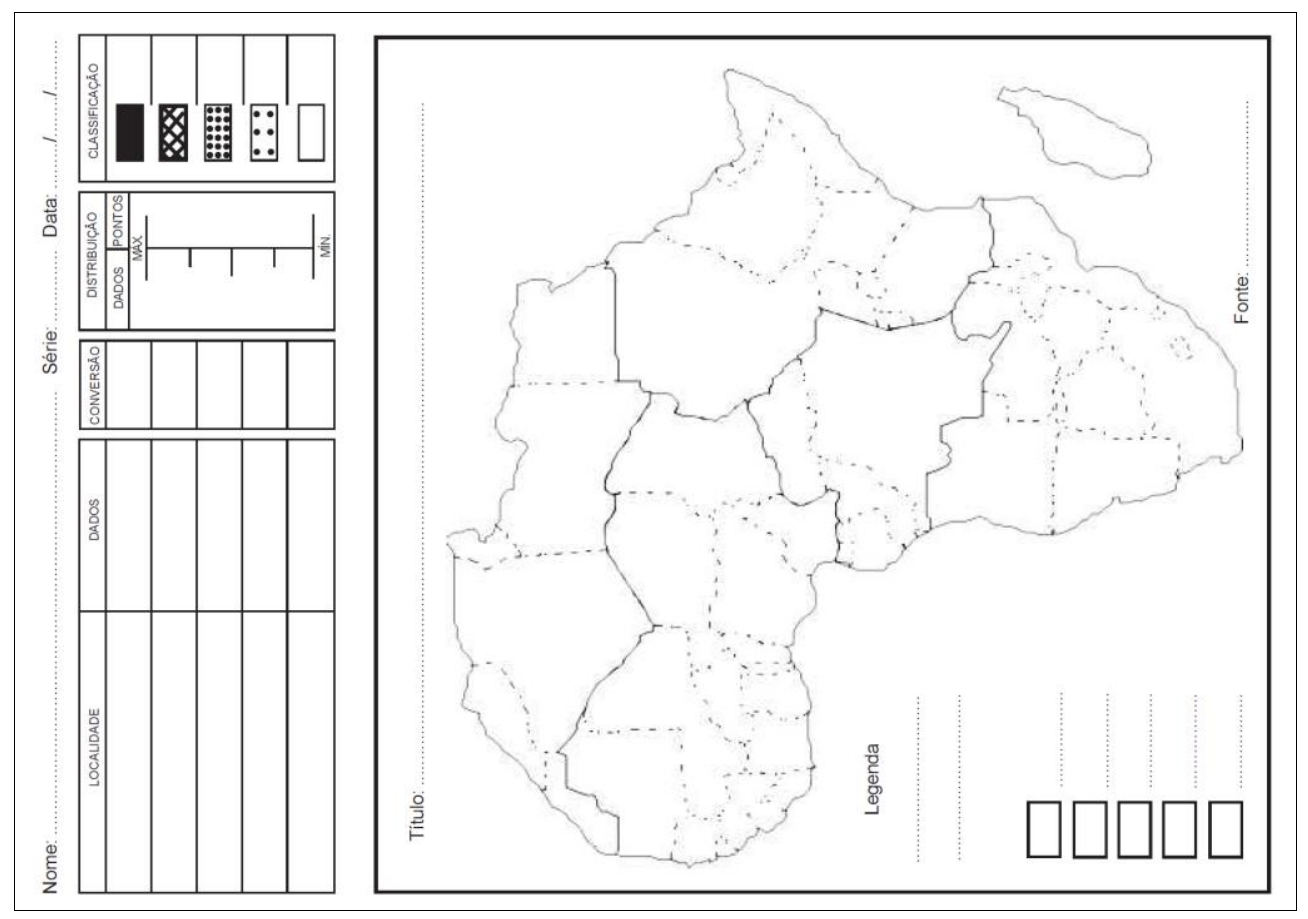

Figura 51 - Matriz simplificada da primeira atividade de elaboração de mapa ordenado com o acompanhamento do professor na lousa. 


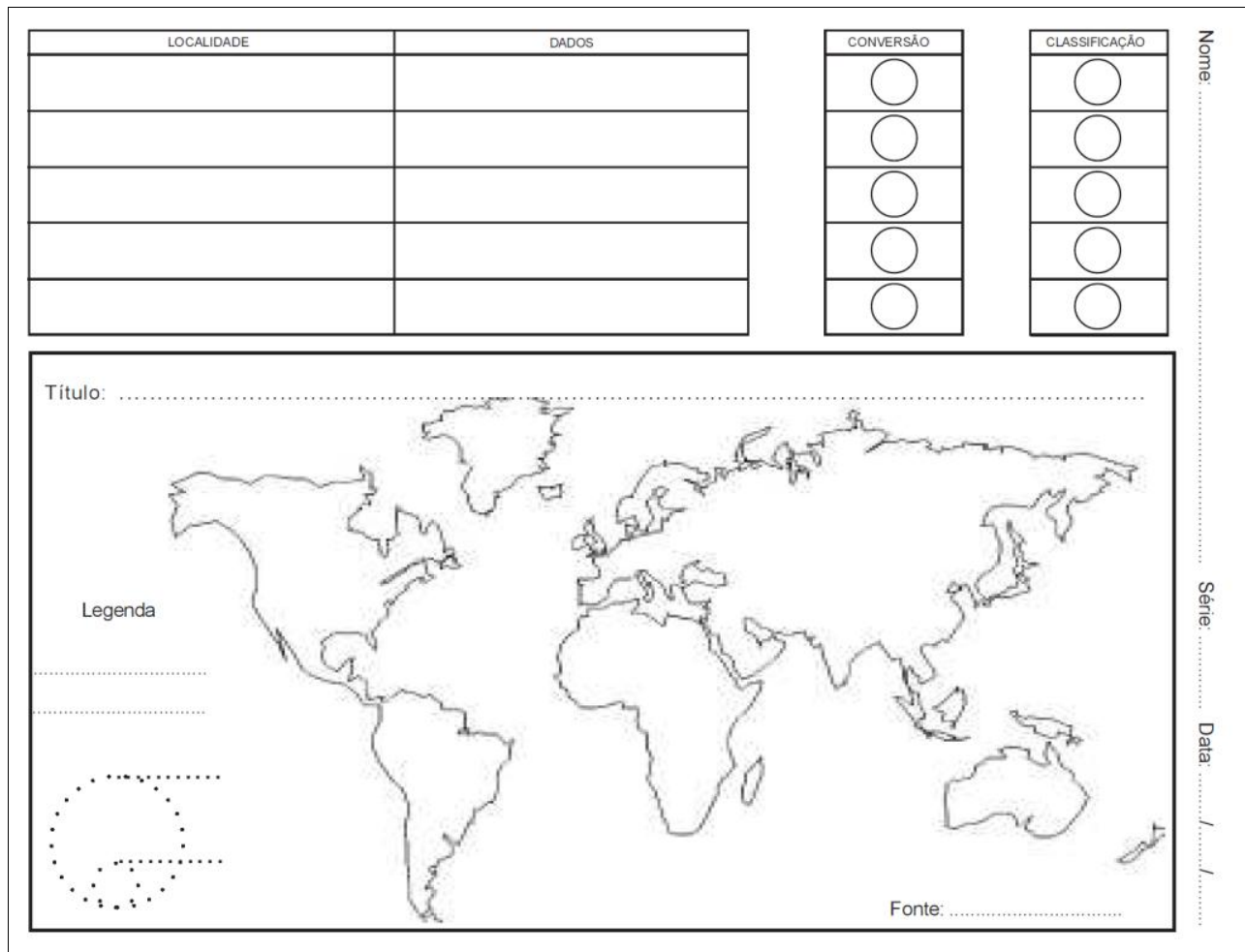

Figura 52 - Matriz simplificada da primeira atividade da Turma $9 J 5$ de elaboração de mapa quantitativo com o uso de gabarito de círculos proporcionais com acompanhamento do professor na lousa.

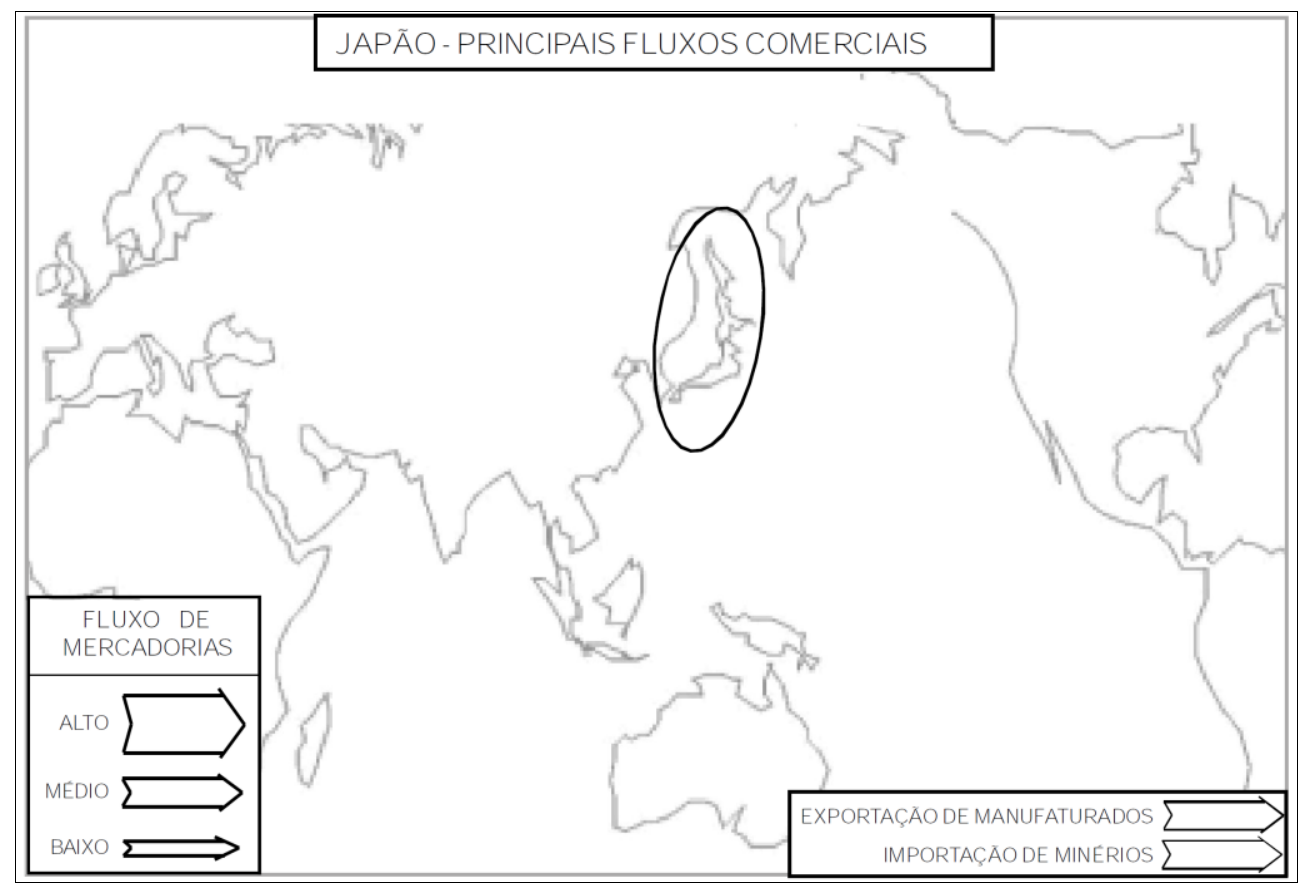

Figura 53 - Matriz sem tabela para a Turma 9J1 com os dados apresentados apenas na lousa para a elaboração de mapa dinâmico com os principais fluxos comerciais do Japão utilizando gabarito de curvas proporcionais e acompanhamento individual do professor. 


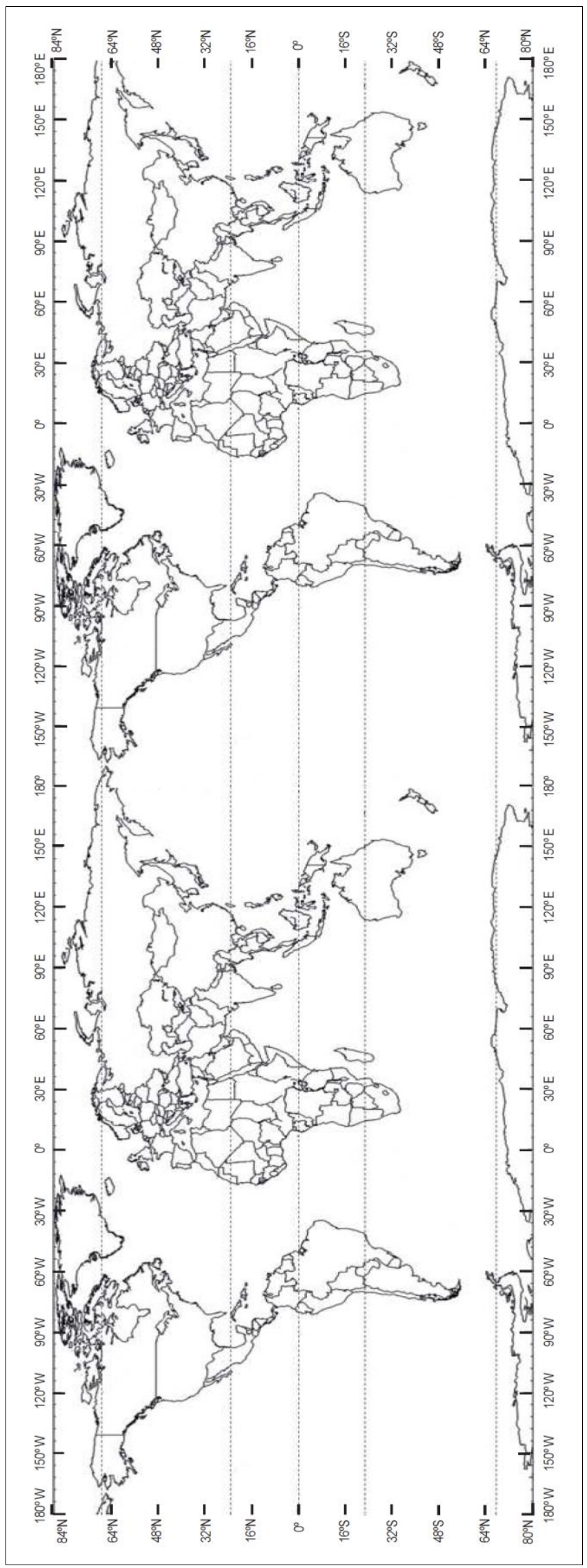

Figura 54 - Matriz da Turma 9J5 do Planisfério em duplicata para raport (emenda das longitudes), com possibilidade de centralização no maior país produtor do minério escolhido entre os cinco apresentados em uma tabela da Apostila e preenchido com gabarito de círculos proporcionais. 


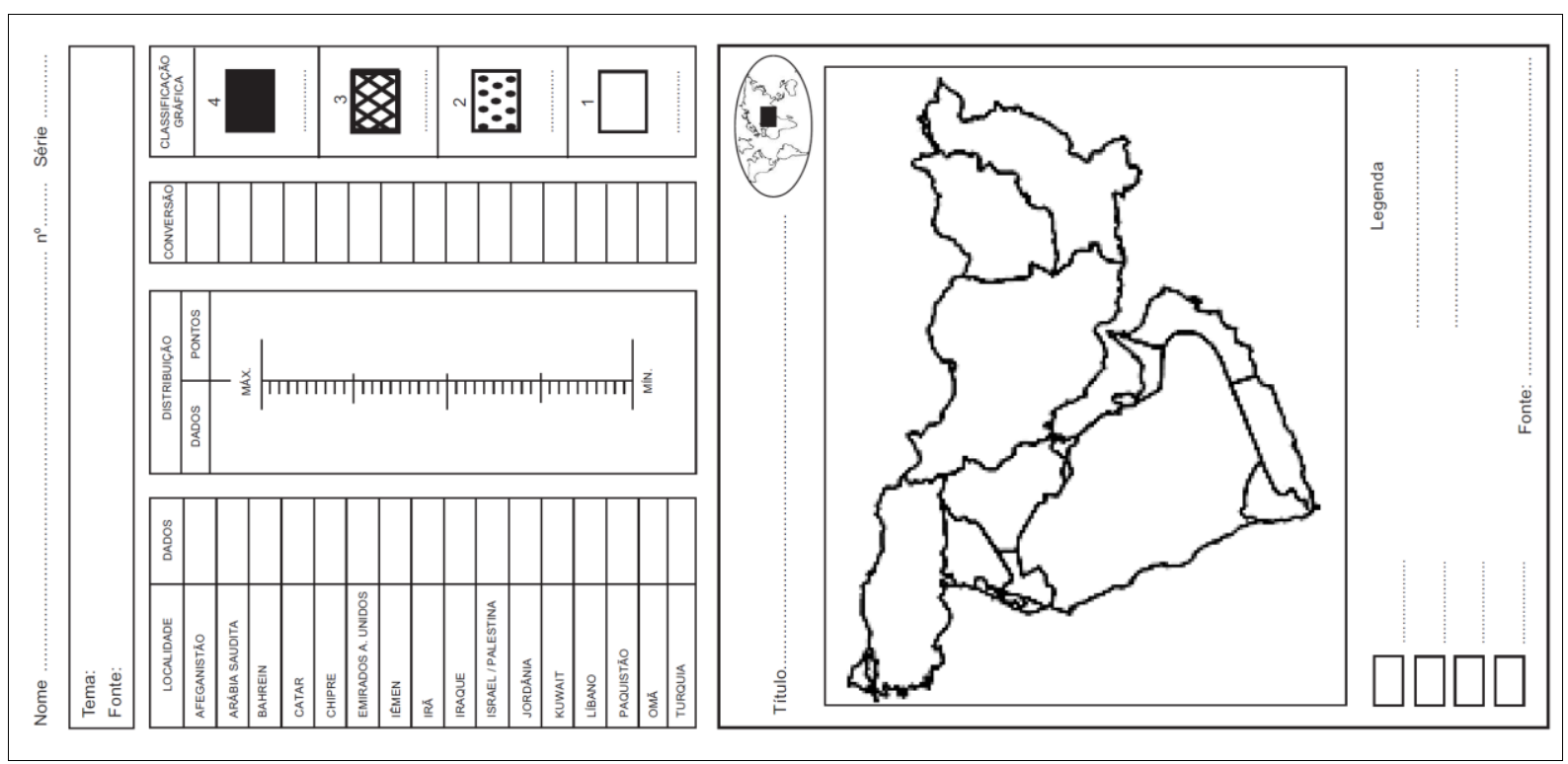

Figura 55 - Matriz da atividade aplicada na Turma 9J3 com dados sobre os recursos hídricos do Oriente Médio para elaboração de mapa ordenado relacionando ao tema da Apostila no período.
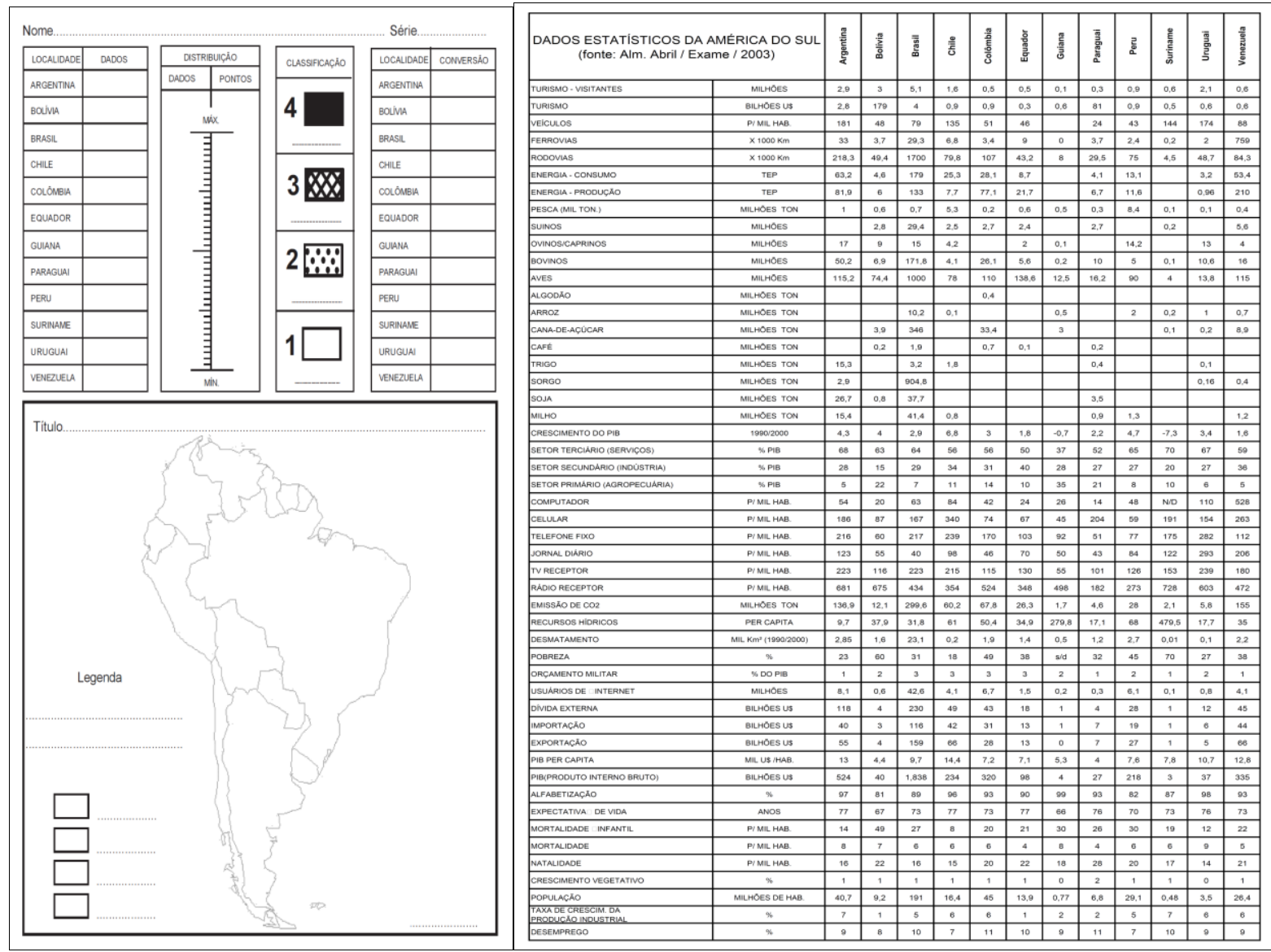

Figura 56 - Matriz para elaboração de um mapa ordenado para as três Turmas a partir de uma tabela com diversos dados estatísticos da América do Sul com o mínimo de acompanhamento do professor na Turma 9J3, e acompanhamento individual e na lousa com as demais Turmas como preparativo para a 3모 Avaliação. 


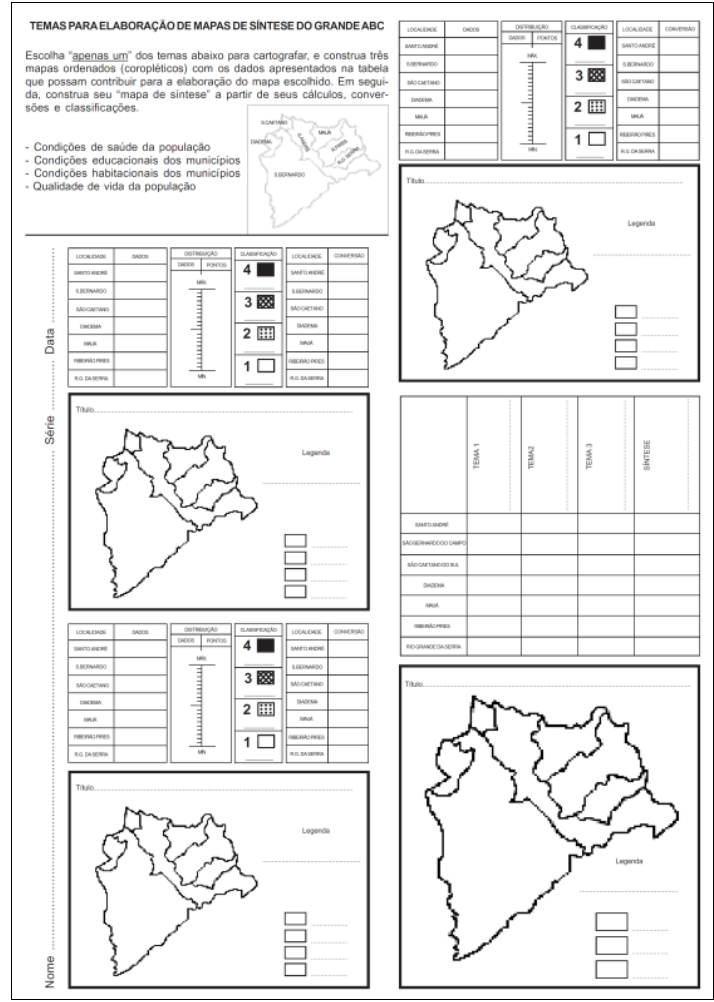

\begin{tabular}{|c|c|c|c|c|c|c|c|c|c|}
\hline \multicolumn{10}{|c|}{ DADOS ESTATÍSTICOS - GRANDE ABC } \\
\hline TEMA & DADOS & FONTE & $\begin{array}{l}\text { SANTT } \\
\text { ANDREE }\end{array}$ & $\begin{array}{l}\text { SAA } \\
\text { BERNAPDO } \\
\text { DO CAMPO }\end{array}$ & $\begin{array}{c}\text { SÃo } \\
\text { CAEARO } \\
\text { Do SUL }\end{array}$ & DAADEMA & MAUA & $\begin{array}{l}\text { RIBEIŔáo } \\
\text { PIRES }\end{array}$ & $\begin{array}{c}\text { RIO GRANDE } \\
\text { DA SERRA }\end{array}$ \\
\hline IDH & $\begin{array}{c}0.001 \\
a \\
1.000\end{array}$ & BBGE2010 & 0,835 & 0,834 & 0,919 & 0,79 & 0,781 & 0,807 & 0,764 \\
\hline RENDA PER CAPITA & $\begin{array}{l}\text { EM } \\
\text { SALARIOS } \\
\text { MiNMOS }\end{array}$ & \begin{tabular}{|l} 
SEADE \\
R2010
\end{tabular} & 3,39 & 3,34 & 5,48 & 1,94 & 1,82 & 2,39 & 1,3 \\
\hline REDE DE ESGOTO & $\%$ & $\begin{array}{l}\text { SEADE } \\
\text { R2010 }\end{array}$ & 90,32 & 87,11 & 99,44 & 92,22 & 75,44 & 81,34 & 59,34 \\
\hline $\begin{array}{l}\text { EMPREGADOS } \\
\text { NA AGRICULTURA }\end{array}$ & $\%$ & $\begin{array}{l}\text { SEADE } \\
\text { 12008 }\end{array}$ & 0,02 & 0,04 & 0,01 & 0 & 0,05 & 0,11 & 0,11 \\
\hline $\begin{array}{l}\text { EMPREGADOS } \\
\text { NA INDÚSTRIA }\end{array}$ & $\%$ & $\begin{array}{l}\text { SEADE } \\
\text { 12010 }\end{array}$ & 19,05 & 36,13 & 22,54 & 55,03 & 43,29 & 37,85 & 42,93 \\
\hline $\begin{array}{l}\text { EMPREGADOS NA } \\
\text { CONSTRUÇĀO CIVLL }\end{array}$ & $\%$ & $\begin{array}{l}\text { SEADE } \\
12010\end{array}$ & 4,23 & 3,65 & 9 & 3,22 & 9,07 & 6,51 & 12,93 \\
\hline $\begin{array}{l}\text { EMPREGADOS } \\
\text { NO COMERCIO }\end{array}$ & $\%$ & $\begin{array}{l}\text { SEADE } \\
12010\end{array}$ & 20,41 & 14,95 & 14,49 & 15,83 & 19,72 & 20,57 & 12,93 \\
\hline $\begin{array}{l}\text { EMPREGADOS NO } \\
\text { SETOR DE SERVIÇOS }\end{array}$ & $\%$ & $\begin{array}{l}\text { SEADE } \\
12010\end{array}$ & 56,29 & 45,23 & 53,96 & 25,92 & 27,88 & 34,96 & 31,08 \\
\hline PIB - 2008 & $\begin{array}{c}\text { PER } \\
\text { CAPTA }\end{array}$ & BBGE2010 & $20.018,82$ & $37.267,11$ & $67.361,35$ & $23.618,26$ & $13.752,84$ & $13.347,20$ & $8.536,14$ \\
\hline AREA & $\mathrm{Km}^{2}$ & IBGE21010 & 175 & 409 & 15 & 31 & 61 & 99 & 37 \\
\hline $\begin{array}{l}\text { DENSIDADE } \\
\text { DEMOGRAFICA }\end{array}$ & HАВКК" & 18GE2010 & $3.866,35$ & $1.872,59$ & $9.708,79$ & $12.519,10$ & $6.803,54$ & $1.144,99$ & $1.192,45$ \\
\hline AUTOMÓVEIS & $\begin{array}{c}p / 1000 \\
\text { hab. }\end{array}$ & BBGE2010 & 450 & 413 & 589 & 233 & 255 & 317 & 173 \\
\hline $\begin{array}{l}\text { DOCENTES NO } \\
\text { ENSINO FUNDAMENTAL }\end{array}$ & $\begin{array}{c}p^{\prime} 11000 \\
\text { hab. }\end{array}$ & $\begin{array}{l}\text { SEADE } \\
2010\end{array}$ & 6.5 & 6.1 & 7.8 & 6.8 & 6.2 & 7.5 & 6.6 \\
\hline MÉDICOS & $\begin{array}{l}\text { p/ } 1000 \\
\text { hab. }\end{array}$ & CRM & 2,52 & 1,44 & 4,25 & 0,13 & 0,15 & 1,11 & 0,05 \\
\hline $\begin{array}{l}\text { ANOS DE ESTUDO DA } \\
\text { P.E.A. (15 A A64 ANOS) }\end{array}$ & MÉDIA & 18GE2010 & 8,42 & 8,31 & 9,76 & 7 & 7,05 & 7,84 & 6,57 \\
\hline $\begin{array}{l}\text { ESTABELECIMENTOS } \\
\text { DE SAUDE-SUS }\end{array}$ & $\begin{array}{c}\mathrm{p} / 10 \mathrm{mill} \\
\text { hab. }\end{array}$ & 18GE2009 & 1,12 & 1,09 & 3,92 & 1,24 & 1,39 & 1,02 & 5,49 \\
\hline
\end{tabular}

Figura 57 - Tabela e matriz utilizada nas três Turmas para elaboração de três mapas analíticos e um mapa de síntese a partir de um tema escolhido por cada dupla de alunos com os dados fornecidos pelo professor.

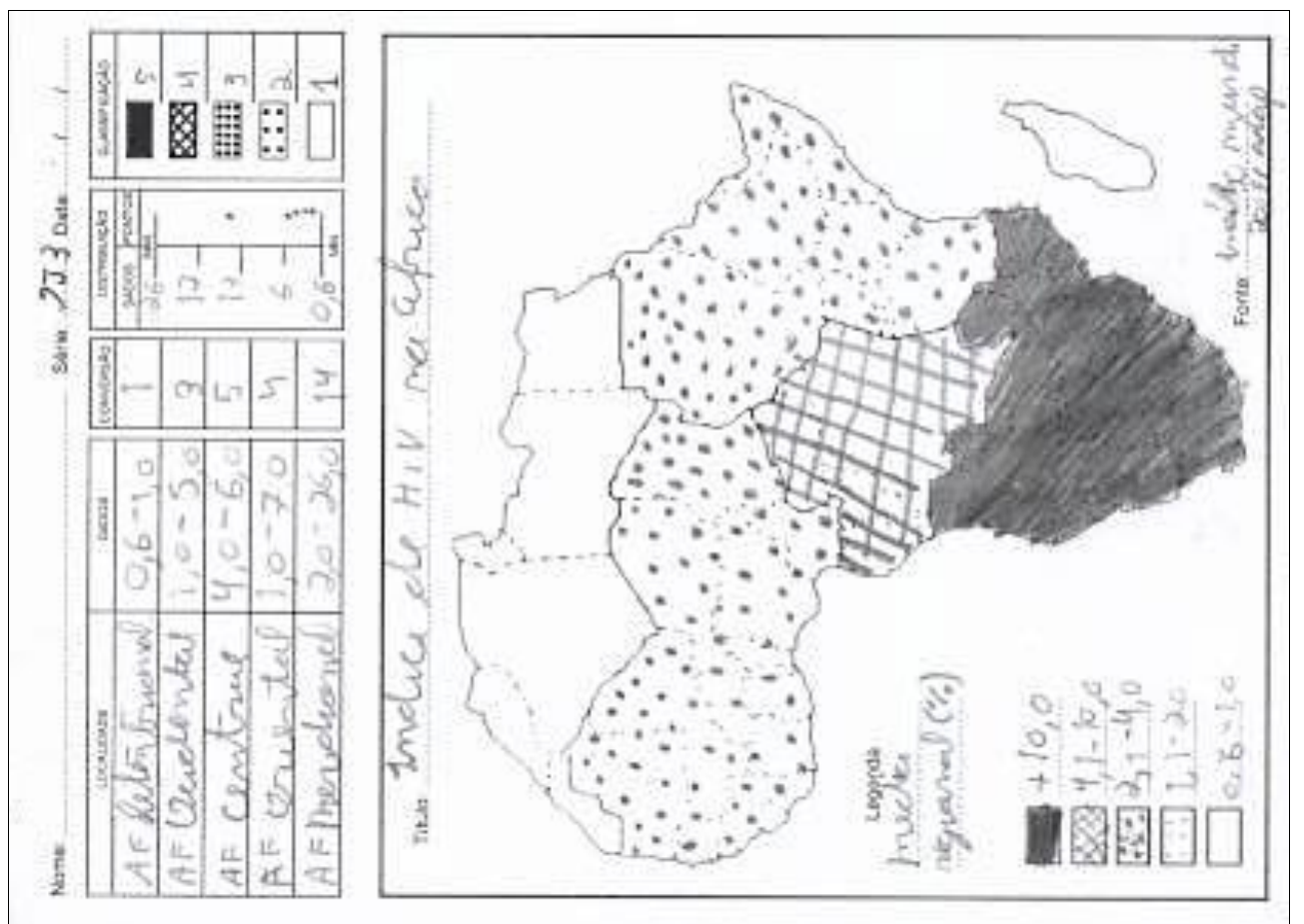

Figura 58 - Mapa ordenado elaborado na Turma 9J3 com acompanhamento do professor na lousa em aproximadamente 40 minutos utilizando granulações em grafite. 


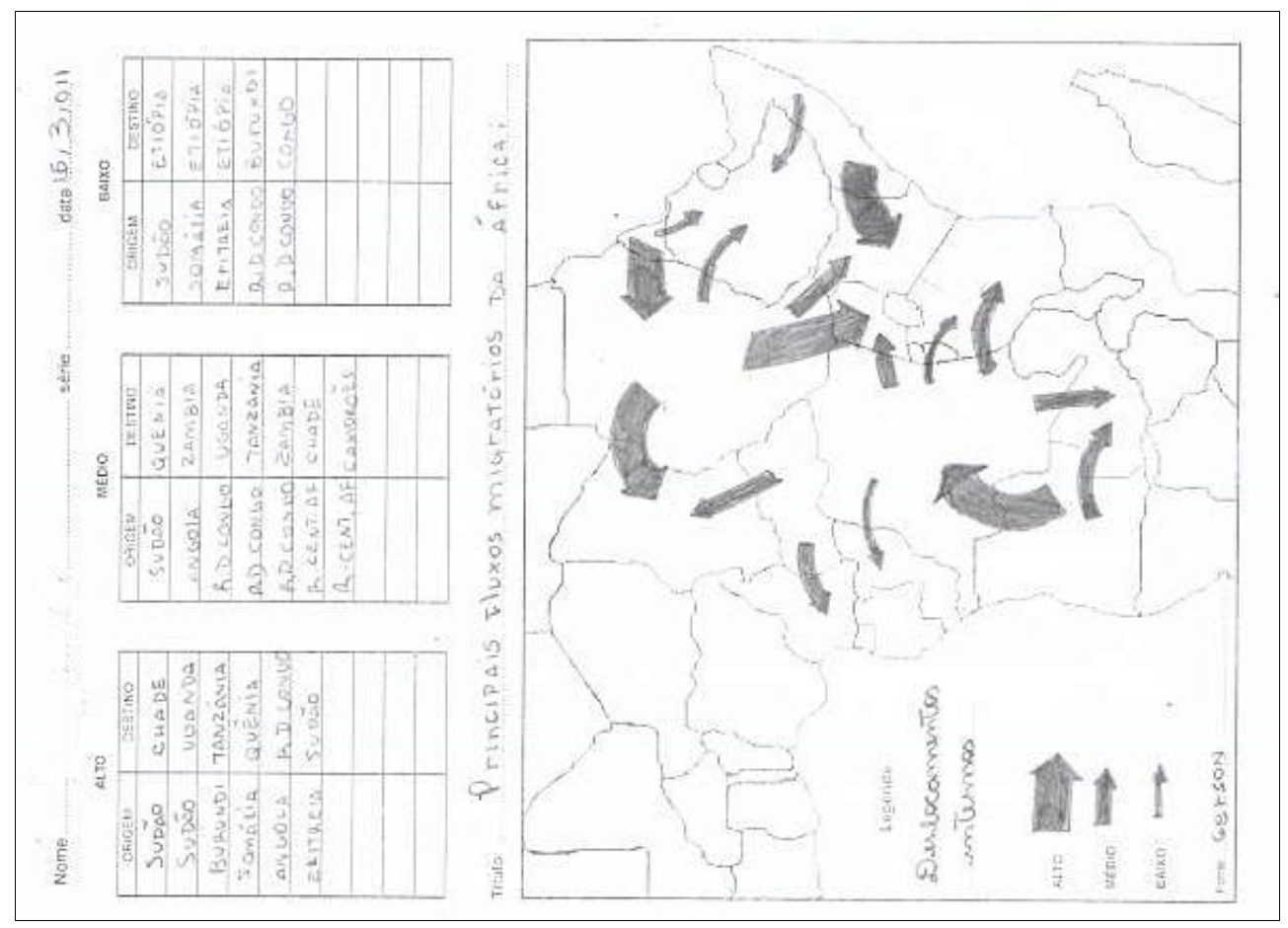

Figura 59 - Mapa dinâmico elaborado na Turma 9J1 com acompanhamento do professor na lousa e individualmente em aproximadamente 50 minutos utilizando gabarito de curvas proporcionais.

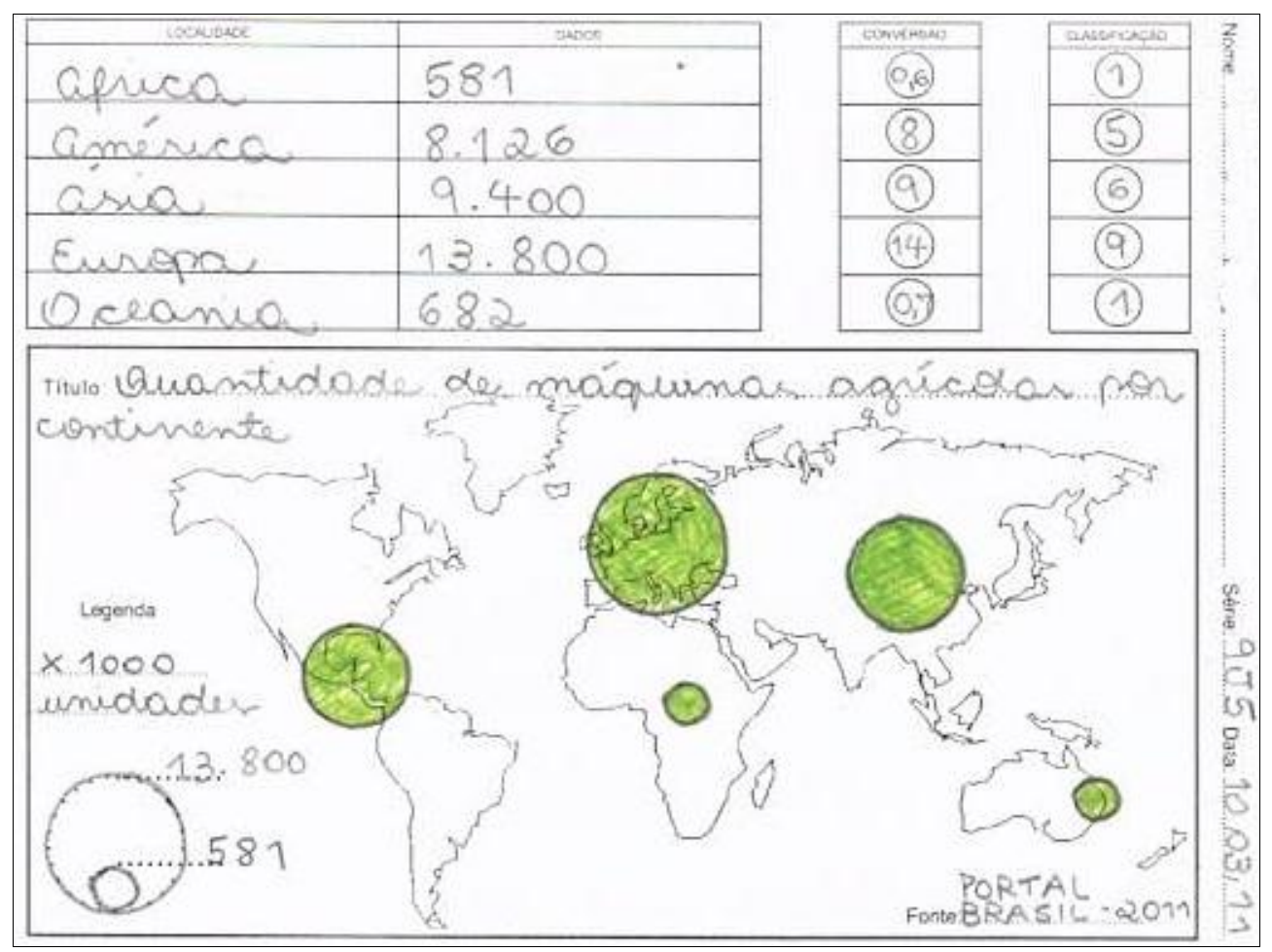

Figura 60 - Mapa quantitativo elaborado na Turma 9J5 com acompanhamento do professor na lousa em aproximadamente 30 minutos utilizando gabarito de círculos proporcionais. 


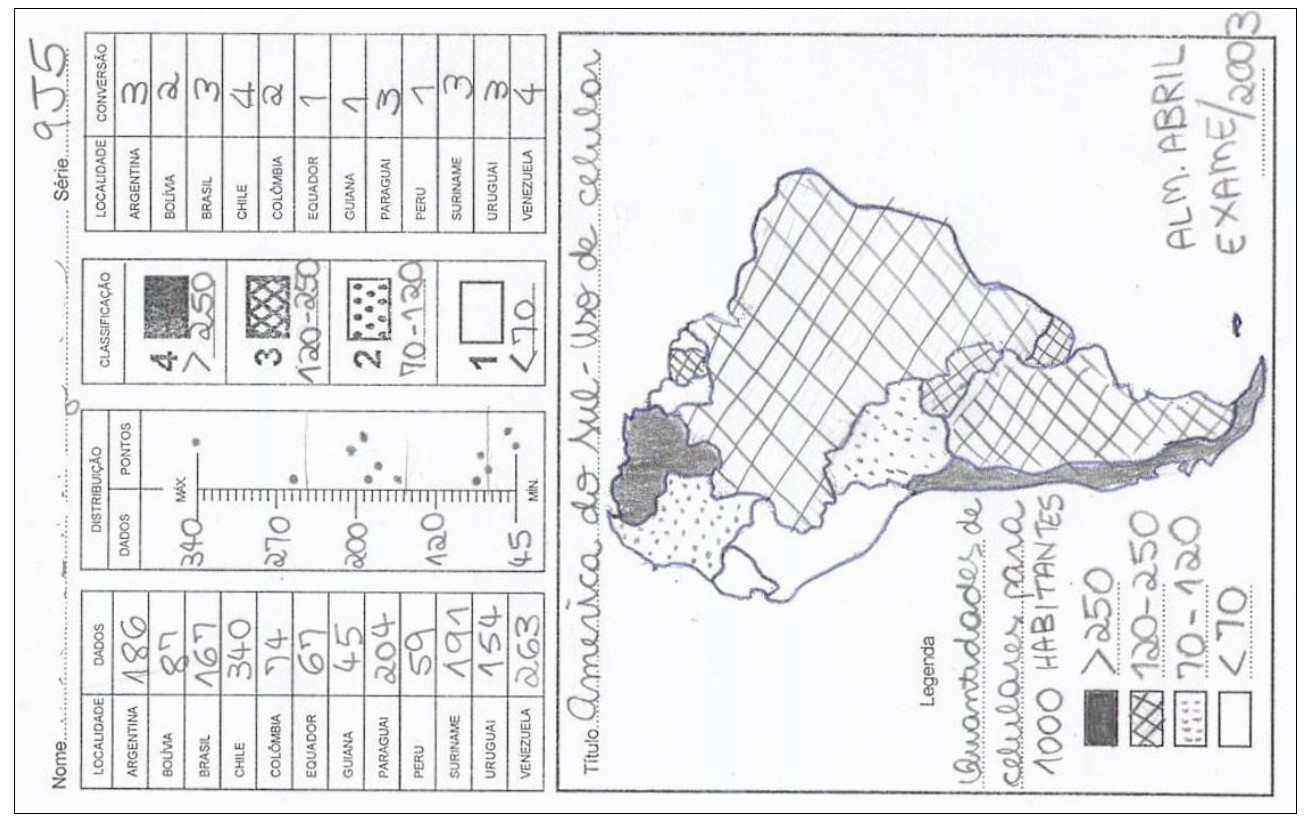

Figura 61 - Mapa ordenado elaborado individualmente nas três Turmas em aproximadamente 40 minutos, a partir de uma planilha fornecida para cada dupla de alunos para a escolha de um dos temas em valores relativos.

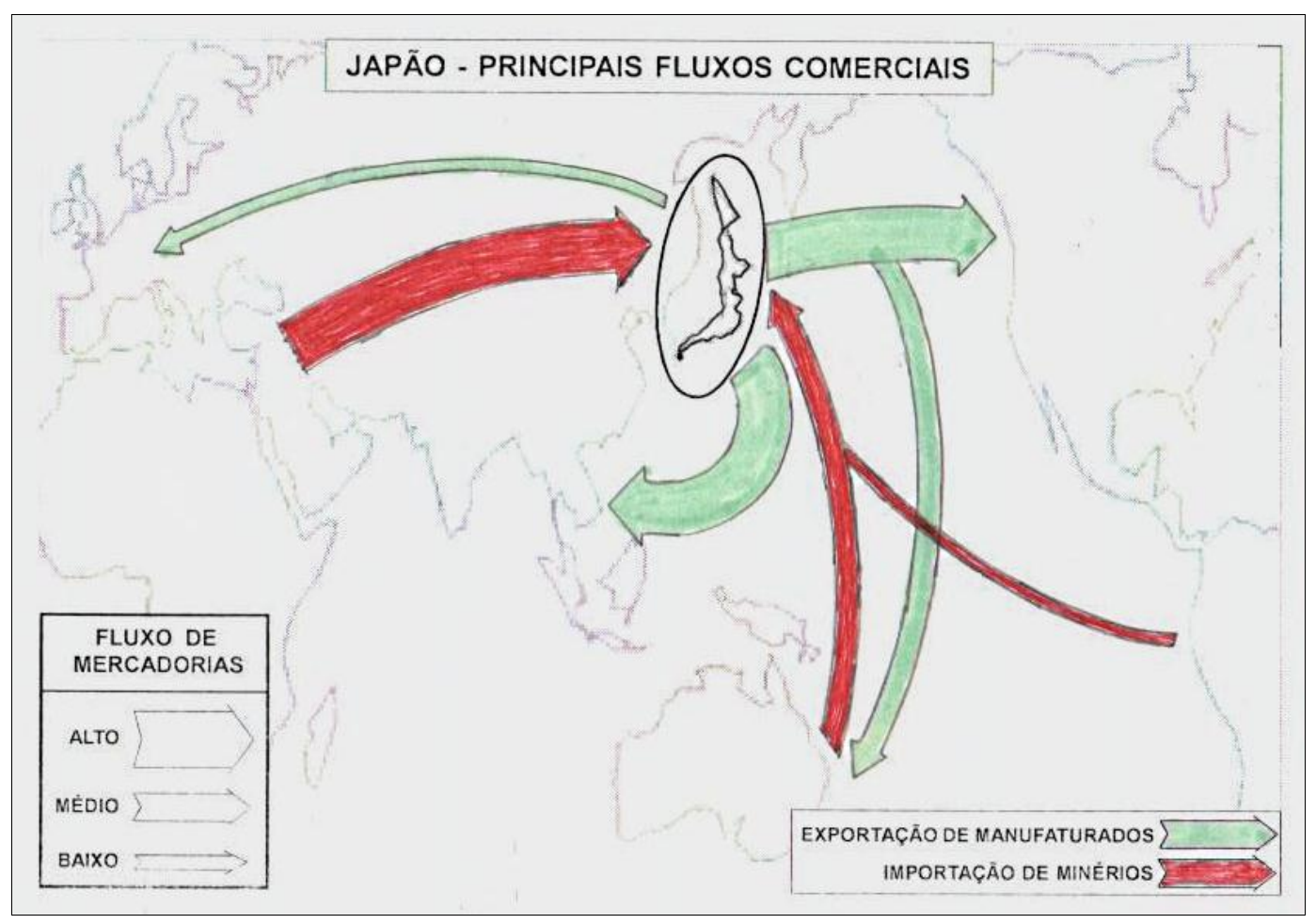

Figura 62 - Mapa dinâmico elaborado pela Turma 9J1 em aproximadamente 50 minutos a partir de dados apresentados na lousa com origem e destino das importações e exportações do Japão, além do tipo de mercadoria e quantidade (alto / médio / baixo) para ser preenchido com gabarito de curvas proporcionais. 


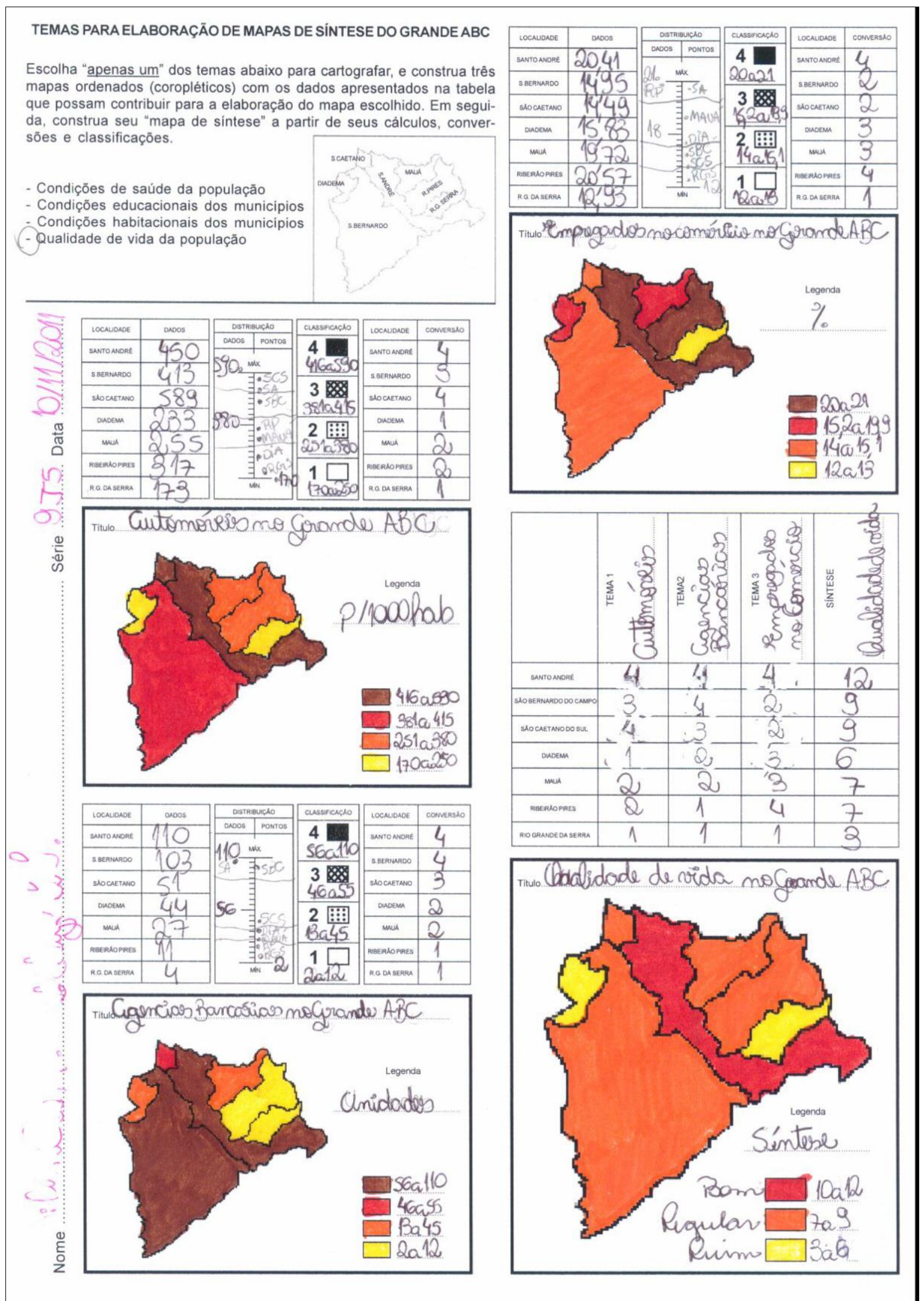

Figura 63 - Mapa de síntese elaborado pelas três Turmas entre 60 a 80 minutos a partir do cálculo de três mapas analíticos com temas relacionados com um dos quatro assuntos apresentados pelo professor a critério de cada dupla de alunos. Embora o professor tenha orientado para utilizar granulações, a maioria dos alunos preferiu utilizar cores ordenadas, e até com caneta hidrocor, que não apresenta bons resultados, mas não foram impedidos pelo professor. 
IMAGENS DOS CADERNOS DOS ALUNOS DO 9o ANO DE ESCOLA PARTICULAR

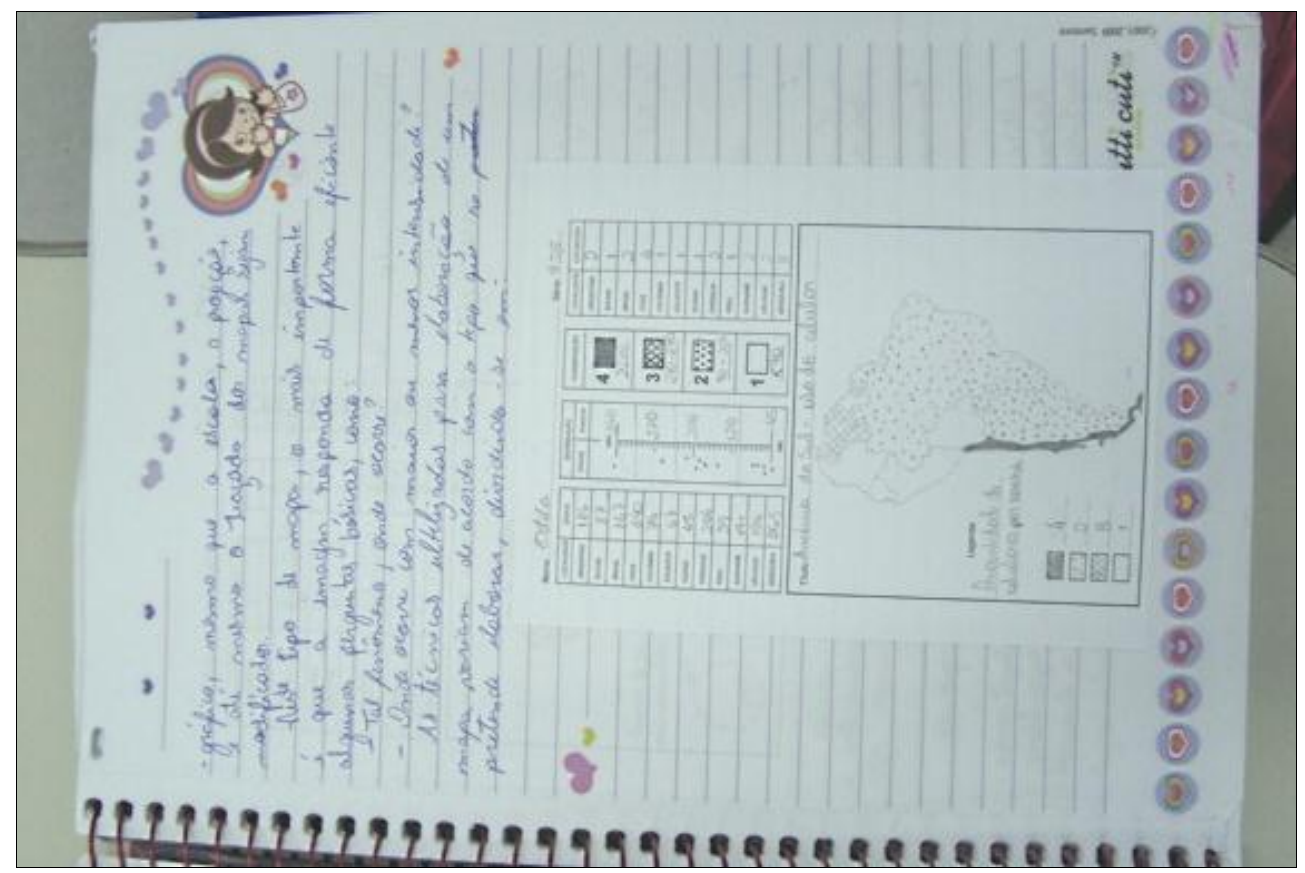

Figura 64 - Mapa ordenado da América do Sul elaborado com critérios de classificação de dados próprios de cada aluno e exemplificado em lousa com tema de interesse dos alunos (uso de celular).

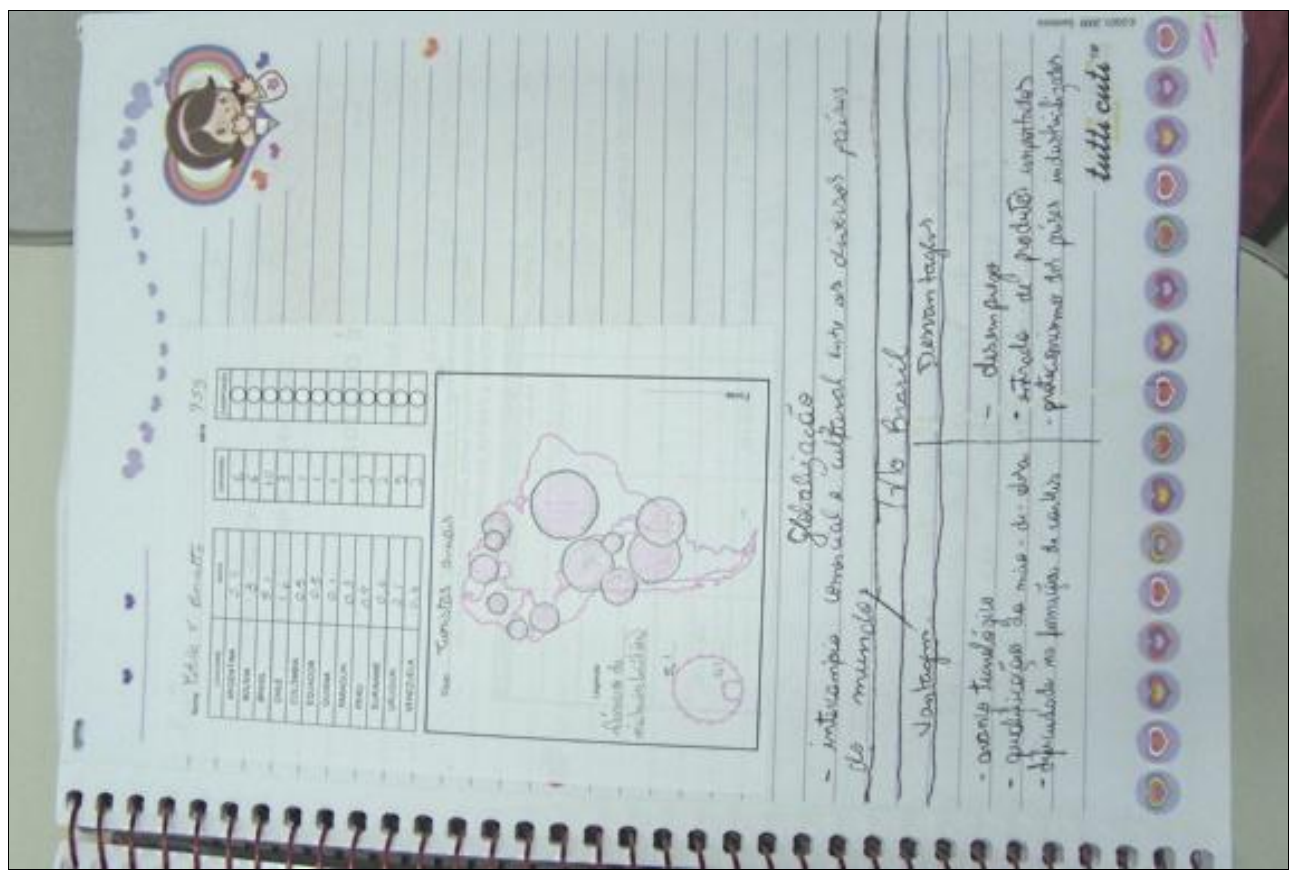

Figura 65 - Mapa quantitativo elaborado com gabarito de círculos proporcionais com tema relacionado ao assunto em estudo (Economia da América do Sul). 


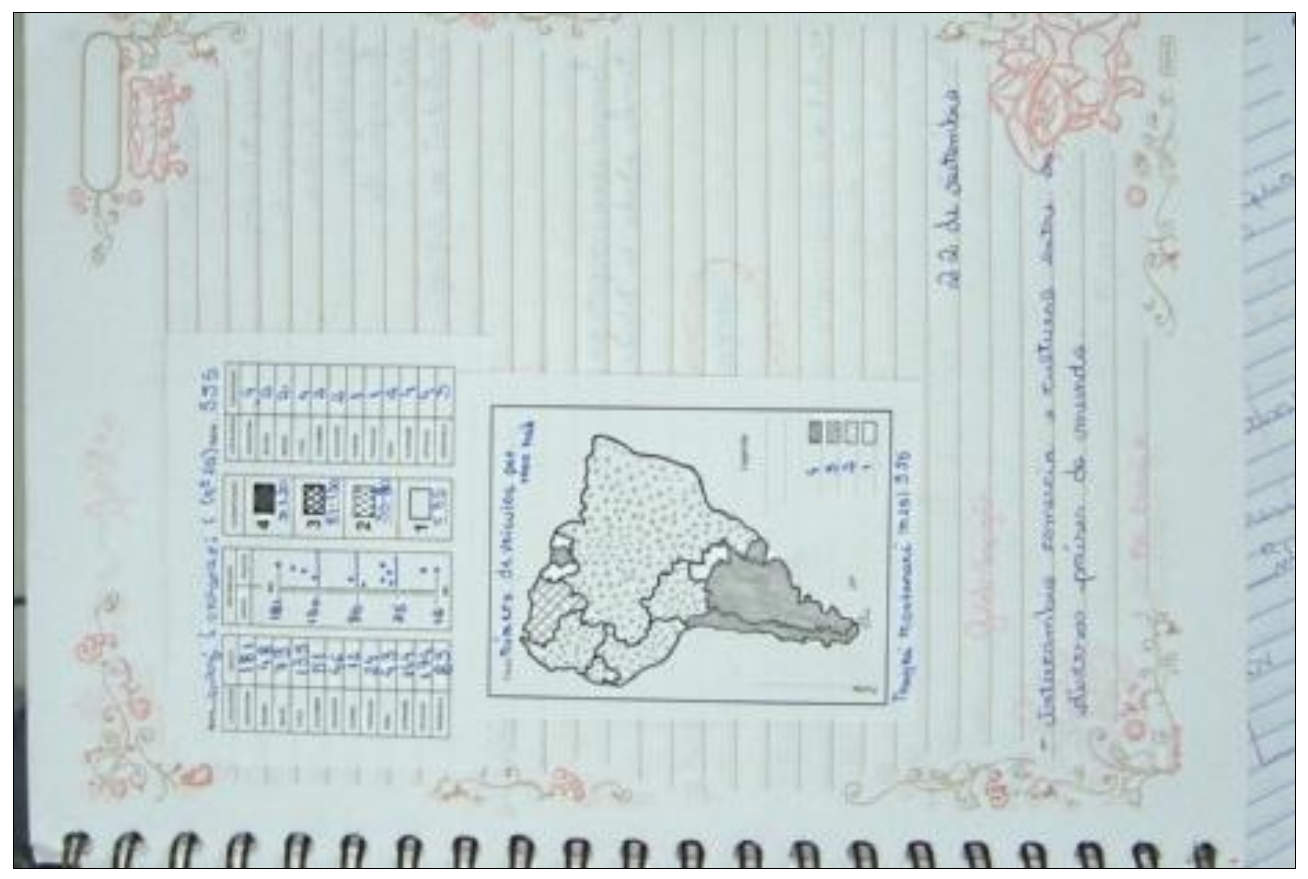

Figura 66 - Mapa ordenado da América do Sul com o tema "automóveis no continente", um dos temas escolhidos e elaborados com critérios de classificação de dados próprios de cada aluno.

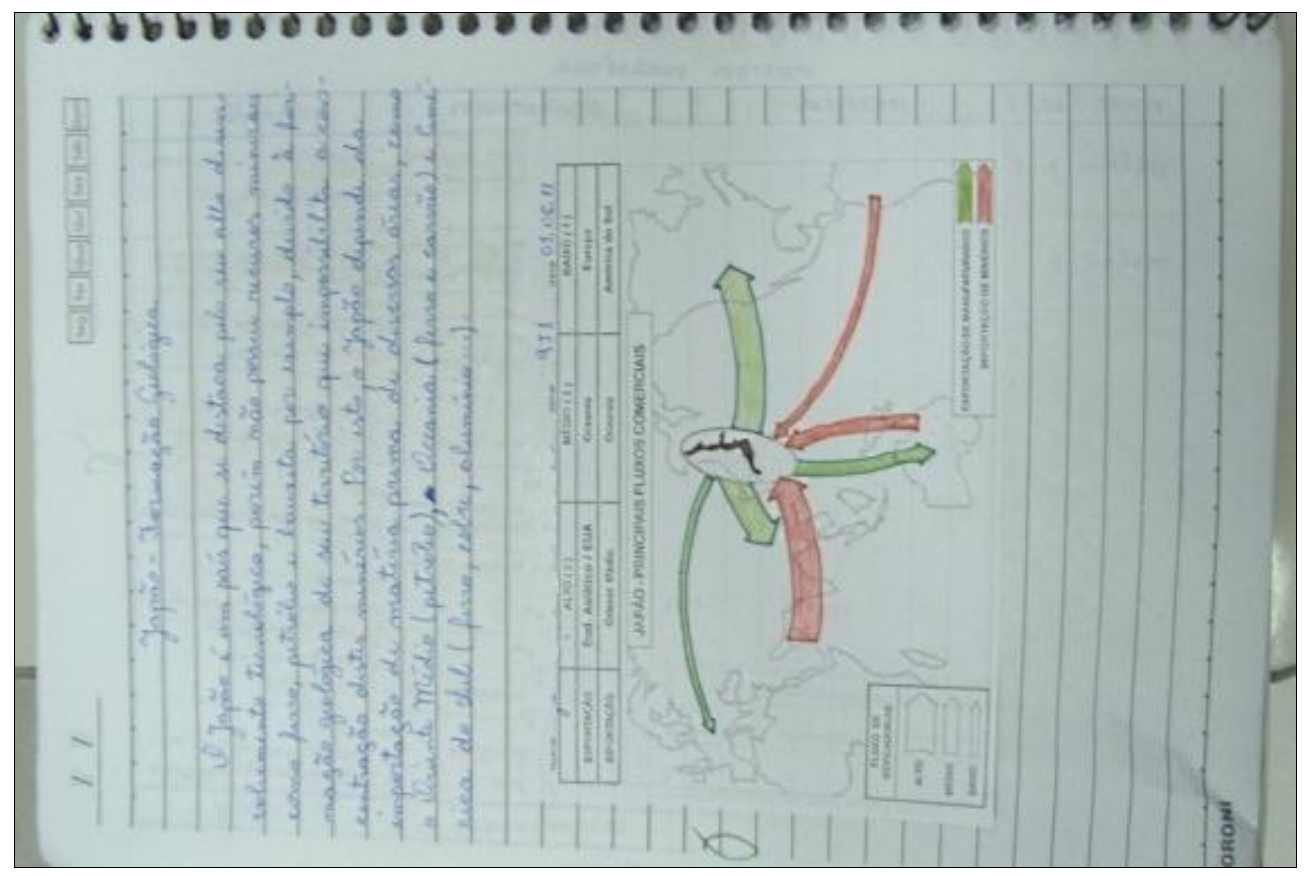

Figura 67 - Mapa dinâmico sobre a economia do Japão elaborado com gabarito de curvas proporcionais. 


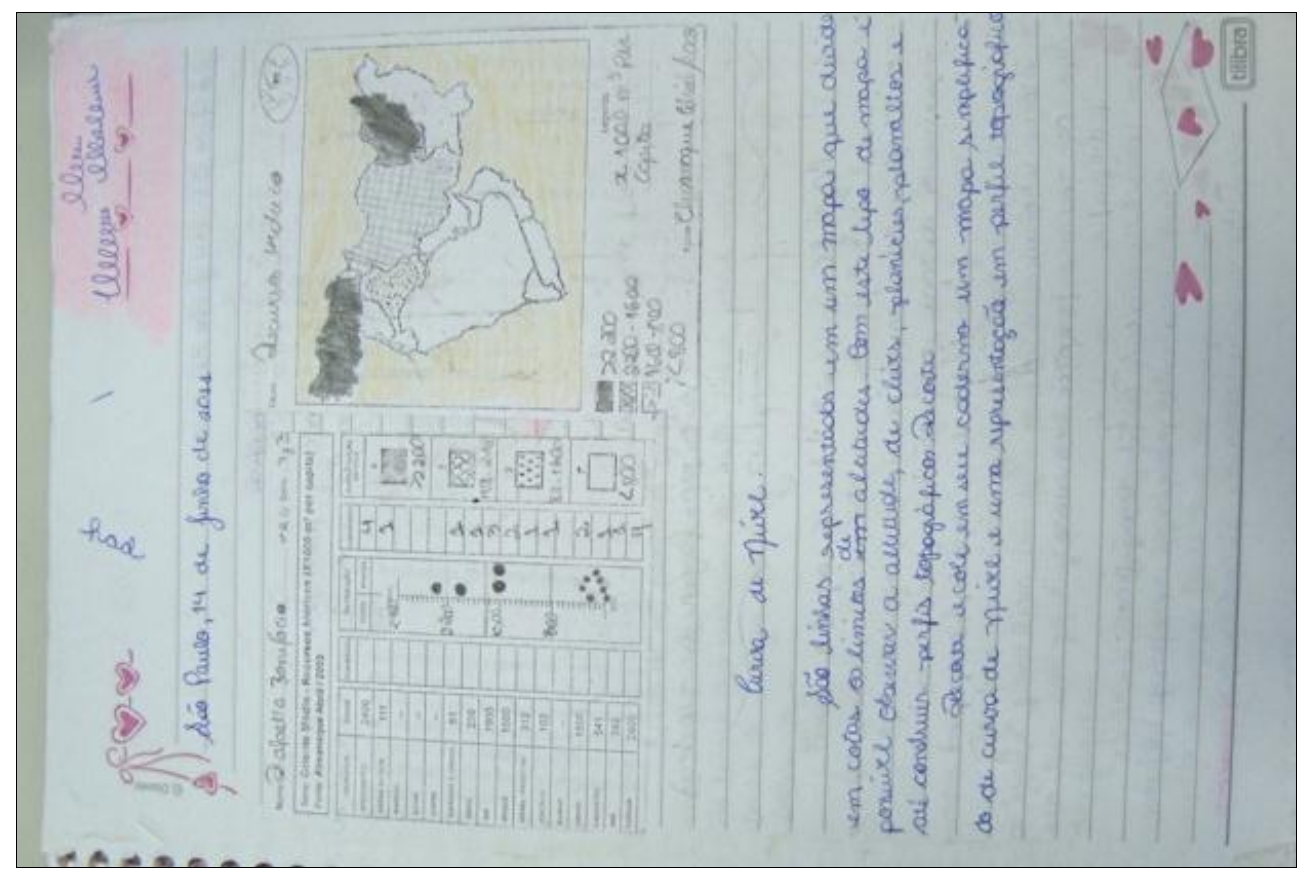

Figura 68 - Mapa ordenado do Oriente Médio elaborado com critérios de classificação de dados próprios de cada aluno.

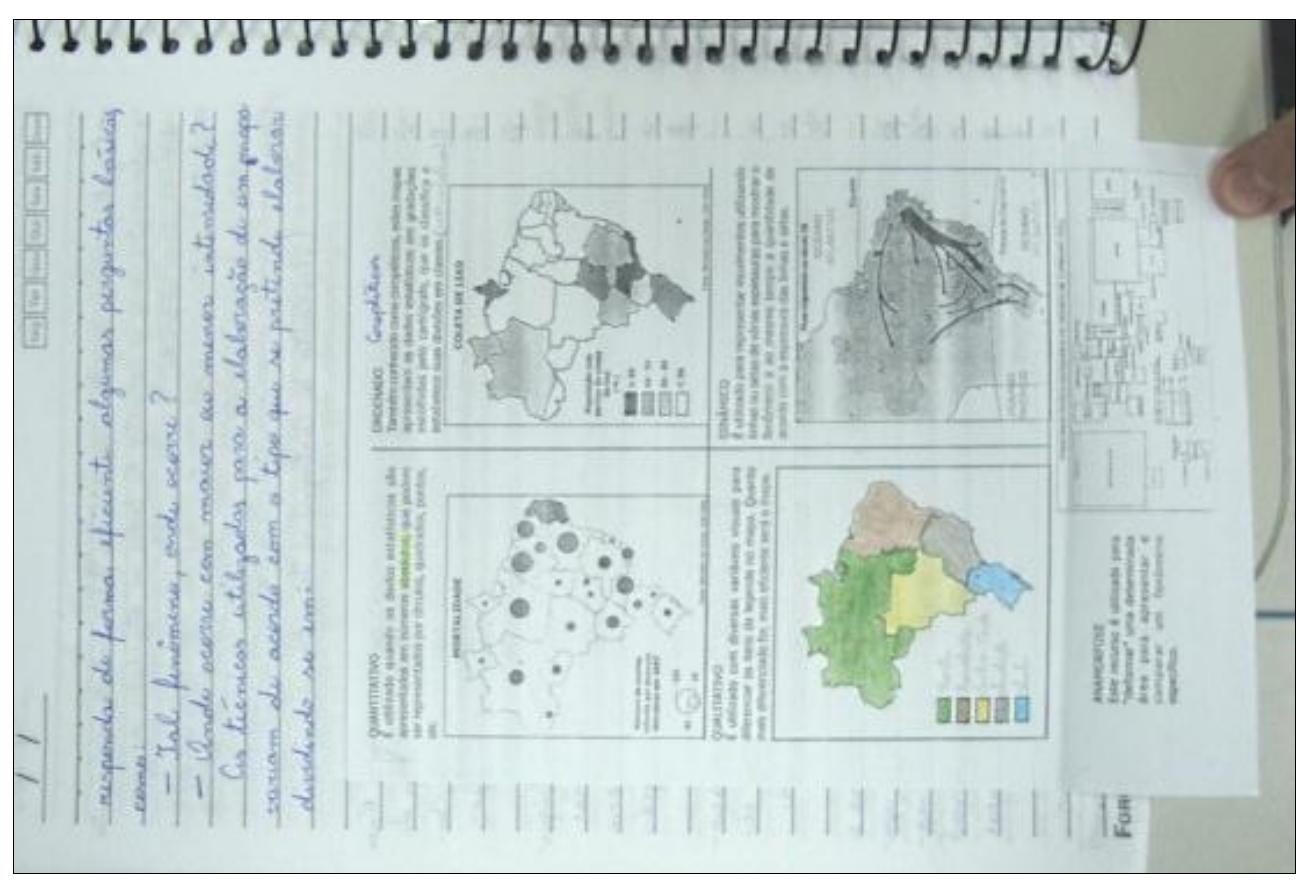

Figura 69 - Exemplos de tipos de mapas temáticos estudados durante a parte teórica sobre o tema. 


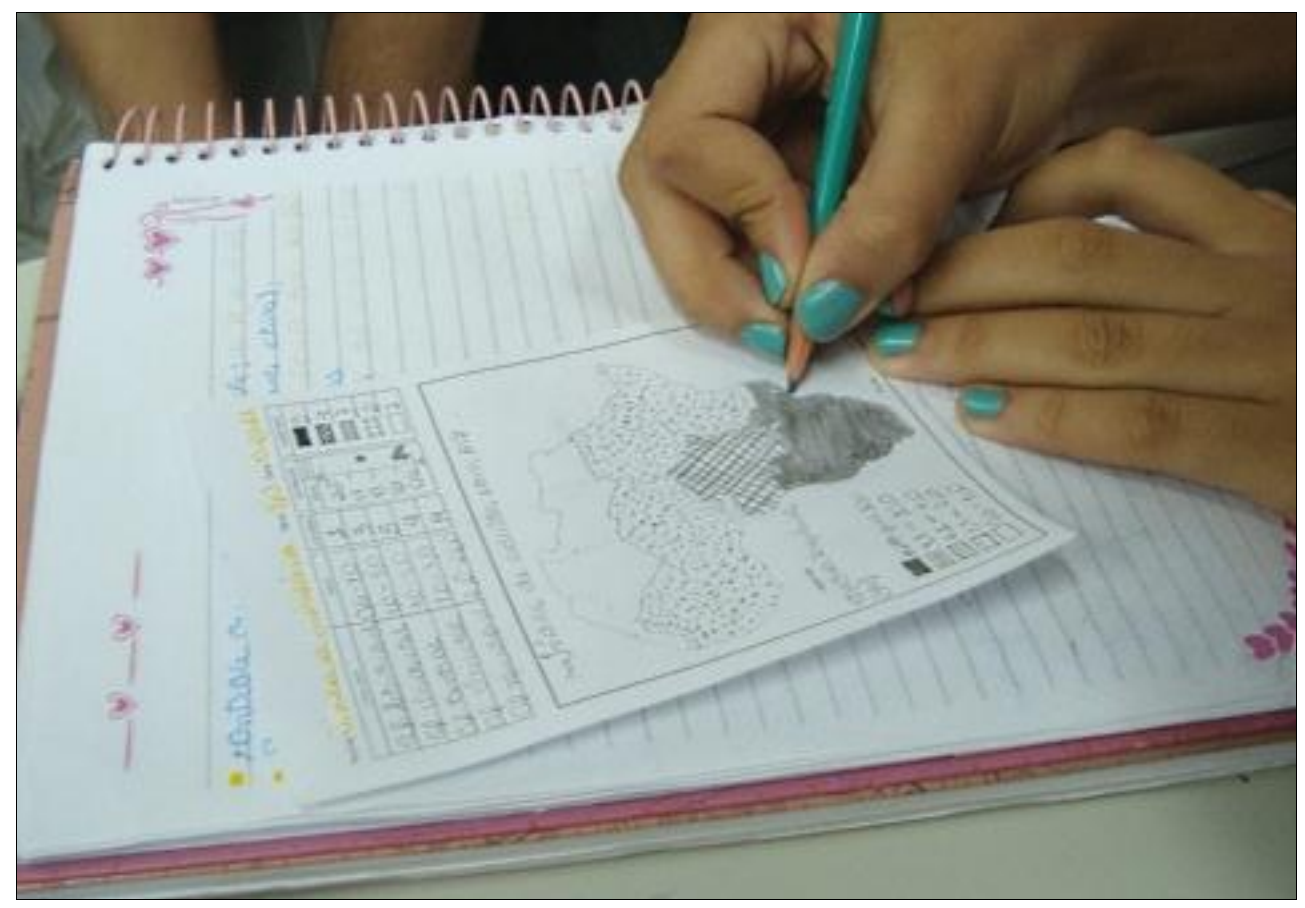

Figura 70 - Preenchimento de mapa ordenado das regiões africanas com granulações utilizando lápis grafite.

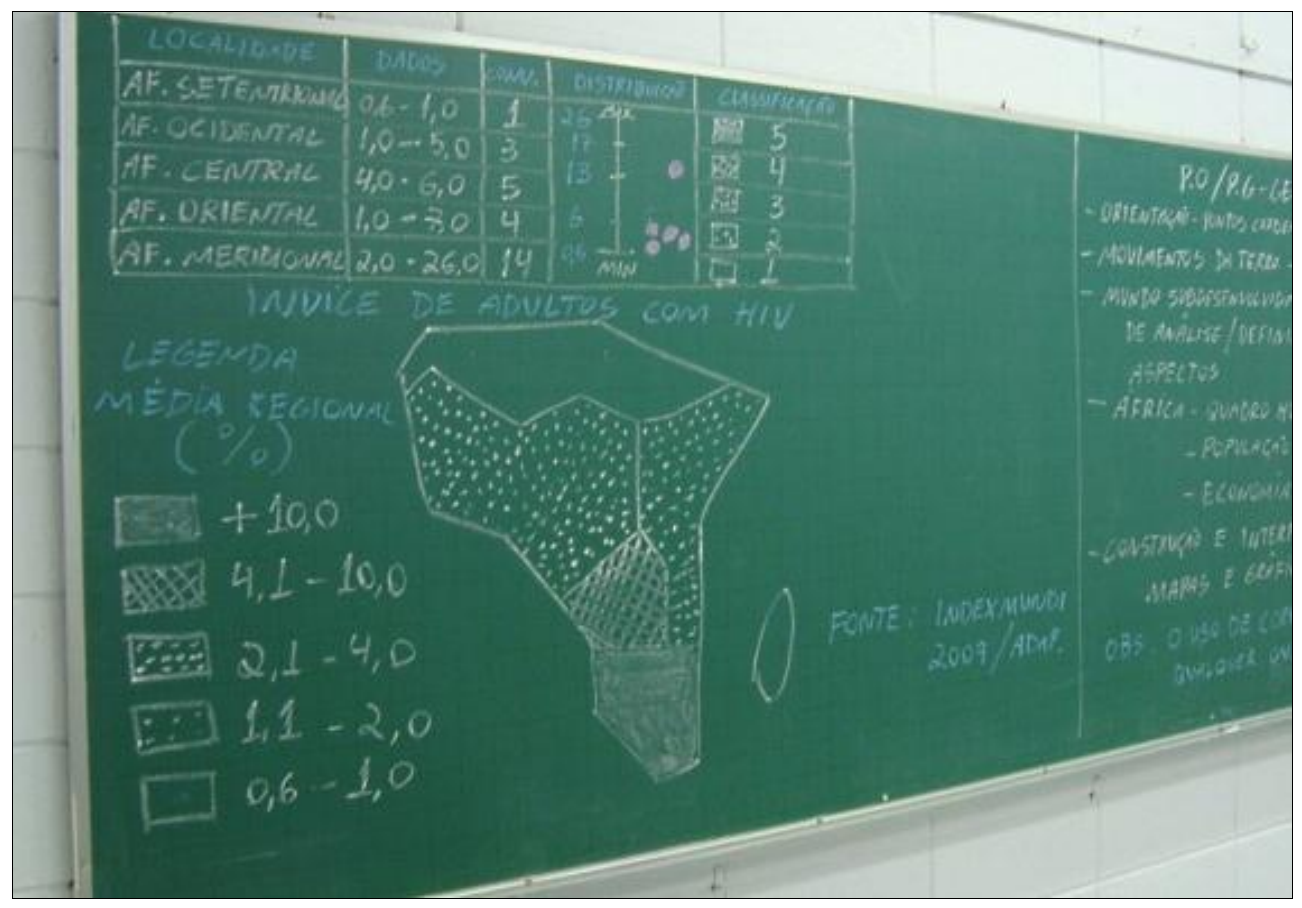

Figura 71 - Croqui das regiões africanas e tabela elaborada em lousa previamente para explicação dos procedimentos para elaboração de mapas ordenados. 


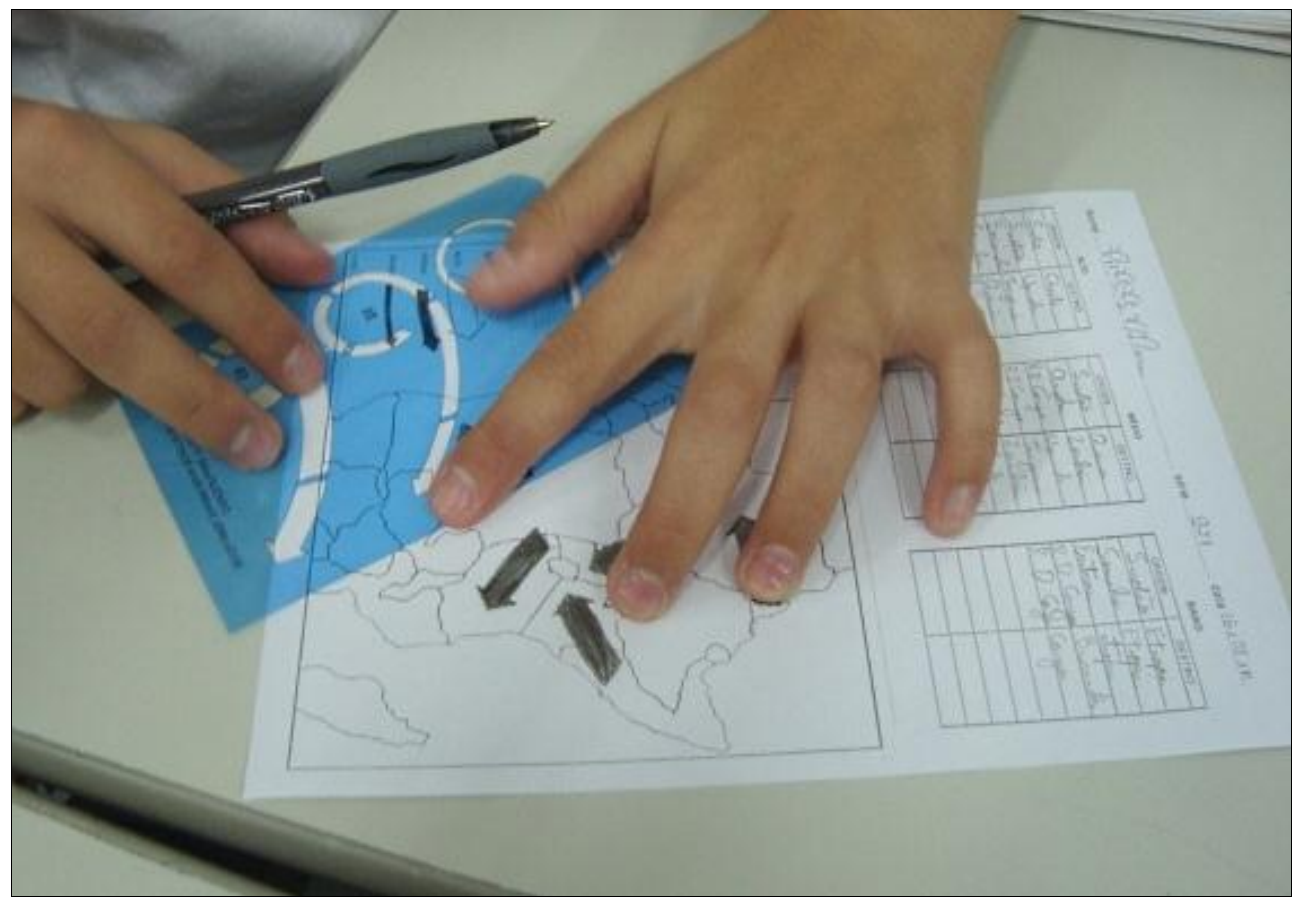

Figura 72 - Elaboração de mapa dinâmico com o uso de gabarito de curvas proporcionais. Os dados de origem/destino e a intensidade alto/médio/baixo foram copiados na tabela pelos alunos a partir da tabela elaborada em lousa.

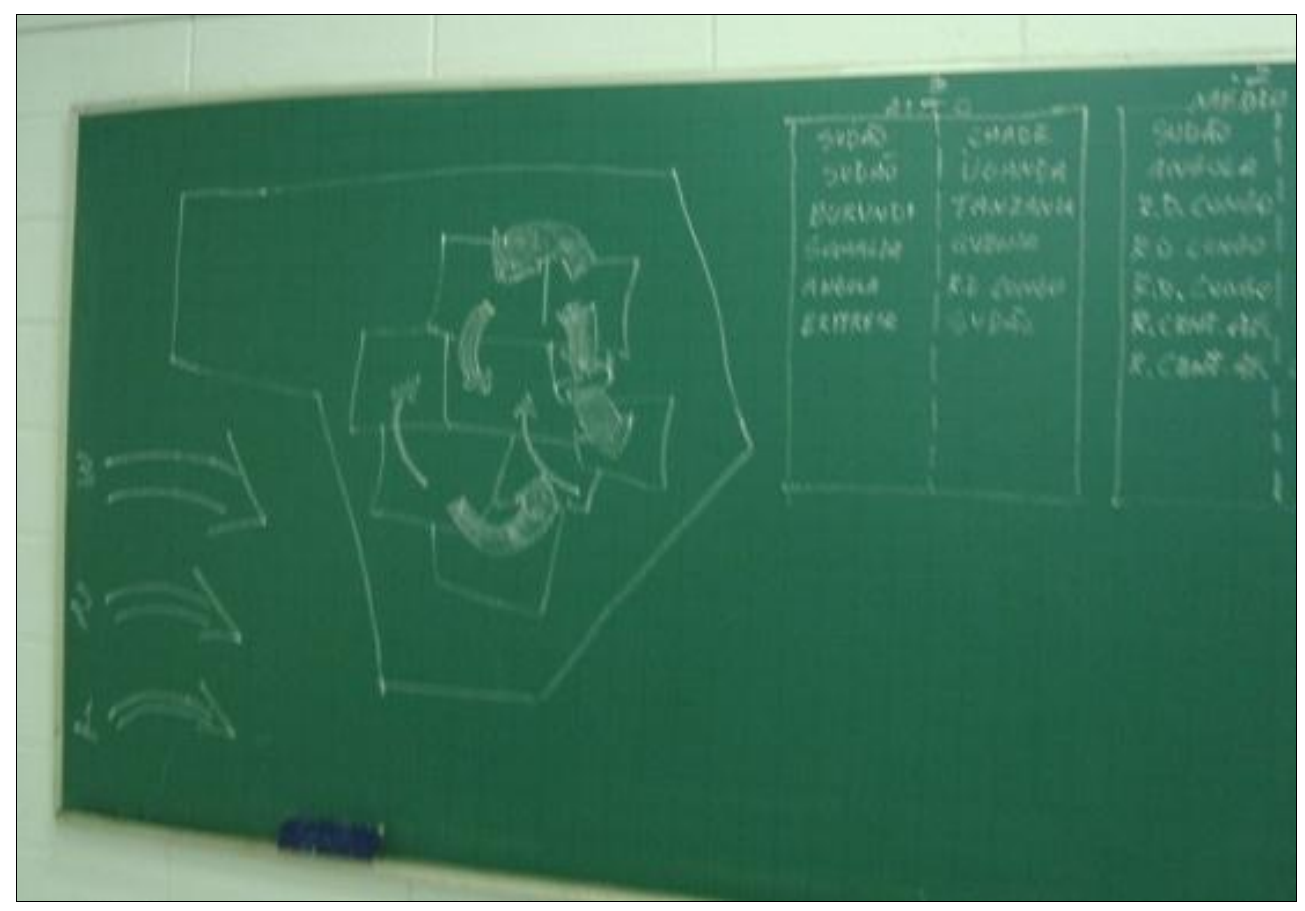

Figura 73 - Croqui e tabela em lousa para explicação dos procedimentos de elaboração de mapa dinâmico com os principais fluxos migratórios do continente africano. 


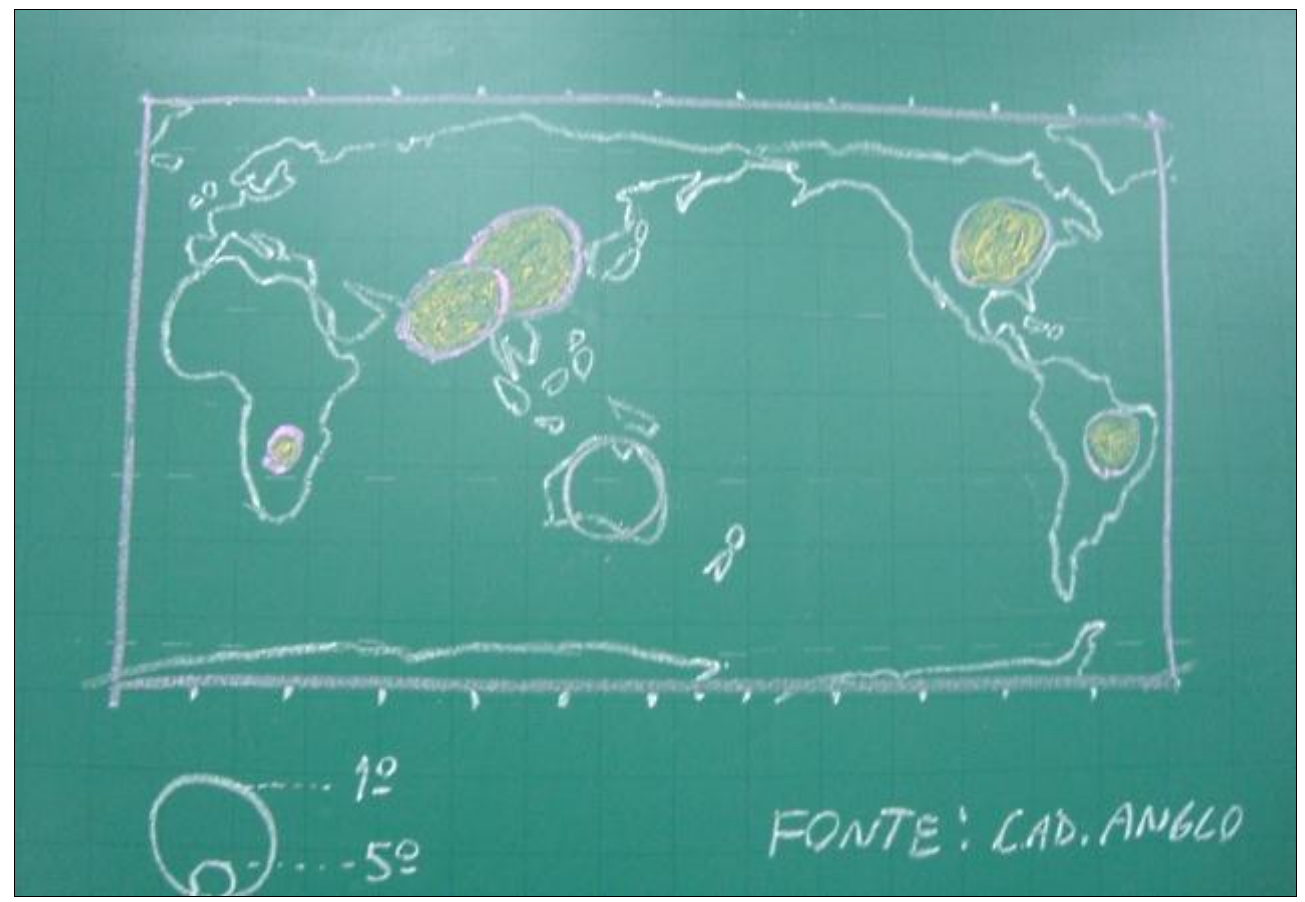

Figura 74 - Planisfério elaborado com gabarito em duplicata para centralização na longitude $180^{\circ}$, como exemplo para os mapas dos alunos.

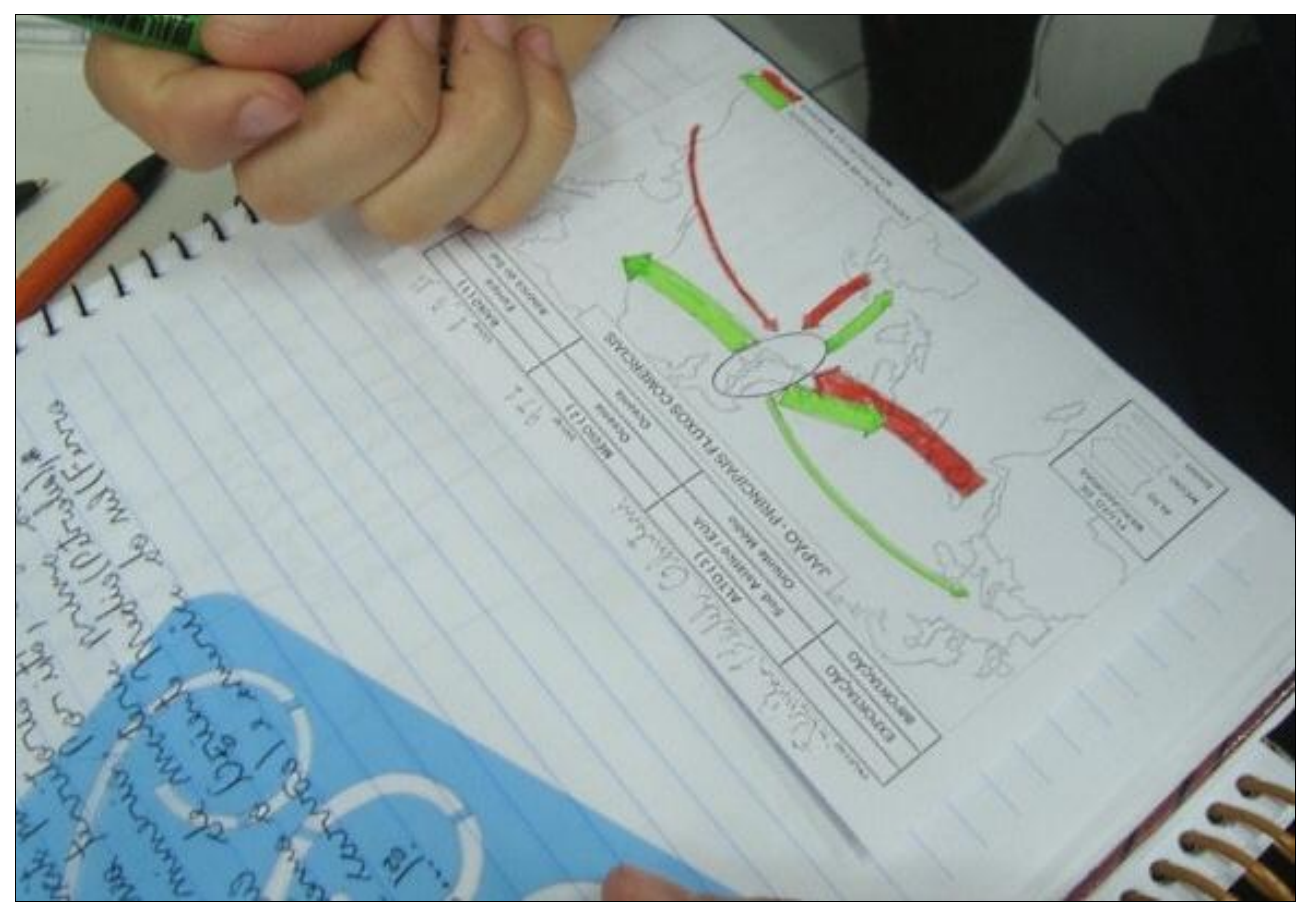

Figura 75 - Elaboração de mapa com os principais parceiros comerciais do Japão utilizando gabarito de curvas proporcionais e matriz com tabela "origem/destino". 


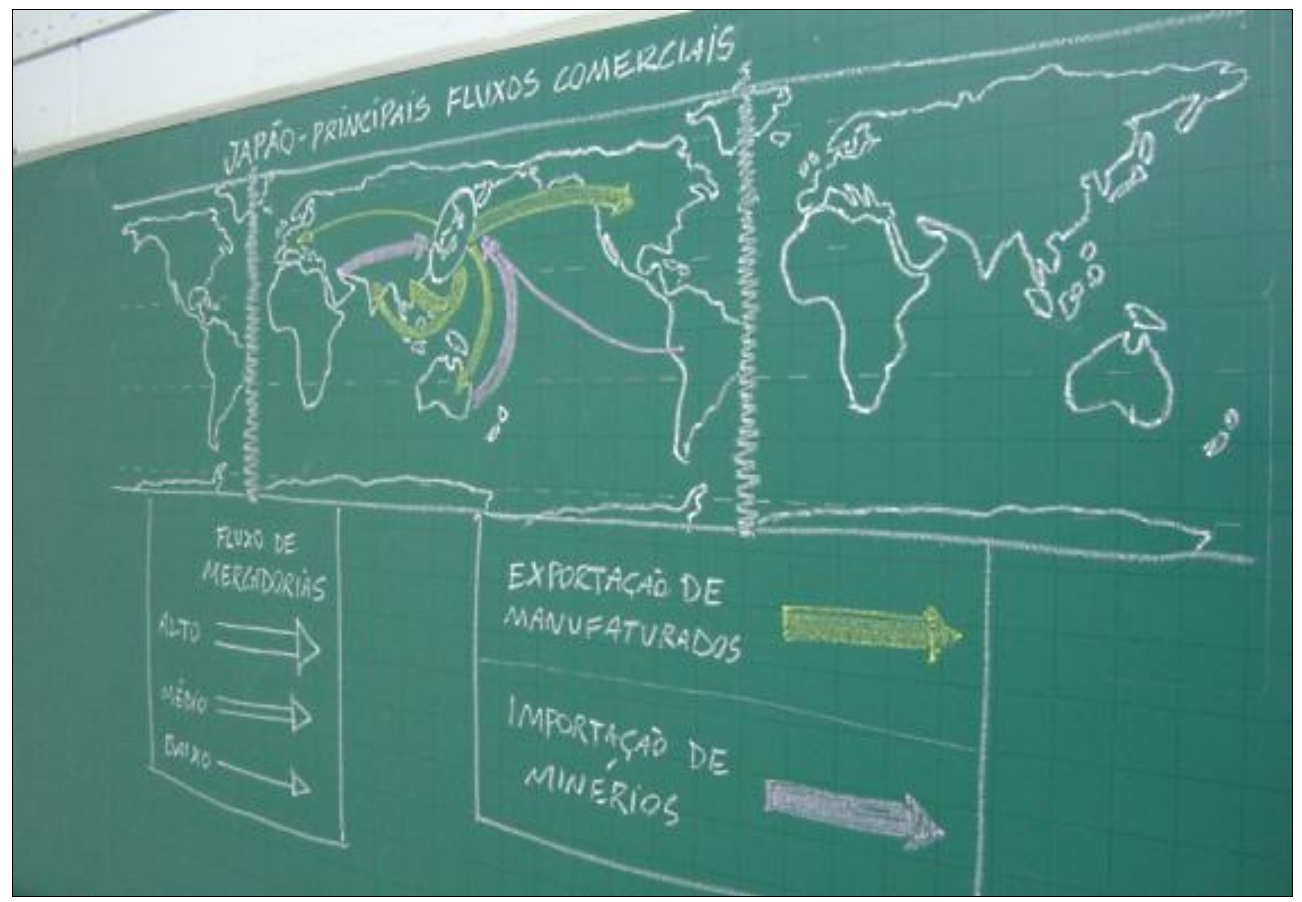

Figura 76 - Planisfério elaborado em lousa com gabarito em duplicata centralizado no Japão para acompanhamento inicial dos procedimentos pelos alunos.

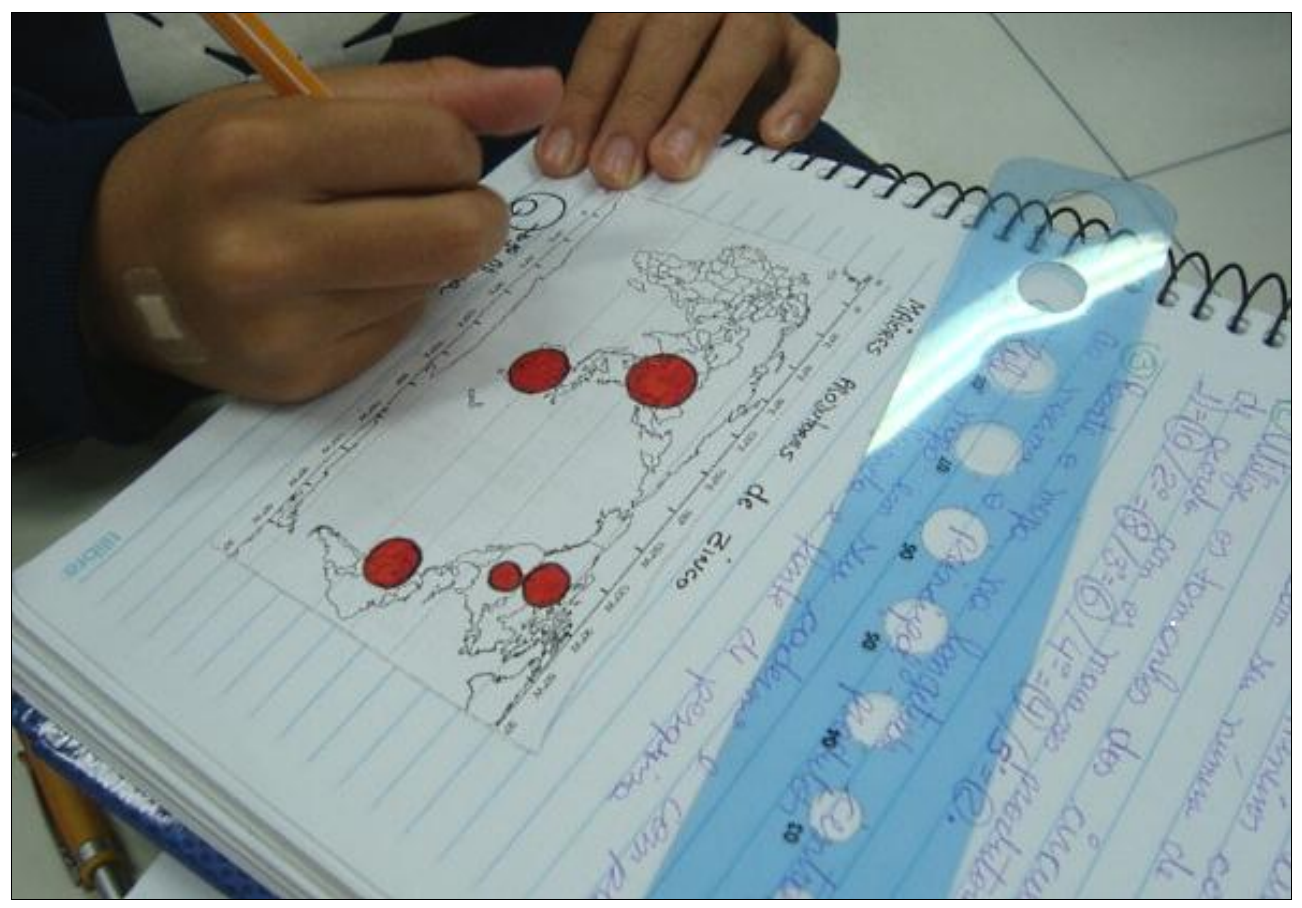

Figura 77 - Preenchimento de mapa quantitativo com o uso de gabarito de círculos proporcionais e matriz em duplicata para raport (emenda das longitudes) centralizado em qualquer localidade. 


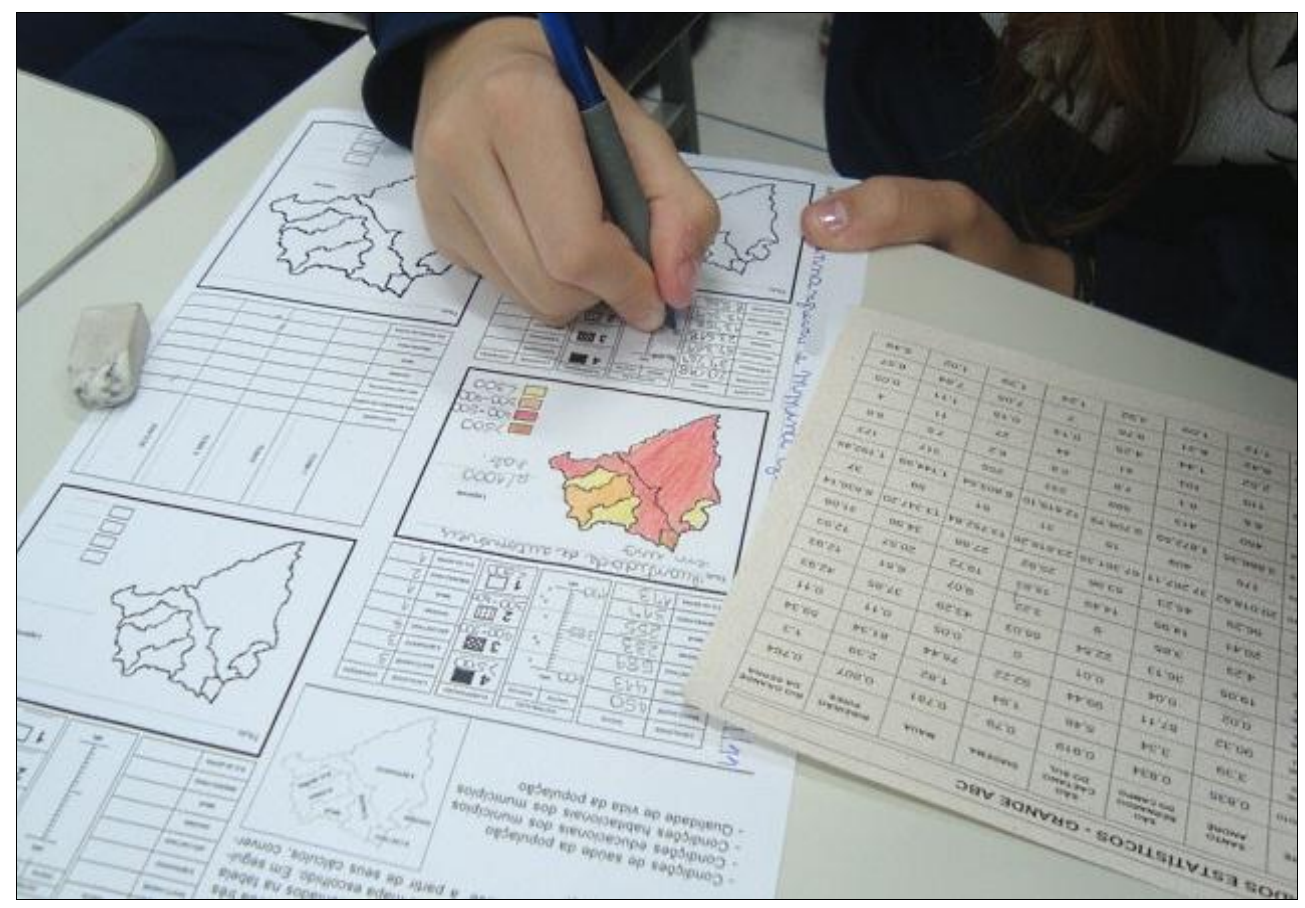

Figura 78 - Elaboração de mapas analíticos e de síntese do Grande ABC a partir de dados em valores relativos apresentados em tabela para construção de mapas ordenados em uma matriz com tabelas e mapas individuais.

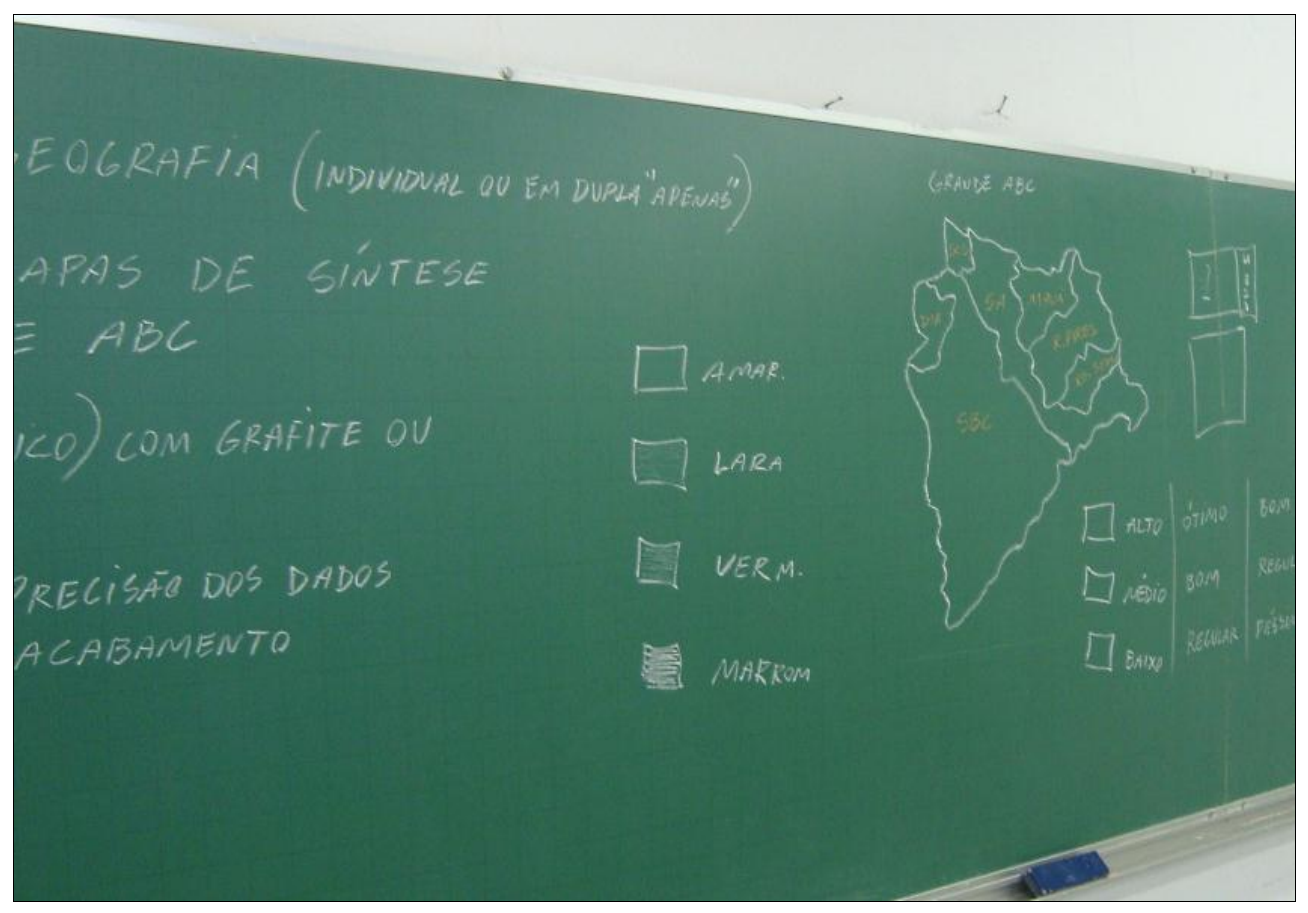

Figura 79 - Mapa do Grande ABC e critérios escritos na lousa para explicação dos procedimentos de elaboração de mapas ordenados, com exemplo de legenda com valores crescentes de cima para baixo. 


\subsection{Atividades realizadas com alunos de Curso de Formação de Professores}

\begin{tabular}{|c|}
\hline Local de aplicação das atividades \\
\hline $\begin{array}{l}\text { Instituição de ensino: Fundação Santo André } \\
\text { Localização: Av. Príncipe de Gales, } 821 \text { - Bairro Príncipe de Gales - Santo André / SP } \\
\text { Série selecionada: 3ํㅡo Ano do Curso de Pedagogia } \\
\text { Número de alunos por sala: } 20 \\
\text { Período de realização: maio a novembro } 2012 \\
\text { Professor da Disciplina: Prof Drª Marilena Nakano }\end{array}$ \\
\hline
\end{tabular}

Em março de 2012, por intermédio da Prof ${ }^{a}$. Drạ. Marilena Nakano foi proposto aplicar atividades cartográficas com a elaboração de mapas temáticos do município de Santo André e Grande ABC pelas alunas do 3ํㅡㄹ Ano do Curso de Pedagogia da Instituição.

Pela oportunidade de trabalhar com atividades no Ensino Superior ter surgido após a elaboração do projeto de pesquisa deste trabalho, e o tempo escasso disponibilizado para trabalhar com as Turmas de Pedagogia, ficou decidido não elaborar avaliações para relatórios comparativos, e sim, aplicar apenas atividades práticas com a metodologia proposta.

Durante a apresentação do projeto de elaboração e conceitos teóricos básicos da Cartografia Temática para elaboração de mapas, foi possível observar o empenho e ao mesmo tempo as dificuldades das alunas em compreender os procedimentos.

A distribuição e classificação dos dados para elaboração de mapas ordenados, assim como os critérios para a escolha de cores ordenadas ou diversas, foram as etapas que apresentaram maiores dúvidas durante os procedimentos.

Foi elaborado um resumo em uma folha A-4 frente e verso, com os conceitos, tipos e aplicações dos principais mapas temáticos utilizados em sala de aula, além de alguns tipos de mapas elaborados em lousa com o uso de gabaritos para explicar os conceitos básicos de Semiologia Gráfica utilizados para a elaboração dos mapas.

Após a aula teórica foi utilizada uma matriz com os procedimentos passo a passo para a construção de três tipos de mapas: ordenado, quantitativo e qualitativo de vários temas sobre a Educação do Grande $A B C$, composto por sete municípios. 
A parte teórica e a prática somaram 2 h30' com a construção de três mapas. A partir da idéia inicial da professora Nakano em elaborar um Atlas da Educação do município de Santo André e Grande ABC com mapas artesanais produzidos pelas alunas do Curso de Pedagogia, a professora buscou dados com o apoio do professor de Cartografia Marcos Marsitsh, professor da disciplina de Geoprocessamento na mesma Instituição, e selecionou diversos temas com valores absolutos e relativos para a construção dos mapas em formato A-4 para posterior análise e cruzamentos. Só não foi possível elaborar mapas dinâmicos por falta de dados estatísticos do tipo origem/destino.

Por iniciativa da professora Nakano, foi selecionado um conjunto de mapas para serem elaborados em papel no formato A-2 (ordenado e diverso) e preenchidos em giz de cera. Para os mapas quantitativos, a professora idealizou lâminas plásticas transparentes para o preenchimento de círculos proporcionais em tinta hidrocor preta com o uso de gabaritos ampliados para este trabalho.

Com os mapas ordenados em papel e os mapas quantitativos em transparência, foi possível fazer o cruzamento entre vários temas apenas sobrepondo as lâminas transparentes sobre o papel e alternando os mapas.

Embora tenham ocorrido poucos encontros para as atividades, foi possível perceber os resultados positivos no final do período, segundo a opinião da professora da disciplina.

Após estas atividades, cinco alunas do Curso, sob orientação da professora Nakano, iniciaram um projeto de Iniciação Científica para elaborar em conjunto, o Atlas da Educação de Santo André, com mapas digitais elaborados com o acompanhamento do professor Marsitch. Durante a discussão dos temas (ainda em curso), dados e aulas de elaboração de mapas com o software Philcarto, já foi possível perceber a familiaridade das alunas com as etapas de distribuição e classificação de dados para mapas coropléticos, o preenchimento e proporção de círculos para os mapas quantitativos, a escolha das cores ordenadas ou diversas, etc. $O$ que pode tornar este projeto útil também na área de didática de Geoprocessamento.

Outras informações e comentários desta atividade encontram-se nas legendas das imagens a seguir. 


\title{
IMAGENS DAS EXPERIÊNCIAS DAS ATIVIDADES DO TRABALHO COM O $3^{\circ}$ ANO PEDAGOGIA
}

\author{
CARTOGRAFIA TEMÁTICA \\ Texto simplificado para elaboração de mapas temáticos escolares no Curso de Pedagogia
}

O estudo dos fenômenos geográficos abrange diversos temas relacionados ao meio físico, humano e econômico, além de temas que mesclam as três áreas, como Meio Ambiente, Fontes de Energia, Conflitos Étnico-religiosos, Urbanização, Geopolítica, Demografia, Educação, Saúde, etc.

Assim como nas demais áreas científicas, além da linguagem escrita, existem outras maneiras de apresentar teorias, dados estatísticos, amostragens, experiências, etc., com o objetivo de facilitar a comunicação com linguagens visuais, como gráficos, tabelas, fluxogramas e mapas temáticos.

A conversão de dados estatísticos em representações visuais é uma maneira eficiente de apresentar uma leitura simples e rápida sobre a ocorrência e/ou variação de um fenômeno específico em um determinado período ou localidade. Quando se refere a uma localidade do "espaço geográfico", a leitura torna-se ainda mais eficaz quando os dados ou fenômenos são apresentados em um mapa. A partir do mapa, é possível obter uma imagem dos dados ou temas sobre um determinado "espaço" e a partir daí, efetuar leitura, comparações, ou correlações sobre diversas abordagens.

Diferente do mapa topográfico, que utiliza escalas e projeções que buscam representar com o máximo de precisão o espaço físico real, os mapas temáticos visam apresentar da maneira mais eficiente possível o fenômeno geográfico, mesmo que a escala, a projeção, e até mesmo o traçado dos mapas sejam prejudicados. Neste tipo de mapa, o mais importante é que a imagem responda de forma eficiente algumas perguntas básicas, como: - Tal fenômeno, onde ocorre? - Onde ocorre com maior ou menor intensidade?

Para representar fenômenos espaciais, é preciso utilizar um tipo de projeção mais adequado, como planisférios, continentes, países, estados, municípios, bairros, regiões específicas, etc., porém, que possa apresentar as informações dos fenômenos da maneira mais eficiente possível, utilizando uma técnica de elaboração adequada para cada tipo de mapa. As técnicas utilizadas para elaboração variam de acordo com o tipo de mapa que se pretende elaborar.

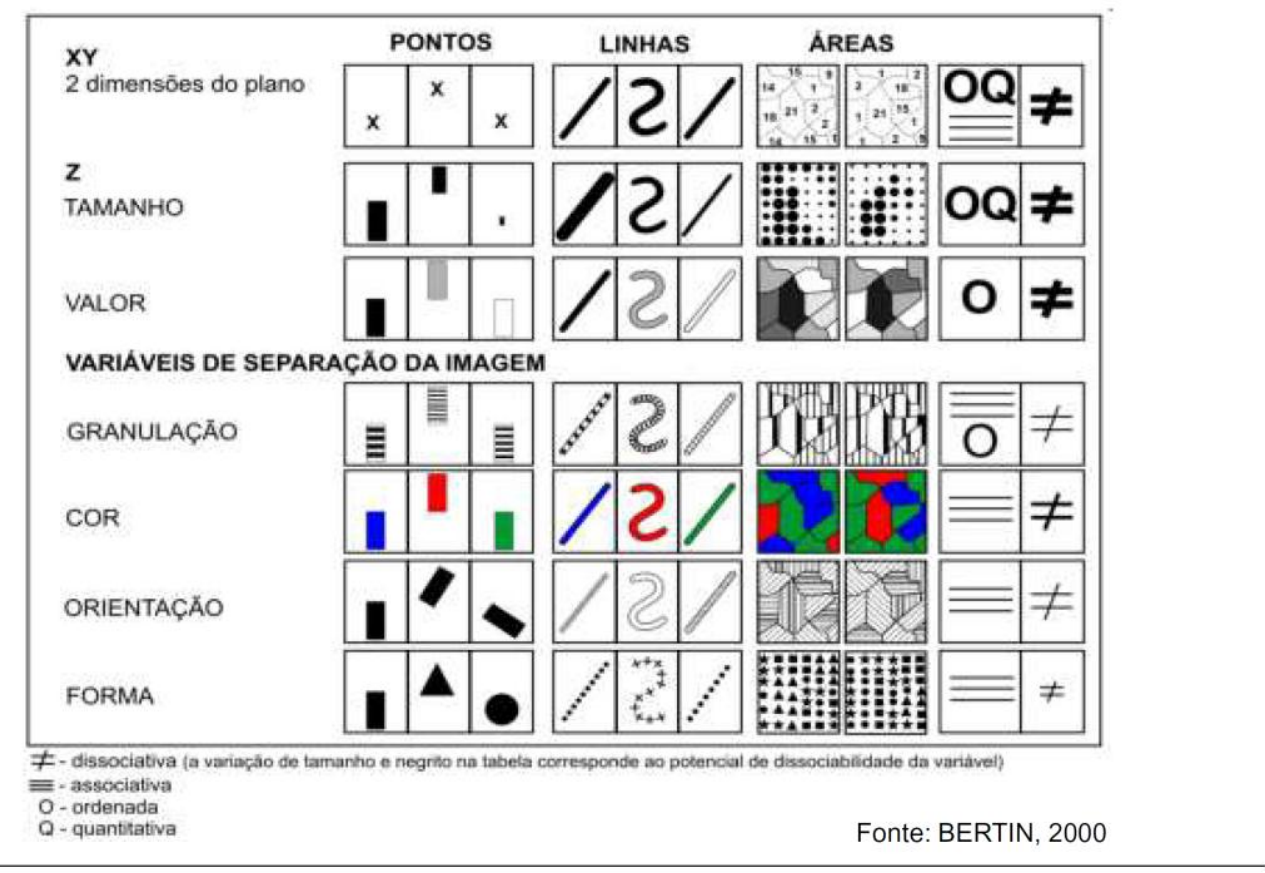

\section{TIPOS DE MAPAS TEMÁTICOS}

Para a elaboração de um mapa temático, existem regras para que sua comunicação seja eficiente e, principalmente, não confunda o leitor em sua interpretação. Basicamente os tipos de mapas mais encontrados são:

Figura 80 - Frente do material utilizado para a parte teórica com noções básicas de Cartografia Temática, Semiologia Gráfica e exemplos das variáveis visuais da imagem de Jacques Bertin. 
ORDENADO (ou coroplético) Utilizado para dados estatísticos relativos. Ex. "\%", "hab/km²", etc.

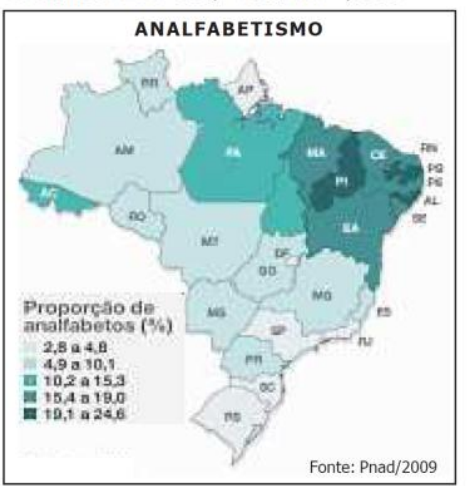

QUANTITATIVO - Utilizado quando os dados estão em valores absolutos. Ex. "em milhões", "X 1000", "unidades", etc.

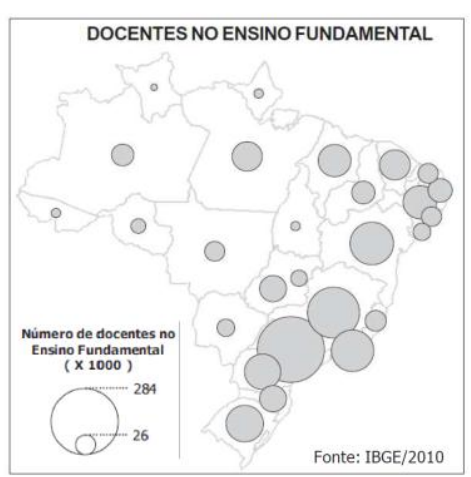

ANAMÓRFICO-Método de representação que substitui os contornos dos mapas por figuras geométricas ou as $\begin{array}{lllllll}d & e & f & o & r & m & a\end{array}$ proporcionalmente a um determinado fenômeno ou quantidade, respeitando apenas suas vizinhanças.
QUALITATIVO - Método ideal para representar "diferenças" em um mapa, ou seja, quando não há hierarquia. Ex. "creche, pré-escola", "federal, estadual, municipal", etc.
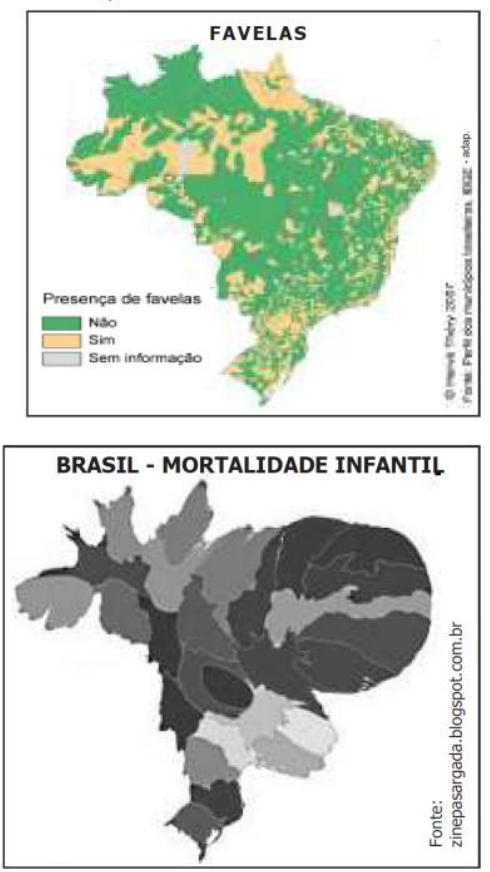

Obs. Em apenas um mapa podem ser representados mais de um fenômeno geográfico assim como mais de um tipo de aplicação.

\section{PROCEDIMENTOS PARA ELABORAÇÃO DE MAPAS (Consulte a matriz para elaboração de mapas)}

Escreva o título do tema escolhido para o mapa. Preencha os dados na tabela "A". Se os dados estiverem em valores relativos, utilize o método "ordenado" (coroplético). Se estiverem em valores absolutos, utilize o método "quantitativo" (círculos, etc.). Caso o tema seja diverso, como um nome ou fenômeno específico de determinadas áreas do mapa, escolha o método "qualitativo". Siga os seguintes procedimentos para:

\section{MAPAORDENADO}

1 - Distribua os dados na tabela "B" marcando com pontos a partir do valor mínimo até o máximo.

2 - Separe os valores em quatro classes.

3 - Transfira os dados classficados para a legenda do mapa "D", e pinte a legenda com cores ordenadas ou com granulações.

4 - Classifique os dados na tabela "C" de acordo com os valores respectivos.

5 - Preencha as cores ou tonalidades da legenda para o mapa.

6 - Escreva as informações complementares para a legenda e cite a fonte pesquisada.

\section{MAPA QUANTITATIVO}

1 - Converta os dados na tabela "C" calculando o valor máximo com o círculo 10 do gabarito e reduza os demais valores na proporção (regra de três). Ex. 10:maior $n^{\circ}=\mathbf{X}$. Memorize na calculadora e multiplique " $X$ " pelos demais valores, fazendo os arredondamentos.

2 - Preencha os círculos com o gabarito no mapa "partindo do tamanho menor para o maior" e pinte-os com apenas uma cor ou tonalidade.

3 - Preencha somente o contorno dos círculos da legenda "D" e escreva o valor máximo e mínimo apresentado.

4 - Escreva as informações complementares para a legenda, e cite a fonte pesquisada.

\section{MAPA QUALITATIVO:}

1 - Classifique os dados na tabela "C" de acordo com os tipos respectivos de cada localidade do mapa.

2 - Preencha as cores, formas ou tonalidades na legenda, e em seguida no mapa.

3 - Escreva as informações complementares para a legenda e cite a fonte pesquisada.

\section{REFERENNCIAS BIBLIOGRÁFICAS}

BERTIN, Jacques. A Neográfica. trad. Jaime Antônio Cardoso. Seleção de Textos, 2000.

FONSECA, F. P.; COSTA, G. P.; OLIVA, J. T.; GIANSANTI, R. Olhar Geográfico: A diversidade do mundo. 6ª série. São Paulo. IBEP, 2006. GIMENO, Roberto e BERTIN, Jacques. A lição de cartografia na escola elementar. Boletim Goiano de Geografia, 1982.

MARTINELLI, Marcello. Mapas da Geografia e Cartografia Temática. São Paulo. Contexto, 6a ed.2011.

Figura 81 - Verso do material com exemplos de mapas e procedimentos para elaboração de mapas ordenados, quantitativos e qualitativos. 


\section{EXERCÍCIOS DE ELABORAÇÃO DE MAPAS - APLICAÇÃO DAS CORES}

Escreva o título do tema escolhido para o mapa. Preencha os dados na tabela "A". Se os dados estiverem em valores relativos, utilize o "método ordenado" (coroplético). Se estiverem em valores absolutos, utilize o "método quantitativo" (círculos, etc.). Caso o tema seja diverso, como um nome ou fenômeno especifico de determinadas áreas do mapa, escolha o "método qualitativo". Siga os seguintes procedimentos para:
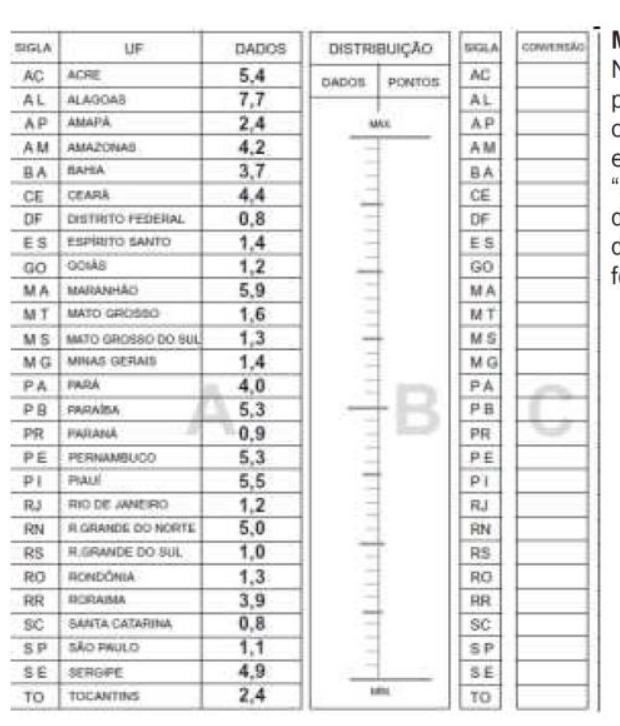

\section{MAPA ORDENADO (COROPLETICO):}

Na tabela "B" escreva o valor mínimo e o máximo. / Some os dois valores e divida por dois para encontrar o valor médio. Repita os procedimentos para encontrar o valor das demais escalas. Marque os dados com pontos e separe os valores em quatro classes. / Transfira os dados classificados para a legenda do mapa "D". / Pinte a legenda com cores ordenadas ou granulações. / Classifique os dados na tabela "C" de acordo com os valores respectivos. / Transfira as cores da legenda para o mapa. / Escreva as informações complementares e cite a fonte pesquisada.

\section{CORES ORDENADAS}
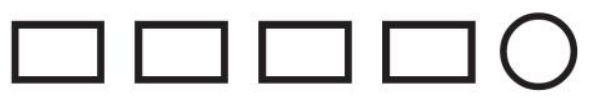

GRANULAÇÕES
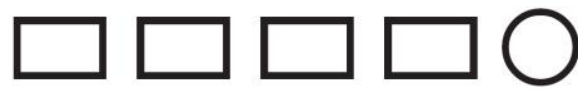

ORDENADAS
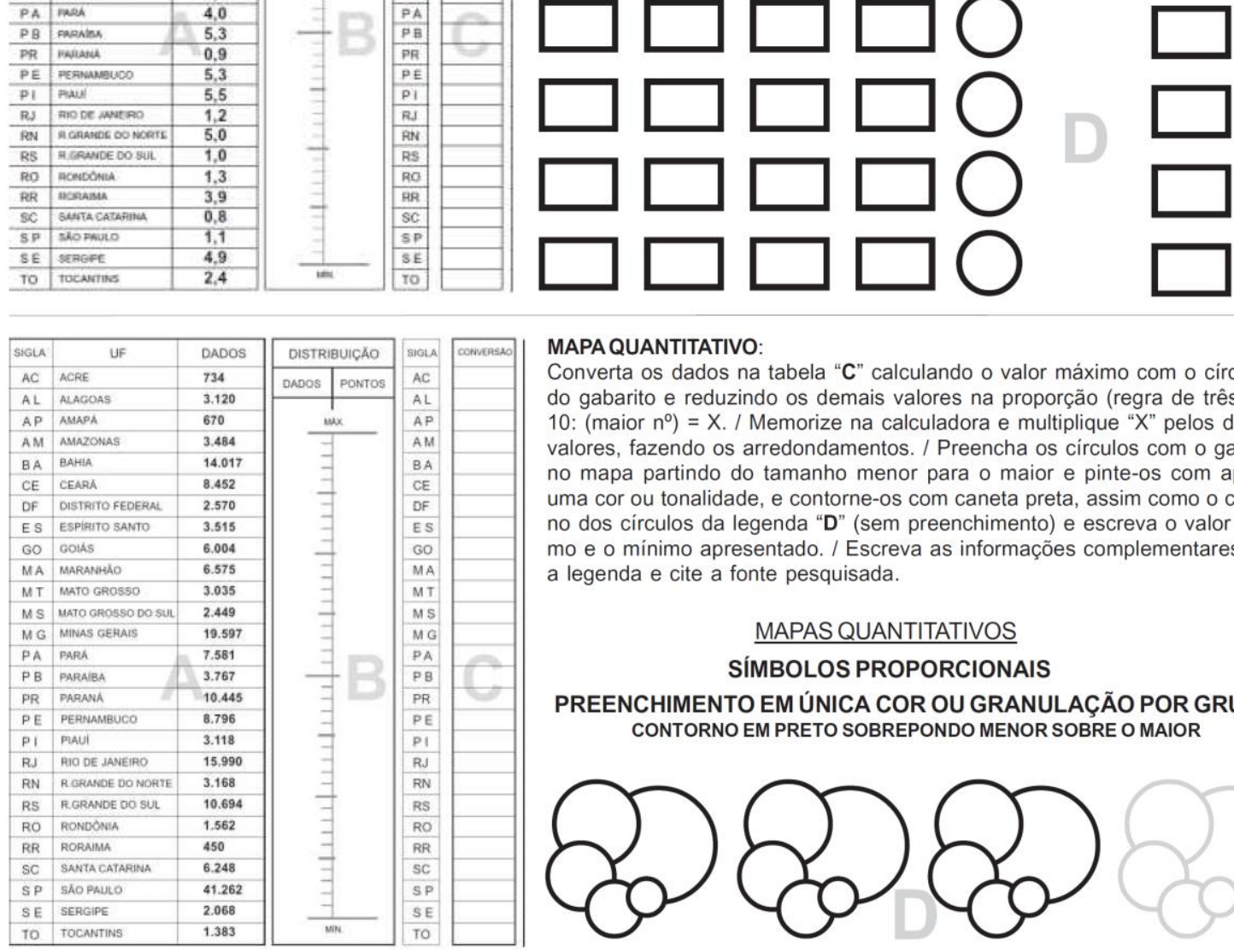

\section{MAPAQUANTITATIVO:}

Converta os dados na tabela "C" calculando o valor máximo com o círculo10 do gabarito e reduzindo os demais valores na proporção (regra de três). Ex. 10: $\left(\right.$ maior $\left.n^{0}\right)=X$. / Memorize na calculadora e multiplique " $X$ " pelos demais valores, fazendo os arredondamentos. / Preencha os círculos com o gabarito no mapa partindo do tamanho menor para o maior e pinte-os com apenas uma cor ou tonalidade, e contorne-os com caneta preta, assim como o contorno dos círculos da legenda "D" (sem preenchimento) e escreva o valor máximo e o minimo apresentado. / Escreva as informações complementares para a legenda e cite a fonte pesquisada.

\section{MAPAS QUANTITATIVOS SÍMBOLOS PROPORCIONAIS}

PREENCHIMENTO EM ÚNICA COR OU GRANULAÇÃO POR GRUPO CONTORNO EM PRETO SOBREPONDO MENOR SOBRE O MAIOR

\begin{tabular}{|c|c|c|c|c|c|}
\hline $\mathbf{N}^{\circ}$ & MUNICIPIO & DADOS & $\begin{array}{l}\text { DISTRRBUICAA } \\
\text { DADOS PONTOS } \\
\end{array}$ & $\mathbf{N}^{\circ}$ & CONVERSAO / CLASSIFICACAO \\
\hline 1 & Santo André & $F \cdot M \cdot P$ & VALOR MAXMOMO & 1 & $\nabla \square \diamond$ \\
\hline 2 & S.Bernardo do Campo & $E-M-P$ & & 2 & 0 \\
\hline 3 & São Caetano do Sul & $M \cdot P$ & & 3 & $\square$ \\
\hline 4 & Diadema & $F-P$ & D. & 4 & 0 \\
\hline 5 & Mauá & $E-P$ & 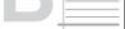 & 5 & 0 \\
\hline 6 & Ribeiräo Pires & $\mathbf{P}$ & & 6 & $\Delta$ \\
\hline 7 & Rio Grande da Serra & & VALOR MINIMO & 7 & \\
\hline
\end{tabular}

\section{MAPA QUALITATIVO:}

Classifique os dados na tabela "C" de acordo com os tipos respectivos de cada localidade do mapa. / Preencha as cores, formas ou tonalidades na legenda, e em seguida no mapa. / Escreva as informações complementares para a legenda e cite a fonte pesquisada.
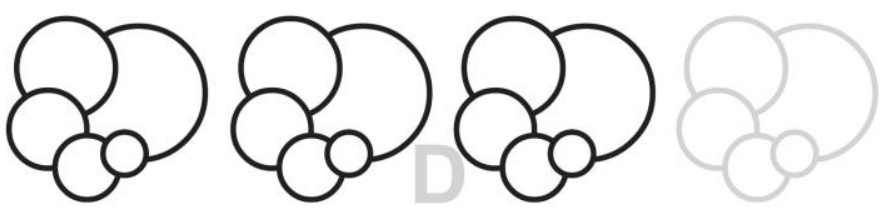

CORES E SIMMBOLOS DIVERSOS E SEMELHANTES EM CORES E GRANULAÇŌES DIVERSAS

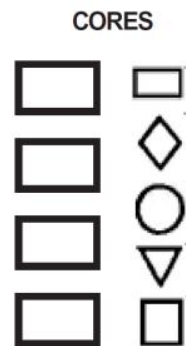

GRANULAÇ̃̃ES

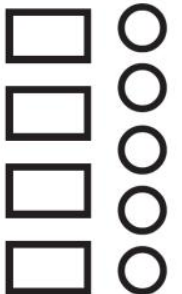

Figura 82 - Exercícios prévios dos procedimentos para elaboração de mapas temáticos. 


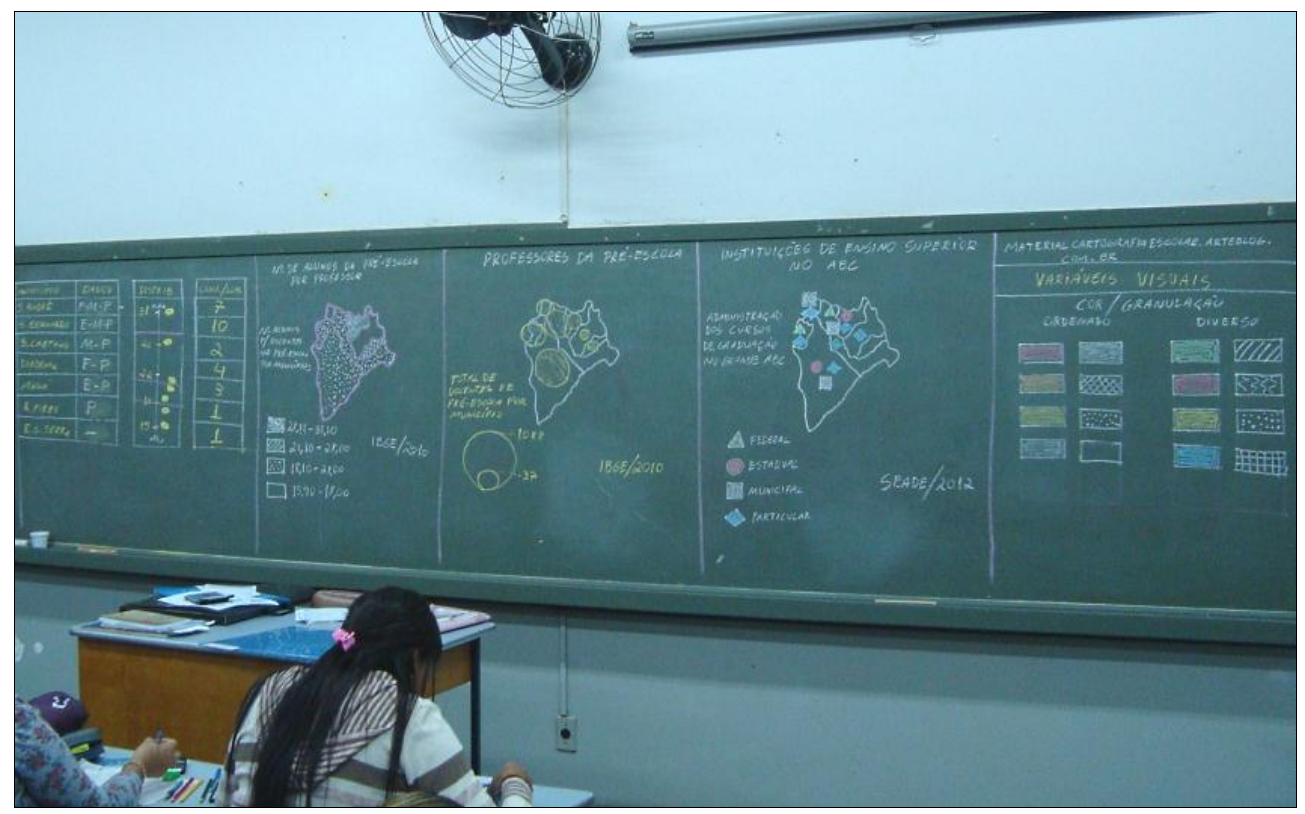

Figura 83 - Tabelas, classificações e tipos de mapas exemplificados em lousa para acompanhamento das alunas, elaborados previamente em lousa com gabarito do mapa do Grande ABC, para aula teórica sobre construção de mapas temáticos.

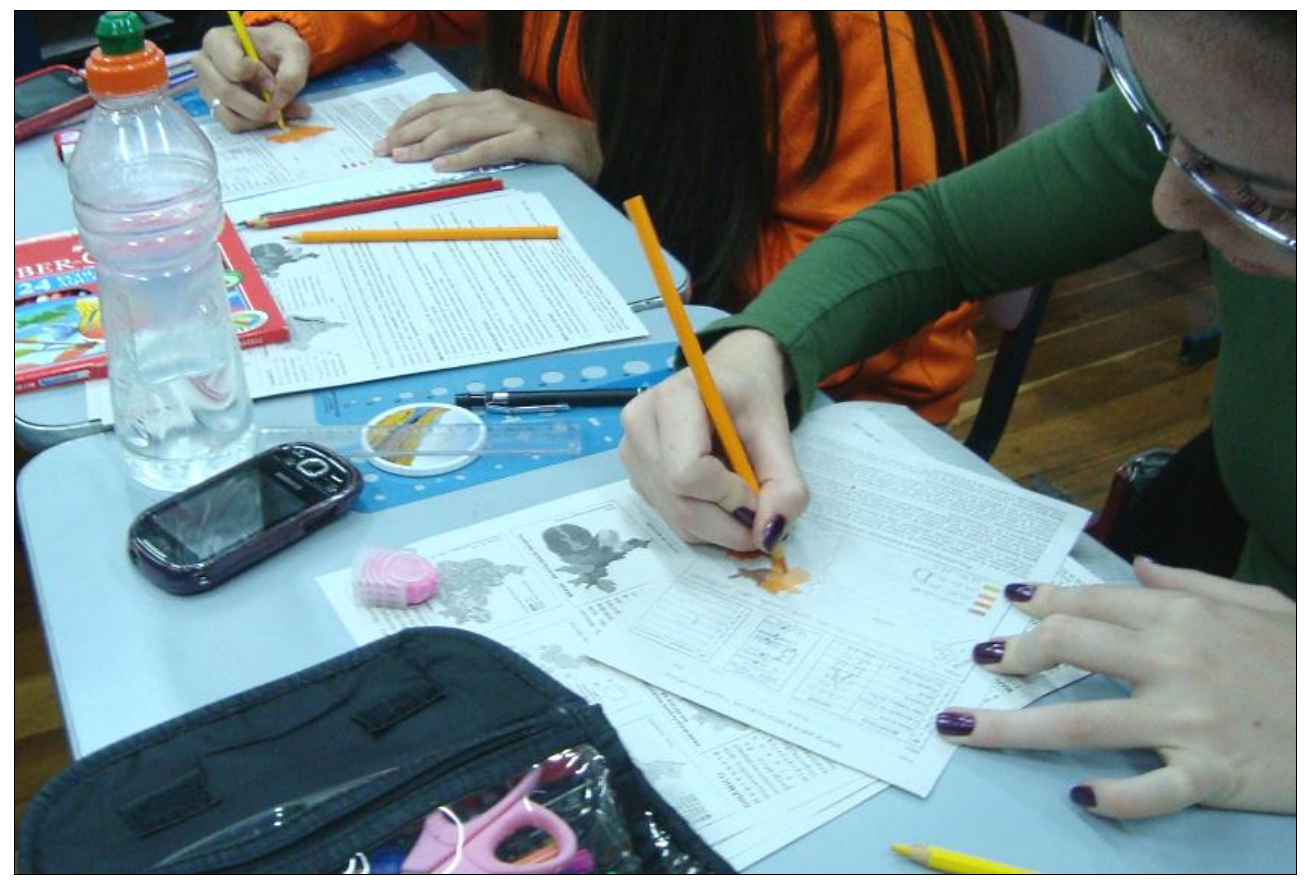

Figura 84 - Preenchimento do mapa ordenado após os exercícios, com utilização de lápis de cor. 


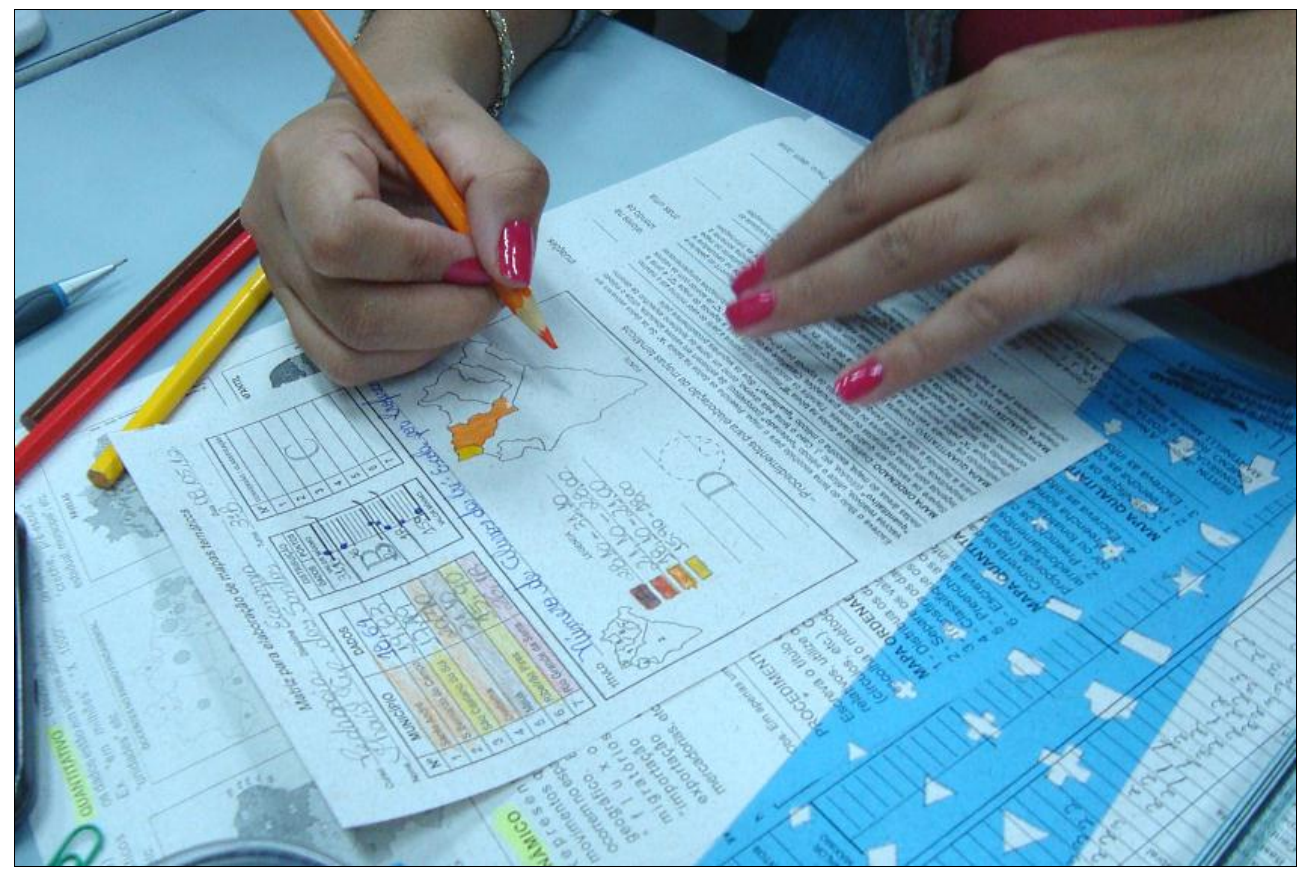

Figura 85 - Preenchimento do mapa ordenado com cores ordenadas. A distribuição e classificação dos dados foram as etapas de maior complexidade apresentadas pelos alunos.

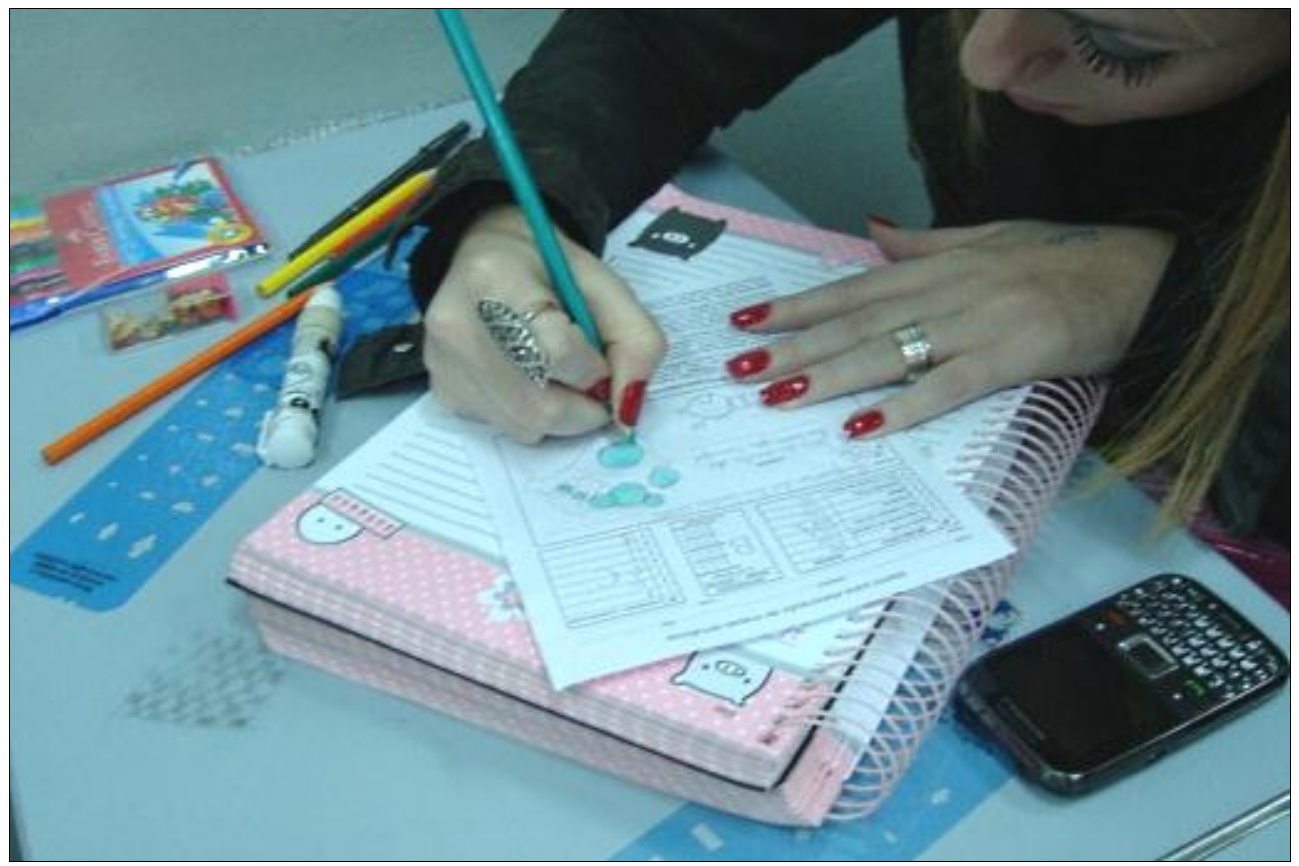

Figura 86 - Preenchimento do mapa quantitativo com gabarito de círculos proporcionais. O cálculo com a conversão dos valores foi elaborado com calculadora, seguindo os procedimentos da matriz. 


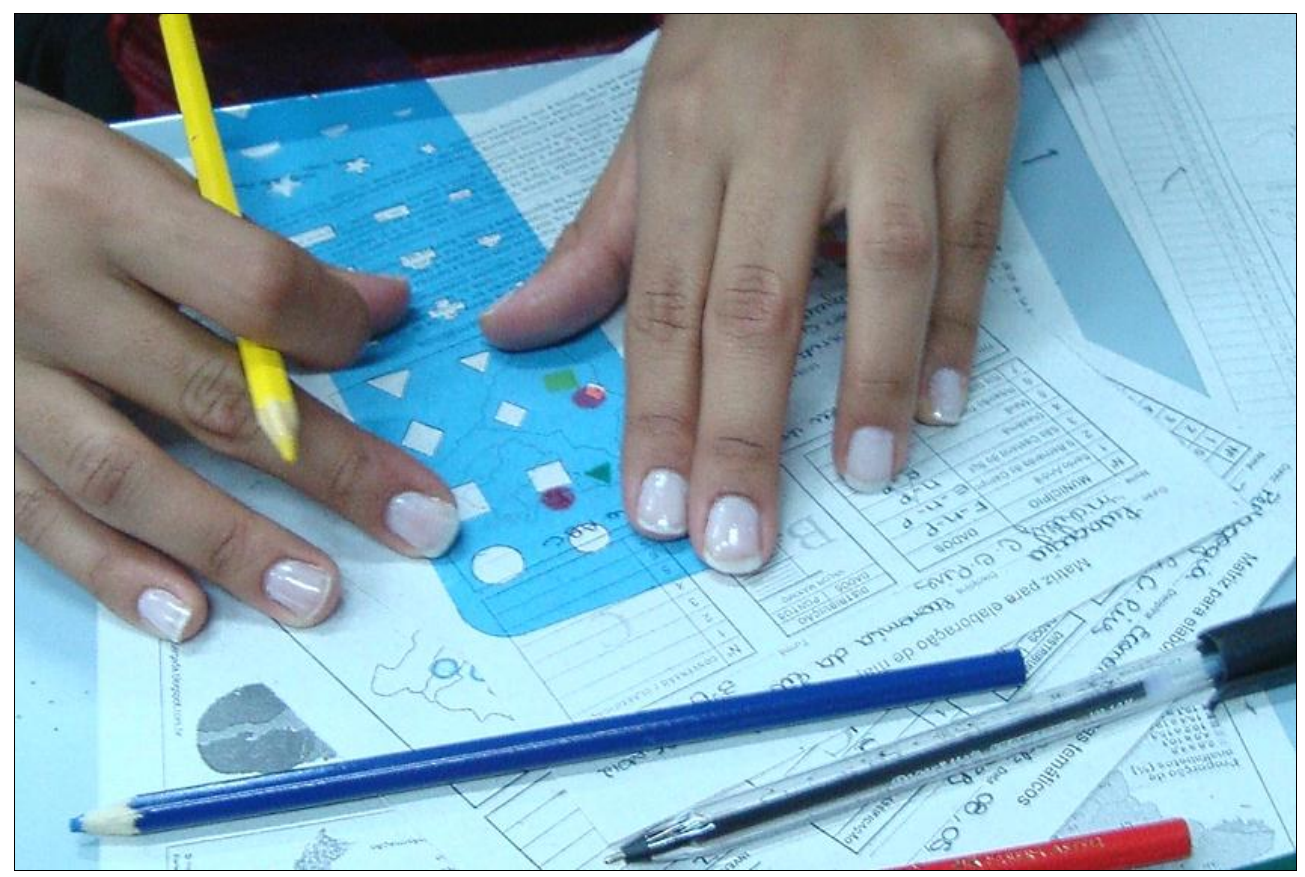

Figura 87 - Preenchimento do mapa qualitativo com gabarito de símbolos diversos com a observação de não ter variação de tamanho entre os símbolos para este tipo de mapa.

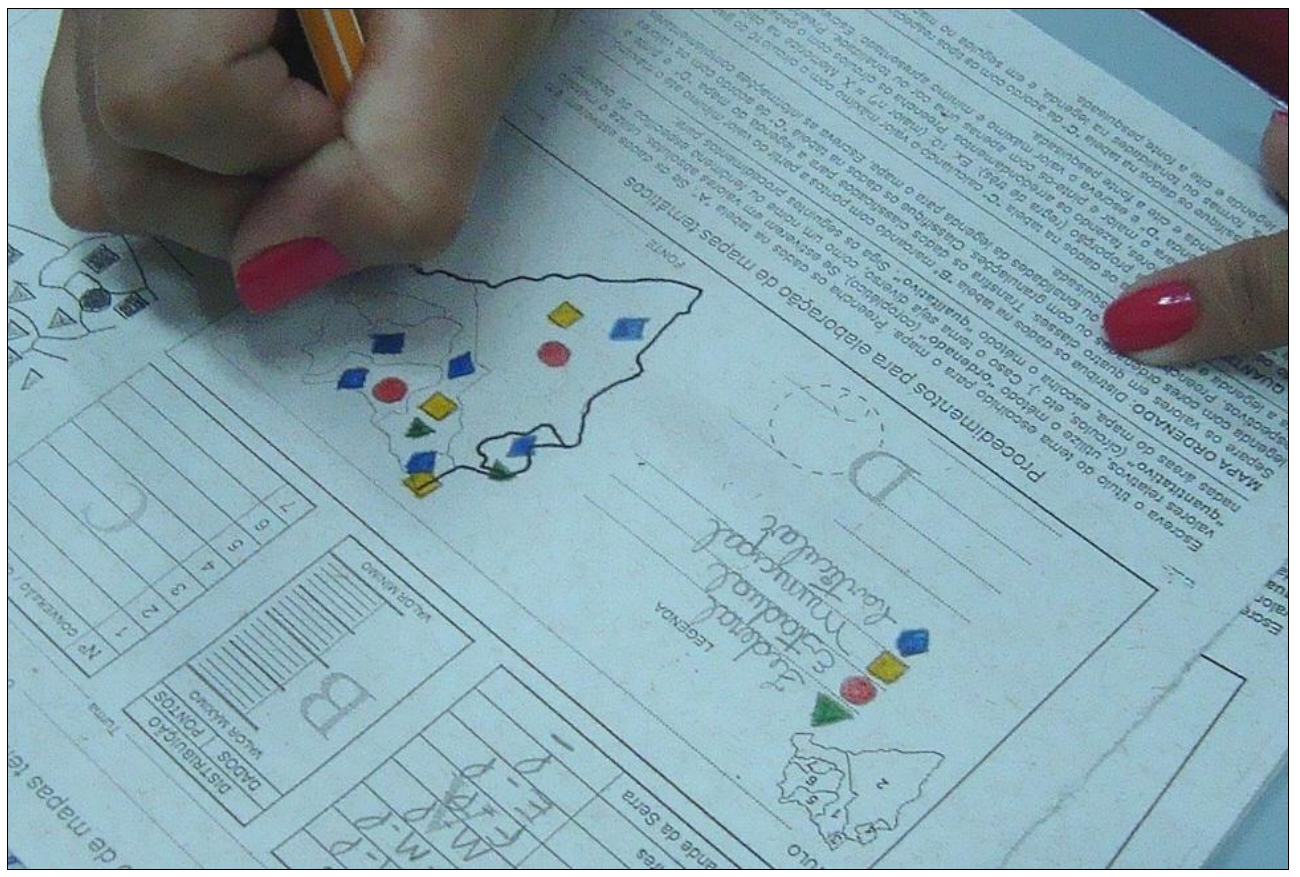

Figura 88 - Preenchimento do contorno do mapa qualitativo e acabamento final do mapa com título, legenda e fonte de pesquisa. 


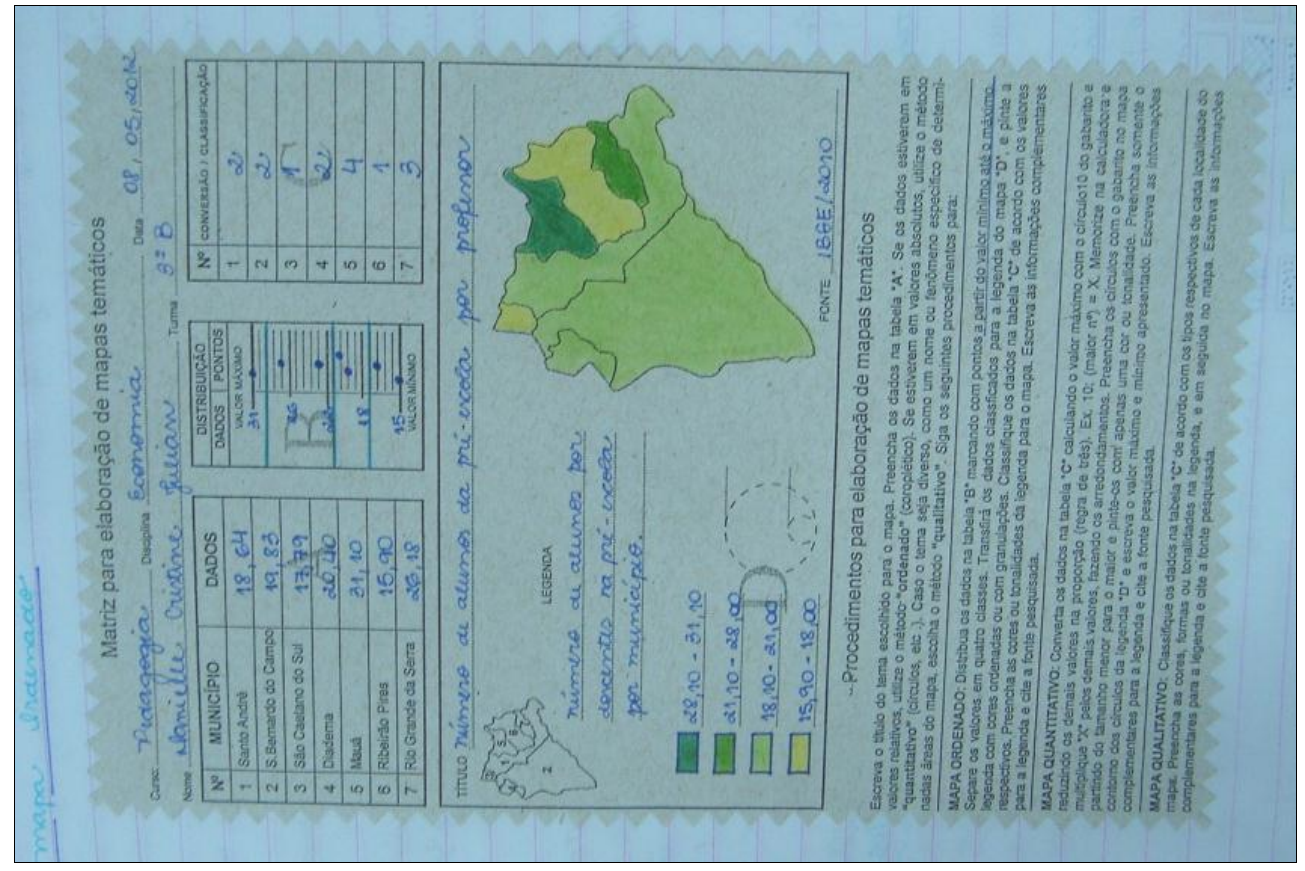

Figura 89 - Exemplo de um mapa ordenado acabado, com tabelas de distribuição, classificação e conversão de dados em matriz para os três tipos de mapas.

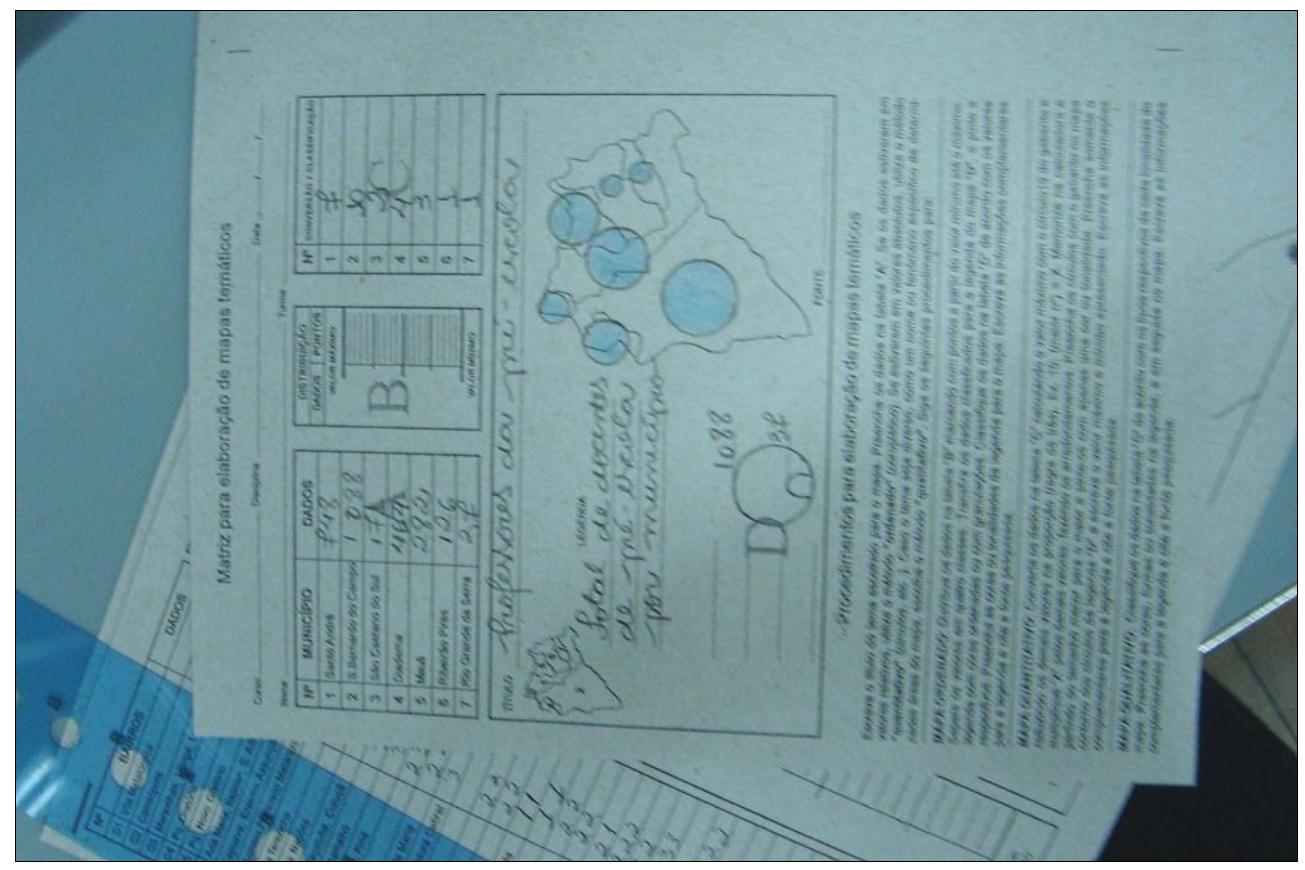

Figura 90 - Exemplo de um mapa quantitativo acabado, com tabelas de distribuição, classificação e conversão de dados em matriz para os três tipos de mapas. 


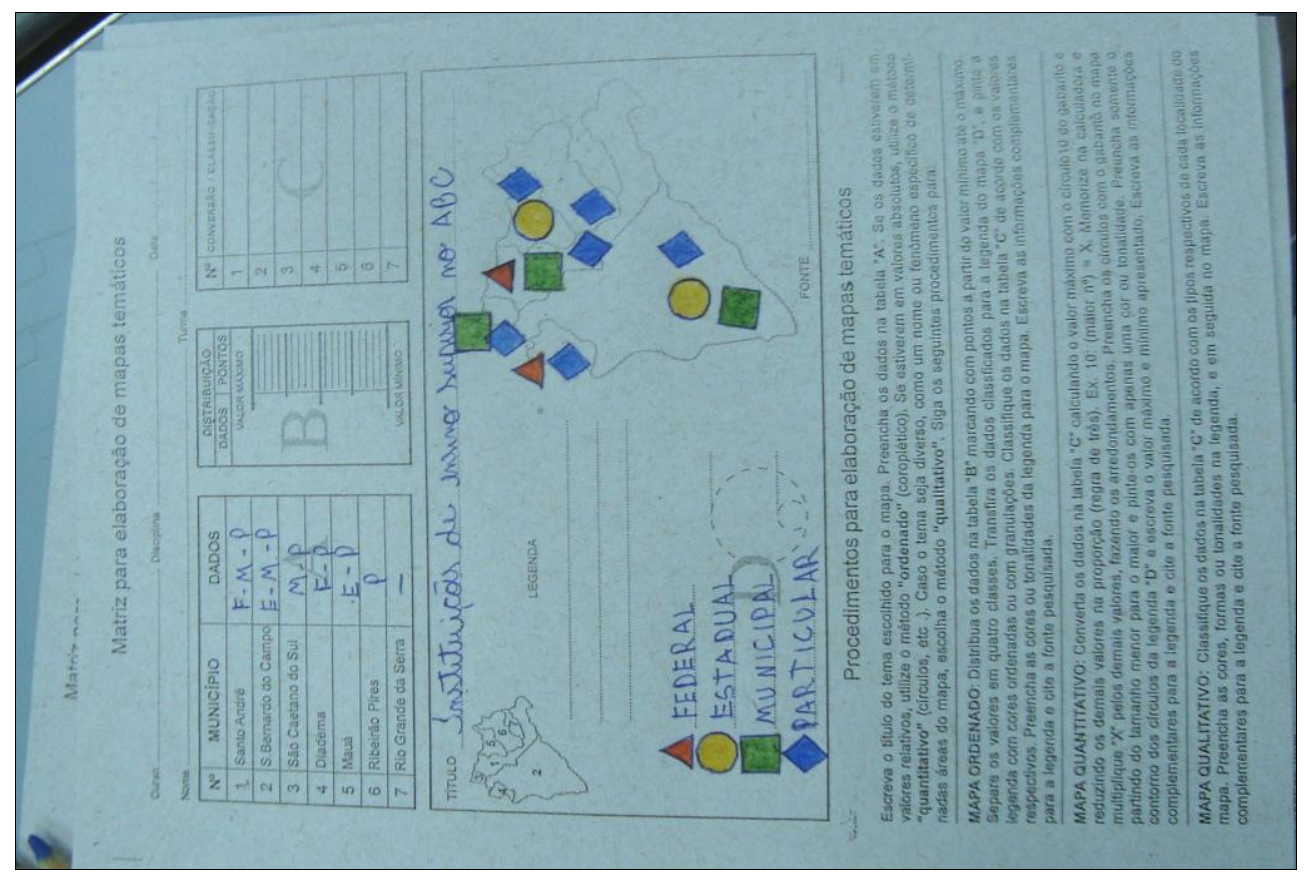

Figura 91 - Exemplo de um mapa qualitativo acabado, com tabela de dados em matriz para os três tipos de mapas.

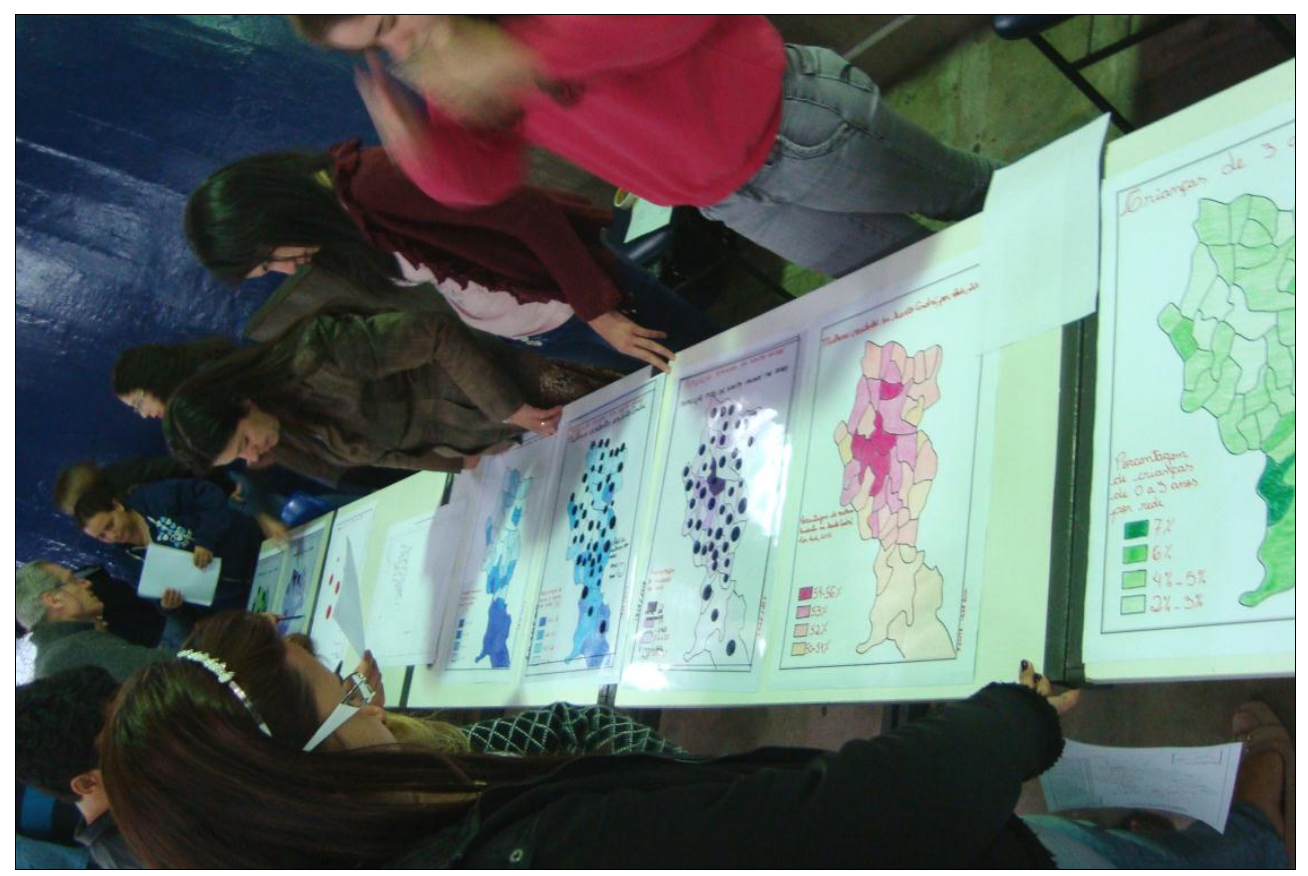

Figura 92 - Exposição de mapas temáticos ordenados em papel para sobreposição de mapas em transparências com círculos proporcionais durante o III Simpósio de Práticas Docentes. Vídeo disponível em: http://materialcartografiaescolar.arteblog.com.br/774959/Exposicao-de-mapastematicos-elaborados-pelas-alunas-do-Curso-de-Pedagogia-da-Fundacao-Santo-Andre/ 


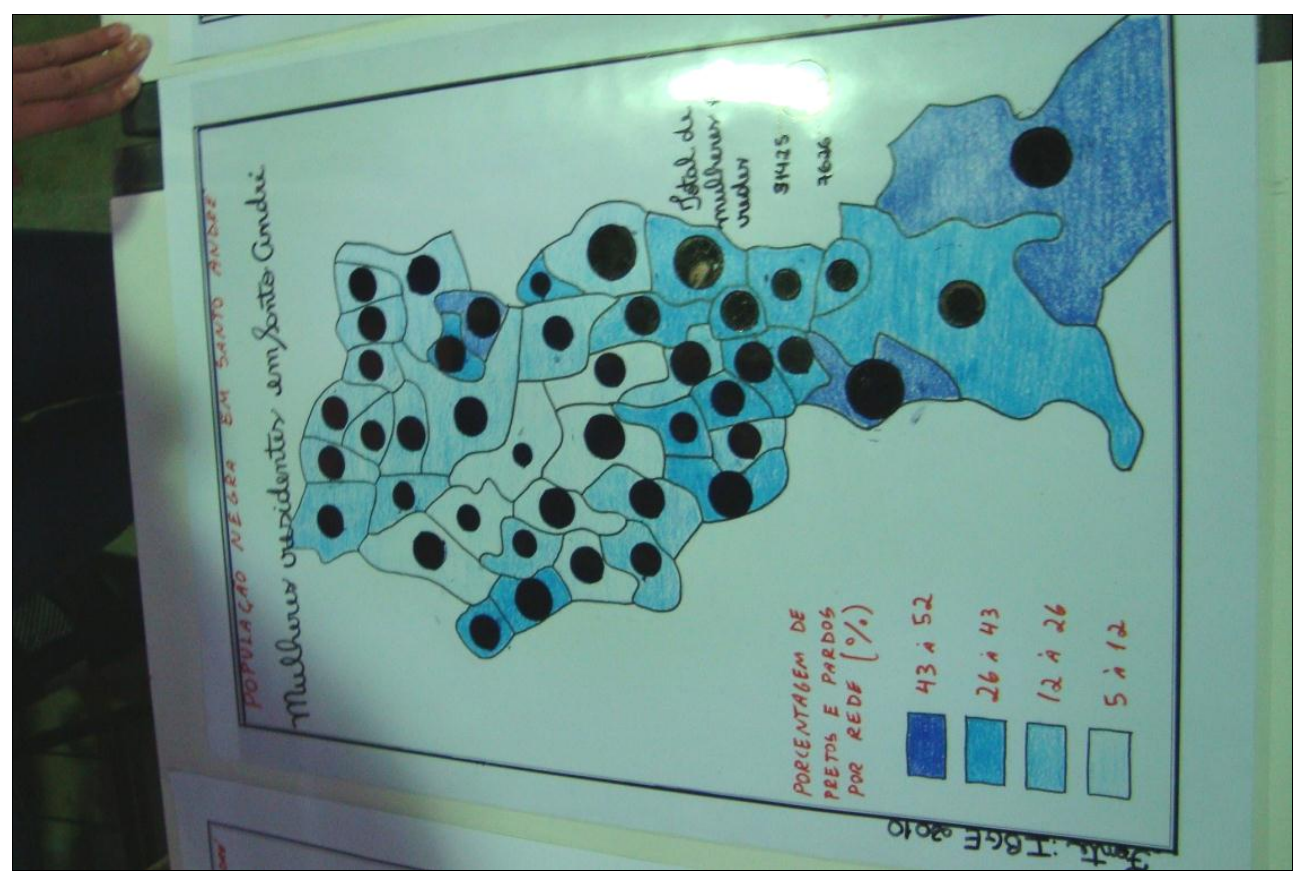

Figura 93 - Exemplo de mapas de Santo André em papel com temas sobrepostos em transparências com diversos temas relacionados à educação durante o III Simpósio de Práticas Docentes.

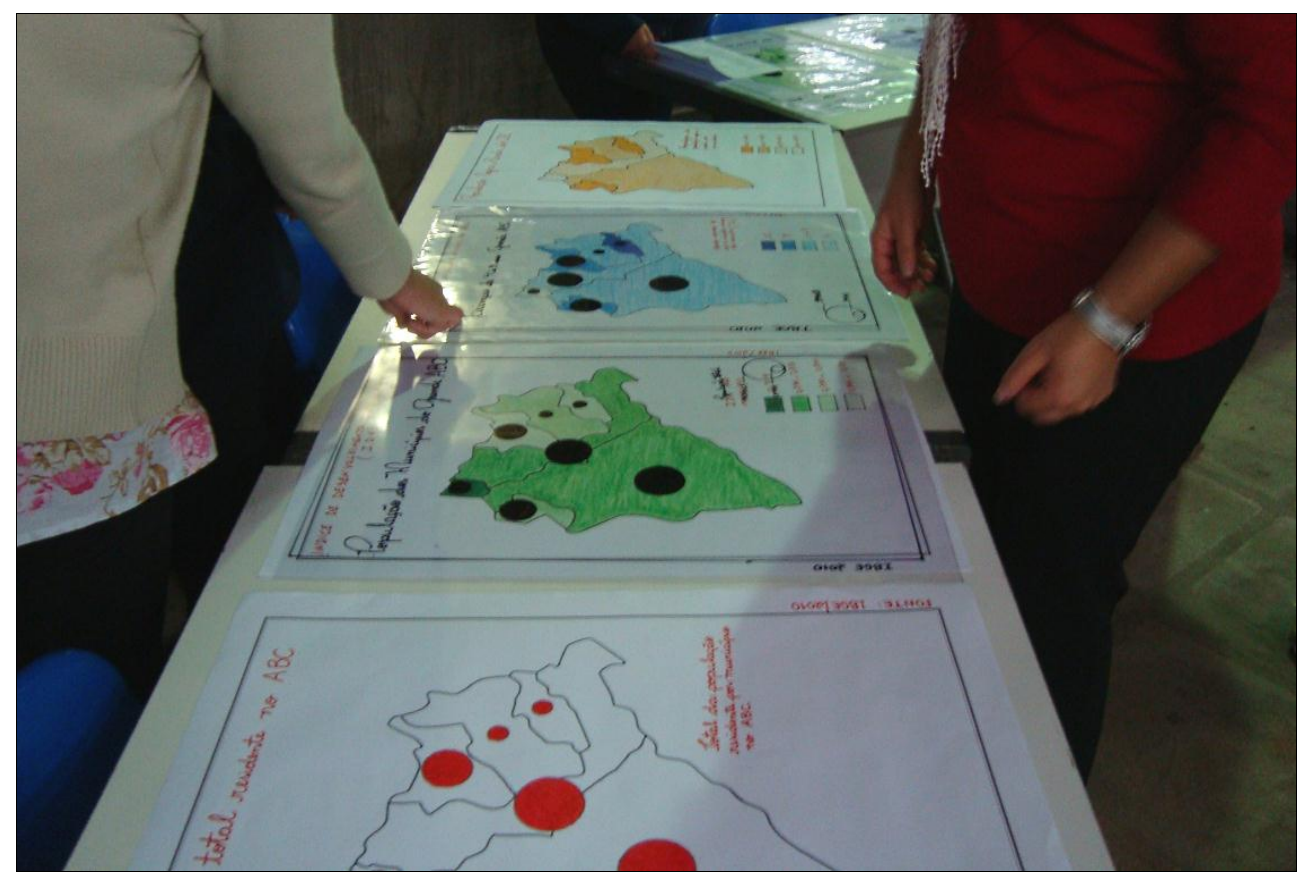

Figura 94 - Exemplo de mapas do Grande ABC em papel com temas sobrepostos em transparências durante o III Simpósio de Práticas Docentes. 
MATRIZES UTILIZADAS NAS EXPERIÊNCIAS COM O 3 ANO PEDAGOGIA

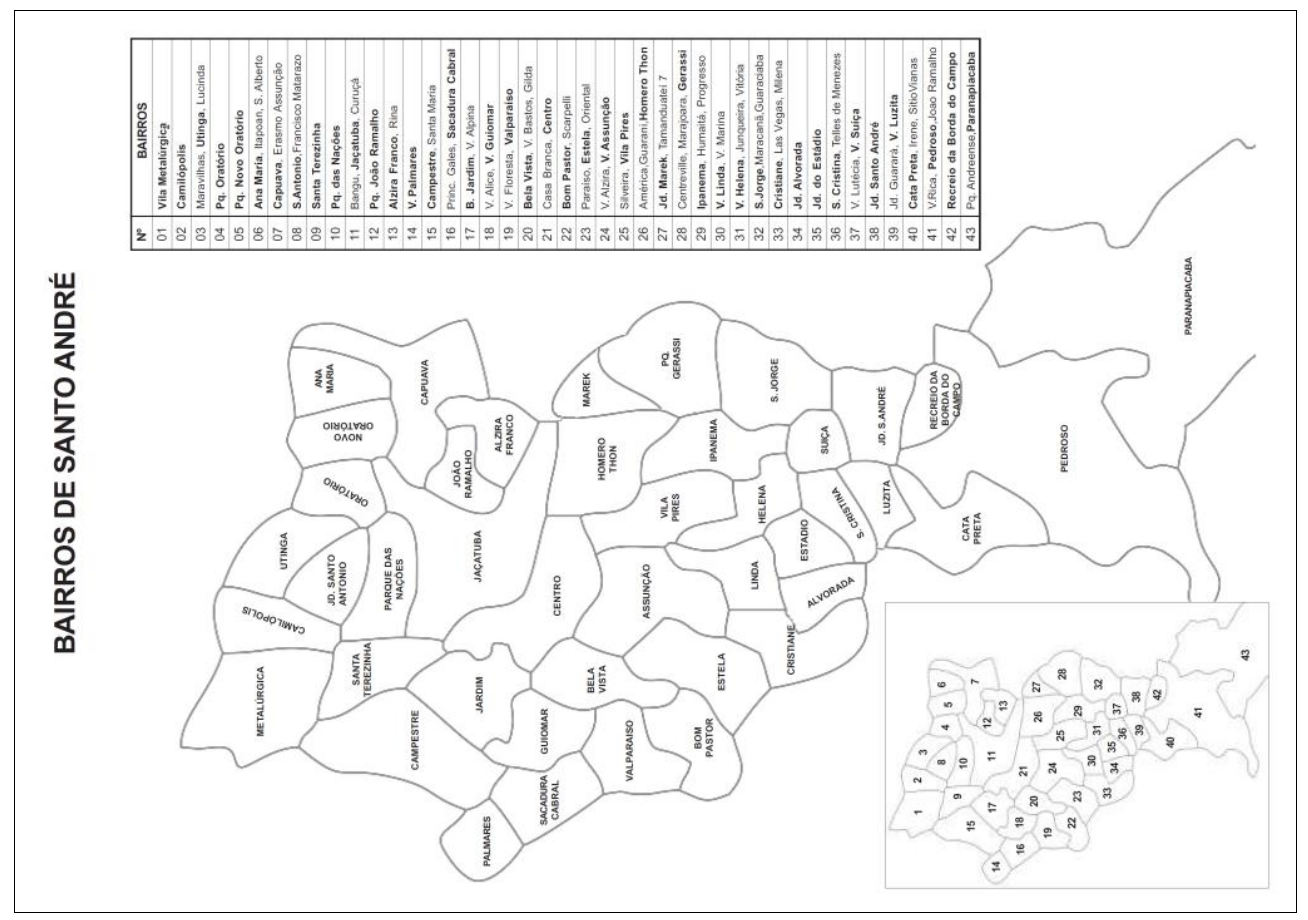

Figura 95 - Matriz do mapa de Santo André dividido por aglomerados dos bairros.

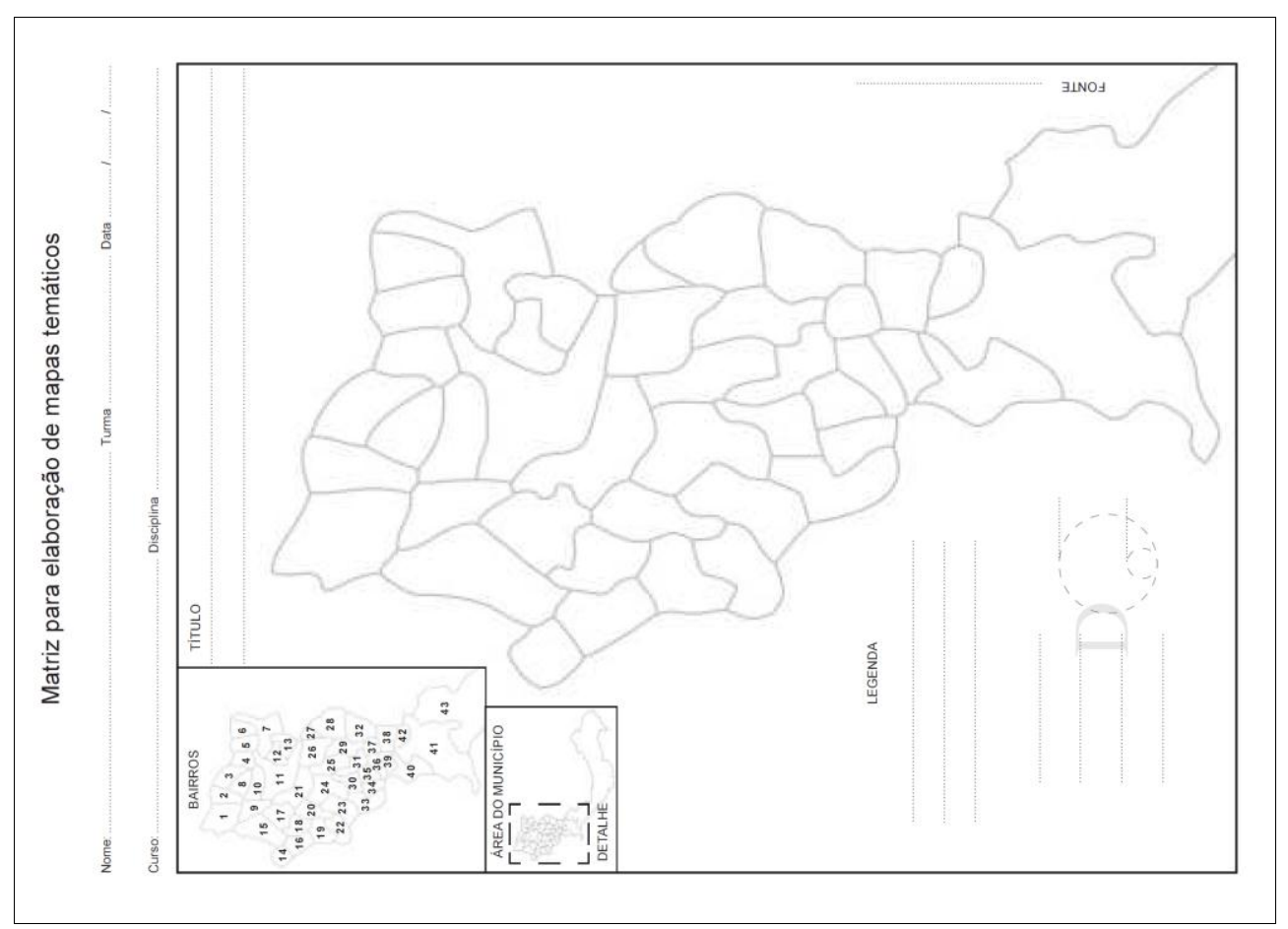

Figura 96 - Matriz e mapa mudo de Santo André para elaboração de mapa ordenado, quantitativo ou qualitativo. 


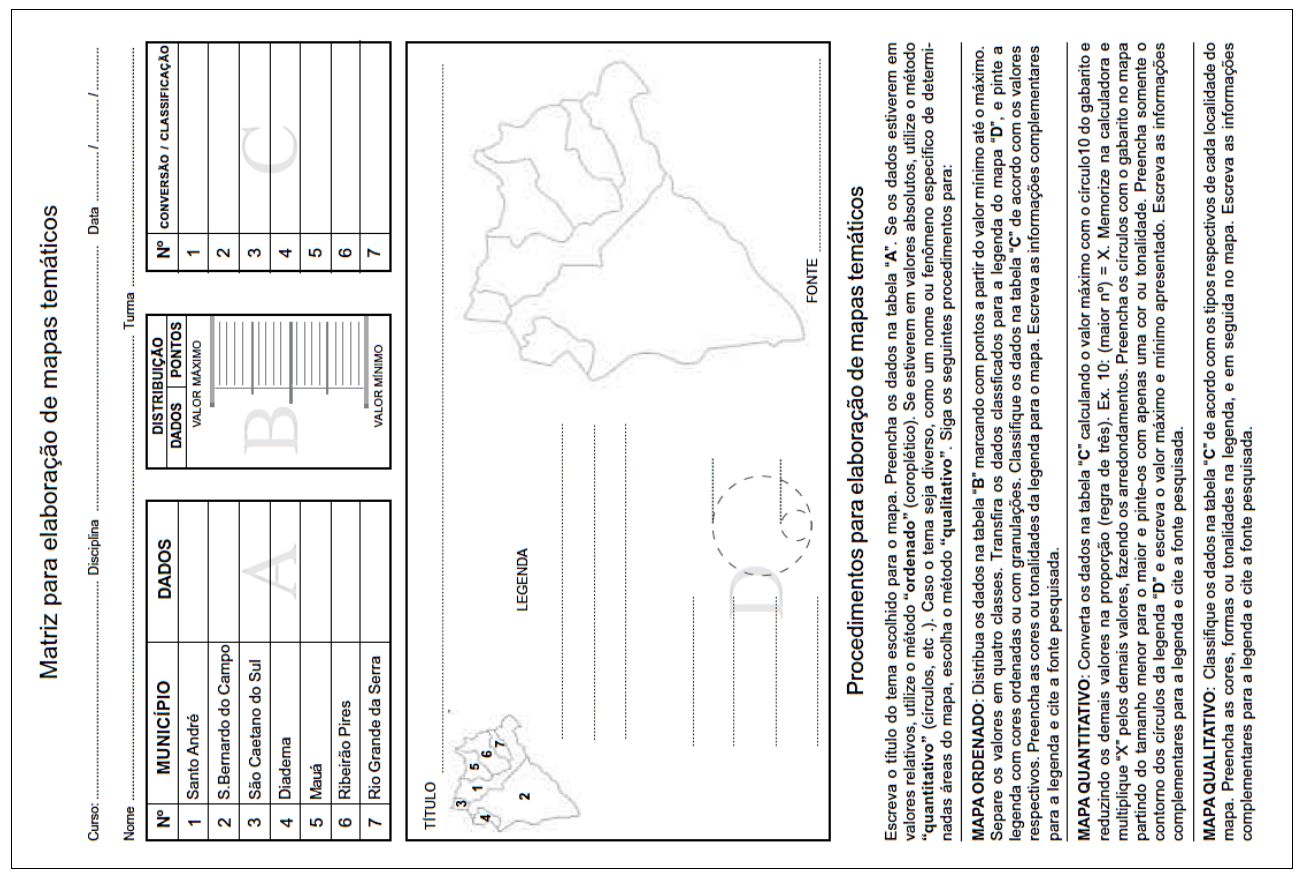

Figura 97 - Matriz com tabela, procedimentos e mapa mudo do Grande ABC para elaboração de mapa ordenado, quantitativo ou qualitativo.

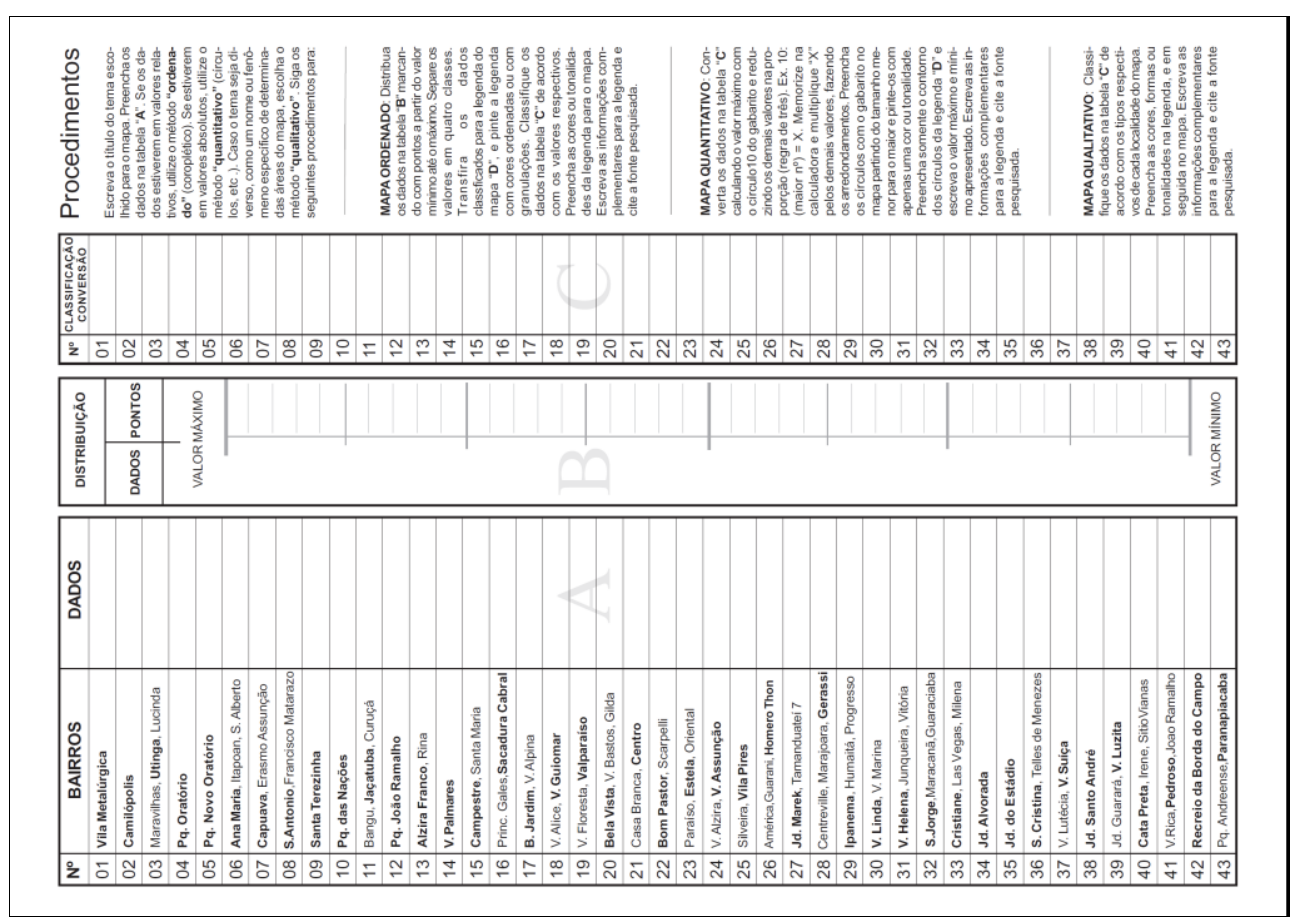

Figura 98 - Tabela com procedimentos para elaboração de mapa ordenado, quantitativo ou qualitativo do município de Santo André. 


\section{5 - CONSIDERAÇÕES FINAIS}

Existe um longo percurso entre 0 que os alunos apresentam de conhecimentos prévios da linguagem cartográfica e o que deveriam apresentar em suas respectivas séries do período escolar em que se encontram.

Durante a realização de todas as atividades, lembrando que participaram desde alunos de 11 anos de idade até adultos acima de 30 anos, houve boa receptividade dos participantes, especialmente por parte dos alunos mais jovens.

Entre os adultos, apesar de serem alunos de curso de formação de professores, houve dificuldade para compreender a importância deste tipo de atividade em sala de aula. Mesmo assim, após a exposição dos mapas construídos artesanalmente em formato grande (painel) no III Simpósio de Práticas Docentes, encontro promovido pela Fundação Santo André que reúne diversas Licenciaturas, vários alunos, ou melhor, professores do Ensino Fundamental I e Pré-Escola, já começaram a desenvolver e adaptar seus materiais didáticos para Cartografia Escolar. Alguns até se interessaram em desenvolver projetos de Iniciação Científica para a elaboração de um Atlas sobre a Educação de Santo André.

Isto comprova que o recurso de construção de mapas artesanais em sala de aula ainda é pouco explorado.

Embora os resultados das atividades com alunos do Ensino Fundamental II ficarem abaixo do esperado em alguns pontos, serviram para aprimorar os métodos e materiais didáticos elaborados durante o período de 2009 e 2012.

$\mathrm{O}$ aspecto positivo das atividades foi visível na receptividade dos alunos em construir mapas, e mesmo com uma cobrança formal de atividade, foi possível perceber a espontaneidade de grande parte dos alunos, alguns até mesmo levantando dúvidas e sugestões sobre os materiais e métodos adotados.

Além disto, acreditamos que o melhor resultado deste trabalho foi tornar possível construir mapas temáticos em sala de aula de forma cotidiana, sem alterar o cronograma da disciplina, de forma rápida, simples e com baixo custo, fatores que podem desestimular até mesmo professores que valorizam a linguagem cartográfica, de aplicar atividades práticas de construção de mapas com seus alunos.

Observar um aluno durante a leitura de um livro didático "passar para a página seguinte" quando encontra um mapa, é algo que nos leva a refletir sobre 
nossas práticas docentes, principalmente para quem leciona uma disciplina que estuda o "espaço geográfico".

Por que as informações apresentadas pelo mapa não despertam o interesse do aluno? Diversos especialistas da Cartografia Escolar procuram responder esta questão. $\mathrm{O}$ fato de uma parte significativa dos mapas presentes em livros didáticos serem apenas ilustrativos, e normalmente não são elaborados pelos autores dos livros, são alguns dos argumentos encontrados para tentar compreender e justificar a pouca utilização de mapas em sala de aula.

Dentro deste universo que envolve sala de aula, Geografia e Cartografia Escolar, existe um número significativo de profissionais que compreendem a necessidade de trabalhar com mapas em sala de aula, mas que por razões diversas, não conseguem.

A partir da realidade destes profissionais, foi proposto este trabalho com 0 objetivo de tornar viável a construção de mapas por alunos do Ensino Fundamental e Médio, e com adaptações para outros ciclos e níveis do Ensino.

Como é possível perceber nas imagens das atividades aplicadas, os materiais didáticos foram aprimorados diversas vezes, até encontrar o formato mais apropriado, mas que podem ser ainda modificados e adaptados de acordo com a realidade encontrada por cada professor ou interessado em construir mapas temáticos artesanais. A possibilidade de aprimoramento destes materiais é infinita tanto para os gabaritos como para as tabelas, matrizes, fundos de mapas e os mapas temáticos.

Esperamos com esta proposta, apresentar mais uma alternativa para os professores de Geografia desenvolverem atividades relacionadas à Cartografia temática em sala de aula, especialmente os professores que dispõem de poucos recursos técnicos e financeiros, o que não impede os professores que não enfrentam estes obstáculos, de aplicar o método com seus alunos, uma vez que atividades manuais são de grande importância no Ensino Fundamental, e muitas vezes, até mais eficientes que as atividades que se utilizam apenas de recursos tecnológicos modernos.

Os materiais apresentados neste trabalho podem ser reproduzidos sem restrições, e o mais importante: em qualquer localidade, como forma de contribuir para a divulgação da Cartografia Escolar nas escolas distantes das grandes cidades.

Quanto ao futuro da Cartografia Escolar, podemos afirmar que com as novas 
mídias que surgiram nos últimos anos, a linguagem cartográfica ampliou ainda mais sua capacidade de representar fenômenos geográficos, e sua importância como linguagem também se tornou mais importante para a sociedade.

Os objetivos pretendidos de formar alunos leitores críticos de mapas, mapeadores conscientes, capazes de ler e interpretar a linguagem cartográfica, ou alunos capazes de estabelecer posturas críticas frente à sociedade, ainda representam um desafio para a Cartografia Escolar. Lutaremos para vencer estes desafios e alcançar nossos objetivos. 


\section{6 - REFERÊNCIAS BIBLIOGRÁFICAS}

ALMEIDA, Rosângela Doin de.(org.) Cartografia Escolar. São Paulo. Contexto, 2ª̣ed. 2011.

ALMEIDA, Rosângela Doin de. Uma Proposta Metodológica para a Compreensão de Mapas Geográficos. 1994. 289 f. Tese (Doutorado em Geografia) - Universidade de São Paulo, São Paulo, 1994.

ALMEIDA, Rosângela Doin de; PASSINI, Elza Yasuko. O espaço geográfico: ensino e representação. São Paulo. Contexto, 1990.

ARCHELA, Rosely Sampaio; THÉRY, Hervé. Orientação Metodológica para Construção e Leiura de Mapas Temáticos. Rev. Confins, ํㅡ 3, 2008. Disponível em: $<$ http://confins.revues.org/3483>

ARCHELA, Roseli. S. Imagem e representação gráfica. In: Geografia - Revista do Departamento de Geociências. Londrina: UEL, v.8, n.1, p.5-11, jan./ jun. 1999. 6p.

AZEVEDO, Tarik Rezende de. A síntese Cartográfica no Ensino: uma experiência no primeiro grau. Departamento de Geografia / FFLCH / USP 1993 - Série TA. Acesso em 14/07/2012.

BERTIN, Jacques. Sémiologie graphique: les diagrammes, les réseaux, les cartes. Paris: Mouton \& Gauthier-Villars, 1967. 432p.

BERTIN, Jacques. A neográfica. Tradução de Jayme Antonio Cardoso. UFPR, julho/2000.

BERTIN, Jacques. Ver ou ler: um novo olhar sobre a Cartografia. Seleção de Textos, São Paulo, n.18, maio, 1988(b), p.41-43.

BERTIN, Jacques. $O$ teste de base da representação gráfica. Trad. Antonio Teixeira Neto. Revista Brasileira de Geografia, Rio de Janeiro, 42(1): jan/mar, 1980, p. 160-182.

BONIN, Serge. Novas perspectivas para o ensino da cartografia. Trad. Antonio Teixeira neto. Boletim Goiano de Geografia, 2(1), jan/jun 1982. p. 73-87.

BRASIL - Ministério da Educação e Cultura. Parâmetros Curriculares Nacionais: terceiro e quarto ciclo do ensino fundamental: Geografia. Brasília: MEC, 1998, 156p.

BRASIL - Ministério da Educação e Cultura. Parâmetros Curriculares Nacionais: Ensino Médio: Geografia. Brasília: MEC, 2000, 109p.

CALLAI, Helena Copetti. A Geografia e a Escola: muda a Geografia? Muda o ensino? Terra Livre, São Paulo, n. 16, 2001. p. 133-152. 
CARMO, Valdirene Ribeiro. Cartografia tátil escolar: experiências com a construção de materiais didáticos e com a formação continuada de professores. Dissertação de Mestrado. USP, 2010.

CASTELLAR, Sonia M.V. A cartografia e a Construção do Conhecimento em Contexto Escolar. In: ALMEIDA, R. Doin (Org.). Novos Rumos da Cartografia Escolar. São Paulo, Contexto, 2011. p. 121-135.

CAVALCANTI, Lana de Sousa. Cotidiano, Mediação Pedagógica e Formação de Conceitos: Uma contribuição de Vygotsky ao ensino da Geografia. Cadernos CEDES vol. 25 nำ66. Campinas, 2005.

CAVALCANTI, Lana de Sousa. Geografia, escola e construção de conhecimentos. Papirus. Campinas, 1998.

DURAND, Marie-Françoise; COPINSCHI, Philippe; MARTIN, Benoit; PLACIDI, Delphine. Atlas da Mundialização: Compreender o espaço mundial contemporâneo. Saraiva. São Paulo, 2009. p. 13-19.

FERREIRA, Graça M. Lemos. Atlas Geográfico Espaço Mundial. S.Paulo. Moderna, 2004.

FONSECA, Fernanda Padovesi. A inflexibilidade do espaço cartográfico, uma questão para a Geografia: análise das discussões sobre o papel da Cartografia. São Paulo, Tese (Doutorado em Geografia), FFLCH/USP, 2004.

FONSECA, Fernanda Padovesi; COSTA, Gilberto P.; OLIVA, Jaime T.; GIANSANTI, Roberto. Olhar Geográfico: A diversidade do mundo. 6ª série. São Paulo. IBEP, 2006.

FONSECA, Fernanda Padovesi; OLIVA, Jaime T. A Geografia e suas linguagens: o caso da Cartografia. In: CARLOS, Ana Fani A. (Org). A Geografia na Sala de Aula. São Paulo: Contexto, 1999. p. 62-78.

FONSECA, Fernanda Padovesi. O potencial analógico da Cartografia. Boletim Paulista de Geografia, São Paulo, n. 87, dez. 2007, p. 85-110.

FONSECA, Fernanda Padovesi; OLIVA, Jaime Tadeu: CARTOGRAFIA. Coleção: Como Eu Ensino. São Paulo, Melhoramentos, 2013, p.62-68.

FRANCISCHETT, Mafalda Nesi. A cartografia escolar crítica. ENPEG2007. GTD 05. Disponível em: <http://www.bocc.ubi.pt/pag/francischett-mafalda-cartografia-escolarcritica.pdf>. Acesso em 15/07/2012.

FRANCISCHETT, Mafalda Nesi. O Prego Quebrou, o Mapa Caiu... .2010. Biblioteca online de Ciências da Comunicação. <http://www.bocc.ubi.pt/_esp/autor.php?codautor=793> . Acesso em 14/07/2012.

GIMENO, Roberto; BERTIN, Jacques. A lição de cartografia na escola elementar. Boletim Goiano de Geografia, 1982. 
GIMENO, Roberto. Apprendre à l'école par la graphique.Paris, Editions Retz, 1980, 192 p.

GIMENO, Roberto. Uma nova abordagem da cartografia na escola elementar. Boletim Goiano de Geografia, n.11, v.1, p. 104-125, jan./dez. 1991.

GIRARDI, Gisele. Leitura de mitos em mapas: um caminho para repensar as relações entre Geografia e Cartografia. Revista Geografares, v. 1, n.1, 2000 p. 41-50.

GIRARDI, Gisele; LACERDA, Lucas C.F.; VARGAS, André A.; LIMA, Ludovico M. Cartografias Alternativas no Âmbito da Educação Geográfica. Rev. Geográfica de América Central. Número Especial EGAL, 2011 - Costa Rica, 2011. p. 1-15.

GOETTEMS, Ellen Martha Pritsch; VACCO, Dominick. Tratamento e Destino de Efluentes Fotográficos: aspectos ambientais. In: Congresso Brasileiro de Engenharia Sanitária e Ambiental, 19․ Foz do Iguaçu/PR, 1997. p.770. Disponível em: <http://www.bvsde.paho.org/bvsacd/abes97/fotografico.pdf>

HARLEY, Brian. Mapas, Saber e Poder. Revista Confins, № 05, 2009. Disponível em $<$ http://confins.revues.org/5724>. Acesso em 15/07/2012

LE SANN, Janine Gisèle. Metodologia para introduzir a geografia no ensino fundamental. In: ALMEIDA, R. D. de (Org.). Cartografia escolar. São Paulo: Contexto, 2007, p. 95-118.

LE SANN, Janine Gisèle. A utilização da Cartografia Temática na Geografia para o Ensino Fundamental. Colóquio Cartografia para Crianças. Rio Claro, 1995.

LE SANN, Janine Gisèle. O papel da Cartografia Temática nas Pesquisas Ambientais. Rev. do Departamento de Geografia, n 16, UFMG. 2005. p. 61-69.

LEITE, Gerson Rodrigues. Materiais Didáticos para Cartografia Escolar. Blog. São Bernardo do Campo. Blogorama.com.br, março/2011. Disponível em: $<$ http://materialcartografiaescolar.arteblog.com.br>

LEITE, Gerson Rodrigues. Materiais Didáticos para Cartografia Escolar: metodologias para a construção de mapas em sala de aula. Dissertação (Mestrado). FFLCH, Universidade de São Paulo, São Paulo, 2014.

LÉVY, Jacques. Uma virada cartográfica? In: ACSELRAD, Henri (org.). Cartografias sociais e território. Rio de Janeiro: UFRJ/IPPUR, 2008. p. 153-167.

MANTOVANI, Angelica C. Di Maio. Reflexões sobre o Ensino de Cartografia Temática na Geografia. Geolab, UDESC, 2010.

<http://www.geolab.faed.udesc.br/sites_disciplinas/Cartografia_tematica/Texto_02_Reflexoe s_CartografiaTemGegrafia.pdf>. Acessado em 14/07/2012.

MARTINELLI Marcello. Cartografia para escolares: um desafio permanente. In: Cartografia para Escolares no Brasil e no mundo. Belo Horizonte.CDRom. 2002. p. 125-128. 
MARTINELLI Marcello. Gráficos e mapas: construa-os você mesmo. São Paulo. Moderna, 1998.

MARTINELLI Marcello. Mapas da Geografia e Cartografia Temática. São Paulo. Contexto, 2011.

MARTINELLI Marcello; FERREIRA, Graça M. L. Cartografia para os Atlas Geográficos para crianças. Colóquio Cartografia para Crianças. Rio Claro, 1995.

NAKANO, Marilena; LEITE, Gerson Rodrigues. Dos Dados aos Mapas: A educação de Santo André se revelando. III SIMPRÁTICA - Simpósio de Práticas Docentes - FAFIL Fundação Santo André, agosto 2012.

OLIVEIRA, Adriano Rodrigo. Geografia e Cartografia Escolar: o que sabem e como ensinam professoras das séries iniciais do ensino fundamental? Educação e Pesquisa, São Paulo, v.34, n.3, set/dez. 2008. p. 481-494.

OLIVEIRA, Lívia de. Estudo Metodológico e Cognitivo do Mapa. In. ALMEIDA, Rosângela Doin de (Org.). Cartografia Escolar. São Paulo: Contexto, 2007. p. 15-41.

OLIVEIRA, Lívia de. Estudo Metodológico e Cognitivo do Mapa. Tese de Livre-Docência. UNESP. Rio Claro, 1978.

PAGANELLI, Tomoko lyda. Para a construção do espaço geográfico na criança. 1982. Dissertação (Mestrado em Educação) - Instituto de Estudos avançados em Educação, Fundação Getúlio Vargas, Rio de Janeiro, 1982.

PAGANELLI, Tomoko I. A Noção de Espaço e de Tempo. Revista Orientação. USP, 1985.

PASSINI, Elza Yasuko. Alfabetização Cartográfica e o Atlas Municipal. 2006. Disponível em: http://observatoriogeograficoamericalatina.org.mx/egal9/Nuevastecnologias/Sig/06.pdf> . Acesso em 14/07/2012.

PASSINI, Elza Yasuko. Os Gráficos em Livros didáticos de Geografia de 5a série: seu significado para alunos e professores. São Paulo: USP, 1996. 279p. (Tese de Doutorado).

PASSINI, Elza Yasuko; ALMEIDA, R.D; MARTINELLI, M. A cartografia para crianças: alfabetização, educação ou iniciação cartográfica? Boletim de Geografia, Maringá, v. 1, Ano 17, p. 125-136, 1999.

PIAGET, Jean. O Nascimento da Inteligência na Criança. Trad. Alvaro Cabral. Rio de Janeiro. Zahar, 1970.

PIAGET, Jean; INHELDER, Barbel. A psicologia da criança. Rio de Janeiro. Difel, 1978.

PRADO, C. Alves; LEAL, Francisco N.; SERRER, Pedro B.; CARVALHO, Pedro I. M. de. A Construção do Mapa Temático em Sala de Aula. AGB, ENG2010. Porto Alegre/RS. 
QUEIROZ, Deise Regina Elias. A Semiologia e a Cartografia Temática. Boletim de Geografia, no 18. 2000. p. 121-127.

REED, Carol. Agonia e Êxtase. Filme que retrata a pintura do teto da Capela Sistina por Michelângelo no século XVI. FOX/EUA, 1965.

SANTAELLA, Lucia. Leitura de Imagens. Coleção Como Eu Ensino. São Paulo, Melhoramentos, 2012. p. 8 - 120.

SIMIÃO, Helaine Cordeiro Rodrigues. Cartografia e Ensino de Geografia: uma breve discussão teórico-metodológica. Dissertação (Mestrado). FFLCH - USP, 2011 p. 98.

SIMIELLI, Maria Elena Ramos. O Mapa como meio de Comunicação Cartográfica: implicações no ensino da geografia do 1 grau. USP, Departamento de Geografia, tese de Doutoramento, 1986.

SIMIELLI, Maria Elena Ramos. Cartografia no ensino fundamental e médio. In: CARLOS, Ana F. A. (org). A Geografia na Sala de Aula. 8ª ed. S.Paulo: Contexto, 2007.p. 92-108.

SIMIELLI, Maria Elena Ramos. O mapa como meio de comunicação e a alfabetização escolar. Cartografia Escolar. Rosângela Doin de Almeida (Org.). 2ª Ed. Contexto, 2011.

THÉRY, Hervè; MELLO, Neli. A. de: Atlas do Brasil. Disparidades e Dinâmicas do Território. São Paulo, EDUSP, 2005. 312p.

VASCONCELLOS, Regina. A Cartografia tátil e o deficiente visual: uma avaliação das etapas de produção e uso do mapa. São Paulo, 1993. Tese (Doutorado em Geografia). Universidade de São Paulo.

VASCONCELLOS, Regina; ANDERSON, Jacqueline. Mapas para e por crianças: possíveis contribuições dos cartógrafos. Colóquio Cartografia para Crianças. Rio Claro, 1995. 


\title{
Materiais Didáticos para Cartografia Escolar: metodologias para a construção de mapas em sala de aula
}

\section{APÊNDICE}

Gerson Rodrigues Leite

\begin{abstract}
Apêndice da Dissertação com os materiais didáticos propostos para reprodução, apresentado ao Departamento de Geografia da Faculdade de Filosofia, Letras e Ciências Humanas da Universidade de São Paulo para a obtenção do título de mestre em Geografia.
\end{abstract}

Orientadora: Prof ${ }^{\mathrm{a}}$. Dr ${ }^{\mathrm{a}}$. Fernanda Padovesi Fonseca 


\section{ÍNDICE DE MATERIAIS DIDÁTICOS EM APÊNDICE}

\section{GABARITOS PARA LOUSA}

Material 01 - Gabarito de mapa mudo - BRASIL 168

Material 02 - Gabarito de mapa mudo - AMÉRICA DO SUL 178

Material 03 - Gabarito de mapa mudo - PLANISFÉRIO - projeção equivalente 187

Material 04 - Gabarito de mapa mudo - PLANISFÉRIO - projeção equidistante 194

Material 05 - Gabarito de mapa mudo - PLANISFÉRIO - projeção poliédrica 203

Material 06 - Gabarito de CíRCULOS PROPORCIONAIS - lousa 208

Material 07 - Gabarito de SÍMBOLOS DIVERSOS / PROPORCIONAIS - lousa 211

\section{GABARITOS INDIVIDUAIS}

Material 08 - Gabarito de CÍRCULOS PROPORCIONAIS - individual 214

Material 09 - Gabarito de SÍMBOLOS DIVERSOS / PROPORCIONAIS - individual . 216

Material 10 - Gabarito de CURVAS PROPORCIONAIS - individual 218

\section{TABELAS E MATRIZES INDIVIDUAIS}

Material 11 - Tabela e procedimentos para cálculos de dados estatísticos - tamanho A-5 220

Material 12 - Tabela e procedimentos para cálculos de dados estatísticos - tamanho A-6 221

Material 13 - Matriz para elaboração de mapas temáticos- BRASIL 222

Material 14 - Matriz para elaboração de mapas temáticos- AMÉRICA DO SUL 223

Material 15 - Matriz para elaboração de mapas temáticos- PLANISFÉRIO- projeção equivalente .. 224 Material 16 - Matriz para elaboração de mapas temáticos- PLANISFÉRIO- projeção equidistante ...225 Material 17 - Matriz para elaboração de mapas temáticos- PLANISFÉRIO- projeção poliédrica ..... 226 Material 18 - Matriz para elaboração de mapas temáticos- EM BRANCO ………............................ 227

Material 19 - PLANISFÉRIO em duplicata para raport (emenda das longitudes) 228 


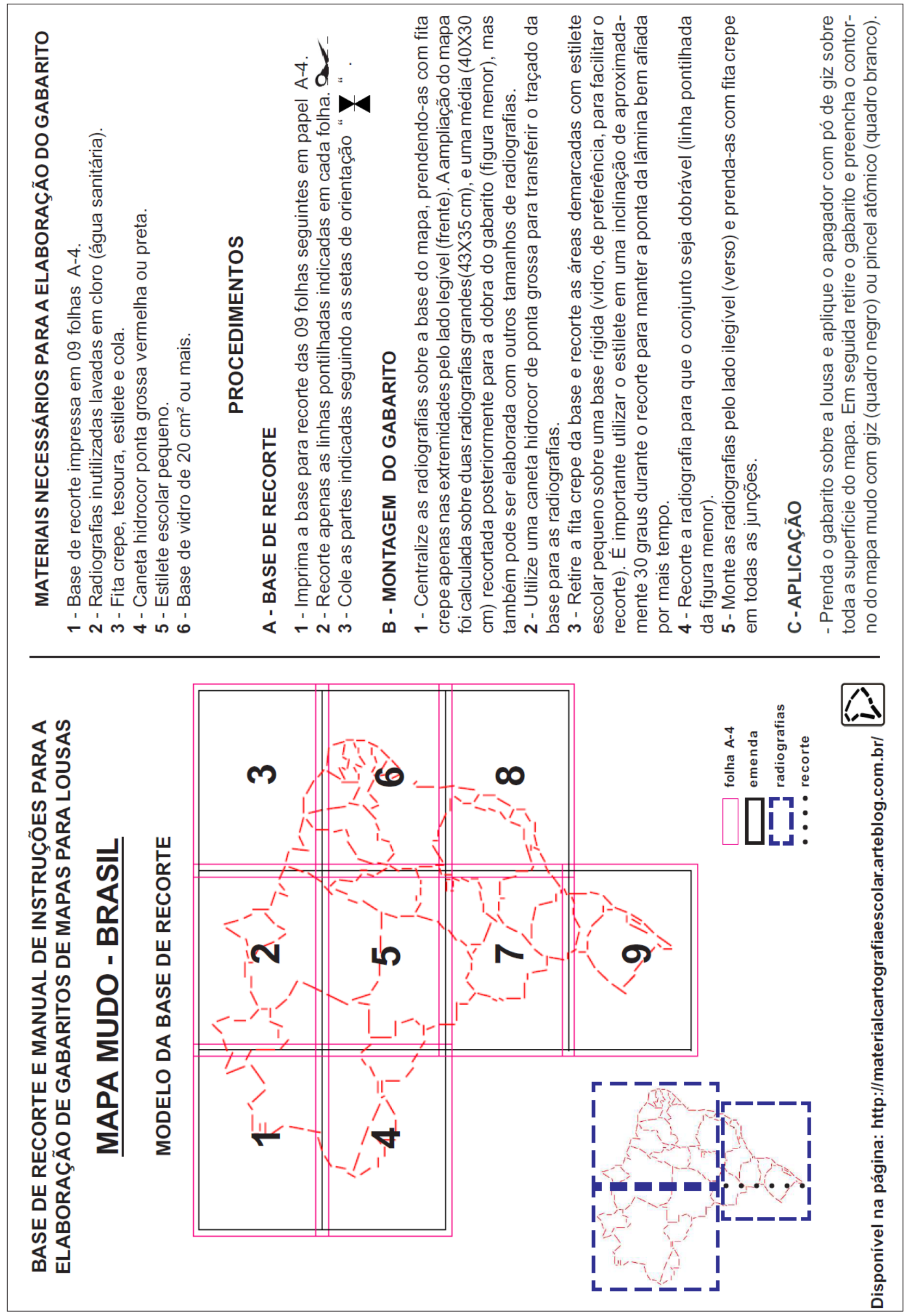


Inbe z0 ецा이 e ә이

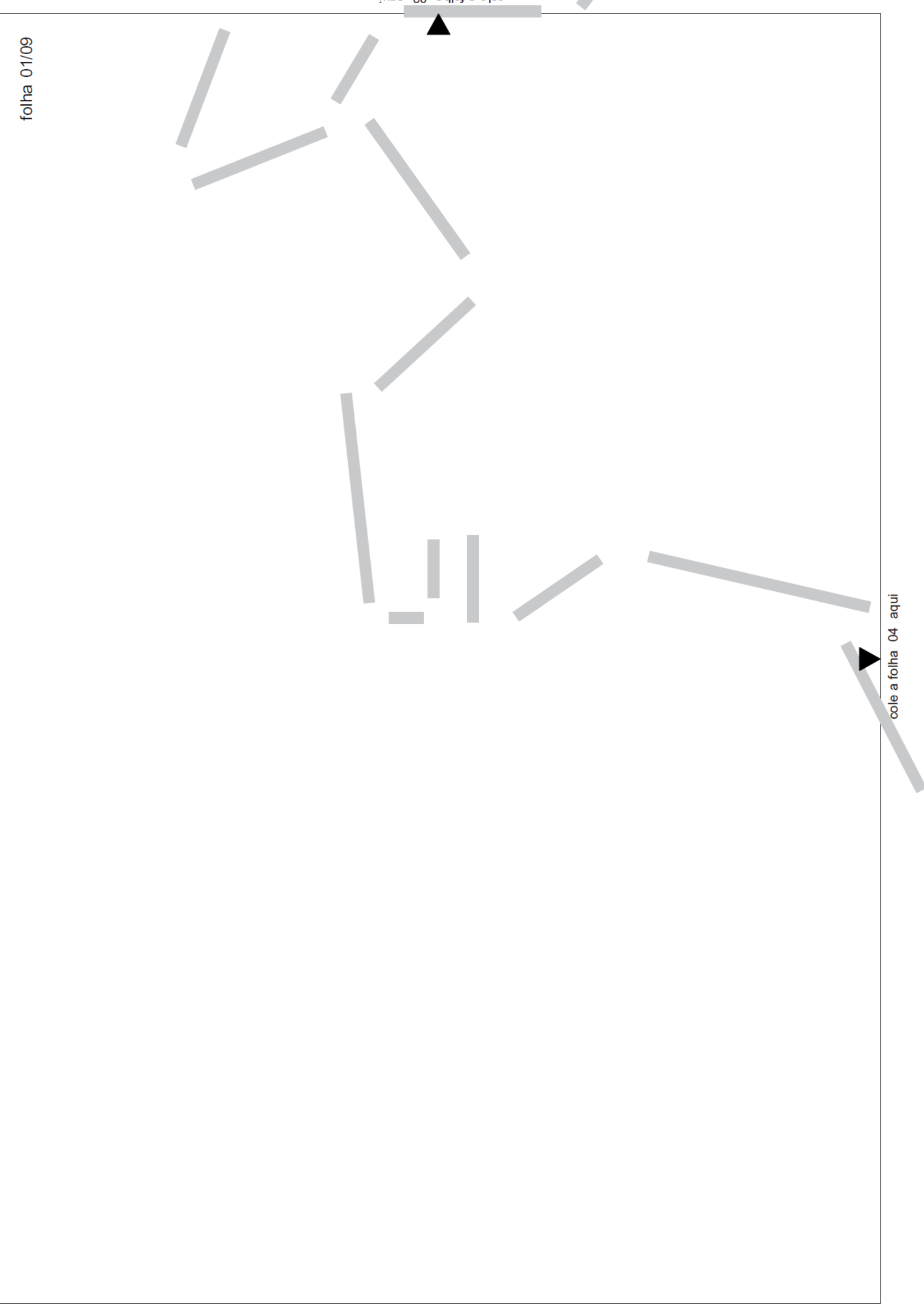




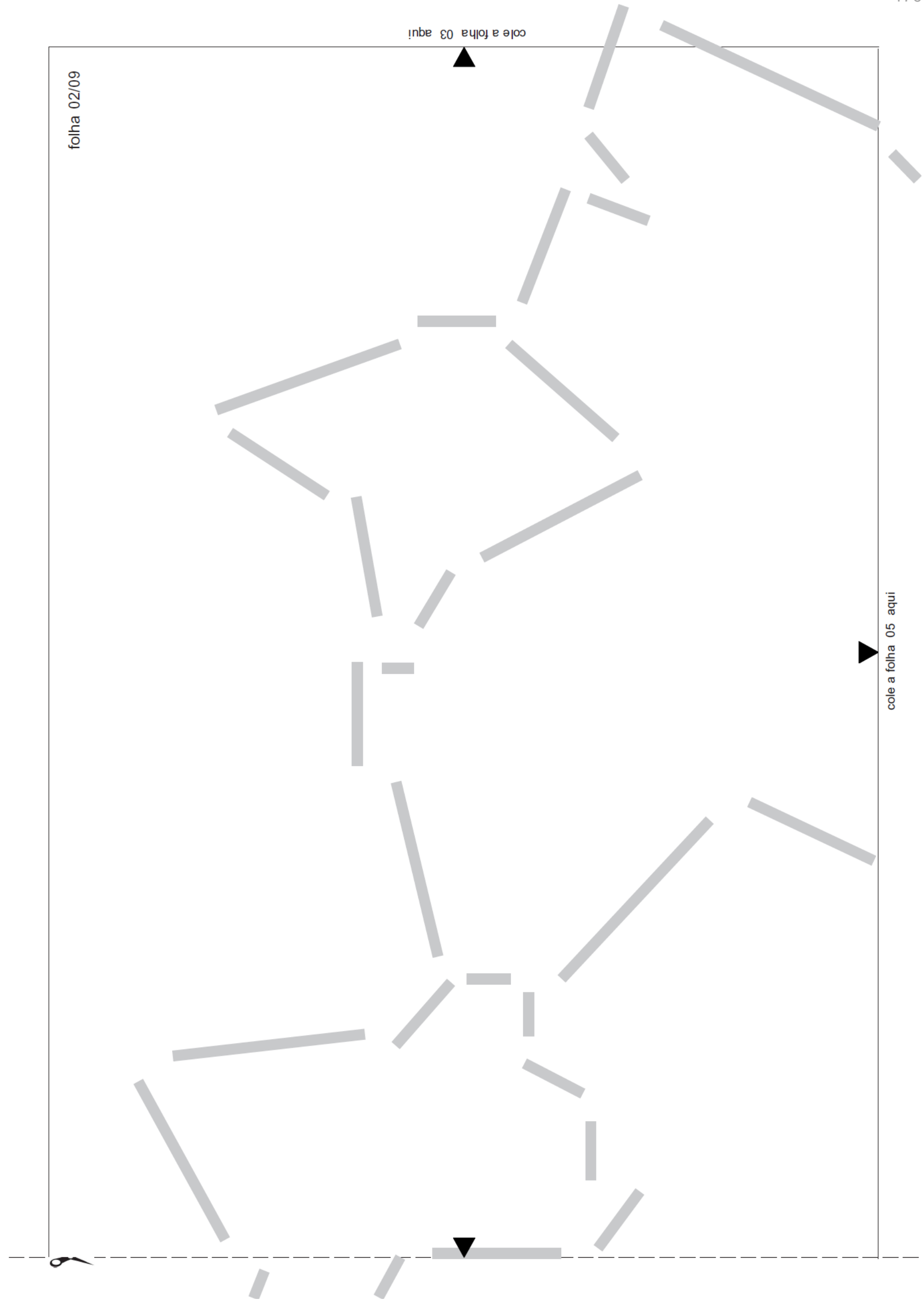




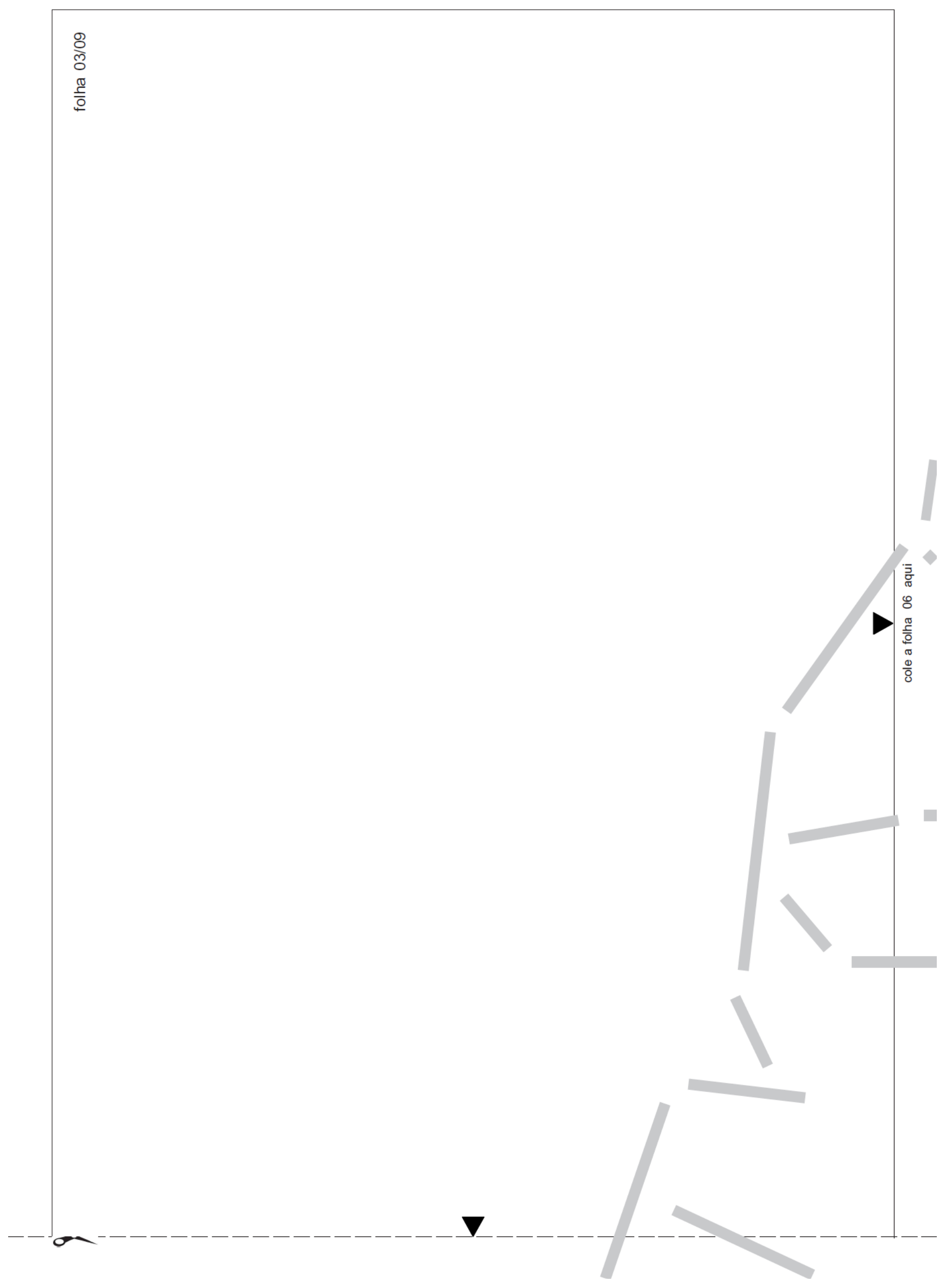




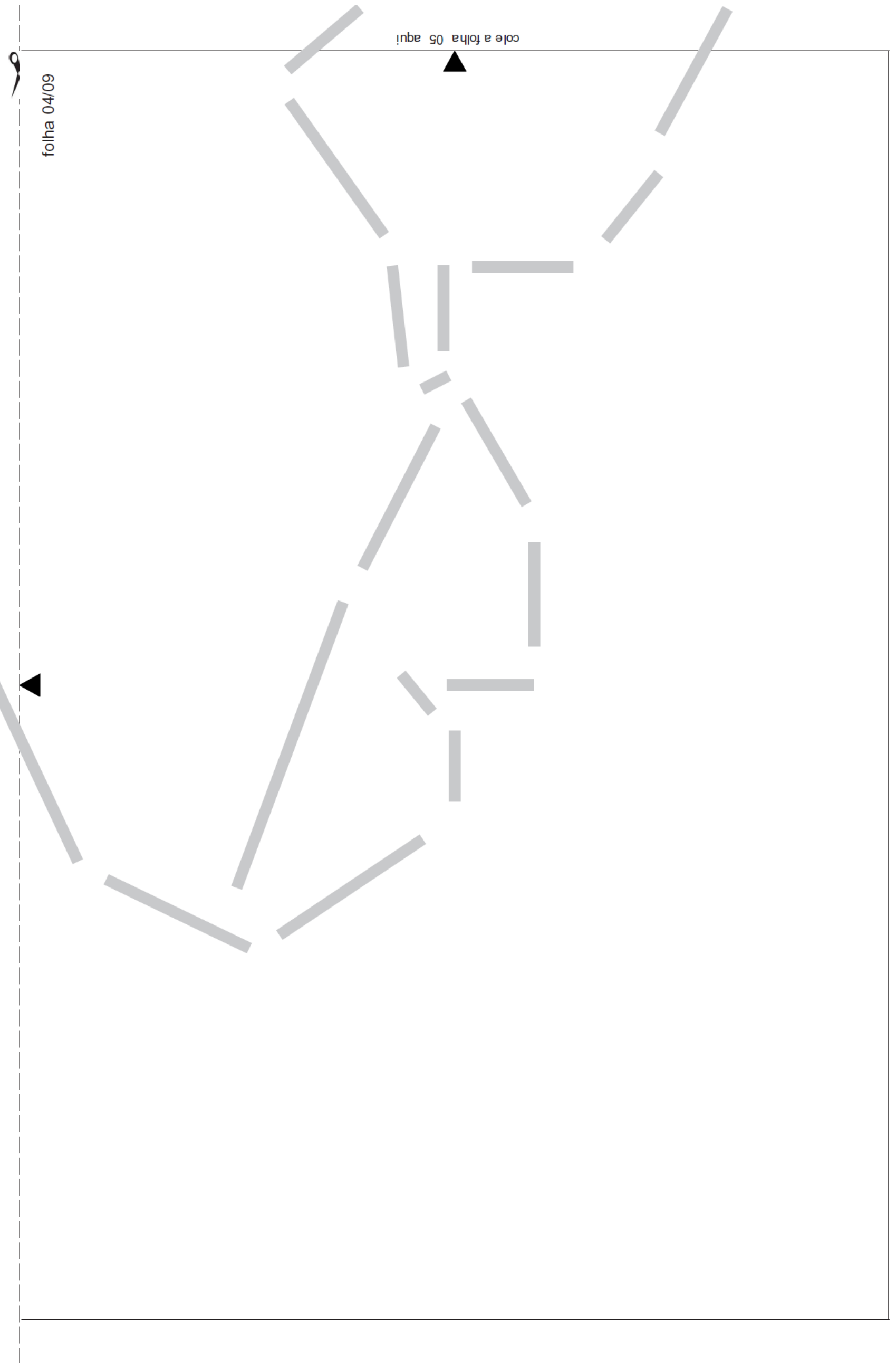




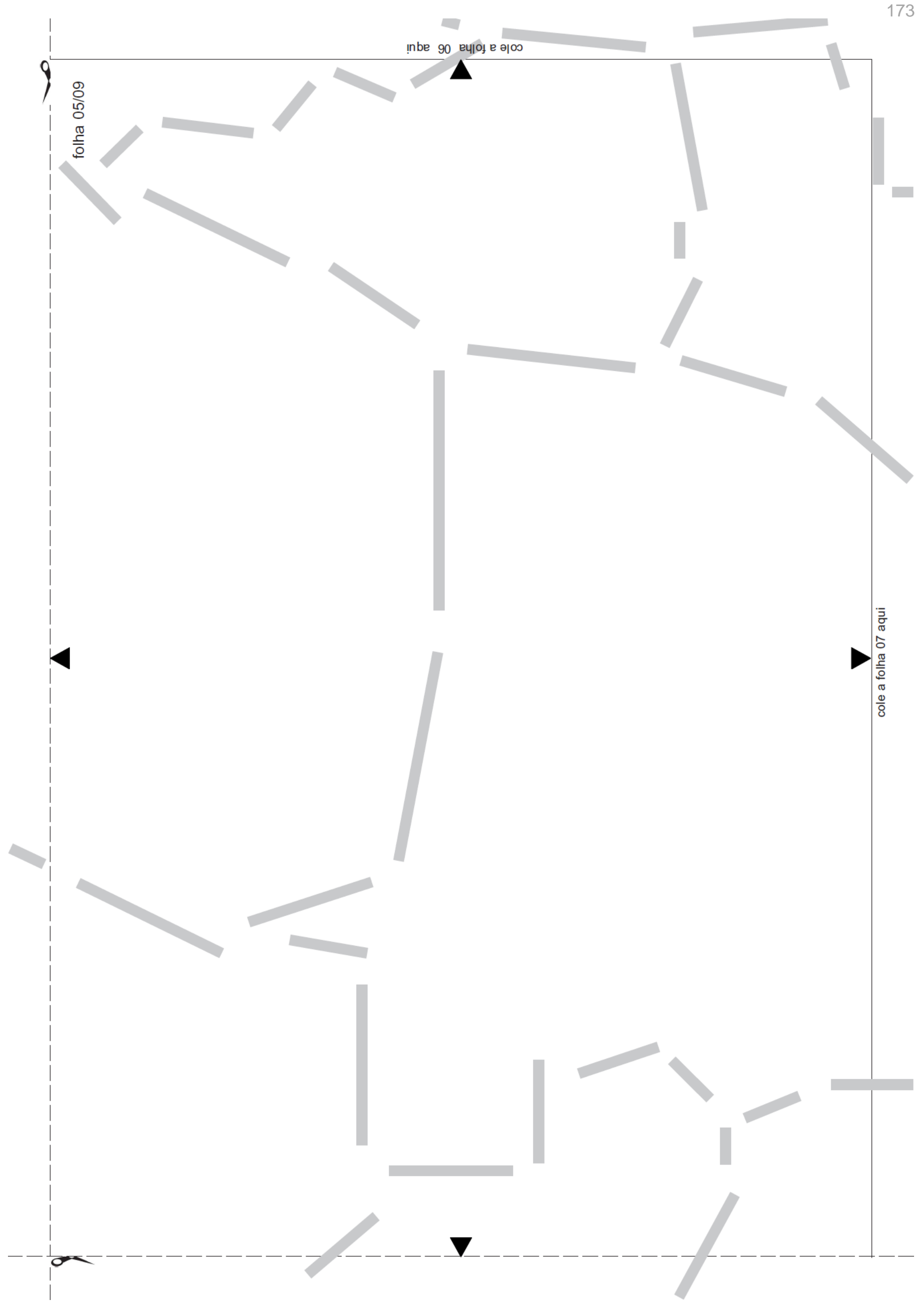




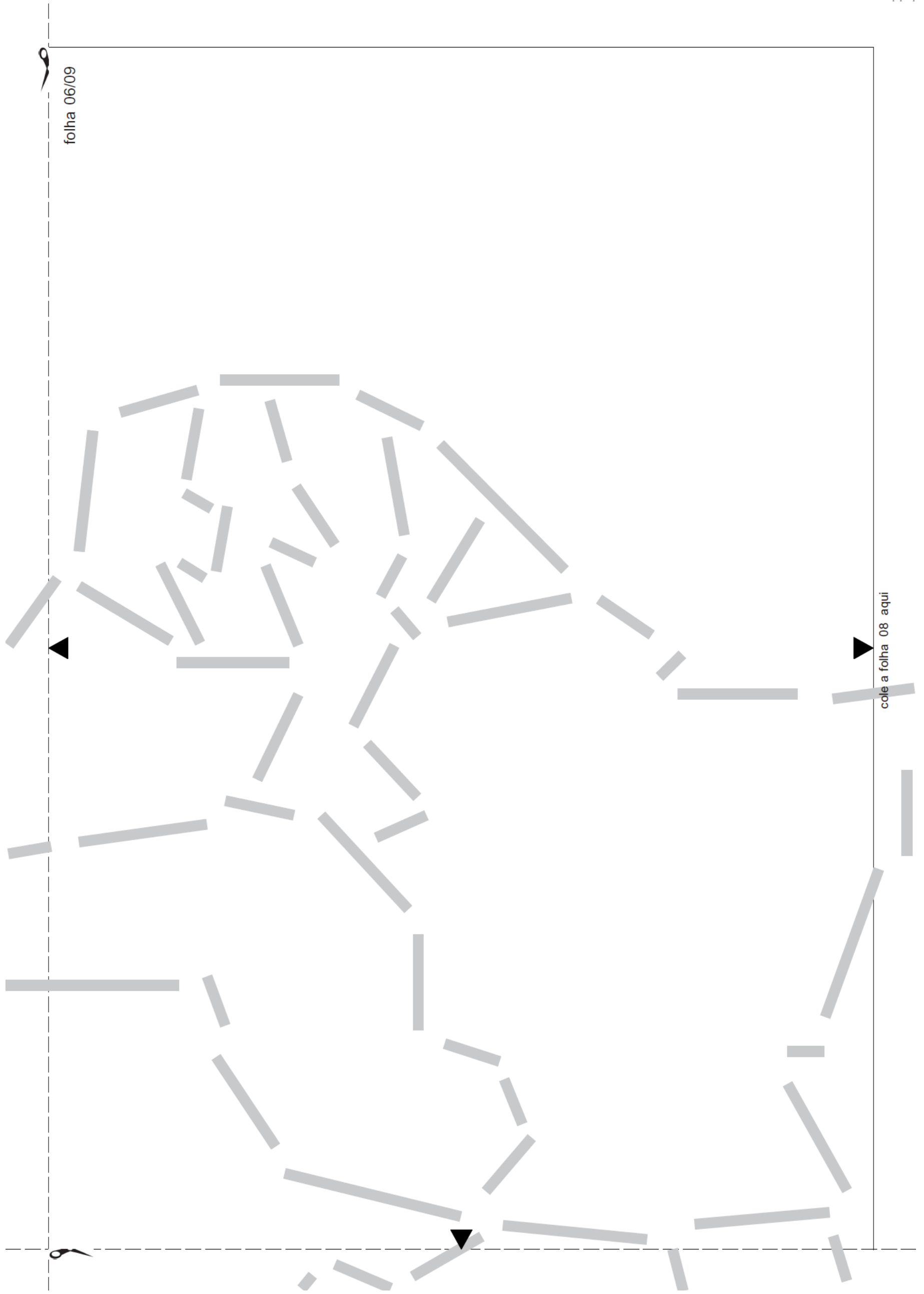




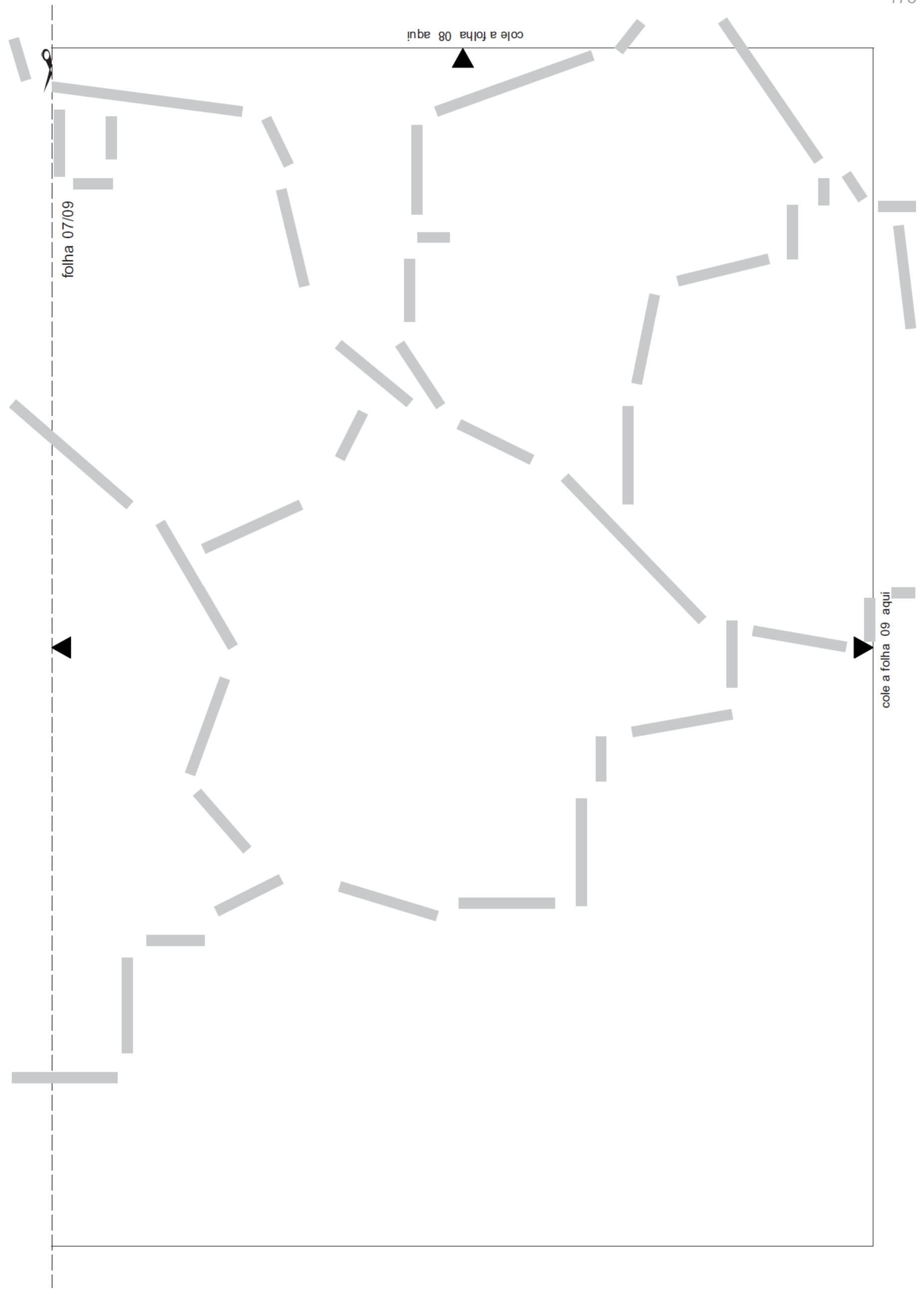


응
00
0
0
은

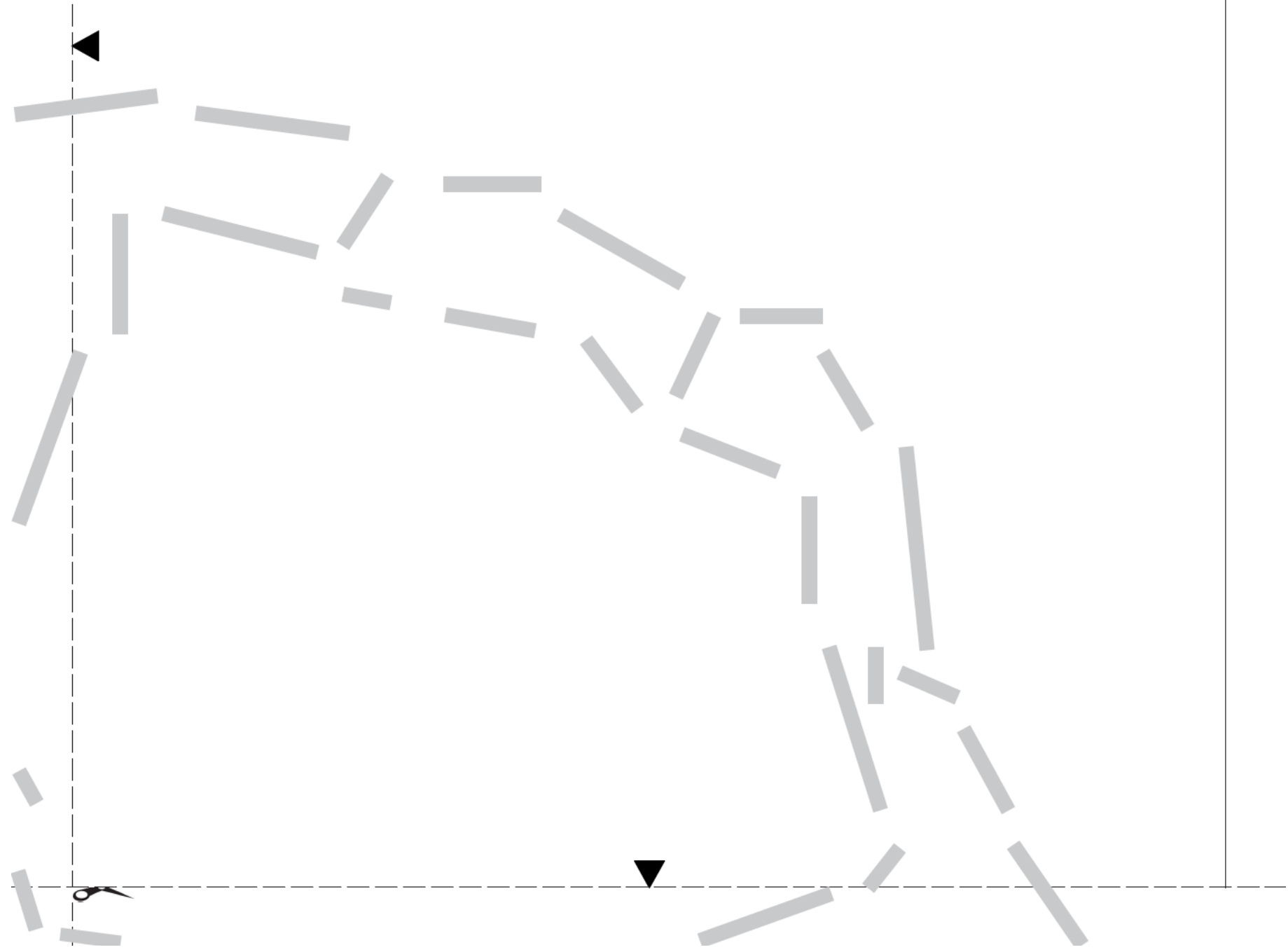




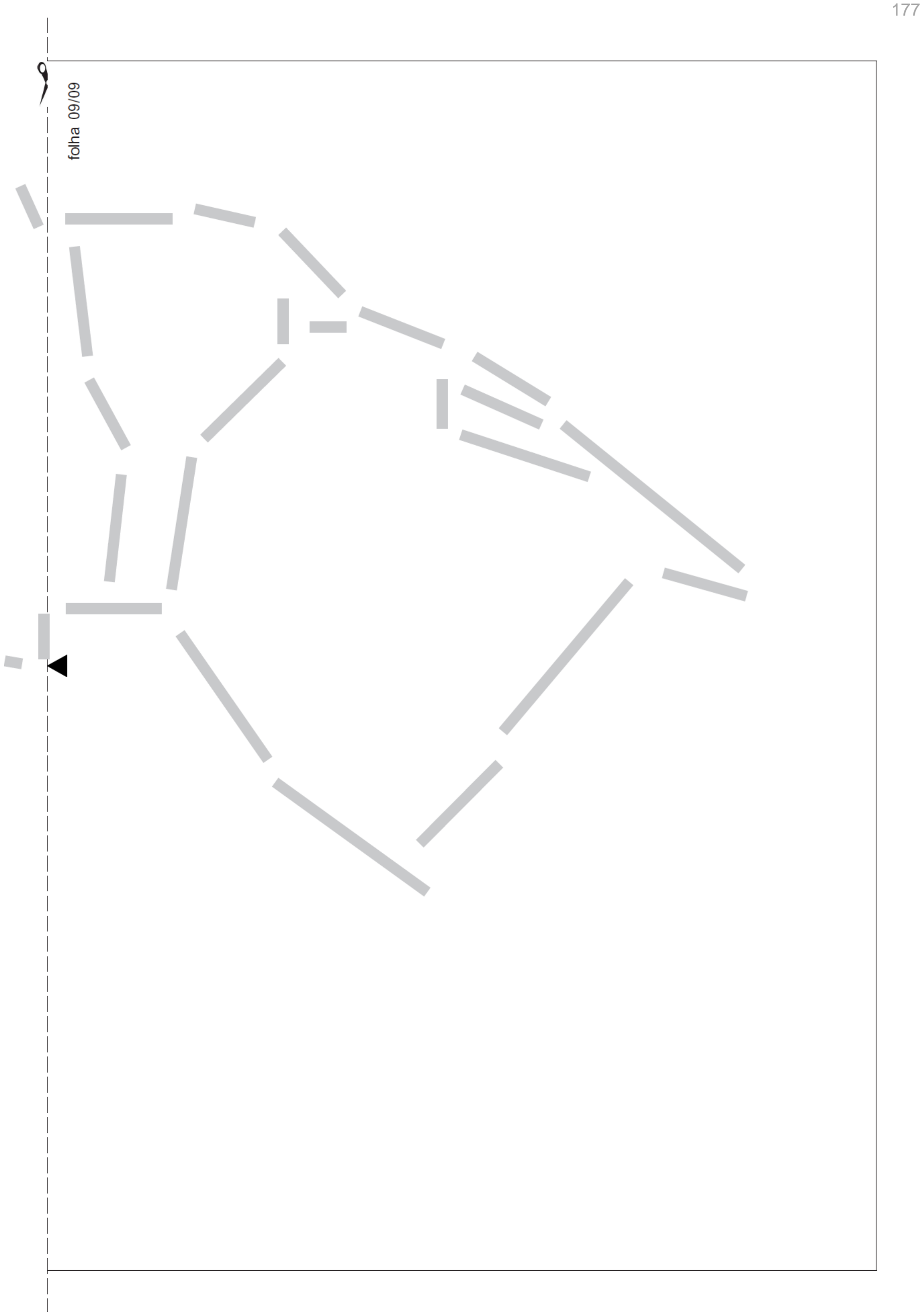




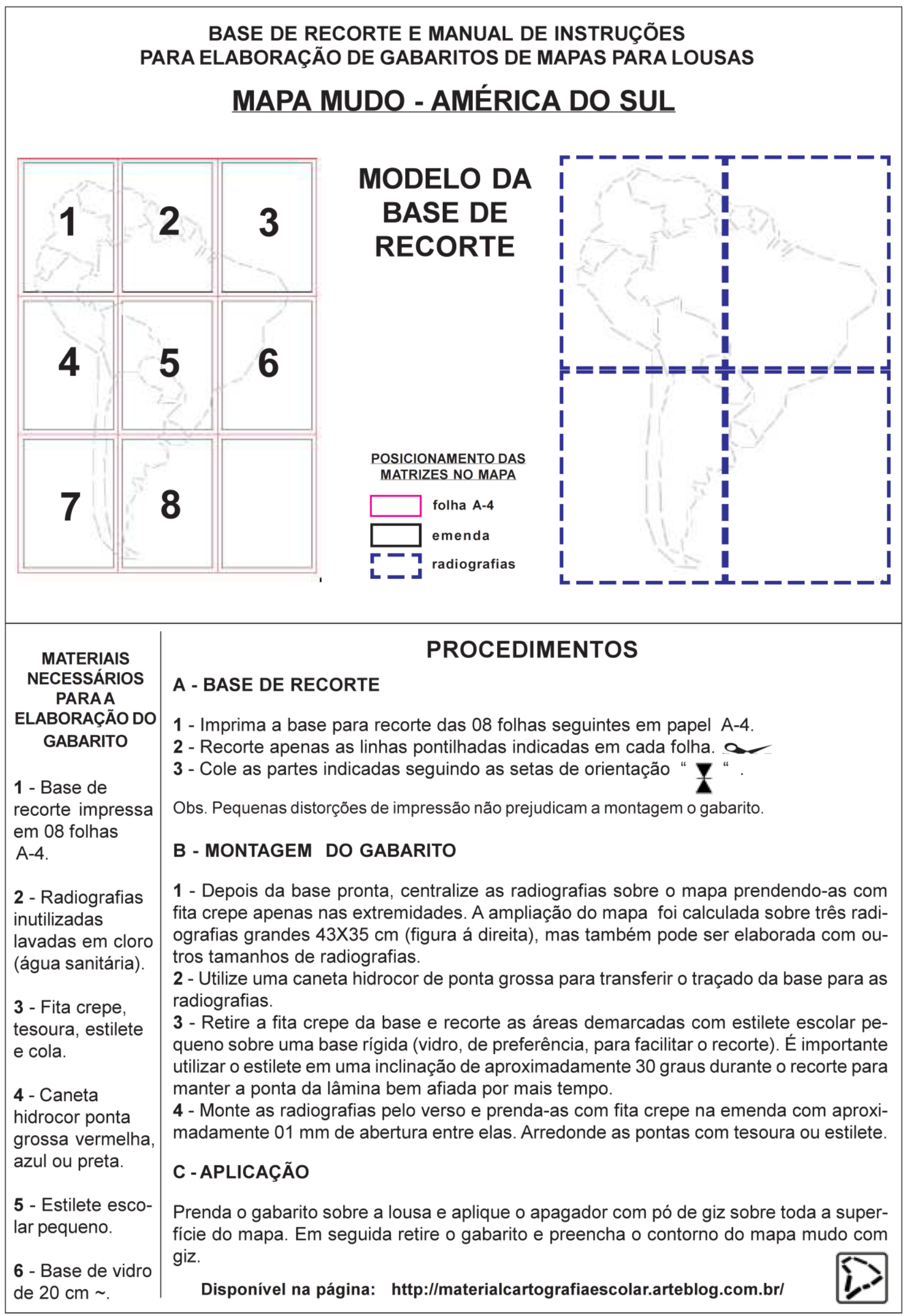




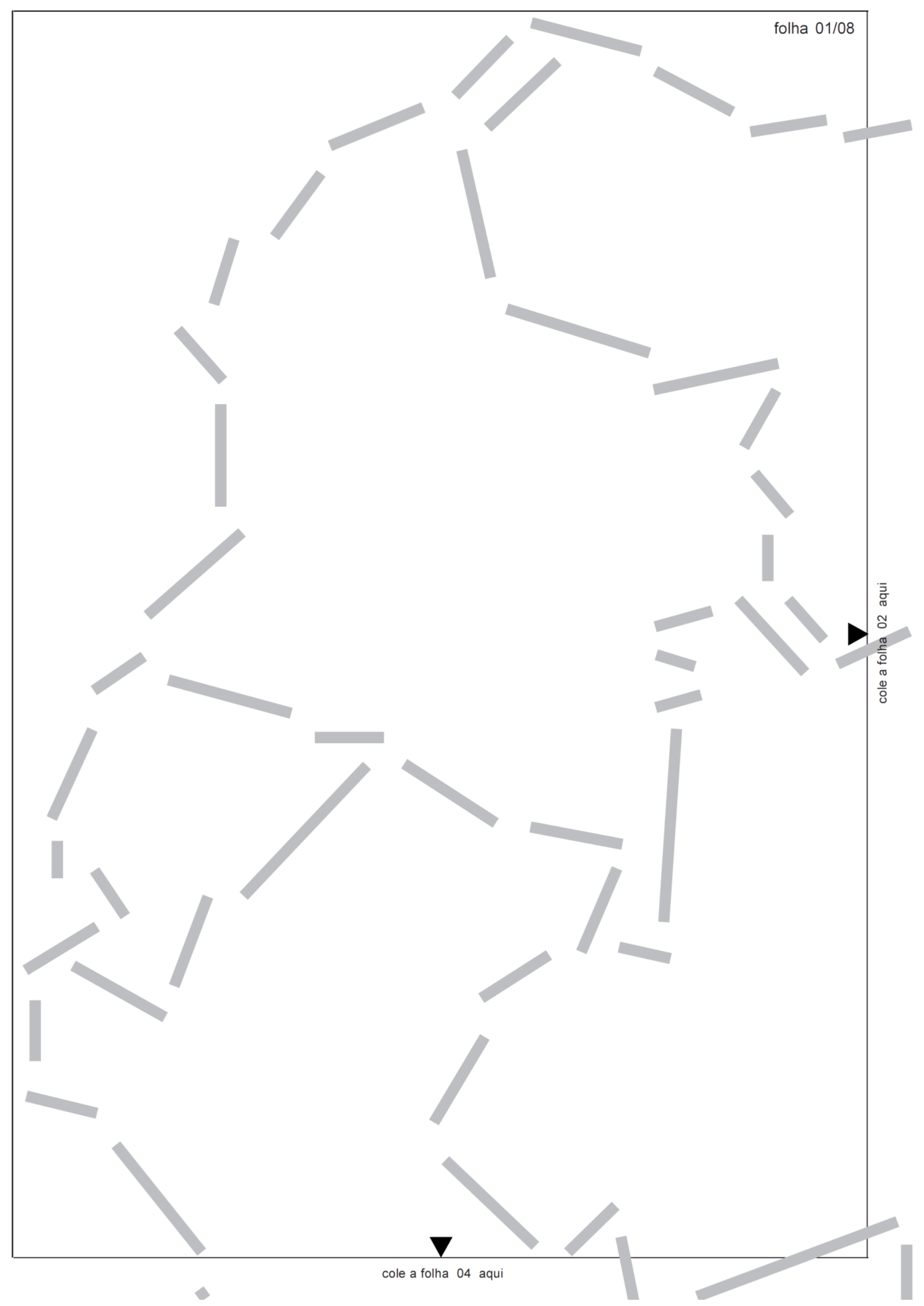




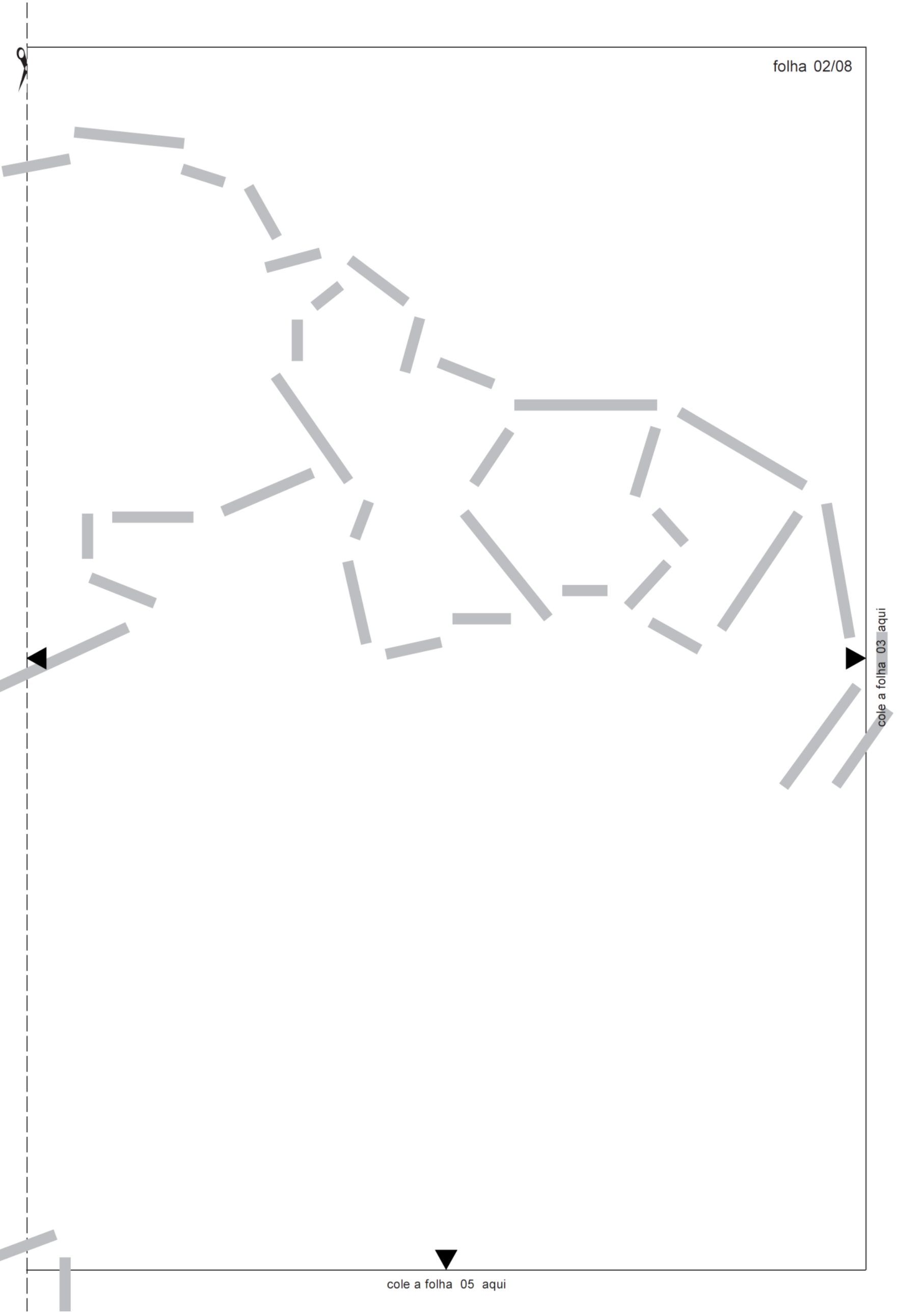




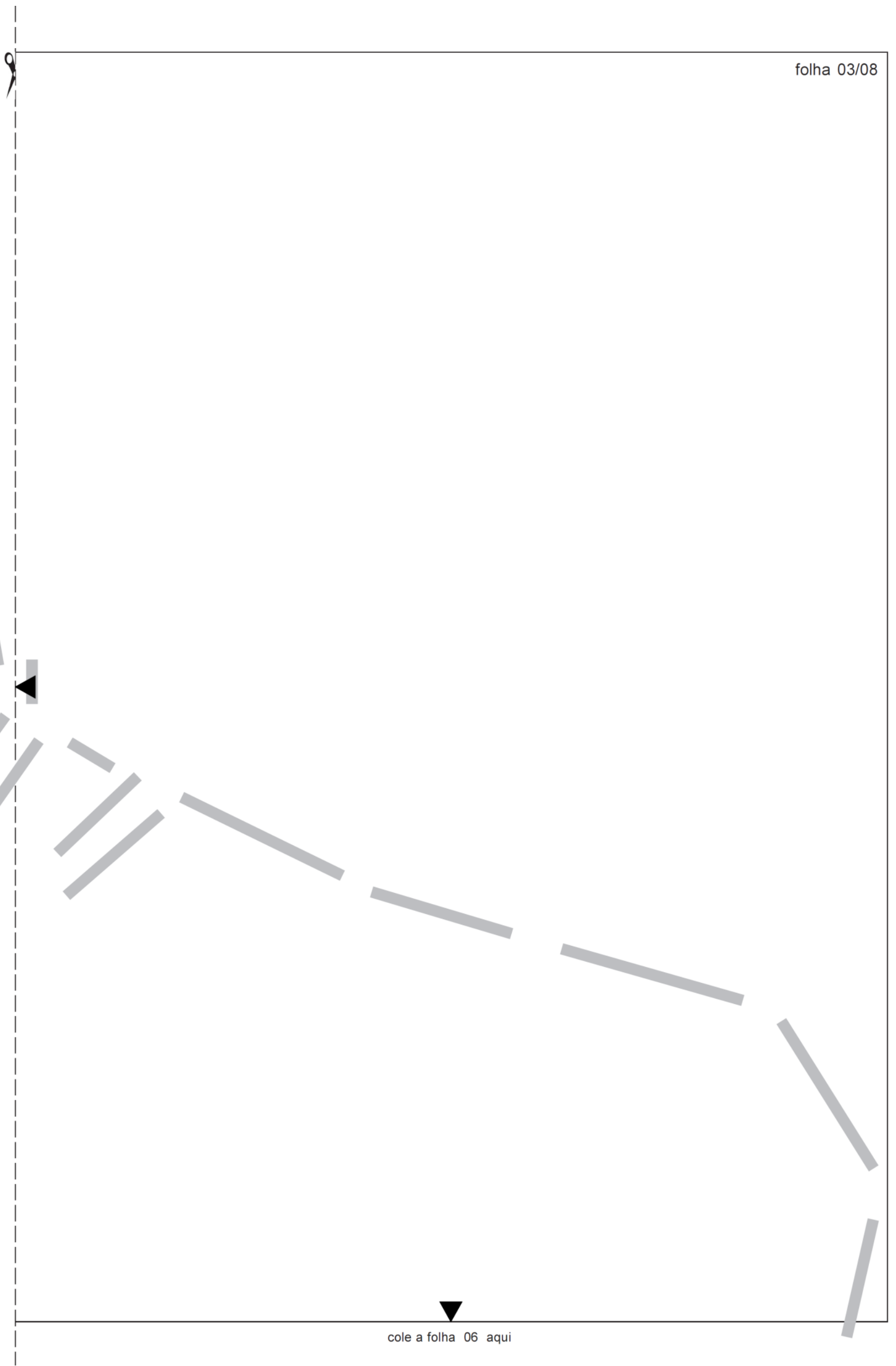




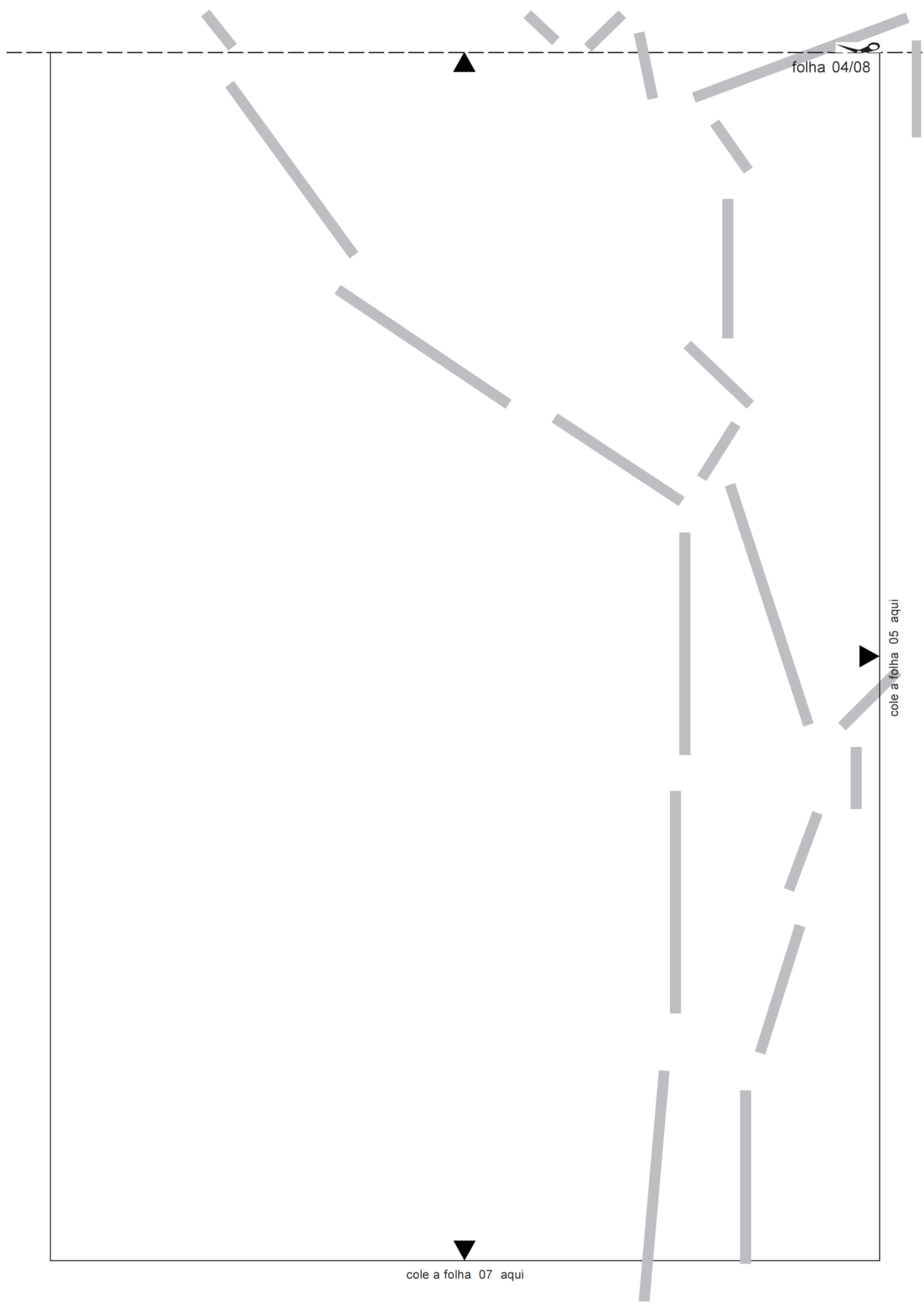




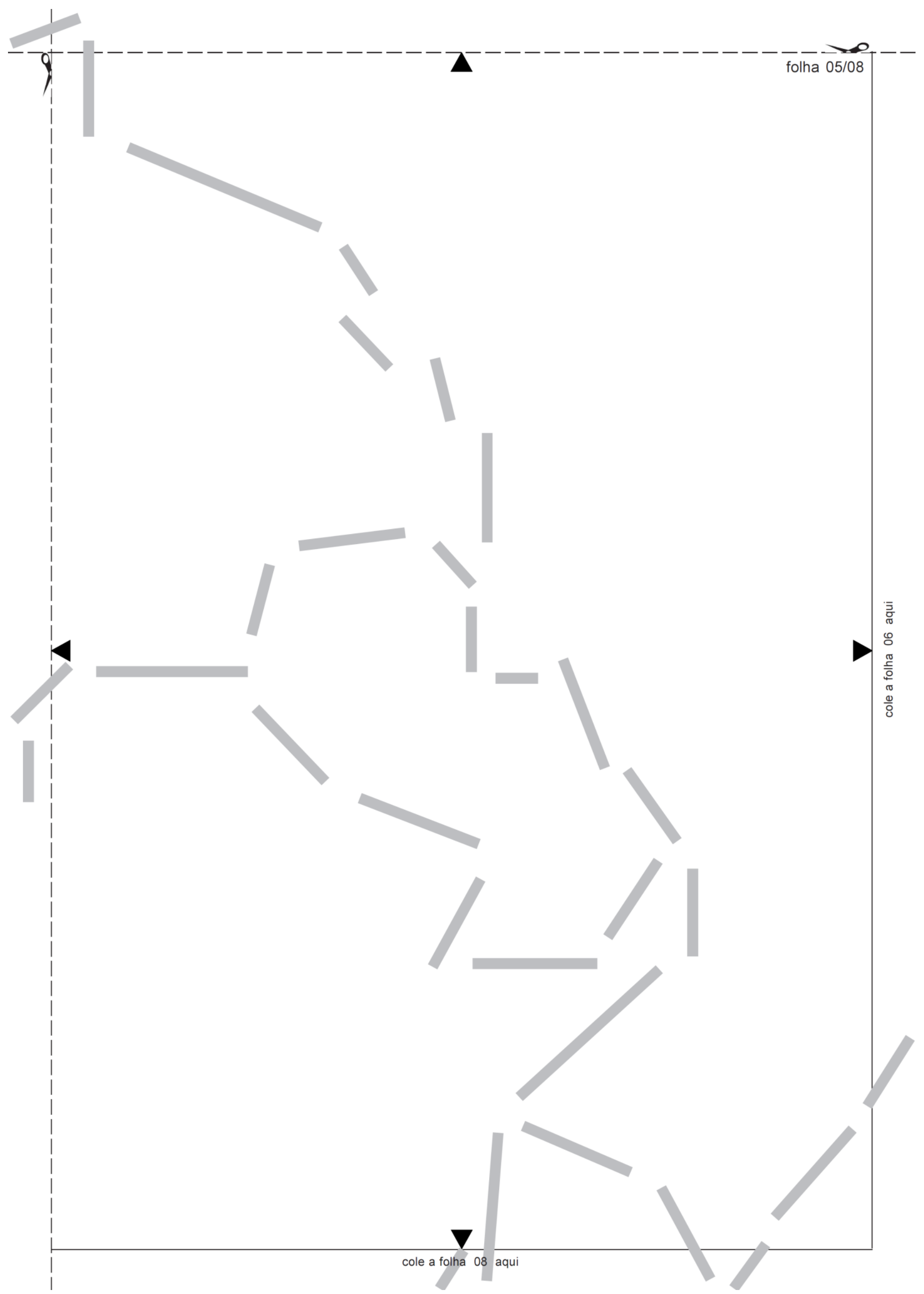


184

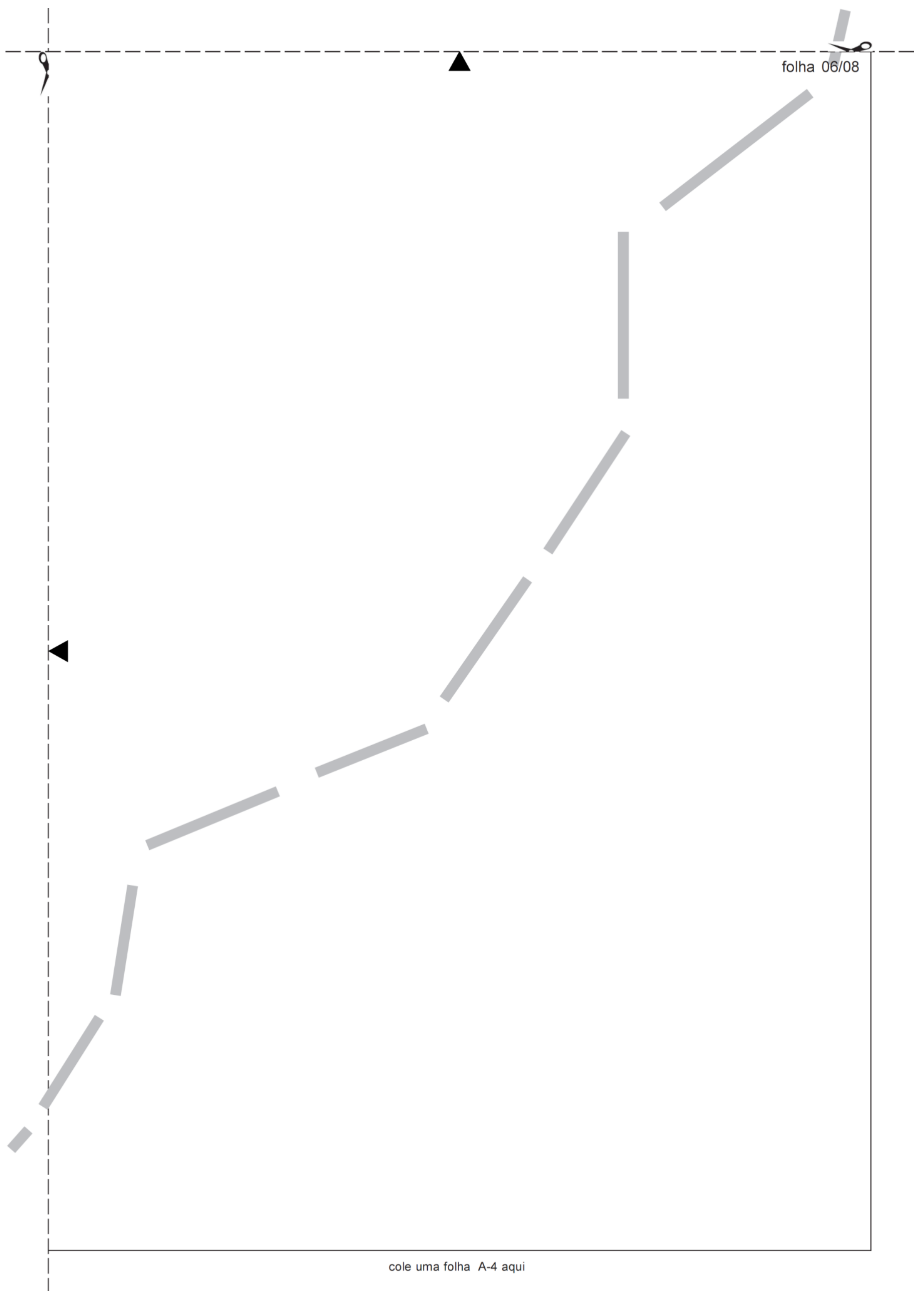




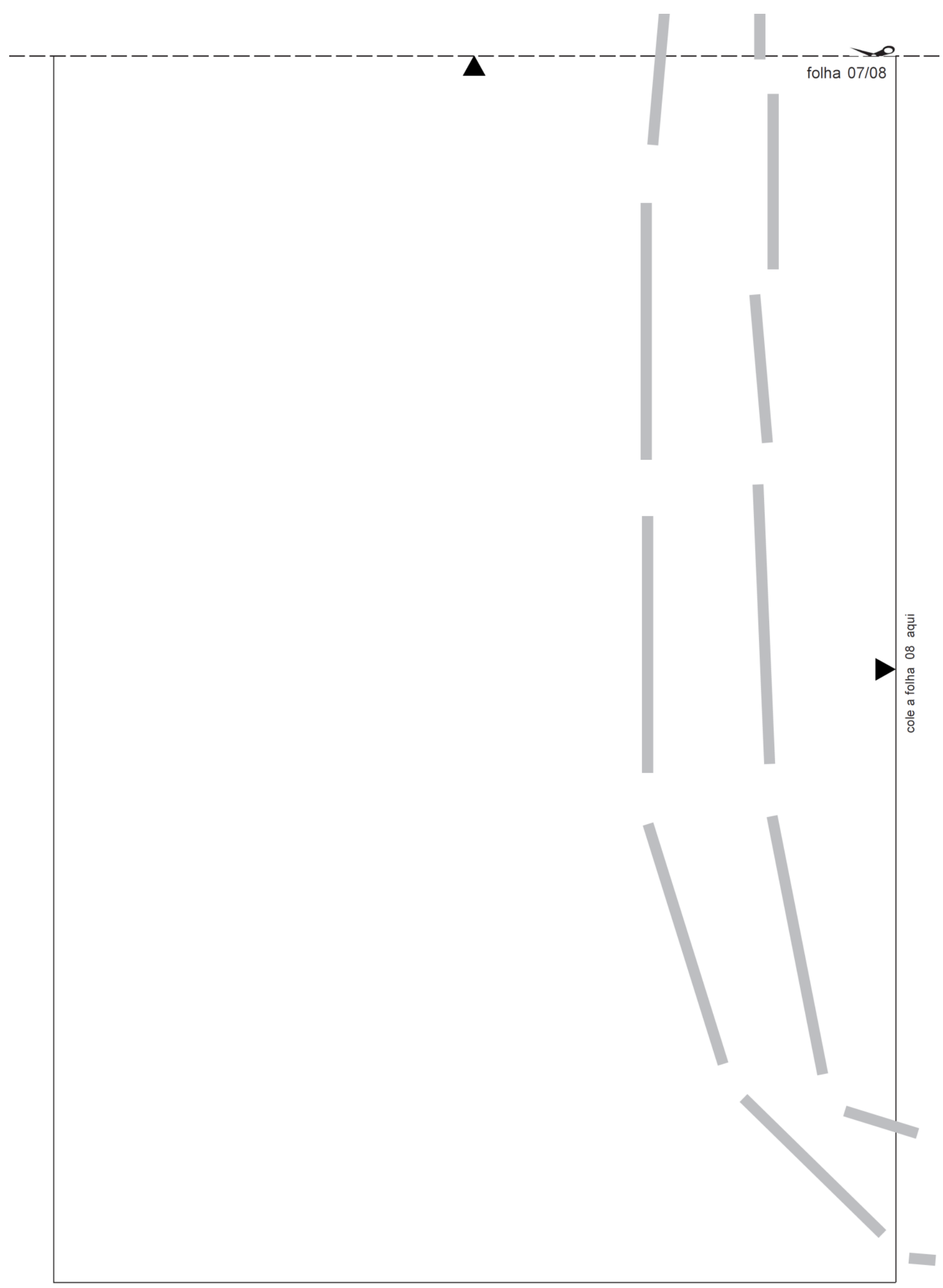


186

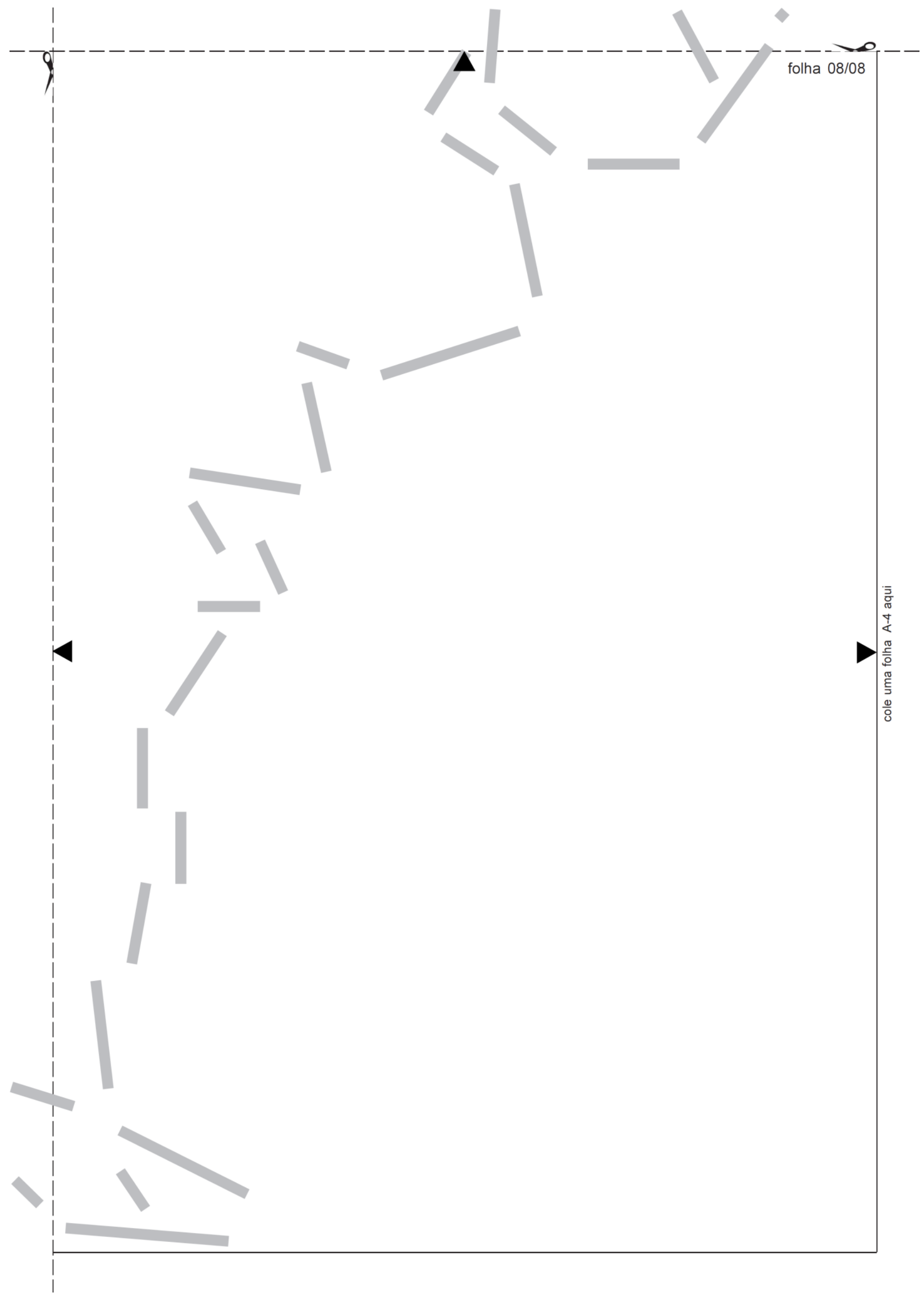




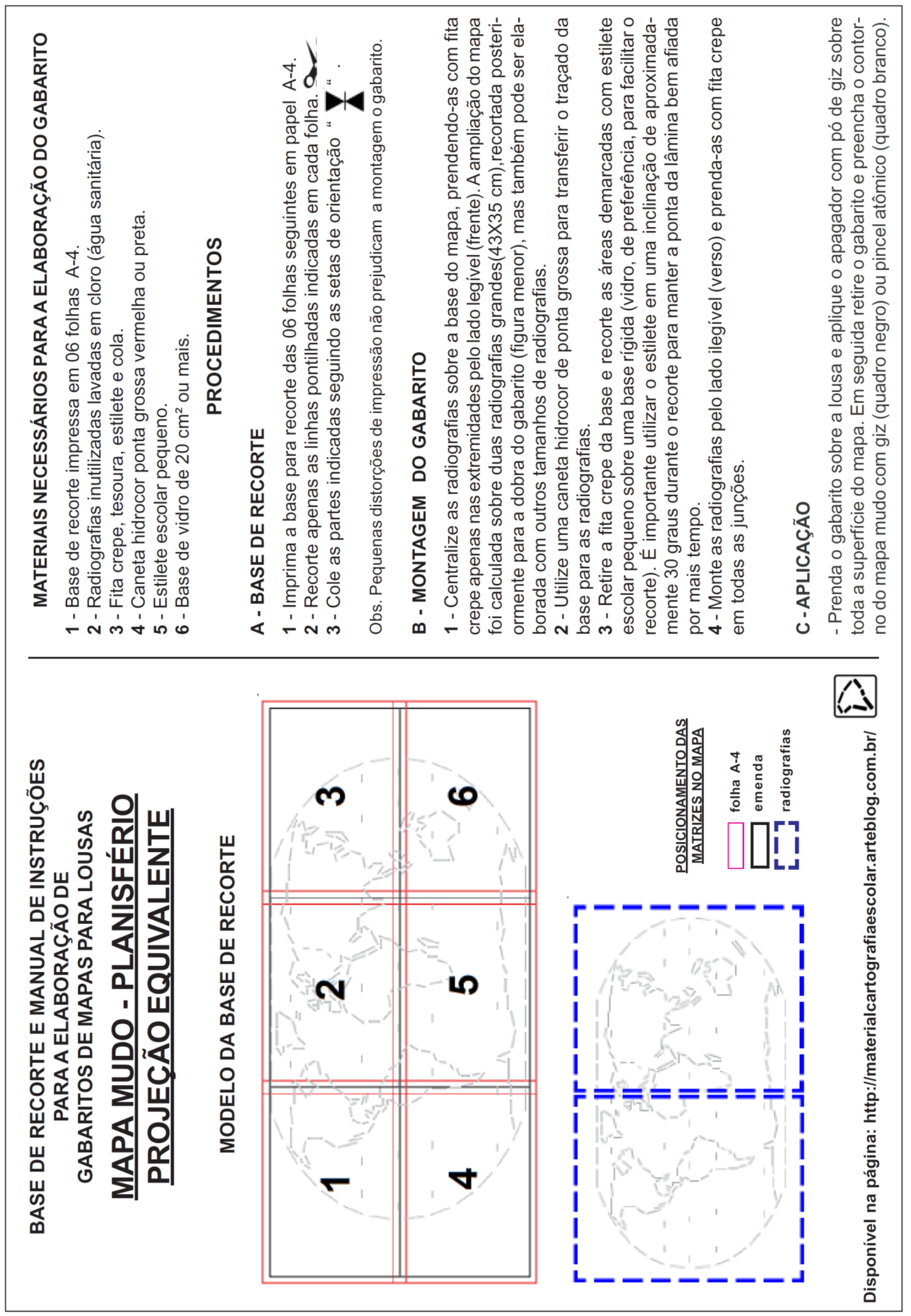


188

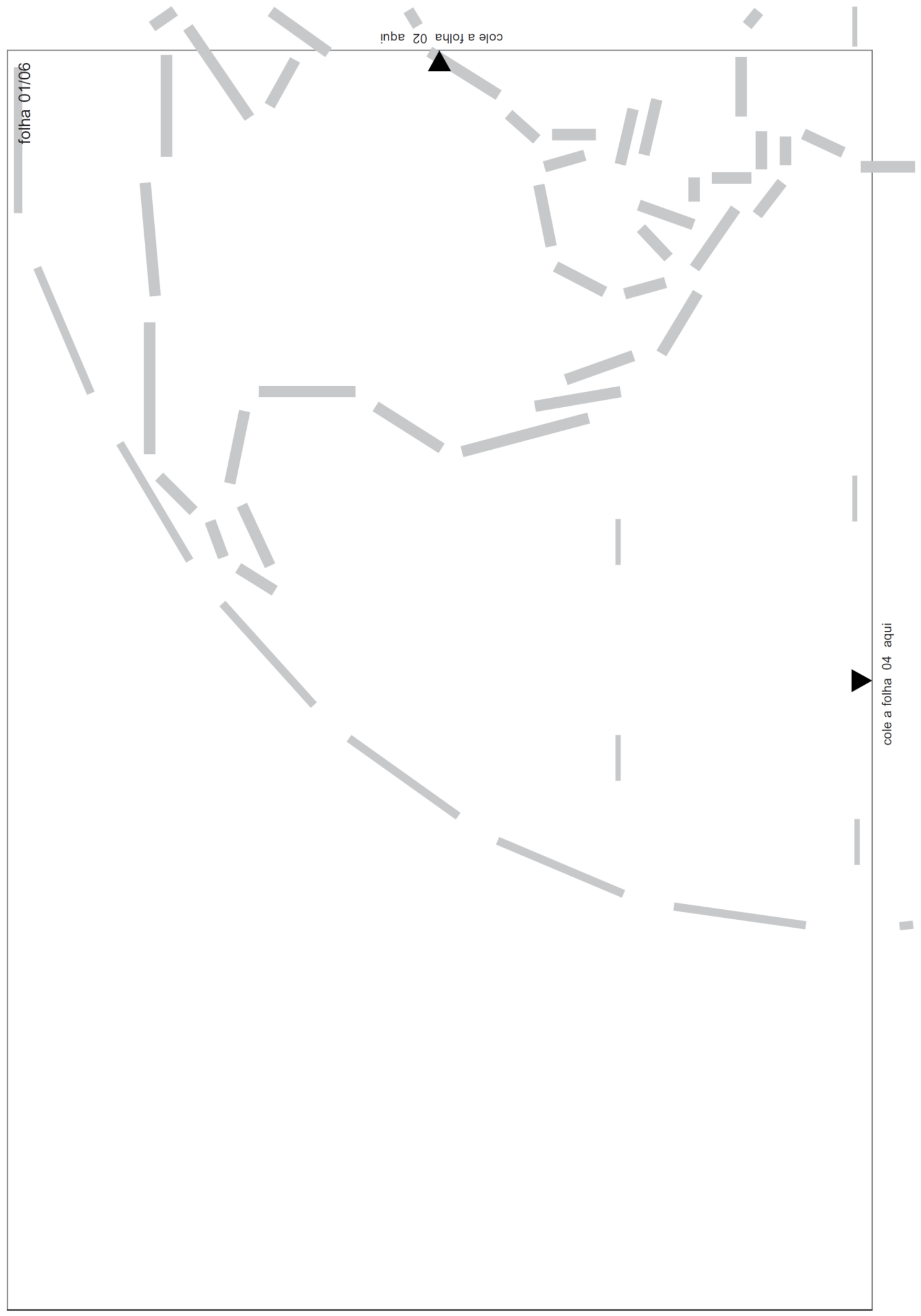




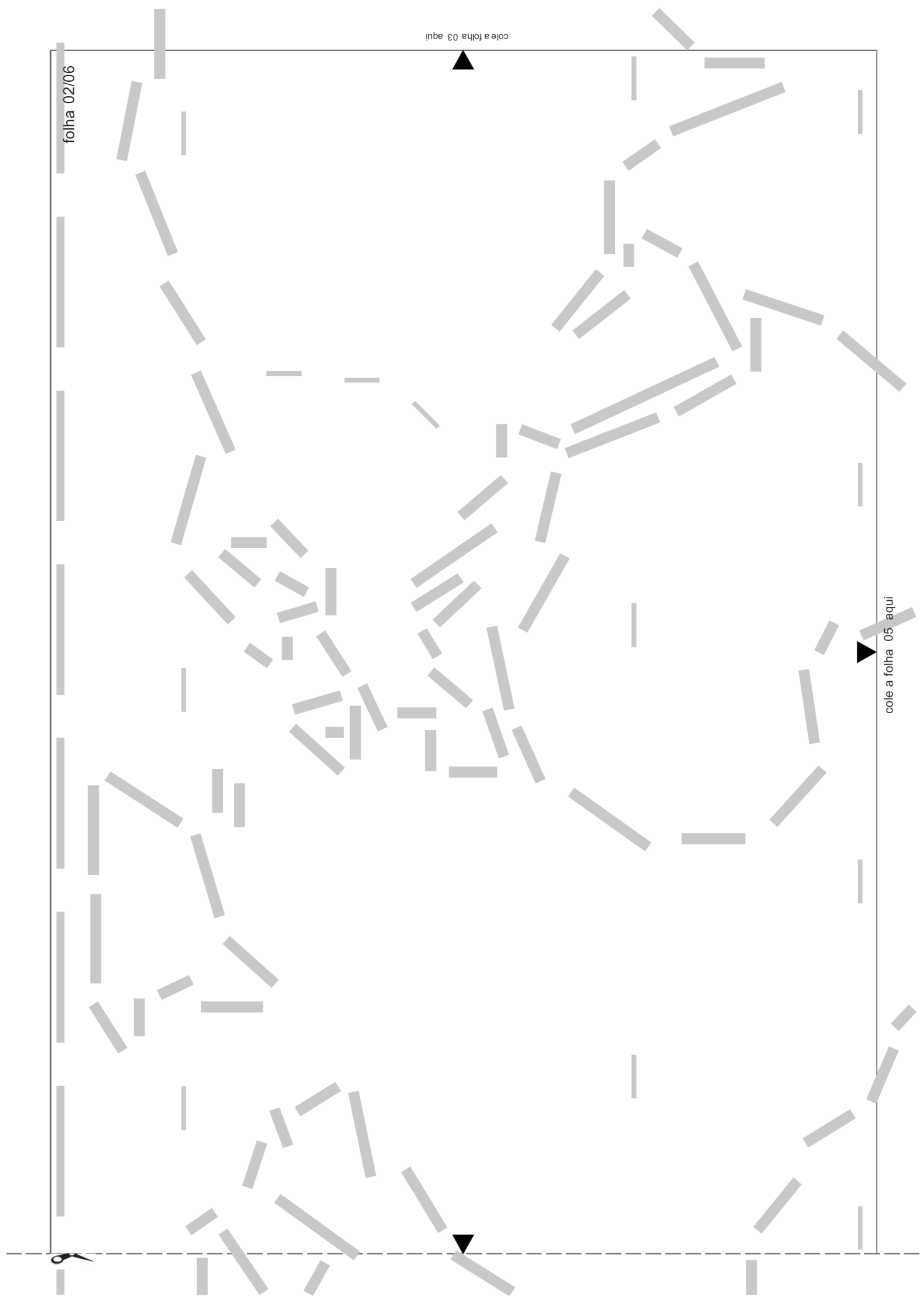




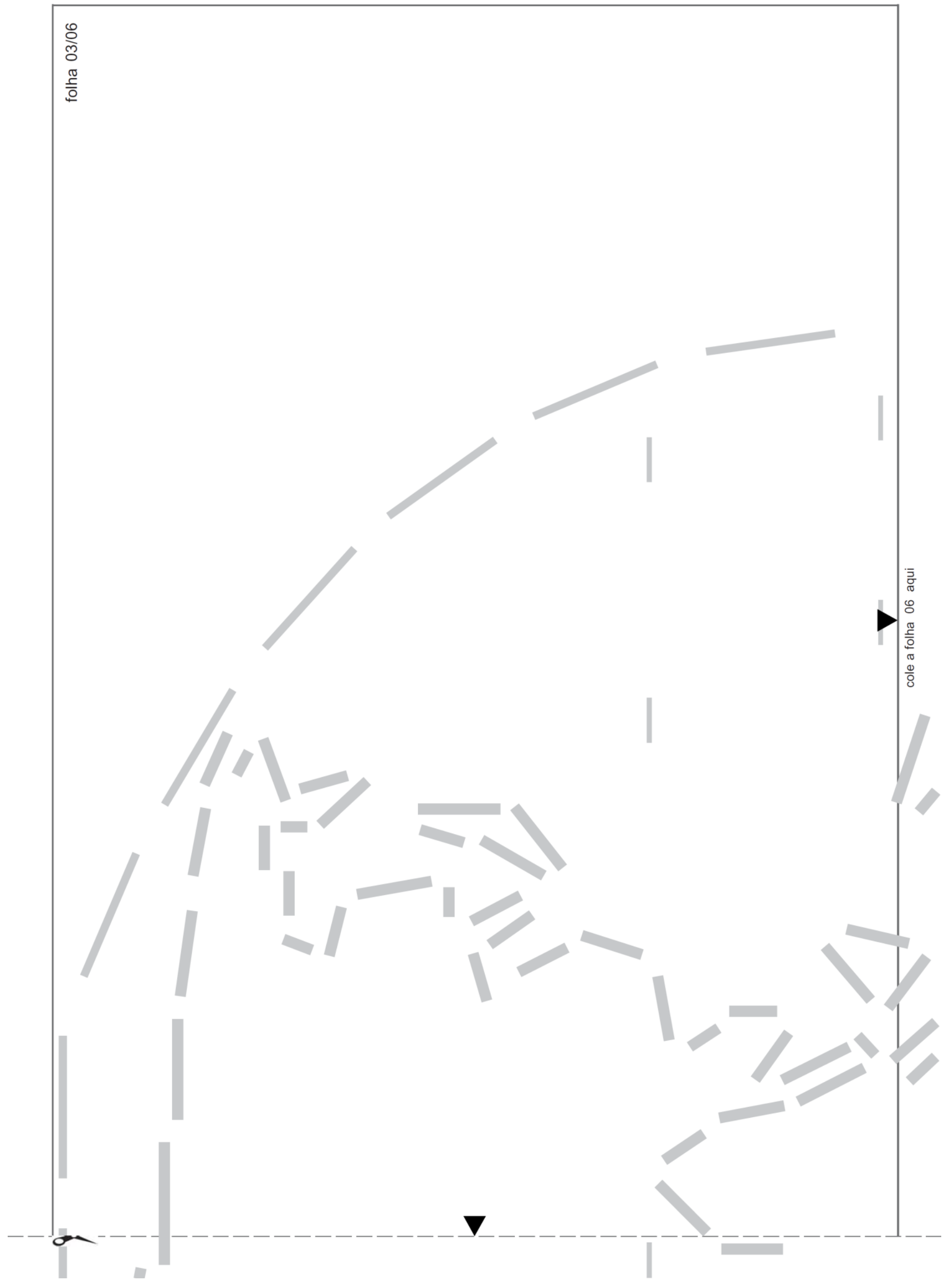


191

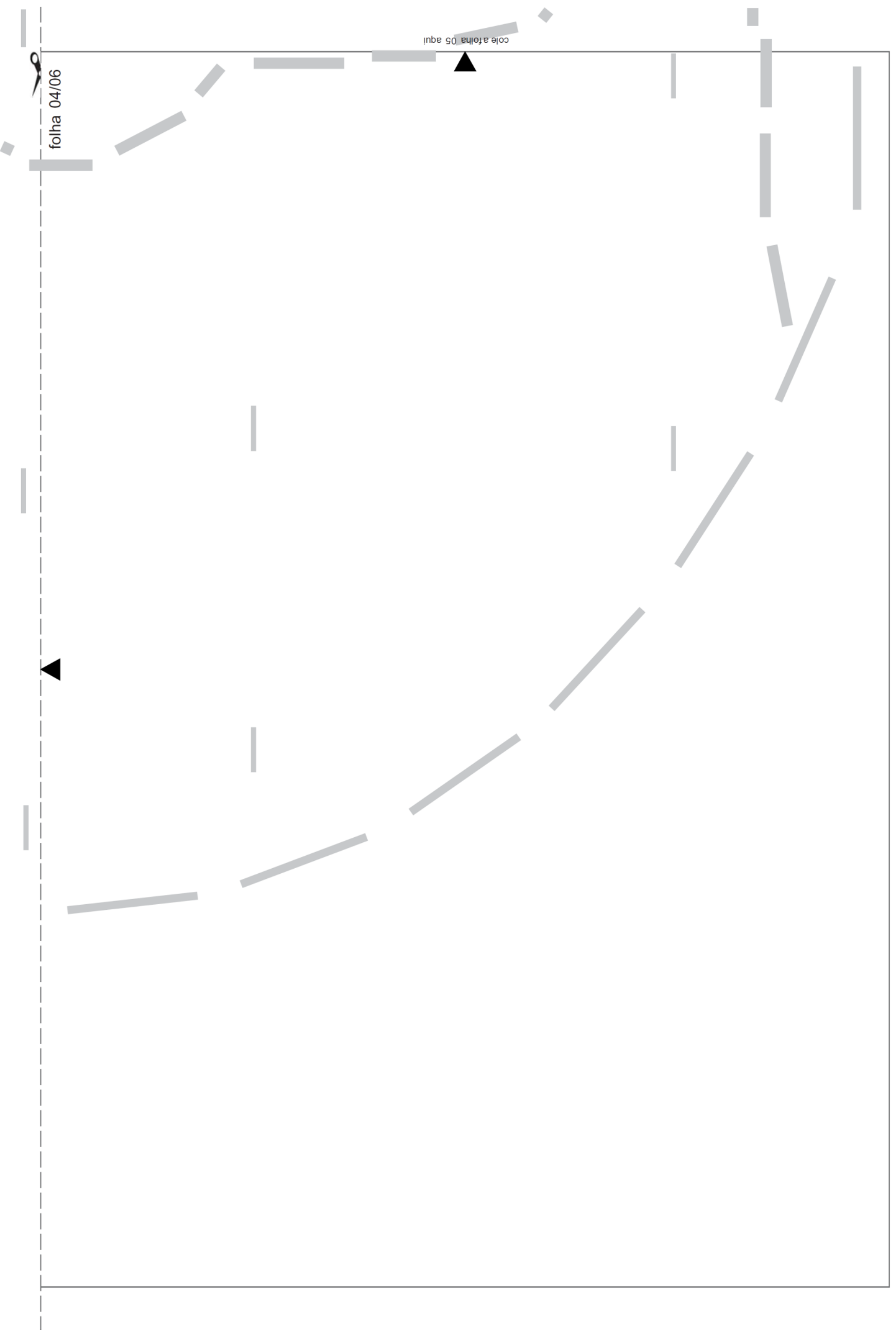


192

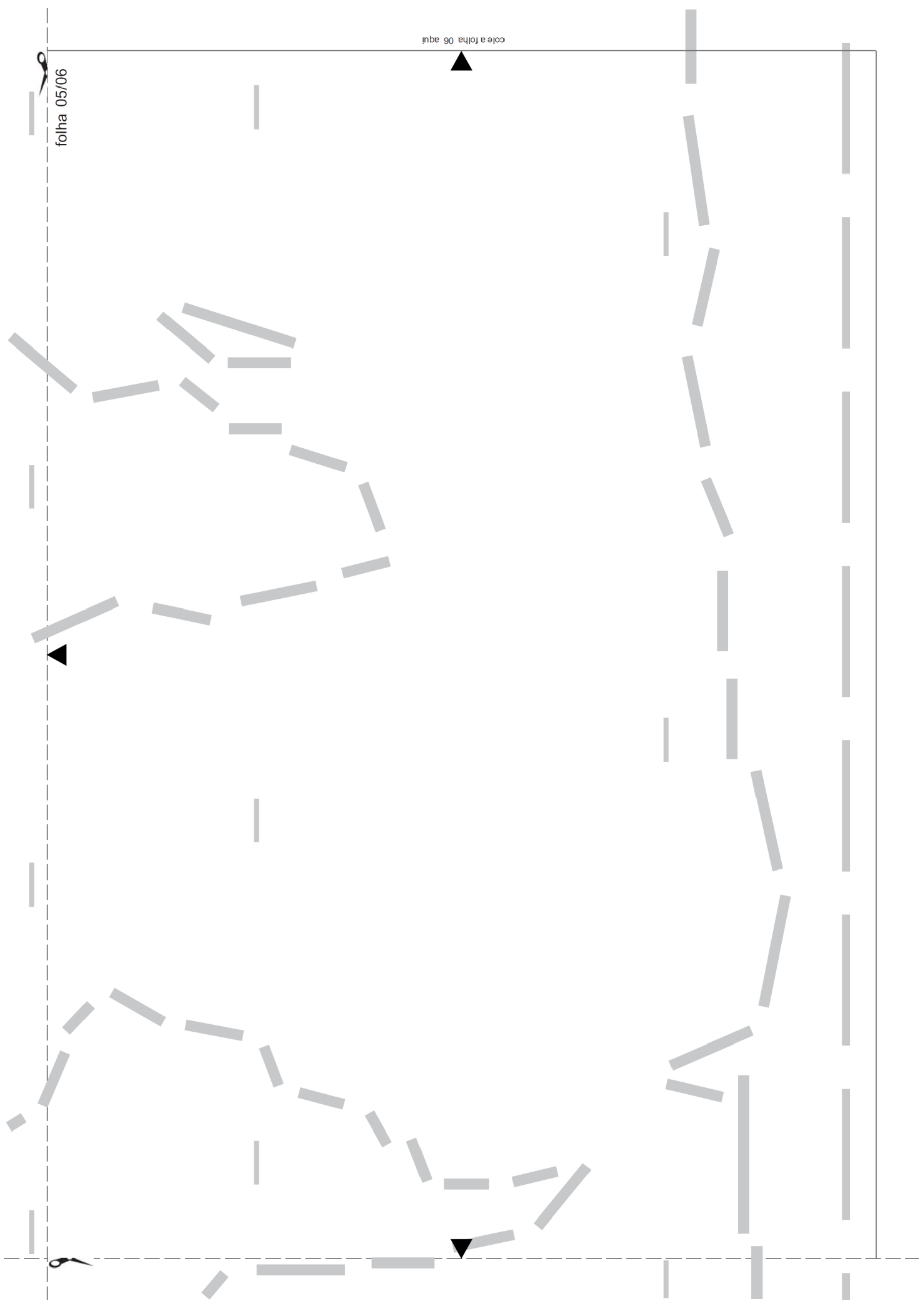




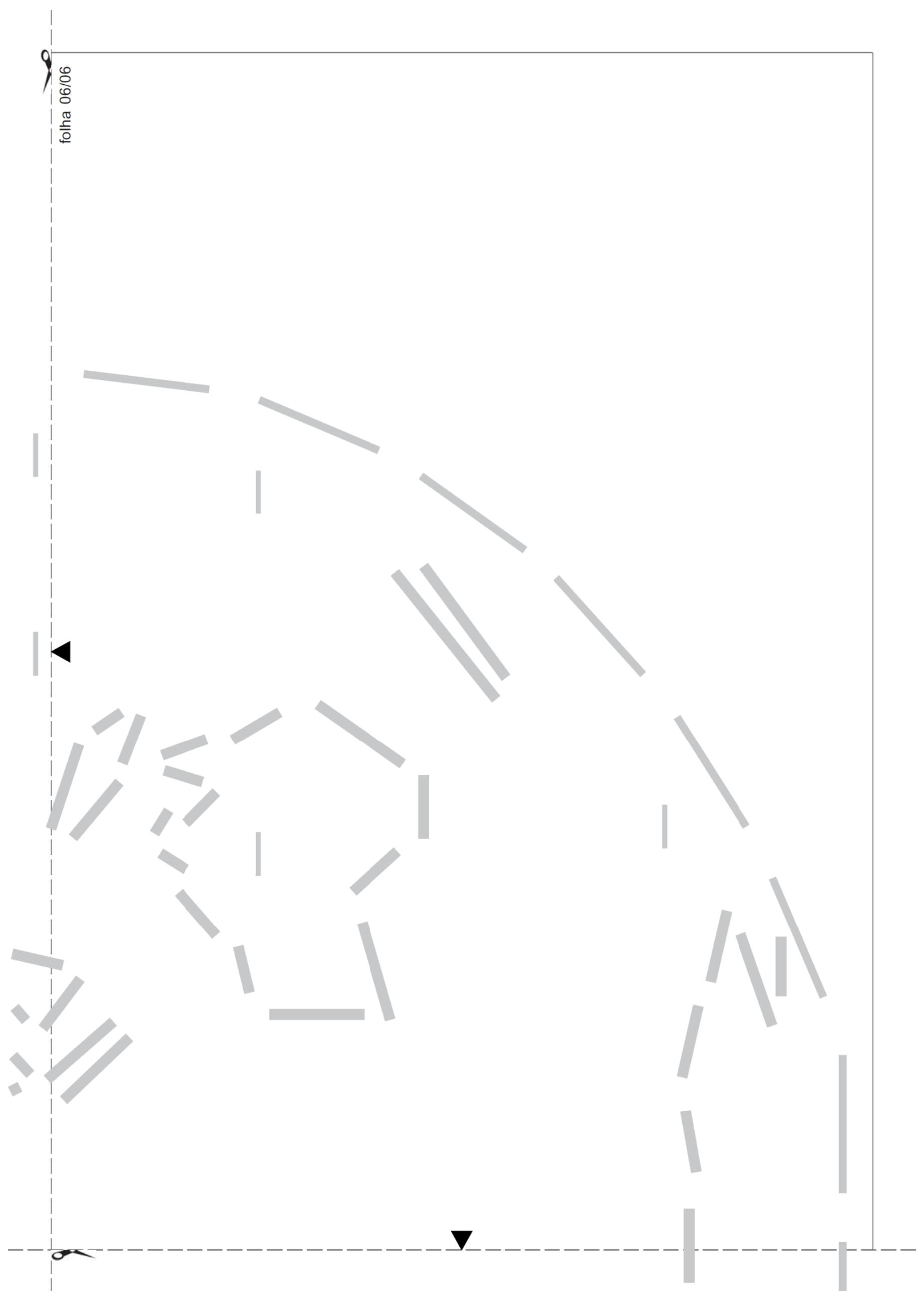




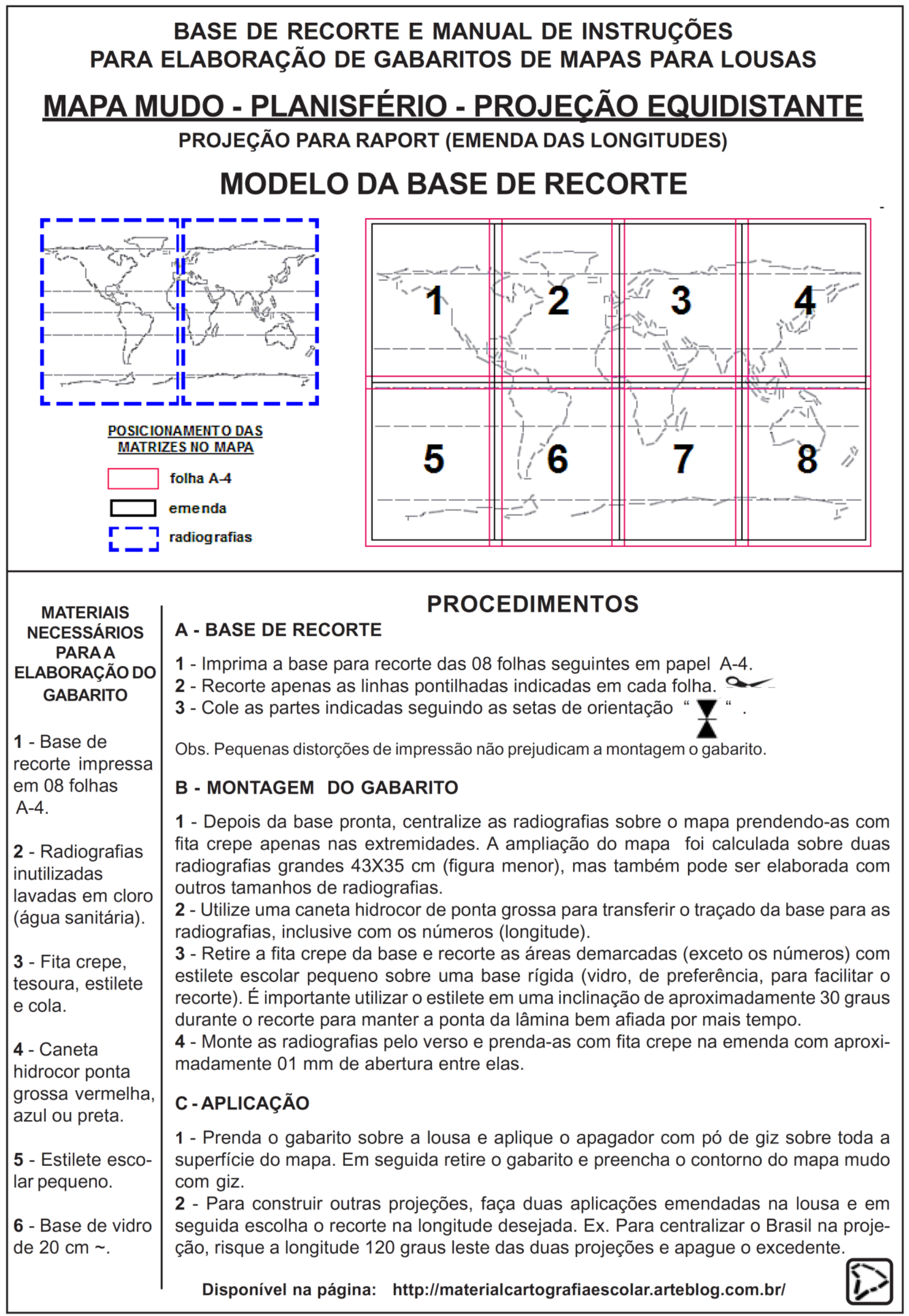




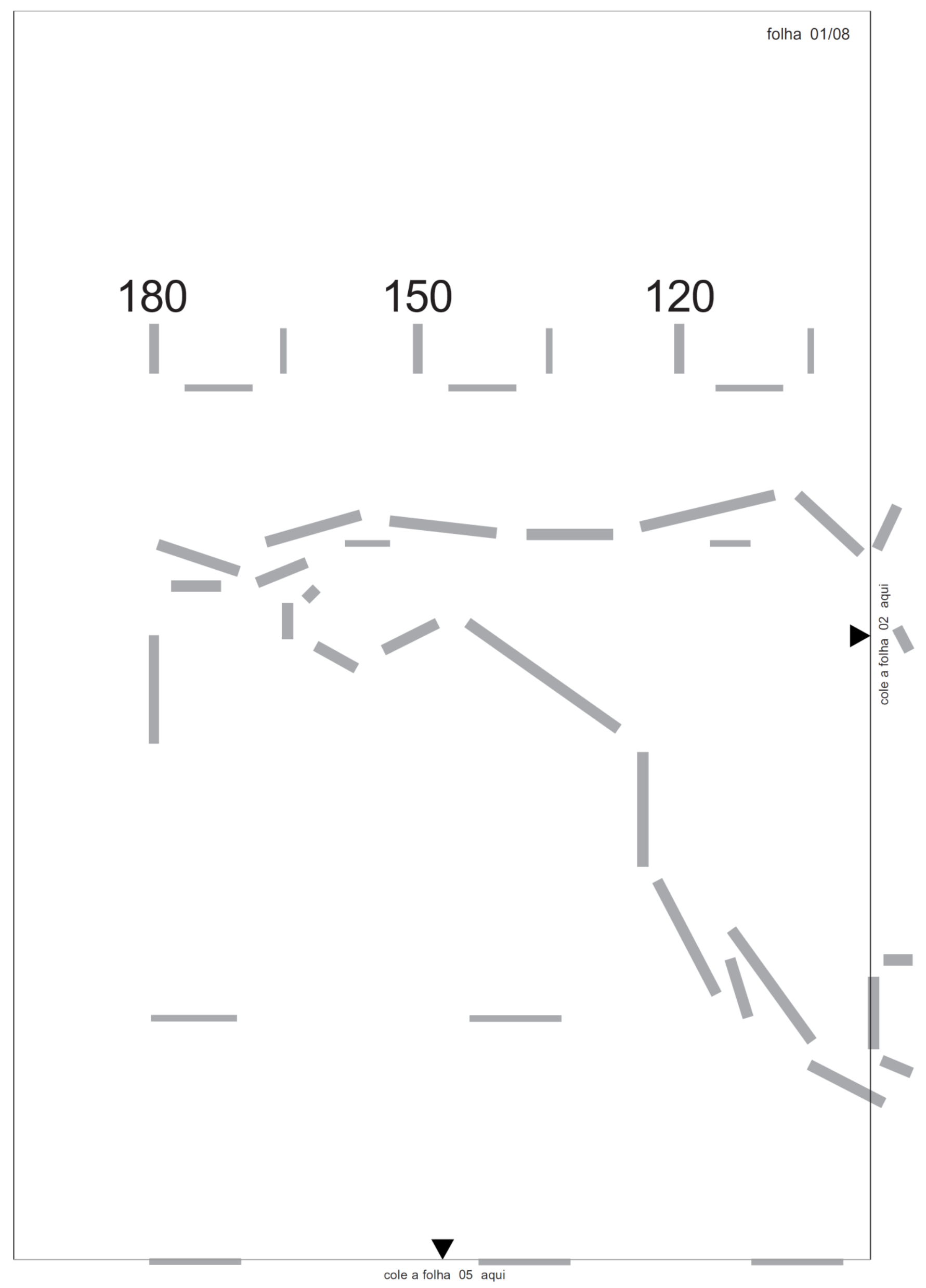




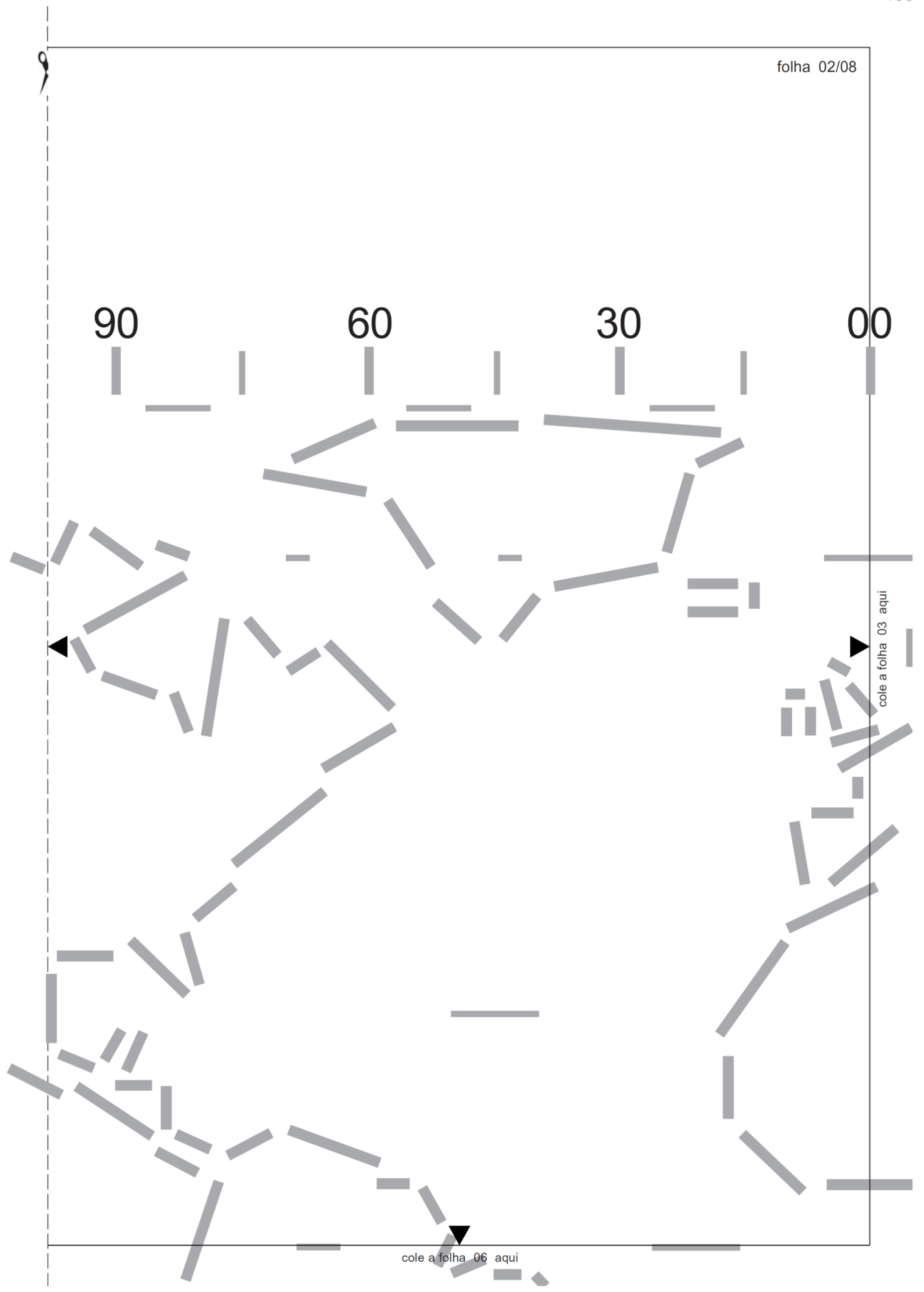




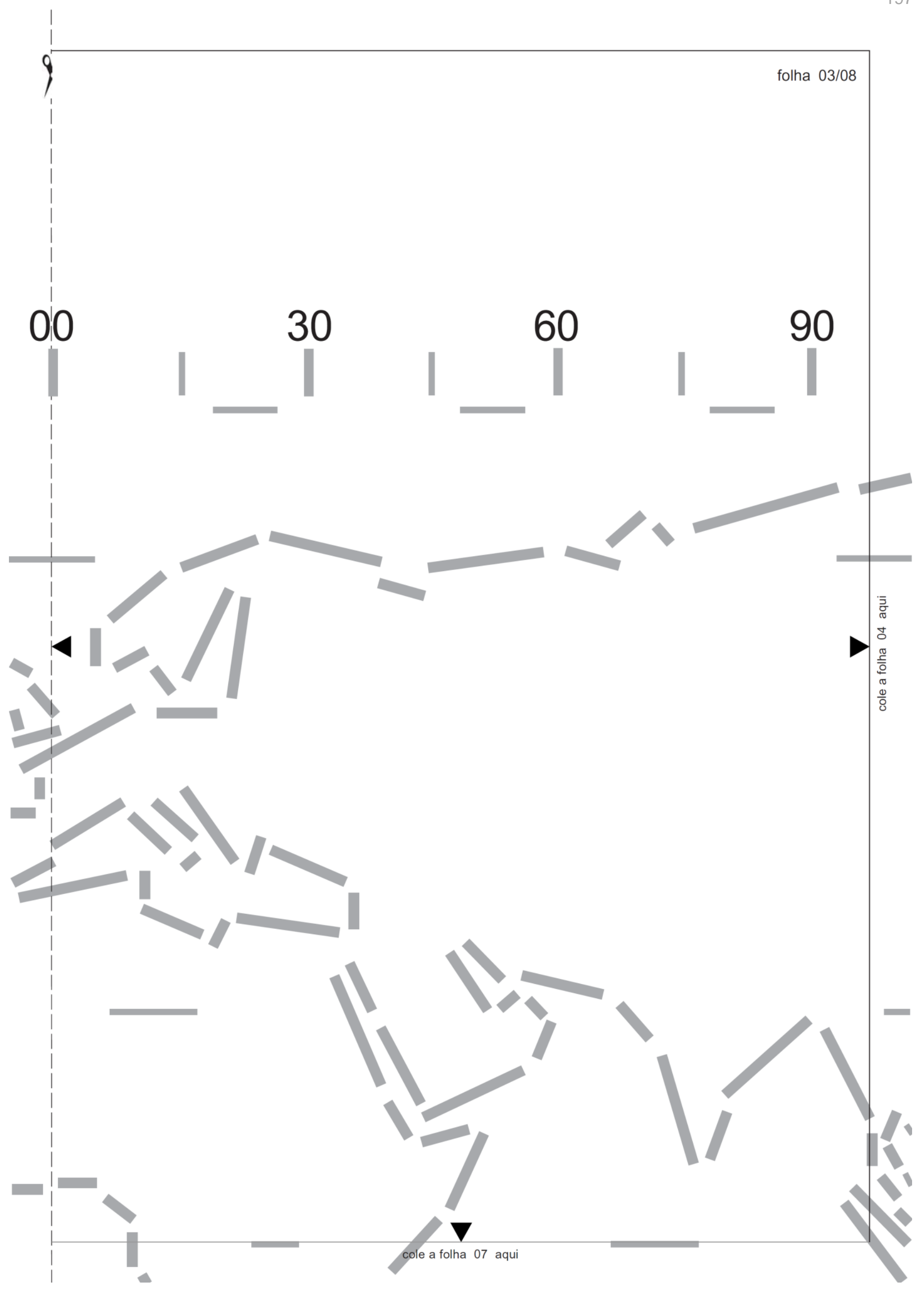




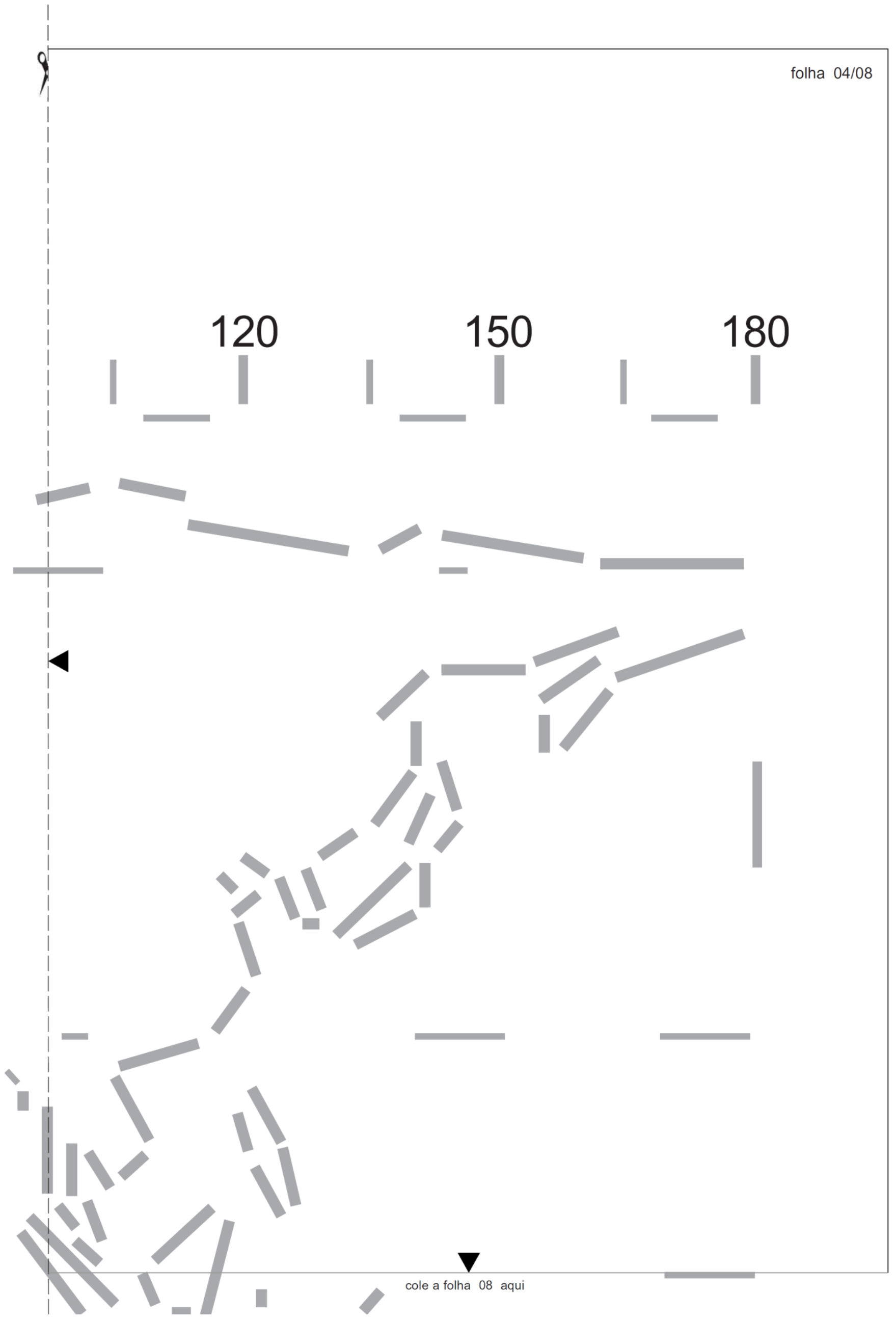




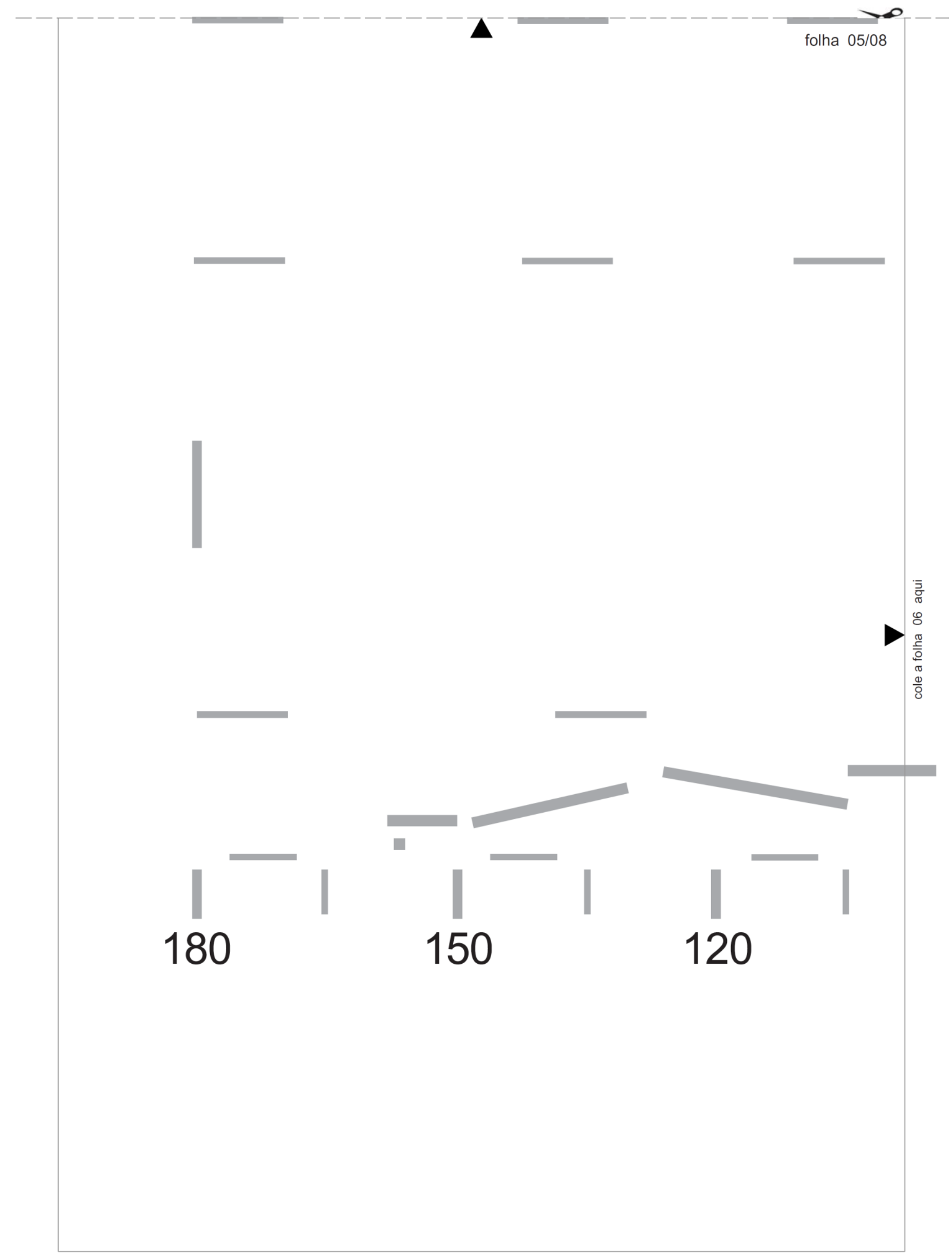




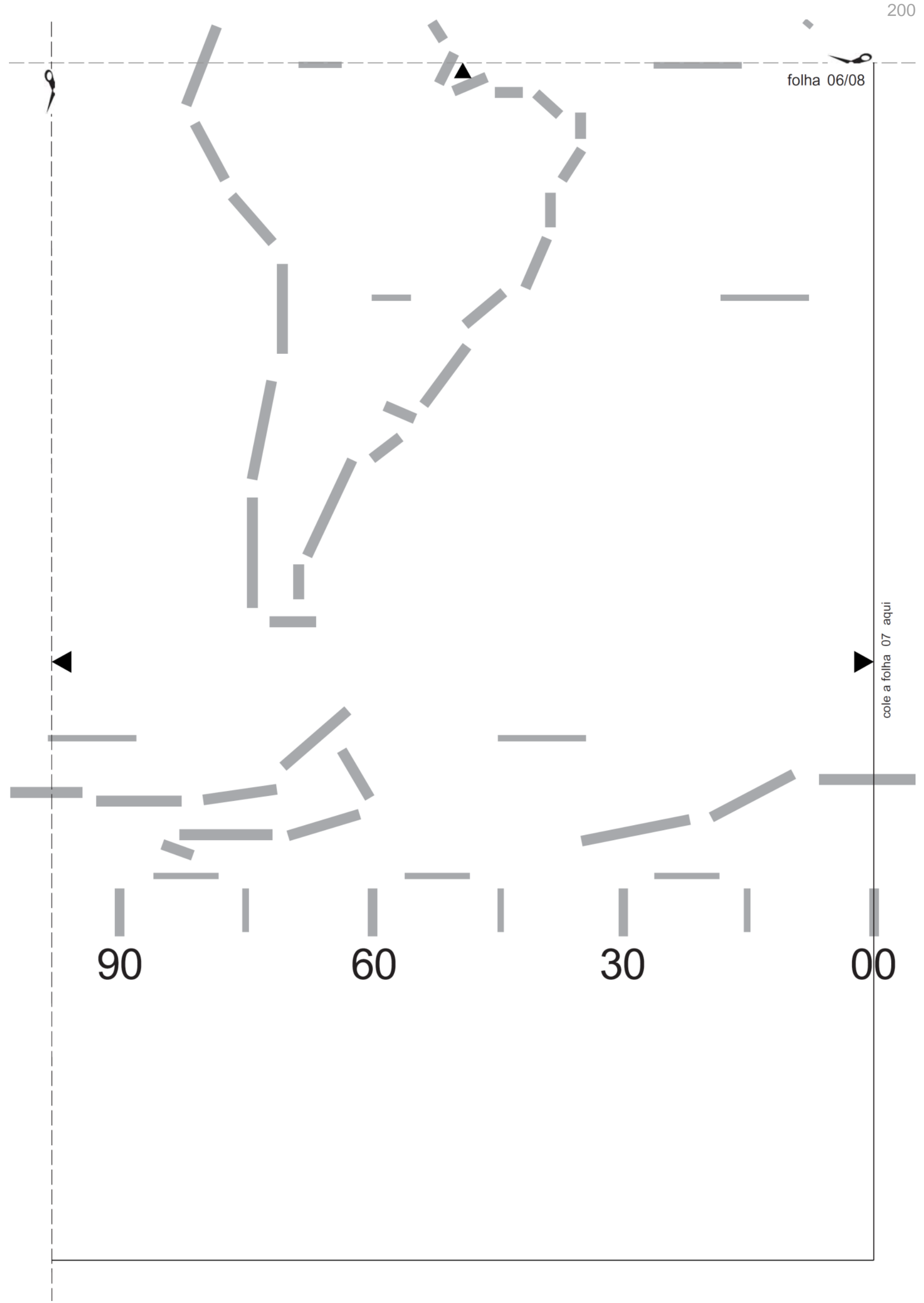




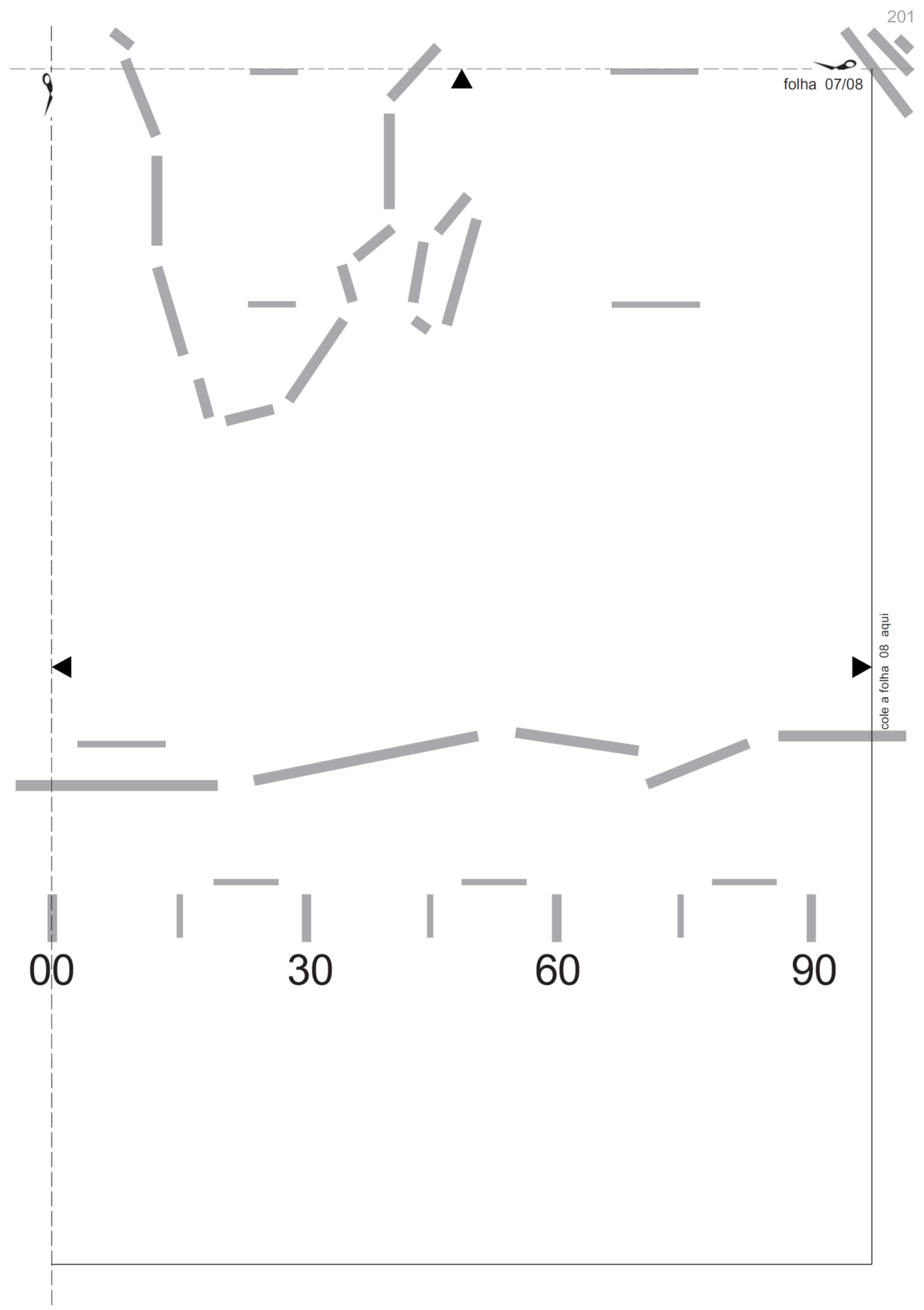




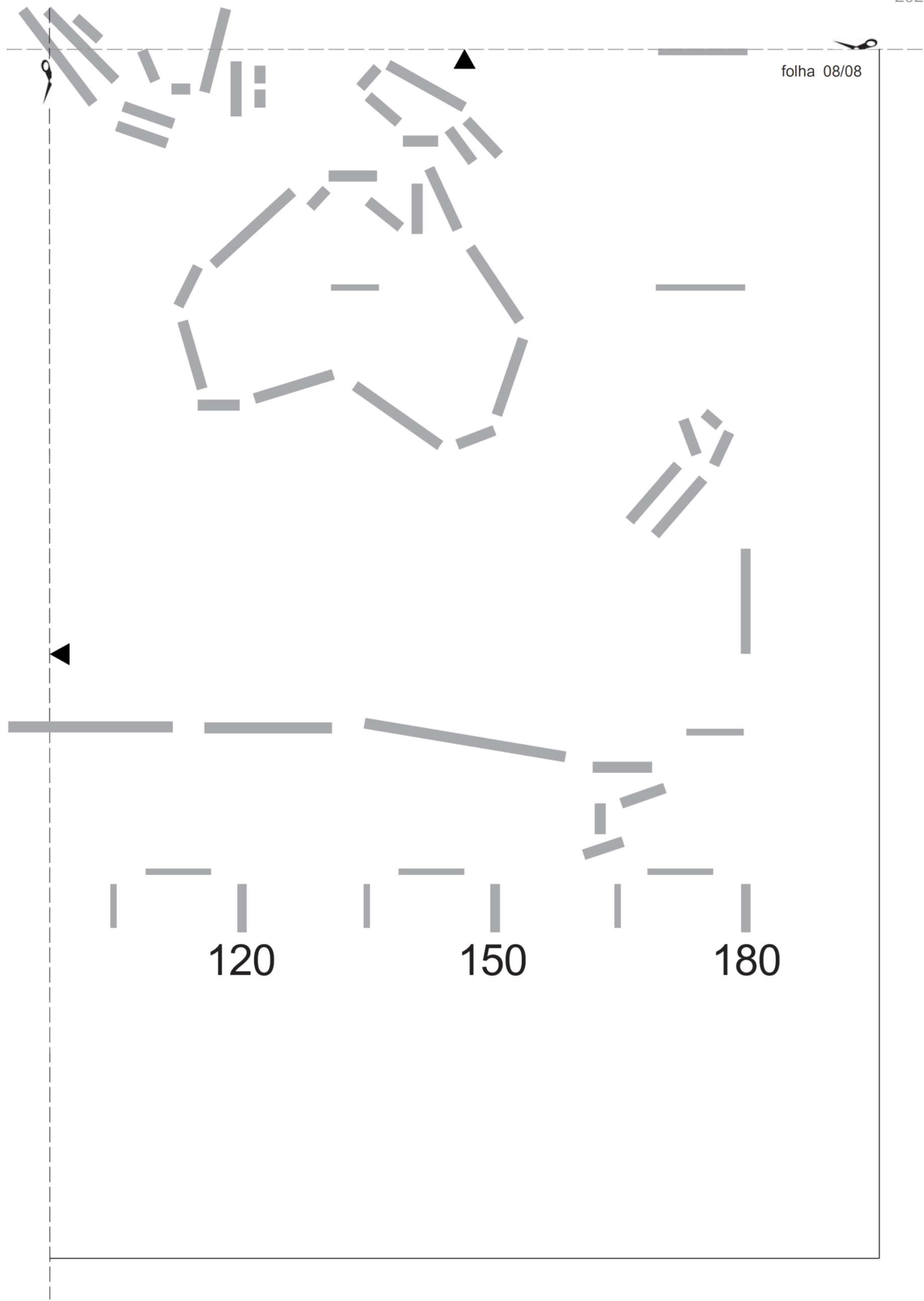




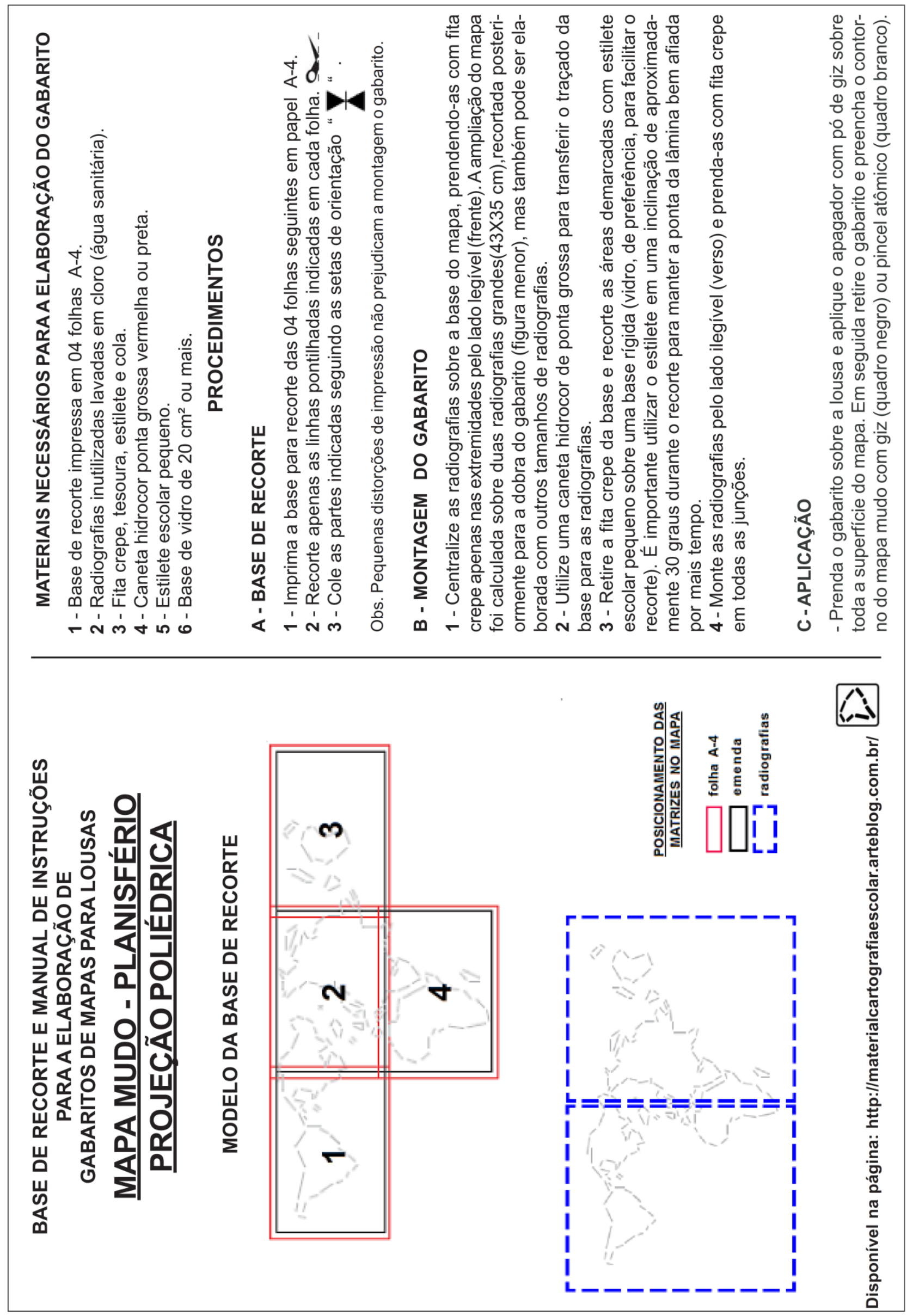




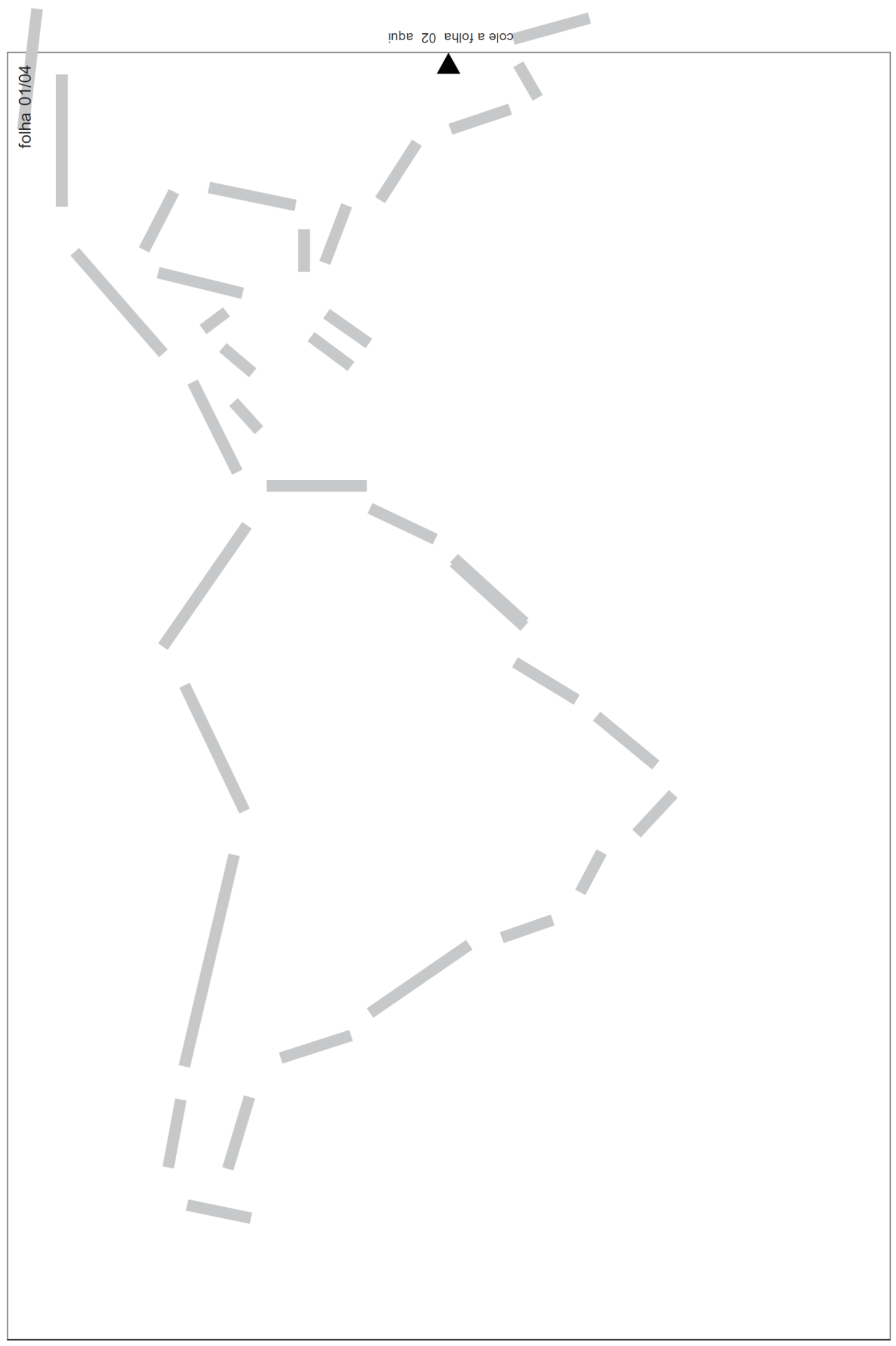




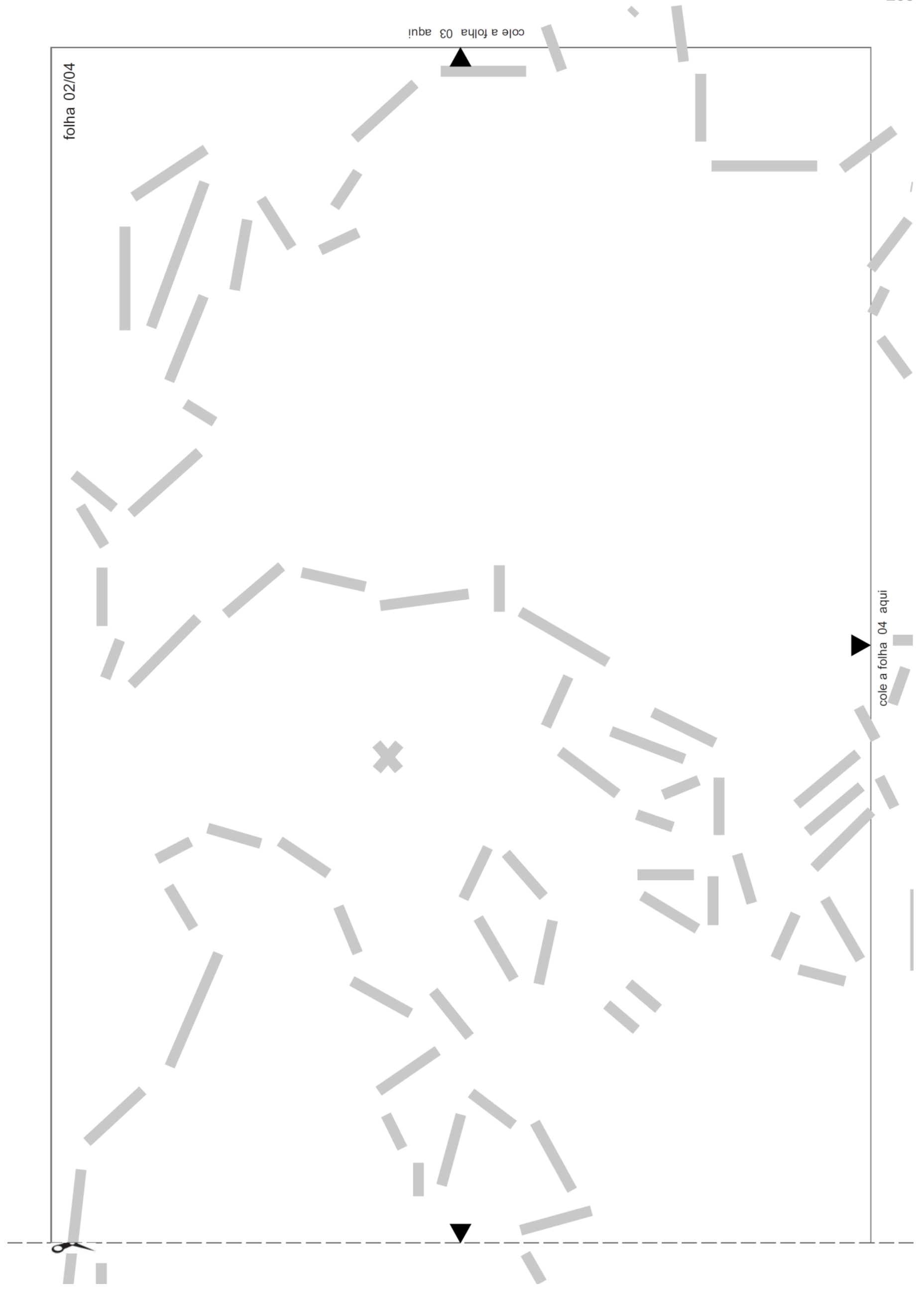


206

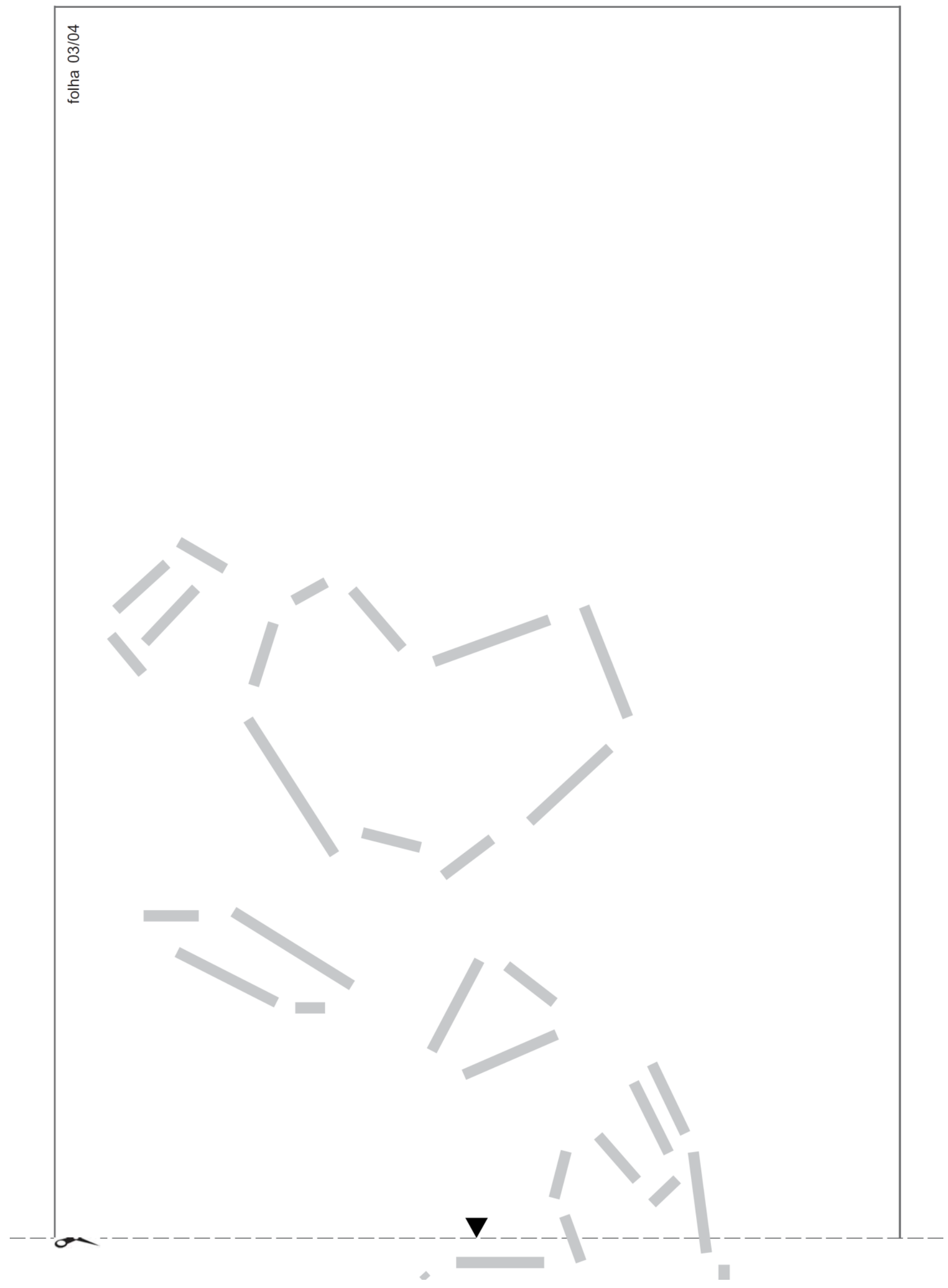




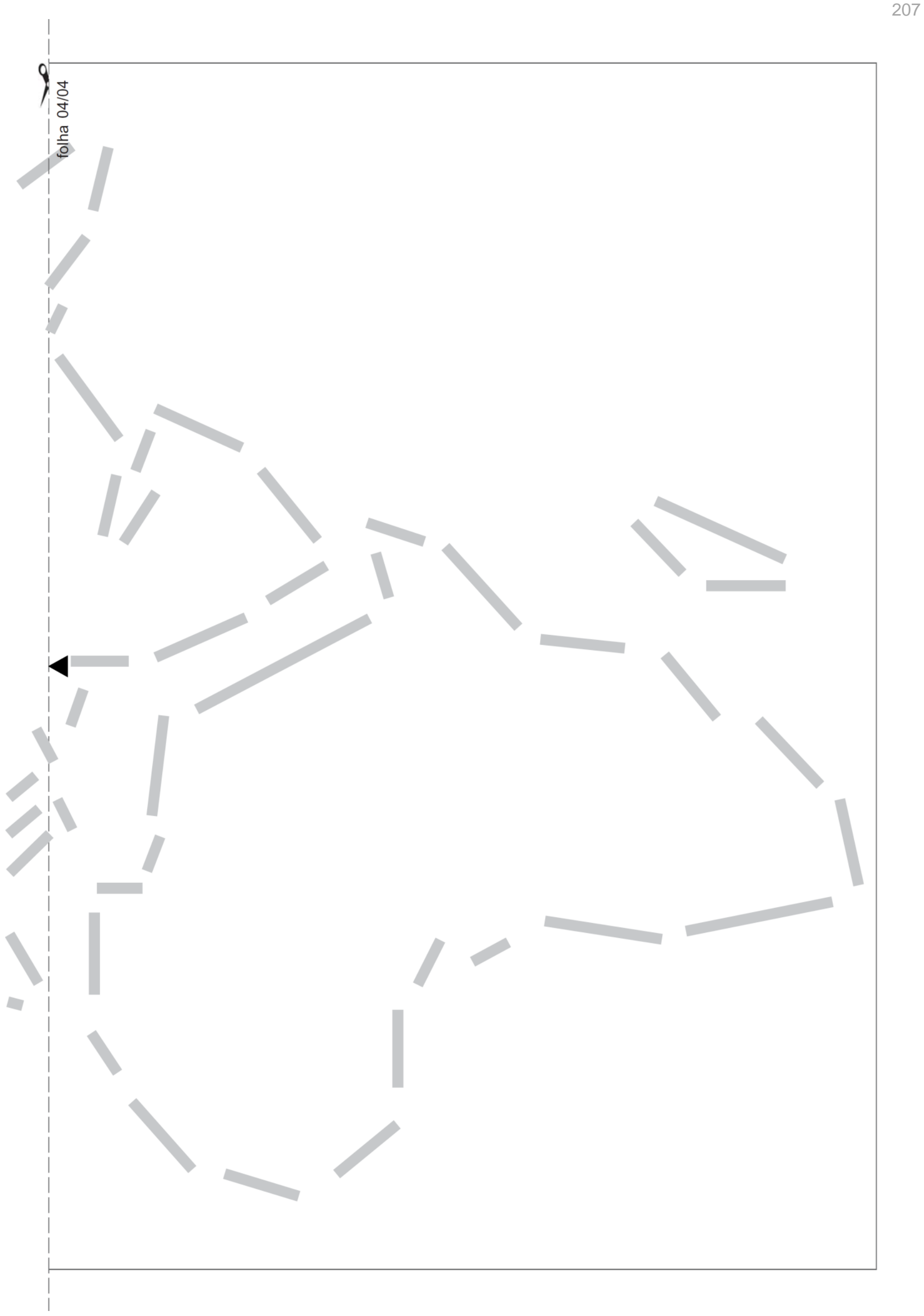




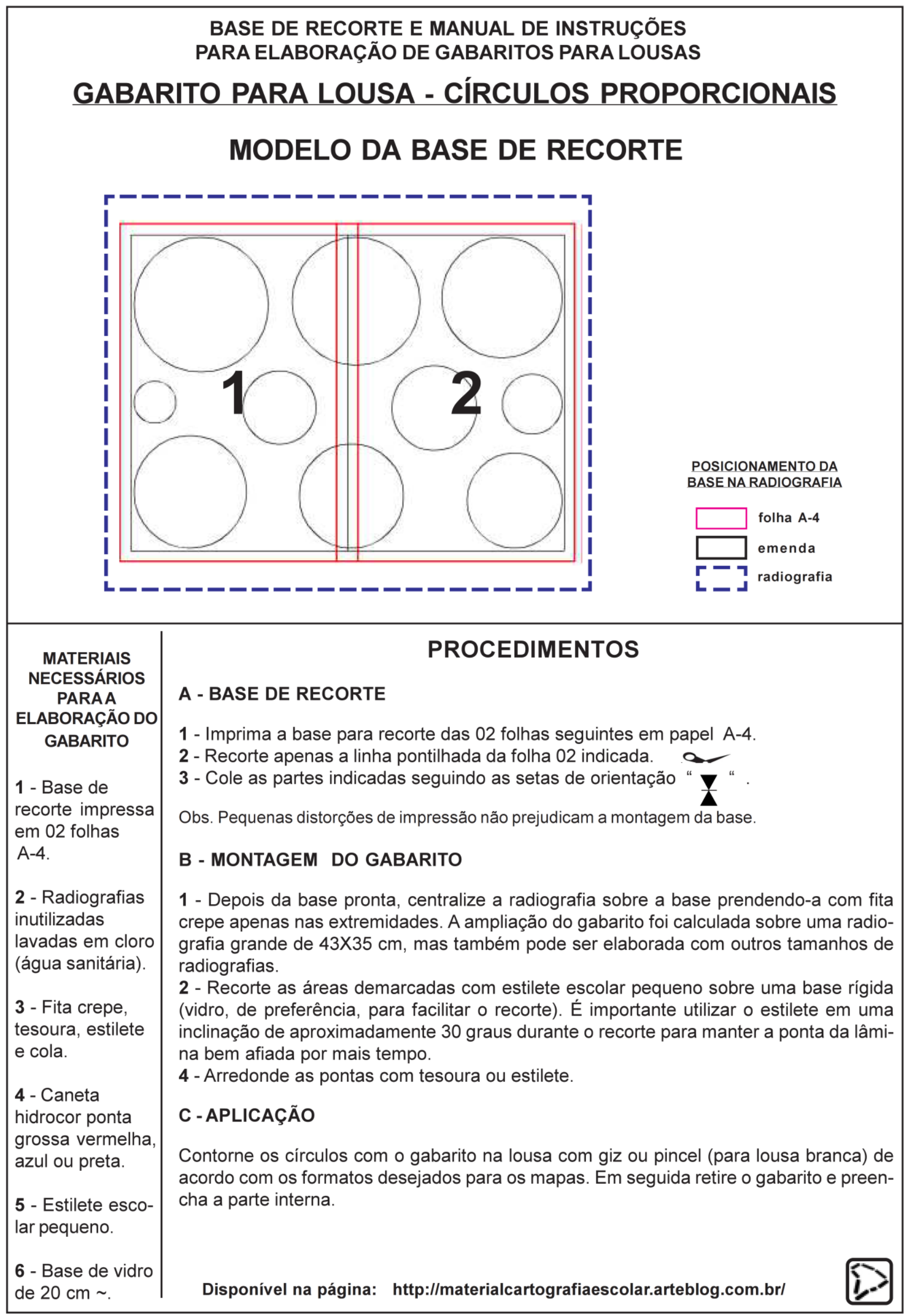




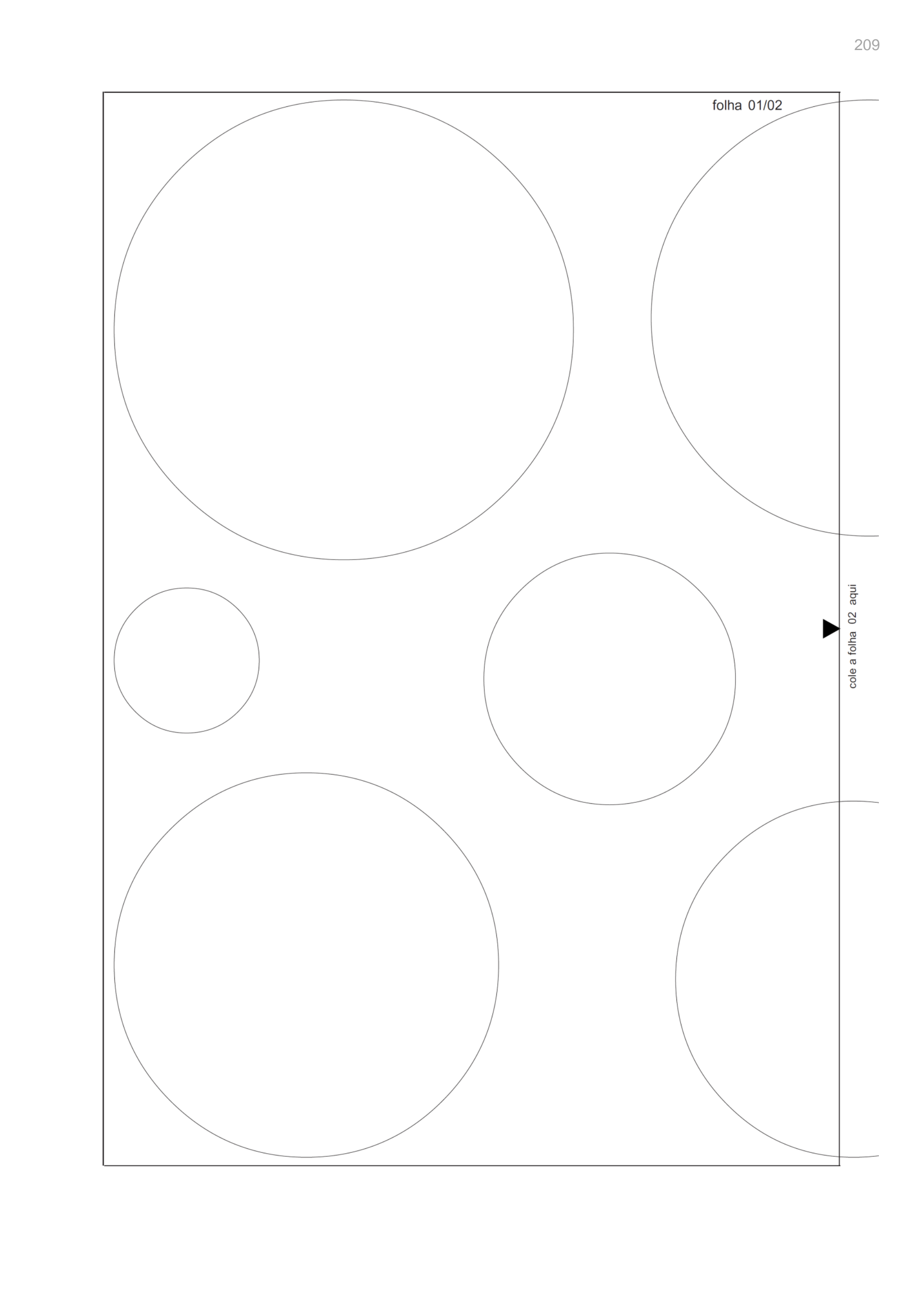




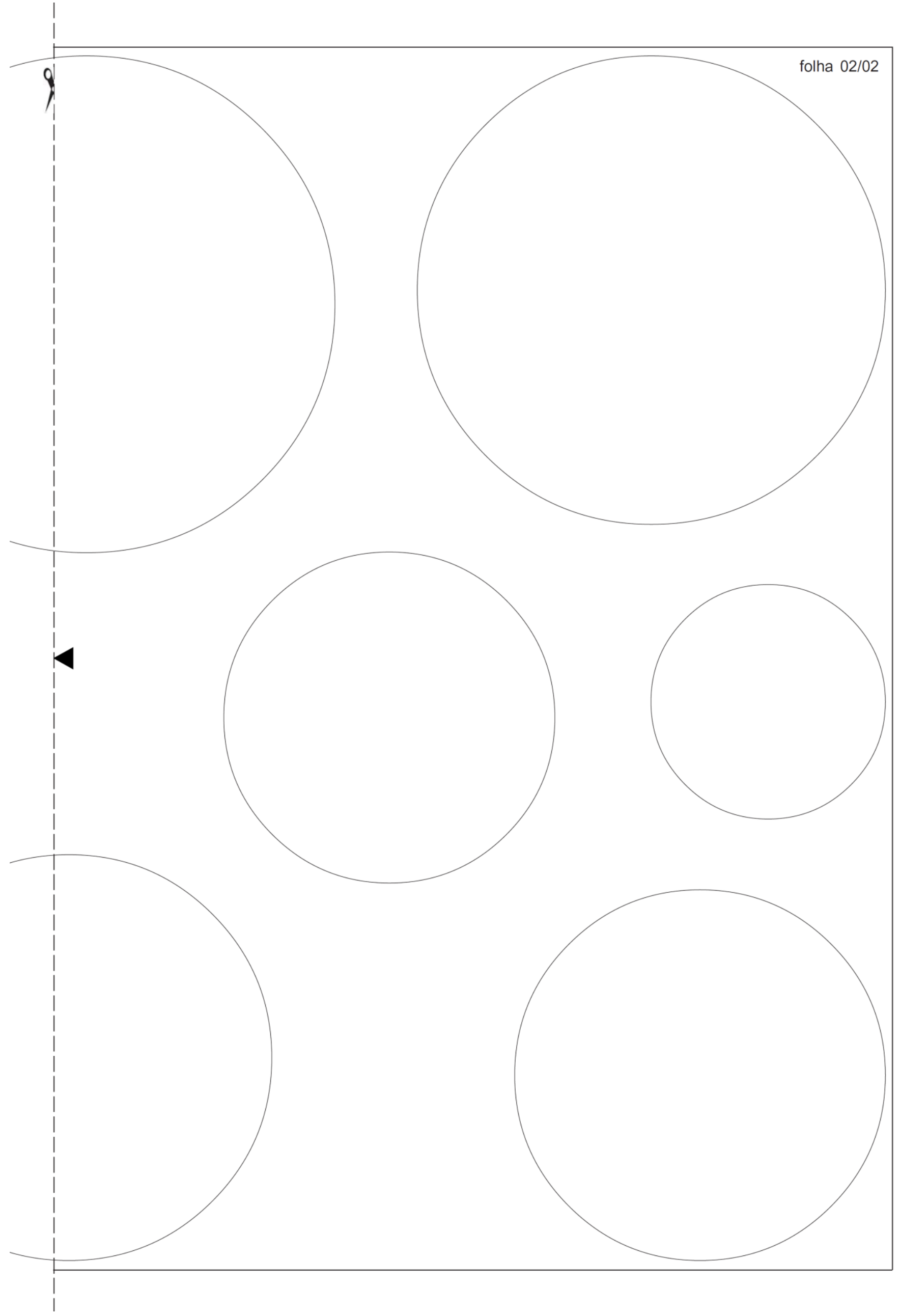




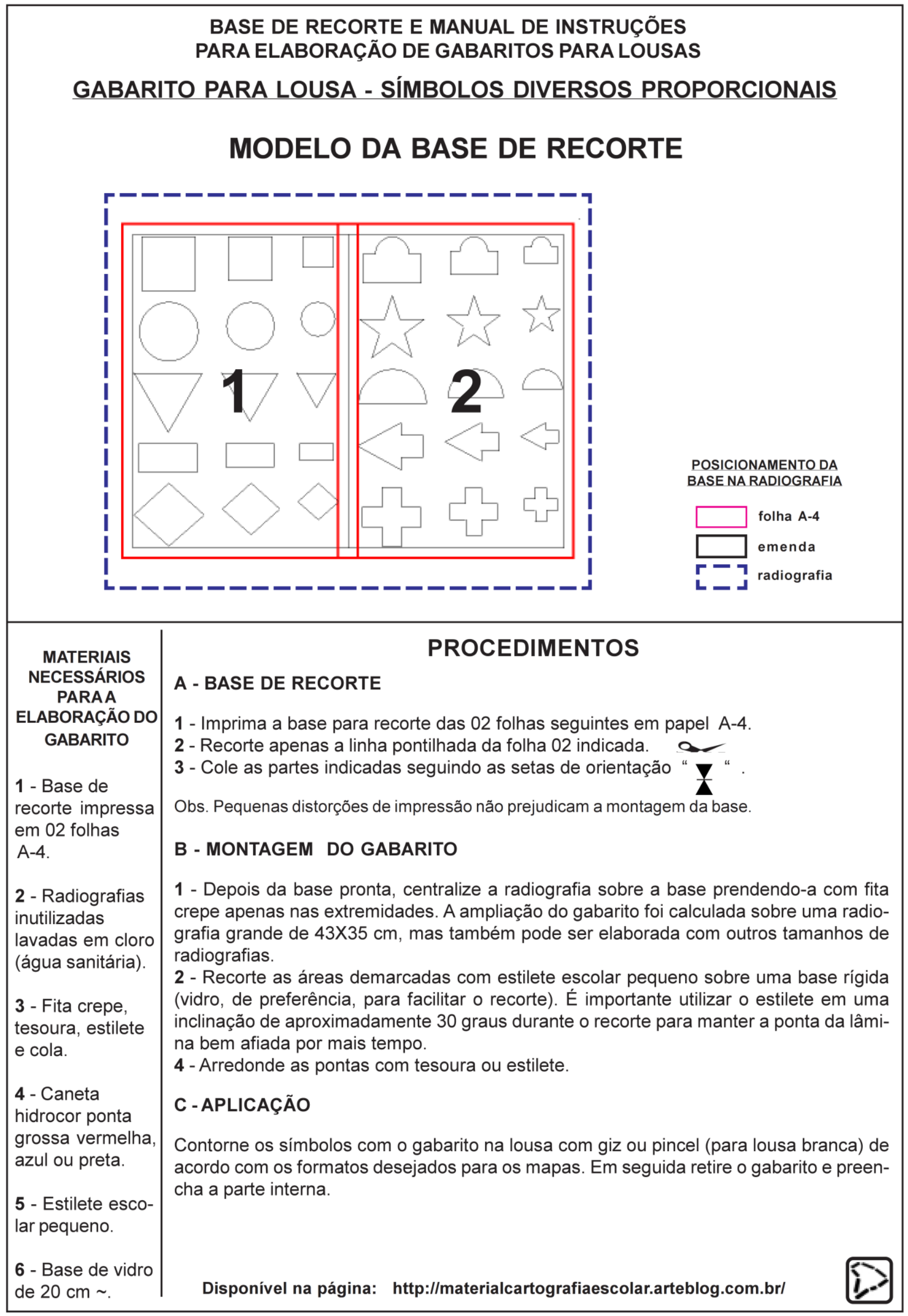




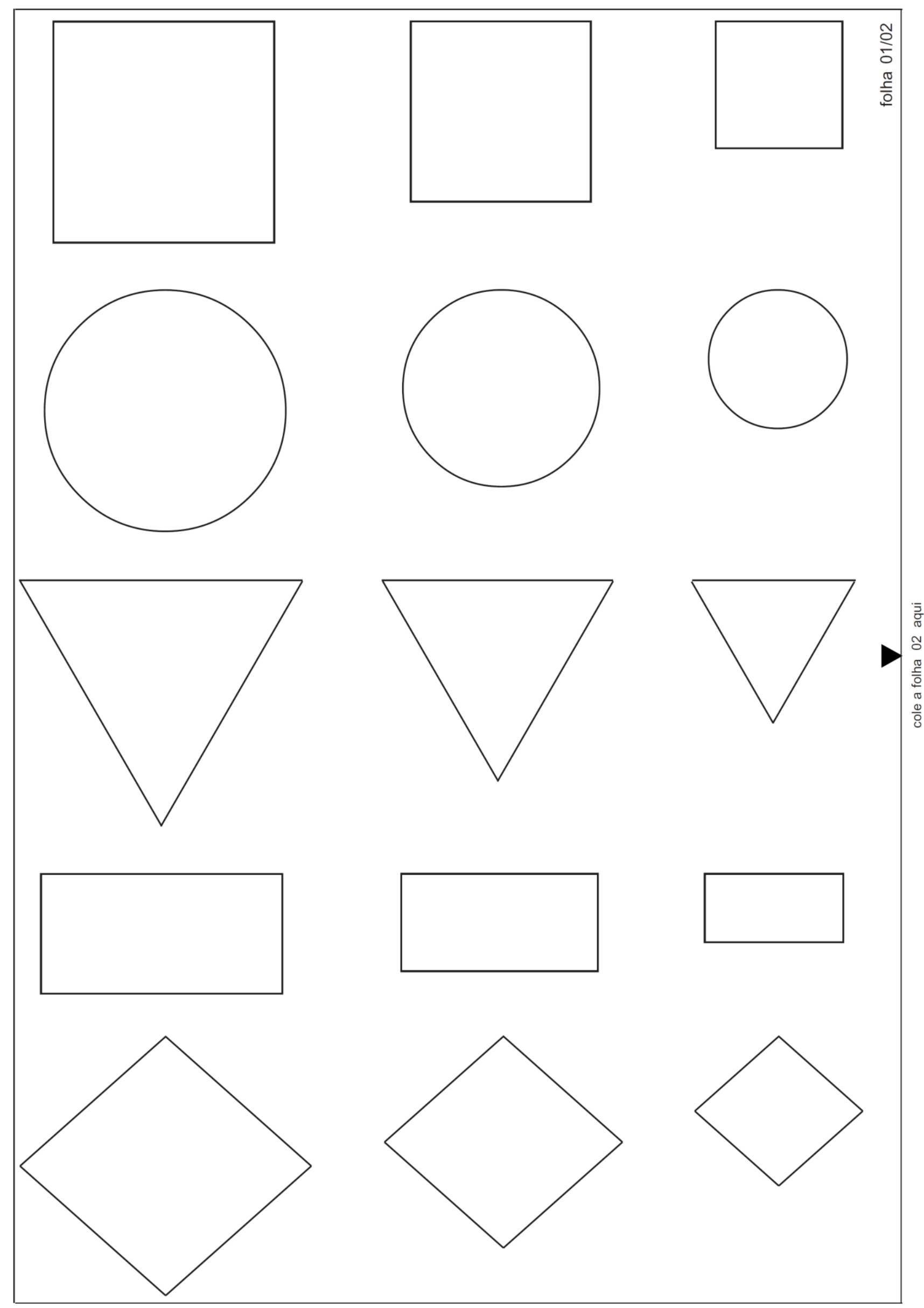



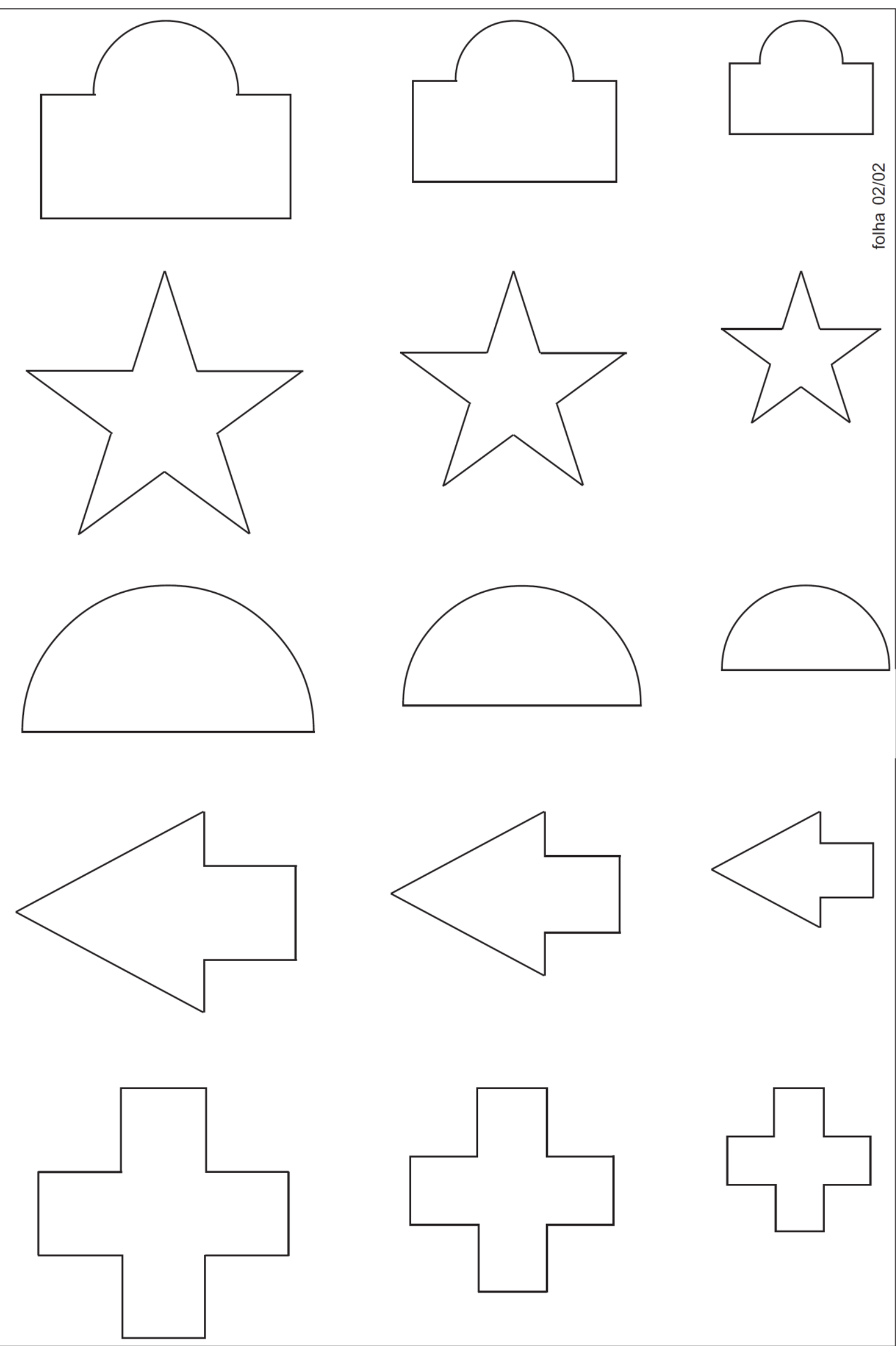


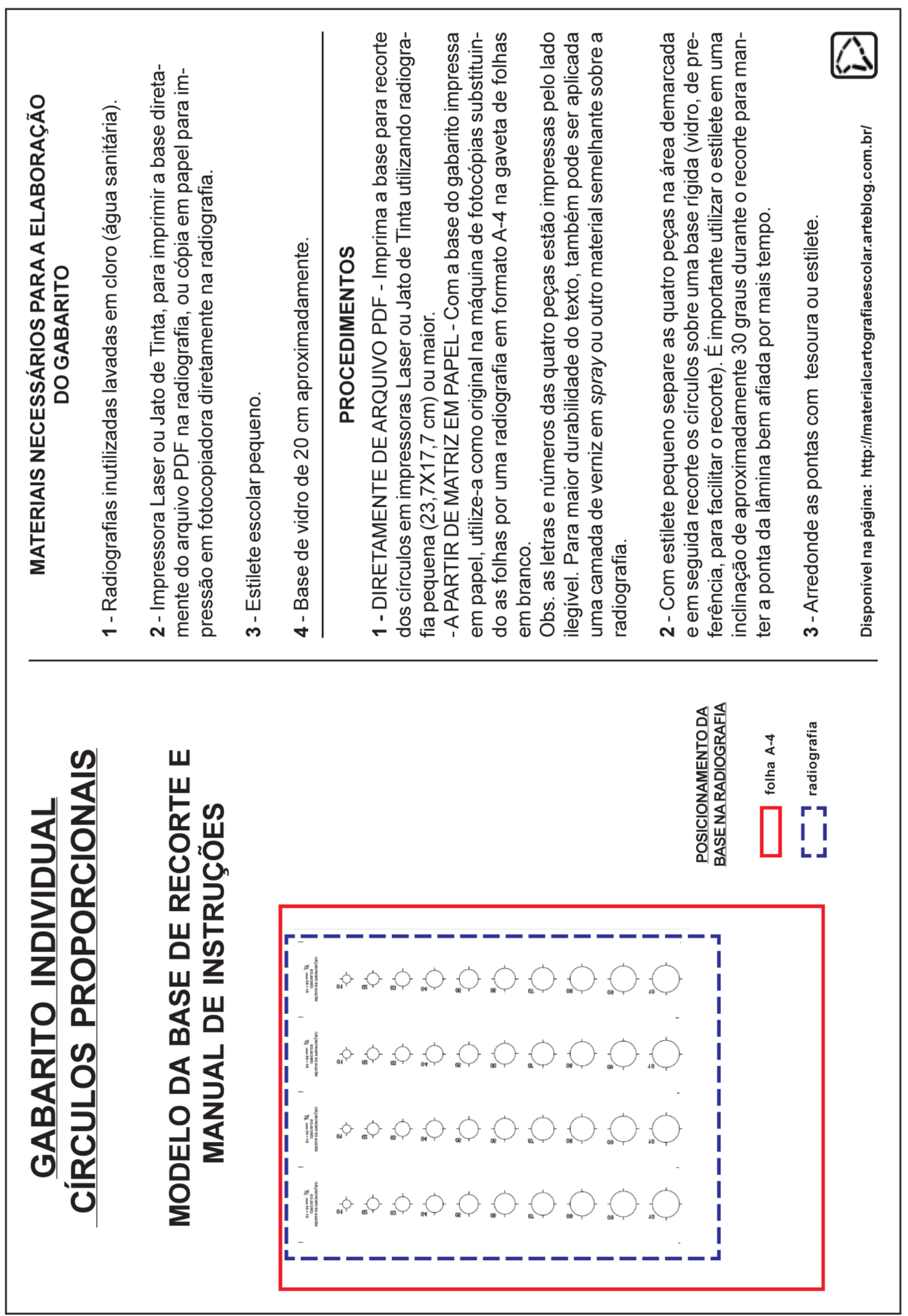


I

cischios

หẸCก $\forall$ DE bВOЬOBČ

$02=05 \mathrm{mw} \cdot \mathrm{Q}$

c|lbCnго?

BẸCก $\forall$ DE ЬBOЬO४Č $\forall$ O

$0 \mathrm{~d}=05 \mathrm{mw} \cdot \mathrm{Q}$

c!bcnгoz

BẸCก $\forall$ DE ЬBOЬOBČ $\forall$ O

$0 \mathrm{~d}=05 \mathrm{~mm} \cdot$

c|!́cnroz

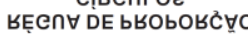

2

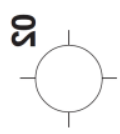

우

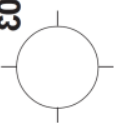

8

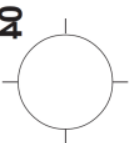

io

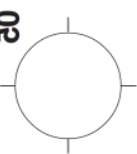

8

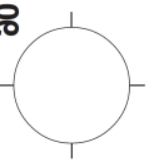

운
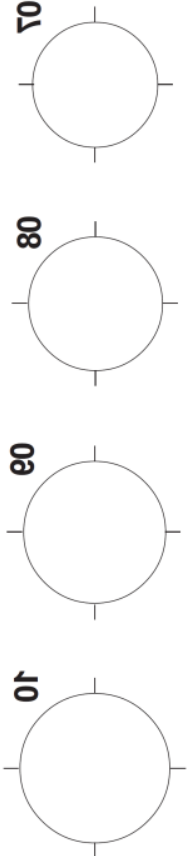

용

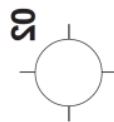

๘
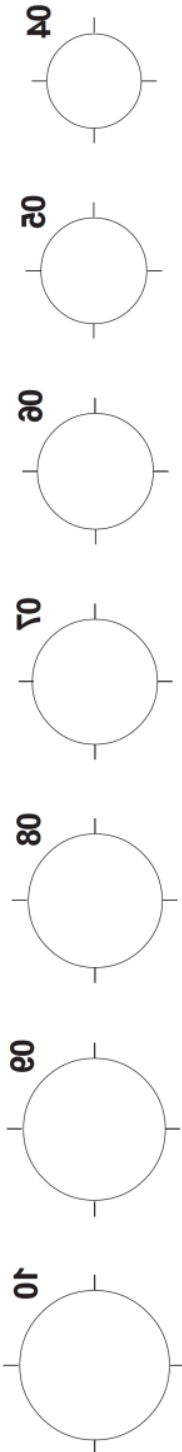

온

요

w
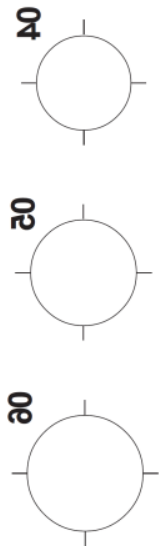

운
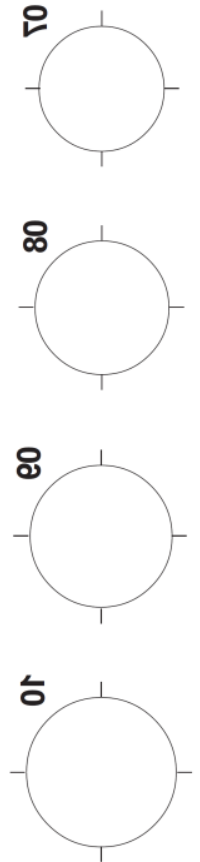

온

요

ఓ
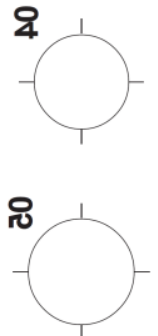

๑

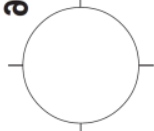

은
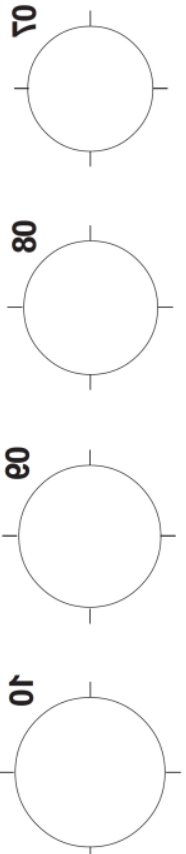


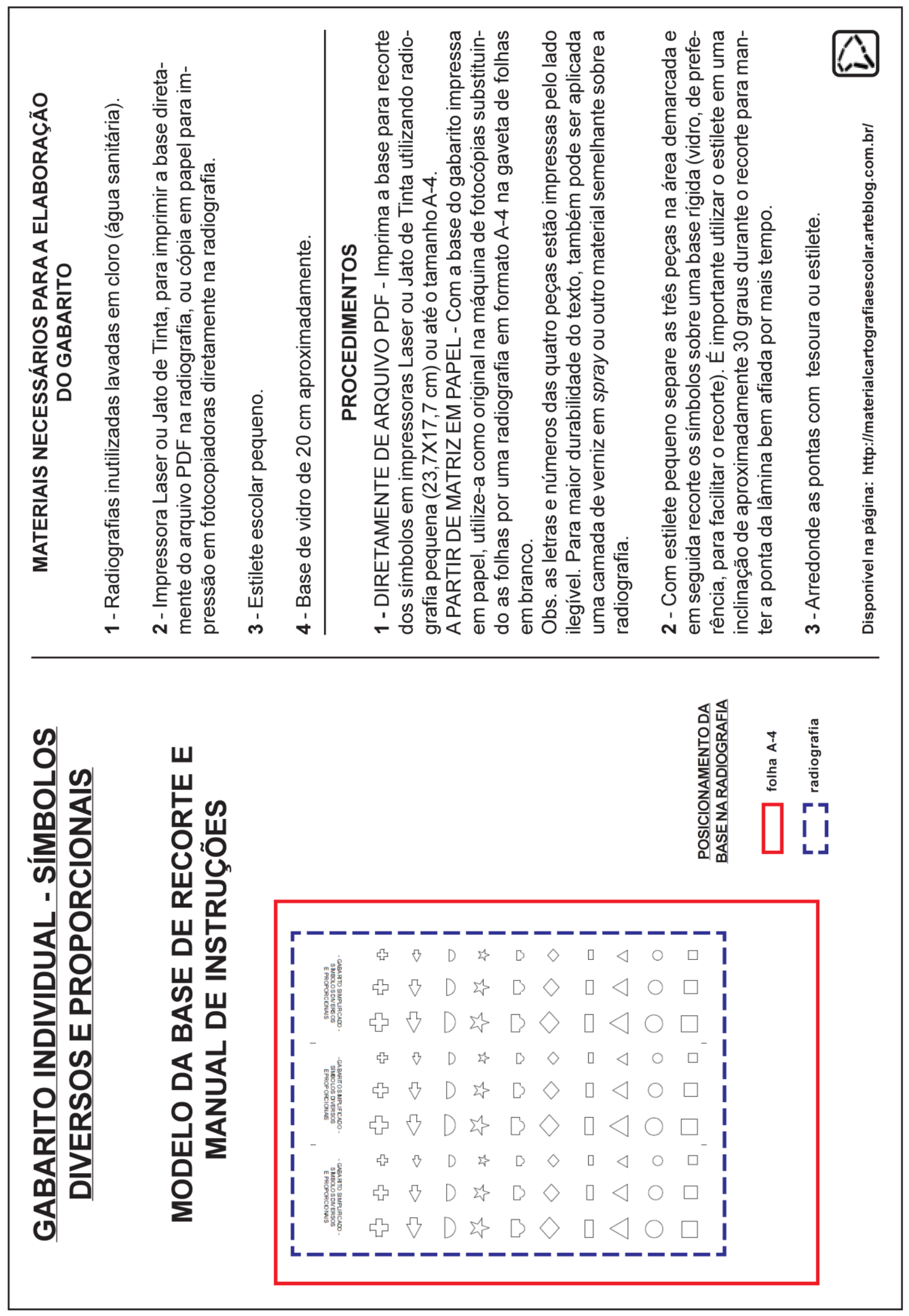


Е ЬВОьОВСІОИНІС

2ІWBOГОО DI^ЕВ2О2

- e $B B \forall B I \perp O$ 2IWbГIEICHDO -
Е ьвоьОВСІОИҰІа

2ІWBOГОО DIАЕВZOZ

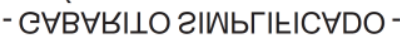

Е ЬВОЬОВСІОИҰІа

2ІWBOГОО DI^ЕВЗОZ

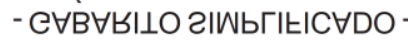

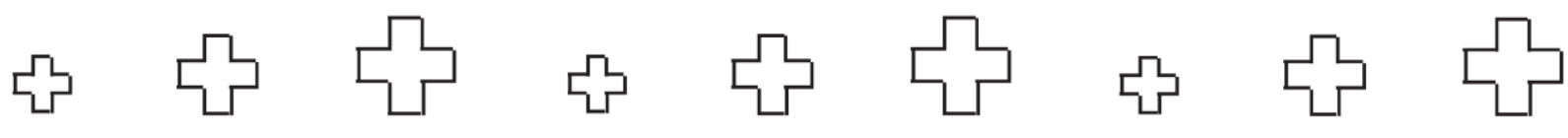

$\Rightarrow b \vec{b} \Rightarrow b \Rightarrow b$

$\nabla \nabla \square \nabla \square \square \vee \square \square$

\& \& \& \& \& \& \& \& \& \& 4

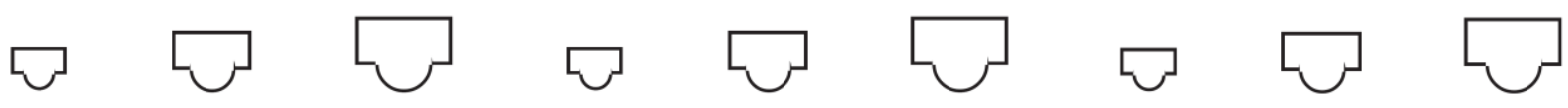

$\diamond \diamond \diamond \diamond \diamond \diamond \diamond \diamond$

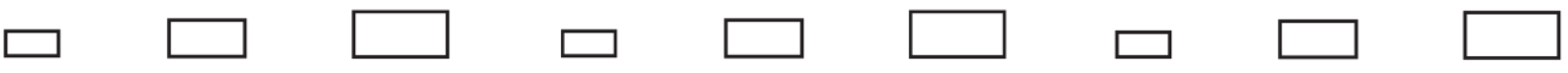

$\Delta \triangle \triangle \Delta \triangle \triangle \Delta \triangle \triangle$

$\circ \circ \bigcirc \circ \circ \bigcirc \circ \circ \bigcirc$

$\square \square \square \square \square \square \square \square \square$ 


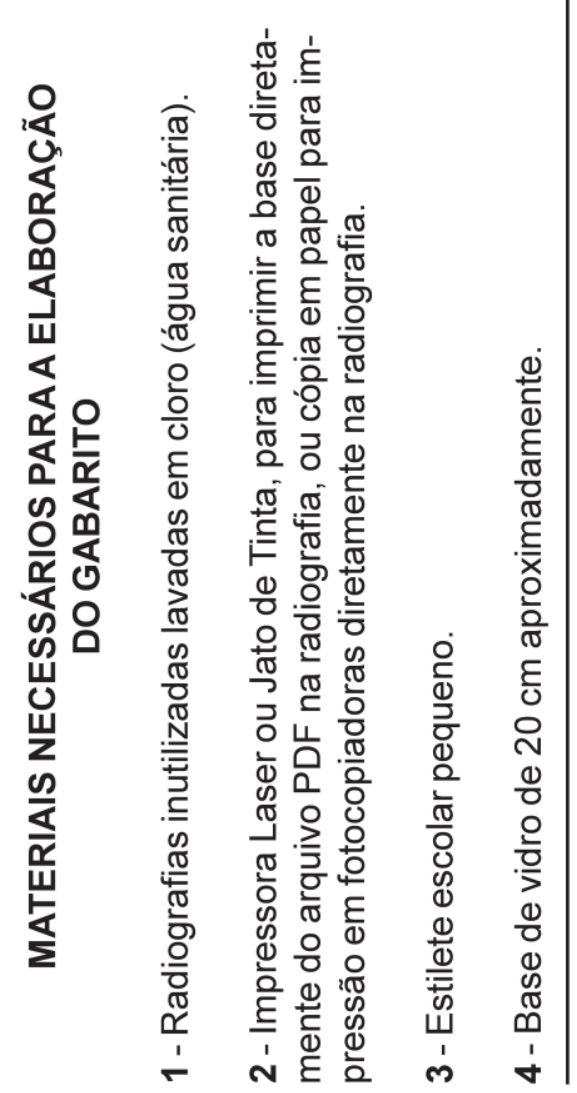

迆.

凶는

뜬응 ह르응

范

め) $\frac{N}{2}$

๙

ब

ฮิ ‡

है

๘

结宁

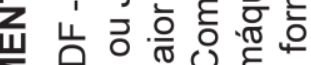

¿

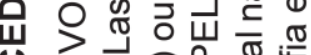

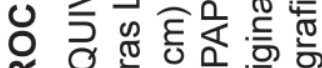

क थ क ते

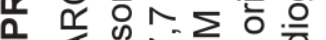

它

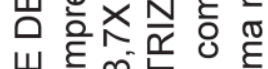

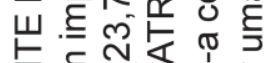

Z

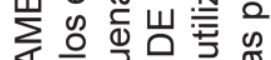

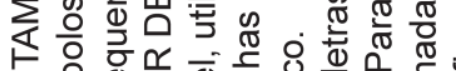

ш 을 Ð

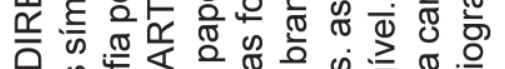

เ 음
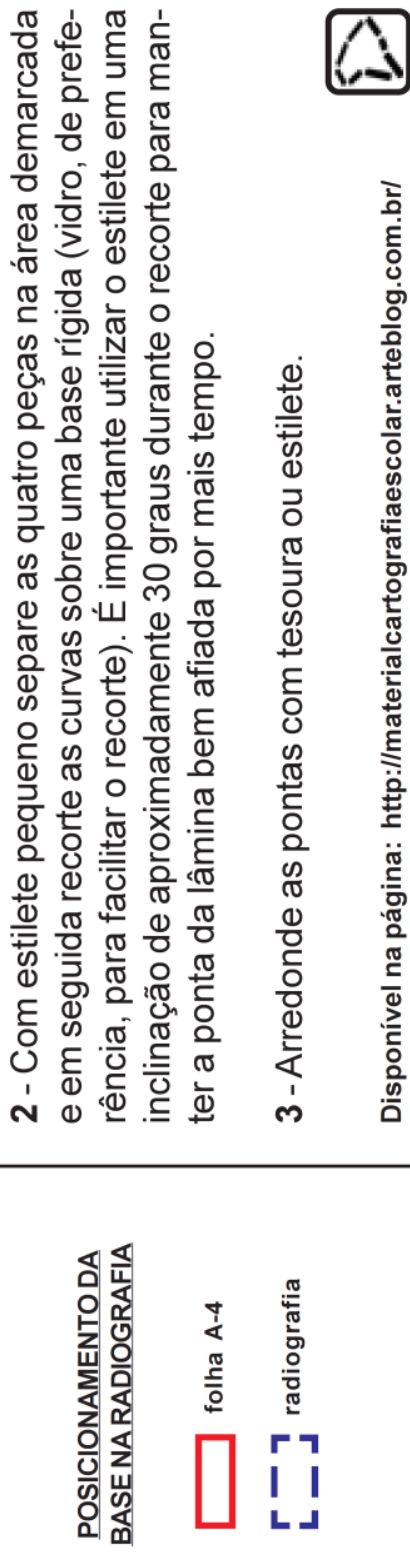


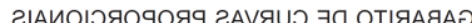
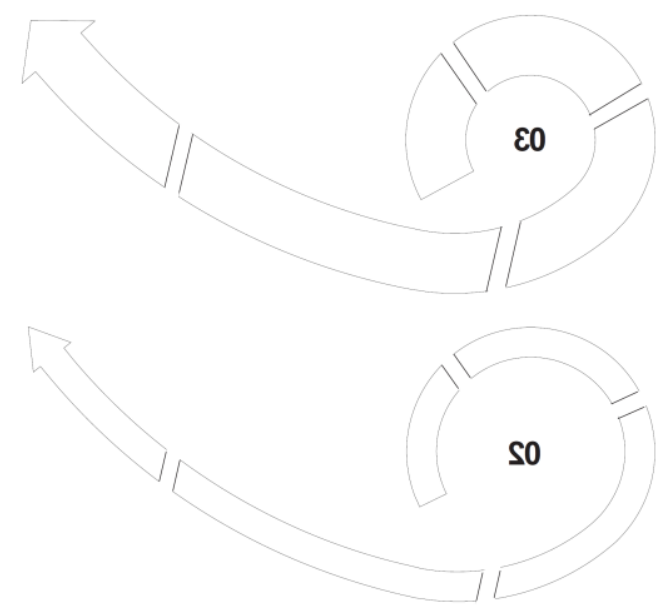

ro

ટІАИОІЈЯОЯОЯЯ ӘАУЯบว ЭО ОТІЯАЯАอ
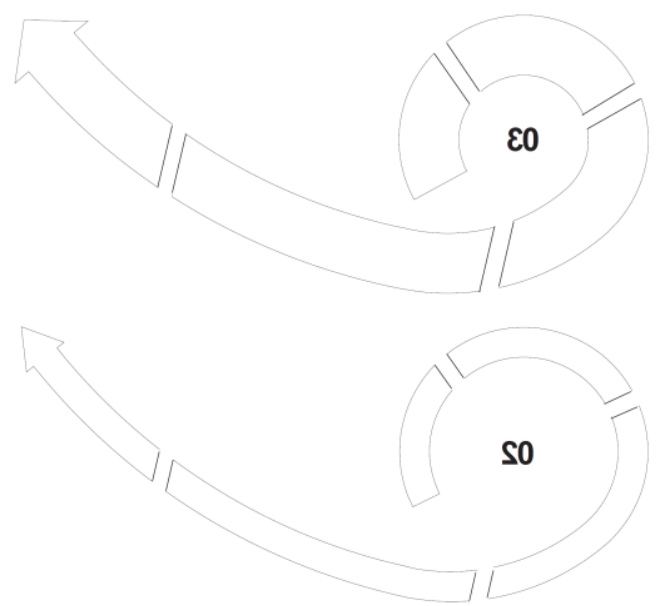

ro
ટાАИОІЈЯОЯОЯЯ ટАVЯUว ЭО ОТІЯАЯАอ

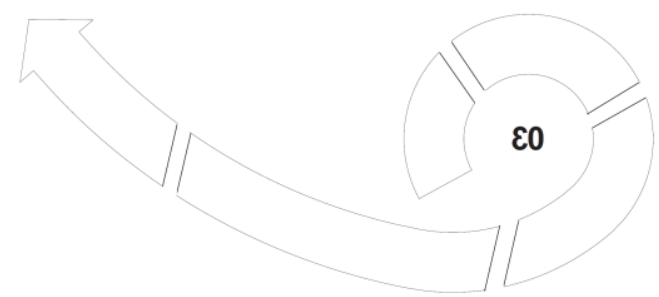

So

ro

ટાАИОІэЯОЯОЯ ГАVЯบว ヨО ОТІЯАЯАอ

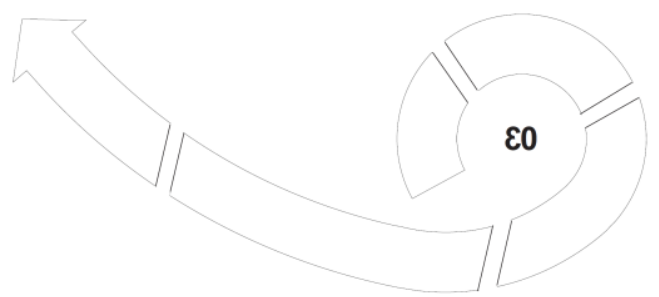

So

ro 
Tema:

\begin{tabular}{|l|l|l|}
\hline $\mathbf{N}^{\circ}$ & LOCALIDADE & DADOS \\
\hline 01 & & \\
\hline 02 & & \\
\hline 03 & & \\
\hline 04 & & \\
\hline 05 & & \\
\hline 06 & & \\
\hline 07 & & \\
\hline 08 & & \\
\hline 09 & & \\
\hline 10 & & \\
\hline 11 & & \\
\hline 12 & & \\
\hline 13 & & \\
\hline 14 & & \\
\hline 15 & & \\
\hline 16 & & \\
\hline 17 & & \\
\hline 18 & & \\
\hline 19 & & \\
\hline 20 & & \\
\hline 21 & & \\
\hline 22 & & \\
\hline 23 & & \\
\hline 24 & & \\
\hline 25 & & \\
\hline 26 & & \\
\hline 27 & & \\
\hline 28 & & \\
\hline 29 & & \\
\hline 30 & & \\
\hline
\end{tabular}

Tema:

\begin{tabular}{|l|l|l|}
\hline $\mathbf{N}^{\circ}$ & LOCALIDADE & DADOS \\
\hline 01 & & \\
\hline 02 & & \\
\hline 03 & & \\
\hline 04 & & \\
\hline 05 & & \\
\hline 06 & & \\
\hline 07 & & \\
\hline 08 & & \\
\hline 09 & & \\
\hline 10 & & \\
\hline 11 & & \\
\hline 12 & & \\
\hline 13 & & \\
\hline 14 & & \\
\hline 15 & & \\
\hline 16 & & \\
\hline 17 & & \\
\hline 18 & & \\
\hline 19 & & \\
\hline 20 & & \\
\hline 21 & & \\
\hline 22 & & \\
\hline 23 & & \\
\hline 24 & & \\
\hline 25 & & \\
\hline 26 & & \\
\hline 27 & & \\
\hline 28 & & \\
\hline 29 & & \\
\hline 30 & & \\
\hline
\end{tabular}

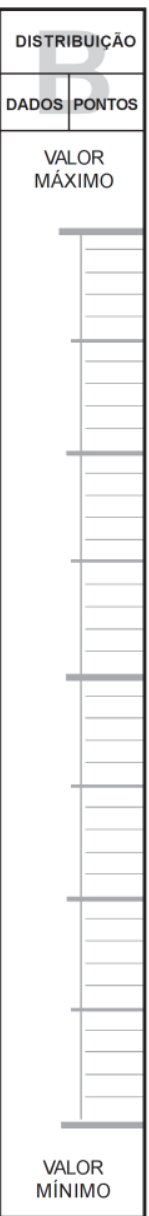

\begin{tabular}{|l|l|}
\hline$N^{\circ}$ & $\begin{array}{c}\text { CLASSIFICACAO } \\
\text { CONVERSAO }\end{array}$ \\
\hline 01 & \\
\hline 02 & \\
\hline 03 & \\
\hline 04 & \\
\hline 05 & \\
\hline 06 & \\
\hline 07 & \\
\hline 08 & \\
\hline 09 & \\
\hline 10 & \\
\hline 11 & \\
\hline 12 & \\
\hline 13 & \\
\hline 14 & \\
\hline 15 & \\
\hline 16 & \\
\hline 17 & \\
\hline 18 & \\
\hline 19 & \\
\hline 20 & \\
\hline 21 & \\
\hline 22 & \\
\hline 23 & \\
\hline 24 & \\
\hline 25 & \\
\hline 26 & \\
\hline 27 & \\
\hline 28 & \\
\hline 29 & \\
\hline 30 & \\
\hline
\end{tabular}

Procedimentos

Fonte Escreva o título do tema escolhido para o mapa. Preencha os dados na tabela "A". Se os dados "stiverem em valores relativos, utilize "metodo ordenado" (coroplético). Se estiverem em valores absolutos, utilize o "metodo quantitativo (circulos...). Caso o tema seja diverso, como um nome ou fenômeno especifico "método qualitativo" Par desiocamentos, "mtilize o "método dinâmico". Siga os seguintes procedimentos para:

MAPA ORDENADO:Na tabela "B" escreva o valor minimo e o máximo./ Some os dois valores divida por dois para encontrar o valor médio. Repita os procedimentos para encontrar o valor das demais eare Transfira os dados classificados para a legenda con "I Pinte cla nadas ou granulacões / Classifique os dados na abela "C" de acordo com os valores respectivos. I Transfira as cores da legenda para mapa e finalize com o acabamento.

MAPA QUANTITATIVO: Converta os dados na tabela "C" calculando o valor máximo com circulo10 do gabarito e reduzindo os demais (maior $\left.n^{\circ}\right)=x$. tiplique " $X$ " pelos demais valores, fazendo arredondamentos. I Preencha os círculos com gabarito no mapa partindo do tamanho menor para o maior e pinte-os com apenas uma cor ou onalidade, e contorne-os com caneta preta, assim como o contorno dos circulos da legenda " (sem preenchimento) e escreva o valor maacabamento

MAPA QUALITATIVO: Classifique os dados na tabela "C" de acordo com os tipos respectivos de cada localidade do mapa. / Preencha as cores, formas ou tonalidades na legenda, e em seguida no mapa. e finalize com o acabamento.

MAPA DINÂMICO: Classifique os dados na tabela "E" "ORIGEM/DESTINO" de acordo com os os valores "ALTO/MEDIO/BAIXO de cada local dade do mapa. / Preencha as setas com o gabarito de acordo com os dados e finalize com acabamento

ACABAMENTO: Escreva as informações com plementares para a legenda e cite a font pesquisada.

Fonte

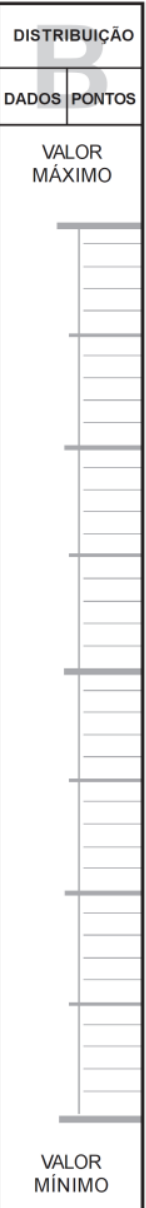

\begin{tabular}{|l|l|}
\hline$N^{\circ}$ & $\begin{array}{c}\text { LLASSIFICACÁÁ } \\
\text { CONVERSAO }\end{array}$ \\
\hline 01 & \\
\hline 02 & \\
\hline 03 & \\
\hline 04 & \\
\hline 05 & \\
\hline 06 & \\
\hline 07 & \\
\hline 08 & \\
\hline 09 & \\
\hline 10 & \\
\hline 11 & \\
\hline 12 & \\
\hline 13 & \\
\hline 14 & \\
\hline 15 & \\
\hline 16 & \\
\hline 17 & \\
\hline 18 & \\
\hline 19 & \\
\hline 20 & \\
\hline 21 & \\
\hline 22 & \\
\hline 23 & \\
\hline 24 & \\
\hline 25 & \\
\hline 26 & \\
\hline 27 & \\
\hline 28 & \\
\hline 29 & \\
\hline 30 & \\
\hline
\end{tabular}

\section{Procedimentos}

Escreva o título do tema escolhido para o mapa Preencha os dados na tabela "A". Se os dado "estiverem em valores relativos, utilize "método ordenado" (coropletico). Se "método quantitativo" (circulos. un. Caso o tema seja diverso, como um nome ou fenômeno especifico de determinadas áreas do mapa escolha "método qualitativo". Para deslocamentos, utilize o metodo dinâmico". Siga os seguintes procedimentos para:

MAPA ORDENADO:Na tabela "B" escreva o vaor minimo e o maximo./ Some os dois valores Rivita por dois para encontrar o valor medio. das demais escalas. Marque os dados com pontos e separe os valores em quatro classes./ Transfira os dados classificados para a legend labela C de acordo com os valores res: mos. Transfira as cores da legenda para mapa e finalize com o acabamento.

MAPA QUANTITATIVO: Converta os dados n "C" calculando o valor máximo com circulo 10 do gabarito reduzindo os demais valores na proporça (regra de três). Ex. 10: maior $\left.n^{\circ}\right)=X$. / Memorize na calculadora e muarredondamentos. / Preencha os círculos com gabarito no mapa partindo do tamanho meno para o maior e pinte-os com apenas uma cor ou tonalidade, e contorne-os com caneta preta. assim como o contorno dos circulos da legenda D (sem preenchimento) e escreva o valor maximento.

MAPA QUALITATIVO: Classifique os dados na tabela "C" de acordo com os tipos respectivos de cada localidade do mapa. / Preencha as cores, formas ou tonalidades na legenda, e em seguida no mapa. e finalize com o acabamento.

MAPA DINÂMICO: Classifique os dados na tabela "E" "ORIGEM/DESTINO" de acordo com os os valores ALTO/MEDIO/BAIXO de cada localidade do mapa. / Preencha as setas com o gabamento.

ACABAMENTO: Escreva as informacões complementares para a legenda e cite a fonte

\begin{tabular}{|c|c|c|}
\hline ORIGEM & ALTO & DESTINO \\
\hline & 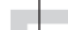 & \\
\hline & 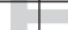 & \\
\hline & 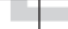 & \\
\hline & & \\
\hline & & \\
\hline & & \\
\hline & & \\
\hline & & \\
\hline & & \\
\hline$\overline{\text { ORIGEM }}$ & MÉDIO & DESTINO \\
\hline & & \\
\hline & & \\
\hline & & \\
\hline & & \\
\hline & & \\
\hline & & \\
\hline & & \\
\hline & & \\
\hline$\overline{\text { ORIGEM }}$ & BAIXO & DESTINO \\
\hline & & \\
\hline & & \\
\hline & & \\
\hline & & \\
\hline & & \\
\hline & & \\
\hline & & \\
\hline & & \\
\hline & & \\
\hline & & \\
\hline
\end{tabular}


Tema:

\begin{tabular}{|c|c|c|}
\hline $\mathbf{N}^{\circ}$ & LOCALIDADE & DADOS \\
\hline 01 & & \\
\hline 02 & & \\
\hline 03 & & \\
\hline 04 & & \\
\hline 05 & & \\
\hline 06 & & \\
\hline 07 & & \\
\hline 08 & & \\
\hline 09 & & \\
\hline 10 & & \\
\hline
\end{tabular}
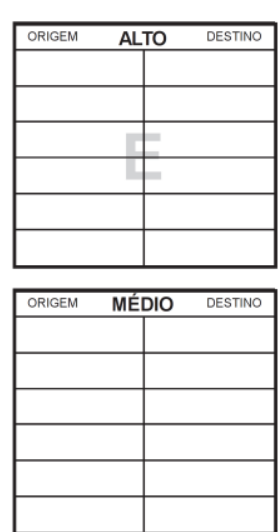

\begin{tabular}{|l|l|}
\hline ORIGEM BAIXO DESTINO \\
\hline & \\
\hline & \\
\hline & \\
\hline & \\
\hline & \\
\hline & \\
\hline
\end{tabular}
Escreva o titulo do tema escolhido tabela " $A$ ". Se os dados estiverem
em valores relativos, utilize 0 "método ordenado" (coroplético). Se estiverem em valores absolutos. "estiverem "mé valores absolutos, (circulos....). Caso o tema seja diverso, como um nome ou determinadas áreas do mapa escolha o "método qualitativo". Para deslocamentos, utilize "método dinâmico". Siga
seguintes procedimentos para: seguintes procedimentos para: dados na tabela "C" calculando ova-
lor máximo com o circulo 10 do gabarito e reduzindo os demais valo. res na proporçăo (regra de três). Ex. 10: $\left(\right.$ maior $\left.n^{\circ}\right)=X . /$ Memorize na cal. culadora e multiplique "X" pelos demais valores, fazendo os arredondamentos./Preencha os cirtindo do tamanho menor para o maior e pinte-os com apenas uma cor ou tonalidade, e contorne-os com caneta preta, assim como o contormáximo e o minimo apresentado e finalize com o acabamento.
PROCEDIMENTOS para o mapa. Preencha os dados na
tabela "A". Se os dados estiverem MAPA QUANTITATIVO: Converta os preenchimento) e escreva $\mathrm{D}$ " (sem
Fonte

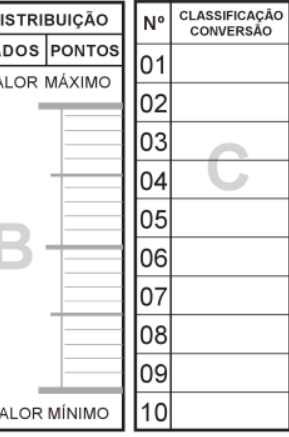

MAPA ORDENADO-Na tabela "B" escreva o valor minimo e o máximo. Some os dois valores e divida por dois para encontrar o valor médio. Repita os procedimentos para en contrar o valor das demais escalas. Marque os dados com pontos e se. ransfira os dados classificados para a legenda do mapa " $\mathrm{D}$ "// Pinte a egenda com cores ordenadas ou granulaçốes./ Classifique os dados a tabela "C" de acordo com os valoTrespectivos. I Transfira as cores ra o mapa e finalize o acabamento.

MAPA QUALITATIVO: Classifique os ados na tabela "C" de acordo com os tipos respectivos de cada local dade do mapa. / Preencha as cores. formas ou tonalidades na legenda. o acabamento.

MAPA DINÂMICO: Classifique os dados na tabela "E" "ORIGEMIDESTINO" de acordo com os os valores "ALTO/MÉDIO/BAIXO de cada locadade do mapa. / Preencha as setas dados e finalize com o acabamento ACABAMENTO: Escreva as informa. cóes complementares para a legenda e cite a fonte pesquisada. pare os valores em quatro classes.

Tema:

\begin{tabular}{|l|l|l|}
\hline$N^{0}$ & LOCALIDADE & DADOS \\
\hline 01 & & \\
\hline 02 & & \\
\hline 03 & & \\
\hline 04 & & \\
\hline 05 & & \\
\hline 06 & & \\
\hline 07 & & \\
\hline 08 & & \\
\hline 09 & & \\
\hline 10 & & \\
\hline
\end{tabular}

Fonte:

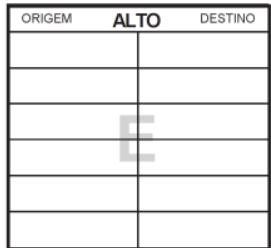

PROCEDIMENTOS

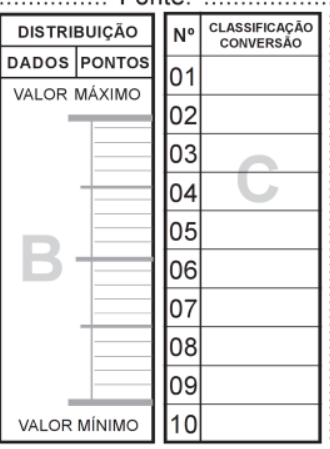

웅

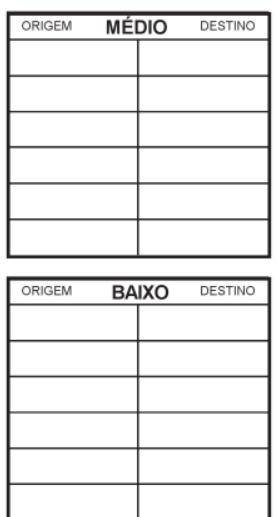
Escreva o titulo do tema escolhido creva o valor mínimo e o máximo. / para o mapa. Preencha os dados na Some os dois valores e divida por ta dados estiverem dois para encontrar o valor medio. em valores relativos, utilize $\circ$ Repita os procedim demais escalas. (arque os dados com pontos e seutilize "mét pare os valores em quatro classes. (circulas Transfira os dados classificados diverso, como um a legenda do mapa "D"./ Pinte a fenômeno legenda com cores ordenadas ou determinadas áreas do granulaçōes./ Classifique os dados " na tabela "C" de acordo com os valoPes respectivos. / Transfira as cores "método dina degenda para o mapa e finalize seguintes procedimentos para: com o acabamento.

MAPA QUALITATIVO: Classifique os MAPA QUANTITATIVO: Converta os $\begin{aligned} & \text { MAPA QUALita } \\ & \text { dados na tabela "C" de acordo com }\end{aligned}$ dados na tabela "C" calculando o va- os tipos respectivos de cada localiIor máximo com o circulo10 do ga- dade do mapa. / Preencha as cores, barito e reduzindo os demais valo- formas ou tonalidades na legenda res na proporção (regra de três). Ex. em seguida no mapa e finalize con 10: $\left(\right.$ maior $\left.^{n}\right)=X . /$ Memorize na cal- em seguida no culadora e multiplique "X" pelos de.mais valores, fazendo os MAP a abla "E" "ORISEMIDESTIculos com o gabarito no mapa par- NO" de acordo com os os valores tindo do tamanho menor para o mai- "ALTO/MÉDIO/BAIXO de cada locaor e pinte-os com apenas uma cor lidade do mapa. / Preencha as setas ou tonalidade, e contorne-os com com o gabarito de acordo com os caneta preta, assim como o contor- dados e finalize com o acabamento. no dos circulos da legenda " $\mathrm{D}$ " (sem preenchimento) e escreva o valor ACABAMENTO: Escreva as informamaximo e o minimo apresentado e çöes complementares para a legeninalize com $\circ$ acabamento. da e cite a fonte pesquisada.

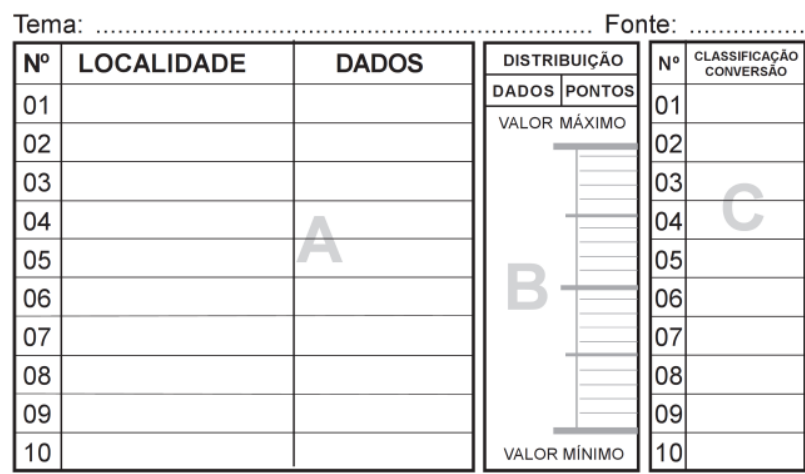

PROCEDIMENTOS

\begin{tabular}{|l|l|}
\hline ORIGEM ALTO DESTINO \\
\hline & \\
\hline & \\
\hline & \\
\hline & \\
\hline & \\
\hline & \\
\hline
\end{tabular}
Escreva o título do tema escolhido para o mapa. Preencha os dados na tabela "A". Se os dados estiverem em valores relativos, utilize "método ordenado" (coroplético). Se estiverem em valores absolutos. utilize o "método quantitativo" (circulos...). Caso o tema seja diverso, como um nome ou fenômeno especifico de determinadas áreas do mapa,

\begin{tabular}{|l|l|}
\hline ORIGEM MÉDIO DESTINO \\
\hline & \\
\hline & \\
\hline & \\
\hline & \\
\hline & \\
\hline & \\
\hline
\end{tabular}

Para deslocamentos, utilize "método dinâmico". Siga os seguintes procedimentos para:

MAPA QUANTITATIVO: Converta os dados na tabela "C" calculando o valor máximo com o circulo10 do gares na proporçăo (regra de três). Ex 10: $\left(\right.$ maior $\left.n^{\circ}\right)=X$. / Memorize na calculadora e multiplique "X" pelos de-

\begin{tabular}{|l|l|}
\hline ORIGEM BAIXO DESTINO \\
\hline & \\
\hline & \\
\hline & \\
\hline & \\
\hline & \\
\hline & \\
\hline
\end{tabular}

mais valores, fazendo arredondamentos. / Preencha os ciror coma o pin o phas una cor caneta preta assim como ocontorno des circulos da legenda " $D$ " ( renchimento) e escreva o valor máximo o minim apresentado finalize com $o$ acabamento.
MAPA ORDENADO-Na tabela "B" escreva o valor mínimo e o máximo che Replta os procedimentos para enMarque os dados com pontos esepare os valores em quatro classes/ Tre "D" egenda com cores orden granuõos / Cles fiqunadas ou " es respectivos. I Transfira as cores da legenda para o mapa e finalize

MAPA QUALITATIVO: Classifique os dados na tabela $C$ de acordo com stipos respectivos de cada localidade do mapa./Preencha as cores, formas ou tonalidades na legenda, em seguida no mapa e finalize com o acabamento.

MAPA DINÂMICO: Classifique os da os na tabela "E" "ORIGEM/DESTINO" de acordo com os os valores ALTO/MÉDIO/BAIXO de cada locadade do mapa. / Preencha as setas com dados e finalize com o acabamento.

ACABAMENTO Escreva as inform çōes complementares para a legenda e cite a fonte pesquisada.
Tema:

\begin{tabular}{|l|l|l|}
\hline$N^{\circ}$ & LOCALIDADE & DADOS \\
\hline 01 & & \\
\hline 02 & & \\
\hline 03 & & \\
\hline 04 & & \\
\hline 05 & & \\
\hline 06 & & \\
\hline 07 & & \\
\hline 08 & & \\
\hline 09 & & \\
\hline 10 & & \\
\hline
\end{tabular}

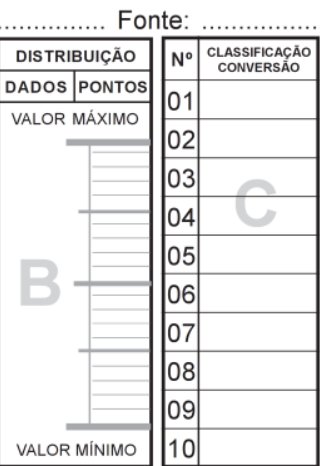

PROCEDIMENTOS

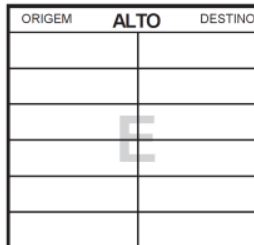

Escreva o título do tema escolhido para o mapa. Preencha os dados na tabela " $A$ ". Se os dados estiverem em valores relativos, utilize o "método ordenado" (coroplético). Se estiverem em valores absolutos,
utilize o "método quantitativo" utilize o "método quantitativo" (circulos....). Caso o tema seja diverso, como um nome ou fenômeno específico de
determinadas áreas do mapa, determinadas áreas do mapa,
escolha o "método qualitativo" \begin{tabular}{|c|l|l|}
\hline ORIGEM MÉDIO DESTINO & $\begin{array}{l}\text { escolha o "método qualitativo". } \\
\text { Para deslocamentos, utilize o } \\
\text { "método dinâmico". Siga os } \\
\text { seguintes procedimentos para: }\end{array}$ \\
\hline
\end{tabular} seguintes procedimentos para MAPA QUANTITATIVO: Converta os dados na tabela "C" calculando o valor máximo com o circulo10 do gares na proporçăa (regra de três). Ex. 10: $\left(\right.$ maior $\left.n^{\circ}\right)=X$. / Memorize na calculadora e multiplique " $X$ " pelos demais valores, fazendo os

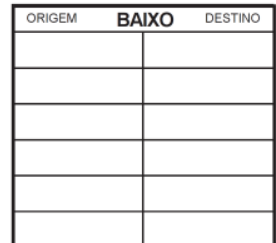
no dos circulos da legenda "D" (sem arredondamentos./Preencha os cir- dos na tabela "E" "ORIGEM/DESTItindo na

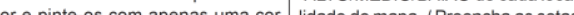
ou tonalide contorne com caneta preta assincomo contor dado e finlize como acaban preenchimento) e escreva o valor ACABAMENTO Escreva as informamáximo e o minimo apresentado e côes complementares para a legenmaxalize com o acabamento.
fina e cite a fonte pesquisada. os dois valores e divida po Repita os procedimentos para enContrar o valor das demais escalas. Tre os valores em quatro classes/ Transfira os dados classificados para a legenda do mapa " $\mathrm{D}$ ",/ Pinte a ranulações / Classifique os dados tabela "C" respectivos. / Transfira as cores enda para o mapa e finalize MAPA QUALITATIVO: Classifique os Des na tabela " $C$ " de acordo com os tipos respectivos de cada locali. ormas ou tonalidades na legenda, seguida no mapa e finalize com 

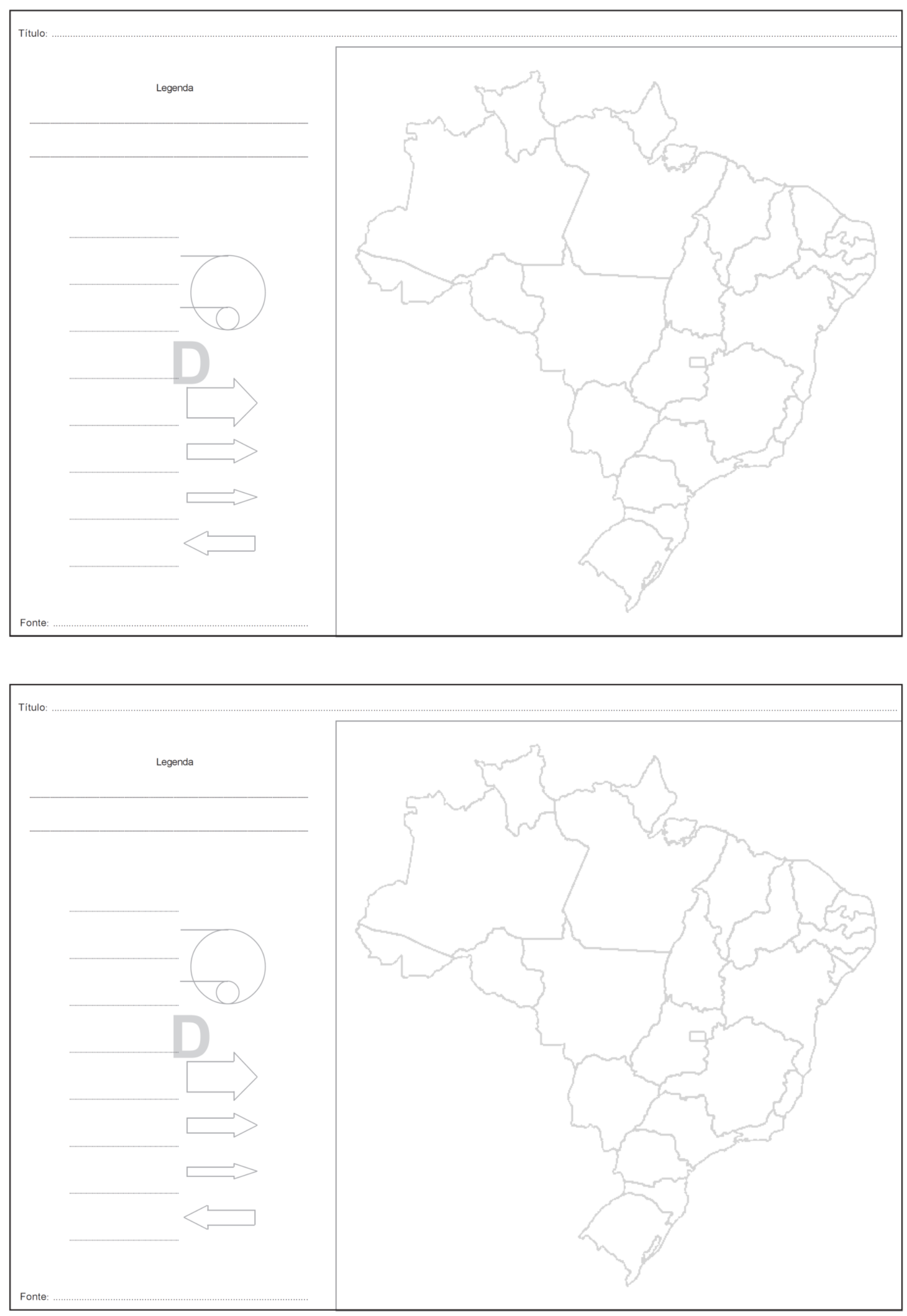

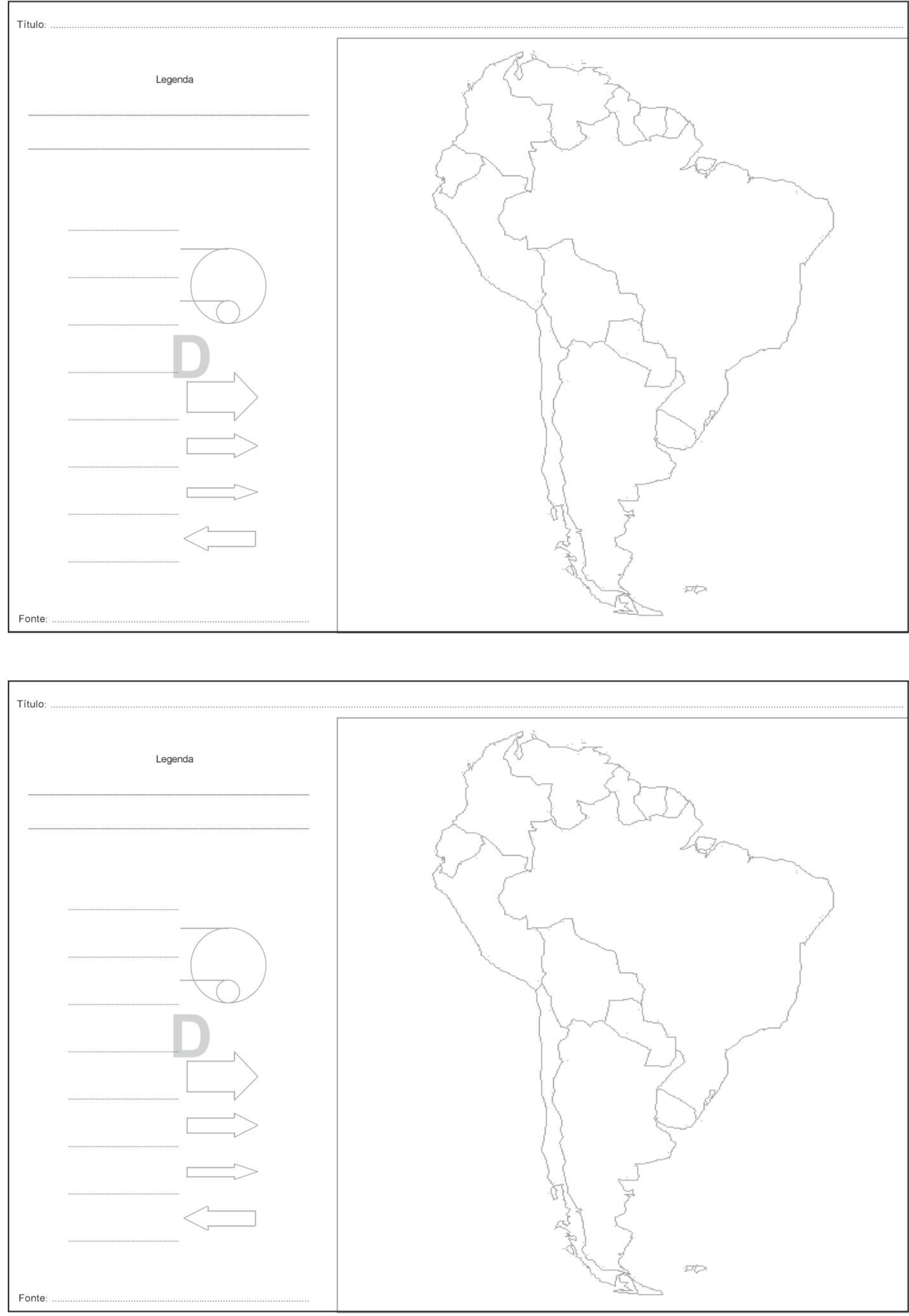

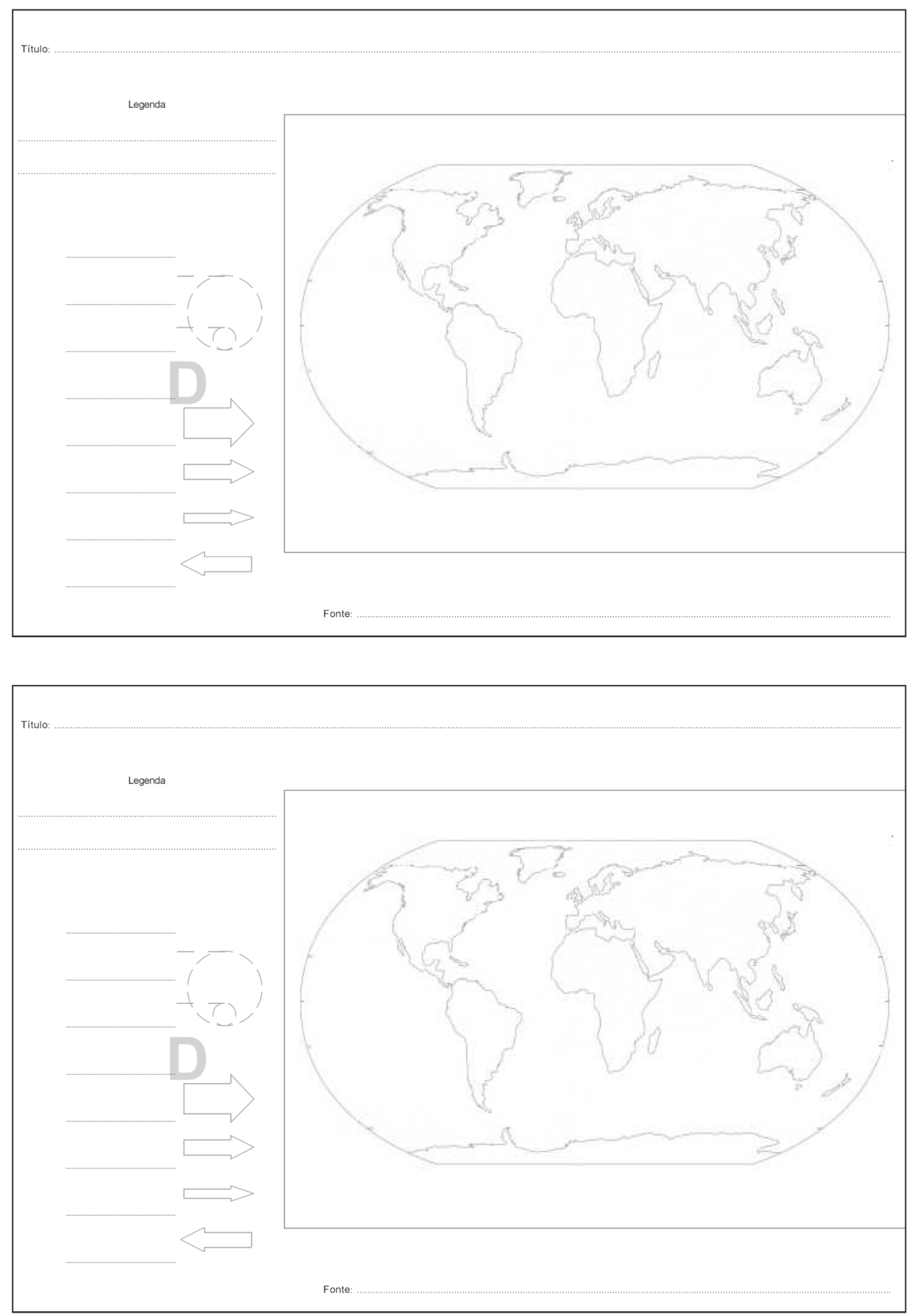

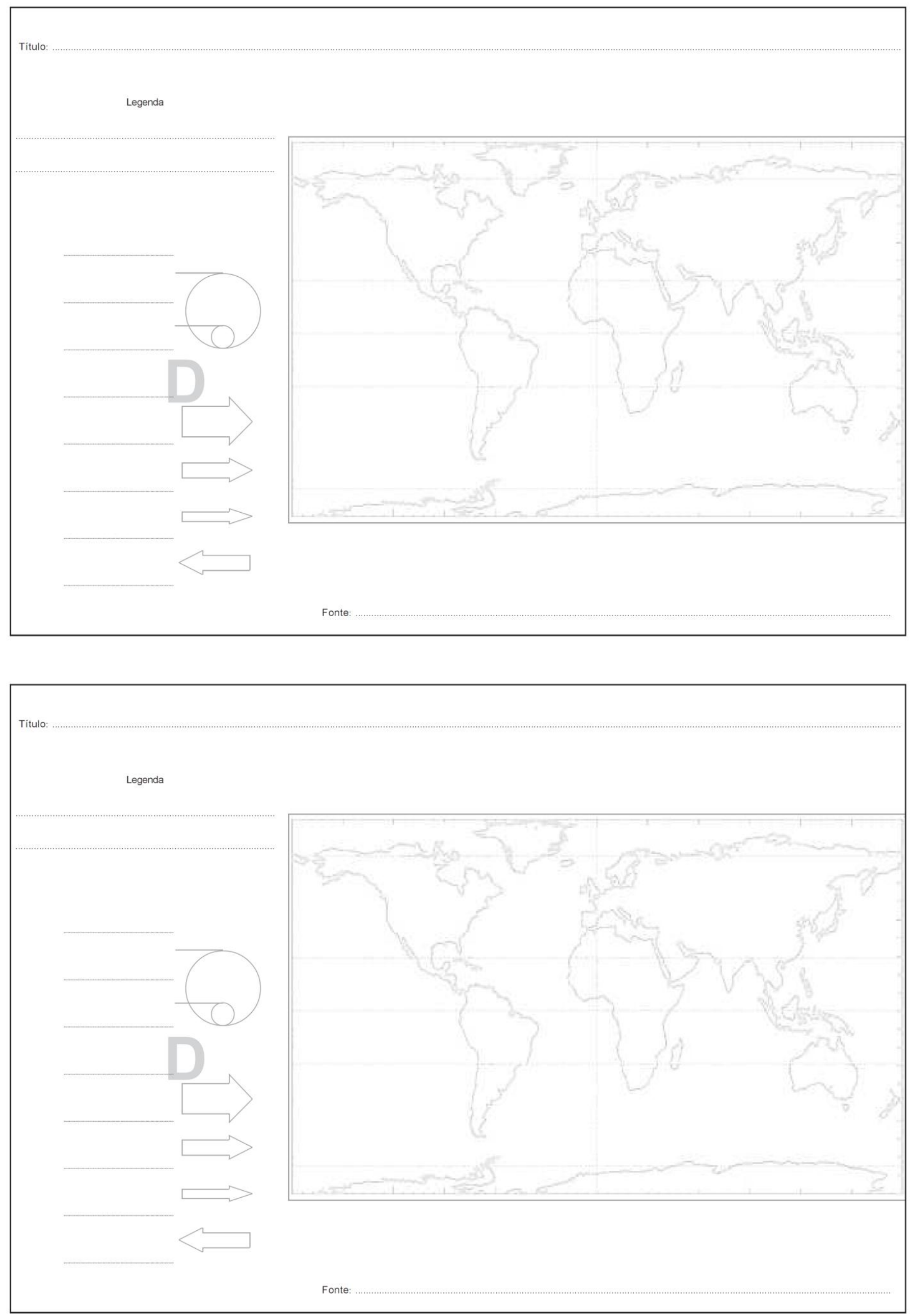

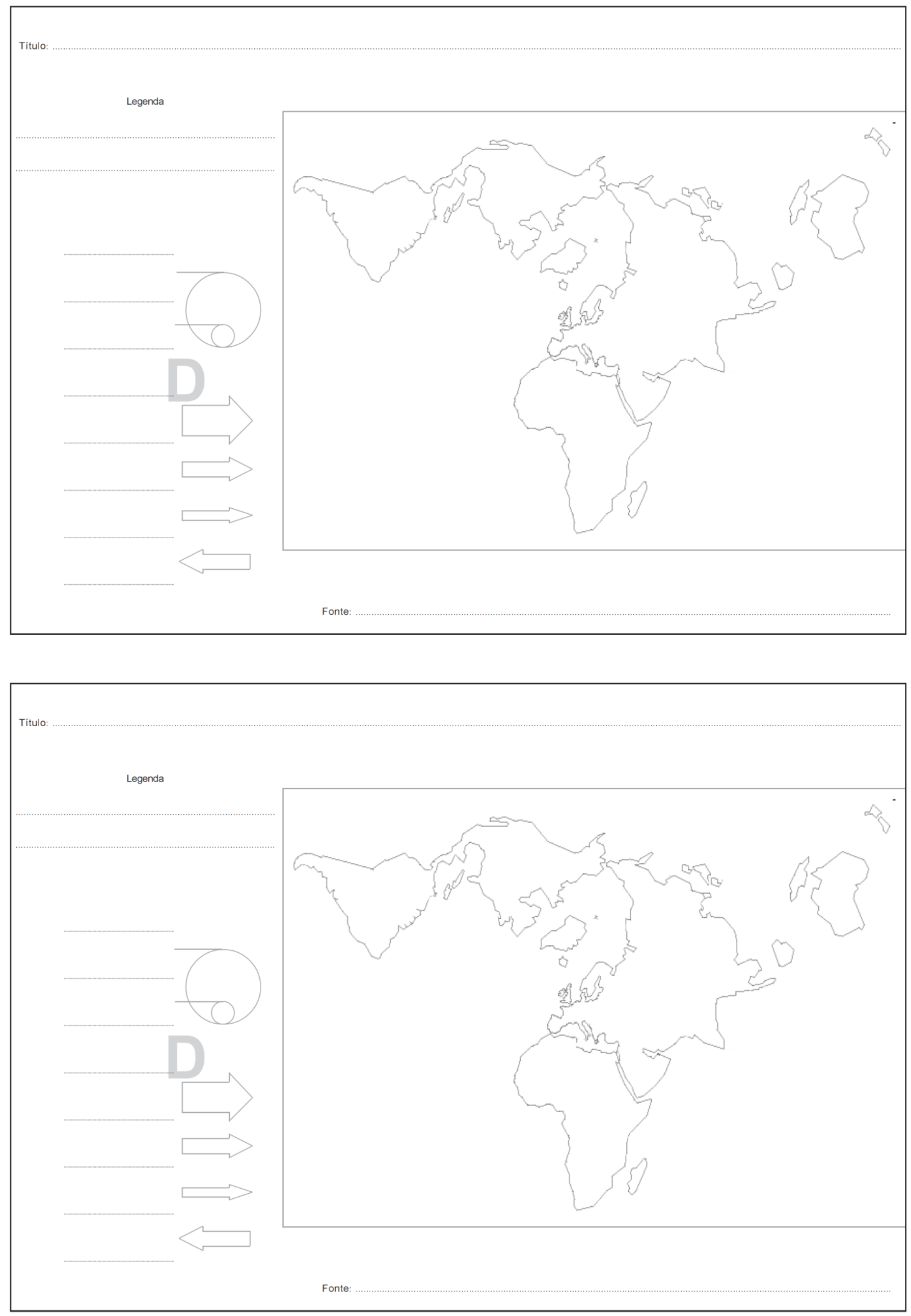

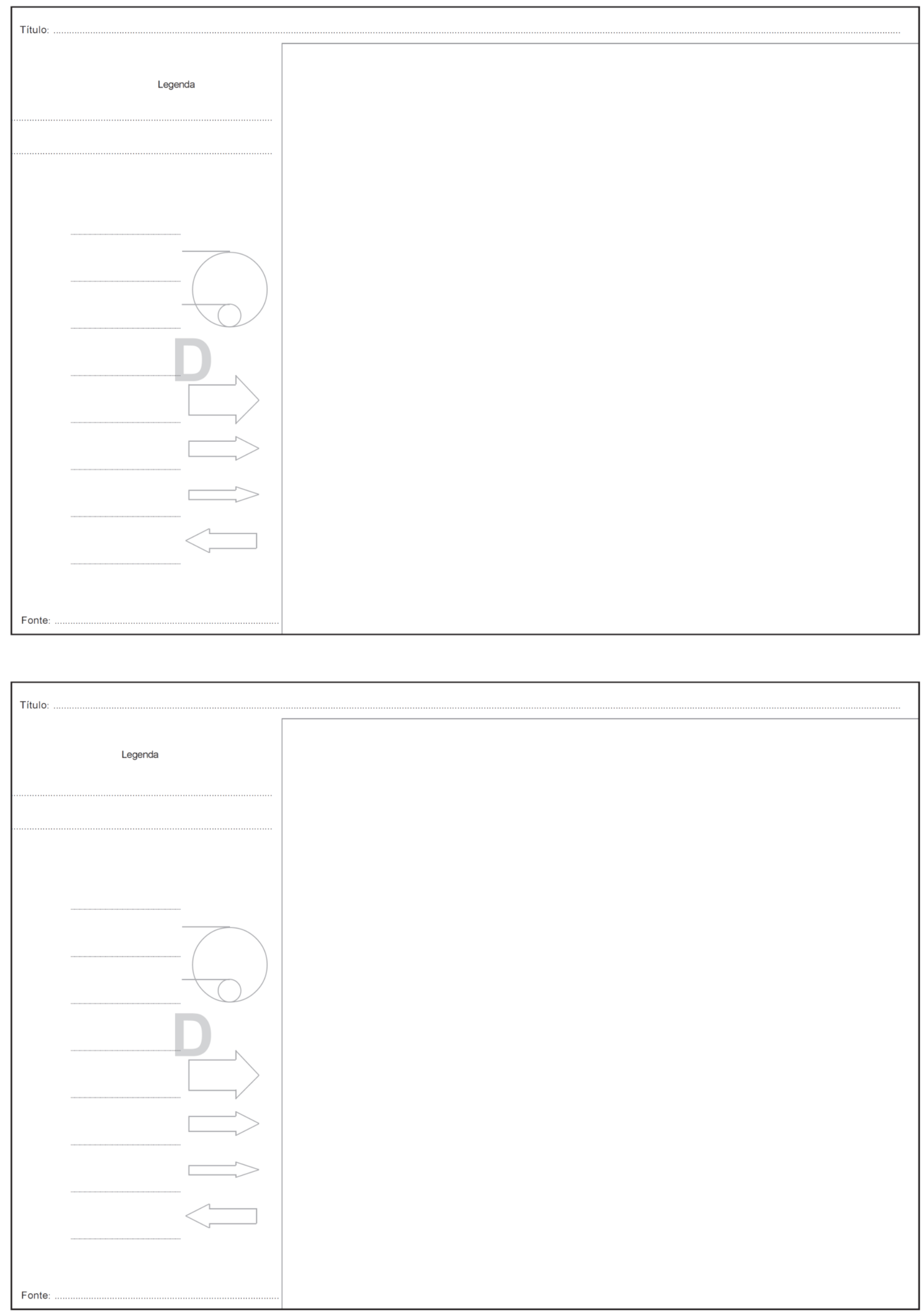

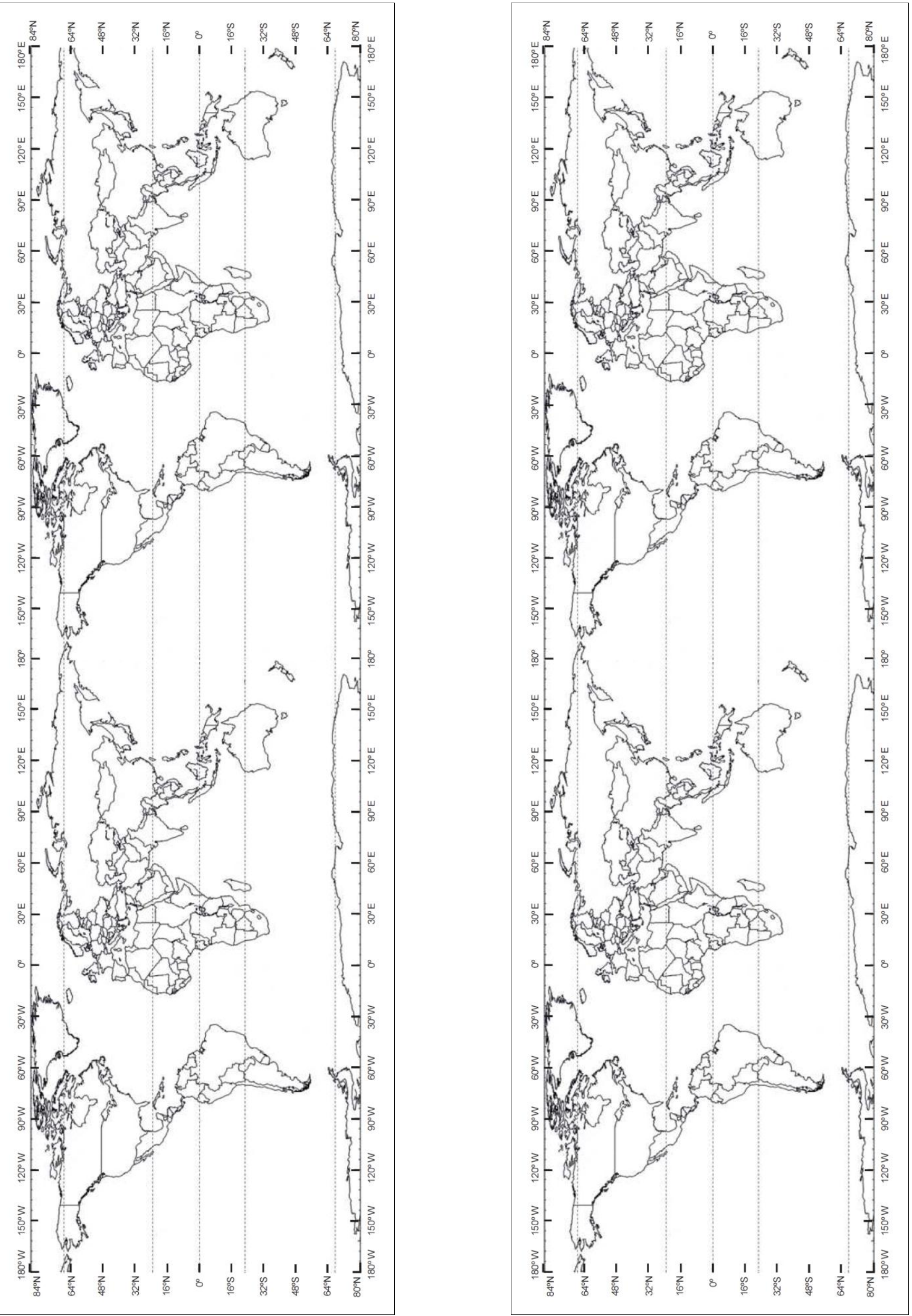